\title{
EXPERIMENT DATA REPORT FOR SEMISCALE ISOTHERMAL TEST PROGRAM HOT-WALL TESTS
}

\author{
E.M. Feldman \\ P.A. Pinson
}

\section{Aerojet nuclear Company}

\author{
NATIONAL REACTOR TESTING STATION \\ Idaho Falls, Idaho - 83401
}




\section{DISCLAIMER}

This report was prepared as an account of work sponsored by an agency of the United States Government. Neither the United States Government nor any agency Thereof, nor any of their employees, makes any warranty, express or implied, or assumes any legal liability or responsibility for the accuracy, completeness, or usefulness of any information, apparatus, product, or process disclosed, or represents that its use would not infringe privately owned rights. Reference herein to any specific commercial product, process, or service by trade name, trademark, manufacturer, or otherwise does not necessarily constitute or imply its endorsement, recommendation, or favoring by the United States Government or any agency thereof. The views and opinions of authors expressed herein do not necessarily state or reflect those of the United States Government or any agency thereof. 


\section{DISCLAIMER}

Portions of this document may be illegible in electronic image products. Images are produced from the best available original document. 


\section{DISCLAIMER}

This report was prepared as an account of work sponsored by an agency of the United States Government. Neither the United States Government nor any agency Thereof, nor any of their employees, makes any warranty, express or implied, or assumes any legal liability or responsibility for the accuracy, completeness, or usefulness of any information, apparatus, product, or process disclosed, or represents that its use would not infringe privately owned rights. Reference herein to any specific commercial product, process, or service by trade name, trademark, manufacturer, or otherwise does not necessarily constitute or imply its endorsement, recommendation, or favoring by the United States Government or any agency thereof. The views and opinions of authors expressed herein do not necessarily state or reflect those of the United States Government or any agency thereof. 


\section{DISCLAIMER}

Portions of this document may be illegible in electronic image products. Images are produced from the best available original document. 
Printed in the United States of America Available from

National Technical Information Service

U. S. Department of Commerce

5285 Port Royal Road

Springfield, Virginia 22151

Price: Printed Copy $\$ 7.60 ;$ Microfiche $\$ 1.45$

\section{LEGAL NOTICE}

This report was prepared as an account of wark sponsored by the United States Government. Neither the United States nor the United States Atomic Energy Commission, nor any of their employees, nor any of their contractors, subcontractors, or their employees, makes any warranty, express or implied, or assumes any legal liability or responsibility for the accuracy, completeness or usefulness of any information, apparatus, product or process disclosed, or represents that its use would not infringe privately owned rights. 
ANCR-1 149

EXPERIMENT DATA REPORT FOR SEMISCALE ISOTHERMAL

TEST PROGRAM HOT-WALL TESTS

by

E. M. Feldman

P. A. Pinson

AEROJET NUCLEAR COMPANY

Date Published - May 1974

PREPARED FOR THE U. S. ATOMIC ENERGY COMMISSION

IDAHO OPERATIONS OFFICE

UNDER CONTRACT NO. AT(10-1)-1375

This report was prepared as an account of work sponsored by the United States Government. Neither the United States nor the United States Atomic Energy Commission, nor any of their employees, nor any of their contractors, subcontractors, or their employees, lekes any warranty, express or implied, or assumes any pletenesility or responsibility for the accuracy, completeness or usefulness of any information, apparatus, product or process disclosed, or represents that its use would not infringe privately owned rights. 


\begin{abstract}
Recorded test data are presented for five hot-wall tests conducted as part of the isothermal test series of the Semiscale Blowdown and Emergency Core Cooling (ECC) Project. These data represent the results of tests in which simulated ECC injection following blowdown was investigated with the semiscale system at $\sim 40$ psig to determine the effects of stored wall heat on simulated ECC delivery to the pressure vessel lower plenum. The data, presented in the form of graphs in engineering units, have been analyzed only to the extent necessary to assure that they are reasonable and correct. The intent of this report is to make available the uninterpreted data from the hot-wall tests for use by others and for support of subsequent interpretative reports and analyses.
\end{abstract}




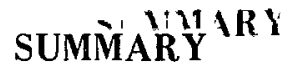

The hot-wall tests were performed in the isothermal portion of the Semiscale Blowdown and Emergency Core Cooling (ECC) Project conducted by Aerojet Nuclear Company for the Atomic Energy Commission. The tests were conducted to determine the effect of stored wall heat on simulated ECC delivery. The experimental system consisted of a pressure vessel with simulated reactor internals; an operating loop with pump, steam generator, and pressúrizer;' a 'blowdown loop with a simulated pump, a simulated steam generator, and rupture assemblies; a pressure suppression system with header and pressure suppression tank; and a simulated ECC system with accumulators and injection pumps.

Each of the five hot-wall tests (Tests $15.1,15.2,15.3,15.4$, and 15.7) was conducted immediately following completion of one of five isothermal blowdown tests (Tests 1001 , $1004,1010,1011$, and 1014, respectively) and rapid draining of the lower plenum of the pressure vessel. Each hot-wall test was initiated by injection of simulated ECC into the cold legs of the operating loop and the blowdown loop. The hot-wall tests provided (a) data for determining the time required for auxiliary cooling water (simulated ECC) to reach the vessel lower plenum and (b) information relative to the effects of steam generation in the vessel downcomer region on the time required for simulated ECC delivery.

In general, instrumentation used in the hot-wall tests functioned as intended and data , loss was minimal. Of more than 700 measurements attempted during the five tests, more: than $90 \%$ were accomplished. The data appear to be satisfactory for subsequent analysis. 


\section{CONTENTS}

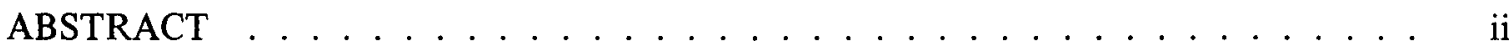

SUMMARY $\ldots \ldots \ldots \ldots \ldots \ldots \ldots \ldots \ldots \ldots \ldots \ldots$ iii

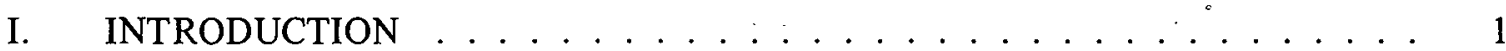

II. SYSTEM AND CONDITIONS FOR HOT-WALL TESTS $\ldots \ldots \ldots \ldots$

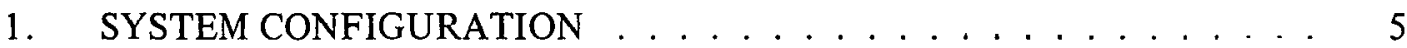

2. INITIAL TEST CONDITIONS AND SEQUENCE OF EVENTS $\ldots \ldots \ldots$

III. DATA PRESENTATION $\ldots \ldots \ldots \ldots \ldots \ldots \ldots \ldots$

IV. REFERENCES . . . . . . . . . . . . . . . . . . . . 202

\section{FIGURES}

1. Average temperature profiles in pressure vessel at start of Test $15.1 \ldots 7$

2. Average temperature profiles in pressure vessel at start of Test $15.2 \ldots \ldots 7$

3. Average temperature profiles in pressure vessel at start of Test $15.3 \ldots \ldots$. . . 8

4. Average temperature profiles in pressure vessel at start of Test $15.4 \ldots \ldots$

5. Average temperature profiles in pressure vessel at start of Test $15.7 \ldots \ldots$

6. 1-1/2-loop semiscale system and instrumentation -- isometric $\ldots \ldots \ldots 11$

7. $1-1 / 2$-loop semiscale system and instrumentation - schematic $\ldots \ldots \ldots 12$

8. Pressure vessel - cross-sectional view showing instrumentation $\ldots \ldots \ldots 13$

9. Pressure vessel - isometric showing instrumentation $\ldots \ldots \ldots \ldots \ldots$

10. Fluid temperatures in operating loop - Test $15.1 \ldots \ldots \ldots 21$

11. Fluid temperatures in operating loop - Test $15.2 \ldots \ldots \ldots 21$

12. Fluid temperatures in operating loop - Test $15.3 \ldots \ldots \ldots 22$

13. Fluid temperatures in operating loop-Test $15.4 \ldots \ldots \ldots 22$ 
14. Fluid temperatures in operating loop - Test $15.7 \ldots \ldots 23$

15. Fluid temperatures in blowdown loop - Test $15.1 \ldots \ldots 23$

16. Fluid temperatures in blowdown loop - Test $15.2 \ldots \ldots 24$

17. Fluid temperatures in blowdown loop - Test $15.3 \ldots \ldots 24$

18. Fluid temperatures in blowdown loop - Test $15.4 \ldots \ldots 25$

19. Fluid temperatures in blowdown loop - Test $15.7 \ldots \ldots 25$

20. Fluid temperatures in pressure suppression system - Test $15.1 \ldots 26$

21. Fluid temperatures in pressure suppression system - Test $15.2 \ldots \ldots$

22. Fluid temperatures in pressure suppression system - Test $15.3 \ldots \ldots 27$

23. Fluid temperatures in pressure suppression system - Test $15.4 \ldots 27$

24. Fluid temperatures in pressure suppression system - Test $15.7 \ldots \ldots$

25. Fluid temperatures in lower plenum at thermocouple rack - Test $15.1 \ldots 28$

26. Fluid temperatures in lower plenum at thermocouple rack - Test $15.2 \ldots 29$

27. Fluid temperatures in lower plenum at thermocouple rack - Test $15.3 \ldots 29$

28. Fluid temperatures in lower plenum at thermocouple rack - Test $15.4 \ldots 30$

29. Fluid temperatures in lower plenum at thermocouple rack -- Test $15.7 \ldots 30$

30. Fluid temperatures in upper portion of downcomer gap - Test $15.1 \ldots \ldots 1$

31. Fluid temperatures in upper portion of downcomer gap -- Test $15.2 \ldots \ldots 1$

32. Fluid temperatures in upper portion of downcomer gap - Test $15.3 \ldots 32$

33. Fluid temperatures in upper portion of downcomer gap - Test $15.4 \ldots 32$

34. Fluid temperatures in upper portion of downcomer gap - Test $15.7 \ldots 33$

35. Fluid temperatures in lower portion of downcomer gap - Test $15.1 \ldots 33$

36. Fluid temperatures in lower portion of downcomer gap - Test $15.2 \ldots$. . . . 34

37. Fluid temperatures in lower portion of downcomer gap - Test $15.3 \ldots 34$

38. Fluid temperatures in lower portion of downcomer gap - Test $15.4 \ldots \ldots 5$ 
39. Fluid temperatures in lower portion of downcomer gap - Test $15.7 \ldots \ldots 35$

40. Fluid temperatures in outlet plenum - Test $15.1 \ldots \ldots$

41. Fluid temperatures in outlet plenum -- Test $15.2 \ldots \ldots$. . . . . . . 36

42. Fluid temperatures in outlet plenum - Test $15.4 \ldots \ldots$. . . . . . . 37

43. Fluid temperatures in outlet plenum - Test $15.7 \ldots \ldots$. . . . . . . 37

44. Fluid temperatures in ECC lines from blowdown loop pump and operating loop pump - Test $15: 2 \ldots \ldots . \ldots . \ldots . \ldots 38$

45. Fluid temperatures in ECC lines from blowdown loop pump and operating loop pump - Test $15.3 \ldots \ldots . \ldots . \ldots . \ldots 38$

46. Fluid temperatures in ECC lines from blowdown loop pump and operating loop pump -- Test $15.7 \ldots \ldots . \ldots . \ldots . \ldots . \ldots 39$

47. Metal temperatures in core barrel - Test $15.1 \ldots \ldots 39$

48. Metal temperatures in core barrel - Test $15.2 \ldots \ldots$. . . . . . . . 40

49. Metal temperatures in core barrel - Test $15.3 \ldots \ldots$. . . . . . . . . . 40

50. Metal temperatures in core barrel - Test $15.4 \ldots \ldots . \ldots$. . . . . . 41

51. Metal temperatures in core barrel - Test $15.7 \ldots \ldots$. . . . . . . . 41

52. Metal temperatures in downcomer filler - Test $15.1 \ldots \ldots$. . . . . . . . 42

53. Metal temperatures in downcomer filler - Test $15.2 \ldots \ldots 42$

54. Metal temperatures in downcomer filler - Test $15.3 \ldots \ldots 4$

55. Metal temperatures in downcomer filler - Test $15.7 \ldots \ldots 4$

56. Metal temperatures in vessel wall - Test $15.4 \ldots \ldots$. . . . . . . . 44

57. Metal temperatures in vessel wall 95 inches from vessel upper flange face - Test $15.1 \ldots \ldots \ldots . \ldots \ldots 4 . \ldots \ldots$

58. Metal temperatures in vessel wall 95 inches from vessel upper flange face - Test $15.2 \ldots \ldots \ldots \ldots$. . . . . . . . . . . . 45

59. Metal temperatures in vessel wall 95 inches from vessel upper flange face - Test 15.3 
60. Metal temperatures in vessel wall 95 inches from vessel upper flange face - Test $15.4 \ldots \ldots \ldots$. . . . . . . . . . . 46

61. Metal temperatures in vessel wall 95 inches from vessel upper flange face - Test $15.7 \ldots \ldots \ldots \ldots$. . . . . . . . . . . 46

62. Metal temperatures in lower plenum vessel wall - Test $15.1 \ldots \ldots$. . . . . . . 47

63. Metal temperatures in lower plenum vessel wall - Test $15.2 \ldots \ldots 4$

64. Metal temperatures in lower plenum vessel wall - Test $15.3 \ldots \ldots$

65. Metal temperatures in lower plenum vessel wall - Test $15.4 \ldots \ldots$. . . . . . 48

66. Metal temperatures in lower plenum vessel wall - Test $15.7 \ldots \ldots$. . . . . 49

67. Metal temperatures in operating loop hot leg Spool 1 - Test $15.1 \ldots$. . . . . 49

68. Metal temperatures in operating loop hot leg Spool 1 - Test $15.2 \ldots \ldots 0$

69. Metal temperatures in operating loop hot leg Spool $1-$ Test $15.3 \ldots 50$

70. Metal temperatures in operating loop hot leg Spool 1 - Test $15.4 \ldots \ldots 1$

71. Metal temperatures in operating loop hot leg Spool 1 - Test $15.7 \ldots \ldots 1$

72. Metal temperatures in operating loop cold leg Spool 19 - Test 15.1 . . . . . . 52

73. Metal temperatures in operating loop cold leg Spool 19 - Test $15.2 \ldots \ldots 2$

74. Metal temperatures in operating loop cold leg Spool 19 - Test $15.3 \ldots 53$

75. Metal temperatures in operating loop cold leg Spool 19 - Test $15.4 \ldots 53$

76. Metal temperatures in operating loop cold leg Spool 19 - Test $15.7 \ldots$. . . . 54

77. Metal temperatures in operating loop cold leg Spool 22 - Test $15.1 \ldots$. . . . 54

78. Metal temperatures in operating loop cold leg Spool 22 - Test $15.2 \ldots 55$

79. Metal temperatures in operating loop cold leg Spool 22 - Test $15.3 \ldots 55$

80. Metal temperatures in operating loop cold leg Spool 22 - Test $15.4 \ldots \ldots 6$

81. Metal temperatures in operating loop cold leg Spool 22 - Test $15.7 \ldots \ldots 6$

82. Metal temperatures in blowdown loop - Test $15.3 \ldots \ldots 7$

83. Metal temperatures in blowdown loop - Test $15.4 \ldots \ldots 7$ 
84. Metal temperatures in blowdown loop - Test $15.7 \ldots \ldots$. . . . . . . 58

85. Metal temperatures in pressure suppression system - Test $15.1 \ldots \ldots$

86. Metal temperatures in pressure suppression system - Test $15.2 \ldots \ldots 9$

87. Momentum flux from drag discs in operating loop hot leg - Test $15.1 \ldots 59$

88. Momentum flux from drag discs in operating loop hot leg - Test $15.2 \ldots 6$

89. Momentum flux from drag discs in operating loop hot leg - Test $15.3 \ldots 60$

90. Momentum flux from drag discs in operating loop hot leg - Test $15.4 \ldots 61$

91. Momentum flux from drag discs in operating loop hot leg - Tcst $15.7 \ldots 61$

92. Momentum flux from drag discs in operating loop cold leg - Test $15.1 \ldots 62$

93. Momentum flux from drag discs in operating loop cold leg - Test $15.2 \ldots 62$

94. Momentum flux from drag discs in operating loop cold leg - Test $15.3 \ldots 6$

95. Momentum flux from drag discs in operating loop cold leg.- Test $15.4 \ldots 6$

96. Momentum flux from drag discs in operating loop cold leg-Test $15.7 \ldots 64$

97. Momentum flux from drag discs in blowdown loop - Test $15.1 \ldots 64$

98. Momentum flux from drag discs in blowdown loop - Test $15.2 \ldots \ldots 5$

99. Momentum flux from drag discs in blowdown loop - Test $15.3 \ldots \ldots 5$

100. Momentum flux from drag discs in blowdown loop - Test $15.4 \ldots 66$

101. Momentum flux from drag discs in blowdown loop - Test $15.7 \ldots 66$

102. Momentum flux from drag discs at core barrel inlet - Test $15: 1 \ldots 67$

103. Momentum flux from drag discs at core barrel inlet - Test $15.2 \ldots \ldots 7$

104. Momentum flux from drag discs at core barrel inlet - Test $15.3 \ldots 68$

105. Momentum flux from drag discs at core barrel inlet -- Test $15.4 \ldots 68$

106. Momentum flux from drag discs at core barrel inlet - Test $15.7 \ldots \ldots 9$

107. Volumetric flow rate from turbine meters in operating loop - Test $15.1 \quad \ldots \quad 69$

108: Volumetric flow rate from turbine meters in operating loop - Test $15.2 \ldots 70$ 
109. Volumetric flow rate from turbine meters in operating loop - Test $15.3 \ldots 70$

110. Volumetric flow rate from turbine meters in operating loop - Test $15.4 \ldots 71$

111. Volumetric flow rate from turbine meters in operating loop - Test $15.7 \ldots 71$

112. Volumetric flow rate from turbine meter in blowdown loop hot leg -- Test 15.1 . 72

113. Volumetric flow rate from turbine meter in blowdown loop hot leg -- Test 15.3 . 72

114. Volumetric flow rate from turbine meter in blowdown loop hot leg - Test 15.4. 73

115. Volumetric flow rate from turbine meter in blowdown loop hot leg - Test 15.7 .73

116. Volumetric flow rate from turbine meter at core barrel inlet - Test $15.1 \ldots 74$

117. Volumetric flow rate from turbine meter at core barrel inlet - Test $15.2 \ldots 74$

118. Volumetric flow rate from turbine meter at core barrel inlet - Test $15.3 \ldots 75$

119. Volumetric flow rate from turbine meter at core barrel inlet - Test $15.4 \ldots 75$

120. Volumetric flow rate from turbine meter at core barrel inlet - Test $15.7 \quad \ldots$. . 76

121. Volumetric flow rate from turbine meter at pressurizer outlet - Test $15.7 \quad \ldots \quad 76$

122. Volumetric flow rate from ECC injection pumps in operating and blowdown loops (turbine meters) - Test $15.1 \ldots \ldots \ldots 77$

123. Volumetric flow rate from ECC injection pumps in operating and blowdown loops (turbine meters) - Test 15.2 . . . . . . . . . 77

124. Volumetric flow rate from ECC injection pumps in operating and blowdown loops (turbine meters) - Test $15.3 \ldots \ldots 78$

125. Volumetric flow rate from ECC injection pump in blowdown loop and ECC accumulators in operating loop (turbine meters) - Test $15.4 \ldots 78$

126. Volumetric flow rate from ECC injection pumps in operating and blowdown loops (turbine meters) - Test $15.7 \ldots \ldots . \ldots 79$

127. Fluid velocity from turbine meters in downcomer gap - Test $15.1 \ldots 79$

128. Fluid velocity from turbine meters in downcomer gap - Test $15.2 \ldots \ldots$

129. Fluid velocity from turbine meters in downcomer gap - Test $15.3 \ldots$. . . . . 80

130. Fluid velocity from turbine meters in downcomer gap - Test $15.4 \ldots \ldots 1$ 
131. Fluid velocity from turbine meters in downcomer gap - Test $15.7 \ldots \ldots 1$

132. Mass flow rate in operating loop hot leg Spool 1 - Test $15.1 \ldots \ldots 2$

133. Mass flow rate in operating loop hot leg Spool $1-$ Test $15.2 \ldots \ldots 2$

134. Mass flow rate in operating loop hot leg Spool 1 - Test $15.3 \ldots \ldots$

135. Mass flow rate in operating loop hot leg Spool 1 - Test $15.4 \ldots 3$

136. Mass flow rate in operating loop hot leg Spool 1 - Test $15.7 \ldots \ldots$. . . . . 84

137. Mass flow rate in operating loop at pump discharge (Spool 19) - Test 15.2 . . 84

138. Mass flow rate in operating loop at pump discharge (Spool 19) - Test $15.3 \ldots 85$

139. Mass flow rate in operating loop at pump discharge (Spool 19) - Test $15.4 \ldots 85$

140. Mass flow rate in operating loop at pump discharge (Spool 19) - Test $15.7 \ldots 86$

141. Mass flow rate in operating loop cold leg Spool 22 - Test $15.1 \ldots 6$

142. Mass flow rate in operating loop cold leg Spool 22 - Test $15.2 \ldots \ldots 7$

143. Mass flow rate in operating loop cold leg Spool $22-$ Test $15.3 \ldots 7$

144. Mass flow rate in operating loop cold leg Spool 22 - Test $15.4 \ldots 8$

145. Mass flow rate in operating loop cold leg Spool 22 - Test $15.7 \ldots$. . . . . 88

146. Mass flow rate in operating loop Spools 5 and 15 - Test $15.1 \ldots$. . . . . 89

147. Mass flow rate in operating loop Spools 5 and 15 - Test $15.2 \ldots$. . . . . 89

148. Mass flow rate in operating loop Spools 5 and $15-$ Test $15.3 \ldots \ldots 0$

149. Mass flow rate in operating loop Spools 5 and 15 - Test $15.4 \ldots$. . . . . 90

150. Mass flow rate in operating loop Spools 5 and 15 - Test $15.7 \ldots \ldots 1$

151. Mass flow rate in blowdown loop Spool 70 - Test $15.1 \ldots \ldots 1$

152. Mass flow rate in blowdown loop Spool 70 - Test $15.2 \ldots \ldots 2$

153. Mass flow rate in blowdown loop Spool 70 - Test $15.3 \ldots . \ldots 2$

154. Mass flow rate in blowdown loop Spool 70 - Test $15.4 \ldots \ldots 3$

155. Mass flow rate in blowdown loop Spool 70 - Test $15.7 \ldots \ldots 3$ 
156. Mass flow rate in blowdown loop Spools 50 and $76-$ Test $15.1 \ldots 94$

157. Mass flow rate in blowdown loop Spools 50 and $76-$ Test $15.2 \ldots 94$

158. Mass flow rate in blowdown loop Spools 50 and $76-$ Test $15.3 \ldots 95$

159. Mass flow rate in blowdown loop Spools 50 and 76 - Test $15.4 \ldots 95$

160. Mass flow rate in blowdown loop Spools 50 and 76 - Test $15.7 \ldots \ldots 6$

161. Mass flow rate at core barrel inlet - Test $15.1 \ldots \ldots$. . . . . . . . . 96

162. Mass flow rate at core barrel inlet - Test $15.2 \ldots \ldots$. . . . . . . . . 97

163. Mass flow rate at core barrel inlet - Test $15.3 \ldots \ldots$. . . . . . . . 97

164. Mass flow rate at core barrel inlet - Test $15.4 \ldots \ldots$. . . . . . . . . 98

165. Mass flow rate at core barrel inlet - Test $15.7 \ldots \ldots$. . . . . . . . 98

166. Fluid density in operating loop hot leg - Test $15.1 \ldots \ldots 9$

167. Fluid density in operating loop hot leg-Test $15.2 \ldots \ldots 9$

168. Fluid density in operating loop hot leg-Test $15.3 \ldots \ldots$. . . . . . . 100

169. Fluid density in operating loop hot leg-Test $15.4 \ldots \ldots$. . . . . . . . 100

170. Fluid density in operating loop hot leg - Test $15.7 \ldots \ldots$. . . . . . . 101

171. Fluid density at operating loop pump inlet and outlet - Test $15.1 \ldots \ldots 10$

172. Fluid density at operating loop pump inlet and outlet - Test $15.2 \ldots 102$

173. Fluid density at operating loop pump inlet and outlet - Test $15.3 \ldots 102$

174. Fluid density at operating loop pump inlet and outlet - Test $15.4 \ldots \ldots 3$

175. Fluid density at operating loop pump inlet and outlet - Test $15.7 \ldots 103$

176. Fluid density in operating loop cold leg - Test $15.1 \ldots \ldots 4$

177. Fluid density in operating loop cold leg - Test $15.2 \ldots \ldots$. . . . . . . . 104

178. Fluid density in operating loop cold leg - Test $15.3 \ldots \ldots$. . . . . 105

179. Fluid density in operating loop cold leg - Test $15.4 \ldots \ldots$. . . . . 105

180. Fluid density in operating loop cold leg - Test $15.7 \ldots \ldots$. . . . . . . 106 
181. Fluid density in blowdown loop - Test $15.1 \ldots \ldots 6$

182. Fluid density in blowdown loop - Test $15.2 \ldots \ldots$. . . . . . . . . 107

183. Fluịd density in blowdown loop - Test $15.3 \ldots \ldots$. . . . . . . . . 107

184. Fluid density in blowdown loop - Test $15.4 \ldots \ldots$. . . . . . . 108

185. Fluid density in blowdown loop - Test $15.7 \ldots \ldots$. . . . . . . . . 108

186. Fluid density in vessel - Test $15.1 \ldots \ldots$. . . . . . . . . . 109

187. Fluid density in vessel - Test $15.2 \ldots \ldots$. . . . . . . . . . . 109

188. Fluid density in vessel - Test $15.3 \ldots \ldots \ldots 110 \ldots$

189. Fluid density in vessel - Test $15.4 \ldots \ldots \ldots \ldots$

190. Fluid density in vessel - Test $15.7 \ldots \ldots \ldots \ldots 11$

191. Fluid density in pressure suppression header - Test $15.1 \ldots \ldots \ldots$. . . . 111

192. Fluid density in pressure suppression header - Test $15.2 \ldots \ldots$. . . . . . 112

193. Fluid density in pressure suppression header - Test $15.3 \ldots \ldots 112$

194. Fluid density in pressure suppression header - Test $15.7 \ldots \ldots$. . . . . . 113

195. Pressure in operating loop -- Test $15.1 \ldots \ldots \ldots \ldots$

196. Pressure in operating loop -- Test 15.2 . . . . . . . . . . . . . . 114

197. Pressure in operating loop -- Test $15.3 \ldots \ldots \ldots 114$

198. Pressure in operating loop - Test $15.4 \ldots \ldots \ldots \ldots 115$

199. Pressure in operating loop -- l'est $15.7 \ldots \ldots \ldots \ldots$

200. Pressure in blowdown loop - Test $15.1 \ldots \ldots \ldots \ldots$

201. Pressure in blowdown loop - Test $15.2 \ldots \ldots \ldots \ldots$

202. Pressure in blowdown loop - Test $15.3 \ldots \ldots \ldots \ldots$. . . . . . . . 117

203. Pressure in blowdown loop - Test $15.4 \ldots \ldots \ldots$. . . . . . . 117

204. Pressure in blowdown loop - Test $15.7 \ldots \ldots \ldots \ldots$. . . . . . . 118

205. Pressure in vessel - Test $15.1 \ldots \ldots \ldots \ldots \ldots$ 
206. Pressure in vessel - Test $15.2 \ldots \ldots \ldots \ldots$

207. Pressure in vessel - Test $15.3 \ldots \ldots \ldots$. . . . . . . . . . 119

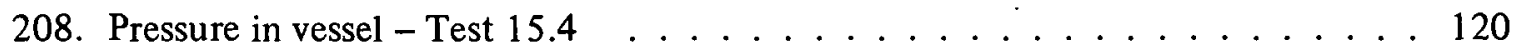

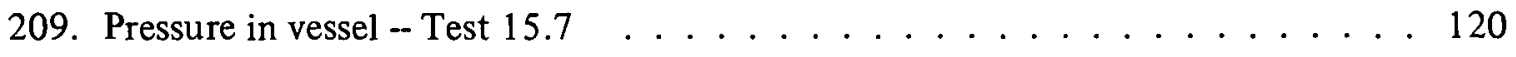

210. Pressure in pressure suppression system - Test $15.1 \ldots \ldots \ldots \ldots \ldots$

211. Pressure in pressure suppression system - Test $15.2 \ldots \ldots \ldots \ldots \ldots$

212. Pressure in pressure suppression system - Test $15.3 \ldots \ldots \ldots \ldots$

213. Pressure in pressure suppression system - Test $15.4 \ldots \ldots \ldots \ldots \ldots \ldots$

214. Pressure in pressure suppression system - Test $15.7 \ldots \ldots \ldots \ldots$

215. Pressure at hot leg stub in upper plenum (LOFT free field pressure transducer $)$ Test $15.1 \ldots \ldots \ldots \ldots \ldots \ldots \ldots$

216. Pressure at hot leg stub in upper plenum (LOFT free field pressure transducer) - Test $15.2 \ldots \ldots \ldots \ldots \ldots \ldots \ldots$

217. Pressure at hot leg stub in upper plenum (LOFT free field pressure transducer) - Test $15.3 \ldots \ldots \ldots \ldots \ldots \ldots$

218. Pressure at hot leg stub in upper plenum (LOFT free field pressure transducer) - Test $15.7 \ldots \ldots \ldots \ldots \ldots \ldots \ldots$

219. Pressure of ECC in accumulators - Test $15.2 \ldots \ldots \ldots \ldots$

220. Pressure of ECC in accumulators - Test $15.4 \ldots \ldots \ldots \ldots \ldots$

221. Differential pressure across operating loop (DP-22-1) - Test $15.1 \ldots \ldots$

222. Differential pressure across operating loop (DP-22-1) - Test $15.2 \ldots \ldots 127$

223. Differential pressure across operating loop (DP-22-1) - Test $15.3 \ldots \ldots 127$

224. Differential pressure across operating loop (DP-22-1) - Test $15.7 \ldots \ldots \ldots 128$

225. Differential pressure, operating loop hot leg (DP-1-5) - Test $15.1 \ldots \ldots \ldots$

226. Differential pressure, operating loop hot leg (DP-1-5) - Test $15.2 \ldots \ldots$

227. Differential pressure, operating loop hot leg (DP-1-5) - Test $15.3 \ldots \ldots$

228. Differential pressure, operating loop hot leg (DP-1-5) - Test $15.4 \ldots \ldots \ldots 130$ 
229. Differential pressure, operating loop hot leg (DP-1-5) - Test $15.7 \ldots \ldots$

230. Differential pressure across steam generator (DP-5-13) - Test $15.1 \ldots 131$

231. Differential pressure across steam generator (DP-5-13) - Test $15.2 \ldots \ldots 131$

232. Differential pressure across steam generator (DP-5-13) - Test $15.3 \ldots \ldots$

233. Differential pressure across steam generator (DP-5-13) - Test $15.4 \ldots \ldots$. . . 132

234. Differential pressure across steam generator (DP-5-13) -- Test $15.7 \ldots \ldots$

235. Differential pressure across pump suction orifice (DP-8-13) - Test $15.1 \ldots 133$

236. Differential pressure across pump suction orifice (DP-8-13) - Test $15.2 \ldots 134$

237. Differential pressure across pump suction orifice (DP-8-13) - Test 15.3 . . . 134

238. Differential pressure across pump suction orifice (DP-8-13) - Test 15.4 . . . 135

239. Differential pressure across pump suction orifice (DP-8-13) - Test $15.7 \ldots \ldots$

240. Differential pressure across operating loop pump inlet (DP-13-15) - Test 15.1 . 136

241. Differential pressure across operating loop pump inlet (DP-13-15) - Test 15.3 . 136

242. Differential pressure across operating loop pump inlet (DP-13-15) - Test 15.4 . 137

243. Differential pressure across operating loop pump inlet (DP-13-15) - Test 15.7 . 137

244. Differential pressure across operating loop pump (DP-19-15) - Test $15.1 \ldots 138$

245. Differential pressure across operating loop pump (DP-19-15) - Test $15.2 \ldots 138$

246. Differential pressure across operating loop pump (DP-19-15) - Test $15.3 \ldots 139$

247. Differential pressure across operating loop pump (SP-19-15) - Test 15.4 . . 139

248. Differential pressure across operating loop pump (DP-19-15) -- Test $15.7 \ldots 140$

249. Differential pressure across operating loop pump, low range (DP-19-15L) Test $15.1 \ldots \ldots \ldots \ldots \ldots$. . . . . . . . . . . . . . . . . . . . . . . .

250. Differential pressure across operating loop pump, low range (DP-19-15L) -Test $15.2 \ldots \ldots \ldots \ldots \ldots \ldots 14 \ldots \ldots \ldots \ldots$

251. Differential pressure across operating loop pump, low range (DP-19-15L) -

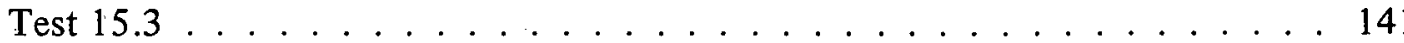


252. Differential pressure across operating loop pump, low range (DP-19-15L) Test $15.7 \ldots \ldots \ldots \ldots \ldots$. . . . . . . . . . . . . . . . . . . . . . . . . .

253. Differential pressure across operating loop cold leg (DP-19-22) - Test 15.1 . . 142

254. Differential pressure across operating loop cold leg (DP-19-22) - Test $15.2 \ldots 143$

255. Differential pressure across operating loop cold leg (DP-19-22) - Test 15.3 . . 143

256. Differential pressure across operating loop cold leg (DP-19-22) - Test 15.4 . . 144

257. Differential pressure across operating loop cold leg (DP-19-22) - Test $15.7 \ldots 144$

258. Differential pressure between cold leg and lower plenum (DP-22-255) Test $15.1 \ldots \ldots \ldots \ldots . \ldots \ldots 145$

259. Differential pressure between cold leg and lower plenum (DP-22-255) -Test $15.2 \ldots \ldots \ldots \ldots \ldots \ldots$. . . . . . . . . . . . . . . . . . . . . . . . . . .

260. Differential pressure between cold leg and lower plenum (DP-22-255)Test $15.3 \ldots \ldots \ldots \ldots \ldots \ldots \ldots$

261. Differential pressure between cold leg and lower plenum (DP-22-255)Test $15.4 \ldots \ldots \ldots \ldots \ldots \ldots$. . . . . . . . . . . . . . . . . . . . . . . . . .

262. Differential pressure between cold leg and lower plenum (DP-22-255)Test $15.7 \ldots \ldots \ldots \ldots \ldots \ldots$. . . . . . . . . . . . . . . . . . . . . . . . .

263. Differential pressure across core (DP-255-207) - Test 15.1 . . . . . . . . 147

264. Differential pressure across core (DP-255-207) - Test $15.2 \ldots \ldots$. . . . . . 148

265. Differential pressure across core (DP-255-207) - Test $15.3 \ldots \ldots$. . . . 148

266. Differential pressure across core (DP-255-207) - Test $15.4 \ldots \ldots$. . . . . . . 149

267. Differential pressure across core (DP-255-207) - Test 15.7 . . . . . . . 149

268. Differential pressure across upper portion of downcomer (DP-213-246) Test $15.1 \ldots \ldots \ldots \ldots \ldots$. . . . . . . . . . . . . . . . . . . . . .

269. Differential pressure across upper portion of downcomer (DP-213-246) -

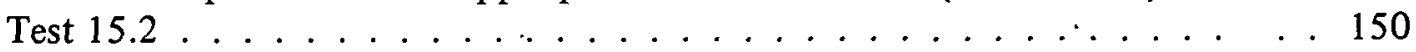

270. Differential pressure across upper portion of downcomer (DP-216-246) Test $15.3 \ldots \ldots \ldots \ldots \ldots 15 \ldots \ldots \ldots$

271. Differentıal pressure across upper pui tionin of downcomer (DP-216-246) -

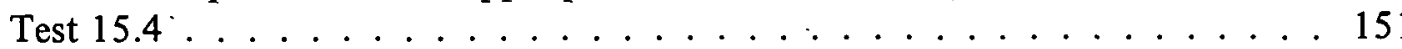


272. Differential pressure across upper portion of downcomer (DP-216-246) Test $15.7 \ldots \ldots \ldots \ldots \ldots \ldots$. . . . . . . . . . . . . . . . . . . . . . . . . .

273. Differential pressure across middle portion of downcomer (DP-246-249) Test $15.1 \ldots \ldots \ldots \ldots \ldots$. . . . . . . . . . . . . . . . . . . . . . . . . .

274. Differential pressure across middle portion of downcomer (DP-246-249) -

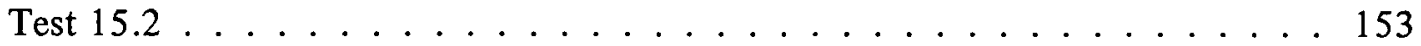

275. Differential pressure across middle portion of downcomer (DP-246-249) Test $15.3 \ldots \ldots \ldots \ldots$. . . . . . . . . . . . . . . . . . . . .

276. Differential pressure across middle portion of downcomer (DP-246-249) Test 15.4

277. Differential pressure across middle portion of downcomer (DP-246-249) Test $15.7 \ldots \ldots \ldots \ldots \ldots$. . . . . . . . . . . . . . . . . . . . . . . . . . . . . .

278. Differential pressure across lower portion of downcomer (DP-249-255) Test $15.1 \ldots \ldots \ldots \ldots \ldots$. . . . . . . . . . . . . . . . . . . . . . . .

279. Differential pressure across lower portion of downcomer (DP-249-255) Test $15.2 \ldots \ldots \ldots \ldots \ldots$. . . . . . . . . . . . . . . . . . . . . .

280. Differential pressure across lower portion of downcomer (DP-249-255) -

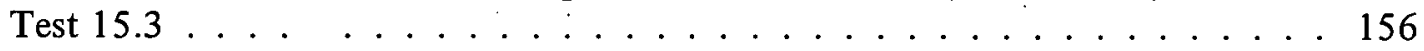

281. Differential pressure across lower portion of downcomer (DP-249-255) Test $15.4 \ldots \ldots \ldots \ldots \ldots \ldots$. . . . . . . . . . . . . . . . . . . . . .

282. Differential pressure across lower portion of downcomer (DP-249-255) Test 15.7

283. Differential pressure across lower plenum (DP-261-255) - Test $15.1 \quad \ldots$. . . 157

284. Differential pressure across lower plenum (DP-261-255) - Test $15.2 \ldots 158$

285. Differential pressure across lower plenum (DP-261-255) - Test $15.3 \ldots 158$

286. Differential pressure across lower plenum (DP-261-255) - Test $15.4 \ldots 159$

287. Differential pressure across lower plenum (DP-261-255) - Test 15.7 . . . . 159

288. Differential pressure across vessel (DP-LOFT) - Test $15.1 \ldots \ldots 60$

289. Differential pressure across vessel (DP-LOFT) - Test $15.2 \ldots \ldots$. . . . . . . 160

290. Differential pressure across vessel (DP-LOFT) - Test $15.3 \ldots \ldots \ldots 1$ 
291. Differential pressure across vessel (DP-LOFT) - Test $15.4 \ldots \ldots 161$

292. Differential pressure across vessel (DP-LOFT) - Test $15.7 \ldots \ldots$. . . . . . 162

293. Differential pressure between vessel upper plenum and blowdown loop hot leg (DP-207-70) - Test 15.1 . . . . . . . . . . . . 162

294. Differential pressure between vessel upper plenum and blowdown loop hot leg (DP-207-70) - Test 15.2 . . . . . . . . . . . . 163

295. Differential pressure between vessel upper plenum and blowdown loop hot leg (DP-207-70) - Test 15.3 . . . . . . . . . . . . 163

296. Differential pressure between vessel upper plenum and blowdown loop hot leg (DP-207-70) - Test 15.4 . . . . . . . . . . . . . . 164

297. Differential pressure between vessel upper plenum and blowdown loop hot leg (DP-207-70) - Test 15.7 . . . . . . . . . . . . . . 164

298. Differential pressure between vessel inlet annulus and blowdown loop cold leg (DP-264-50) - Test 15.1 . . . . . . . . . . . . 165

299. Differential pressure between vessel inlet annulus and blowdown loop cold leg (DP-264-50) - Test 15.2 ... . . . . . . . . . . 165

300. Differential pressure between vessel inlet annulus and blowdown loop cold leg (DP-264-50) - Test 15.3 . . . . . . . . . . . . 166

301. Differential pressure between vessel inlet annulus and blowdown loop cold leg (DP-264-50) - Test 15.4 . . . . . . . . . . 166

302. Differential pressure between vessel inlet annulus and blowdown loop cold leg (DP-264-50) - Test $15.7 \ldots \ldots$. . . . . . . . . . . 167

303. Differential pressure across blowdown loop hot leg nozzle (DP-76-61) -Test $15.1 \ldots \ldots \ldots \ldots$. . . . . . . . . . . . . 167

304. Differential pressure across blowdown loop hot leg nozzle (DP-76-61) Test $15.2 \ldots \ldots \ldots \ldots$. . . . . . . . . . . . . . . 168

305. Differential pressure across blowdown loop hot leg nozzle (DP-76-61) -Test $15.3 \ldots \ldots \ldots \ldots$. . . . . . . . . . . . . . . . . . . . . . . . .

306. Differential pressure across blowdown loop hot leg nozzle (DP-76-61) Test $15.4 \ldots \ldots \ldots \ldots$. . . . . . . . . . . . . . . . . . . . . . . . .

307. Differential pressure across blowdown loop hot leg nozzle (DP-76-61) Test 15.7 
308. Differential pressure between simulated pump and throat of blowdown loop hot leg nozzle (DP-76-HN2) - Test 15.2 . . . . . . . . . . . . 170

309. Differential pressure between simulated pump and throat of blowdown loop hot leg nozzle (DP-76-HN2) - Test 15.4 . . . . . . . . . . 170

3.10. Differential pressure between simulated pump and throat of blowdown loop hot leg nozzle (DP-76-HN2) - Test $15.7 \ldots \ldots \ldots 17$

311. Differential pressure across simulated pump (DP-96-76) - Tcst $15.1 \ldots \ldots$

312. Differential pressure across simulated pump (DP-96-76) - Test $15.2 \ldots 172$

313. Differential pressure across simulated pump (DP-96-76) - Test.15.3 . . . . 172

314. Differential pressure across simulated pump (DP-96-76) - Test $15.4 \ldots 173$

315. Differential pressure across simulated pump (DP-96-76) - Test $15.7 \ldots 1.73$

316. Differential pressure across simulated steam generator (DP-70-96) Test $15.1 \ldots \ldots \ldots \ldots \ldots$. . . . . . . . . . . . . . . . . . . . . . . . . . . .

317. Differential pressure across simulated steam generator (DP-70-96) Test $15.2 \ldots \ldots \ldots \ldots \ldots$. . . . . . . . . . . . . . . . . . . . . . . . . . . .

318. Differential pressure across simulated steam generator (DP-70-96) Test $15.3 \ldots \ldots \ldots \ldots \ldots \ldots$

319. Differential pressure across simulated steam generator (DP-70-96) -Test 15.4

320. Differential pressure across simulated steam generator (DP-70-96) Test $15.7 \ldots \ldots \ldots \ldots \ldots$. . . . . . . . . . . . . . . . . . . . . . . . .

321. Differential pressure across blowdown loop cold leg nozzle diverging section (DP5-HN2-HN4) - Test 15.2 . . . . . . . . . 176

322. Differential pressure across blowdown loop cold leg nozzle diverging section (DP5-HN2-HN4) - Test 15.3 . . . . . . . . . . . . 177

323. Differential pressure across blowdown loop cold leg nozzle diverging section (DP5-HN2-HN4) - Test 15.4 177

324. Differential pressure across blowdown loop hot leg nozzle diverging section (DP6-HN2-HN4) - Test 15.7 . . . . . . . . . . . . . . 178

325. Differential pressure across blowdown loop hot leg nozzle, Station 61 (DP-HNT-61) - Test 15.2 
326. Differential pressure across blowdown loop hot leg nozzle, Station 61 (DP-HN4-61) - Test $15.3 \ldots \ldots \ldots$

327. Differential pressure across blowdown loop hot leg nozzle, Station 61 (DP-HN4-61) - Test 15.7

328. Differential pressure between vessel upper plenum and pressure suppression tank vapor chamber (DP-207-89) - Test 15.1 . . . . . . . . . . . 180

329. Differential pressure between vessel upper plenum and pressure suppression tank vapor chamber (DP-207-89) - Test 15.2 . . . . . . . . . . . 180

330. Differential pressure between vessel upper plenum añd pressure suppression tank vapor chamber $($ DP-207-89) $\rightarrow$ Test $15.3 \ldots \ldots$. . . . . . . 181

331. Differential pressure between vessel upper plenum and pressure suppression tank vapor chamber (DP-207-89) - Test 15.4 . . . . . . . . . . . . . 181

332. Differential pressure between vessel upper plenum and pressure suppression tank vapor chamber (DP-207-89) - Test 15.7 . . . . . . . . . . . 182

333. Differential pressure between pressure suppression header and pressure suppression tank downcomer entrance (DP-81-83) - Test 15.1 . . . . . . . 182

334. Differential pressure between pressure suppression header and pressure suppression tank vapor chamber (DP-81-89) -- Test $15.2 \ldots \ldots$. . . . . 183

335. Differential pressure between pressure suppression header and pressure suppression tank vapor chamber (DP-81-89) - Test 15.3

336. Differential pressure between pressure suppression header and pressure suppression tank vapor chamber (DP-81-89) - Test 15.4

337. Differential pressure between pressure suppression header and pressure suppression tank vapor chamber (DP-81-89) - Test 15.7

338. Differential pressure between pressure suppression tank downcomer entrance and exit (DP-83-85) - Test 15.

339. Differential pressure between pressure suppression header and pressure suppression tank downcomer exit (DP-81-85) - Test 15.2 . . . . . . . . 185

340. Differential pressure between pressure suppression header and pressure suppression tank downcomer exit (DP-81-85) - Test 15.3 . . . . . . . . 186

341. Differential pressure between pressure suppression header and pressure suppression tank downcomer exit (DP-81-85) - Test 15.4 
342. Differential pressure between pressure suppression header and pressure suppression tank dow ncomer exit (DP-81-85) - Test 15.7 . . . . . . . . 187

343. Differential pressure between pressure suppression tank downcomer entrance and pressure suppression tank vapor chamber (DP-83-89) - Test 15.1 . . . . . 187

344. Liquid level in pressure suppression tank - Test $15.1 \ldots \ldots$. . . . . . . 188

345. Liquid level in pressure suppression tank - Test $15.2 \ldots \ldots$. . . . . . . . . 188

346. Liquid level in pressure suppression tank - Test $15.3 \ldots$. . . . . . . . . . . . 189

347. Liquid level in pressure suppression tank - Test $15.4 \ldots \ldots$. . . . . . . . . . 189

348. Liquid level in pressure suppression tank - Test $15.7 \ldots \ldots$. . . . . . . . . 190

349. Pump speed - Test $15.1 \ldots \ldots \ldots$. . . . . . . . . . . . 190

350. Pump speed - Test $15.2 \ldots \ldots \ldots \ldots 1 . \ldots \ldots \ldots$

351: Pump speed - Test $15.3 \ldots \ldots \ldots 19 \ldots \ldots$

352. Pump speed - Test $15.4 \ldots \ldots \ldots \ldots$. . . . . . . . . . . . . . . . . . . . .

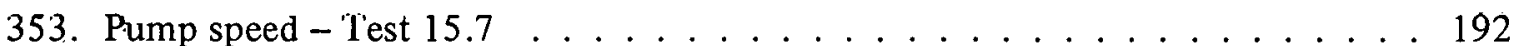

354. Pump power - Test $15.1 \ldots \ldots \ldots$. . . . . . . . . . . . 193

355. Pump power - Test $15.2 \ldots \ldots \ldots$. . . . . . . . . . . 193

356. Pump Power - Test $15.3 \ldots \ldots$. . . . . . . . . . . . . . 194

357. Pump power - Test $15.4 \ldots \ldots \ldots$. . . . . . . . . . . . . 194

358. Pump power - Test $15.7 \ldots \ldots \ldots \ldots$. . . . . . . . . . . . . . . . . . .

359. Pump torque - Test $15.1 \ldots \ldots \ldots \ldots$. . . . . . . . . . . . . . . . . .

360. Pump torque - Test $15.2 \ldots \ldots \ldots \ldots \ldots$

361. Pump torque - Test $15.4 \ldots \ldots \ldots \ldots \ldots$. . . . . . . . . . . . . . . . . . . .

362. Pump torque - Test $15.7 \ldots \ldots \ldots \ldots$. . . . . . . . . . 197

363: Flow direction in downcomer gap - Test $15.3 \ldots \ldots$. . . . . . . . 197

364. Flow direction in downcomer gap - Test $15.4 \ldots \ldots$. . . . . . . . . 198

365. Flow direction in downcomer gap - Test $15.7 \ldots \ldots$. . . . . . . 198 
366. Displacement of pressure suppression header - Test $15.1 \ldots \ldots$. . . . . 199

367. Displacement of pressure suppression header - Test $15.2 \ldots \ldots 9$

368. Displacement of pressure suppression header - Test $15.3 \ldots 200$

369. Displacement of pressure suppression header - Test $15.4 \ldots \ldots$. . . . . . 200

370. Displacement of pressure suppression header - Test $15.7 \ldots \ldots$. . . . . 201

\section{TABLES}

I. Initial Metal Temperatures in Pressure Vessel Downcomer Filler Piece, Core Barrel, and Vessel Wall . . . . . . . . . . . . . . . . . 6

II. Data Presentation for Isothermal Hot-Wall Tests . . . . . . . . . . . . . 15 


\title{
EXPERIMEN T DATA REPORT FOR SEMISCALE ISOTHERMAL
}

\author{
TEST PROGRAM HOT-WALL TESTS
}

\section{INTRODUCTION}

The isothermal test program is part of the Semiscale Blowdown and Emergency Core Cooling (ECC) Project conducted by Aerojet Nuclear Company. The project is part of an overall AEC-sponsored research and development program directed at (a) quantifying the physical processes controlling system behavior during a postulated loss-of-coolant accident (LOCA) in a pressurized water reactor (PWR), and (b) providing an experimental data base for assessing reactor safety evaluation models.

The 1-1/2-loop semiscale system in which the isothermal test program was conducted includes both an intact operating loop and a broken, or blowdown, loop. The operating loop simulates three unbroken loops of a PWR, and the blowdown loop simulates one broken loop of a PWR. Relative to previous experimental systems, the 1-1/2-loop semiscale system provides a source of more representative coupled-system response data from which to obtain a correspondingly more comprehensive understanding of the thermal and hydraulic processes following an LOCA.

The major emphasis in the isothermal experiments was on ECC delivery. The hot-wall tests were conducted to determine the effects of stored wall heat on simulated ECC delivery. The purpose of the hot-wall tests was (a) to determine the time required for auxiliary cooling water (simulated ECC) to reach and fill the lower plenum of the pressure vessel and (b) to investigate the effect of steam generation in the vessel downcomer region on the time required for simulated ECC delivery. As an initial condition for these tests, the semiscale pressure vessel and associated piping had to be relatively hot, 350 to $550^{\circ} \mathrm{F}$. This prerequisite was fulfilled in the normal course of events that accompanied isothermal blowdown tests in which simulated ECC injection was not used. Consequently, each of the five hot-wall tests was conducted following an isothermal blowdown test which did not utilize simulated ECC injection or in which the ECC injection locations were such that the temperatures of the walls of the pressure vessel and related piping were maintained above $350^{\circ} \mathrm{F}$.

The five hot-wall tests and the corresponding isothermal tests which preceded the hot-wall tests are as follows:

\begin{tabular}{cc} 
Hot-Wall Test & Blowdown Test \\
\cline { 2 - 2 } 15.1 & 1001 \\
15.2 & 1004 \\
15.3 & 1010 \\
15.4 & 1011 \\
15.7 & 1014
\end{tabular}


References $1,2,3,4$, and 5 provide information and data on the isothermal tests that preceded the hot-wall tests and Reference 6 provides a description of the isothermal test program, test configuration, and instrumentation.

The test configuration and conditions for each hot-wall test are summarized briefly as follows:

\section{Test 15.1}

(1) Test 15.1 was initiated by injection of simulated ECC into the cold legs of the operating loop and blowdown loop at $42.5 \mathrm{sec}$ following blowdown initiation during isothermal blowdown Test 1001.

(a) Simulated ECC injection flow in the operating loop was $\sim 21$ gpm average for at least $167 \mathrm{sec}$ :

(b) Simulated ECC injection flow in the blowdown loop was calculated to be $\sim 7 \mathrm{gpm}^{[\mathrm{a}]}$ average for at least $167 \mathrm{sec}$.

(2) Other test configuration elements were identical to those for isothermal blowdown Test $1001^{[1]}$; that is, the downcomer gap size was 0.5 inch, the standard (long) lower plenum configuration $(L / D=2.8: 1)$ was used with the thermal shield installed, and the $100 \%$ break area nozzles were used.

\section{Test 15.2}

(1) Test 15.2 was initiated by injection of simulated ECC into the cold legs of the operating loop and blowdown loop at $58 \mathrm{sec}$ following blowdown initiation during isothermal blowdown Test 1004.

(a) Simulated ECC injection flow in the operating loop was $\sim 52 \mathrm{gpm}$ average for $\sim 62.5 \mathrm{sec}$.

(b) Simulated ECC injection flow in the blowdown loop was $\sim 7 \mathrm{gpm}$ average for $\sim 62.5 \mathrm{sec}$.

(2) Other test configuration elements were identical to those for isothermal blowdown Test $1004^{[2]}$; that is, the downcomer gap size was 0.5 inch, the standard (long) lower plenum configuration (L/D $=2.8: 1$ ) was used with the thermal shield installed, and the $100 \%$ break area nozzles were used.

[a] Data were not available for simulated ECC injection flow in the blowdown loop for Test 15.1; indicated flow of $\sim 7 \mathrm{gpm}$ was calculated from data taken during other hot-wall tests. 


\section{Test 15.3}

(1) Test 15.3 was initiated by injection of simulated ECC into the cold legs of the operating loop and blowdown loop at $86 \mathrm{sec}$ following blowdown initiation during isothermal blowdown Test 1010 .

(a) Simulated ECC injection flow in the operating loop was $\sim 51 \mathrm{gpm}$ average for $\sim 47 \mathrm{sec}$.

(b) Simulated ECC injection flow in the blowdown loop was $\sim 7 \mathrm{gpm}$ average for $\sim 47 \mathrm{sec}$.

(2) Other test configuration elements were identical to those for isothermal blowdown Test $1010^{[3]}$; that is, the downcomer gap size was 1.0 inch, the standard (long) lower plenum configuration ( $\mathrm{L} / \mathrm{D}=2.8: 1$ ) was used with the thermal shield installed, and the $100 \%$ break area nozzles were used.

\section{Test 15.4}

(1) Test 15.4 was initiated by injection of simulated ECC into the cold legs of the operating loop and blowdown loop at $23 \mathrm{sec}$ following blowdown initiation during isothermal blowdown Test 1011.

(a) Simulated ECC injection flow in the operating loop was $\sim 66.1 \mathrm{gpm}$ average for at least $57 \mathrm{sec}$.

(b) Simulated ECC injection flow in the blowdown loop was $\sim 7$ gpm average for at least $57 \mathrm{sec}$.

(2) Other test configuration elements were identical to those for isothermal blowdown Test $1011^{[4]}$; that is, the downcomer gap size was 1.69 inches, the standard (long) lower plenum configuration ( $\mathrm{L} / \mathrm{D}=2.8: 1$ ) was used with the thermal shield installed, and the $80 \%$ break area nozzles were used.

\section{Test 15.7}

(1) Test 15.7 was initiated by injection of simulated ECC into the cold legs of the operating loop and blowdown loop at $81 \mathrm{sec}$ following blowdown initiation during isothermal blowdown Test 1014.

(a) Simulated ECC injection flow in the operating loop was $\sim 50 \mathrm{gpm}$ average for $\sim 45 \mathrm{sec}$.

(b) Simulated ECC injection flow in the blowdown loop was $\sim 7 \mathrm{gpm}$ average for $\sim 45 \mathrm{sec}$. 
(2) Other test configuration elements were identical to those for isothermal blowdown Test $1014^{[5]}$; that is, the downcomer gap size was $1.0 \mathrm{inch}$, the standard (long) lower plenum configuration ( $\mathrm{L} / \dot{\mathrm{D}}=2.8: 1$ ) was used with the thermal shield installed, and the flow path was through one $100 \%$ break area nozzle (on the simulated pump discharge side in the blowdown loop) as a result of actuation of only one of the two rupture assemblies during Test 1014.

The purpose of this report is to present the uninterpreted test data in a readily usable form for use by the nuclear community in advance of detailed analysis and interpretation. Section II briefly describes the system configurătion and initial test conditions and events that are applicable to the hot-wall tests. Section III presents the data graphs and provides comments and supporting information necessary for interpretation of the data. Reference 6 is recommended as an additional source of information regarding the isothermal experimental system and program; test conditions and procedures; instrument locations, nomènclature, and accuracies; and methods of obtaining and processing the data. 


\section{SYSTEM AND CONDITIONS FOR HOT-WALL TESTS}

The system configuration, initial test conditions, and events and conditions following blowdown initiation that are specific to the hot-wall tests are presented in this section.

\section{SYSTEM CONFIGURATION}

The 1-1/2-loop isothermal semiscale system used for the hot-wall tests consisted of a pressure vessel with internals; an operating loop with a steam generator, pump, and pressurizer; a blowdown loop with a simulated steam generator, a simulated pump, and two rupture assemblies; a pressure suppression system with a suppression tank and a header; and a simulated ECC system with accumulators and injection pumps.

The standard lower plenum $(\mathrm{L} / \mathrm{D}=2.8: 1$ ) was used in the pressure vessel for all hot-wall tests. This plenum configuration consists of the standard (long) lower head and the downcomer filler extension. The vessel lower plenum was thermally insulated with the thermal shield, which consists of the thermal sleeve and the bottom thermal liner plate. Two vessel downcomer filler pieces were used to vary the downcomer gap; the 0.5-inch downcomer gap was used for Tests 15.1 and 15.2 and the 1.0-inch downcomer gap was used for Tests 15.3 and 15.7. The vessel downcomer filler piece was removed to provide the 1.69-inch downcomer gap for Test 15.4.

The simulated ECC injection system was used for the hot-wall tests. For all hot wall tests except Test 15.4, the operating loop ECC injection pump supplied water to the cold leg of the operating loop, and the blowdown loop ECC injection pump supplied water to the blowdown loop at the simulated pump discharge side of the break. For Test 15.4, only the two ECC accumulators supplied water to the operating loop. The ECC accumulators were connected in series. The outlet flow was split into two parallel paths to facilitate measurement. The flows were recombined prior to injection into the operating loop. Air or steam pressure in the pressure suppression tank was regulated at $\sim 40$ psig to maintain about this pressure in the system during each hot-wall test; three check valves in the upper portion of the pressure suppression tank downcomer facilitated system pressurization while precluding water flow from the tank back into the blowdown loop.

\section{INITIAL TEST CONDITIONS AND SEQUENCE OF EVENTS}

Each hot-wall test was conducted following completion of an isothermal blowdown test and rapid draining of the lower plenum of the pressure vessel. The hot-wall tests were begun at times varying from 23 to $86 \mathrm{sec}$ after the isothermal blowdown tests were initiated. Simulated ECC, as cold as practicable $\left(50\right.$ to $\left.60^{\circ} \mathrm{F}\right)$, was injected into the cold legs of the operating loop and the blowdown loop for durations which varied from $\sim 45 \mathrm{sec}$ to at least $167 \mathrm{sec}$. Air pressure in the pressure suppression tank was regulated at $\sim 40$ psig to maintain about this pressure in the system throughout each hot-wall test. 
Table I gives the metal temperatures in several regions of the pressure vessel at the time each hot-wall test was initiated $(t=0 \mathrm{sec})$, which was the time at which injection of simulated ECC was begun. Figures 1 through 5 show profiles of the average inilial metal temperatures at different locations in the pressure vessel. A significantly different temperature profile is shown for Test 15.7, which was a single-ended break test.

\section{$\underline{\text { TABLE I }}$}

INITIAL METAL TEMPERATURES IN PRESSURE VESSEL

DOWNCOMER FILLER PIECE, CORE BARREL, AND VESSEL WALL

\begin{tabular}{|c|c|c|c|c|c|c|}
\hline \multirow[b]{2}{*}{$\begin{array}{l}\text { Measurement } \\
\text { Location }[a] \\
\end{array}$} & \multirow[b]{2}{*}{$\begin{array}{c}\text { Detector } \\
\text { Designation }\end{array}$} & \multicolumn{2}{|c|}{ Initial Meta } & \multicolumn{3}{|c|}{ Temperatures $\left({ }^{\circ} \mathrm{F}\right)$} \\
\hline & & $\begin{array}{l}\text { Test } \\
15.1 \\
\end{array}$ & $\begin{array}{l}\text { Test } \\
15.2 \\
\end{array}$ & $\begin{array}{l}\text { Test } \\
15.3 \\
\end{array}$ & $\begin{array}{l}\text { Test } \\
15.4 \\
\end{array}$ & $\begin{array}{l}\text { Test } \\
15.7 \\
\end{array}$ \\
\hline 48 & $T M-48 D-0$ & 530 & 530 & 500 & -- & 491 \\
\hline 48 & $T M-48 D-180$ & 520 & 520 & -- & -- & 491 \\
\hline 47 & $T M-47 C-0$ & 495 & 502 & 500 & 492 & 482 \\
\hline 47 & $T M-47 C-180$ & 508 & 502 & 445 & -- & 503 \\
\hline 63 & $T M-63 D-45$ & 535 & 530 & 490 & 517 & 520 \\
\hline 63 & $T M-63 D-225$ & 522 & -- & -- & 512 & -- \\
\hline 62 & $T M-62 C-45$ & 505 & 493 & 485 & 460 & 478 \\
\hline 78 & TM-78D-0 & 532 & 530 & 485 & 502 & 535 \\
\hline 78 & TM-78D-180 & 530 & 530 & 485 & 500 & 529 \\
\hline 77 & $T M-77 C-0$ & $490^{\circ}$ & 490 & 475 & 430 & 470 \\
\hline 77 & TM-77C-180 & 505 & 490 & 478 & 470 & 500 \\
\hline 95 & $T M-94 C-45$ & $468^{\circ}$ & 468 & 450 & 360 & 470 \\
\hline 95 & $T M-94 C-16-45$ & 462 & 465 & $450^{\circ}$ & 360 & 445 \\
\hline 95 & TM-95D-45 & 505 & 510 & 455 & 457 & -- \\
\hline 95 & $T M-95 D-225$ & 520 & 520 & 460 & 460 & 530 \\
\hline 116 & $T M-116 D-45$ & 460 & 365 & 362 & --- & 525 \\
\hline 116 & TM-116D-225 & 480 & 415 & 376 & --- & 525 \\
\hline 116 & $T M-116 \mathrm{~V}-0$ & --- & -- & -- & 382 & -- \\
\hline 116 & $\mathrm{TM}-116 \mathrm{~V}-180$ & -- & -- & -- & 380 & $-\infty$ \\
\hline
\end{tabular}

[a] Measurement location denotés approximate distance (in.) below pressure vessel upper flange face.

[b] Detector designations are defined in Reference.6. 


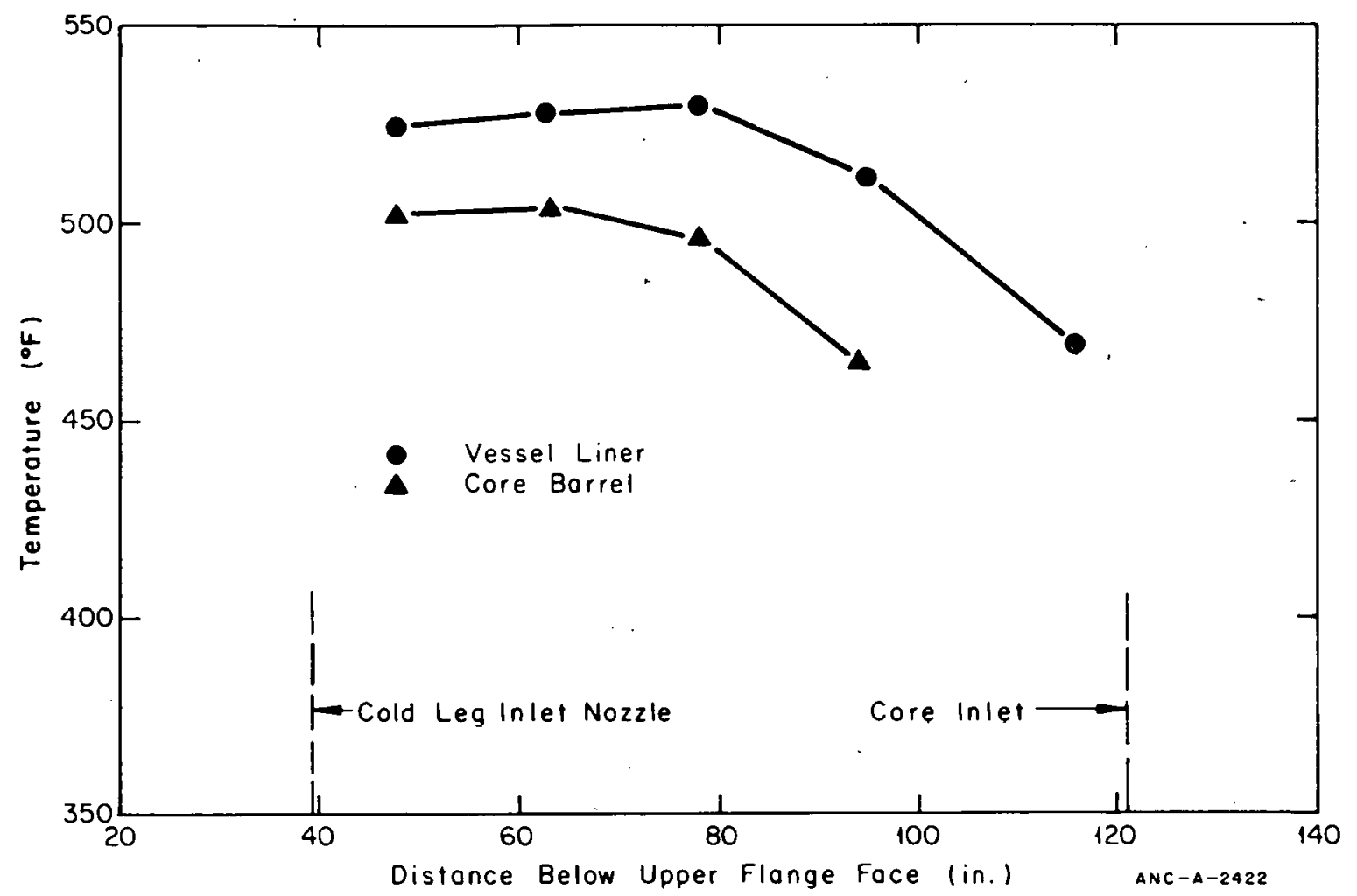

Fig. 1 Average temperature profiles in pressure vessel at start of Test 15.1 .

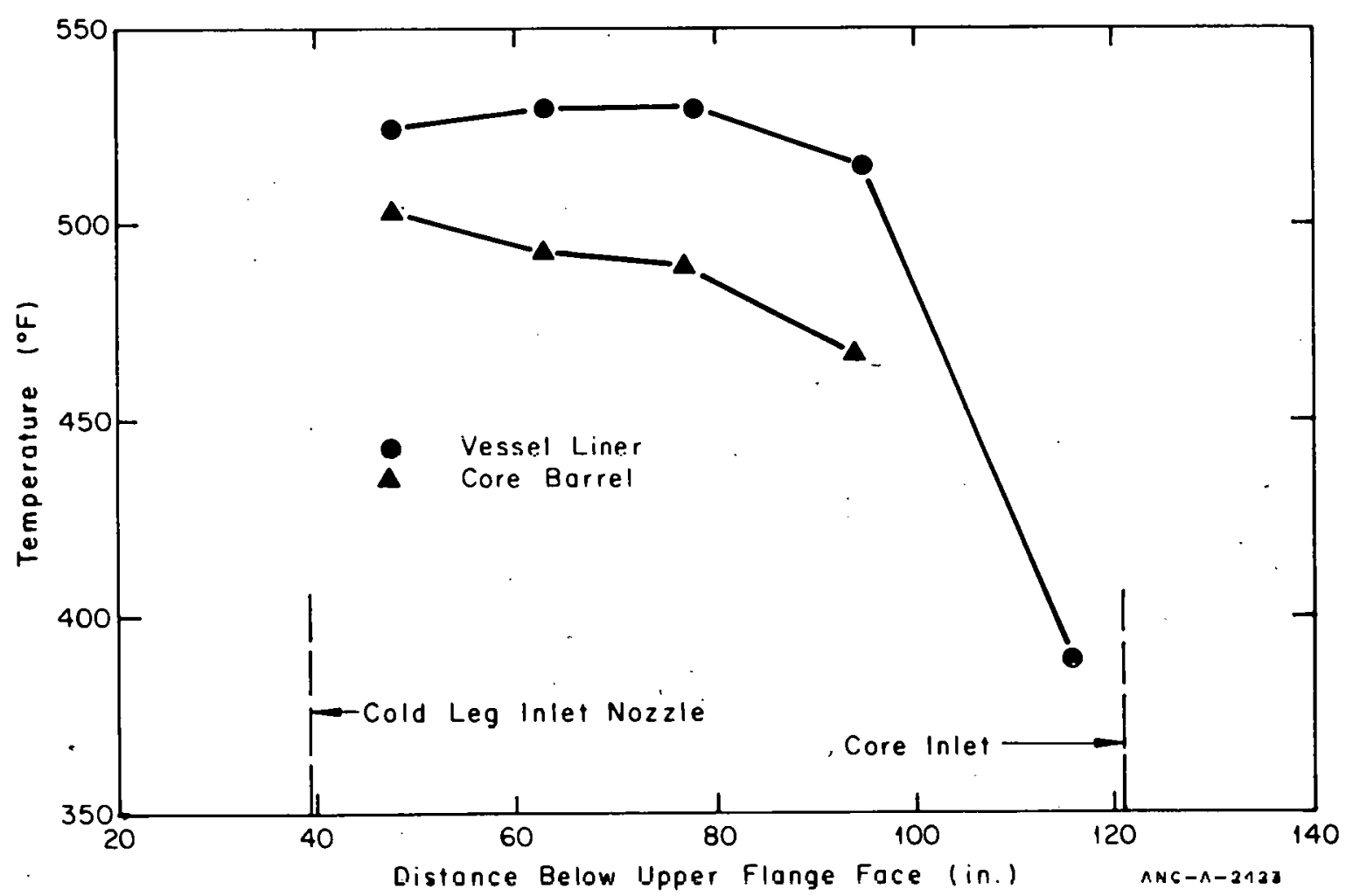

Fig. 2 Average temperature profiles in pressure vessel at start of Test 15.2 . 


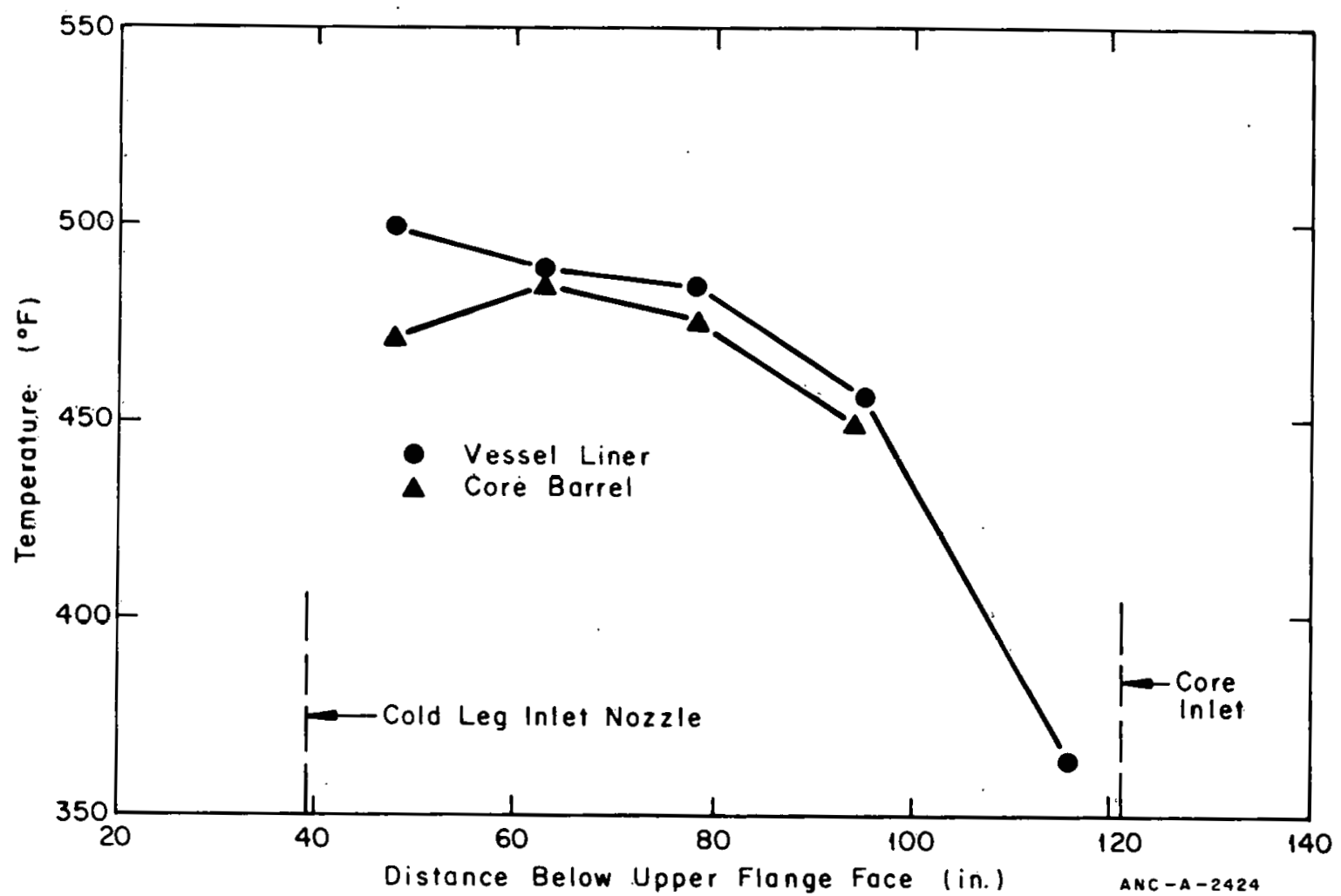

Fig. 3 Average temperature profiles in pressure vessel at start of Test 15.3 .

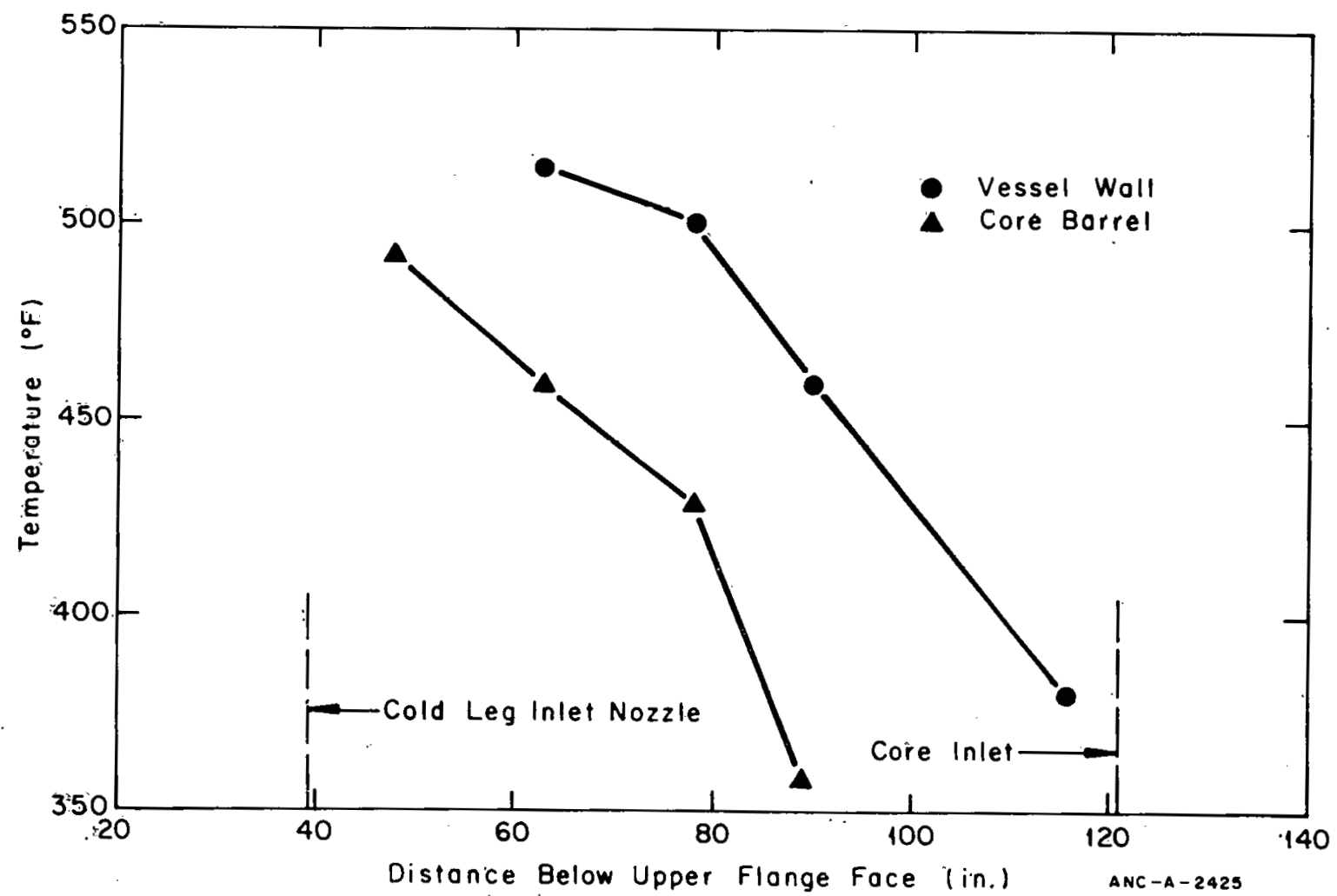

Fig. 4 Average temperature profiles in pressure vessel at start of Test 15.4 . 


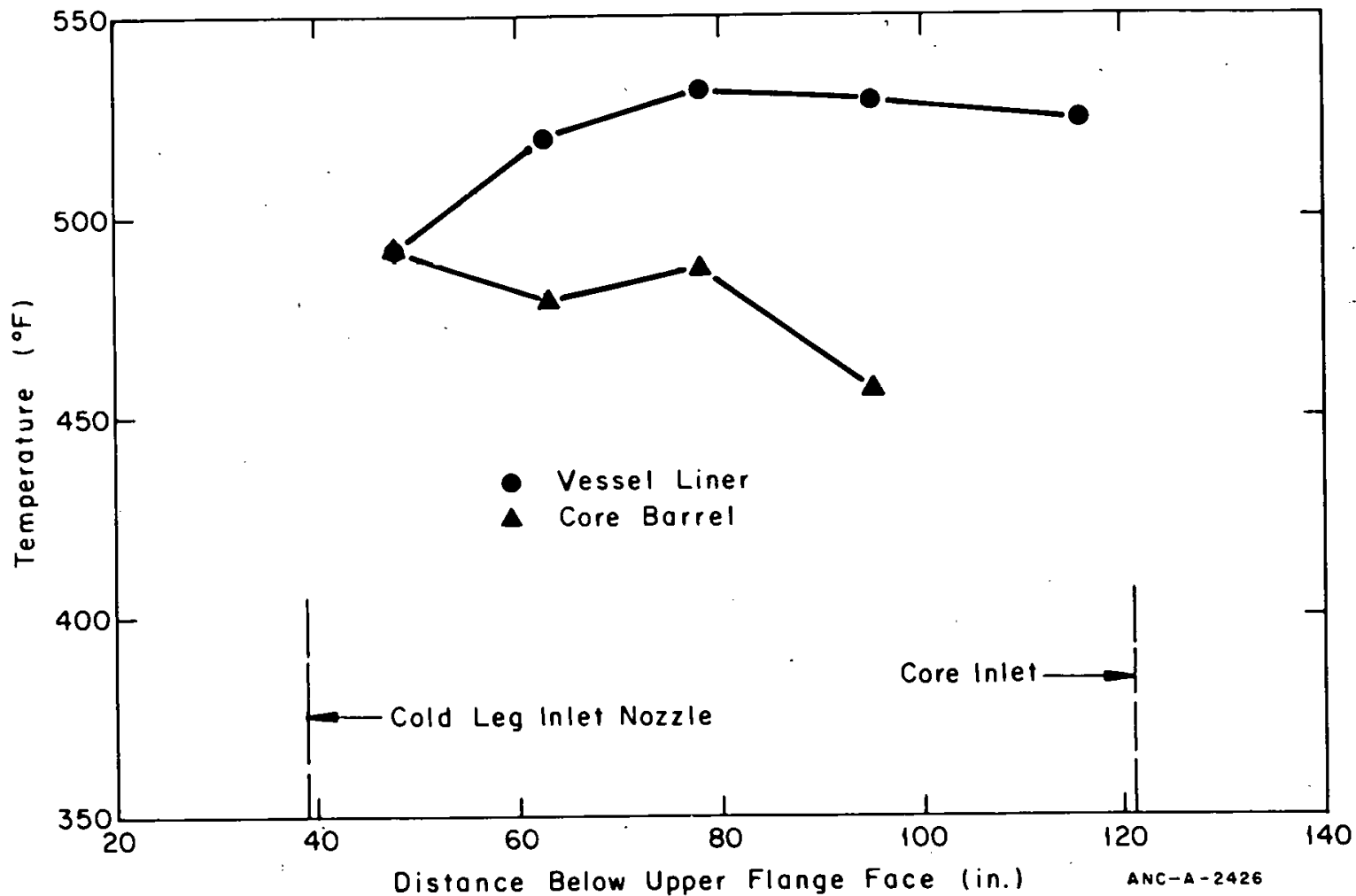

Fig. 5 Average temperature profiles in pressure vessel at start of Test 15.7 . 


\section{DATA PRESENTATION}

The data from semiscale isothermal program hot-wall tests are presented with brief comment. Processing and analysis have been performed only to the extent necessary to obtain appropriate engineering units and to assure that the data are reasonable and correct. In all cases, in converting transducer output to engineering units, a homogeneous fluid was assumed. Further interpretation and analysis should consider that sudden decompression processes such as those occurring in the isothermal tests may have subjected the measurement devices to nonhomogeneous fluid conditions.

Figures 6 through 9 and Table II provide supporting information for interpretation of the data shown in Figures 10 through 370. Figures 6 through 9 show- the locations of all measurements in the hot-wall test system. Table II groups the measurements taken during the hot-wall tests according to measurement type; identifies the specific measurements, their locations, and the range over which the data are considered valid; provides brief comments regarding the data; and references the measurements and comments to the corresponding figure on which the data are presented. The data are presented in many instances in the form of composite graphs of a given variable at several locations during a single test. Zero seconds on all graphs is the time of initiation of simulated ECC injection.

Reference 6 provides more detailed information regarding the isothermal experimental system and program; test conditions and procedures; instrument locations, nomenclature, and accuracies; and methods of obtaining and processing the data. 


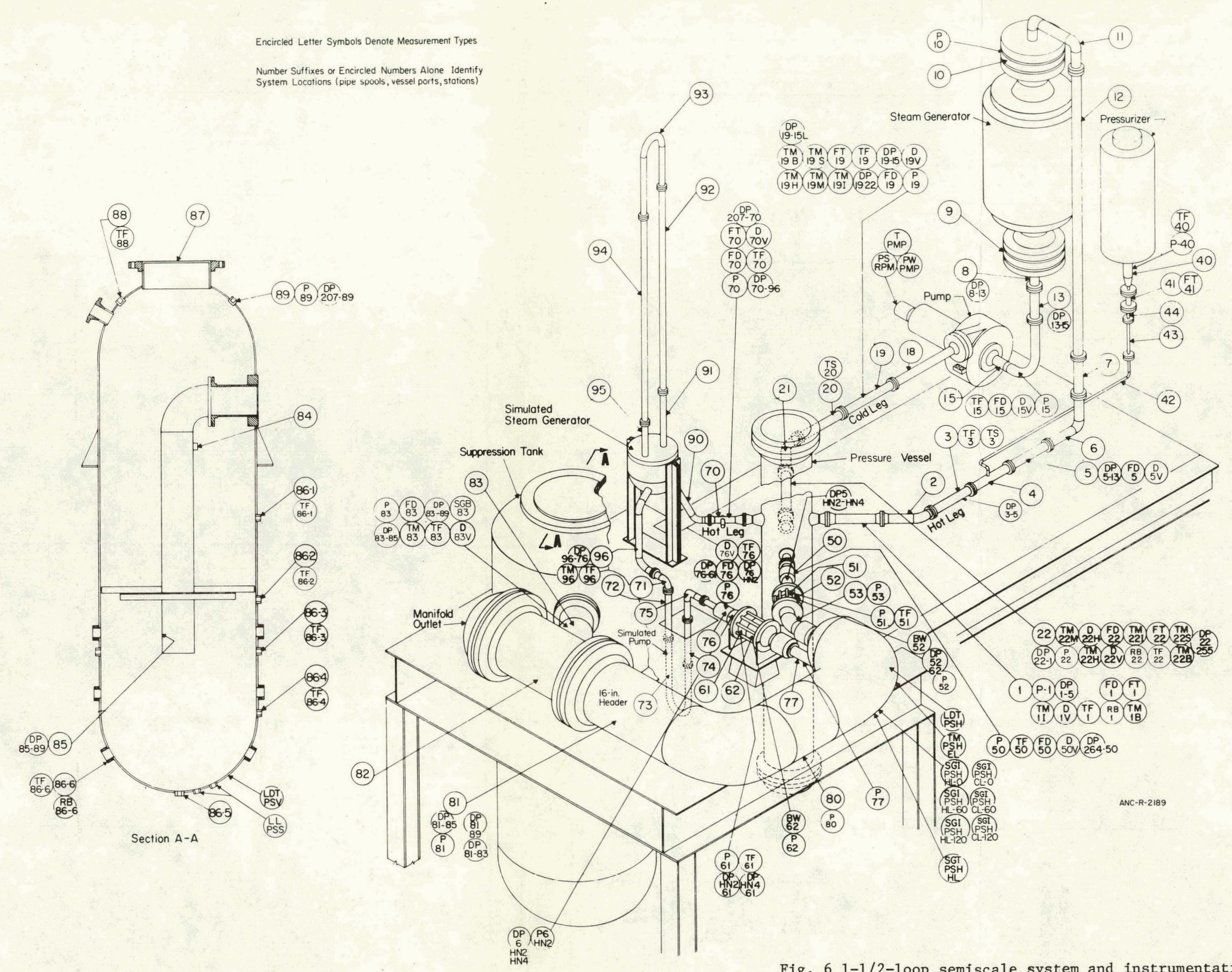

Fig. 6 1-1/2-1oop semiscale system and instrumentation -- isometric. 


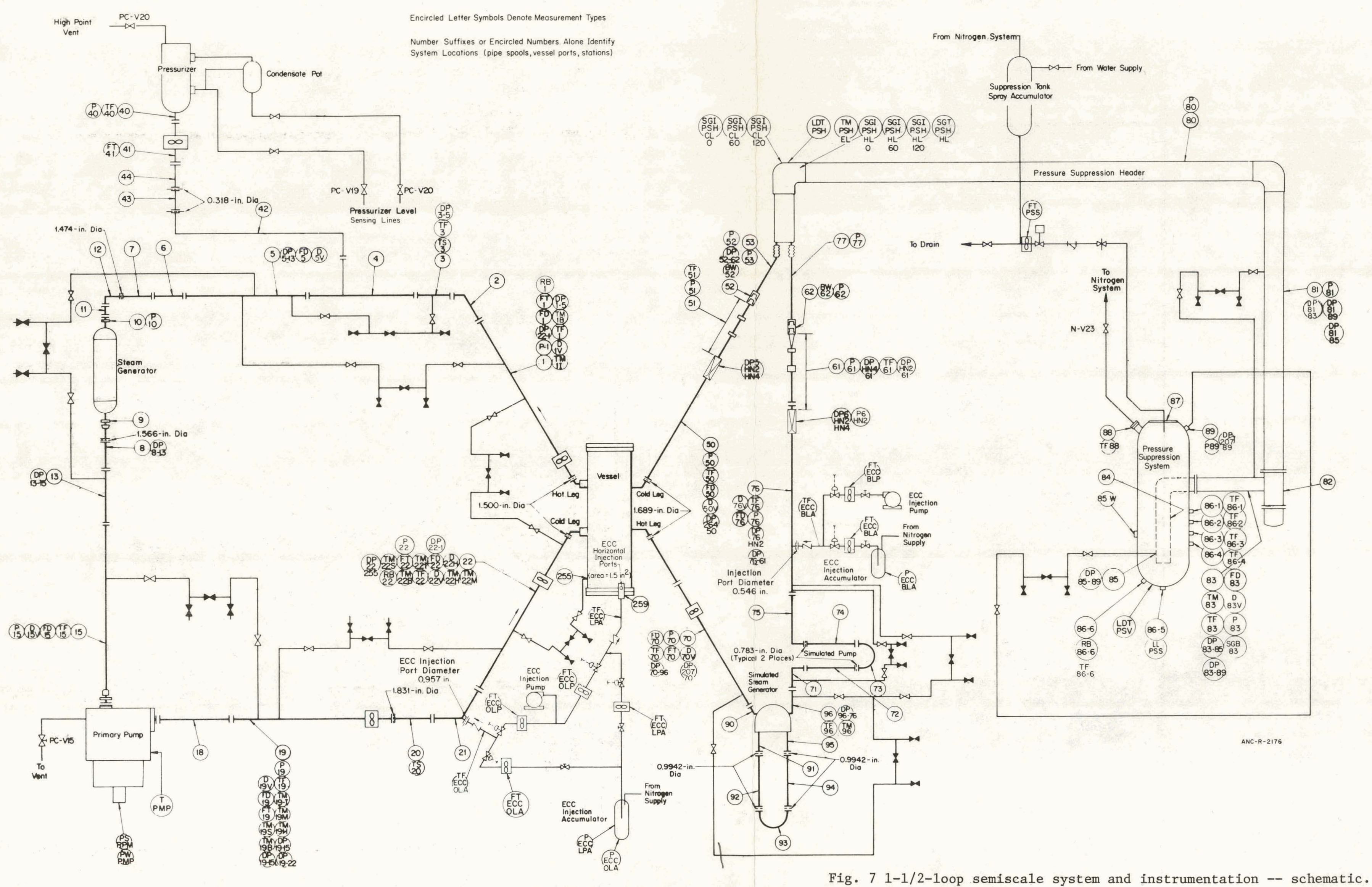




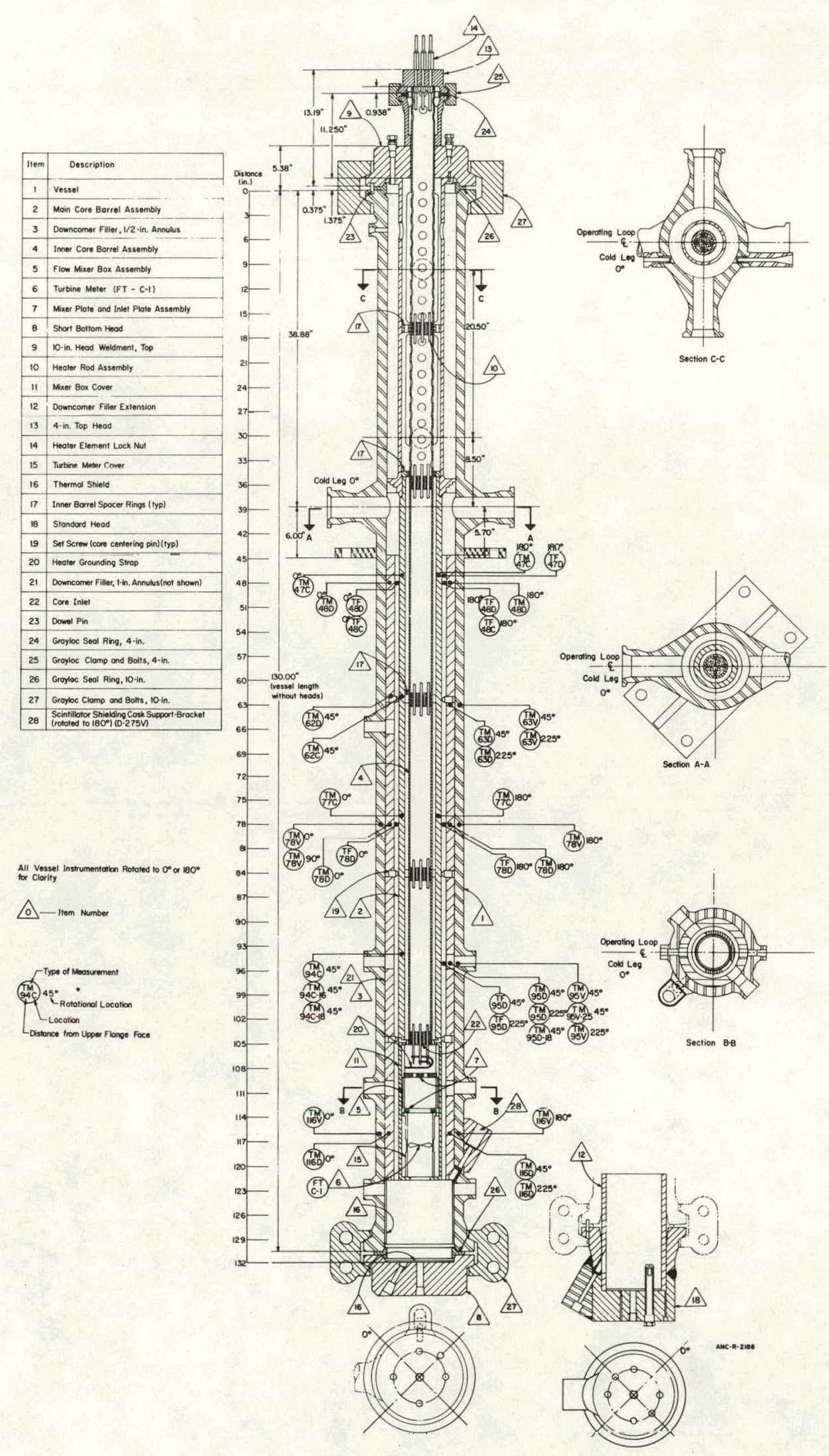

Fig. 8 Pressure vessel -- cross sectional view showing instrumentation. 

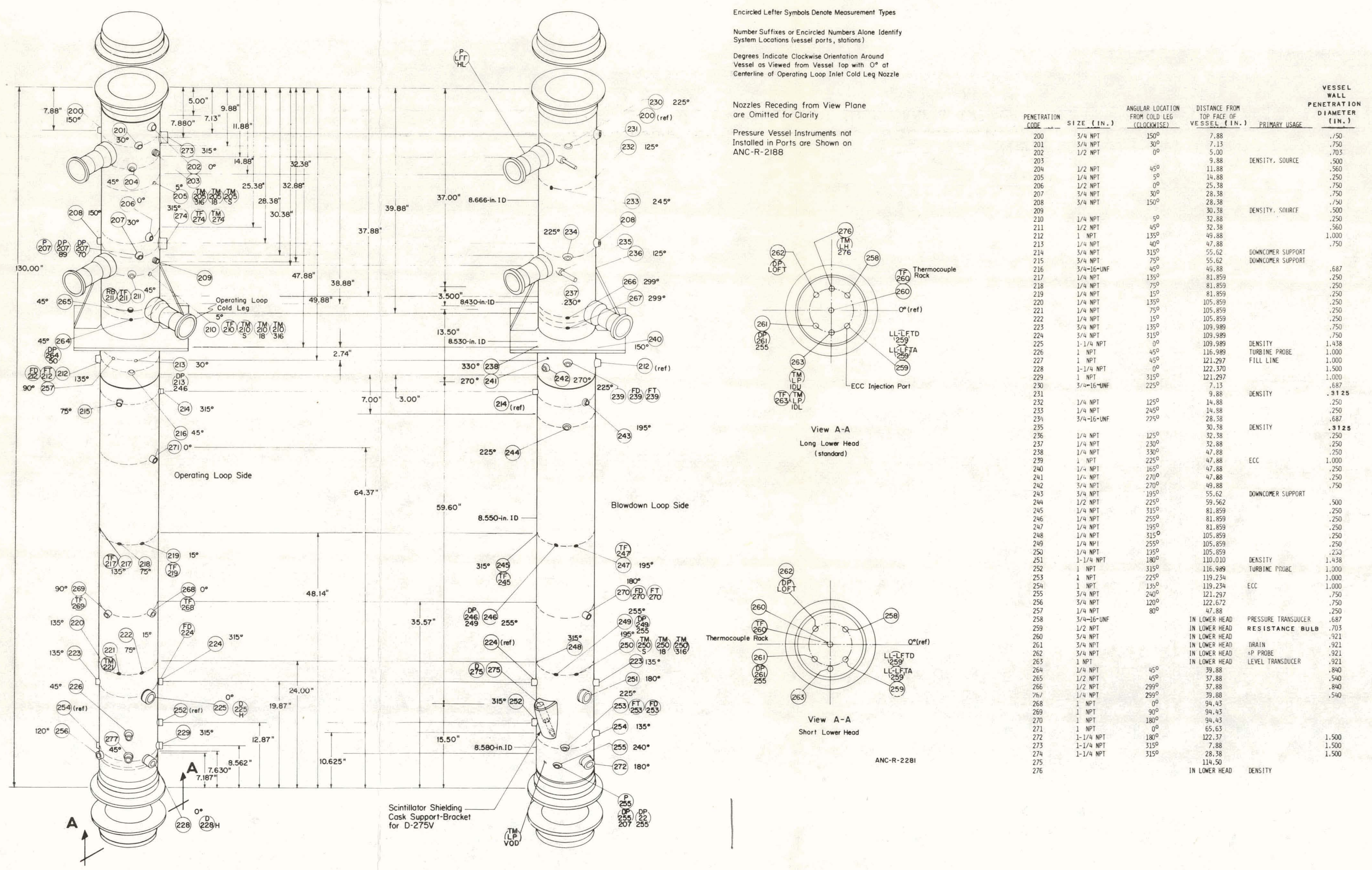

Fig. 9 Pressure vesse1 -- isometric showing instrumentation. 
TABLE II

DATA PRESENTATION FOR ISOTHERMAL HOT-WALL TESTS

\begin{tabular}{|c|c|c|c|c|}
\hline Measurement [a] & Locacton $|b|$ & $\operatorname{Rang} e^{(c, 0)}$ & Flgure [d] & Comment $[\mathrm{d}]$ \\
\hline FLUID TEMPERATURE & & & & $\begin{array}{l}\text { Chinmel-Al umel thermocouples; estimated } \\
\text { accurncy to withln } \pm 7^{\circ} \mathrm{F} \text {. }\end{array}$ \\
\hline Operat1ng Loop & & $33-650^{\circ} \mathrm{F}$ & $10-14$ & \\
\hline$T F-1$ & Hat lee. Spant 1 & & & * \\
\hline$T F-15$ & Pump suction, Spool 15 & & & \\
\hline$T F=19$ & Pump discharge, Spool 19 & & & · \\
\hline TF -22 & Cold leg, Spool 22 & & & . \\
\hline TF -40 & Pressurizer out let, Spool 40 & & & \\
\hline TS-3 & Hot leg, Spool 3 & & & TS-3 is a shielded themocouple \\
\hline TS-20 & cold leg, Spool 20. & & & $\begin{array}{l}\text { TS-20, a shielded thermocouple, failed } \\
\text { dur1ng Tests } 15.1 \text {, } 15.3 \text {, and } 15.7 \text {. TS-20 } \\
\text { was not used during Test } 15.4\end{array}$ \\
\hline Blowdown Loop & & $33-650^{\circ} \mathrm{F}$ & $15-19$ & \\
\hline $\mathrm{Tr}-50$ & Cold leg, Spool 50 & & & \\
\hline TF-51 & Cold $1 \mathrm{cg}$ downstrean of vessel-side nozzle & & & \\
\hline $\mathrm{TF}-70$ & Hot leg, Spool 70 & & & \\
\hline $\mathrm{TF}-76$ & Cold 1e8, Spool 76 & & & fF-76 falled during Test 15.2 \\
\hline TF-96 & Sltululed sleàu generator diacharge, Spool 96 & & & TF-96 was not used during Tests 15.1 and 15.2 \\
\hline \multicolumn{5}{|l|}{ Pressurc Suppression System } \\
\hline TF-83 & $\begin{array}{l}\text { Header near downcomer entrance (1 inch from } \\
\text { ID of header on bottom) }\end{array}$ & $33-650^{\circ} \mathrm{F}$ & $20-24$ & TF-83 was not used during Test 15.4 \\
\hline TF-B6-3 & Suppression vessel, Station $86-3$ & $33-300^{\circ} \mathrm{F}$ & & \\
\hline$T F-86-4$ & Suppression vossel, Station $86-4$ & $33-300^{\circ} \mathrm{F}$ & & TF-86-4 falled during Tests $15.3,15.4$, and 15.7 \\
\hline$T F-88$ & $\begin{array}{l}\text { Suppresston vessel vapor chamber, } 2 \text { inches } \\
\text { from tank wall }\end{array}$ & $33-650^{\circ} \mathrm{F}$ & & \\
\hline $\mathrm{RB}-86-6$ & Suppression vessel water, Station $86-6$ & $0-1000^{\circ} \mathrm{F}$ & & $\begin{array}{l}\text { RB-86-6 is a resistance bulb flutd temperature } \\
\text { detector }\end{array}$ \\
\hline $\begin{array}{l}\text { Lower Plenum (Vertical ther- } \\
\text { mocouple Rack) }\end{array}$ & & $33-650^{\circ} \mathrm{F}$ & & $\begin{array}{l}\text { Nhe thermocouples spaced at } 2-\text { inch intervals } \\
\text { upward from } 21.75 \text { inches above botton of the } \\
\text { lower head }\end{array}$ \\
\hline $\mathrm{TF}-260-2$ & 2-inch level from inside borcom of lower head & & $25-29$ & \\
\hline$T F-260-4$ & 4-1nch level from Inside bottom of lower head & & & \\
\hline TF-260-6 & 6-1nch level from inside bottom of lower head & & & \\
\hline$T F-260-8$ & 8-1nch level from inside boctom of lower head & & & • \\
\hline$T F-260-10$ & 10-inch level from inside bot tom of lower head & & & \\
\hline TF-260-12 & 12-inch level from inside bottom of lower head & & & $\begin{array}{l}\text { TF-260-12 date could not be digitized for } \\
\text { Test } 15.2 \text {. TP-260-12 failed during Test } \\
15.3 \text { and } 15.7\end{array}$ \\
\hline$T F-260-16$ & 14-1nch level from Inside bottom of lower head & & & \\
\hline$T P-260-16$ & 16-1nch level from inside botton of lower hed & & & 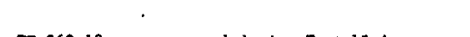 \\
\hline$T F-260-18$ & 18-1nch level from Inside bottom of lower head & & & $\begin{array}{l}\text { TP-260-18 was not used during Test } 15.4 . \\
\text { TP-260-18 falled durting Tooto } 15.3 \text { and } 15.7\end{array}$ \\
\hline Downcomer Gap & & $33-650^{\circ} \mathrm{F}$ & - & \\
\hline$T P-47 \mathrm{D}-180$ & $\begin{array}{l}248 \text { inches, } 180^{\circ} \text {, extending } 1 / 8 \text { inch into fluld } \\
\text { from veseel wall side }\end{array}$ & & $30,31,32$ & TF-47D-180 was not used during Test 15.4 \\
\hline TF $-48 \mathrm{C}-180$ & $\begin{array}{l}28 \text { inches, } 180^{\circ} \text {, extending } 1 / 8 \text { inch into fluid } \\
\text { from core barrel }\end{array}$ & & $30-34$ & \\
\hline $\mathrm{TF}-48 \mathrm{D}-0$ & $\begin{array}{l}\text { 248 inches, } 0^{\circ} \text {, extending } 1 / 8 \text { inch into tluid } \\
\text { from vessel wail side }\end{array}$ & & $30,31,32$ & TF-48D-0 was not used during Test 15.4 \\
\hline TP-78D-0 & 278 Inches, $0^{\circ}$ & & $35,36,37,39$ & TP-78D-0 was not used during Test 15.4 \\
\hline$T F-78 D-180$ & 278 inches, $180^{\circ}$ & & $35,36,37,39$ & TP-78D-180 was not used during Test 15.4 \\
\hline$T F-95 D-45$ & 295 inches, $45^{\circ}$ & & 35,37 & $\begin{array}{l}\text { TF-95D-45 falled during Tests } 15.2 \text { and } 15.7 \\
\text { TP-95D-45 was not used during test } 15.4\end{array}$ \\
\hline TP-95D-225 & थ95 1nches, $225^{\circ}$ & & $35,36,37,39$ & TP-95D-255 was not used during Test 15.4 \\
\hline TF-214 & Ss.62 1trches, $315^{\circ}$ & & 33 & TY +214 was waed only dur1ng Test 15.4 \\
\hline$T F-215$ & 55.62 1nches, $75^{\circ}$ & & 33 & TF-2.15 was used only during Test 15.4 \\
\hline$T F-217$ & 81,86 Inches, $135^{\circ}$ & & 38 & TF-217 was used only dur1ng rest 15.4 \\
\hline $\mathrm{TF}-219$ & 81.86 Inches, $15^{\circ}$ & & 38 & TF-219 was used only during Test 15.4 \\
\hline $\mathrm{TP}-245$ & 81.86 inches, $315^{\circ}$ & & 38 & TT-245 was used only during Test 15.4 \\
\hline$T F-247$ & 81.86 Inches, $195^{\circ}$ & • & 38 & TP-247 was used only durting Test 15.4 \\
\hline TF-268 & 94.43 Inches, $0^{\circ}$ & & 38 & TP-268 was uged only during Test 15.4 \\
\hline TF-269 & 94.43 inches, $90^{\circ}$ & & 38 & TP-269 was used only during Test 15.4 \\
\hline Outler Plenum & 10 & $33-650^{\circ} \mathrm{F}$ & $40-43$ & \\
\hline$T F-211$ & 32.4 1nches, $45^{\circ}$ & & & TF-211 falled during Test 15.3 \\
\hline TP-263 & In lower plenum head, Station 263 & & & $\begin{array}{l}\text { TF-263 failed during Test } 15.4 \text { and was not } \\
\text { used during Tests 15.1, 15.2, 15.3, and } 15.7\end{array}$ \\
\hline$T F-274$ & 28.38 Inches, $315^{\circ}$ & & & $\begin{array}{l}\text { Tr-274 was not used during Tests 15.3, 15.4, } \\
\text { and } 15.7\end{array}$ \\
\hline ECc Sygrem & & $33-300^{\circ} \mathrm{F}$ & $44-46$ & $\cdot$ \\
\hline$T P-E C C-B L P$ & In line from blowdown loop ECC infection pump & & & $\begin{array}{l}\text { TF-ECC-BLP was not used during Test } 15.1 . \\
\text { FF-ECC-BL? falled durfng Test } 15.4\end{array}$ \\
\hline TP-ECC-OLP & In line from operating loop ECc inject in pump & & & $\begin{array}{l}\text { TF-ECC-OLP was not used during Tests } 15.1 \text {, } \\
15.3 \text {, and } 15.4\end{array}$ \\
\hline TP BOO OLS & $\begin{array}{l}\text { In line frnm nerratine loog ECC infection } \\
\text { accuaulator }\end{array}$ & & & $\begin{array}{l}\text { TP-Ecc-oLA falled during Test } 15.4 \text { and was } \\
\text { 110L usti dus lug Teowo } 15.1 ; 15.6,15.3 \text {, tas } \\
15.7\end{array}$ \\
\hline
\end{tabular}


TABLE II (contd.)

DATA PRESENTATION FOR ISOTHERMAL HOT-WALL TESTS

\begin{tabular}{|c|c|c|c|c|}
\hline Measurement $[\mathrm{a}]$ & Locat ion $[\mathrm{b}]$ & Range $^{|c, d|}$ & Eigure ${ }^{\{\mathrm{d}\}}$ & Conment $\mid \mathrm{d}\rceil$ \\
\hline METAL TEMPERATURE & & & & $\begin{array}{l}\text { Chromel-Alumel chermocouples; estimated } \\
\text { accuracy to with1n } \pm 7^{\circ} \mathrm{F}\end{array}$ \\
\hline Core Barrel & & $33-650^{\circ} \mathrm{F}$ & $47-51$ & \\
\hline$T M-47 C-0$ & 247 1nches, $0^{\circ}, 1 / 8$ inch from oD & & & TM-47C-0 failed during Test 15.4 \\
\hline$T-47 C-180$ & 47 Inches, $180^{\circ}, 1 / 8$ inch from $O D$ & & & $\begin{array}{l}\text { TM-47C-180 data for Test } 15.2 \text { could not be } \\
\text { disitized }\end{array}$ \\
\hline$T M-62 C-45$ & Q62 inches, $45^{\circ}, 1 / 8$ inch from od & & & \\
\hline$T M-77 C-0$ & 277 inches, $0^{\circ}, 1 / 8$ inch from od & . & & \\
\hline$T M-77 C-180$ & 277 inches, $180^{\circ}, 1 / 8$ inch from od & & & \\
\hline$T M-94 C-45$ & w95 inches, $45^{\circ}, 1 / 8$ inch from $O D$ & & & $\begin{array}{l}\text { TM-94C-45 falled about } 46 \mathrm{sec} \text { after blowdown } \\
\text { during Test } 15.2\end{array}$ \\
\hline$\pi i-94 C-16-45$ & 295 Inches, $45^{\circ}, 1 / 16$ inch from ID & & & \\
\hline Dowasomer Filler & & $37-65 n^{\circ} 5$ & 59 ES & 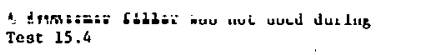 \\
\hline$T M-48 D-0$ & $\sim 48$ inches, $0^{\circ}, 1 / 16$ inch from ID & & & \\
\hline$T M-48 D-180$ & 2 48 1nches, $180^{\circ}, 1 / 16$ inch from id & & & TM-48D-180 failed dur1ng Test 15.3 \\
\hline$T M-63 D-45$ & 263 Inches, $45^{\circ}, 1 / 16$ Inch from ID & & & . \\
\hline$T M-63 D-225$ & ح63 Inches, $225^{\circ}, 1 / 8$ Inch from $0 D$ & & & $\begin{array}{l}\text { TM-63D-225 falled during Tests } 15.2,15.3 \text {, } \\
\text { and } 13.7\end{array}$ \\
\hline$T M-78 D-0$ & 278 1nches, $0^{\circ}, 1 / 16$ inch from 10 & & & \\
\hline TM-78D-180 & 278 inches, $180^{\circ}, 1 / 16$ inch from id & & & \\
\hline$T M-95 D-45$ & 295 Inches, $45^{\circ}, 1 / 16$ inch from ID & & & \\
\hline TM-95D-225 & 295 Inches, $225^{\circ}, 1 / 16$ inch from id & & & \\
\hline$T M-116 \mathrm{D}-0$ & w116 inches, $0^{*} 1 / 16$ inch from ID & & & $\begin{array}{l}\text { TM-116D-0 was not used durfing Tests } 15.1 \\
\text { and } 15.2\end{array}$ \\
\hline$T M-116 D-45$ & 2116 inches, $45^{\circ}, 1 / 16$ inch from ID & & & \\
\hline$T M-116 D-225$ & w116 Anches, $225^{\circ}, 1 / 16$ inch from ID & & & \\
\hline Vessel Wall & & $33-650^{\circ} \mathrm{F}$ & & \\
\hline$T M-95 V-45$ & $\approx 95$ inches, $45^{\circ}, 1 / 2$ inch fros od & & $57,58,59,61$ & TM-95V-45 was not used during Test 15.4 \\
\hline$T M-95 D-45$ & n95 1nches, $45^{\circ}, 1 / 16$ inch from ID & & $57,58,59,61$ & TM-95D-45 was not used during Test 15.4 \\
\hline TM-95D-18-45 & थ95 Inches, $45^{\circ}, 0.176$ Inch from ob & & So. 61 & $\begin{array}{l}\text { TM-95D-18-45 was not used during Testa } \\
15.1,15.2 \text {, and } 15.4\end{array}$ \\
\hline$T i-63 V-45$ & w63 1nches, $45^{\circ}, 1 / 4$ inch from ID & & 56 & TM-63V-4.5 was uked only during Test 1.5 .4 \\
\hline$T M-63 V-225$ & $\sim 63$ 1nches, $225^{\circ}, 1 / 4$ tnch from id & & 56 & TM-63V-225 was used only during Test 15.4 \\
\hline$T M-78 V-0$ & w78 inches, $0^{\circ}, 1 / 4$ fnch from 10 & & 56 & TM-78V-0 was used only during Test 15.4 \\
\hline$T M-78 V-90$ & 278 inches, $90^{\circ}, 1 / 5$ inch from in & & s6 & TM-78V-90 was used only during Test 15.4 \\
\hline TM- $95 V-25-45$ & $\approx 95$ inches, $45^{\circ}, 1 / 4$ inch from 10 & & 56,60 & TM-95V-25-45 was used only during Test 15.4 \\
\hline TM-95V-22S & थ 95 Inches, $225^{\circ}, 1 / 4$ inch from ID & & 56,60 & TM-9SV-225 was used only during Test 15.4 \\
\hline TM-116V-0 & 2116 inches, $0^{\circ}, 1 / 4$ 1nch from id & & 56 & $\mathrm{TM}-116 \mathrm{~V}-0$ was used only during Test 15.4 \\
\hline$T M-116 \mathrm{~V}-180$ & w116 inches, $180^{\circ}, 1 / 4$ inch from ID & & 56 & TM-116V-180 was used only during Test 15.4 \\
\hline Lower Plenum Vessel Wall & & $33-650^{\circ} \mathrm{F}$ & $62-66$ & \\
\hline TM-LH-276 & In lower plenum head & & & \\
\hline TMI-LP-1DL & $\begin{array}{l}4.9 \text { Inches below lower plenum upper Grayloc } \\
\text { flange face. } 270^{\circ} \text { from cold leg conterlitir, } \\
1 / 16 \text { inch from to of filler piece }\end{array}$ & & & \\
\hline TN-LP-IDU & $\begin{array}{l}5,0 \text { inches above lower plenum upper Grayloc } \\
\text { fiange face, } 270^{\circ} \text { from cold leg centerline, } \\
1 / 16 \text { inch from to of filler piece }\end{array}$ & & & TM-LP-IDU falled during Test 15.3 \\
\hline$T M-L P-Y O D$ & $\begin{array}{l}\text { On vessel OD } 5.0 \text { inches above lower plenum } \\
\text { upper Grayloc flange face, } 270^{\circ} \text { from cold } \\
\text { leg centerline }\end{array}$ & & & \\
\hline Operating Loop & & $33-650^{\circ} \mathrm{P}$ & & \\
\hline TM-1B & Hot leg, Spool 1, 1/8 tneh from ID (bottom) & & $67-71$ & $\begin{array}{l}\text { TM-1B system was not cal1brated for Tests } \\
15.4 \text { and } 15.7 \text {. Data prior to } 0.5 \text { sec are } \\
\text { not. physirsi result far. Tast } 1.5 .7\end{array}$ \\
\hline$T M-1 I$ & Hot 1 eg, Spool $1,1 / 8$ inch from ID (top) & & $67-71$ & \\
\hline$T M-19 B$ & Cold leg, Spool 19, 1/8 inch frow ID (botcom) & & $72-76$ & TM-19B falled during Tests 15.2 and 15.3 \\
\hline$T M-19 H$ & Cold leg, Spool 19, 1/8 inch from ID (mIddle) & & $72-76$ & \\
\hline$T H-19 I$ & Cold leg, Spool 19, 1/8 1nch ID (top) & & $72-76$ & \\
\hline TM-19M & Cold log, Speed $19,2 / 4$ ineh from ID (cop) & & $72-76$ & TA 19 was not uasd during Teat 15.4 \\
\hline$T M-19 S$ & Cold leg, Spool 19, outside surface (top) & & $32-76$ & \\
\hline$\hat{T M M}-22 B$ & Cold leg, Spool 22, 1/8 inch from ID (bottom) & & $77-81$ & \\
\hline TM-22H & Cold leg, Spool 22, 1/8 inch from ID (mIddle) & & $77-81$ & \\
\hline$T M=22 . I$ & Cold leg, Spool 22, 1/8 Inch frow ID (top) & & $77-81$ & $\begin{array}{l}\text { TM-221 falled dur 1ng Test } 15.7 \text {. TM-22I } \\
\text { was not used during Tests } 15.1 \text { and } 15.2\end{array}$ \\
\hline IMM-22M & Cold leg, Spool 22, $1 / 4$ Inch from to (top) & & $77-81$ & THY-22M was not used during Test 15.4 \\
\hline TM-22S & Cold leg, Spool 22, outside surface (top) & & $77-81$ & \\
\hline Blowdown Loop & & $33-650^{\circ} \mathrm{F}$ & & \\
\hline 96 & Stmulaced pump suction, Spool $96,1 / 16$ 1nch & & $82-84$ & $\begin{array}{l}\text { TM-96 was not used during Tests } 15.1 \text { and } \\
15.2\end{array}$ \\
\hline Pressure Suppression System & & & $85-86:$ & - \\
\hline$T \mathbf{T M}-83$ & Header, on surface near f1rst elbow & & & TM-83 was used only during Test 15.2 \\
\hline TM-PSH-EL & Header, on surface near first elbow & & & $\begin{array}{l}\text { TH-PSH-EL was used only during Tests } \\
15.1 \text { and } 15.2\end{array}$ \\
\hline
\end{tabular}


TABLE II (contd.)

DATA PRESENTATION FUK ISU'IHEKMAL HOT-WALL TESTS

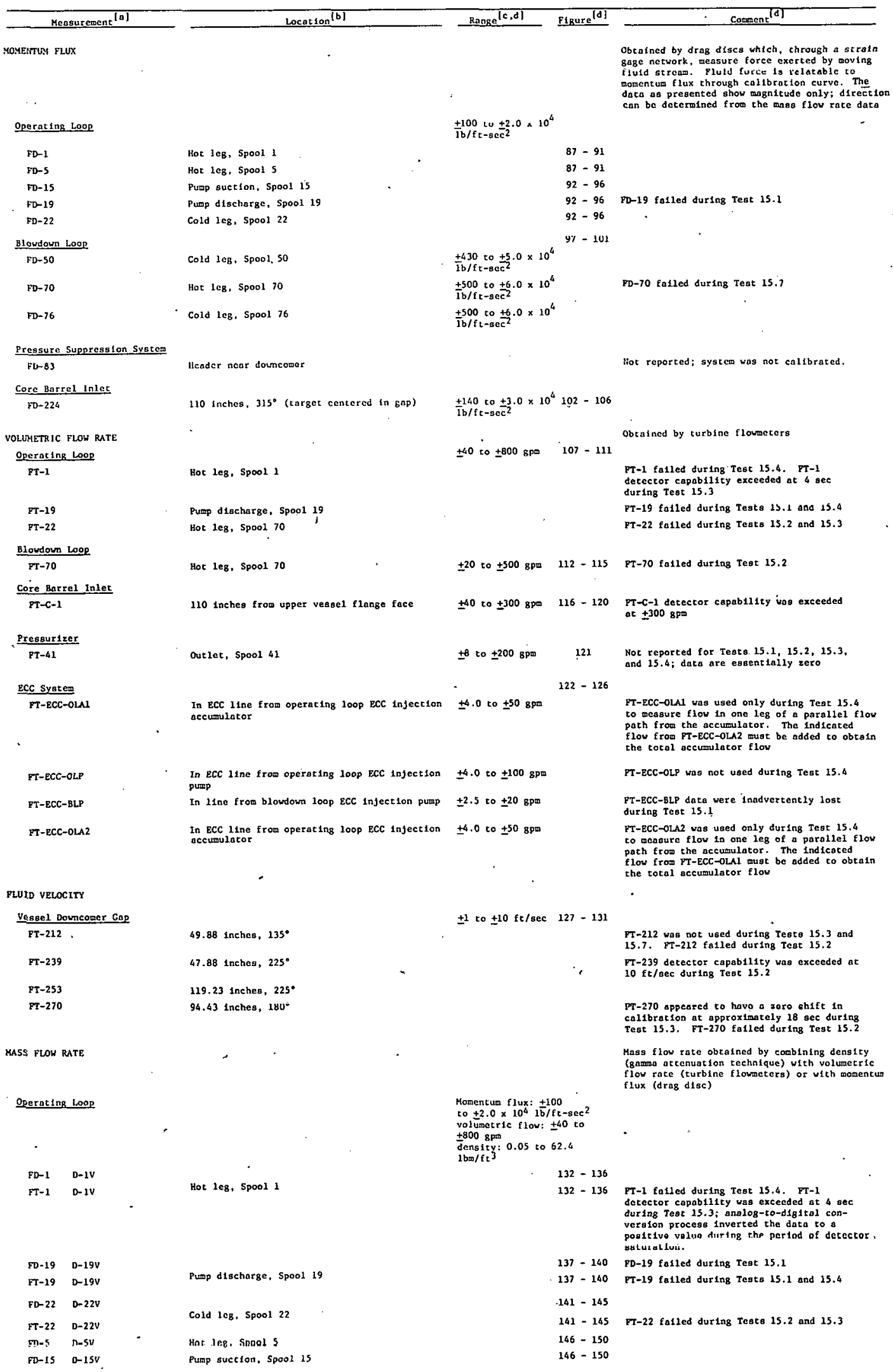


TABLE II (contd.)

DATA PRESENTATION FOR ISOTHERMAL HOT-WALL TESTS

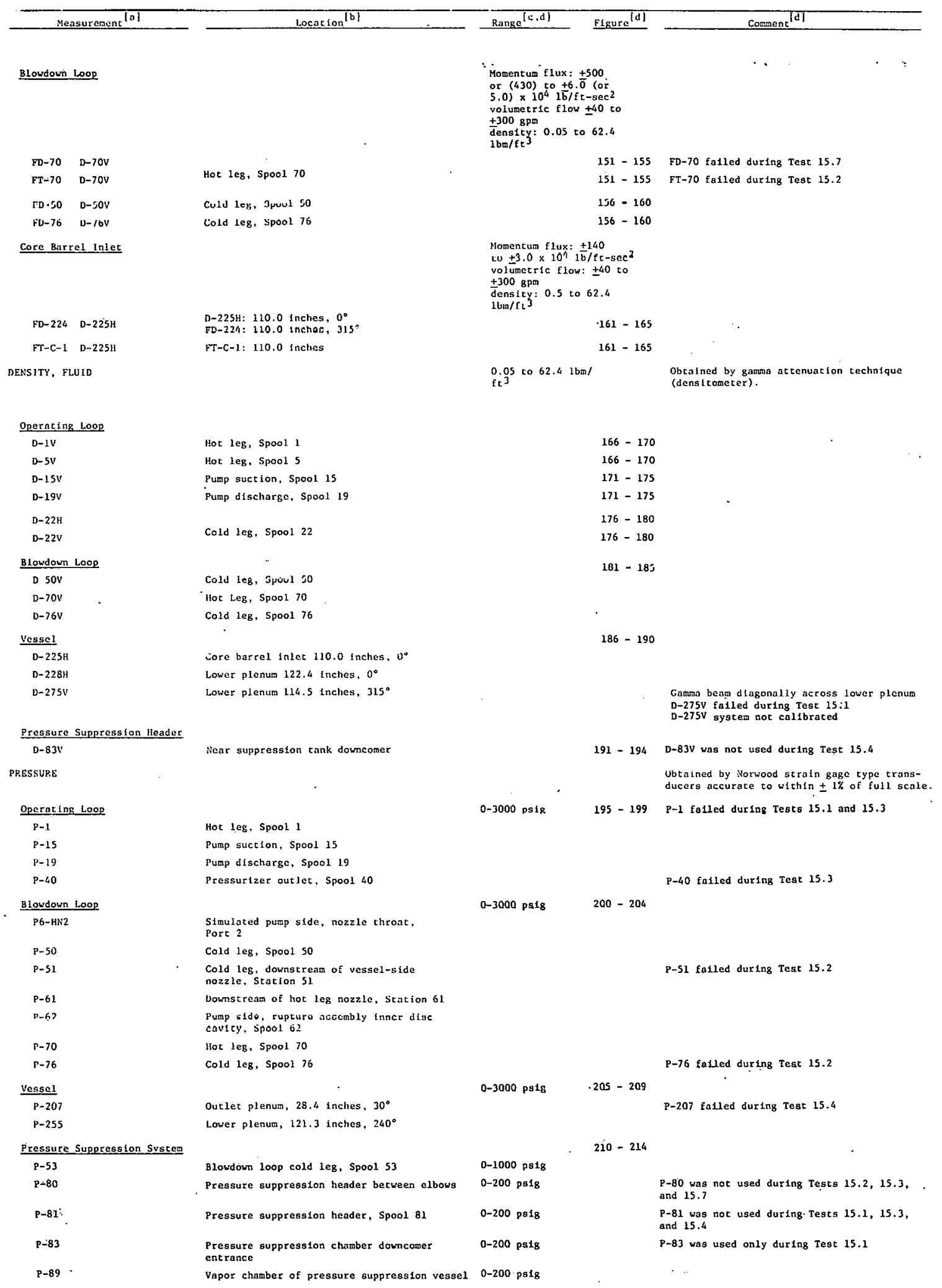


TABLE II (contd.)

DATA PRESENTATION FOR ISOTHERMAL HOT-WALL TESTS

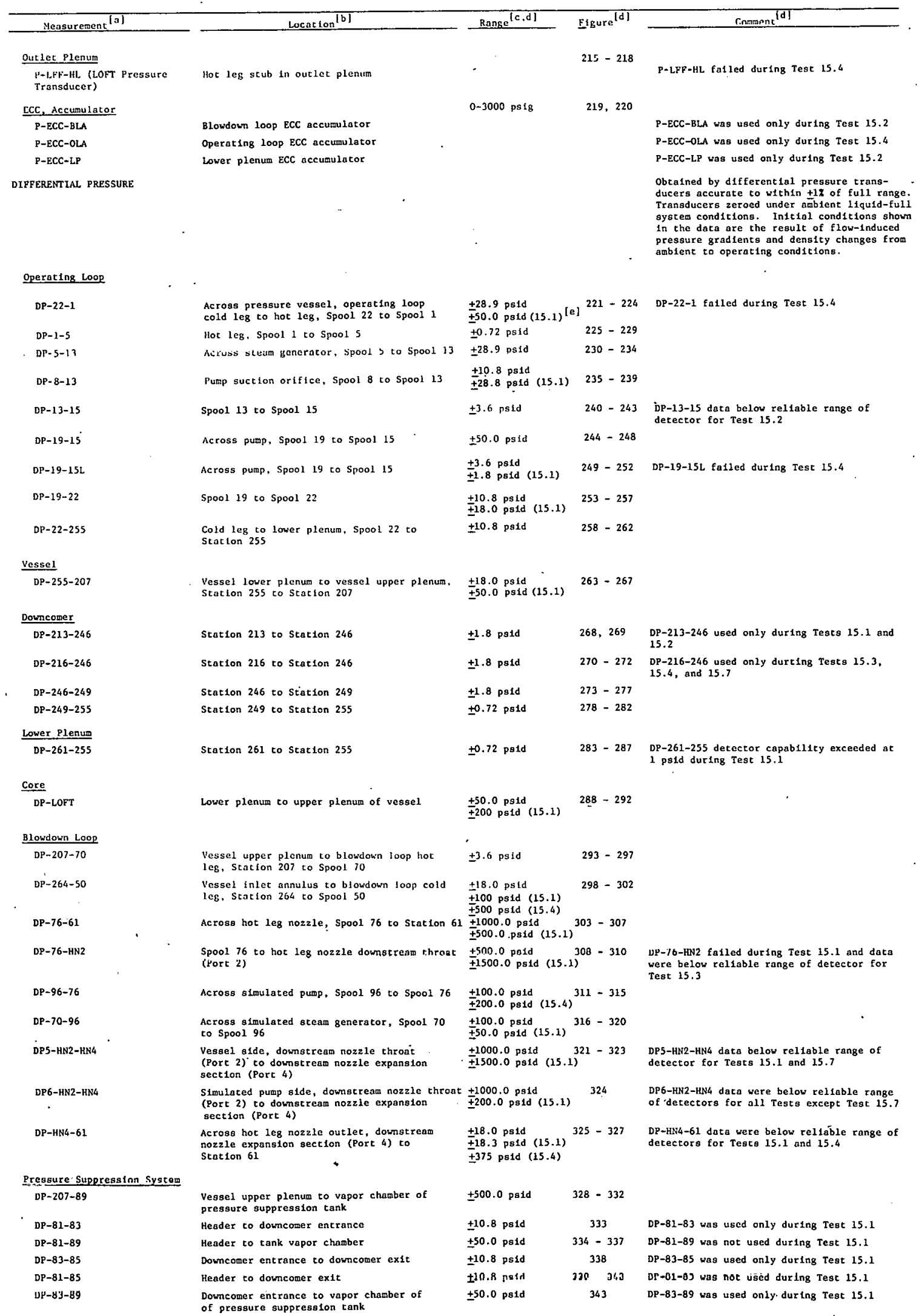


TABLE II (contd.)

DATA PRESENTATION FOR ISOTHERMAL HOT-WALL TESTS

\begin{tabular}{|c|c|c|c|c|}
\hline Mensurement $[\mathrm{a}]$ & Location ${ }^{[\mathrm{b}]}$ & Range $\mid c, d]$ & Figure ${ }^{[d]}$ & Comment $^{[\mathrm{d}]}$ \\
\hline $\begin{array}{l}\text { LIQUTD LEVEL. } \\
\text {, }\end{array}$ & • & & $\cdot \cdot$ & $\begin{array}{l}\text { Liquid level in lower plenum is indicated } \\
\text { by density measurements } \mathrm{D}-228 \mathrm{H} \text { and } \mathrm{D}-275 \mathrm{~V} \\
\text { And by differential pressure measurement } \\
\text { DP-261-255 }\end{array}$ \\
\hline Lower Plenum & Port 259 & & & System not calibrated, data not digitized. \\
\hline \multicolumn{5}{|l|}{ LL-LFTA-259 } \\
\hline \multicolumn{5}{|l|}{ LL-LFTD-259 } \\
\hline \multicolumn{5}{|l|}{ Presusure Suppression System } \\
\hline LL-PSS & Suppression tank & 3.64 poid & $344-348$ & $\begin{array}{l}\text { Obtalned by differencial pressure cell having } \\
\text { one leg connected to a standpipe and the } \\
\text { other leg attached to a put ill the botton } \\
\text { of rhp nressure suppression tank }\end{array}$ \\
\hline PUMP CHARACTERISTICS & Operating loop pump & & . & \\
\hline \multicolumn{5}{|l|}{ Pump Speed } \\
\hline FS-RTH & & - & $349-353$ & \\
\hline \multicolumn{5}{|l|}{ Pump Power } \\
\hline PN-PNP & & -- & $354-358$ & \\
\hline \multicolumn{5}{|l|}{ Pump_Torque } \\
\hline $\mathrm{T}-\mathrm{pqup}$ & & -- & $359-362$ & T-PYP falled during Test 15.3 \\
\hline TIME OF BREAK & & & & $\begin{array}{l}\text { Data not presented; measurenent established } \\
\text { time of rupture as indicated by } t=0 \text { seconds } \\
\text { on all data plots }\end{array}$ \\
\hline \multicolumn{5}{|l|}{ Blowdown Loop } \\
\hline$B W-52$ & Cold leg, vessel side & & & \\
\hline BW-62 & Cold leg, slmulated pump side & & & \\
\hline \multicolumn{5}{|l|}{ FLOW DIRECTION } \\
\hline \multicolumn{5}{|l|}{ Downcomer Gap } \\
\hline$S-271$ & 65.6 1nches, $0^{\circ}$, Station 271 & & $.363-365$ & s-271 was not used for Tests 15.1 and 15.2 \\
\hline DISPLICEMENT & & & & $\begin{array}{l}\text { System not calibrated, data useful unly lu: } \\
\text { relative motion indication. }\end{array}$ \\
\hline Pressure Suppression Syscem & & & $366-370$ & \\
\hline LDT-PSH & Header first elbow (horizontal deflection) & & & $\checkmark$ \\
\hline LDT-PSV & $\begin{array}{l}\text { Bencath suppression vessel (vessel vertical } \\
\text { deflection) }\end{array}$ & & & 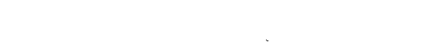 \\
\hline STRAIN & & & & $\begin{array}{l}\text { No callbration step avallable; data signal } \\
\text { extremely low. }\end{array}$ \\
\hline \multicolumn{5}{|l|}{ Pressurc Suppression Susten } \\
\hline SGI-PSH-HL-O & $\begin{array}{l}\text { Header, outside first elbow at inpingerent } \\
\text { from cold lcg, simulated pump side, } 0^{\circ}\end{array}$ & . & & \\
\hline $\mathrm{SLL} 1-\mathrm{HSH}-\mathrm{HL}-60$ & $\begin{array}{l}\text { Heador, outstide first elbow at impingement } \\
\text { From cold leg. simulated pump side, } 60^{\circ}\end{array}$ & & & \\
\hline SGI-PSH-HL- 120 & $\begin{array}{l}\text { Header, outside first elbow at } 1 \text { mpingement } \\
\text { from cold } 1 \mathrm{eg}, \text { simulated pump side, } 120^{\circ}\end{array}$ & & & \\
\hline SGT-PSH-HL. & On top of header near first elbow & & & \\
\hline \multicolumn{5}{|c|}{ [a] Measurement nomenelature is defined in Reference 6 . } \\
\hline \multicolumn{5}{|c|}{ [b] Measurement locations are shown in Figures 6 through 9 . } \\
\hline \multicolumn{5}{|c|}{ (c) The range Indicated is that over wilich the measurement is considered valld. } \\
\hline \multicolumn{5}{|c|}{$\begin{array}{l}\text { (d) Ranges, figure numbers, and comments apply to all measurements within a category unless i } \\
\text { The figure numbers correspond to the data plots presented. }\end{array}$} \\
\hline
\end{tabular}




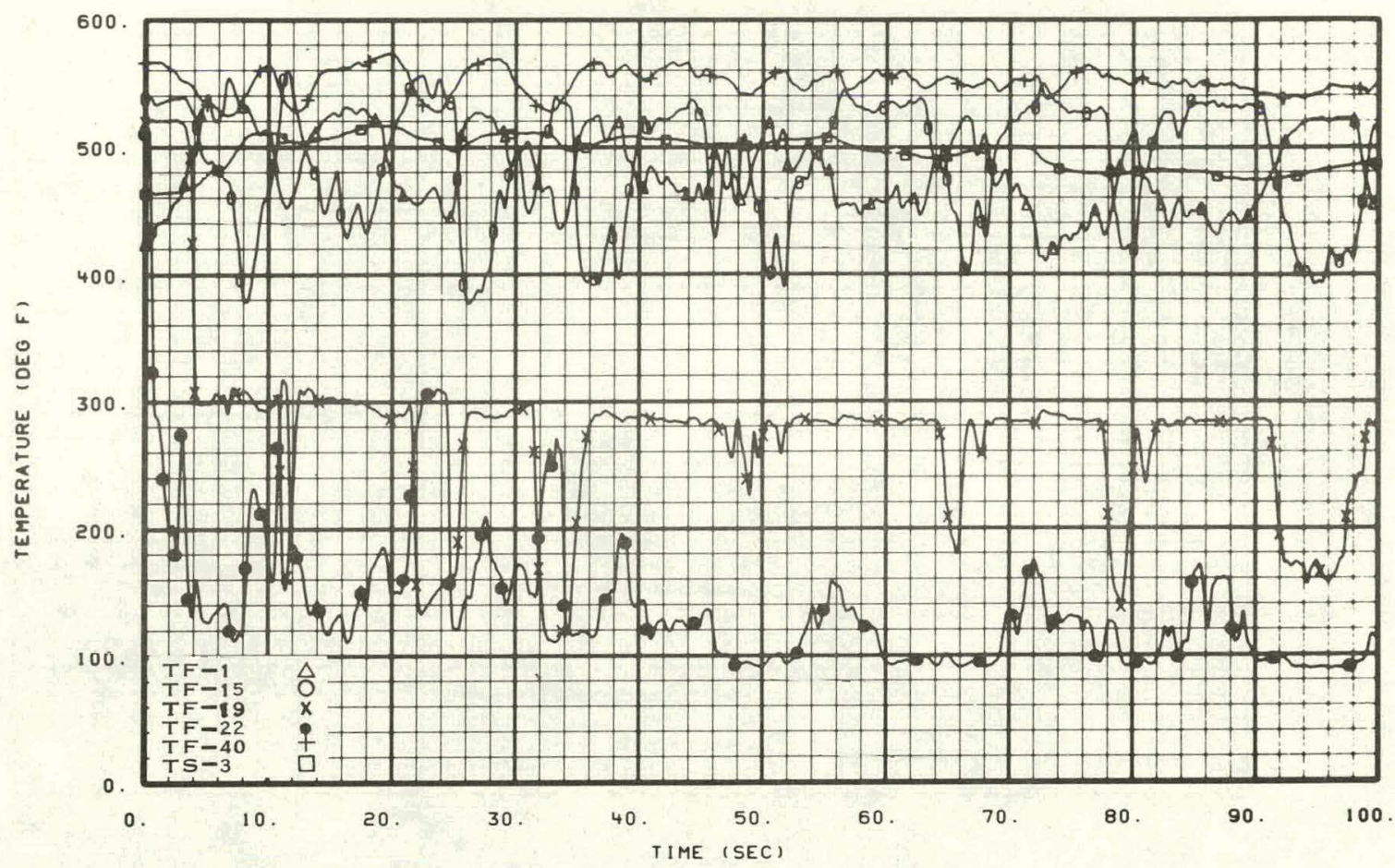

Fig. 10 Fluid temperatures in operating loop -- Test 15.1.

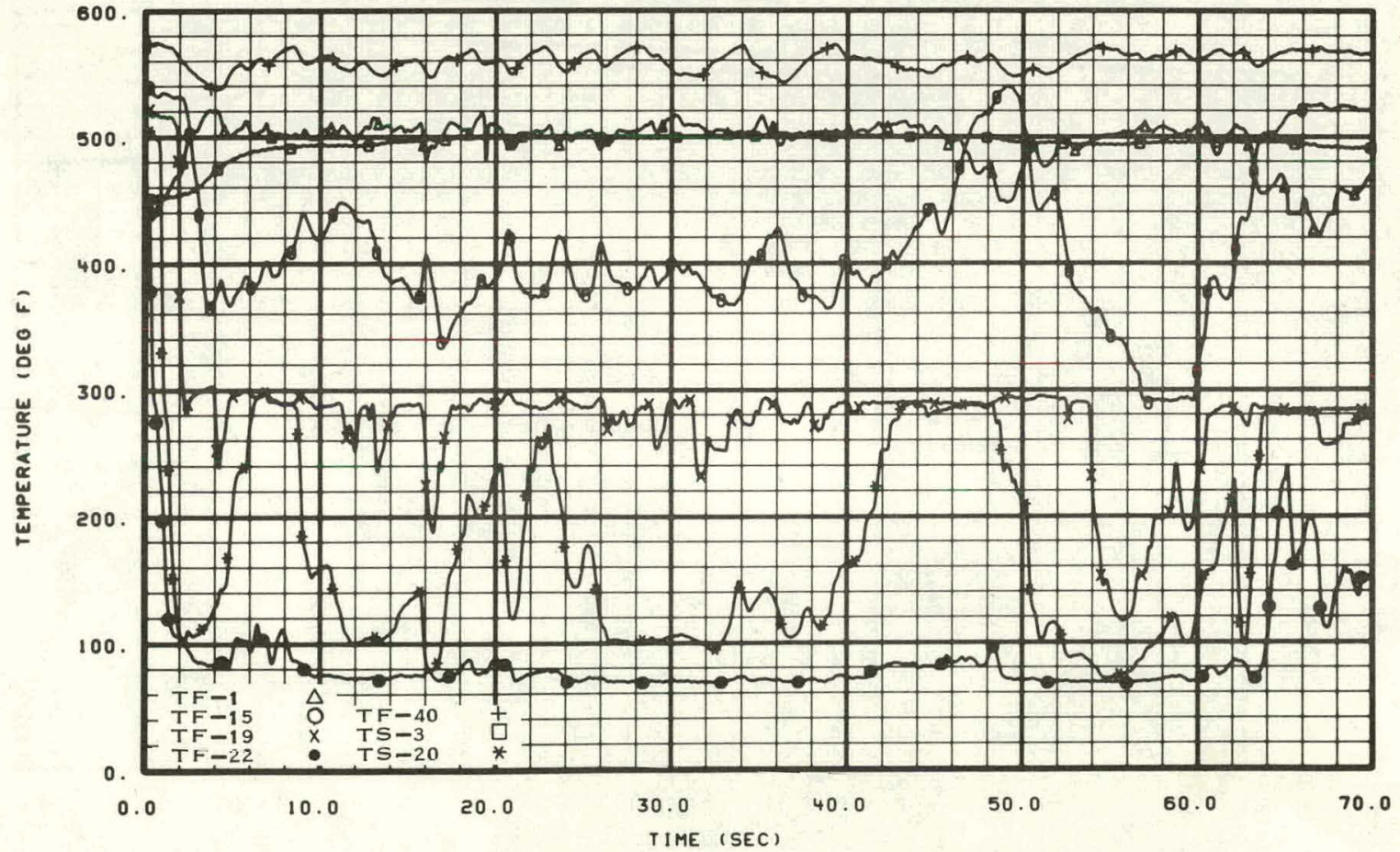

Fig. 11 Fluid temperatures in operating loop -- Test 15.2. 


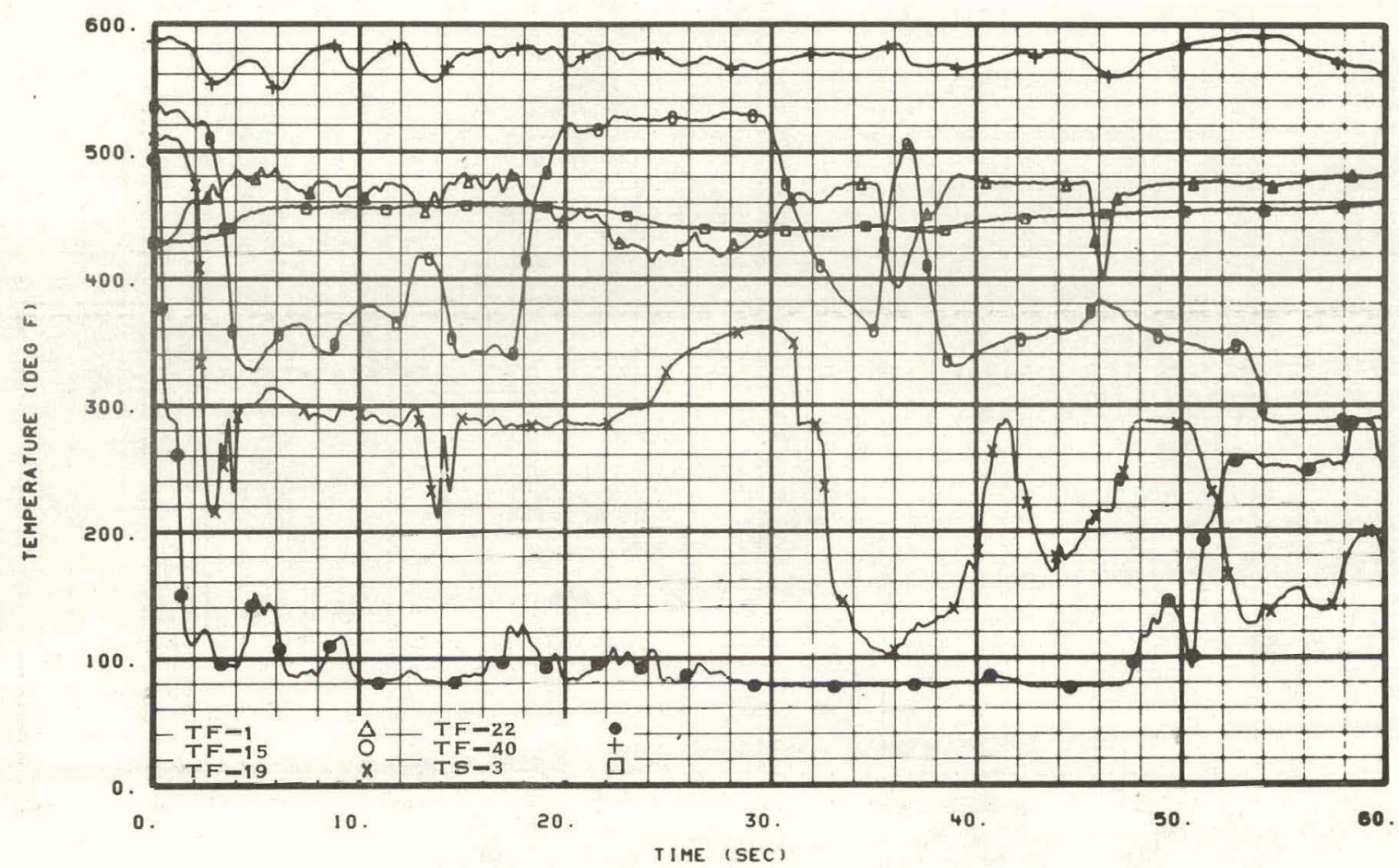

Fig. 12 Fluid temperatures in operating loop -- Test 15.3.

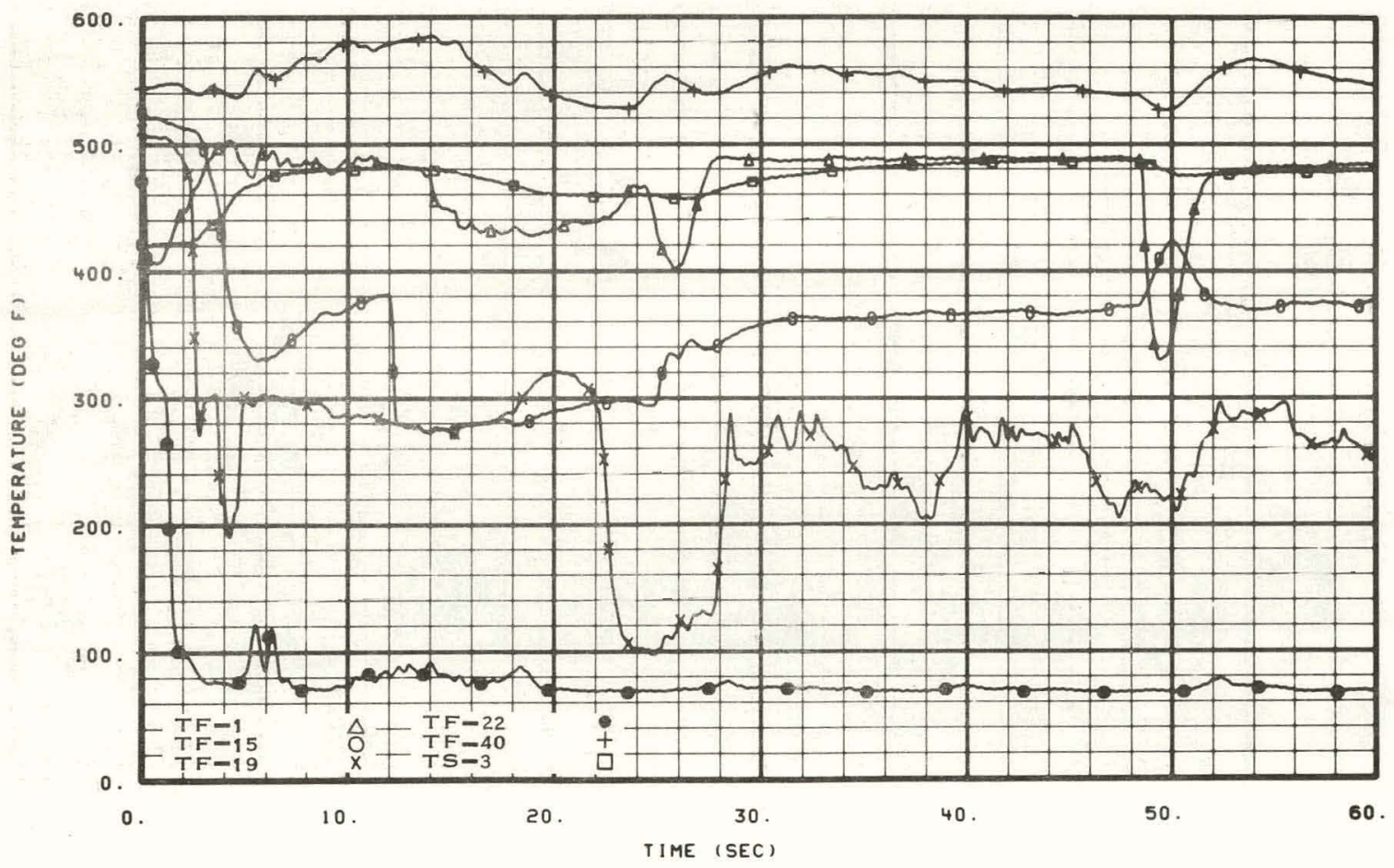

Fig. 13 Fluid temperatures in operating loop -- Test 15.4. 


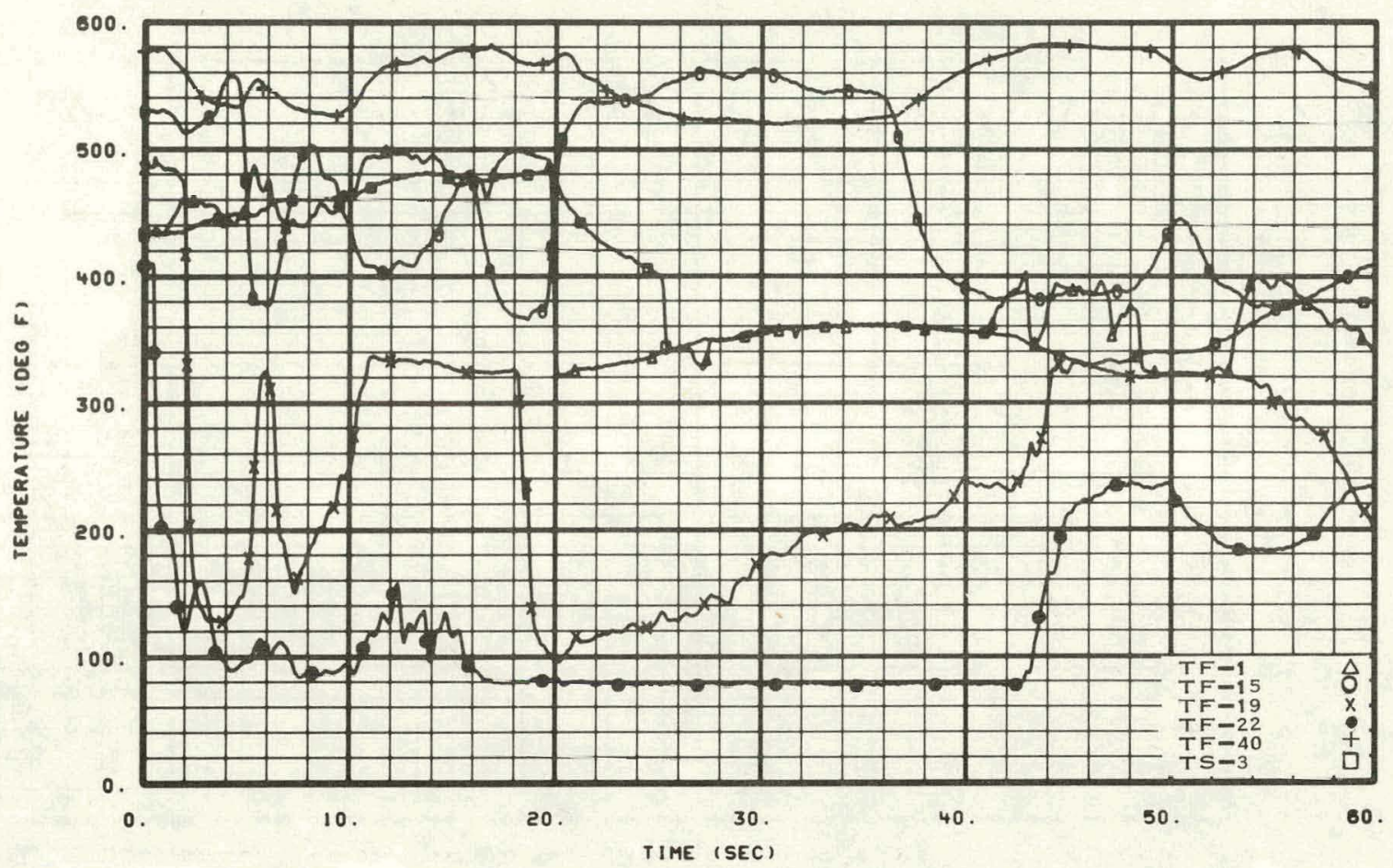

Fig. 14 Fluid temperatures in operating loop -- Test 15.7.

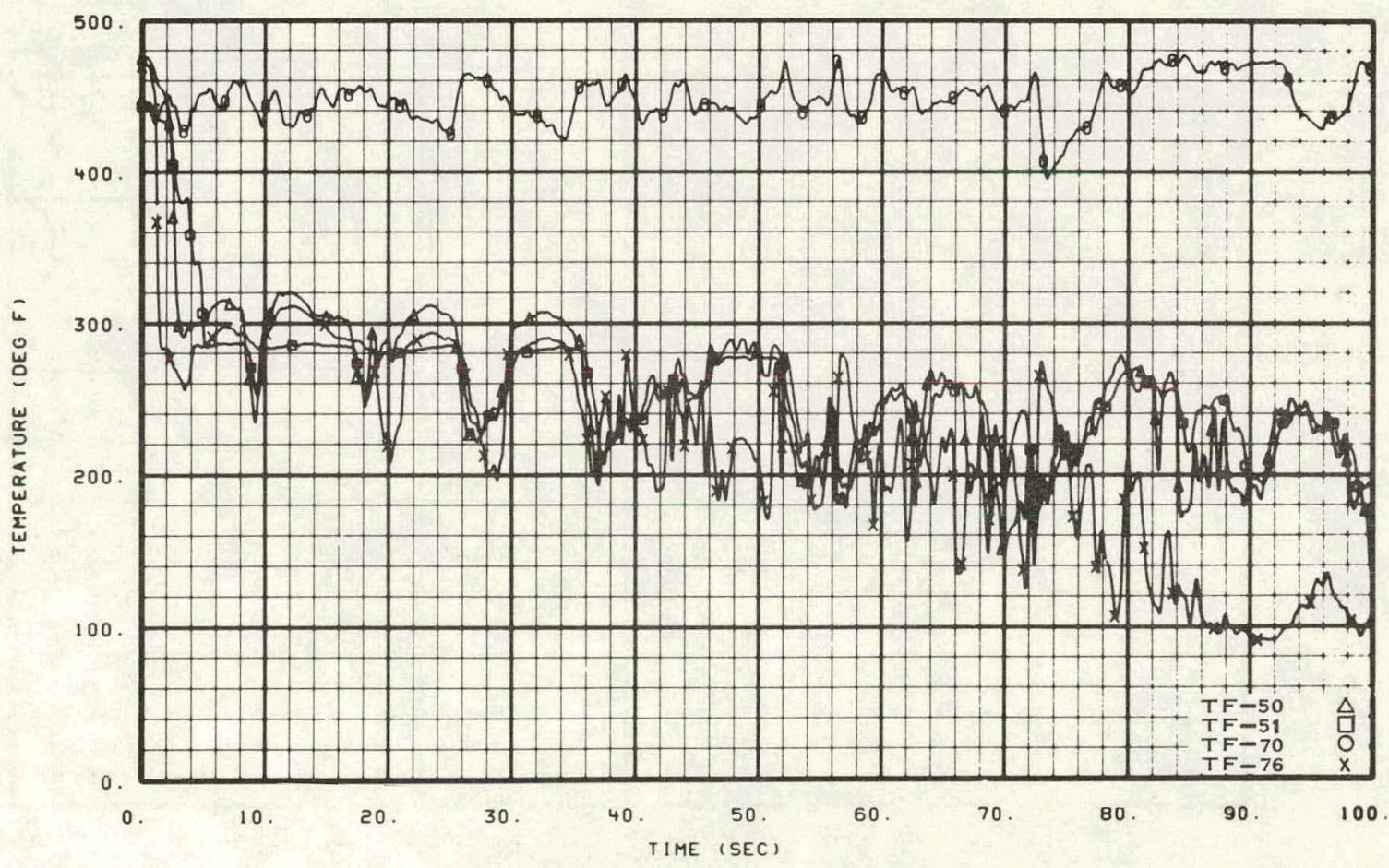

Fig. 15 Fluid temperatures in blowdown loop -- Test 15.1. 


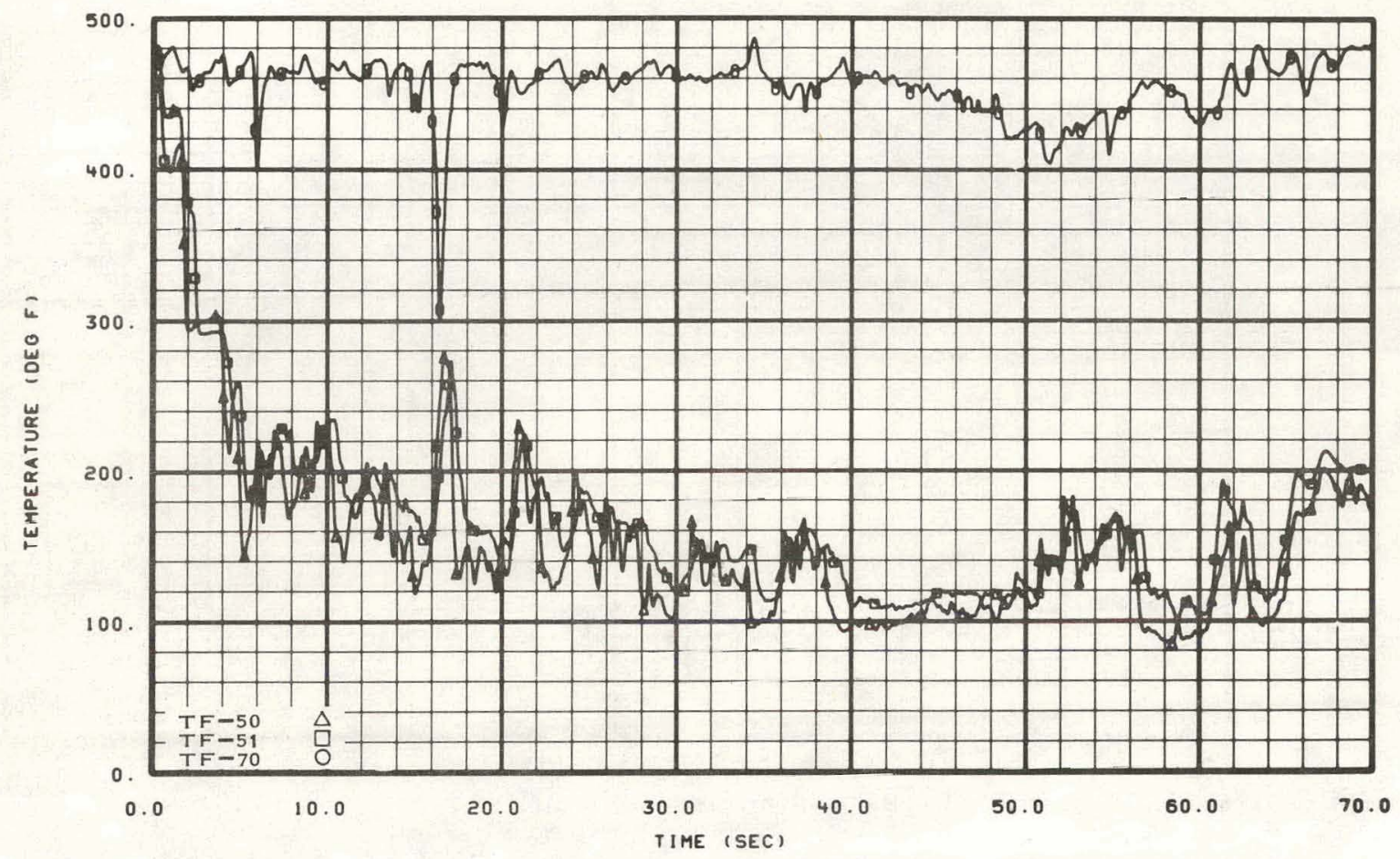

Fig. 16 Fluid temperatures in blowdown loop -- Test 15.2.

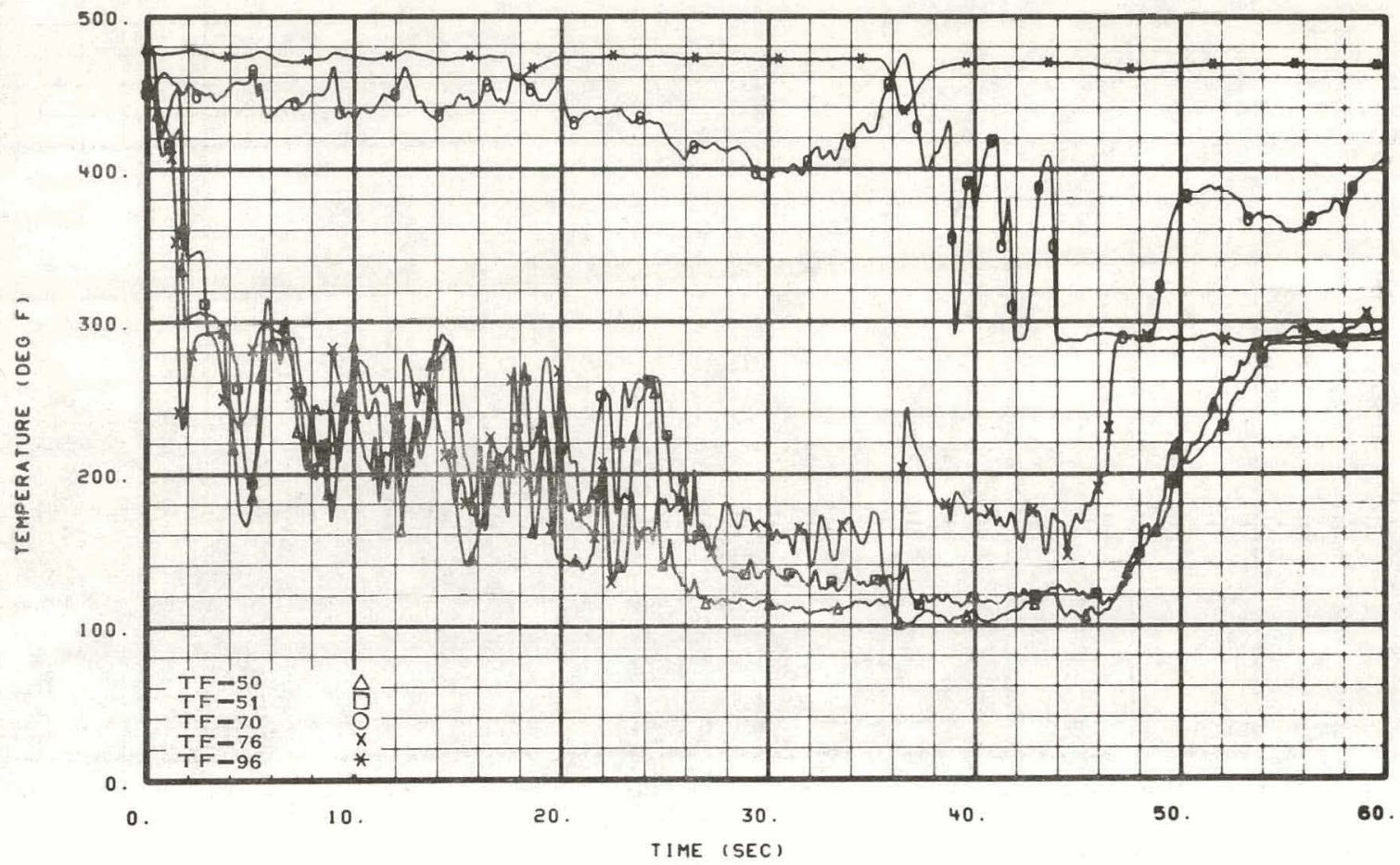

Fig. 17 Fluid temperatures in blowdown loop -- Test 15.3. 


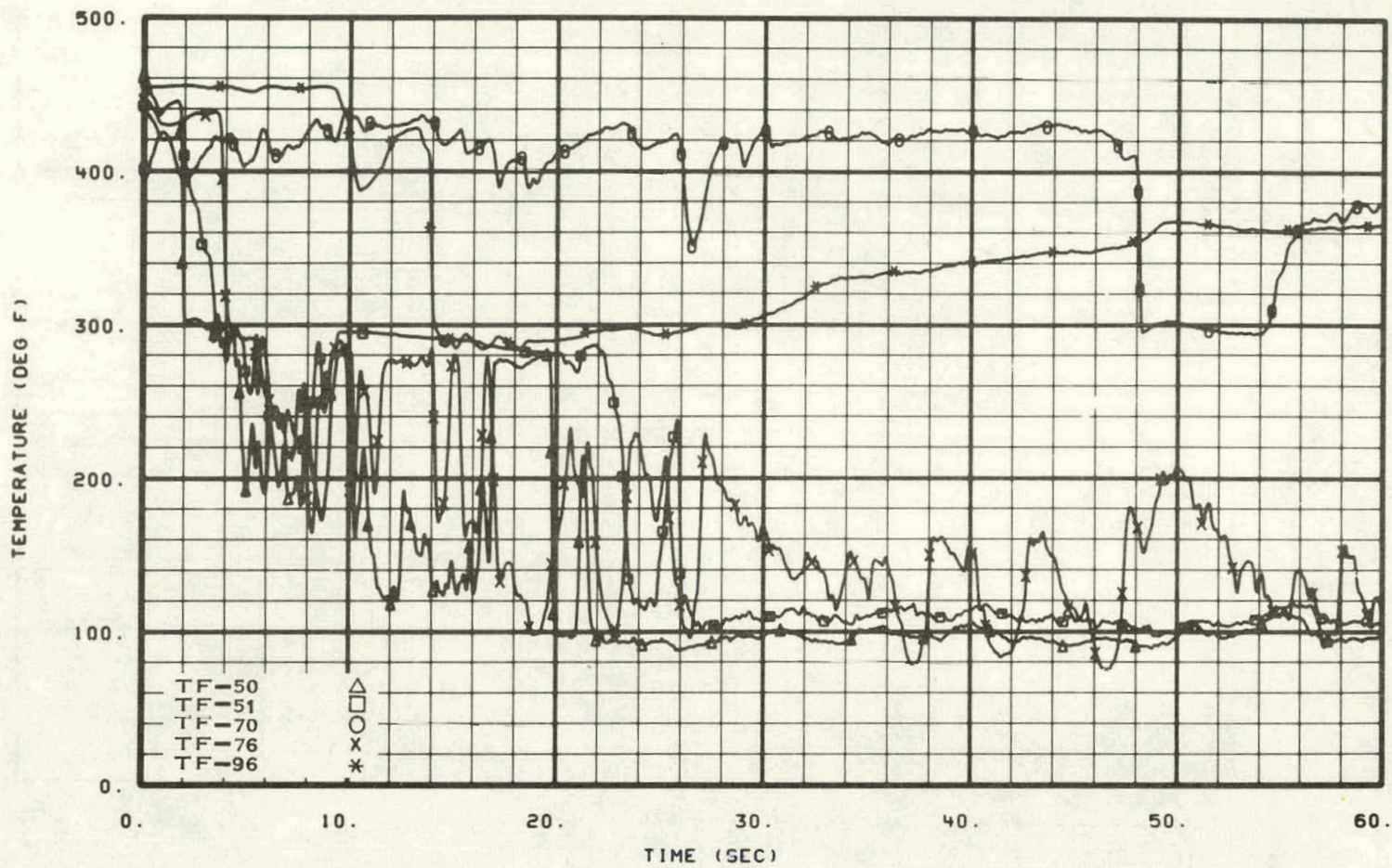

Fig. 18 Fluid temperatures in blowdown loop -- Test 15.4 .

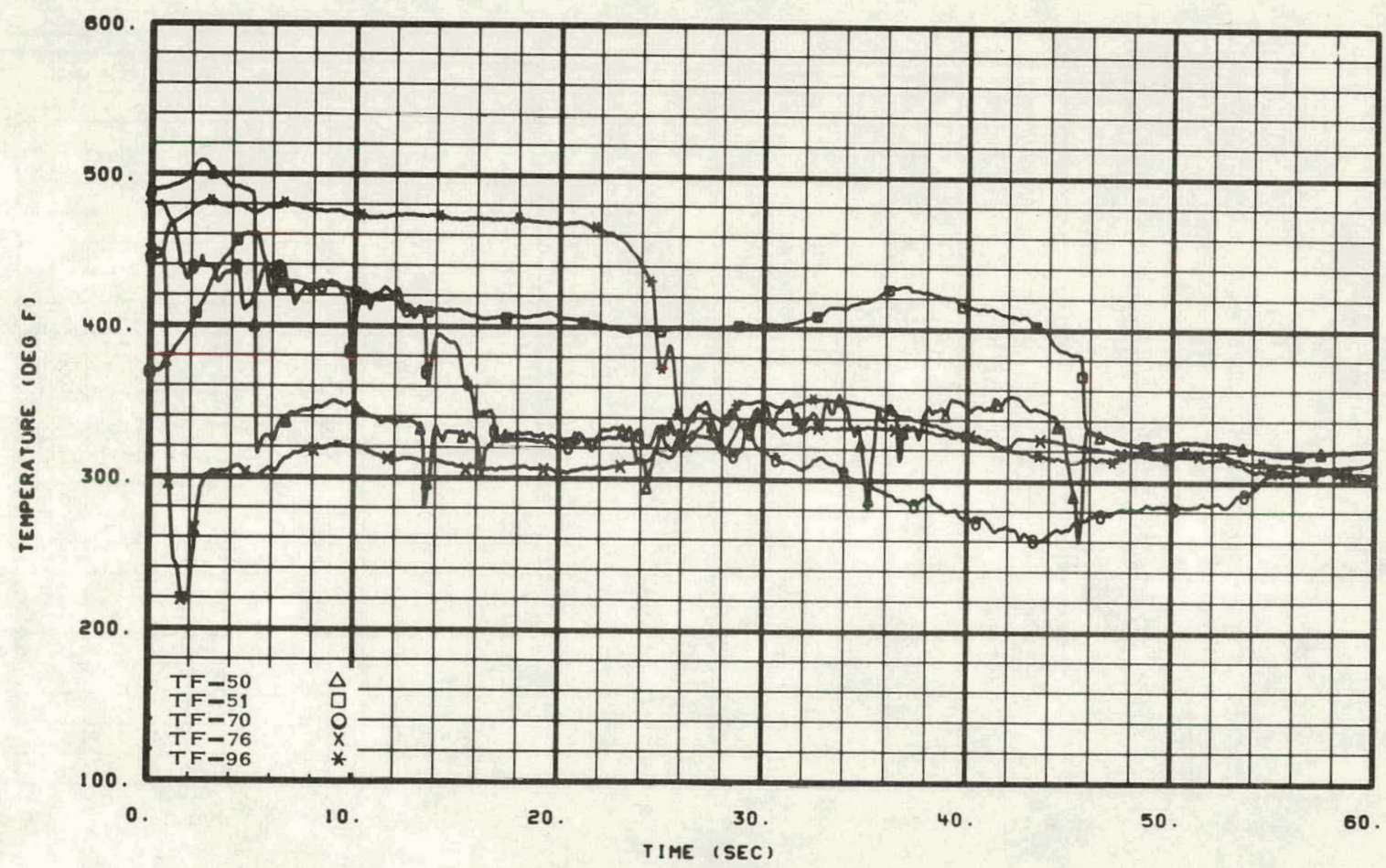

Fig. 19 Fluid temperatures in blowdown loop -- Test 15.7. 


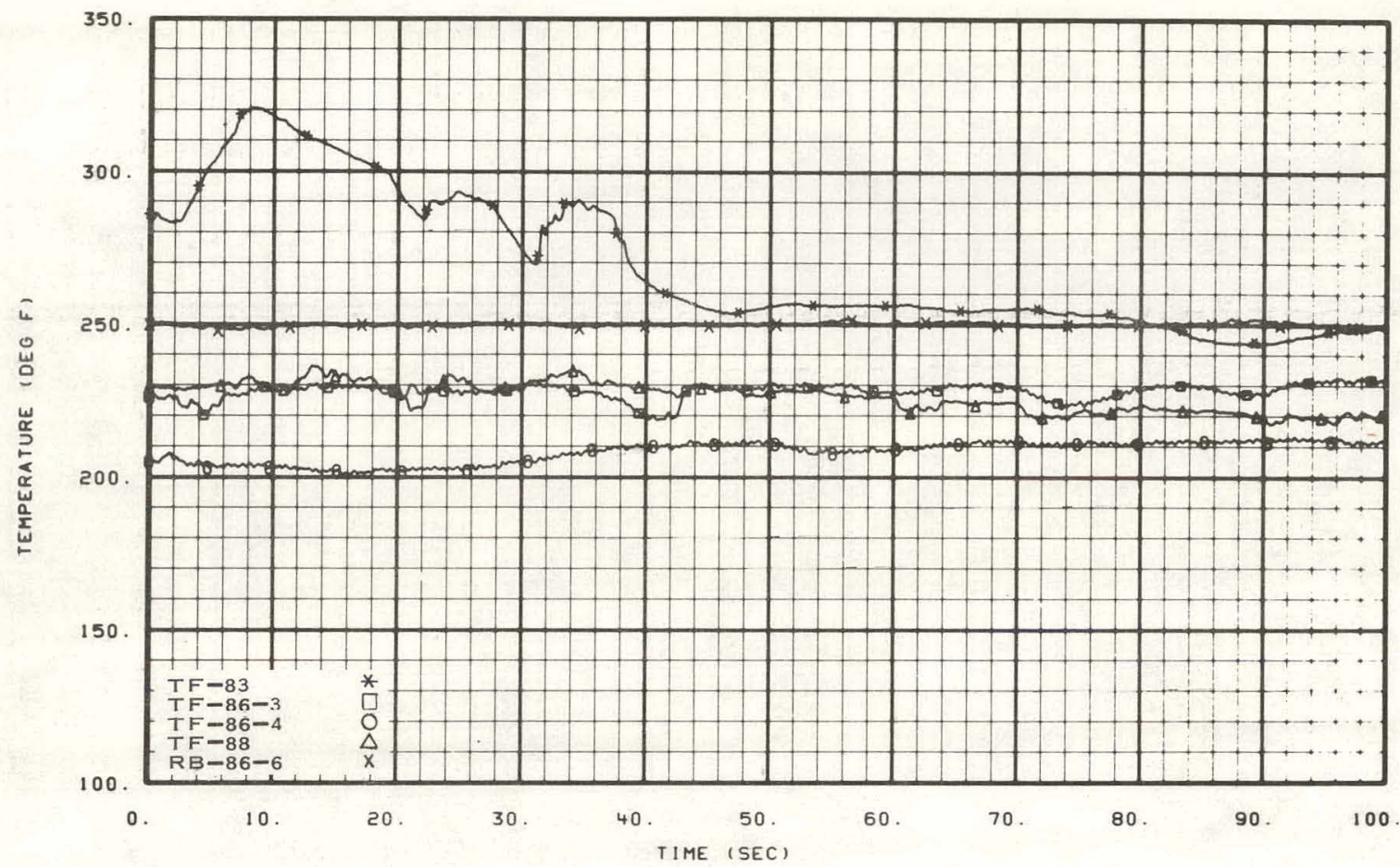

Fig. 20 Fluid temperatures in pressure suppression system -- Test 15.1.

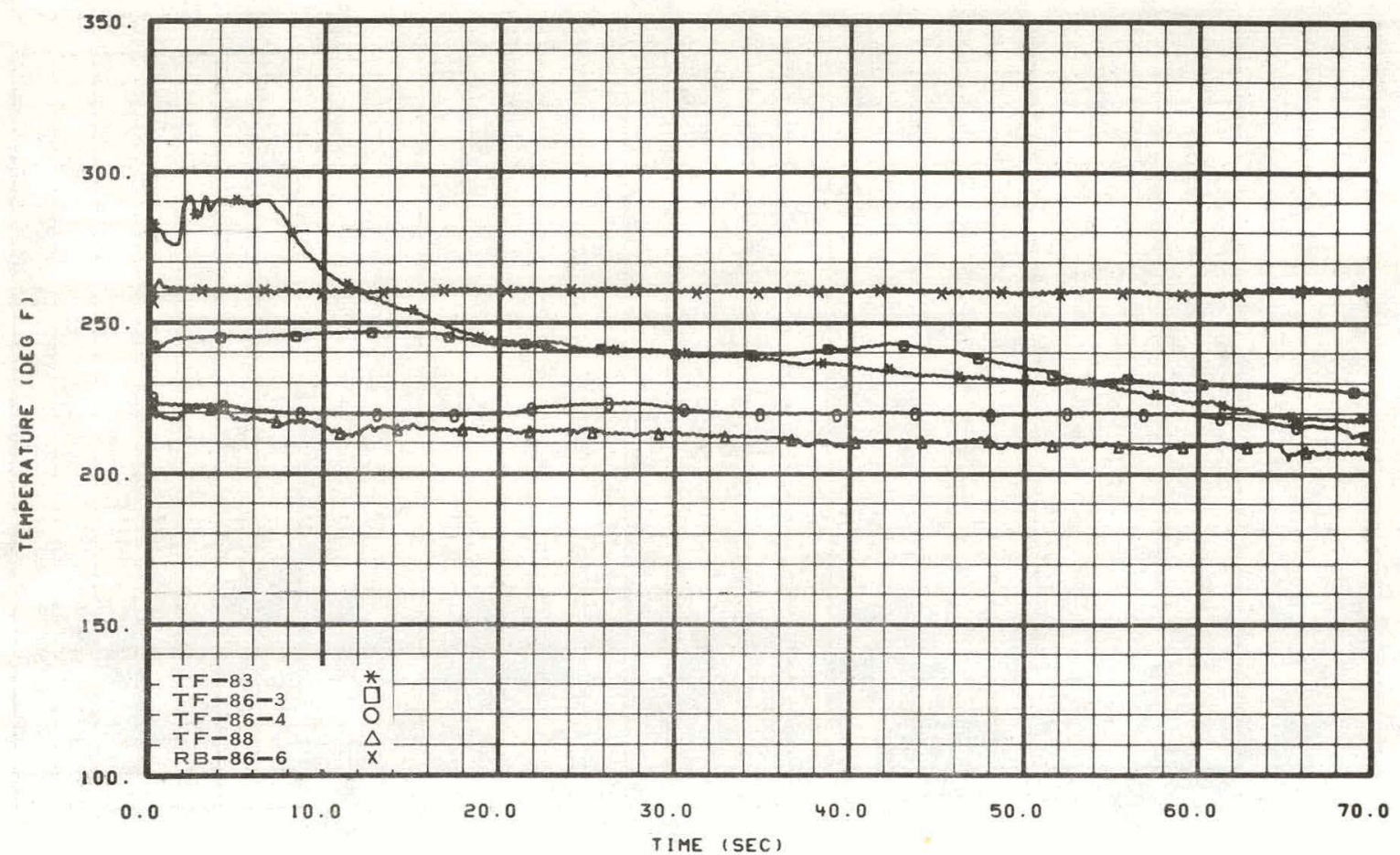

Fig. 21 Fluid temperatures in pressure suppression system -- Test 15.2. 


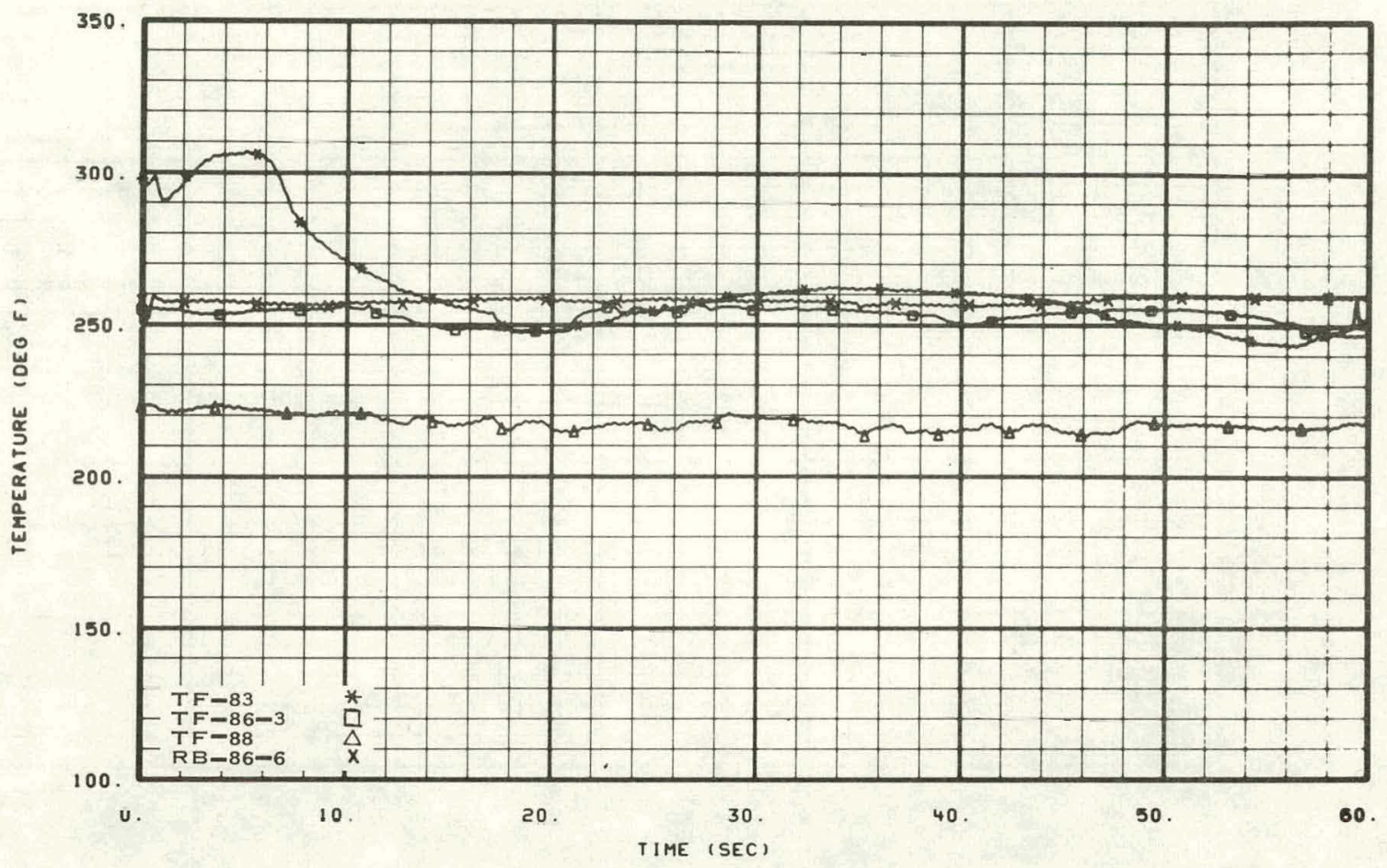

Fig. 22 Fluid temperatures in pressure suppression system -- Test 15.3.

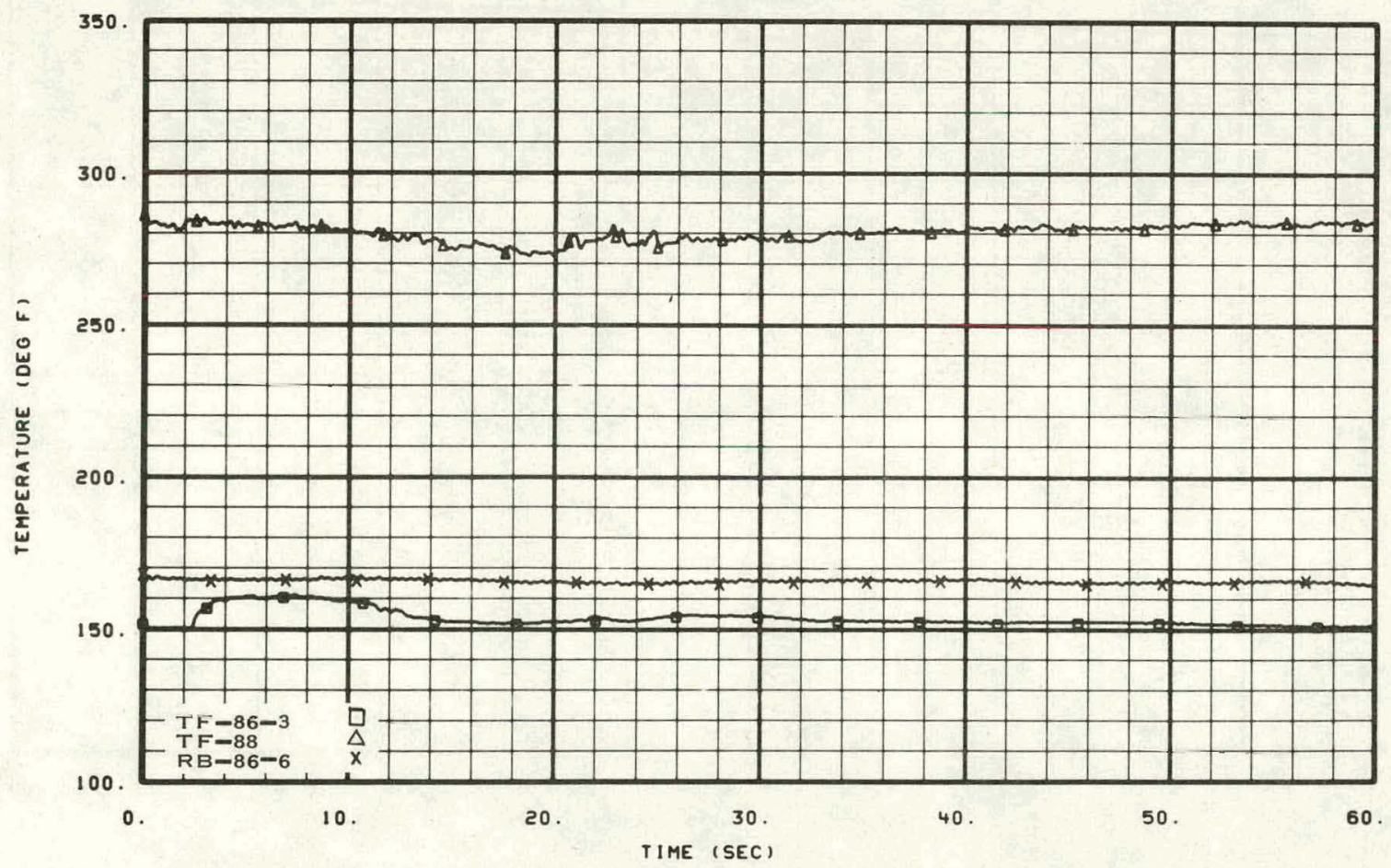

Fig. 23 Fluid temperatures in pressure suppression system -- Test 15.4. 


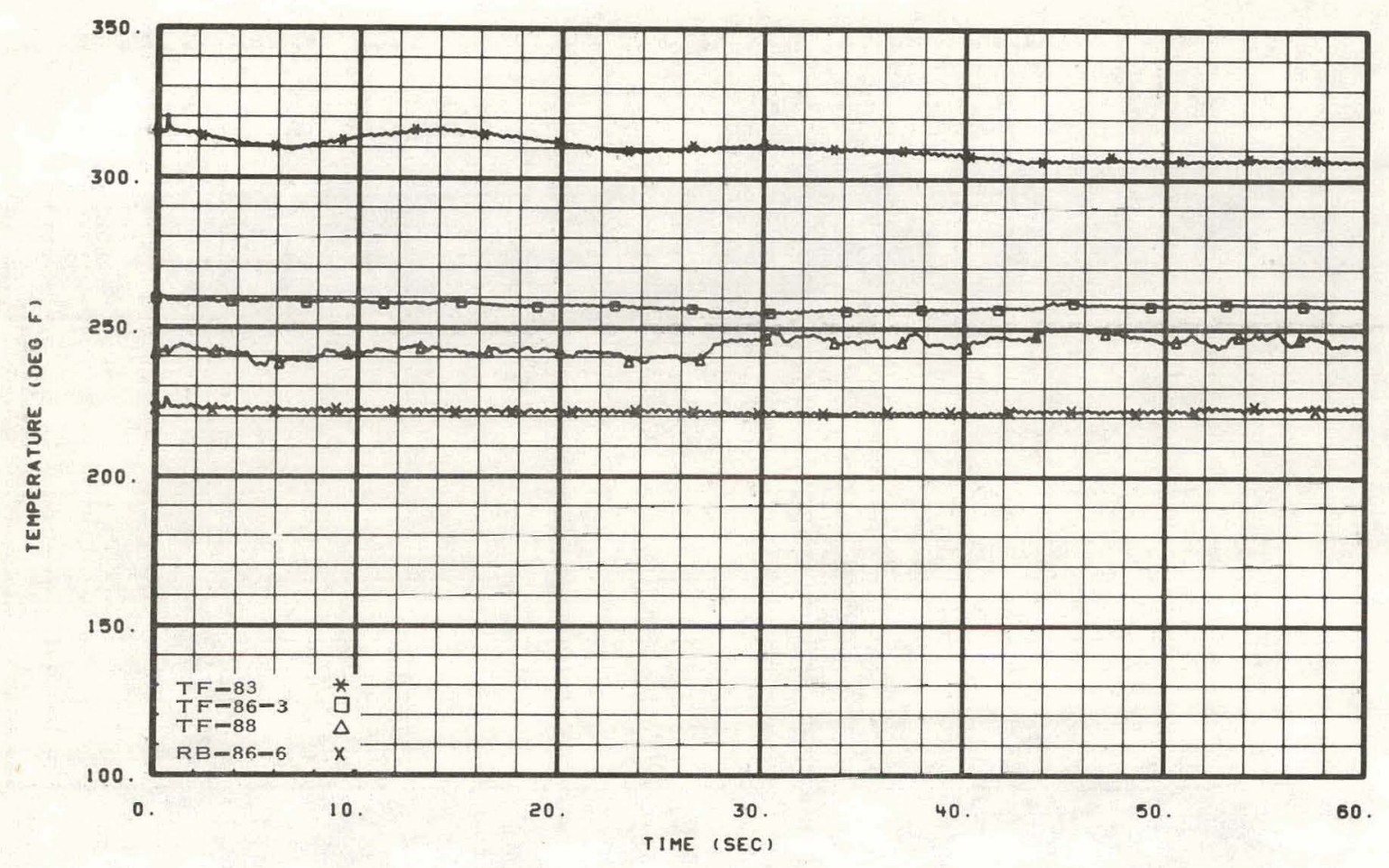

Fig. 24 Fluid temperatures in pressure suppression system -- Test 15.7 .

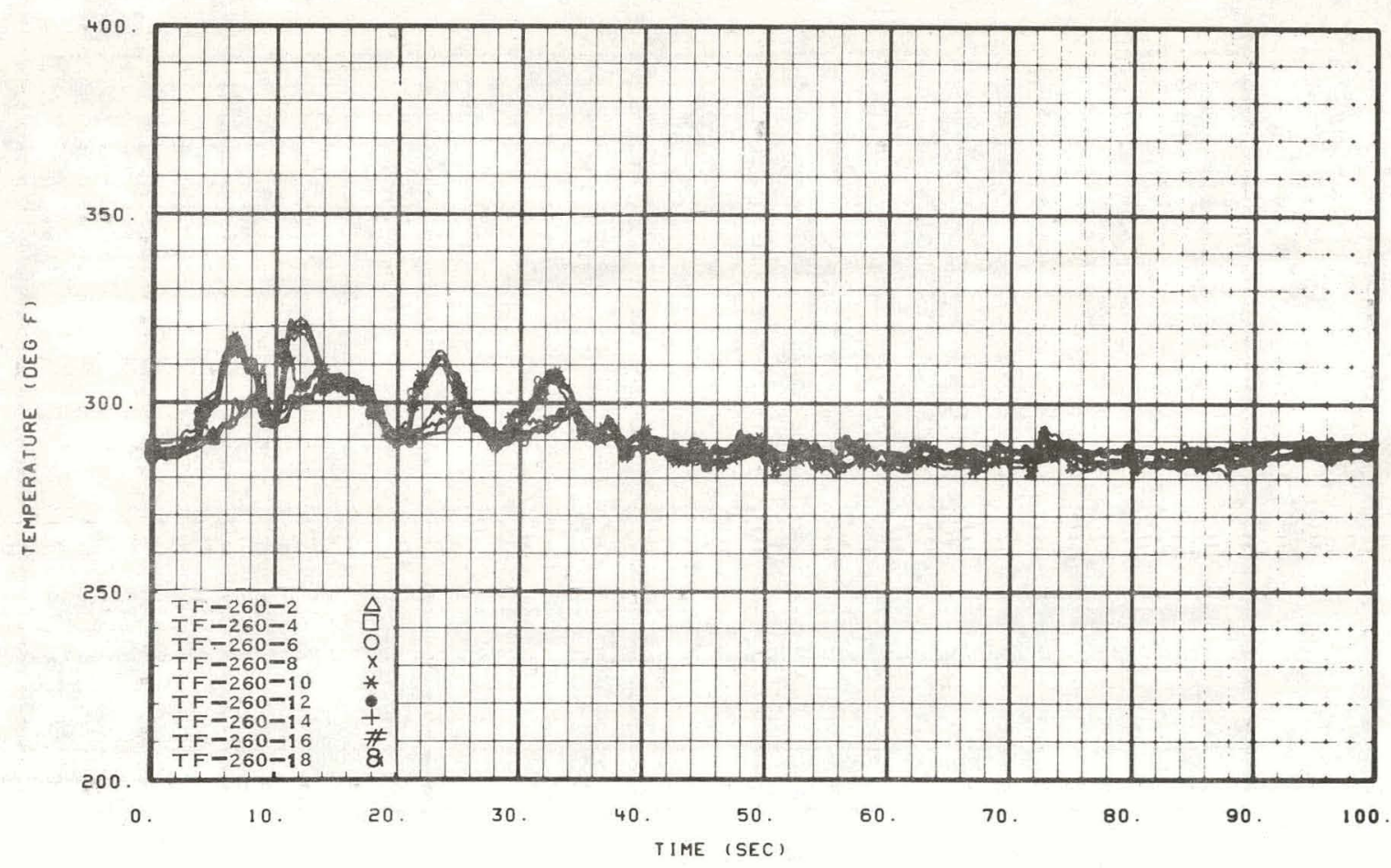

Fig. 25 Fluid temperatures in lower plenum at thermocouple rack -- Test 15.1 . 


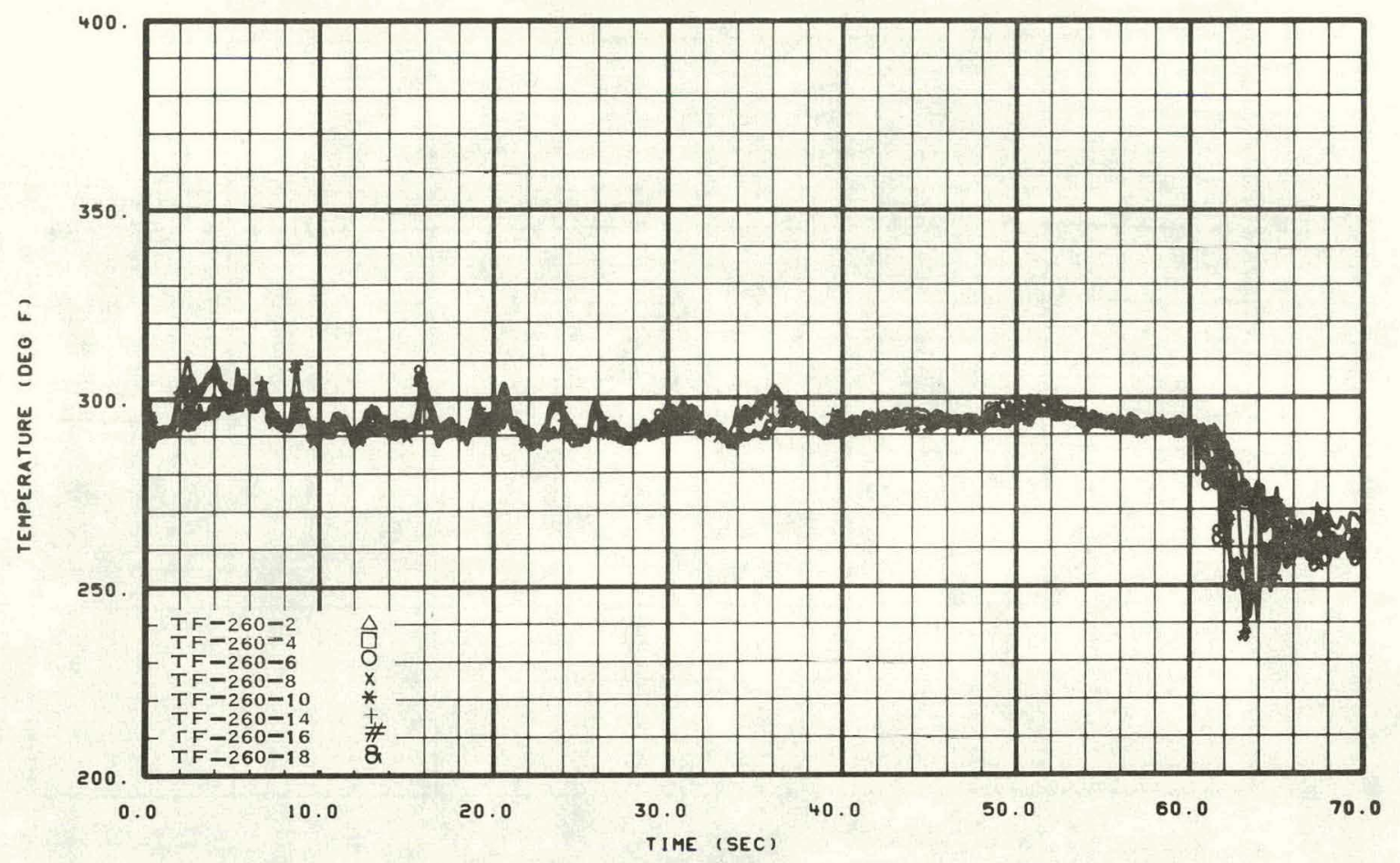

Fig. 26 Fluid temperatures in lower plenum at thermocouple rack -- Test 15.2 .

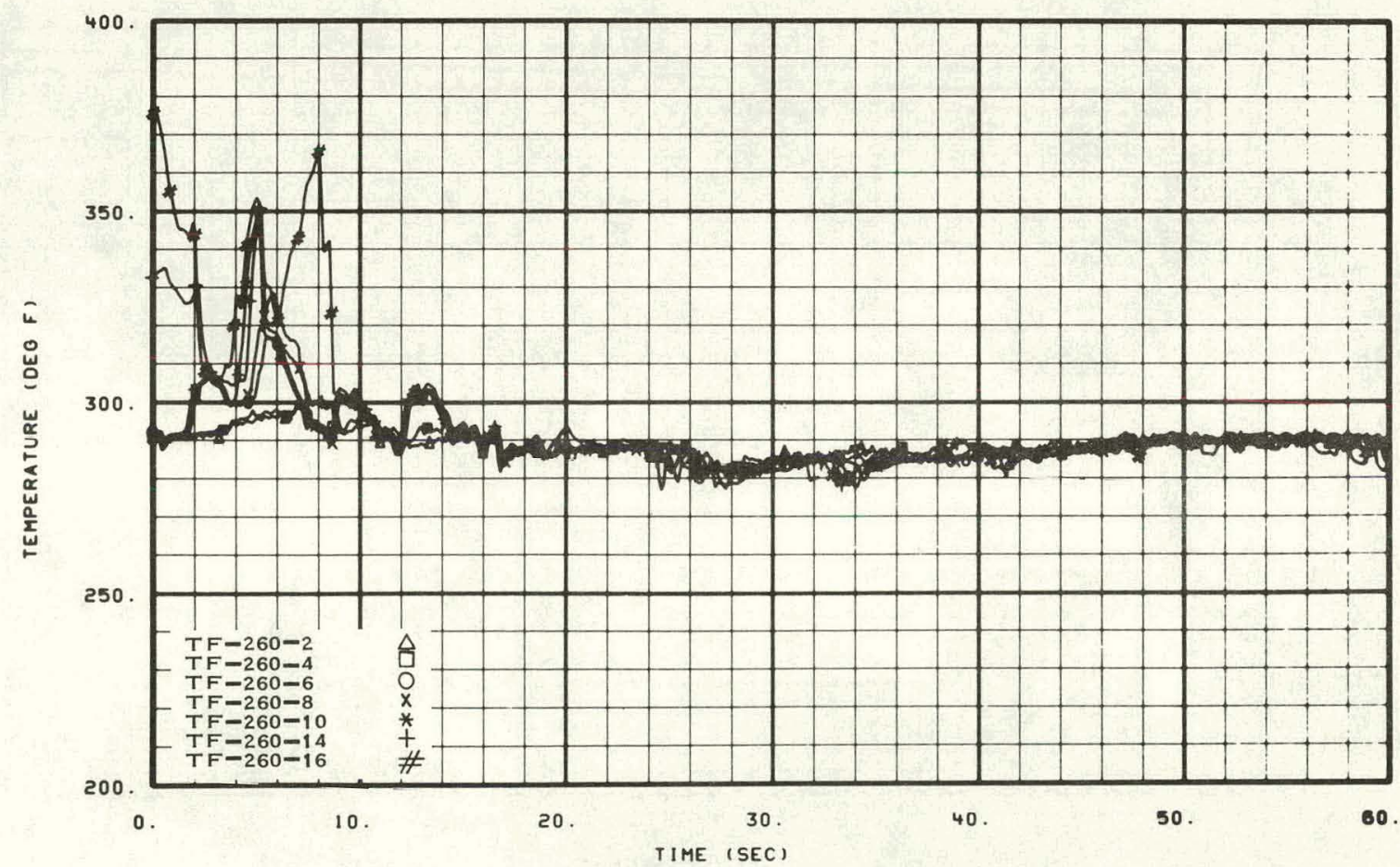

Fig. 27 Fluid temperatures in lower plenum at thermocouple rack -- Test 15.3 . 


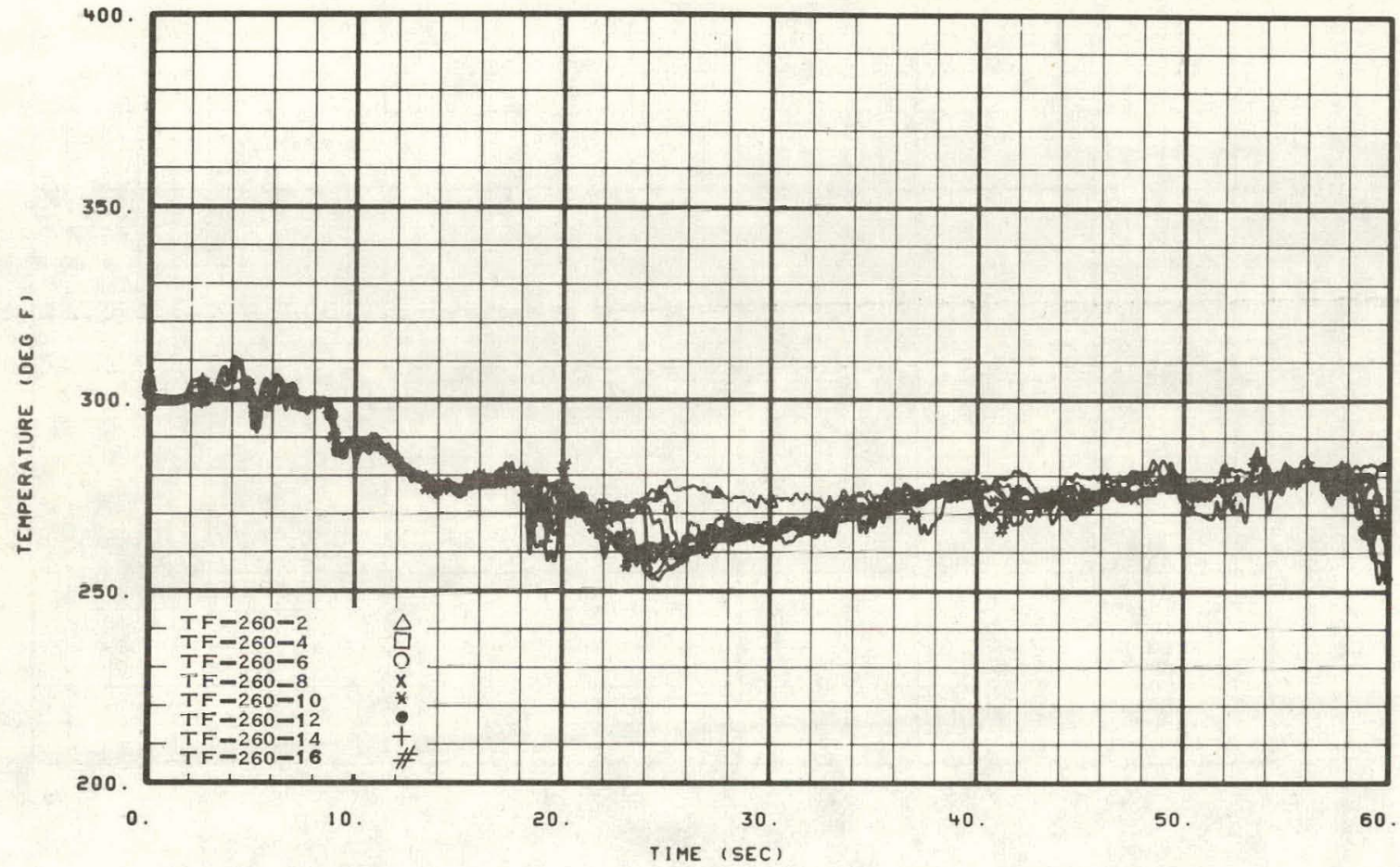

Fig. 28 Fluid temperatures in lower plenum at thermocouple rack -- Test 15.4 .

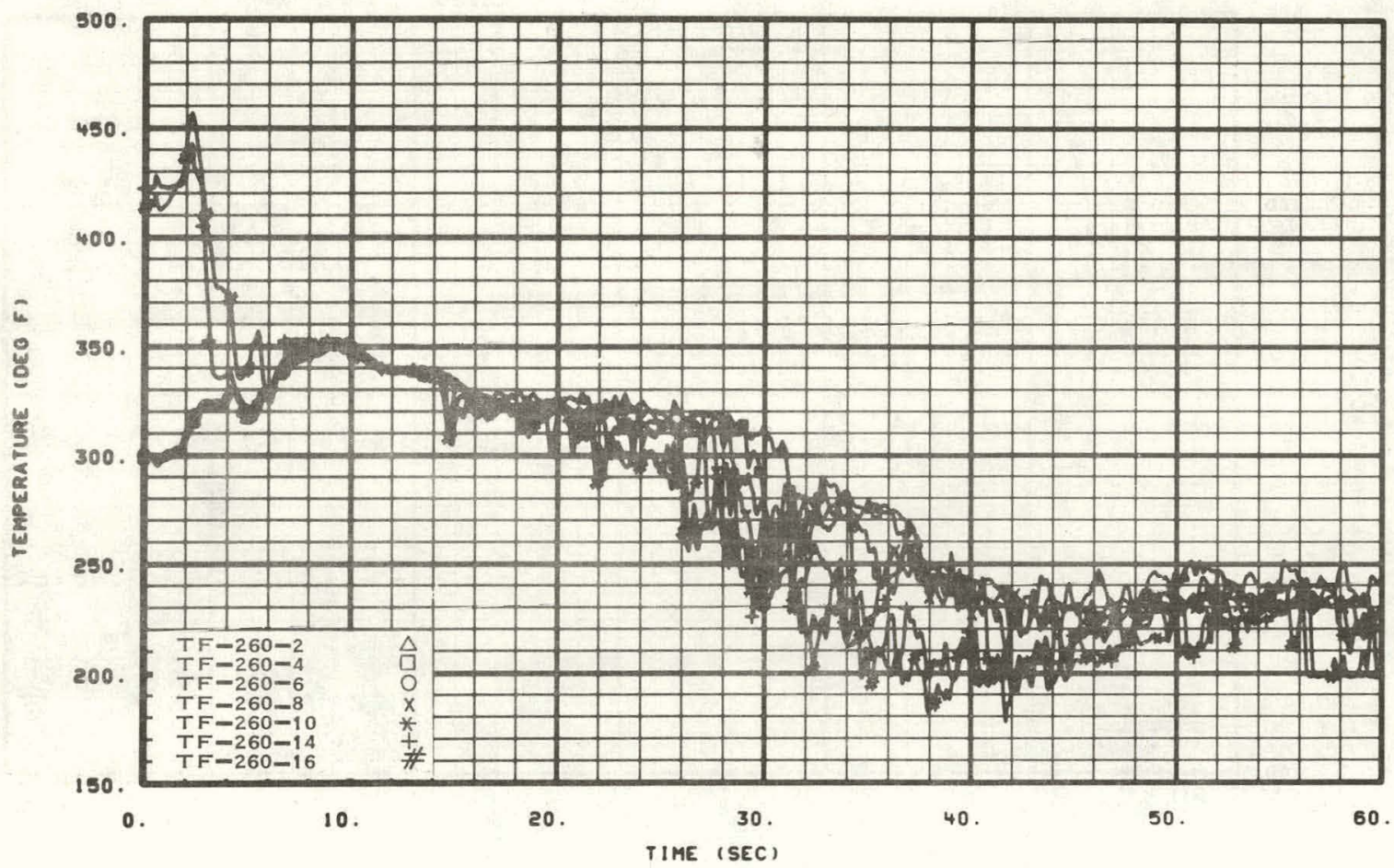

Fig. 29 Fluid temperatures in lower plenum at thermocouple rack -- Test 15.7 . 


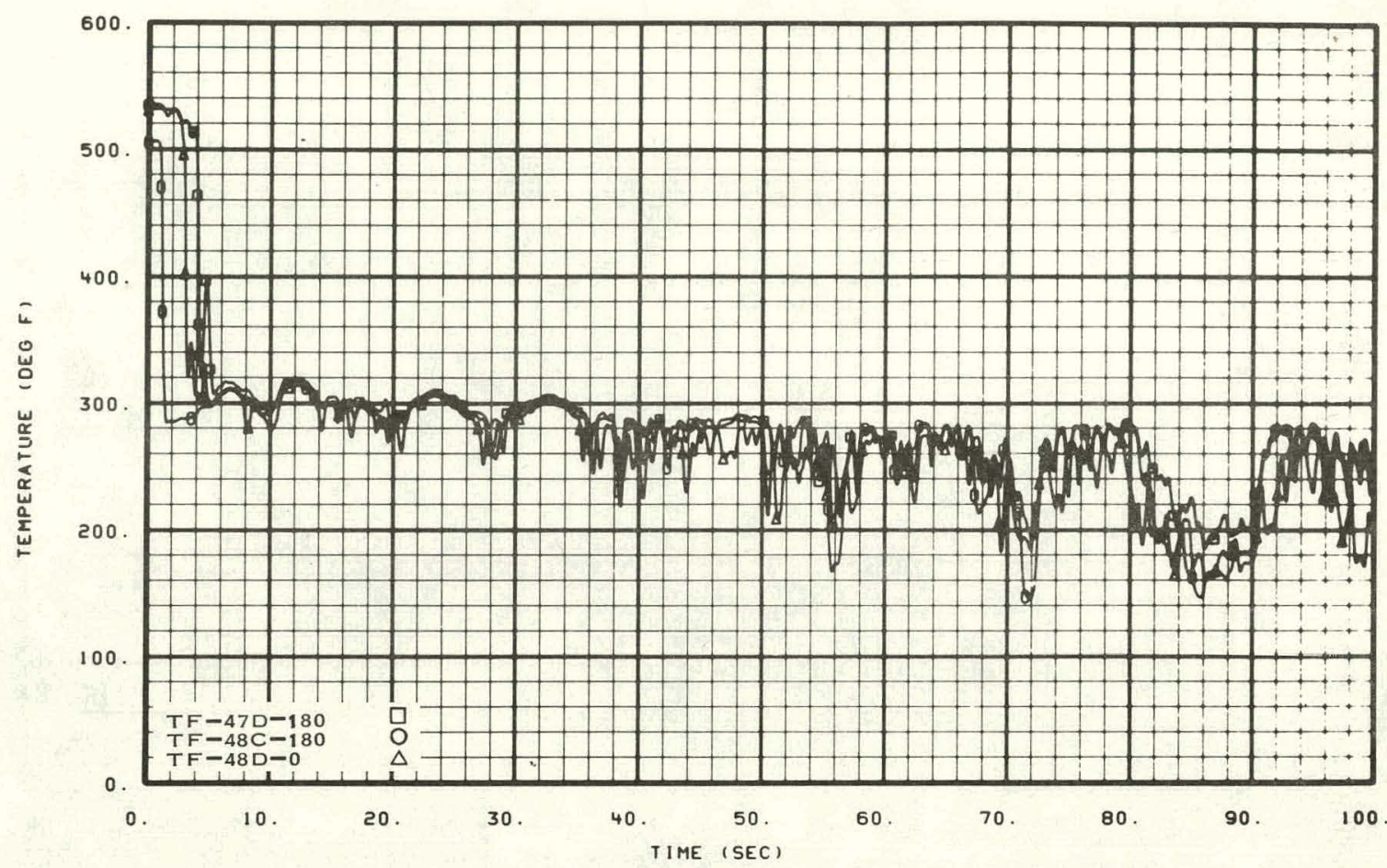

Fig. 30 Fluid temperatures in upper portion of downcomer gap -- Test 15.1.

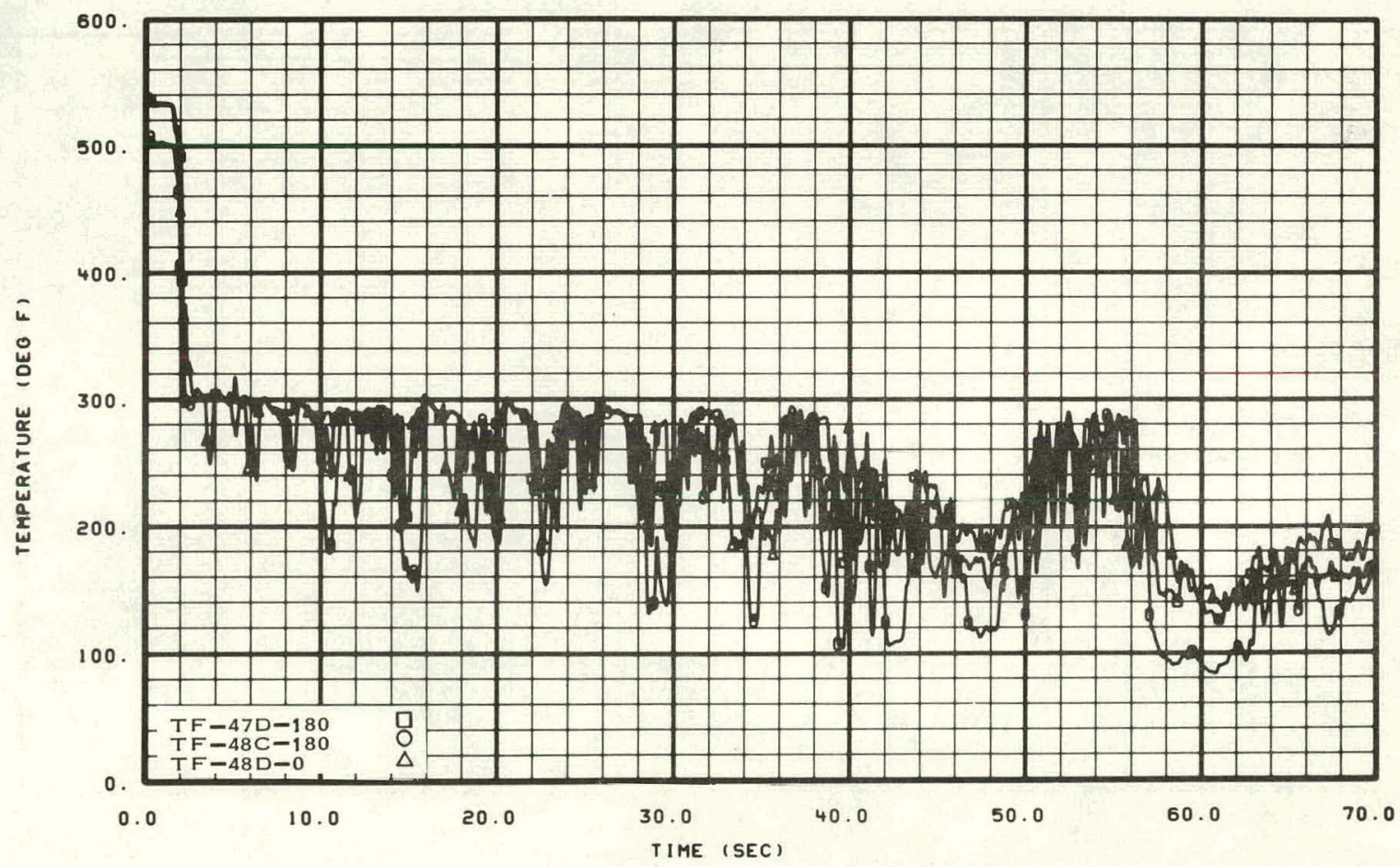

Fig. 31 F111त temperatures in upper portion of downcomer gap -- Test 15.2. 


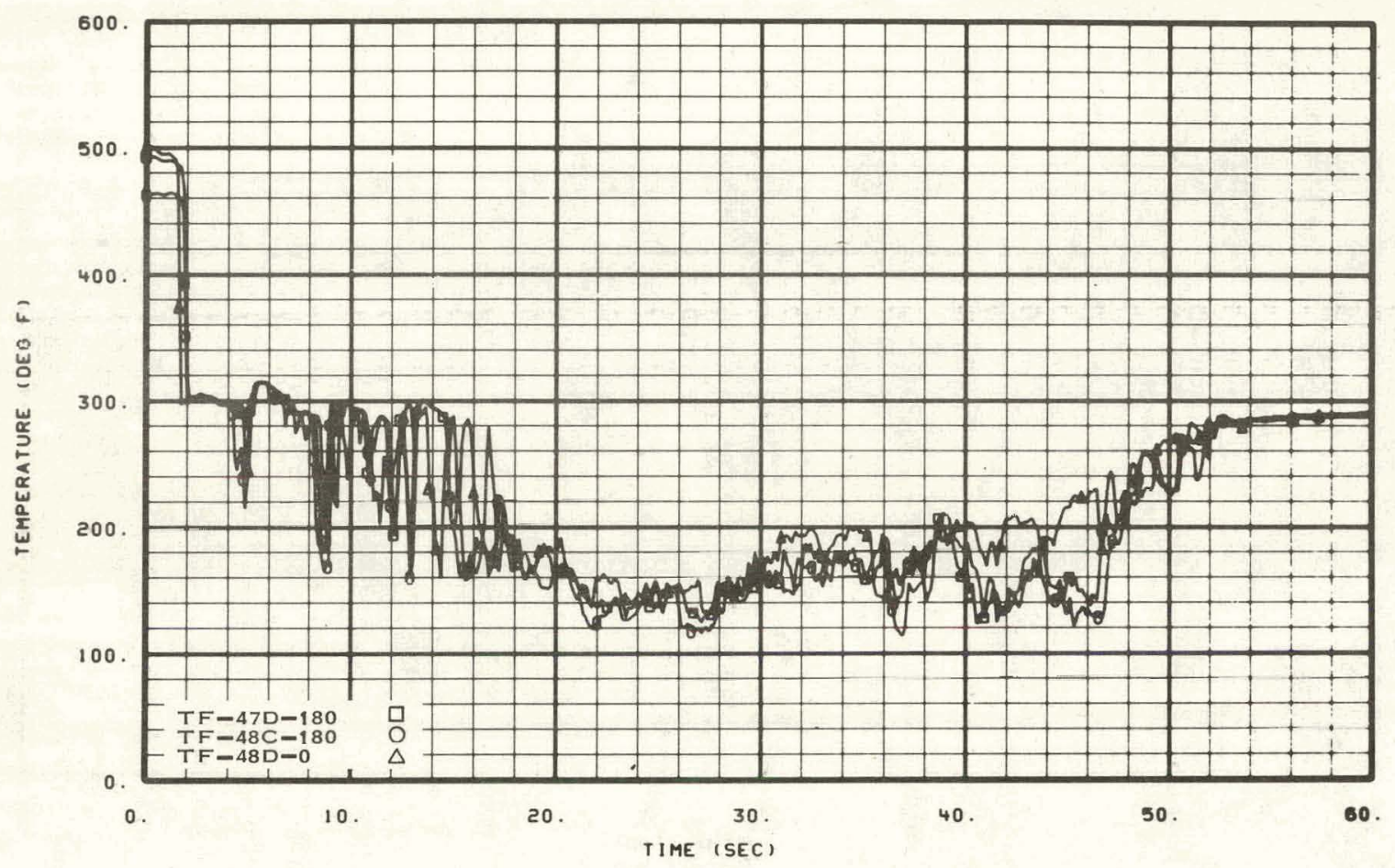

Fig. 32 Fluid temperatures in upper portion of downcomer gap -- Test 15.3.

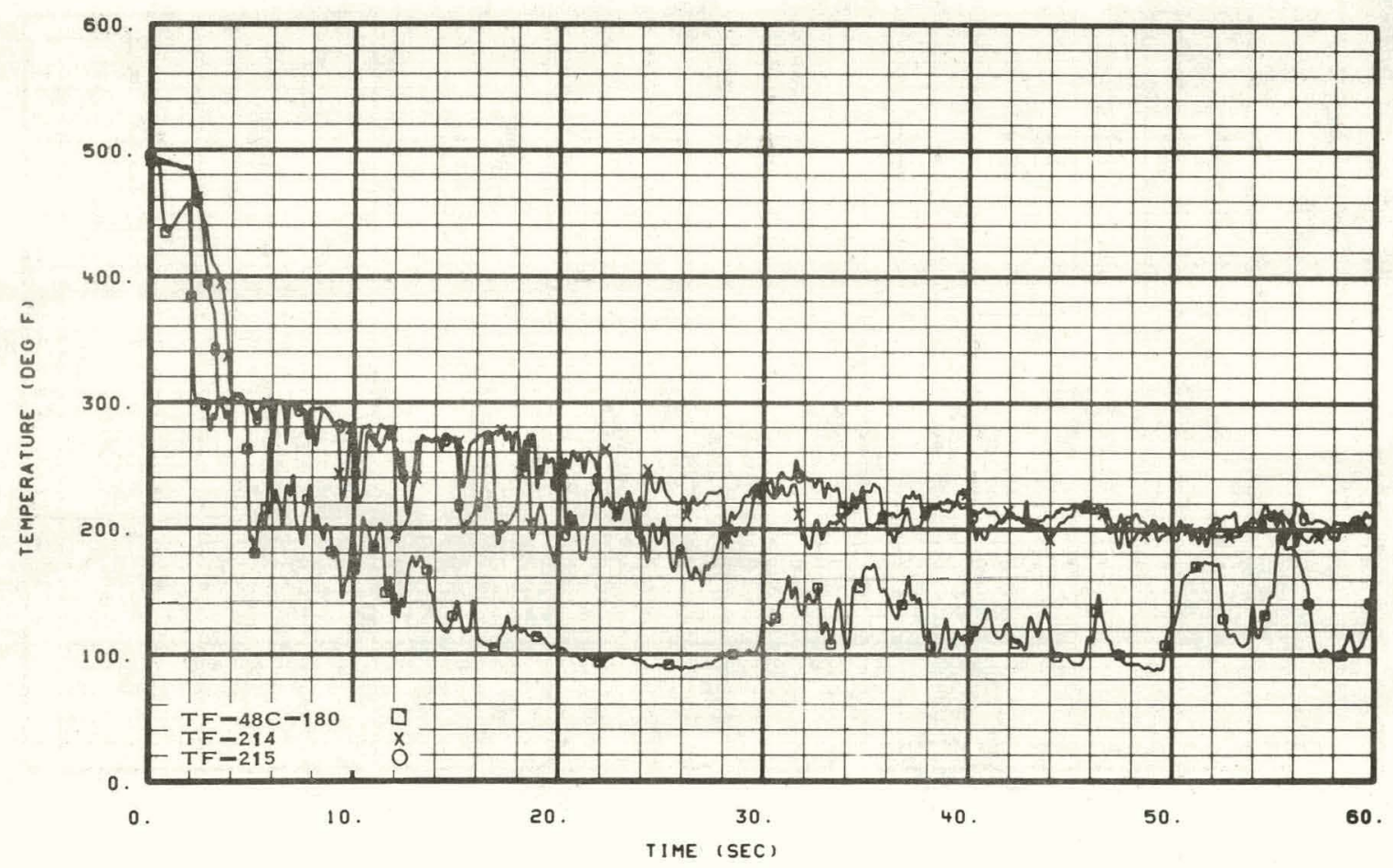

Fig. 33 Fluid temperatures in upper portion of downcomer gap -- Test 15.4. 


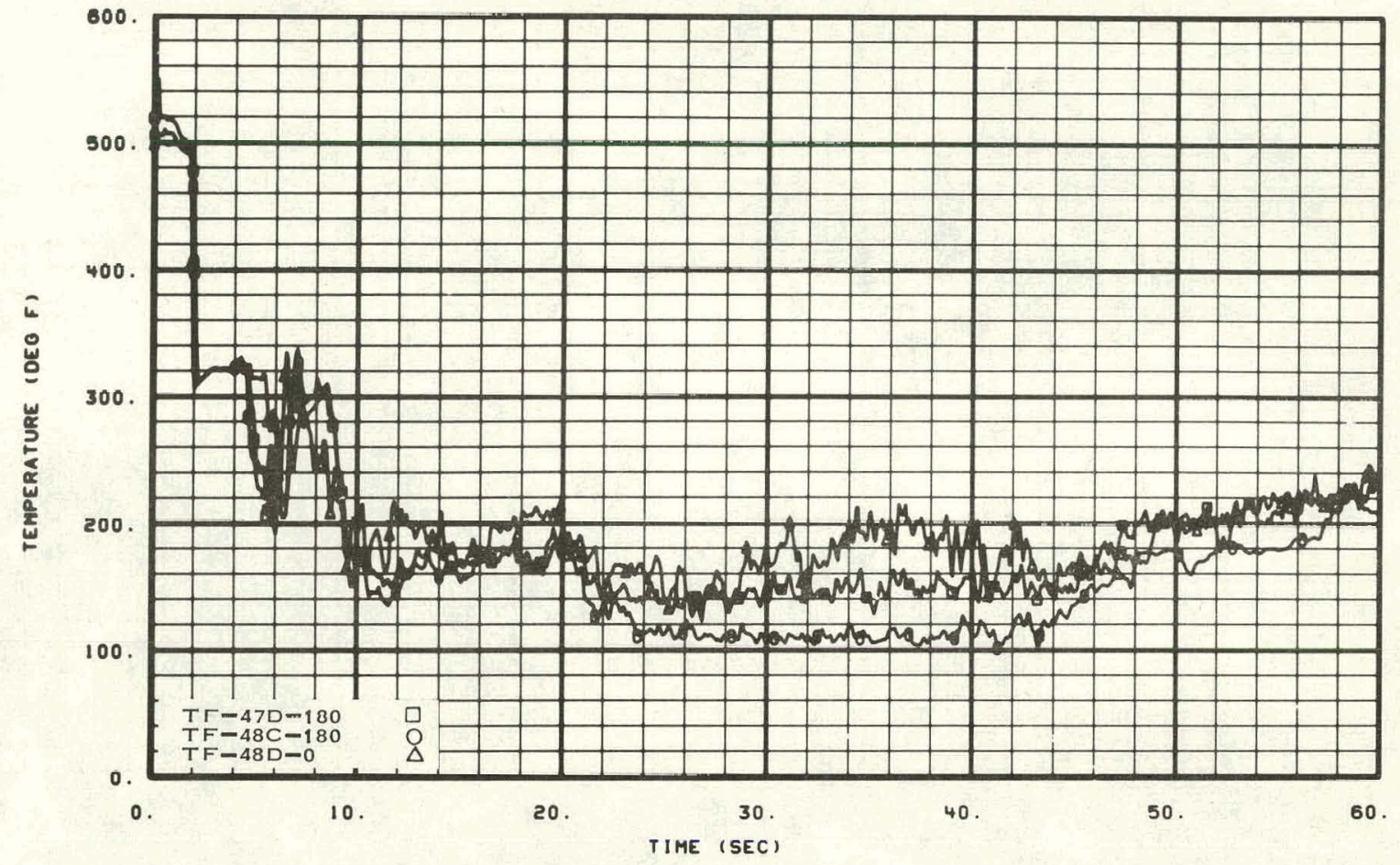

Fig. 34 Fluid temperatures in upper portion of downcomer gap -- Test 15.7 .

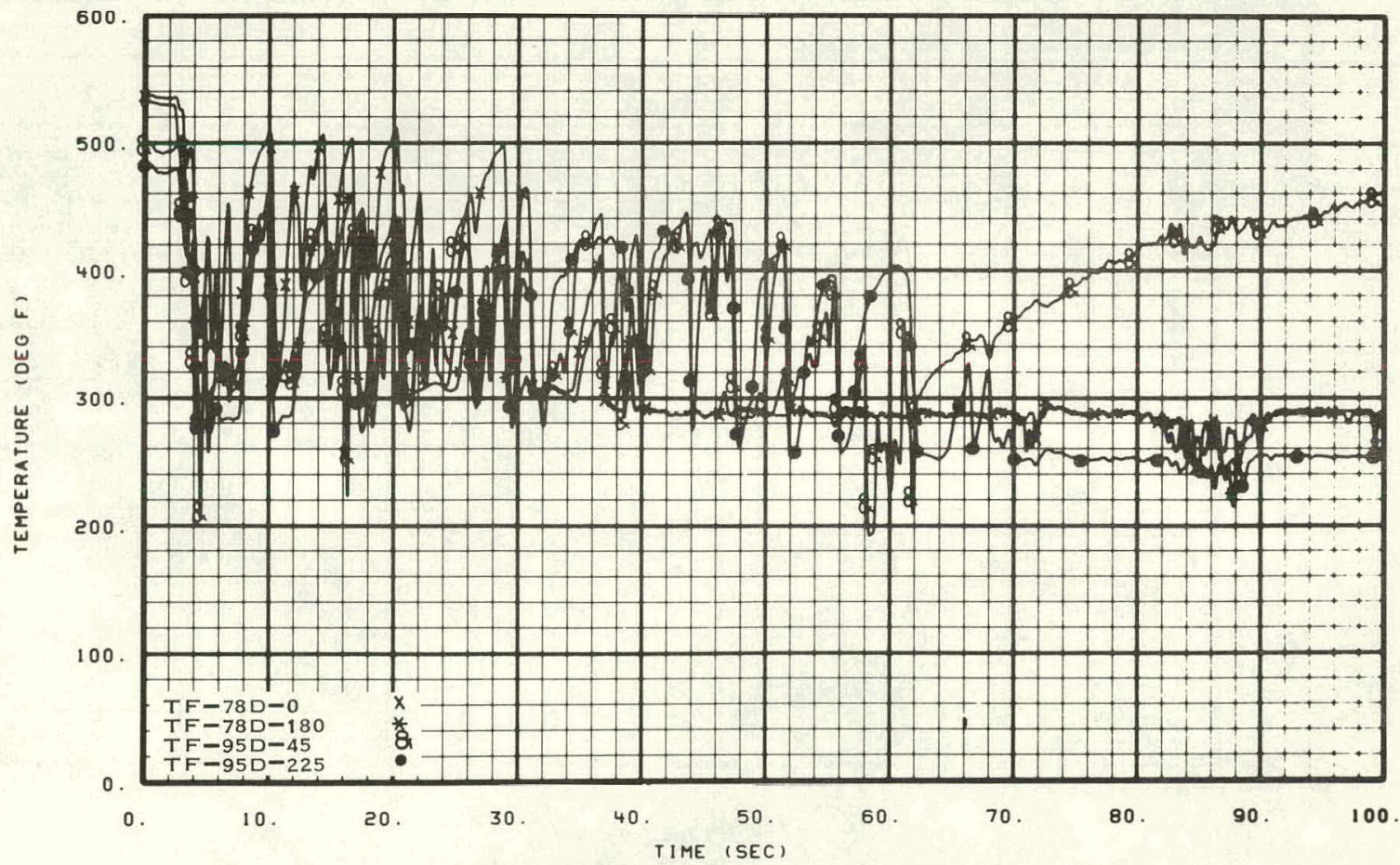

Fig. 35 Fluid temperatures in lower portion of downcomer gap -- Test 15.1. 


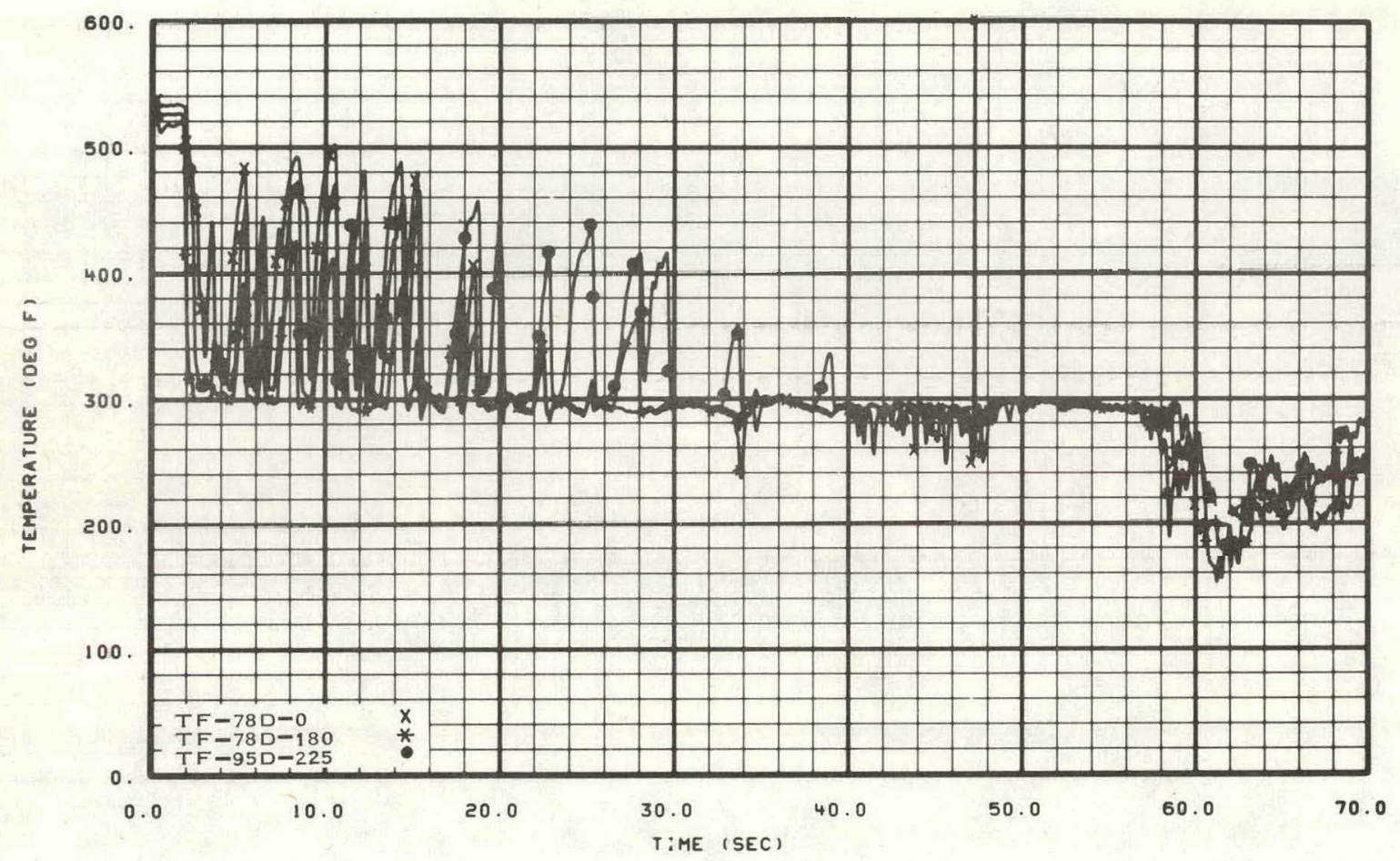

Fig. 36 Fluid temperatures in lower portion of downcomer gap -- Test 15.2.

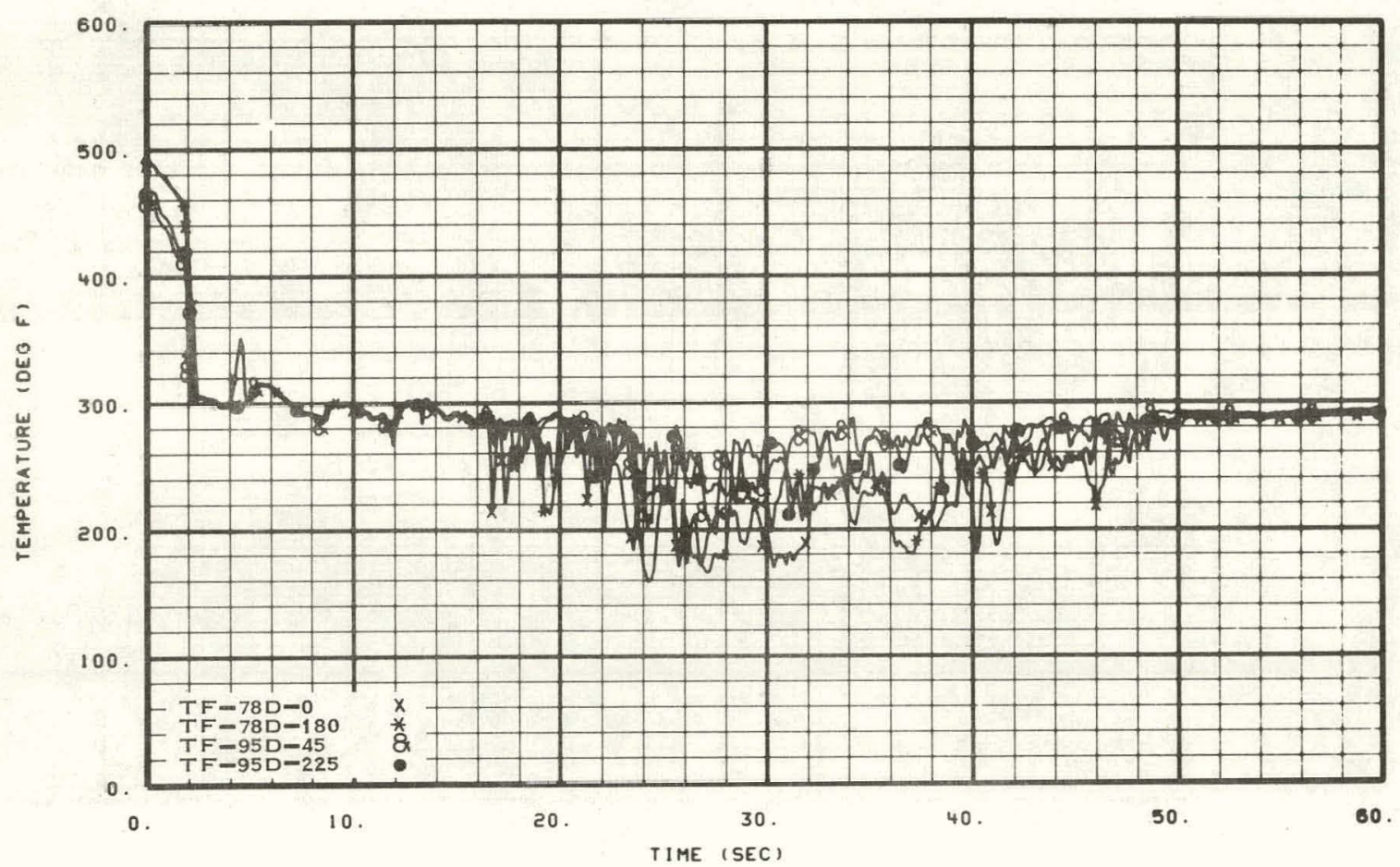

Fig. 37 Fluid temperatures in lower portion of downcomer gap -- Test 15.3. 


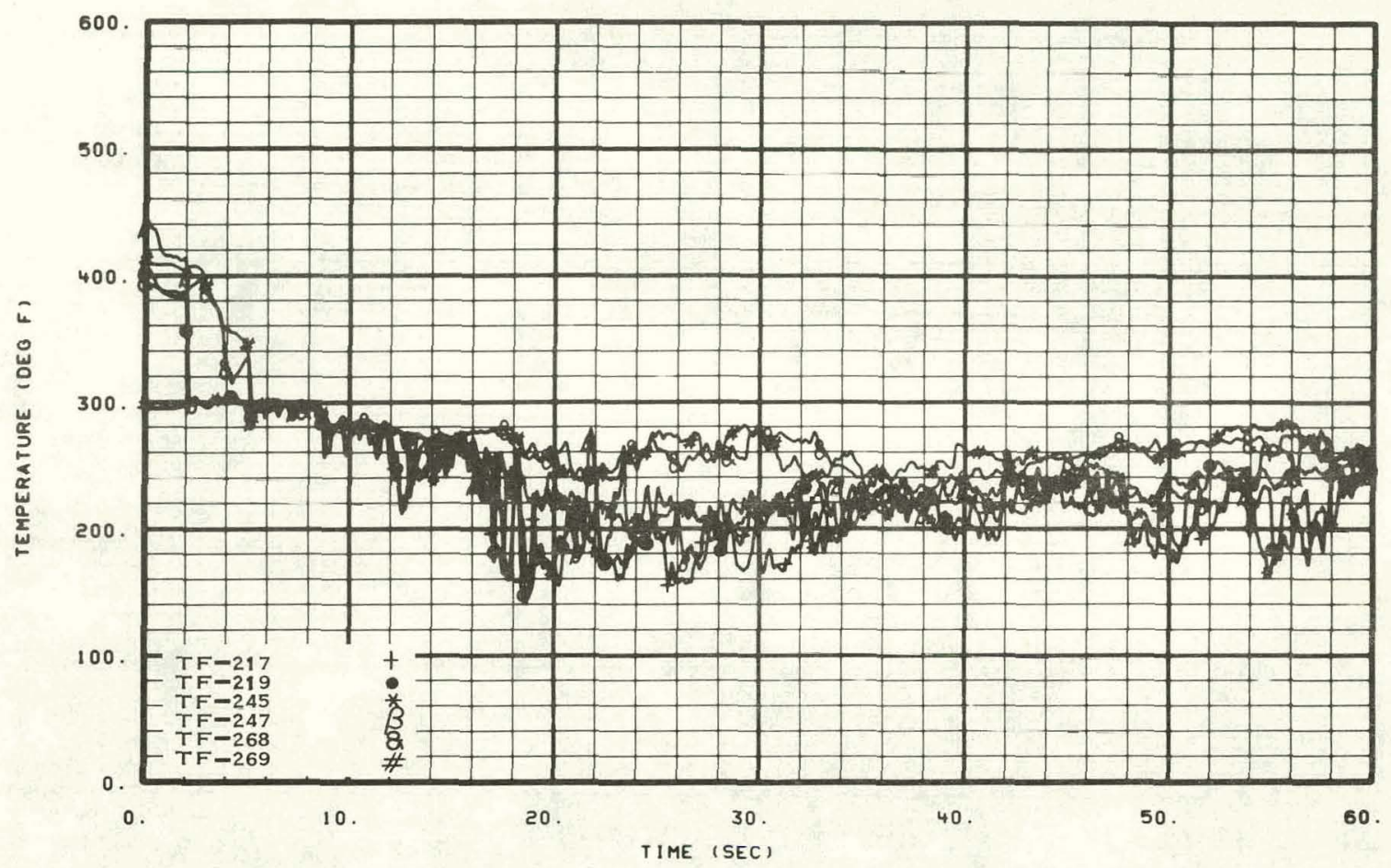

Fig. 38 Fluid temperatures in lower portion of downcomer gap -- Test 15.4 .

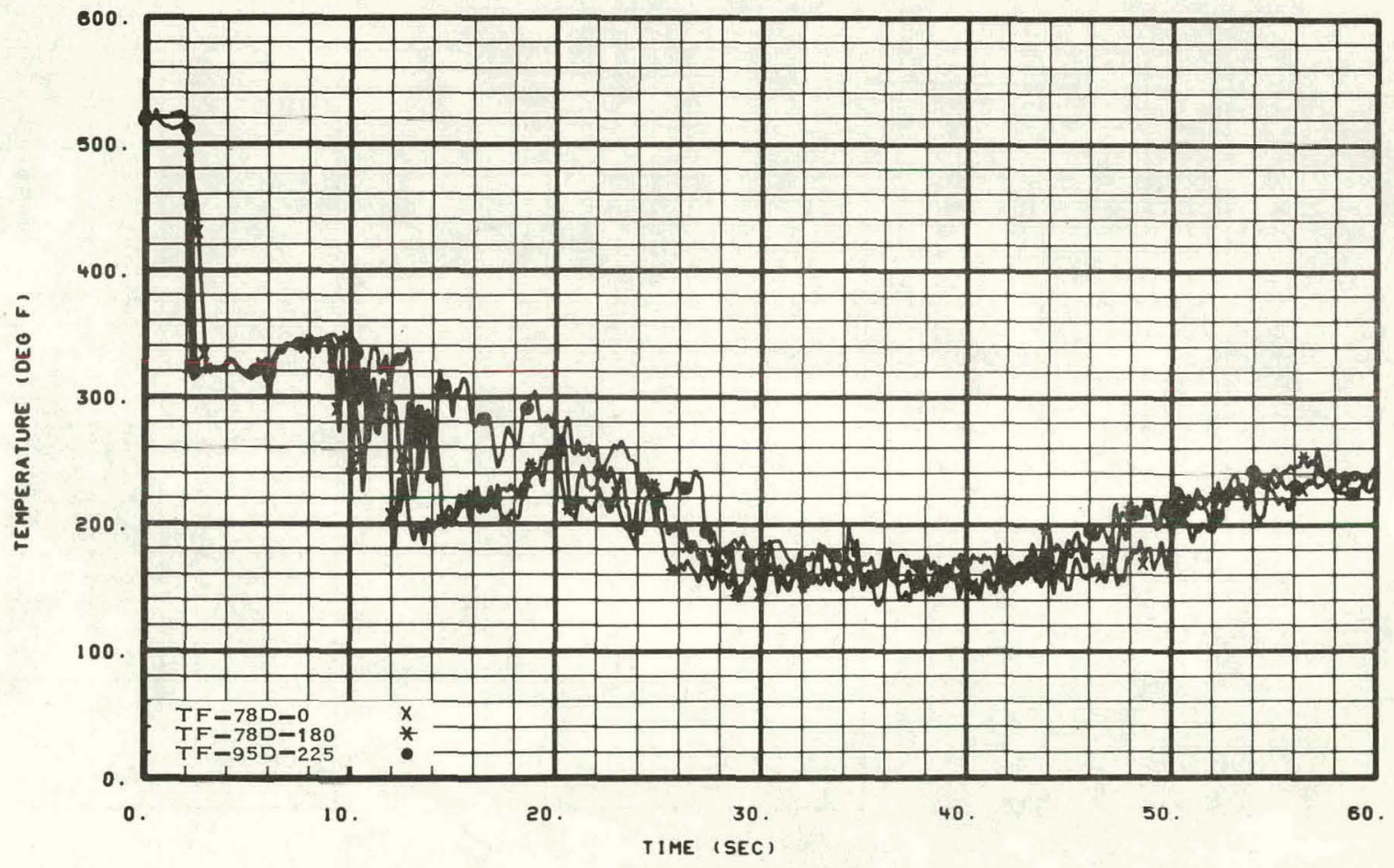

Fig. 39 Fluid temperatures in lower portion of downcomer gap -- Test 15.7. 


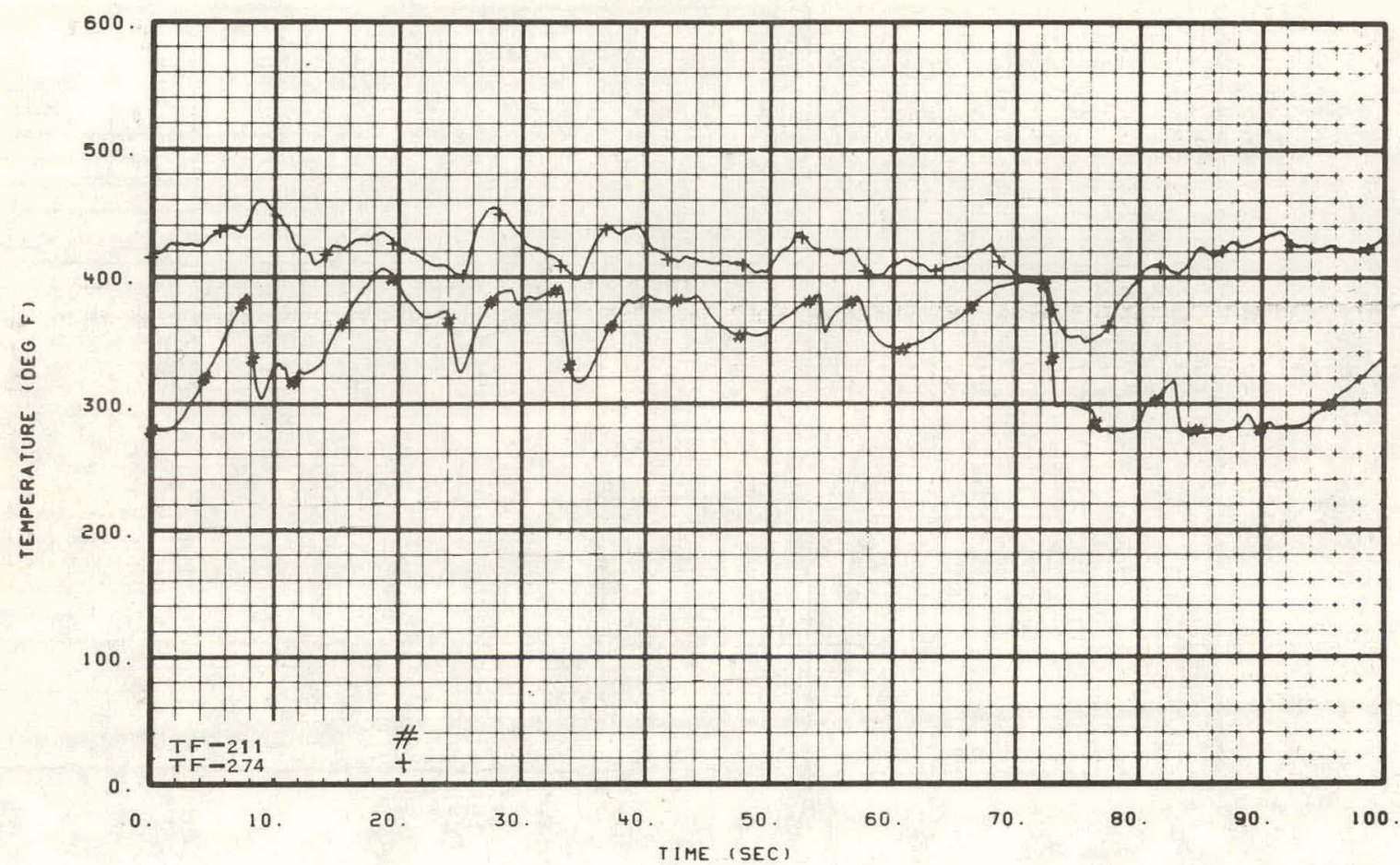

Fig. 40 Fluid temperatures in outlet plenum -- Test 15.1.

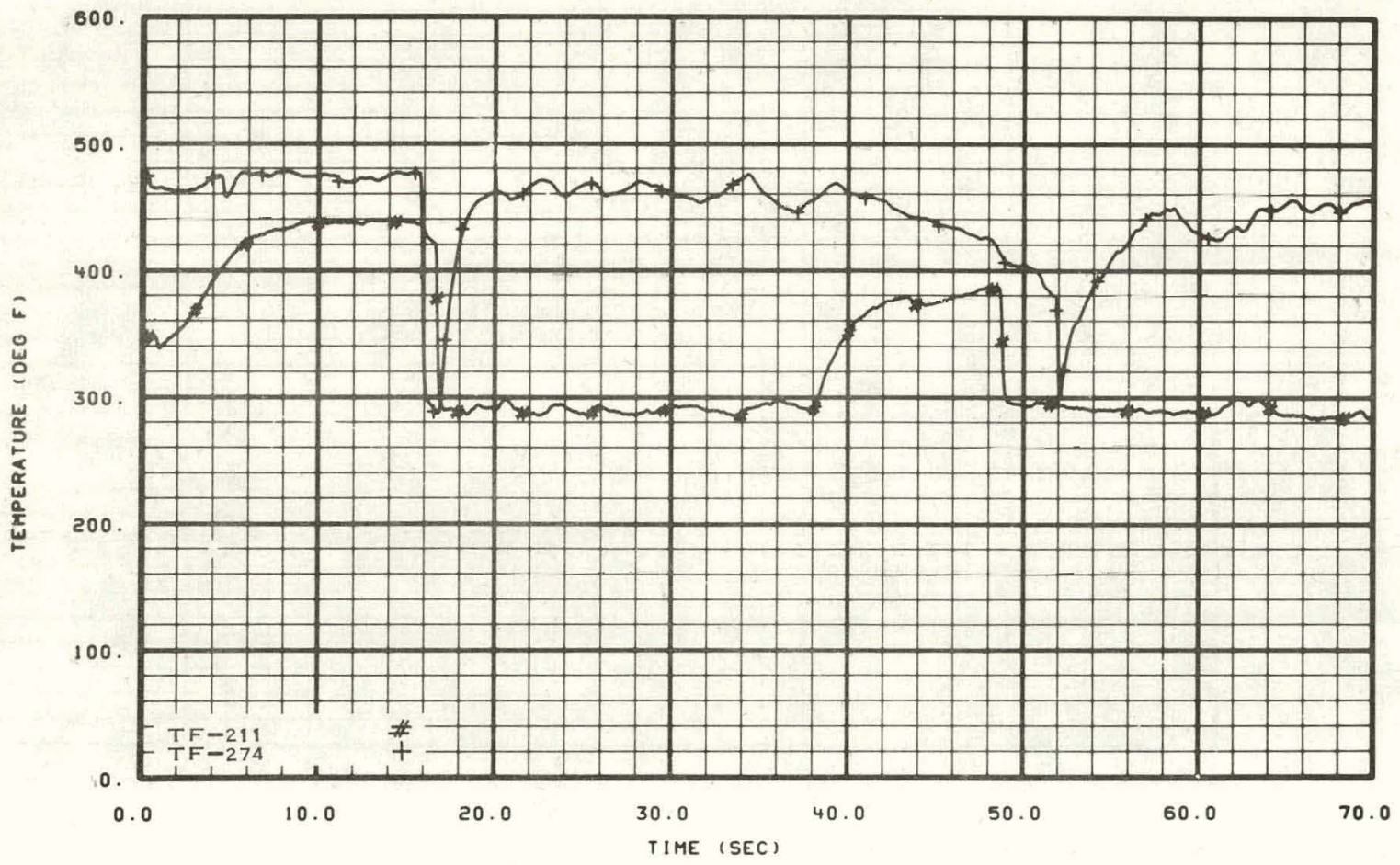

Fig. 41 Fluid temperatures in outlet plenum -- Test 15.2. 


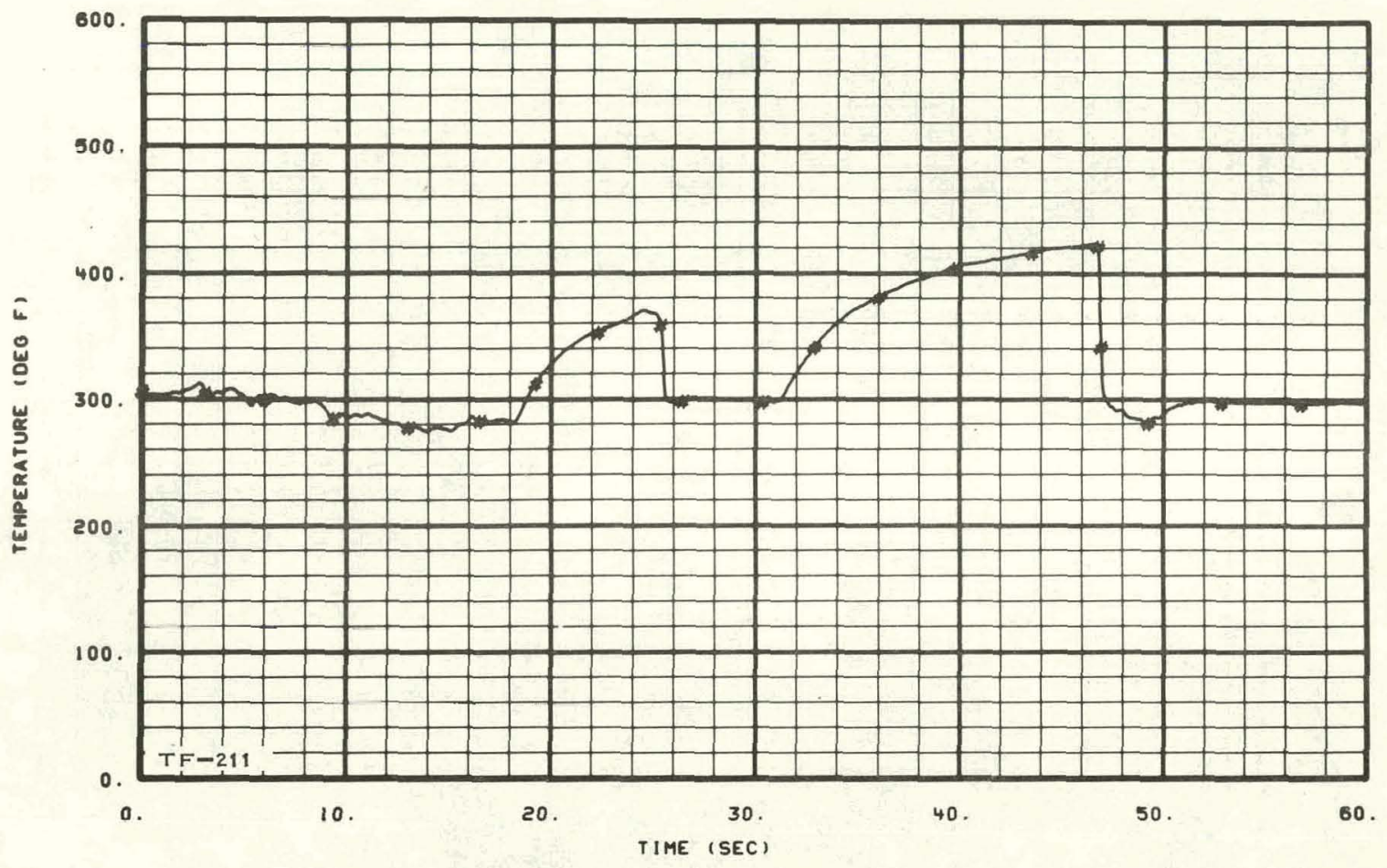

Fig. 42 Fluid temperatures in outlet plenum -- Test 15.4.

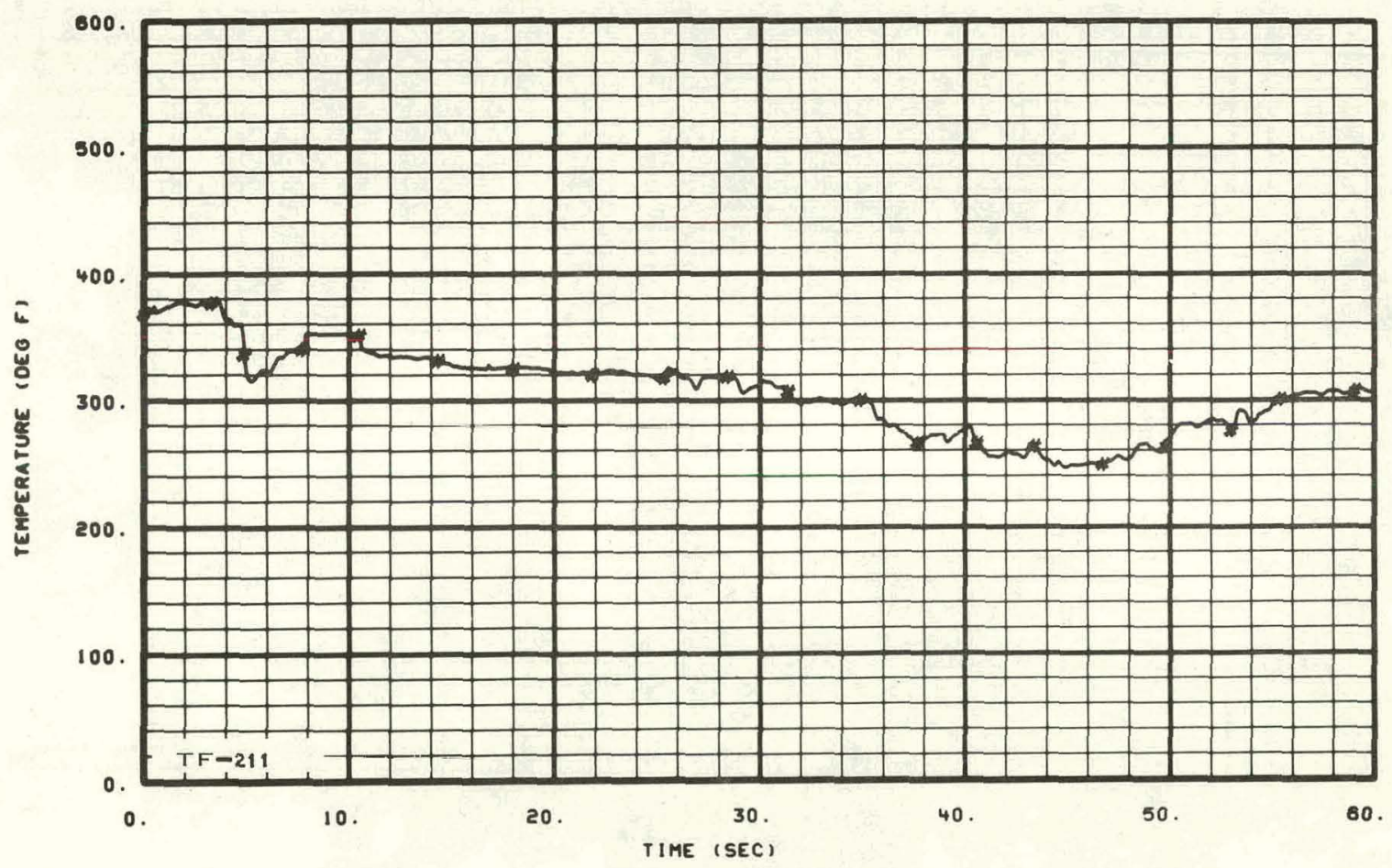

Fig. 43 Fluid temperatures in outlet plenum -- Test 15.7. 


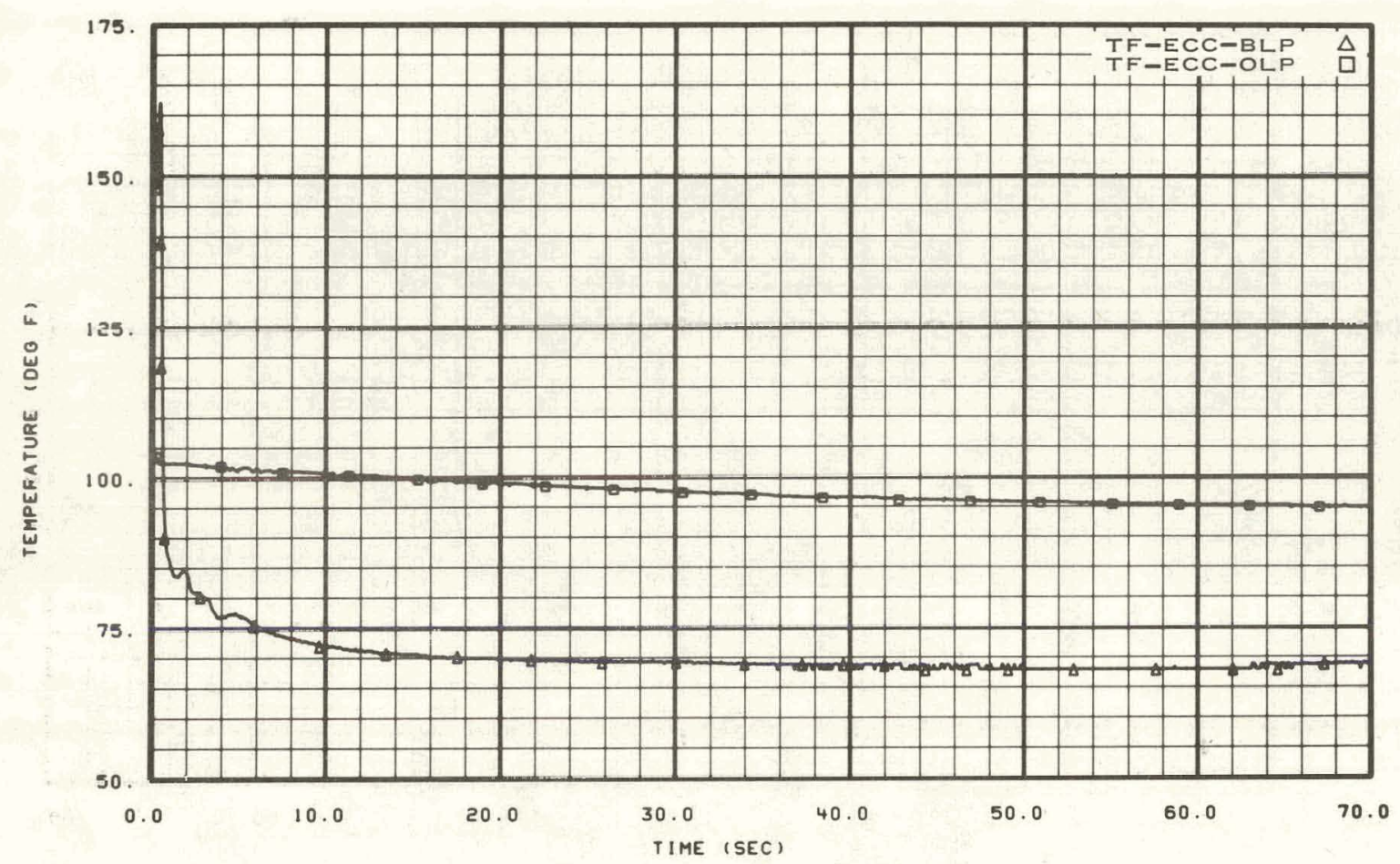

Fig. 44 Fluid temperatures in ECC lines from blowdown loop pump and operating loop pump -- Test 15.2.

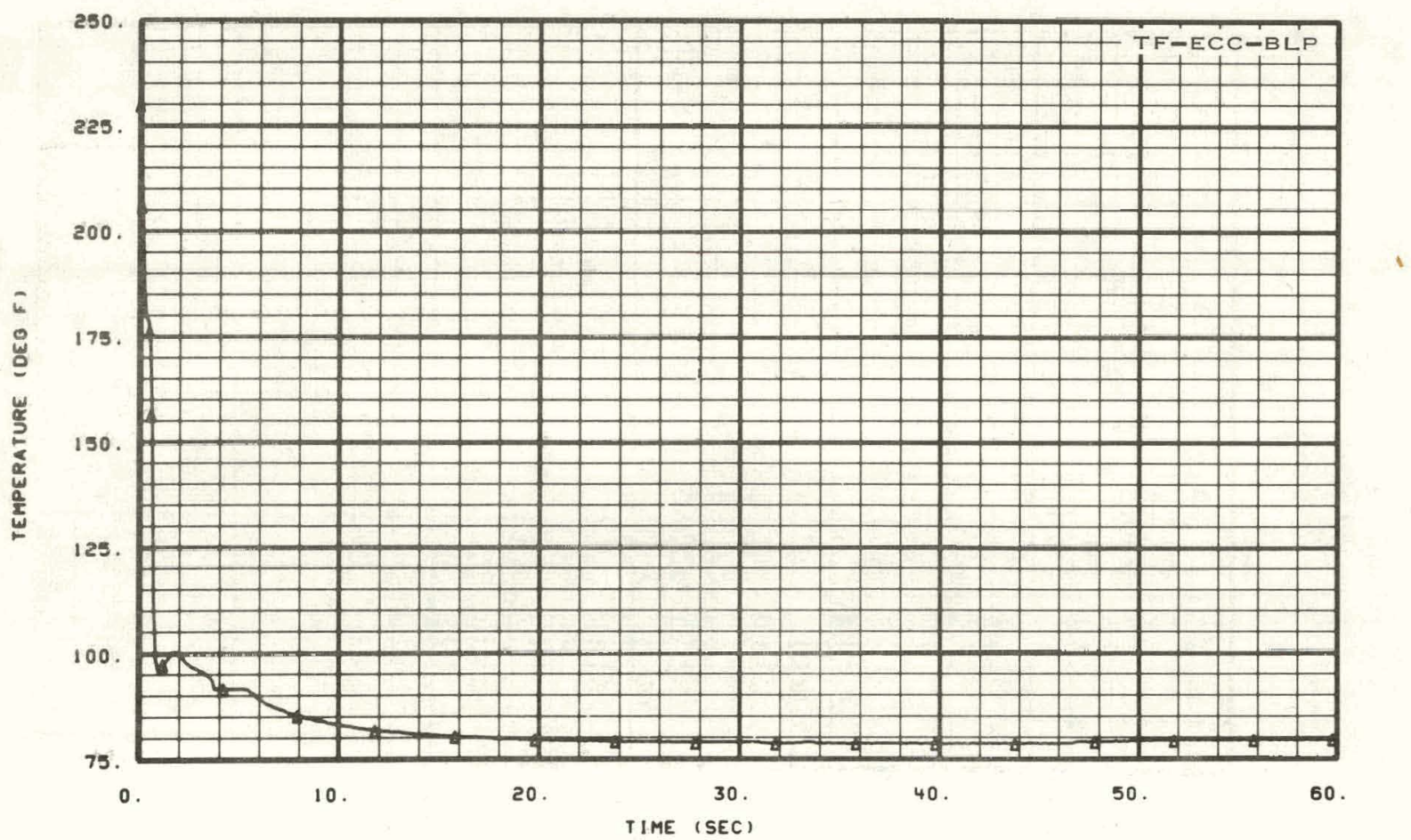

Fig. 45 Fluid temperatures in ECC lines from blowdown loop pump and operating loop pump -- Test 15.3. 


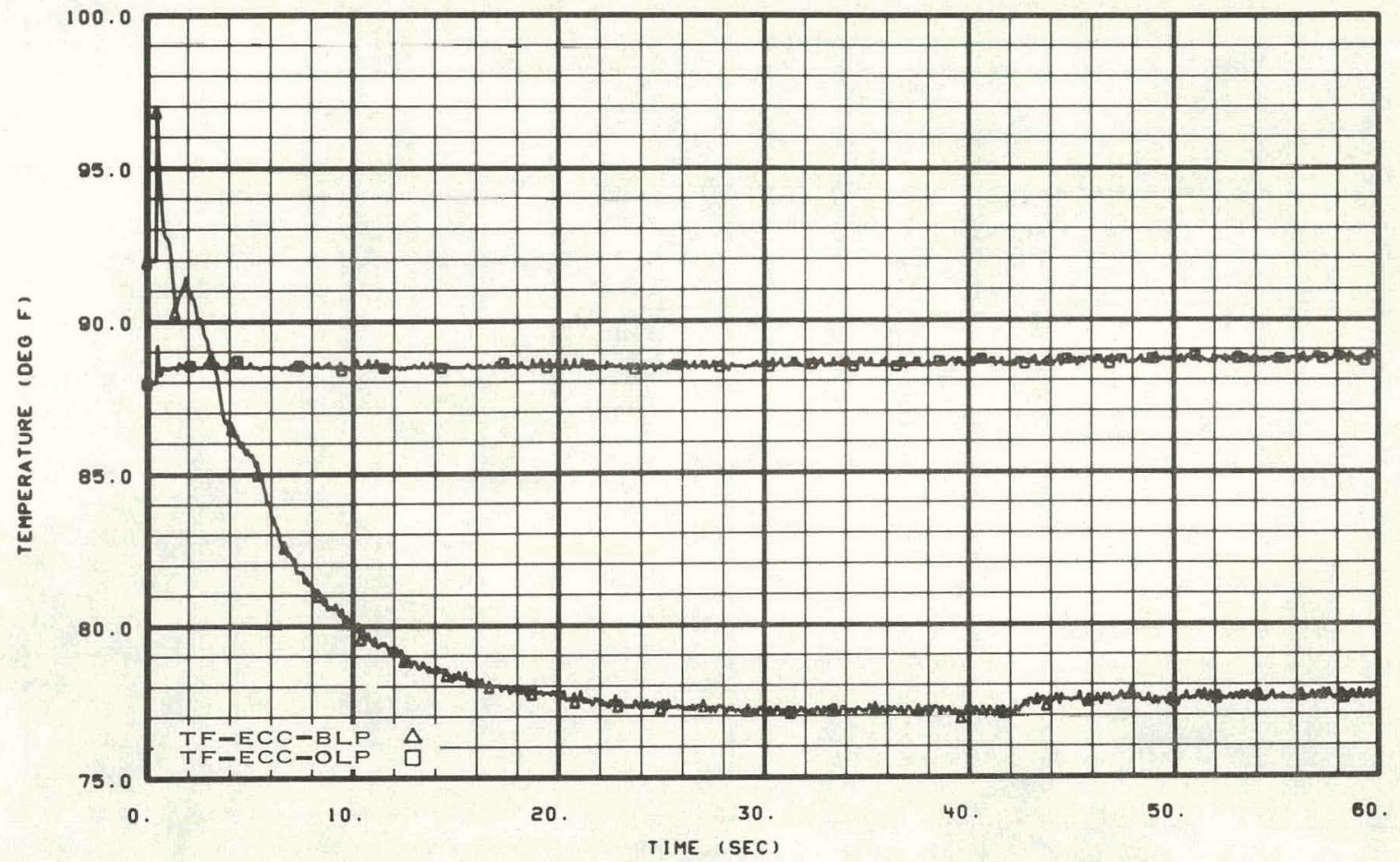

Fig. 46 Fluid temperatures in ECC lines from blowdown loop pump and operating loop pump -- Test 15.7 .



Fig. 47 Metal temperatures in core barre1 -- Test 15.1. 


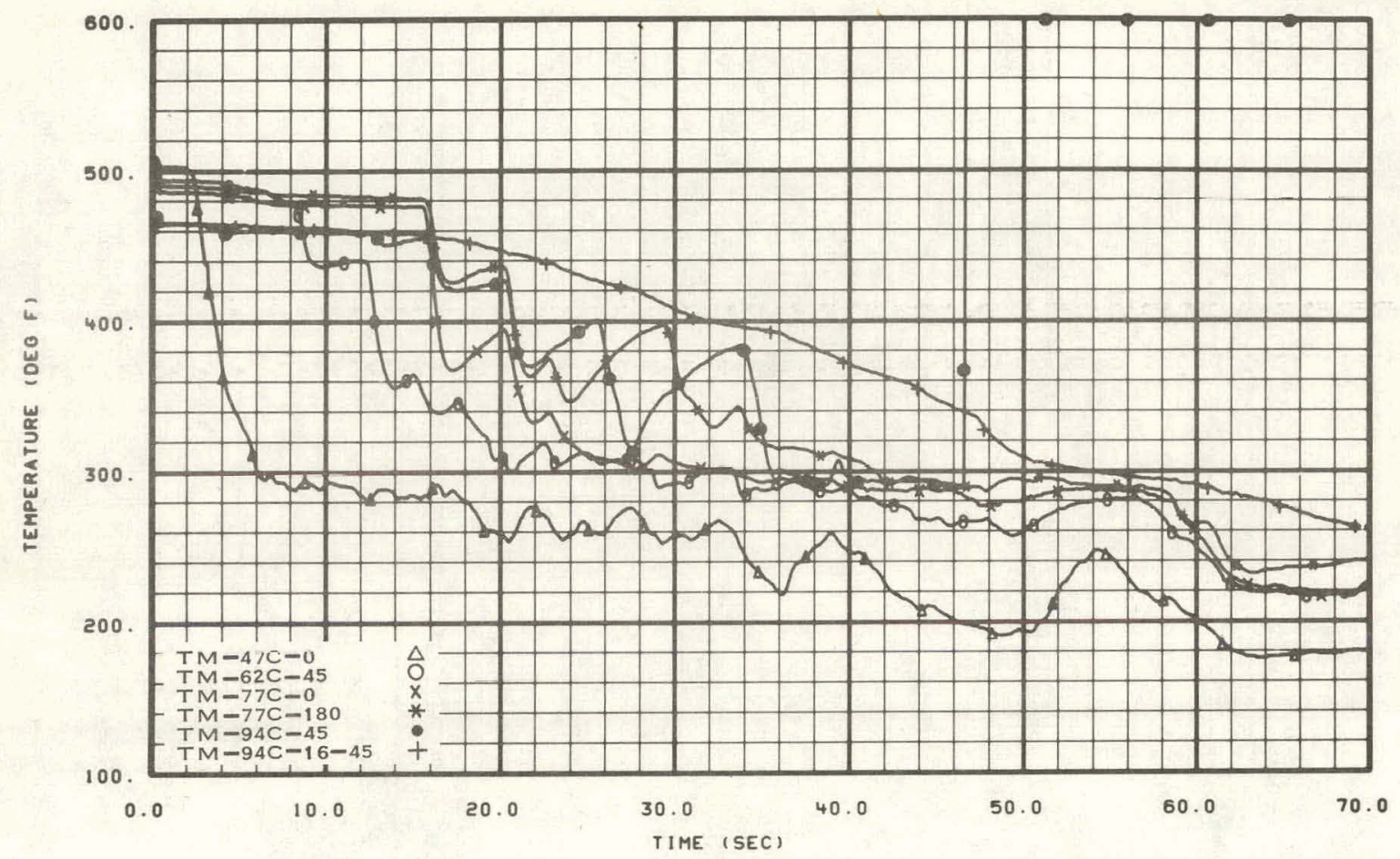

Fig. 48 Metal temperatures in core barrel -- Test 15.2.

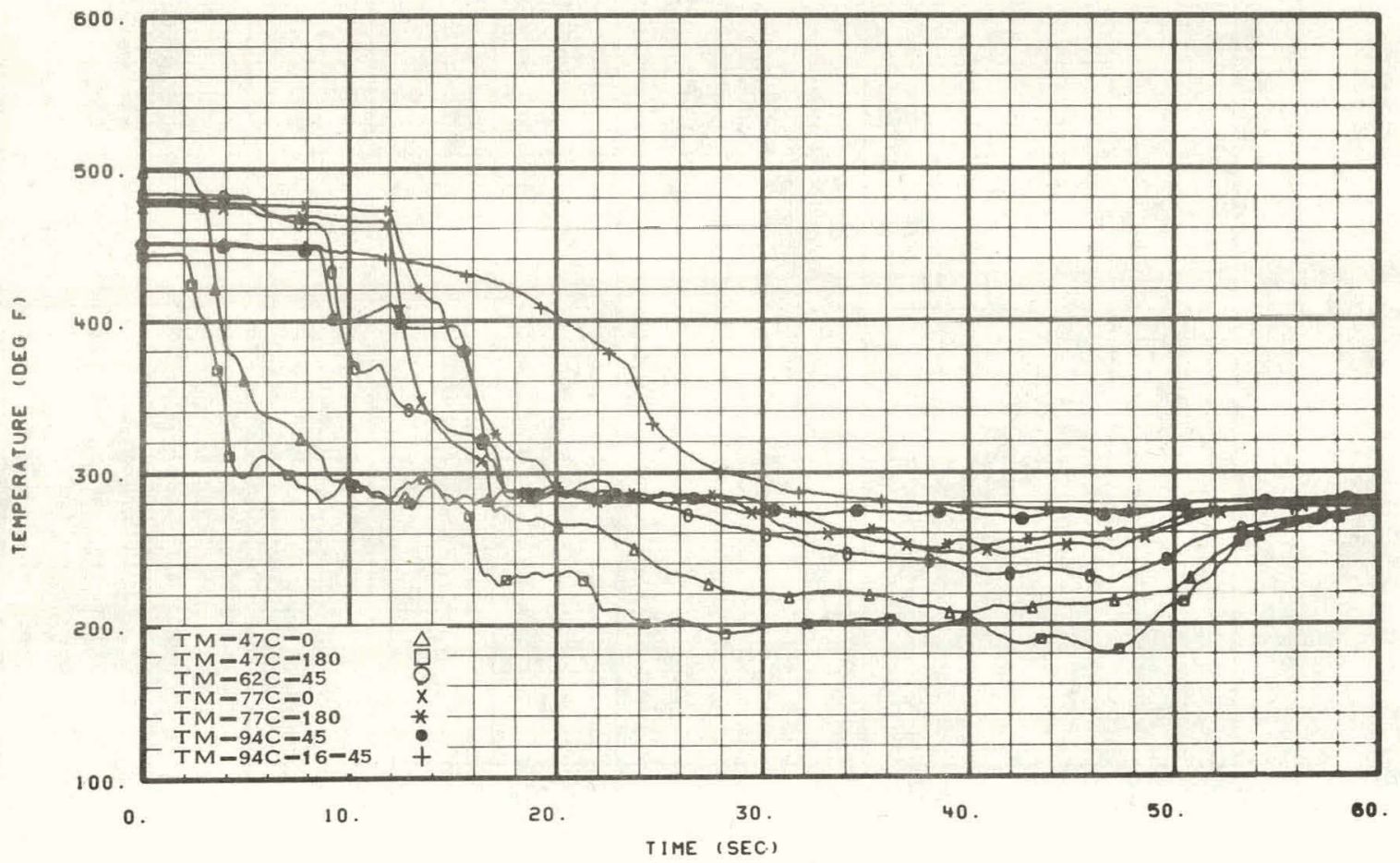

Fig. 49 Metal temperatures in core barrel -- Test 15.3. 


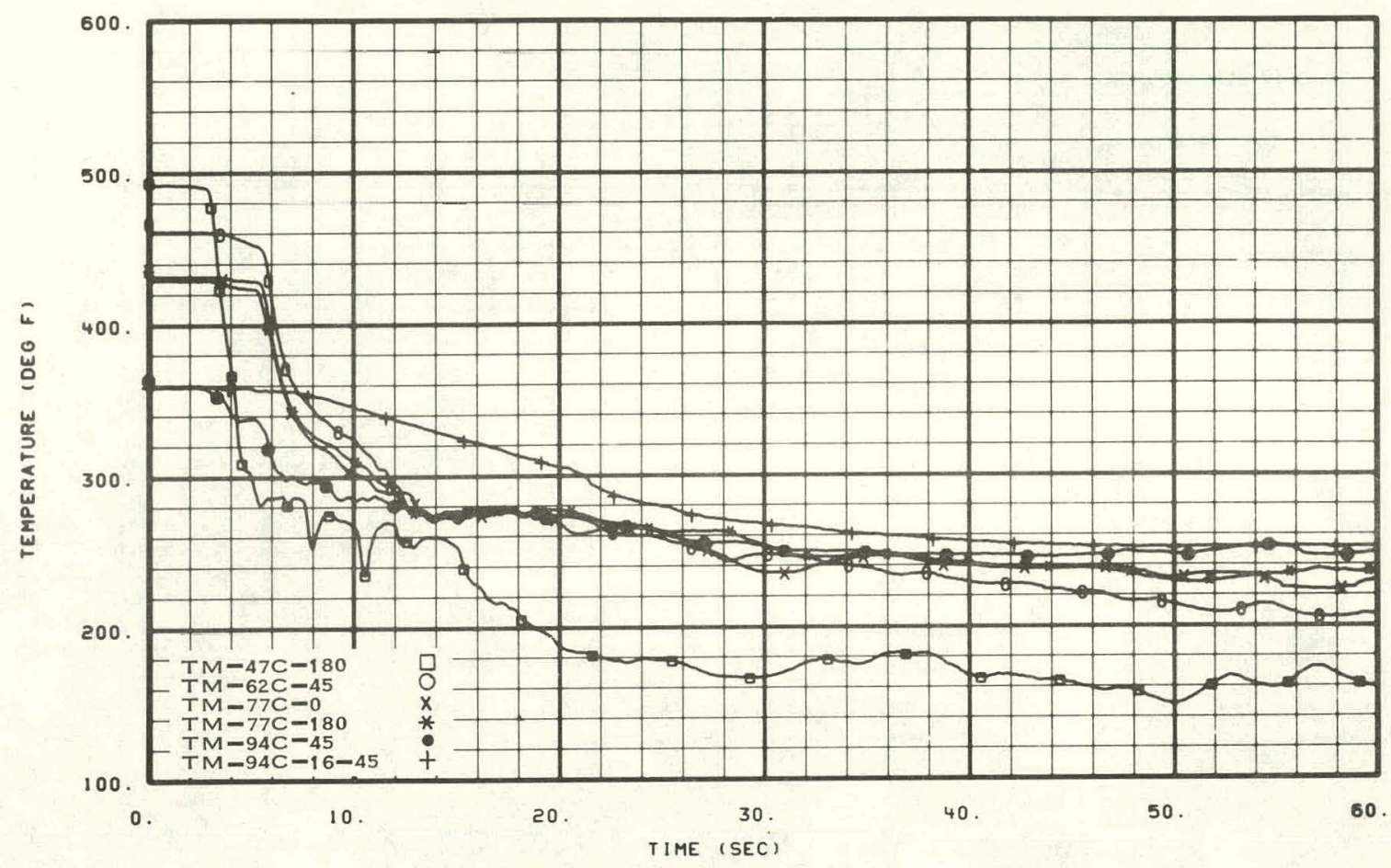

Fig. 50 Metal temperatures in core barrel -- Test 15.4.

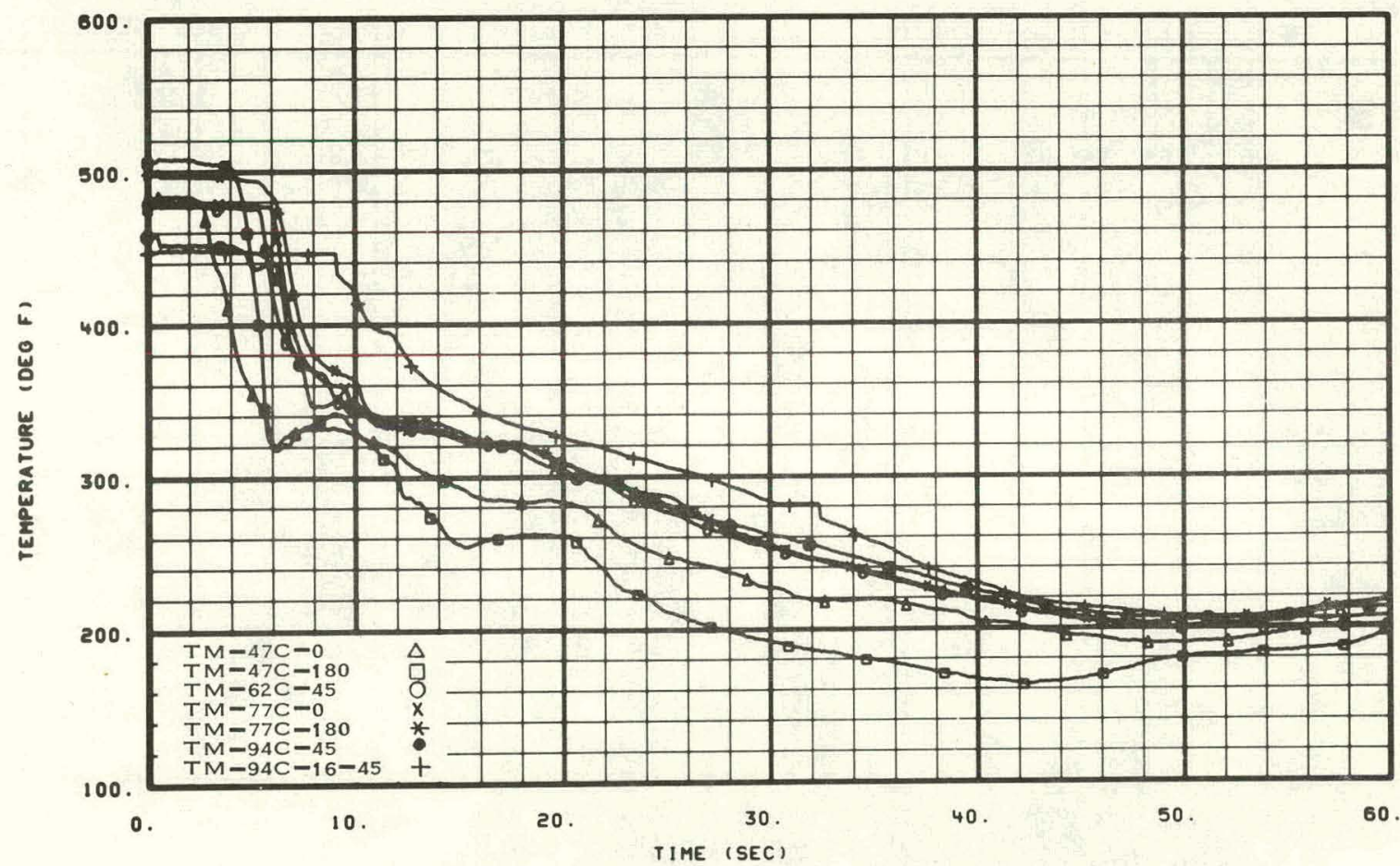

Fig. 51 Metal temperatures in core barrel -- Test 15.7. 


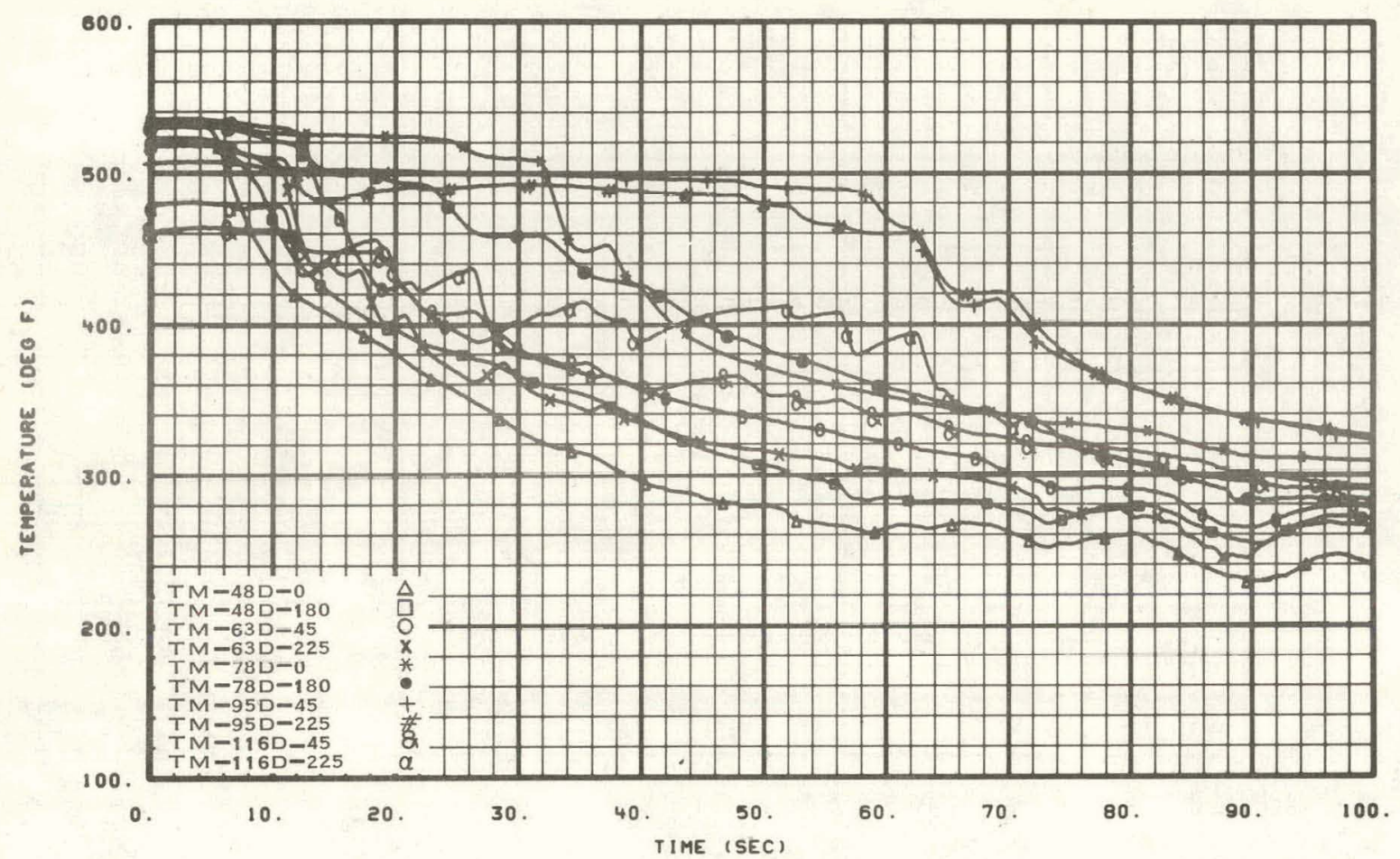

Fig. 52 Metal temperatures in downcomer filler -- Test 15.1.

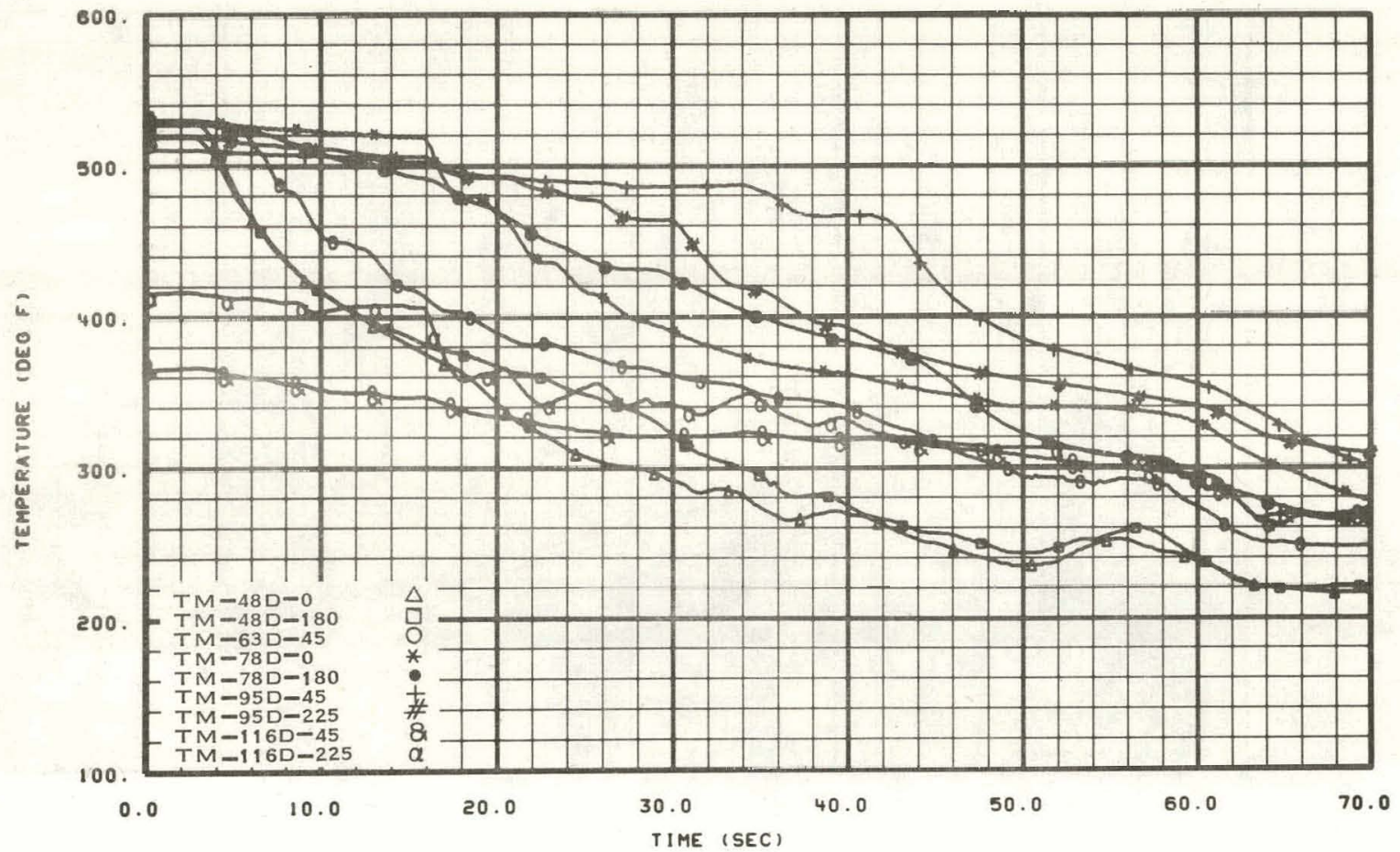

Fig. 53 Metal temperatures in downcomer filler -- Test 15.2. 


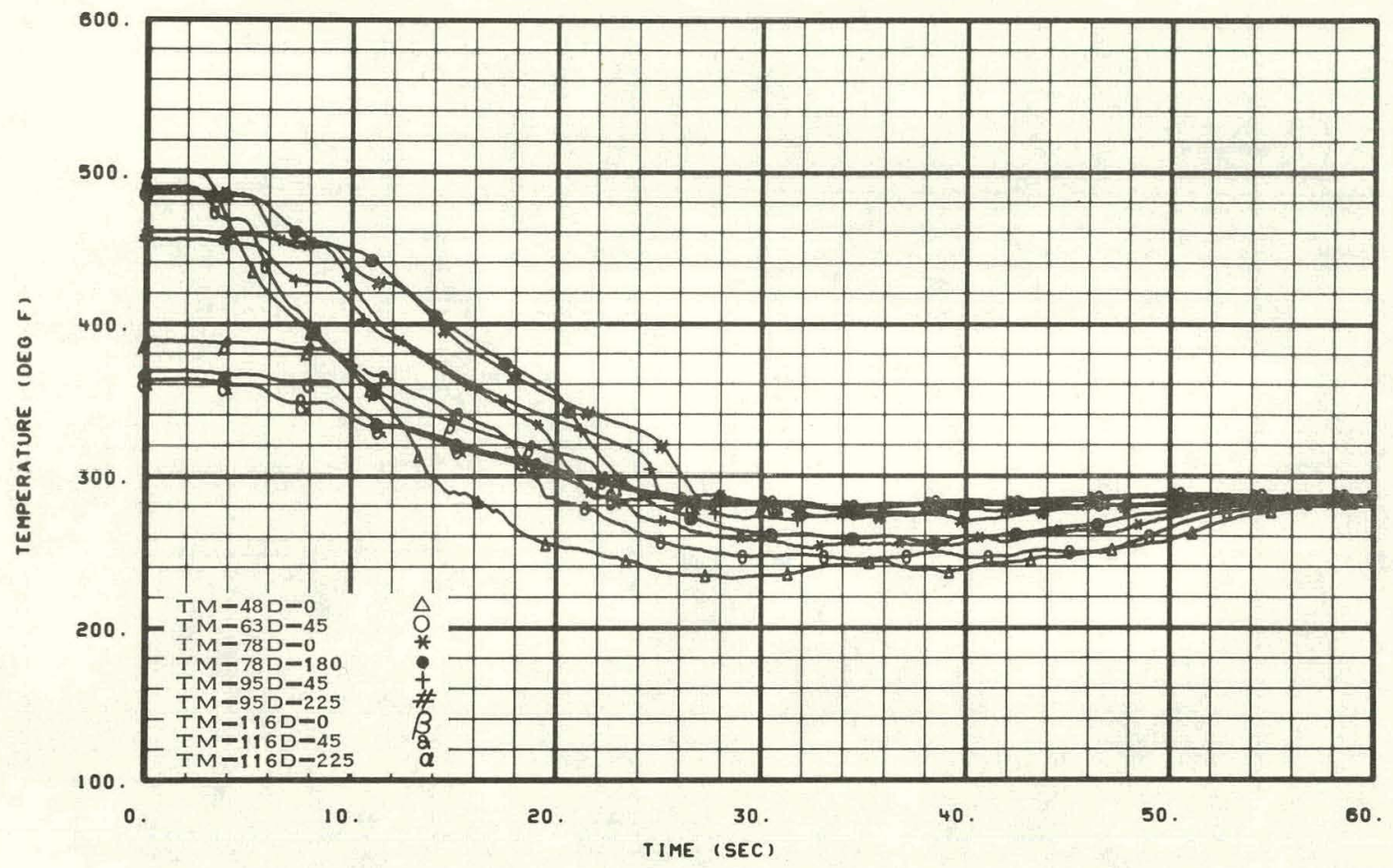

Fig. 54 Metal temperatures in downcomer filler -- Test 15.3.

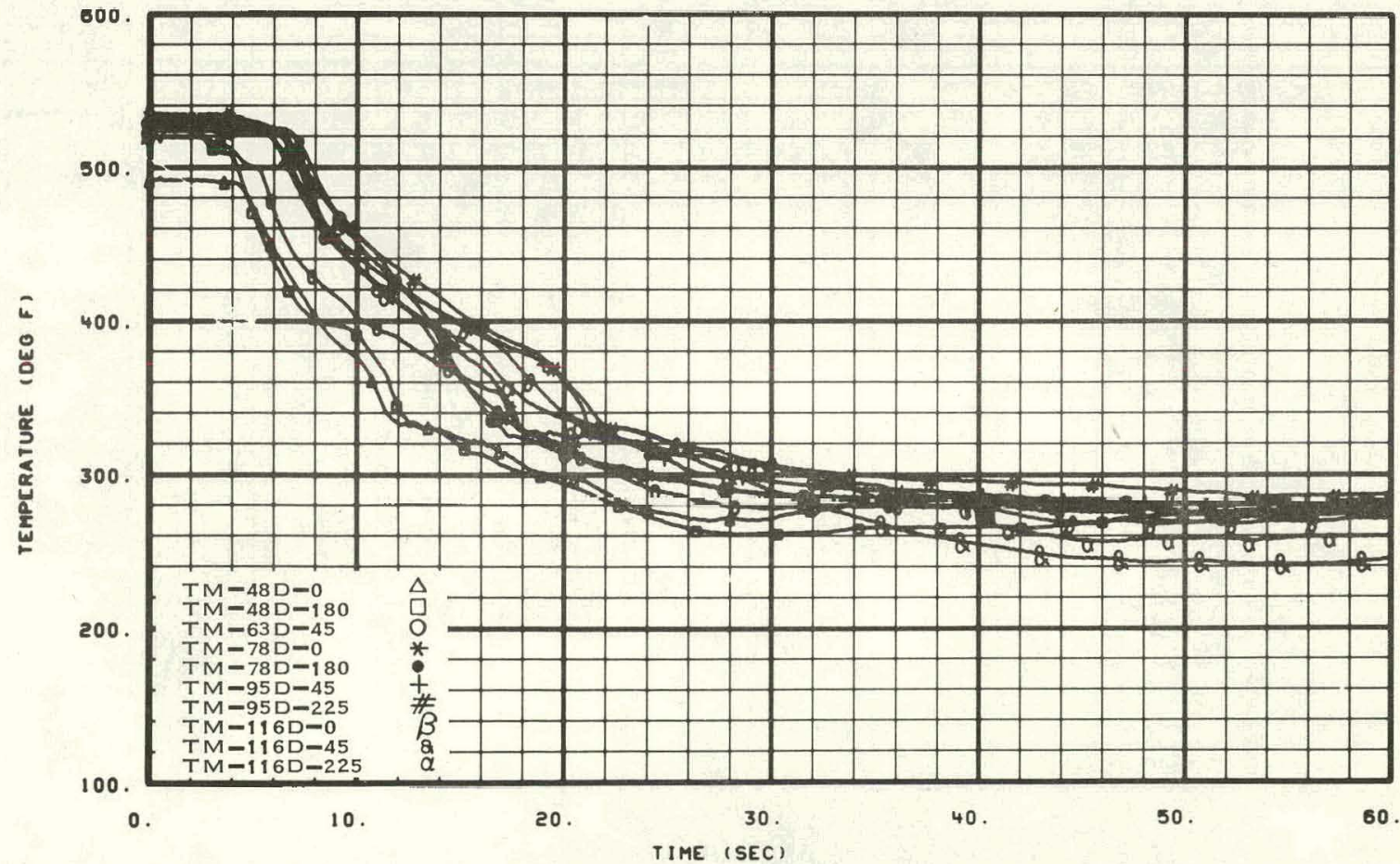

Fig. 55 Metal temperatures in downcomer filler -- Test 15.7. 


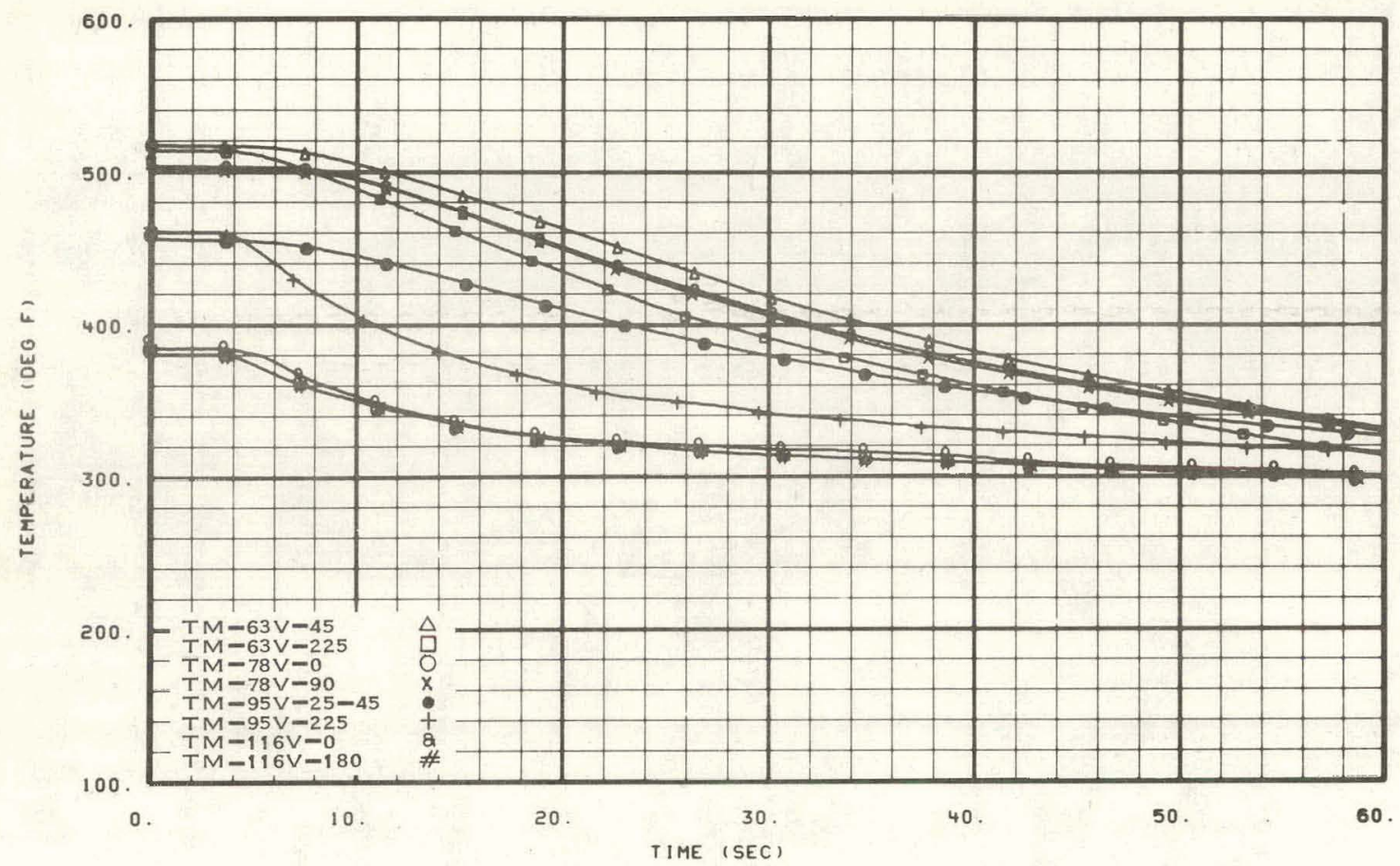

Fig. 56 Metal temperatures in vessel wall -- Test 15.4.

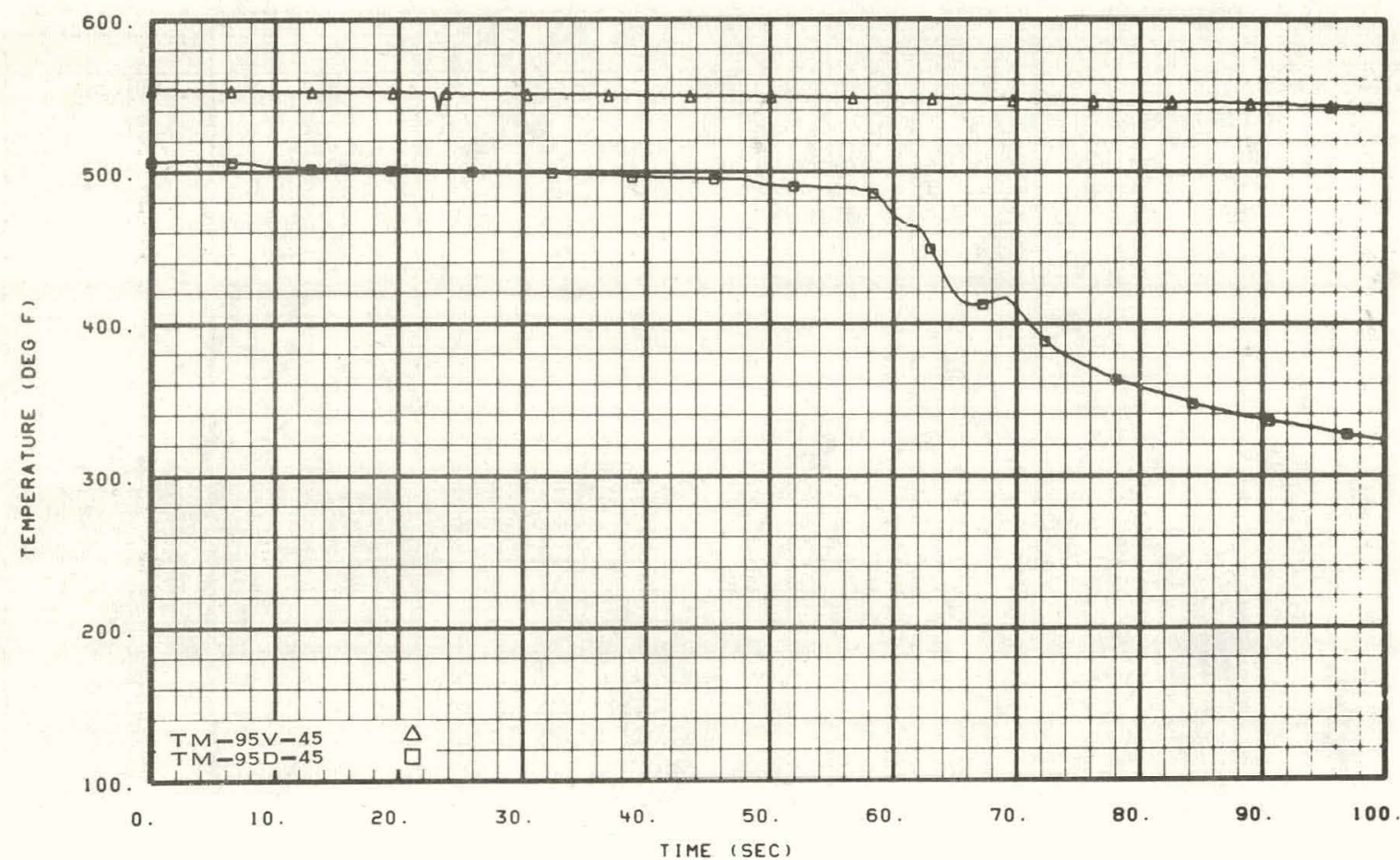

Fig. 57 Metal temperatures in vessel wall 95 inches from vessel upper flange face -- Test 15.1 . 


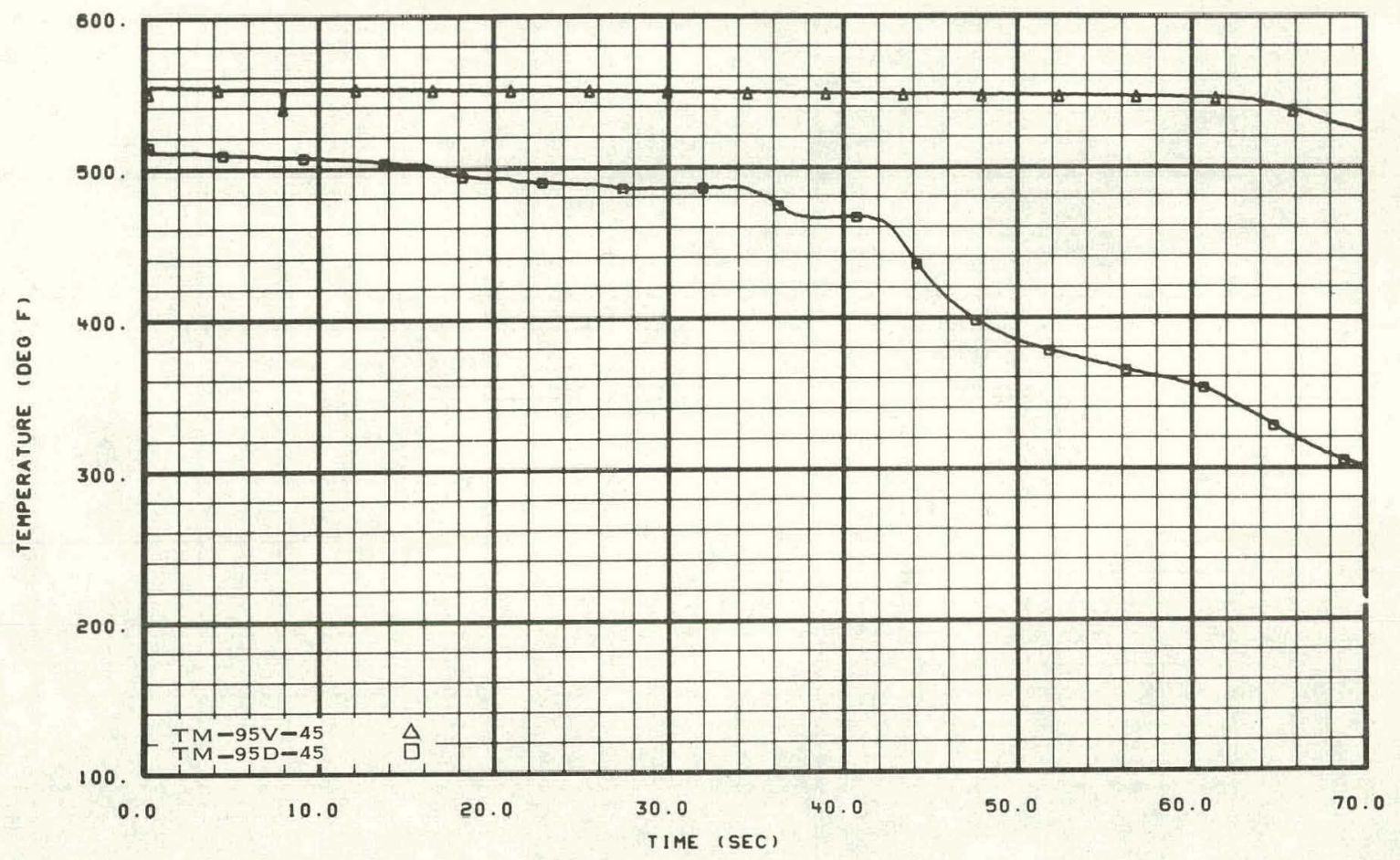

Fig. 58 Metal temperatures in vessel wall 95 inches from vessel upper flange face -- Test 15.2 .

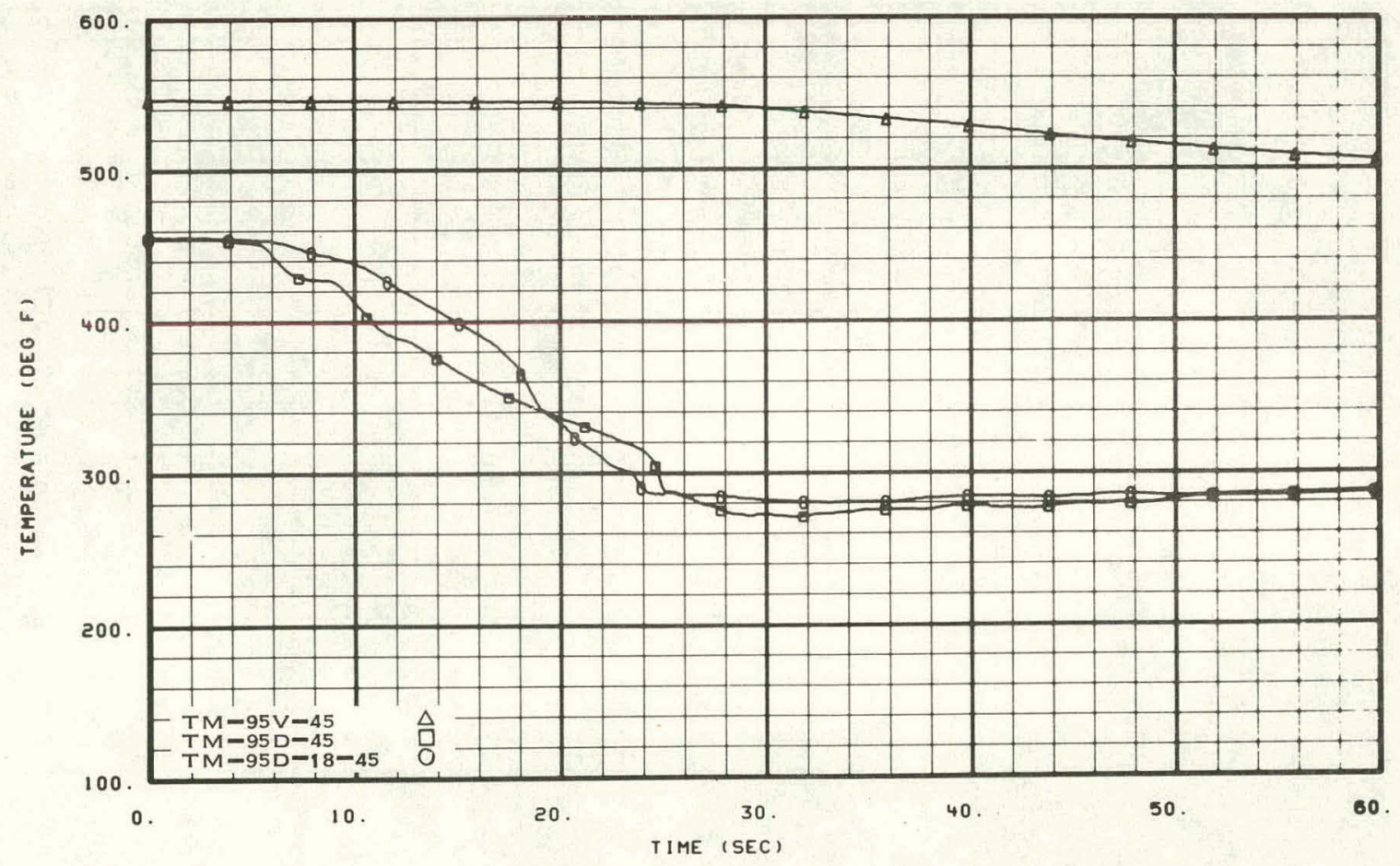

Fig. 59 Metal temperatures in vessel wall 95 inches from vessel upper flange face -- Test 15.3. 


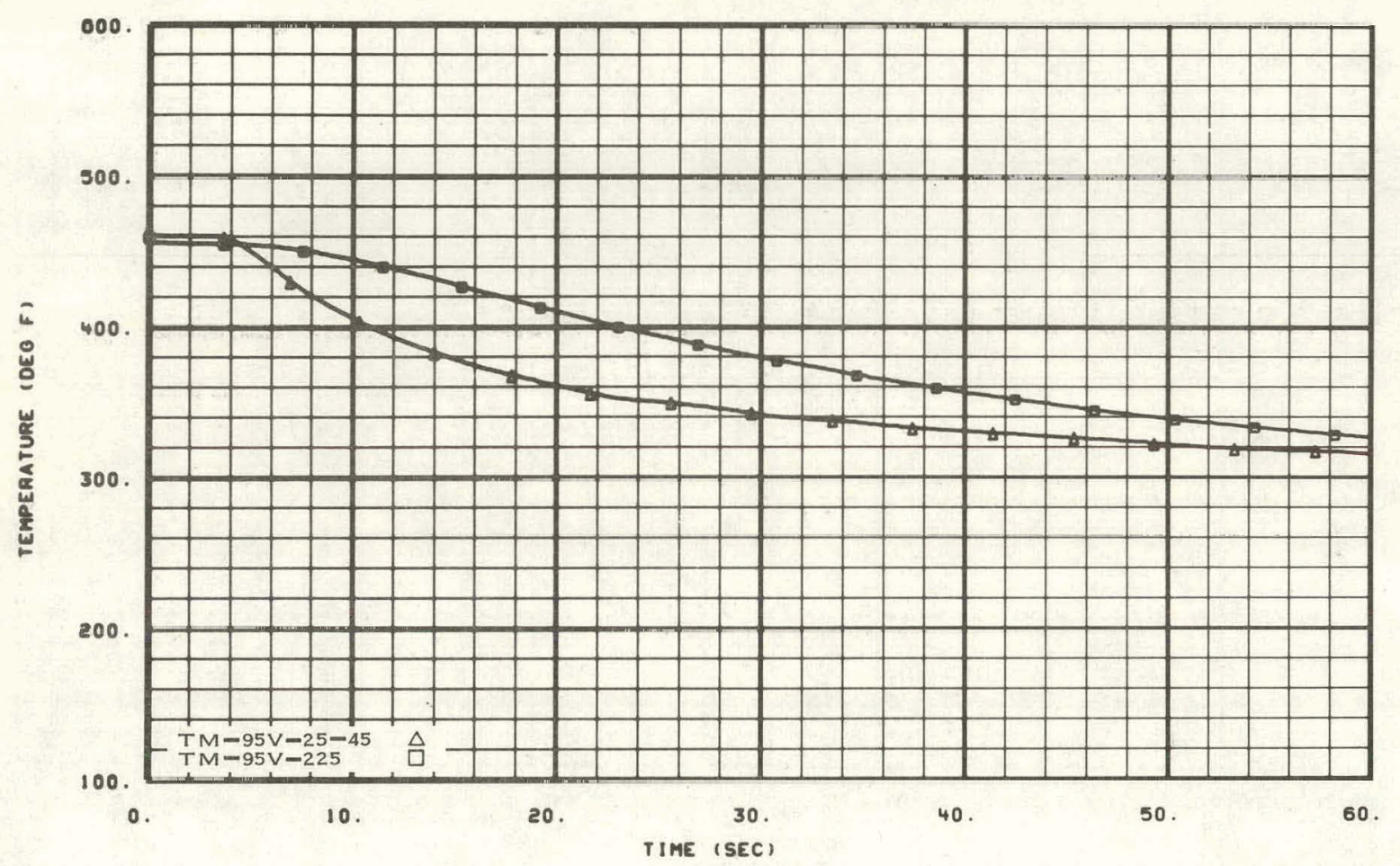

Fig. 60 Metal temperatures in vessel wall 95 inches from vessel upper flange face -- Test 15.4 .

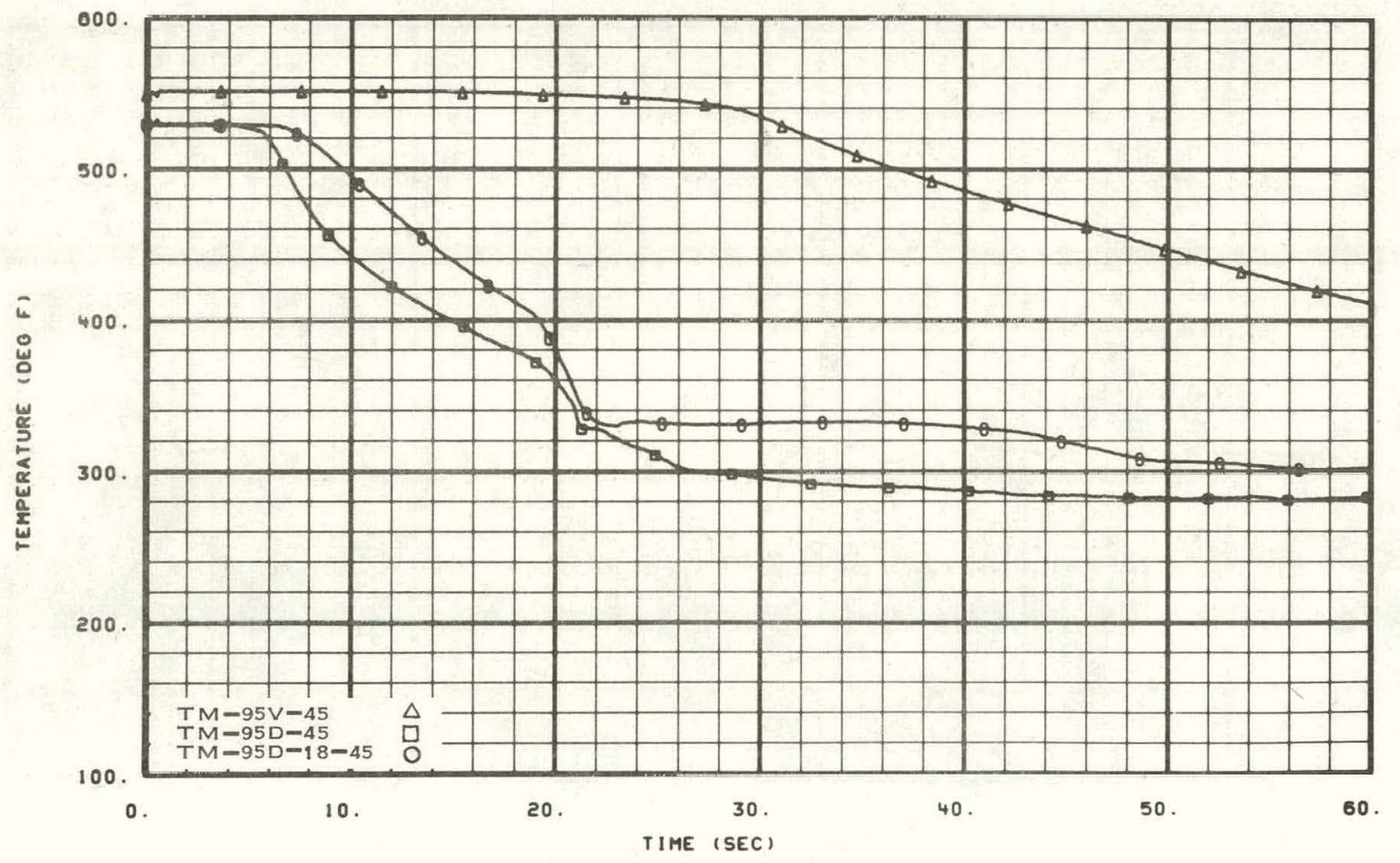

Fig. 61 Metal temperatures in vessel wa11 95 inches from vessel upper flange face -- Test 15.7 . 


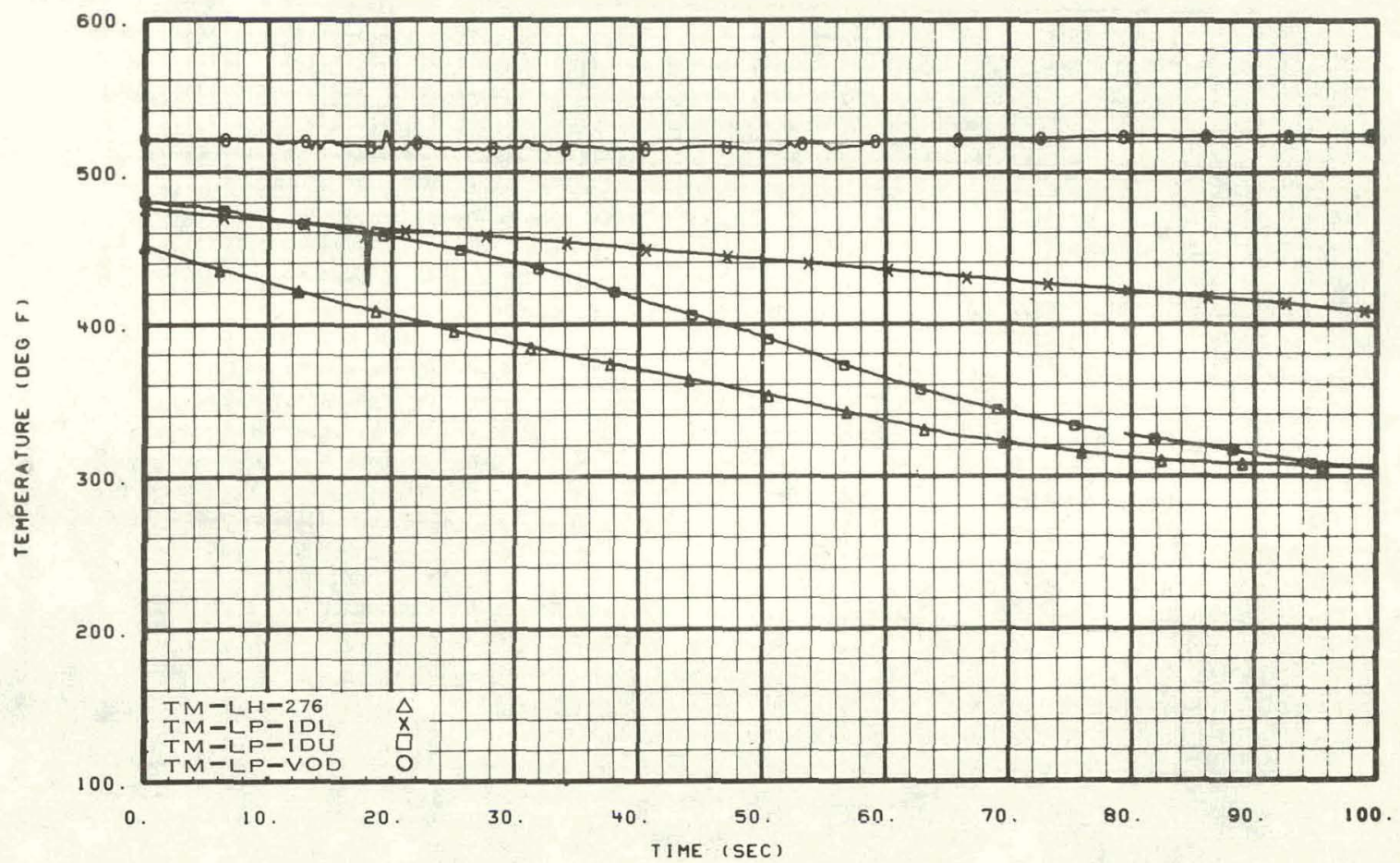

Fig. 62 Metal temperatures in lower plenum vessel wa11 -- Test 15.1.

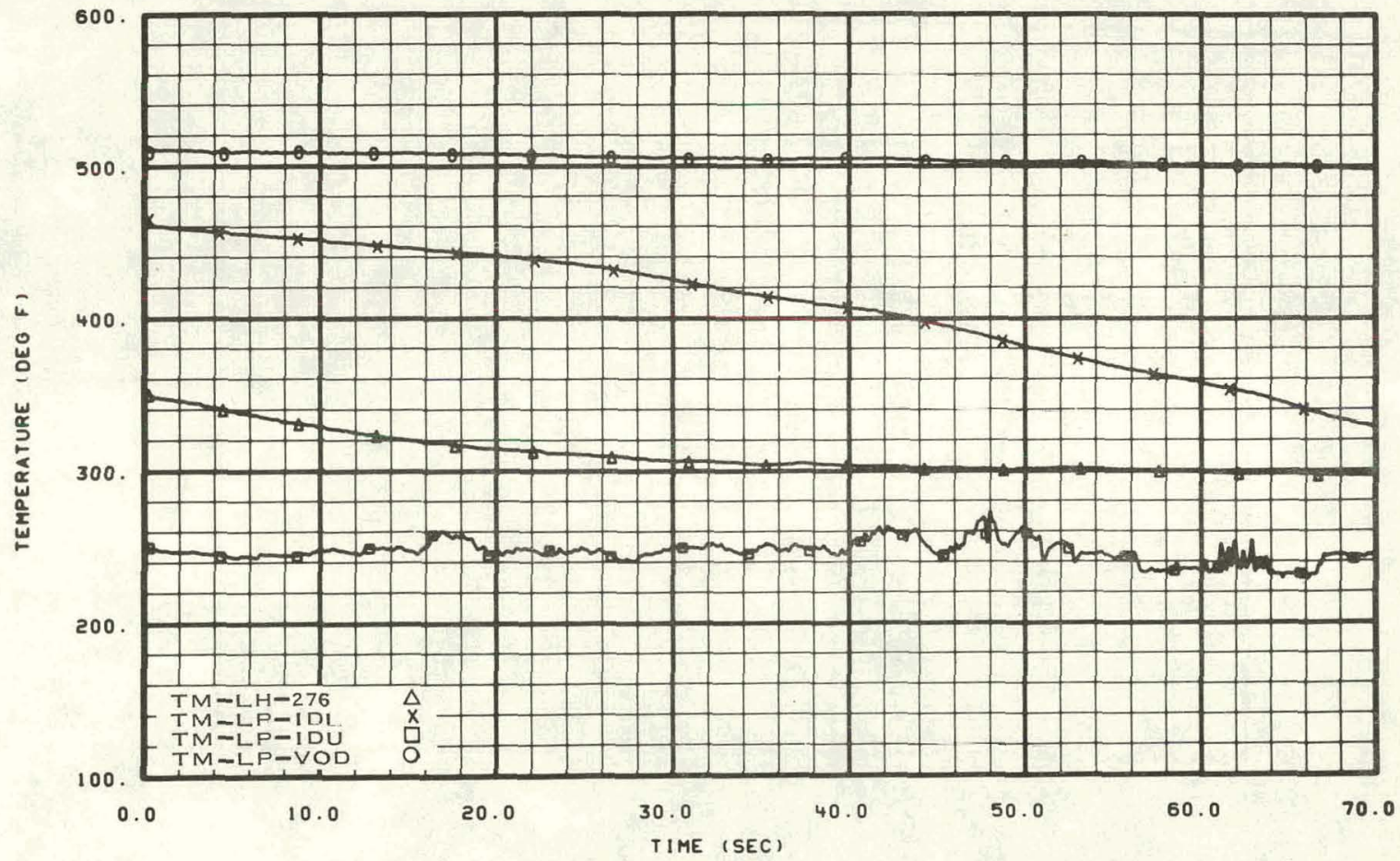

Fig. 63 Metal temperatures in lower plenum vessel wall -- Test 15.2. 


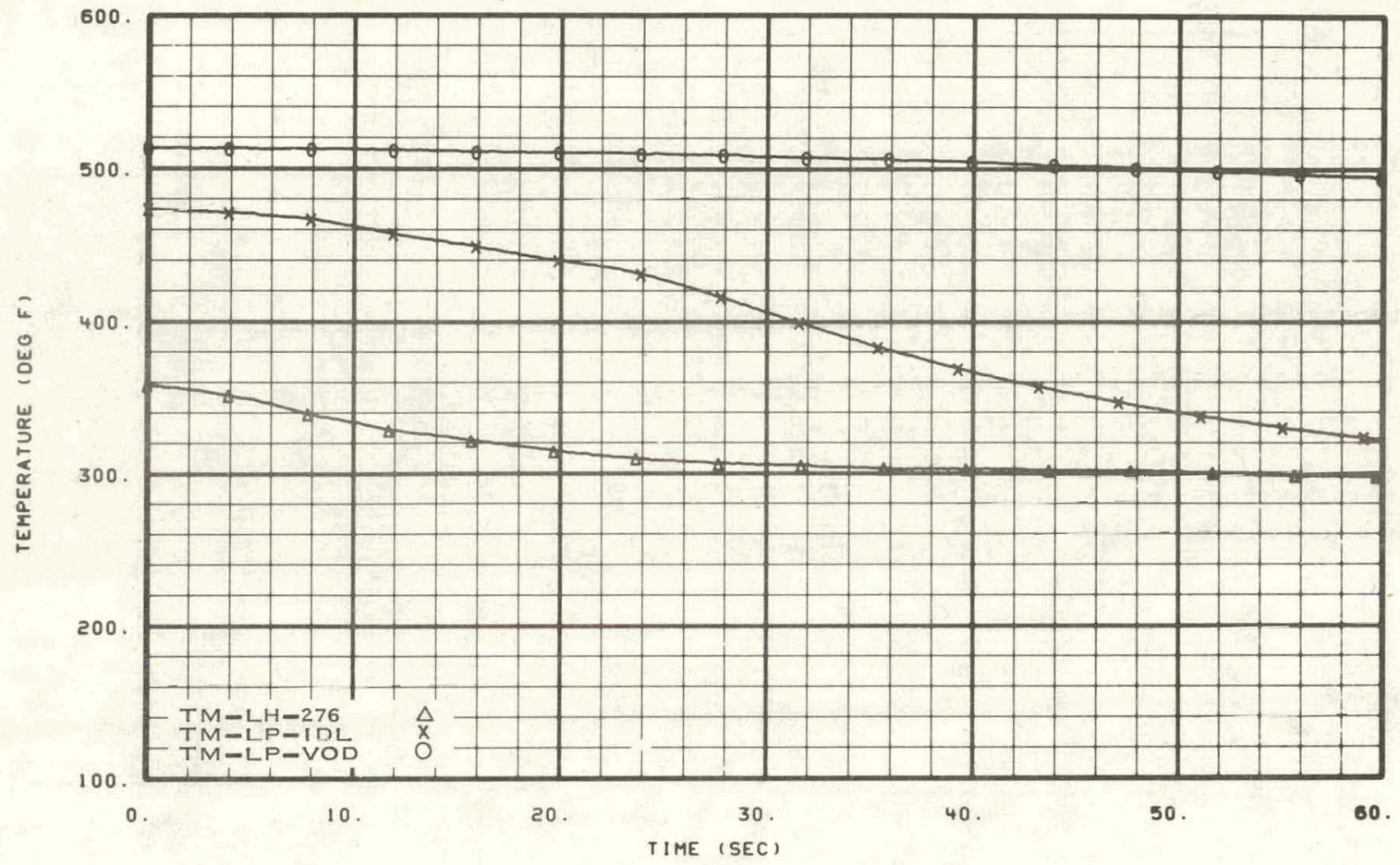

Fig. 64 Metal temperatures in lower plenum vessel wall -- Test 15.3.

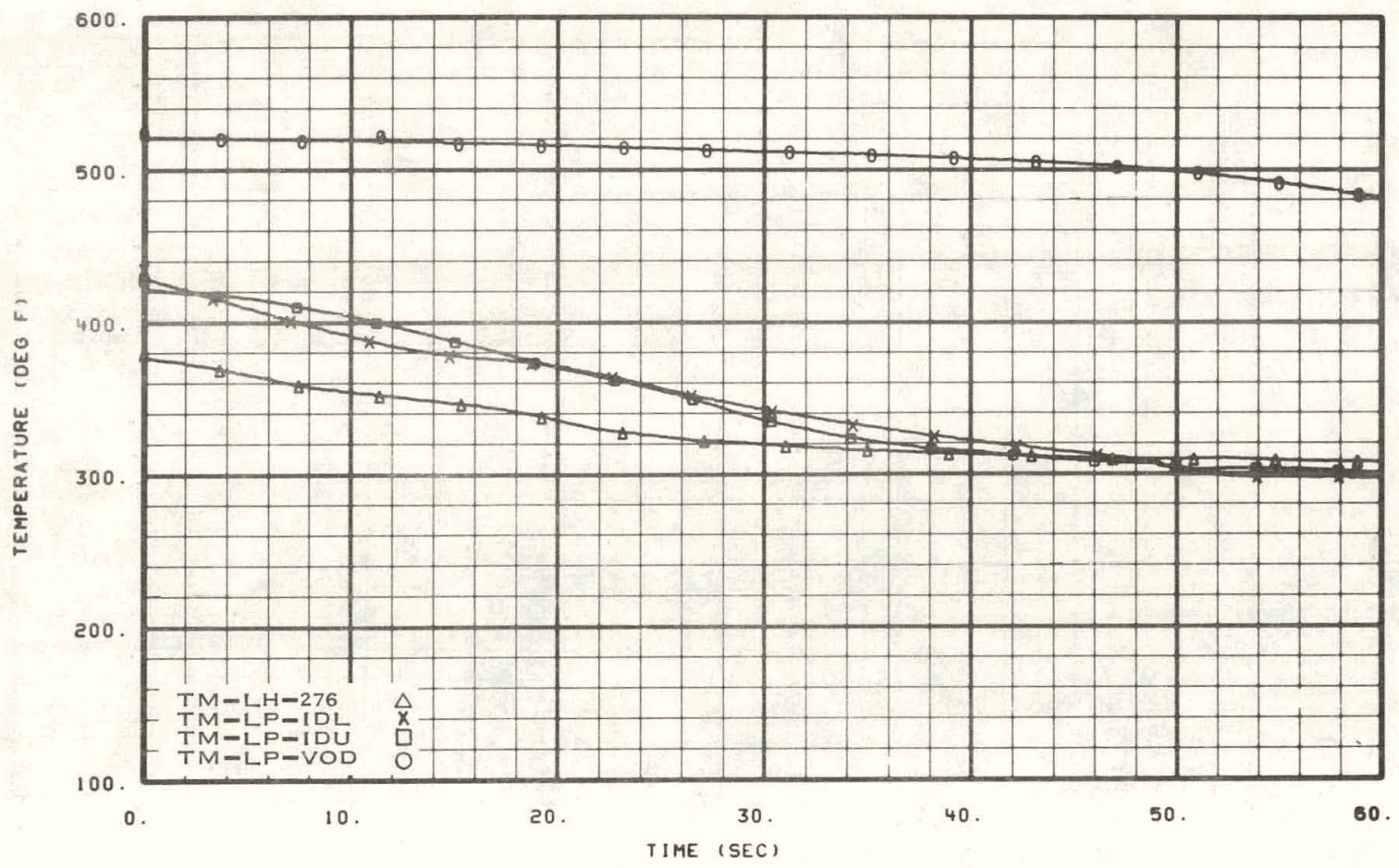

Fig. 65 Metal temperatures in lower plenum vessel wa11 -- Test 15.4 . 


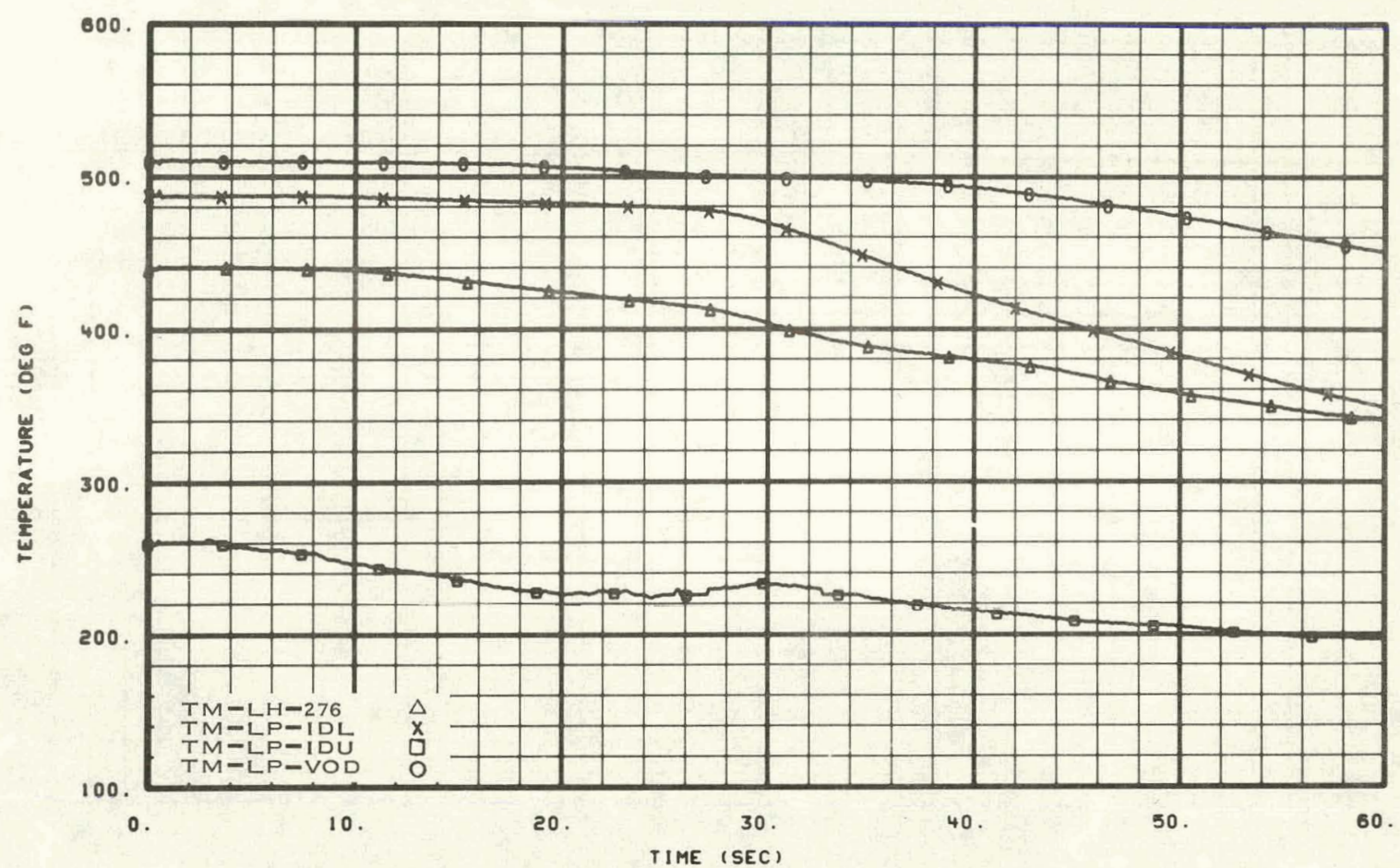

Fig. 66 Metal temperatures in lower plenum vessel wall -- Test 15.7 .

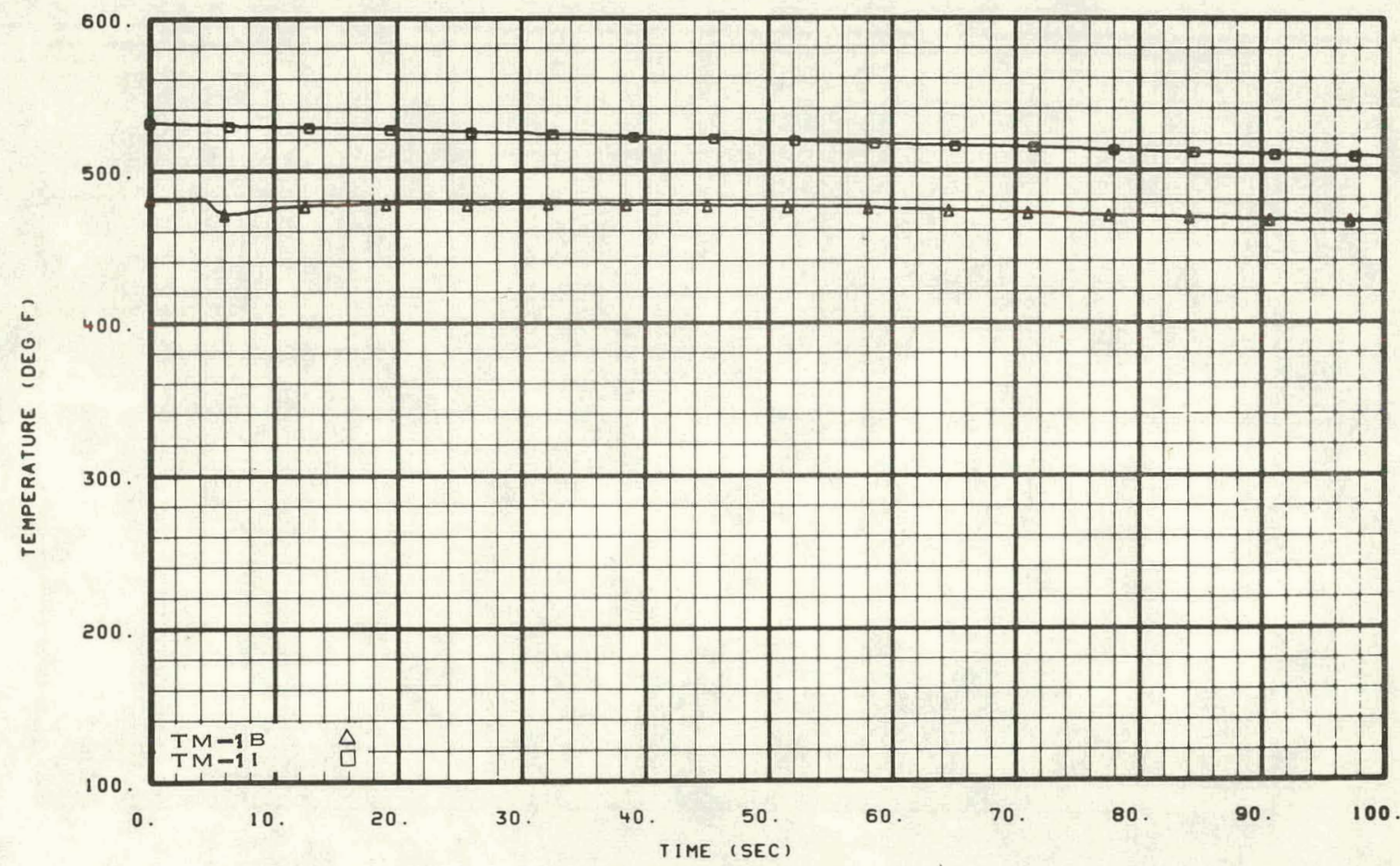

Fig. 67 Metal temperatures in operating loop hot leg Spool 1 -- Test 15.1 . 


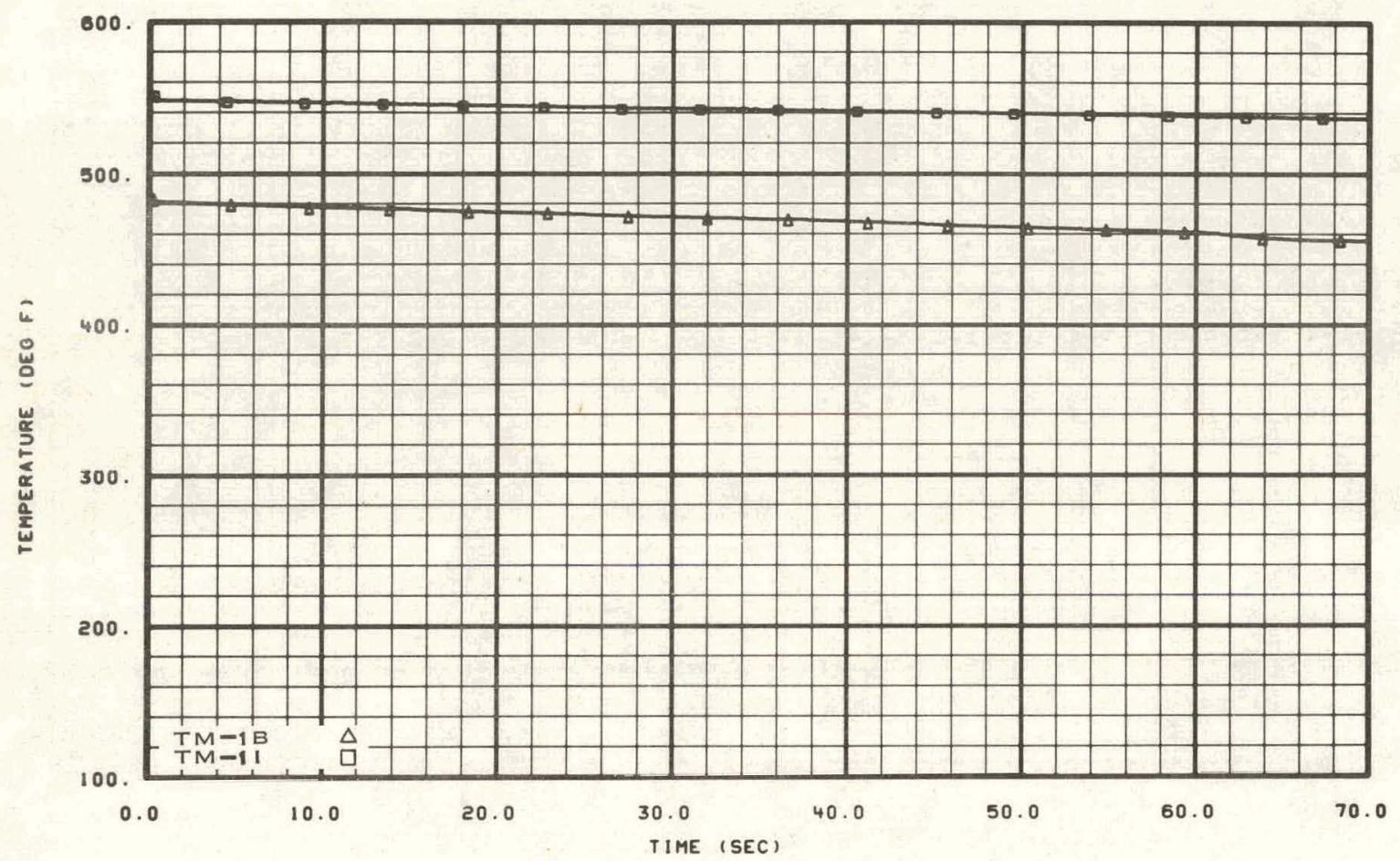

Fig. 68 Metal temperatures in operating loop hot leg Spool 1 -- Test 15.2.

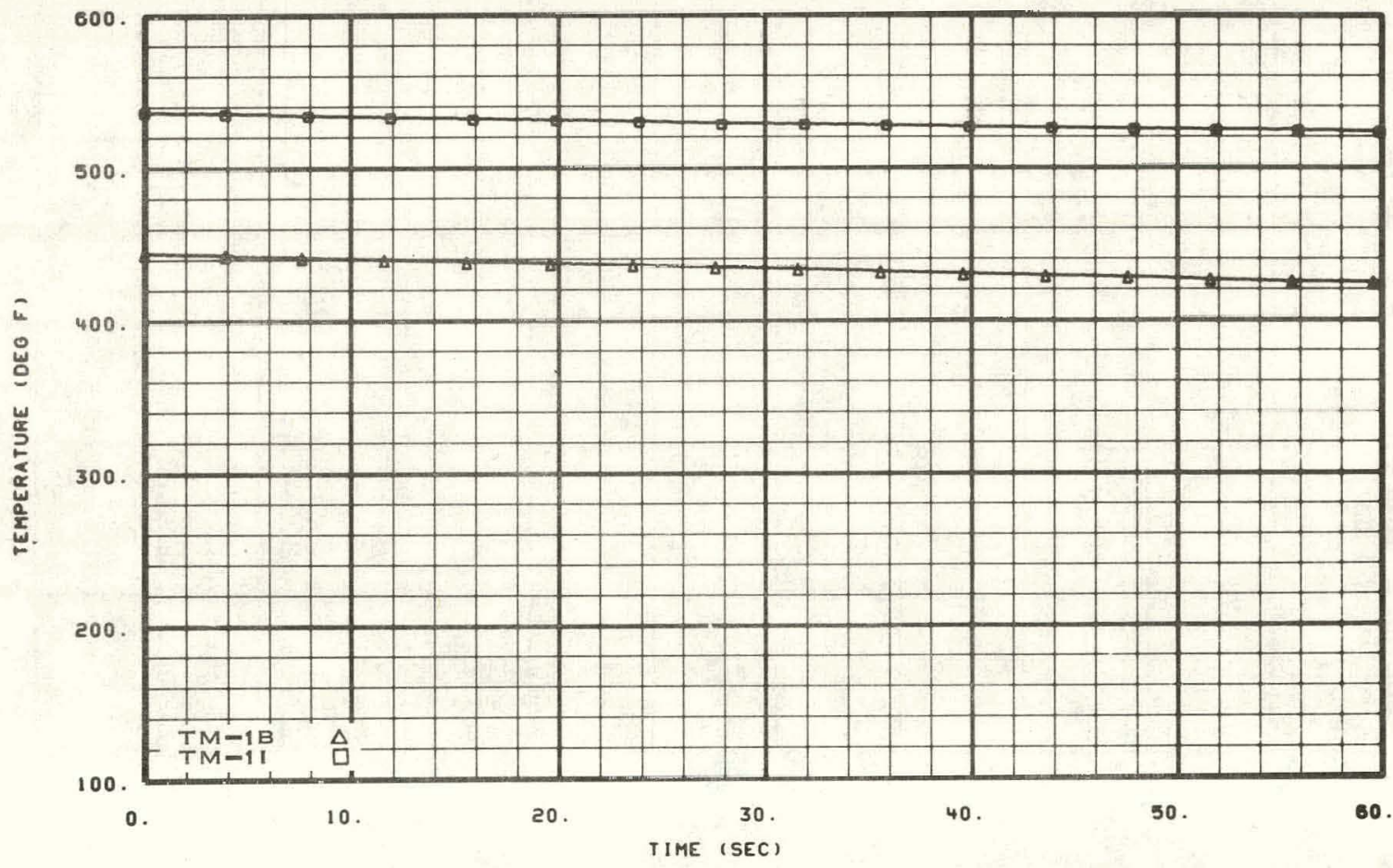

Fig. 69 Metal temperatures in operating loop hot leg Spool 1 -- Test 15.3. 


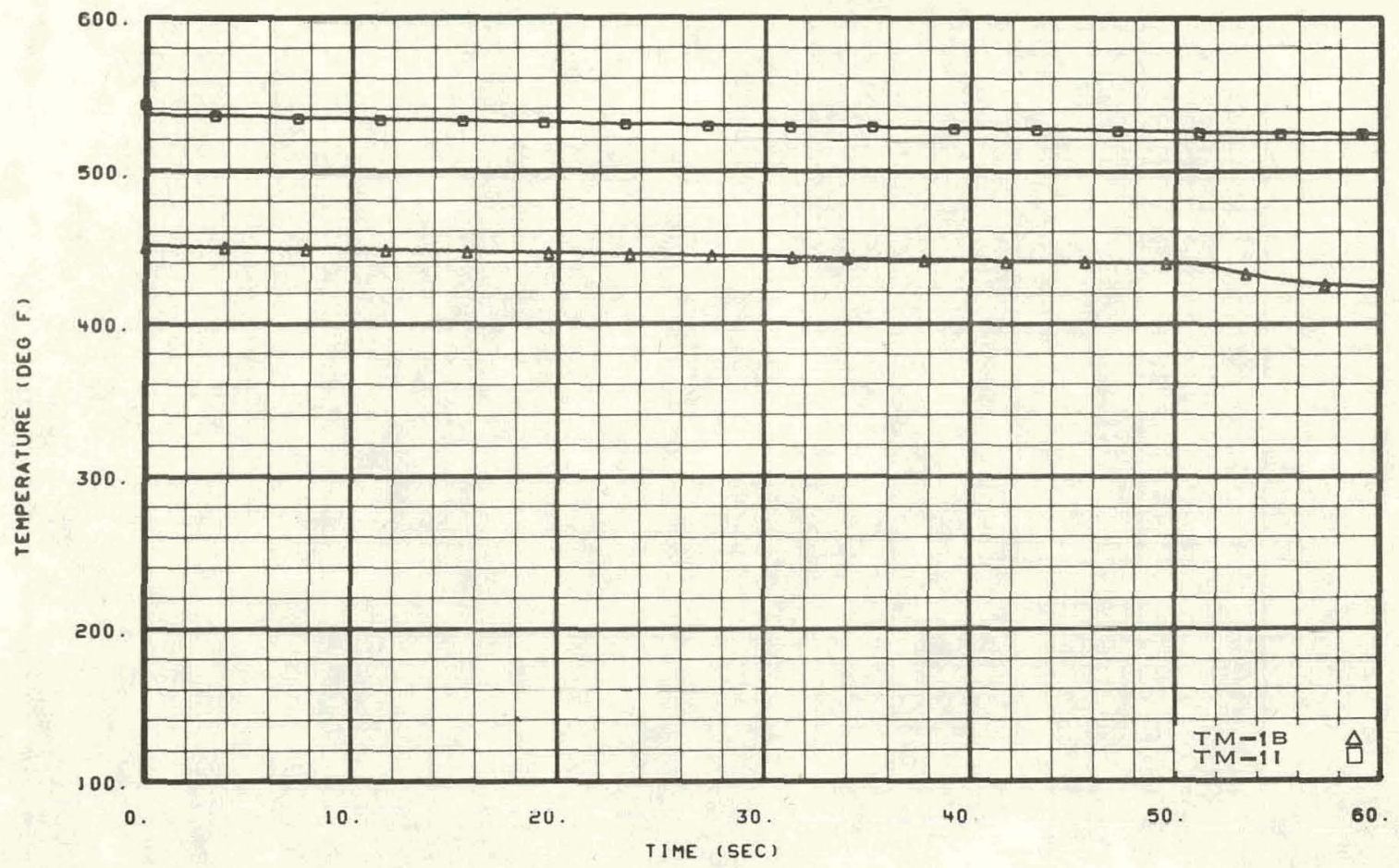

Fig. 70 Metal temperatures in operating loop hot leg Spool 1 -- Test 15.4 .

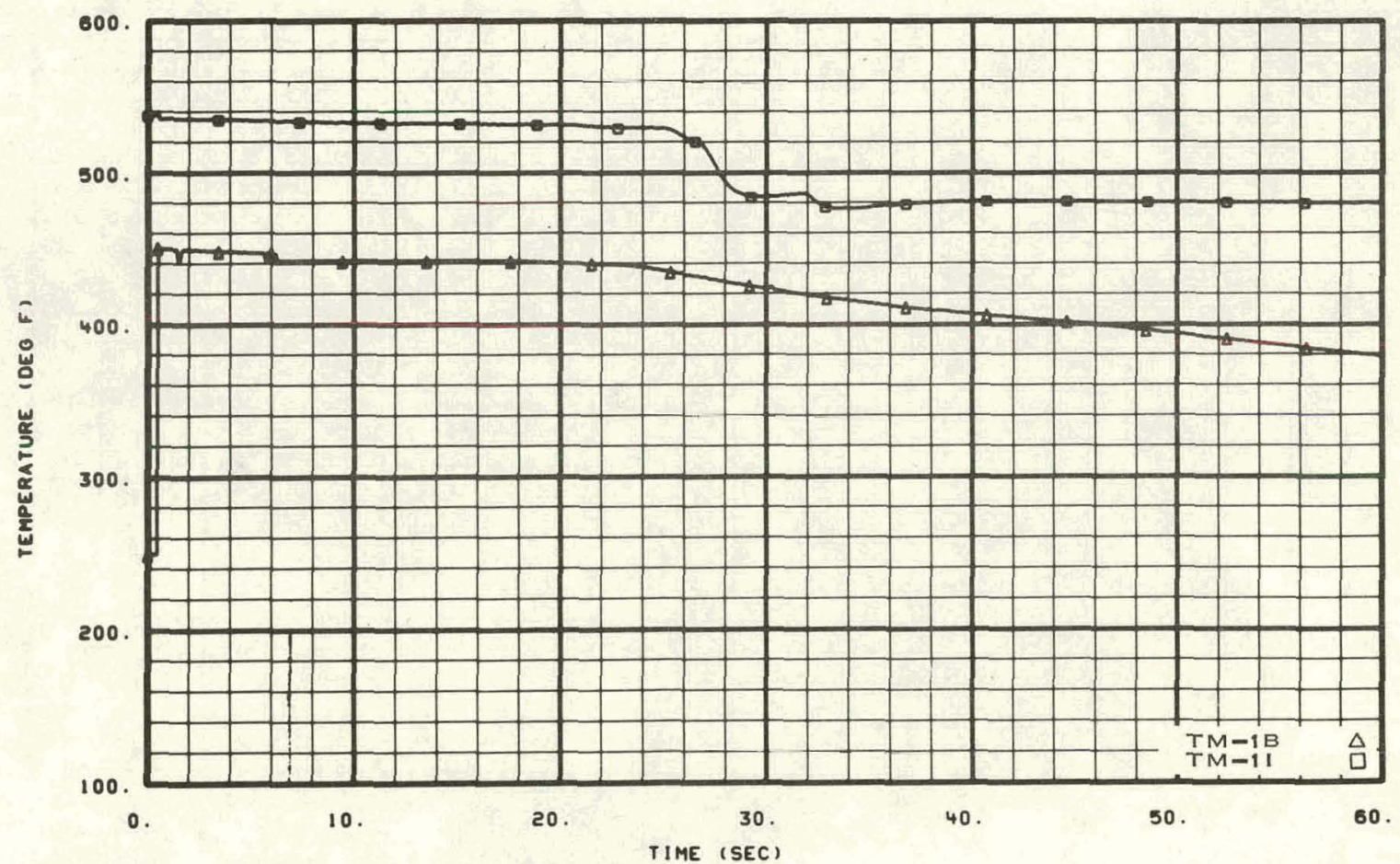

Fig. 71 Metal temperatures in operating loop hot leg Spool 1 -- Test 15.7. 


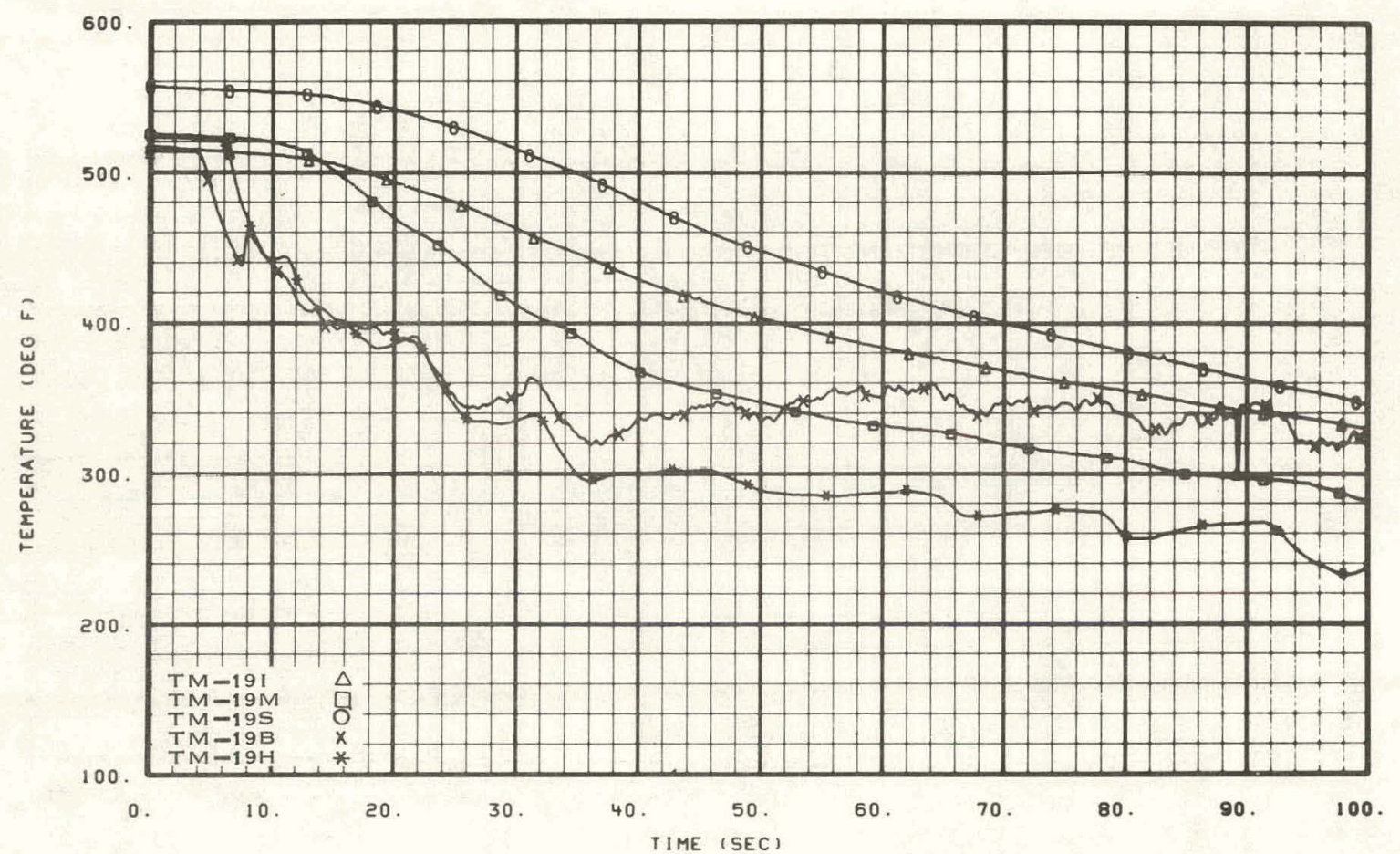

Fig. 72 Metal temperatures in operating loop cold leg Spool 19 -- Test 15.1 .

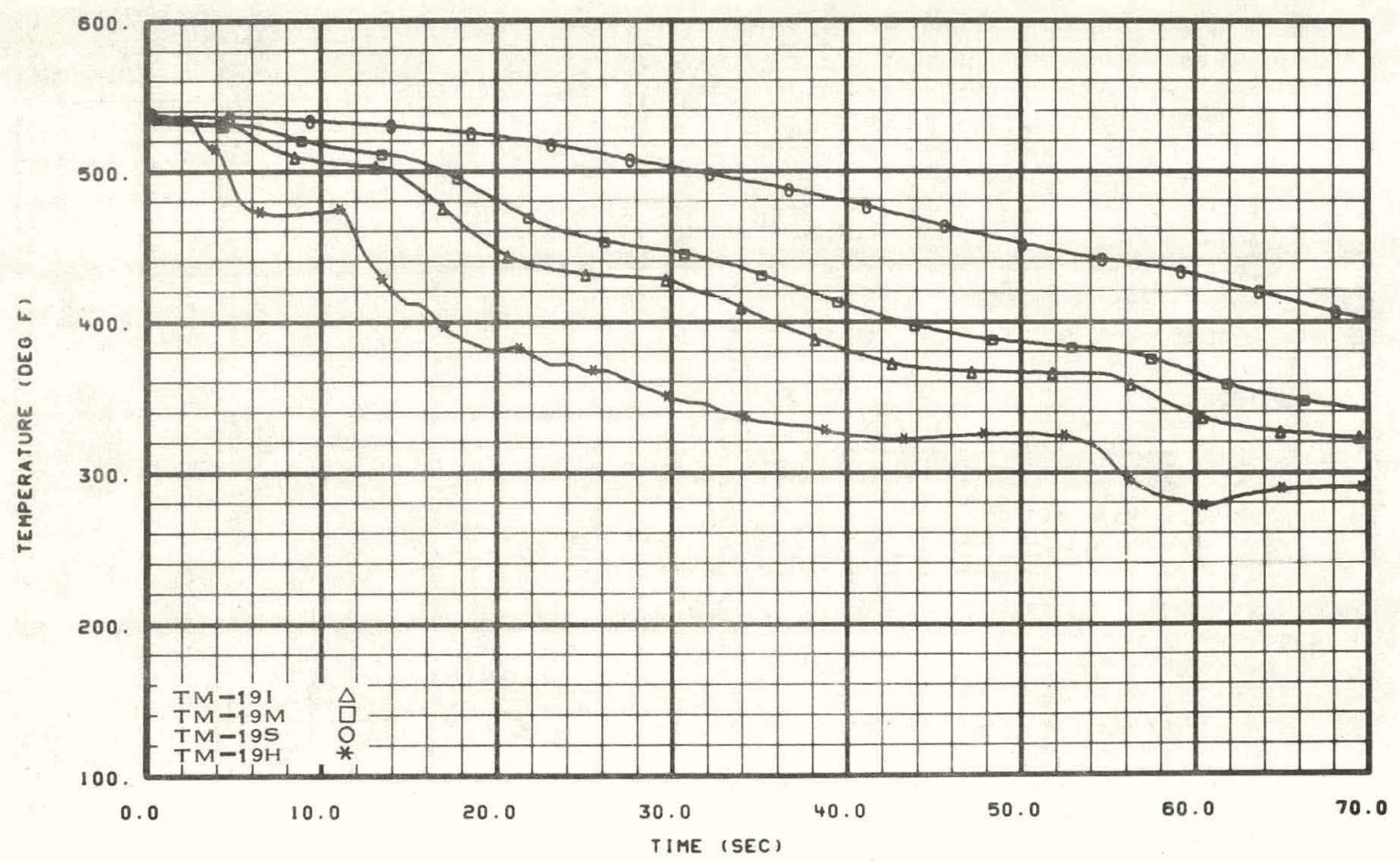

Fig. 73 Metal temperatures in operating loop cold leg Spool 19 -- Test 15.2 . 


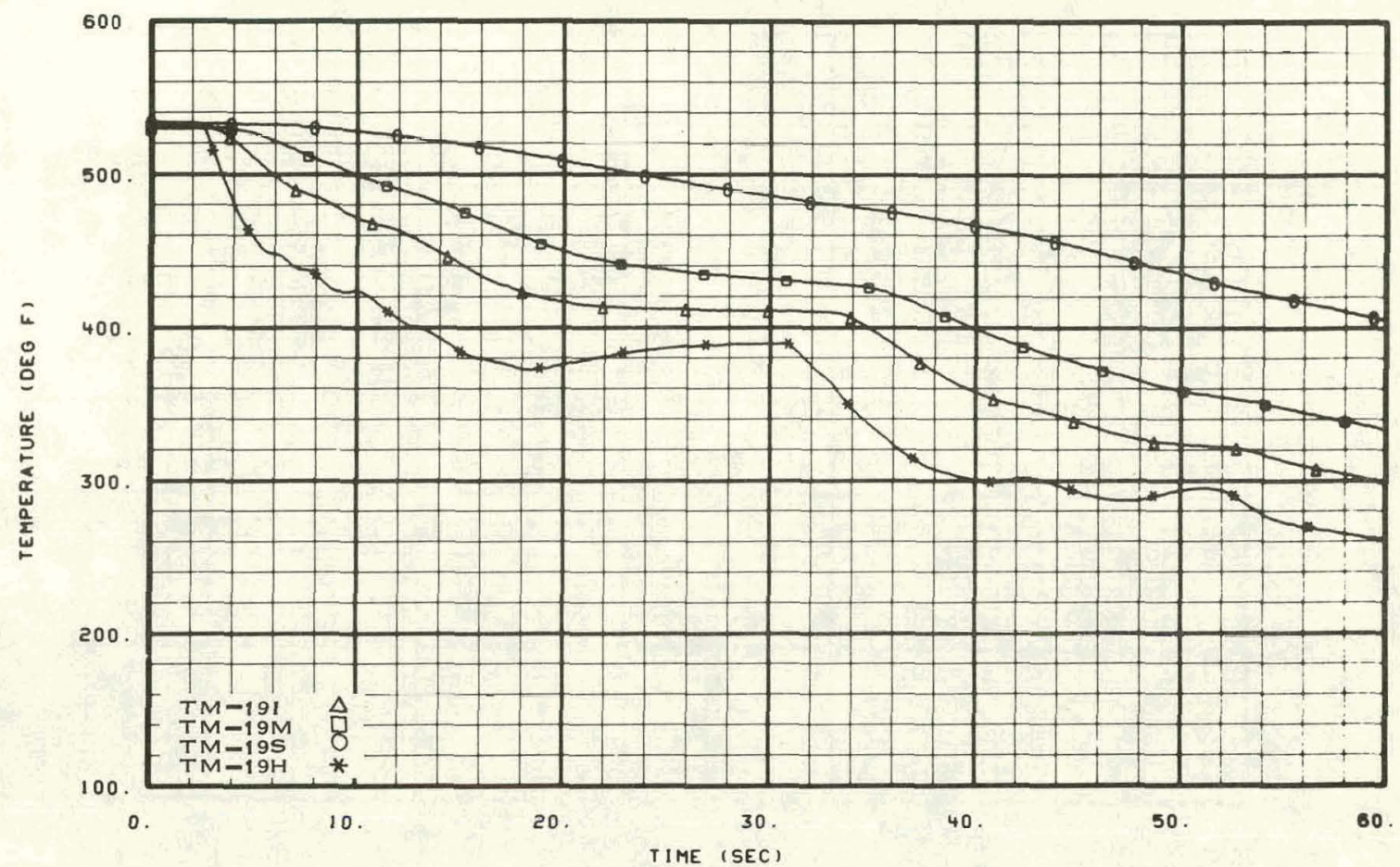

Fig. 74 Metal temperatures in operating loop cold leg Spool 19 -- Test 15.3 .

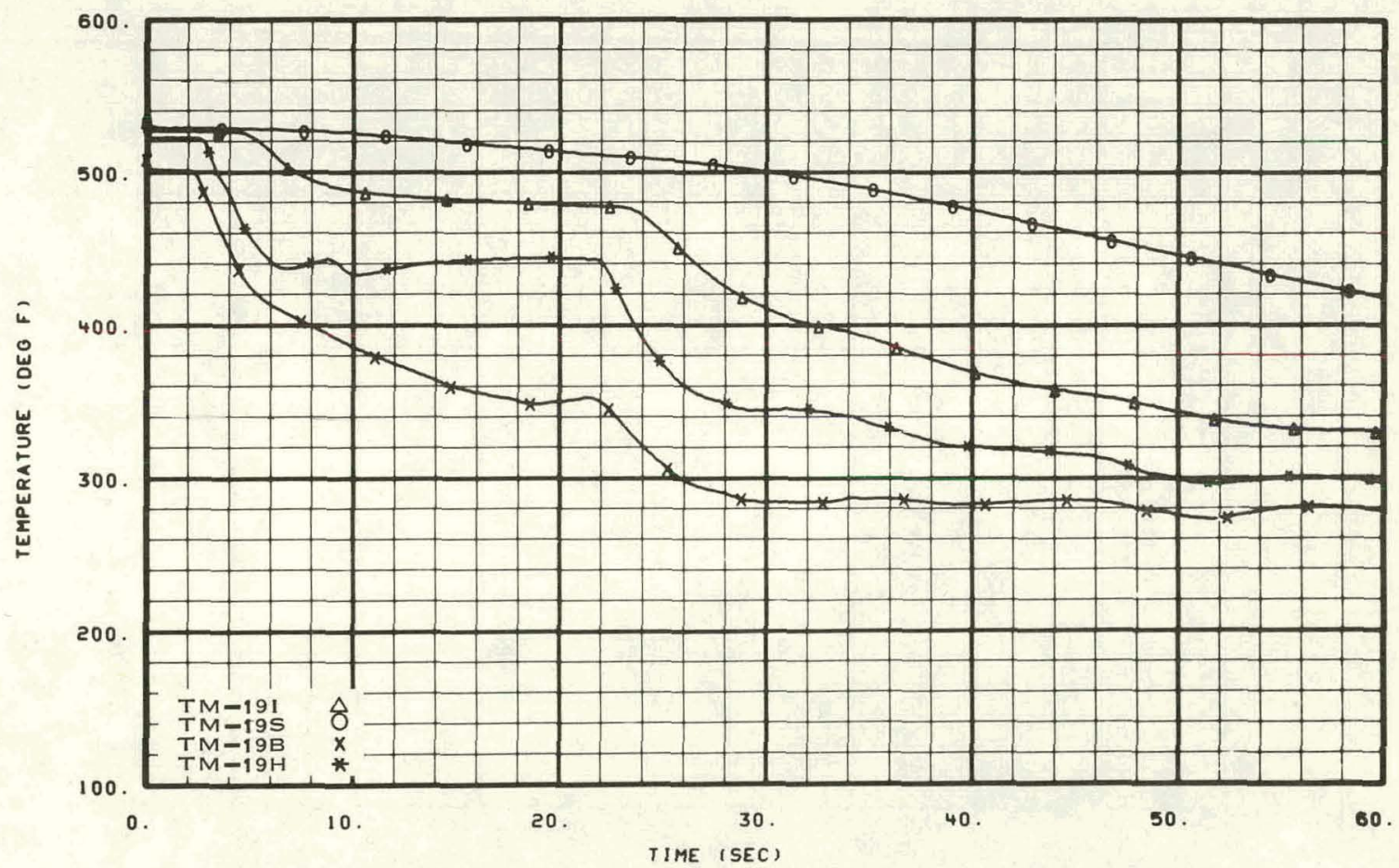

Fig. 75 Metal temperatures in operating loop cold leg Spool 19 -- Test 15.4 . 


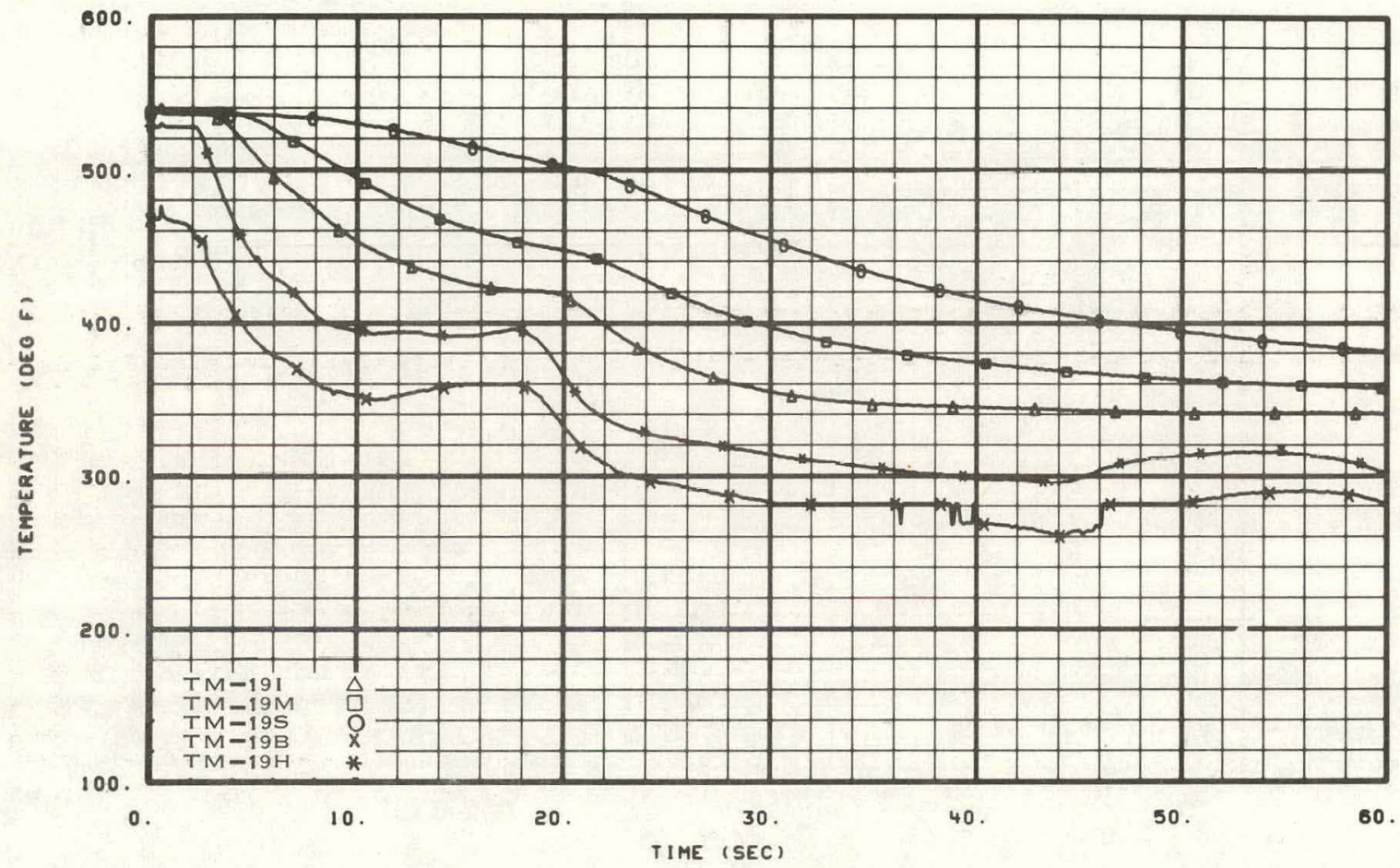

Fig. 76 Metal temperatures in operating loop cold leg Spool 19 -- Test 15.7.

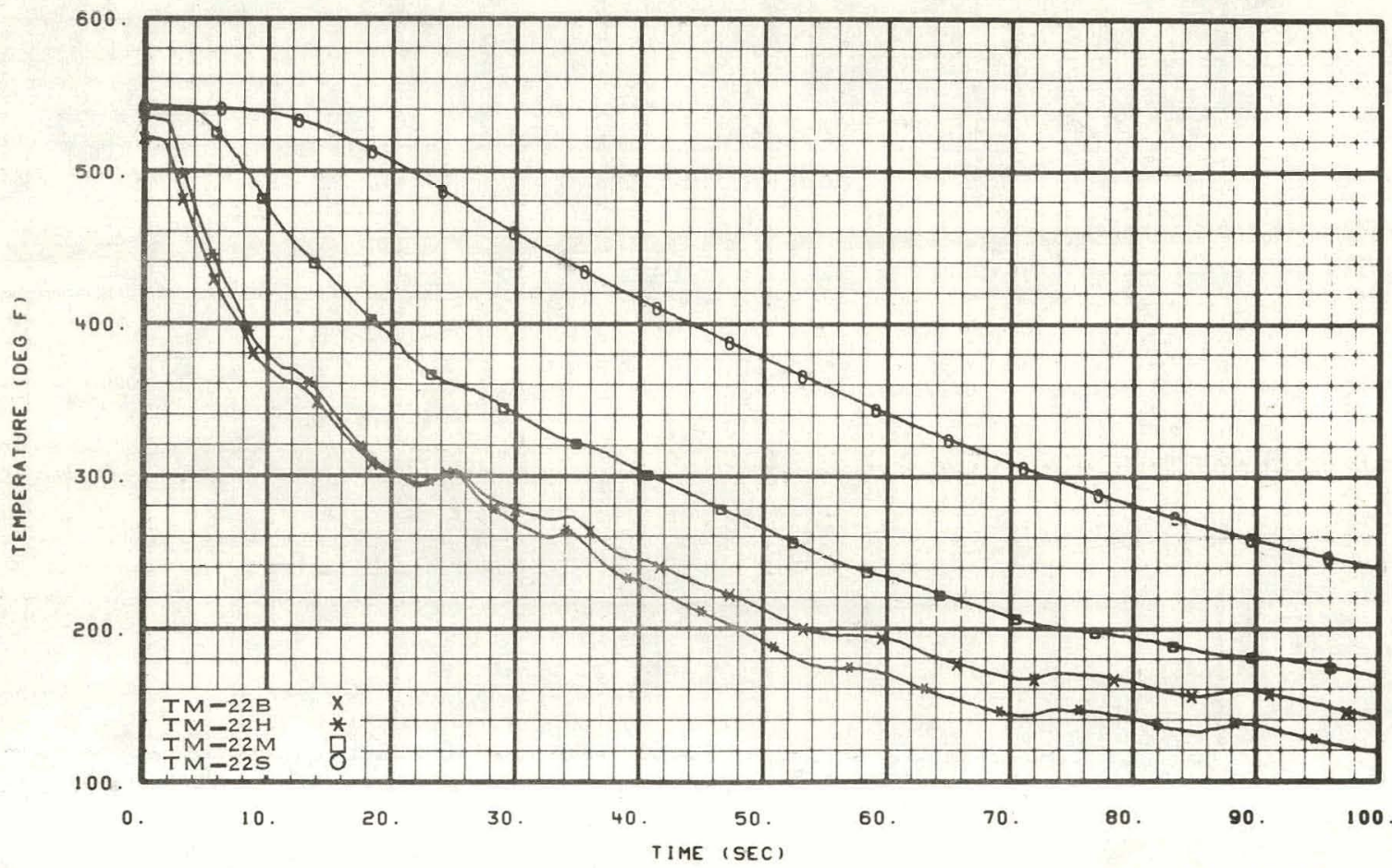

Fig. 77 Metal temperatures in operating loop cold leg Spool 22 -- Test 15.1. 


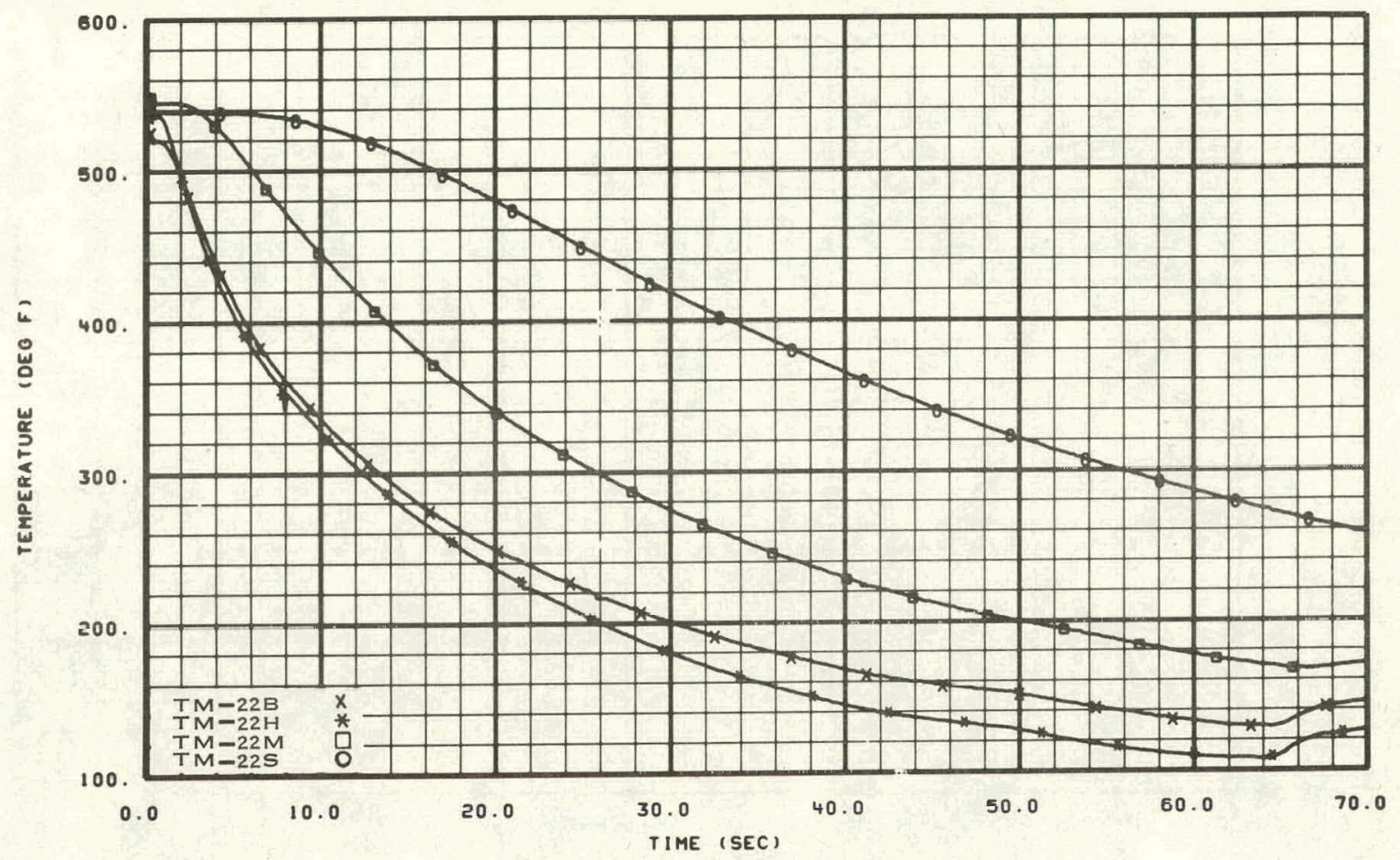

Fig. 78 Metal temperatures in operating loop cold leg Spool 22 -- Test 15.2 .

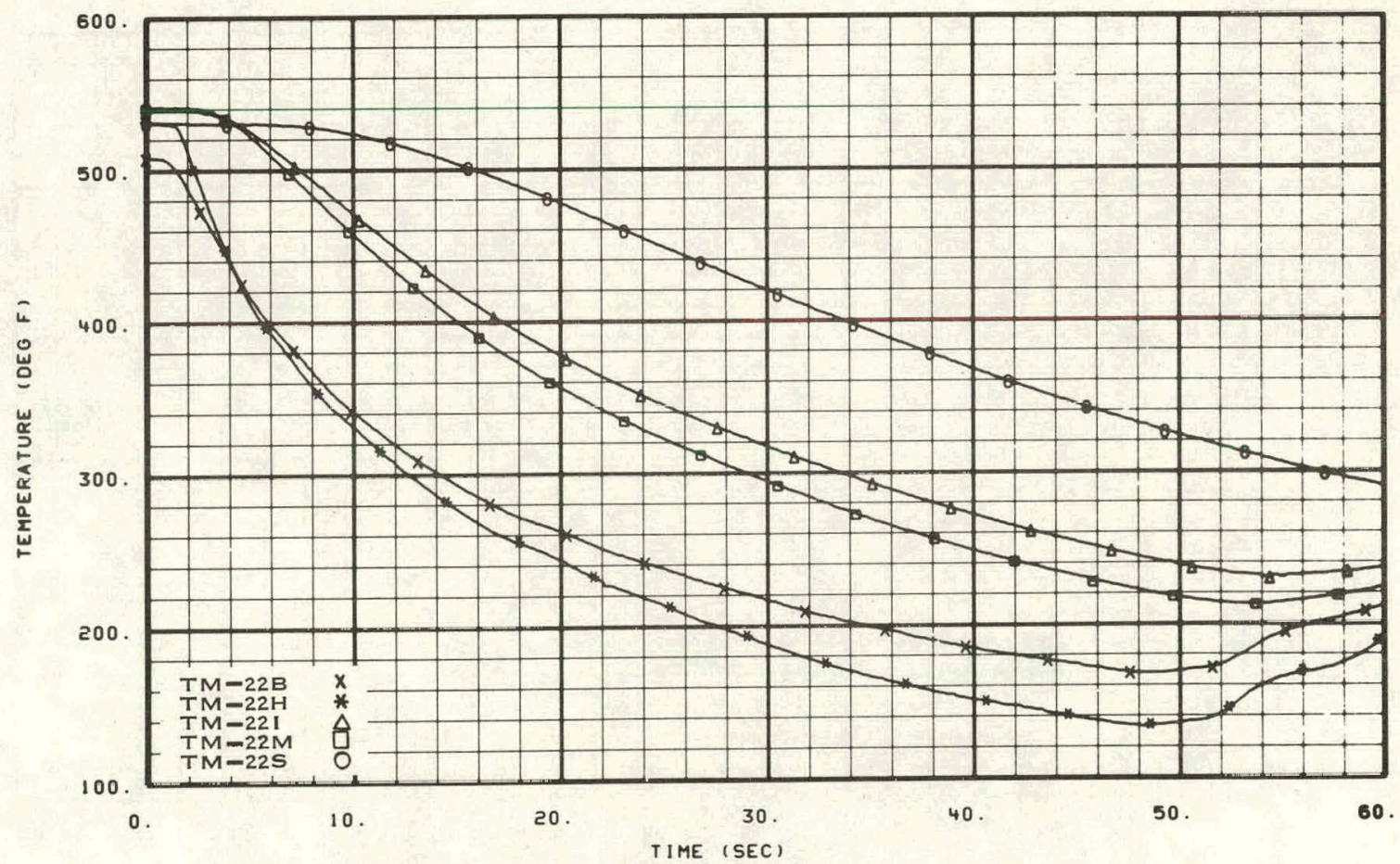

Fig. 79 Metal temperatures in operating loop cold leg Spool 22 -- Test 15.3 . 


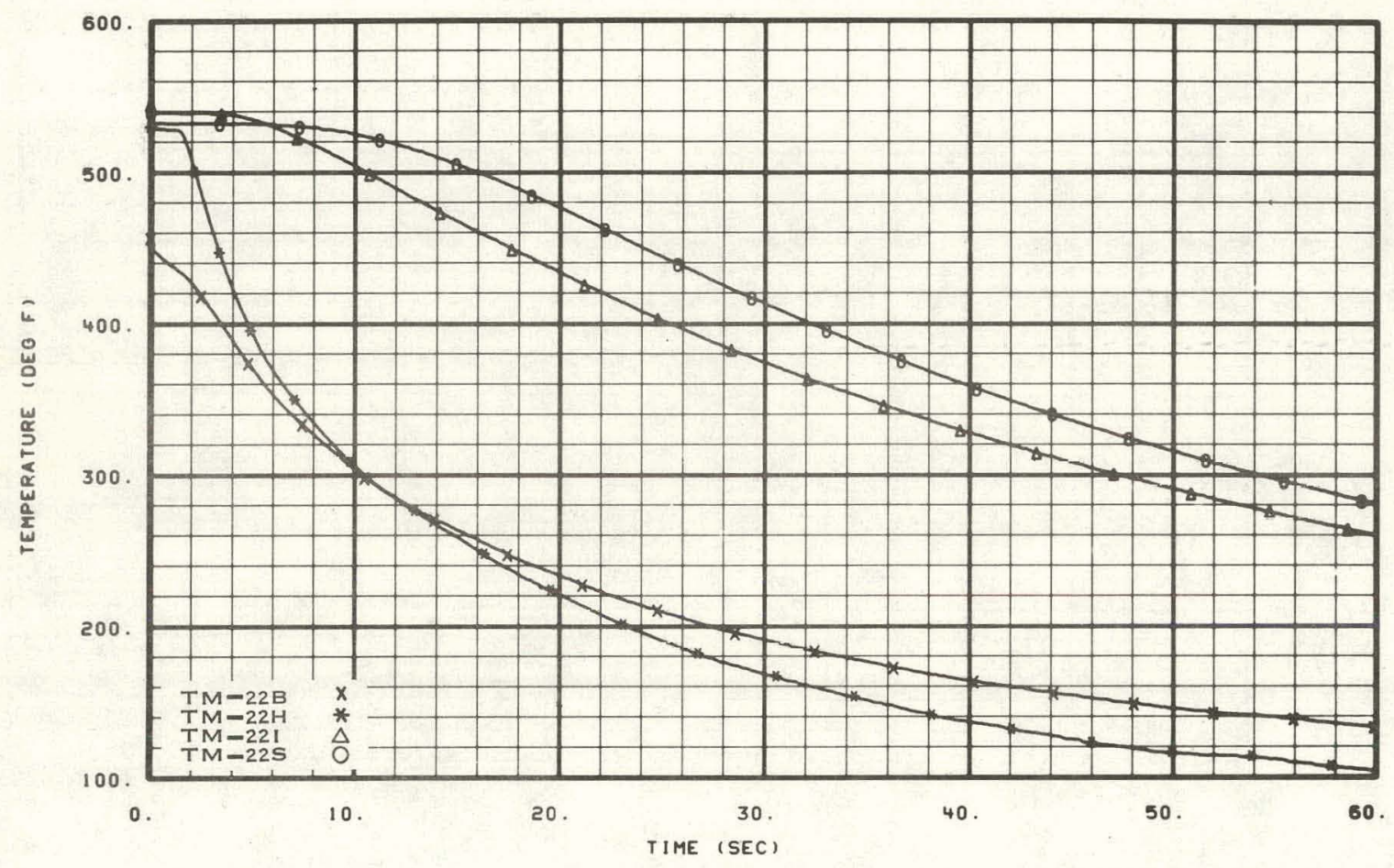

Fig. 80 Metal temperatures in operating loop cold leg Spool 22 -- Test 15.4 .

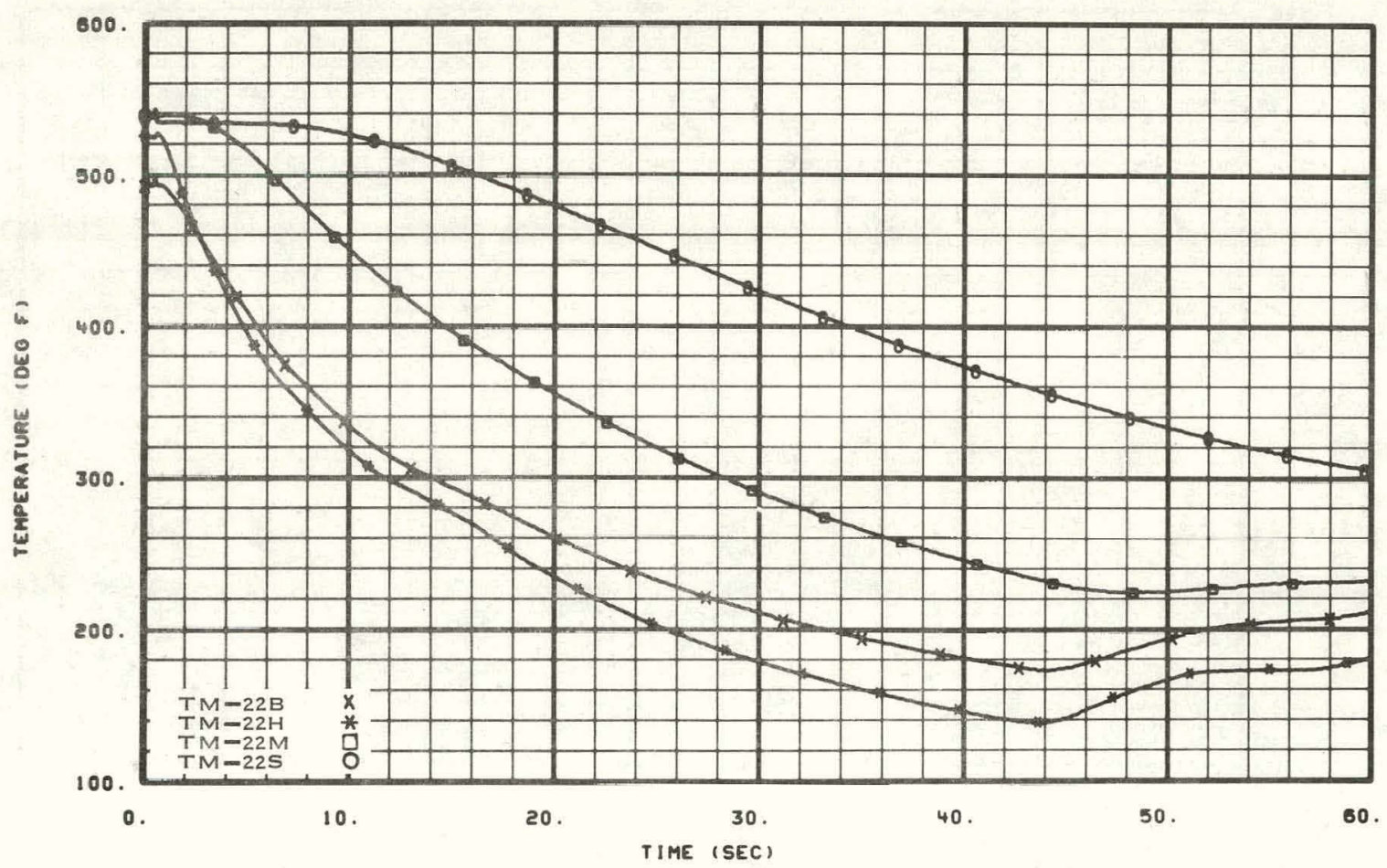

Fig. 81 Metal temperatures in operating loop cold leg Spool 22 -- Test 15.7 . 


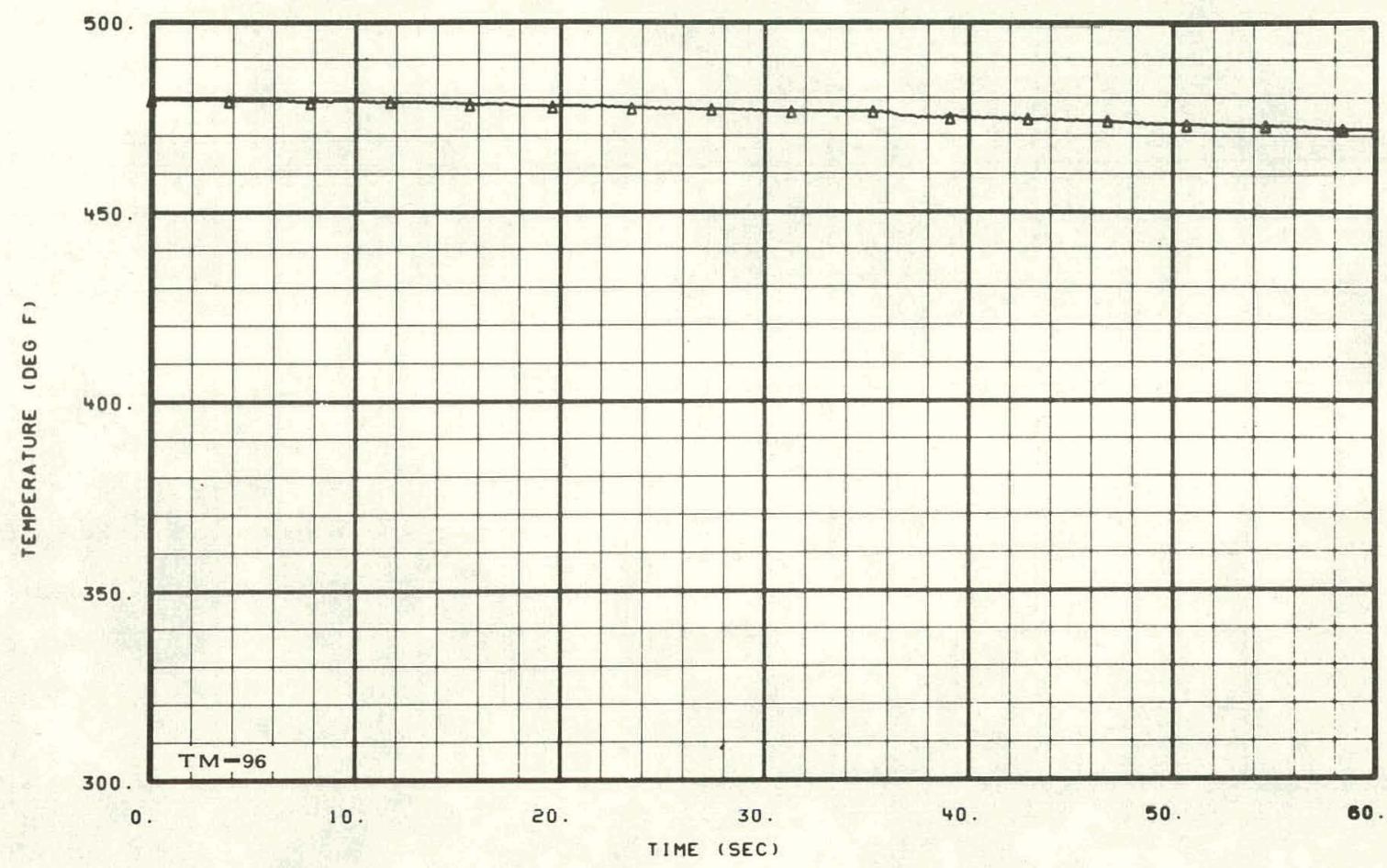

Fig. 82 Metal temperatures in blowdown loop -- Test 15.3.

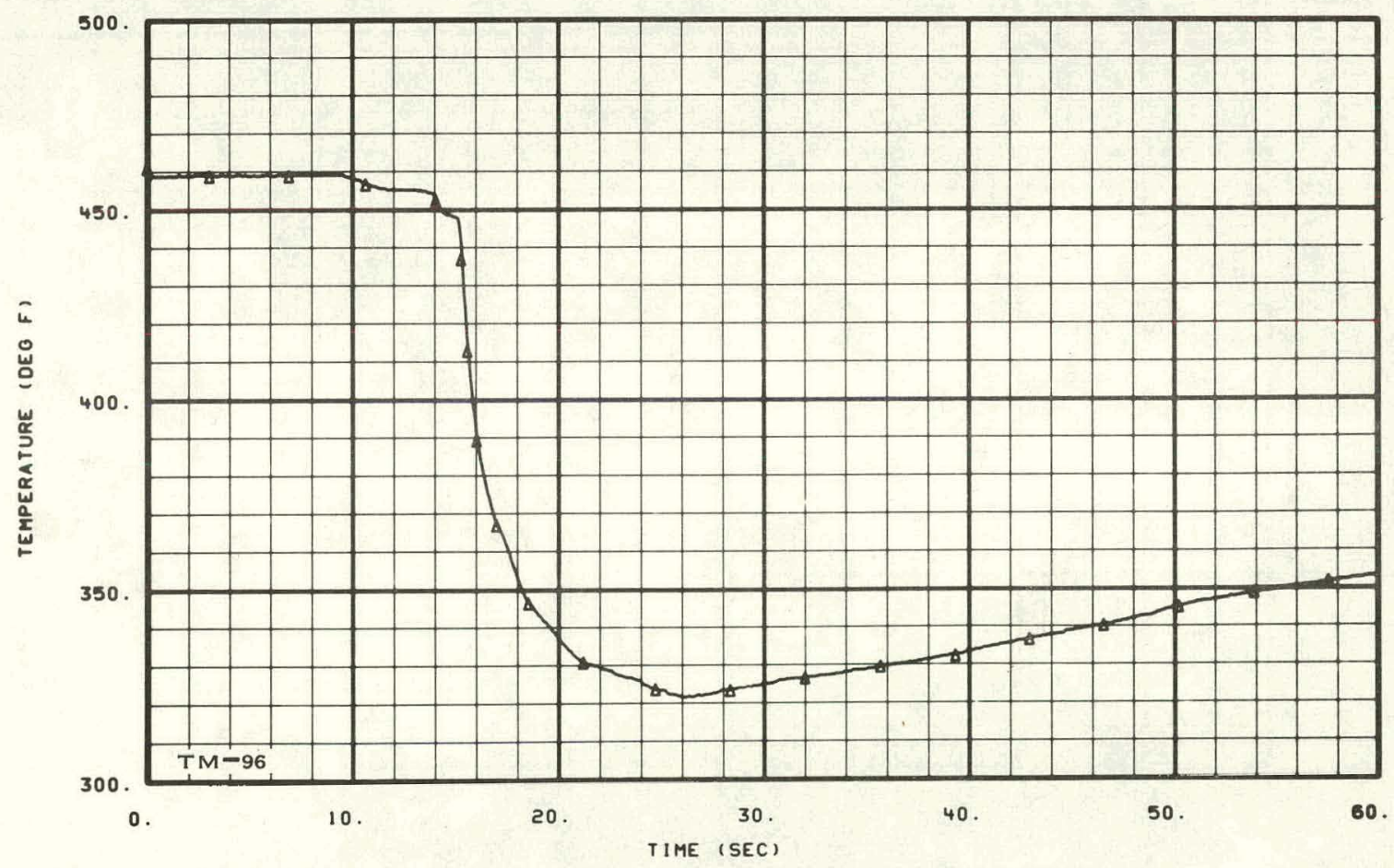

Fig. 83 Metal temperatures in blowdown loop -- Test 15.4 . 


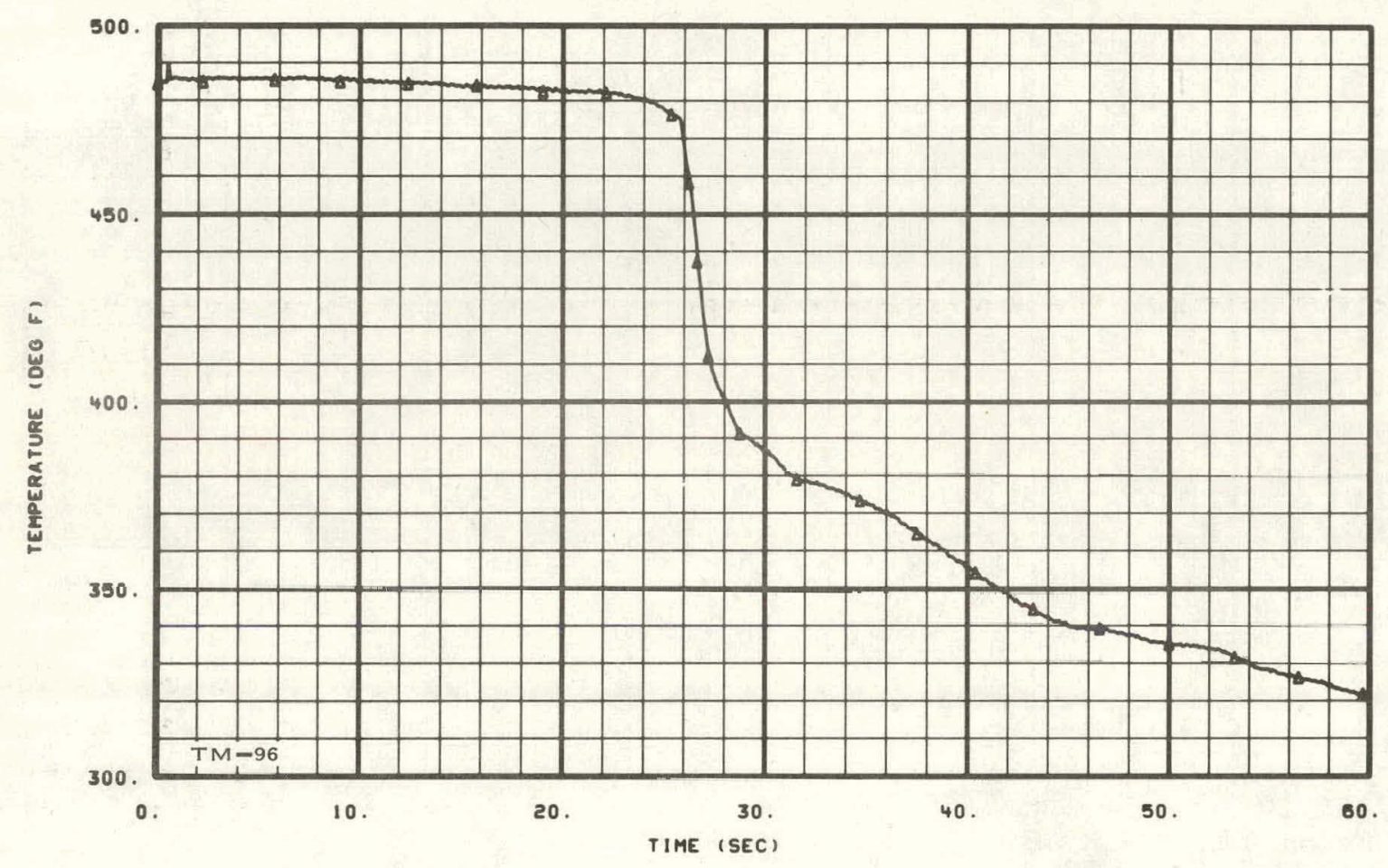

Fig. 84 Metal temperatures in blowdown loop -- Test 15.7.

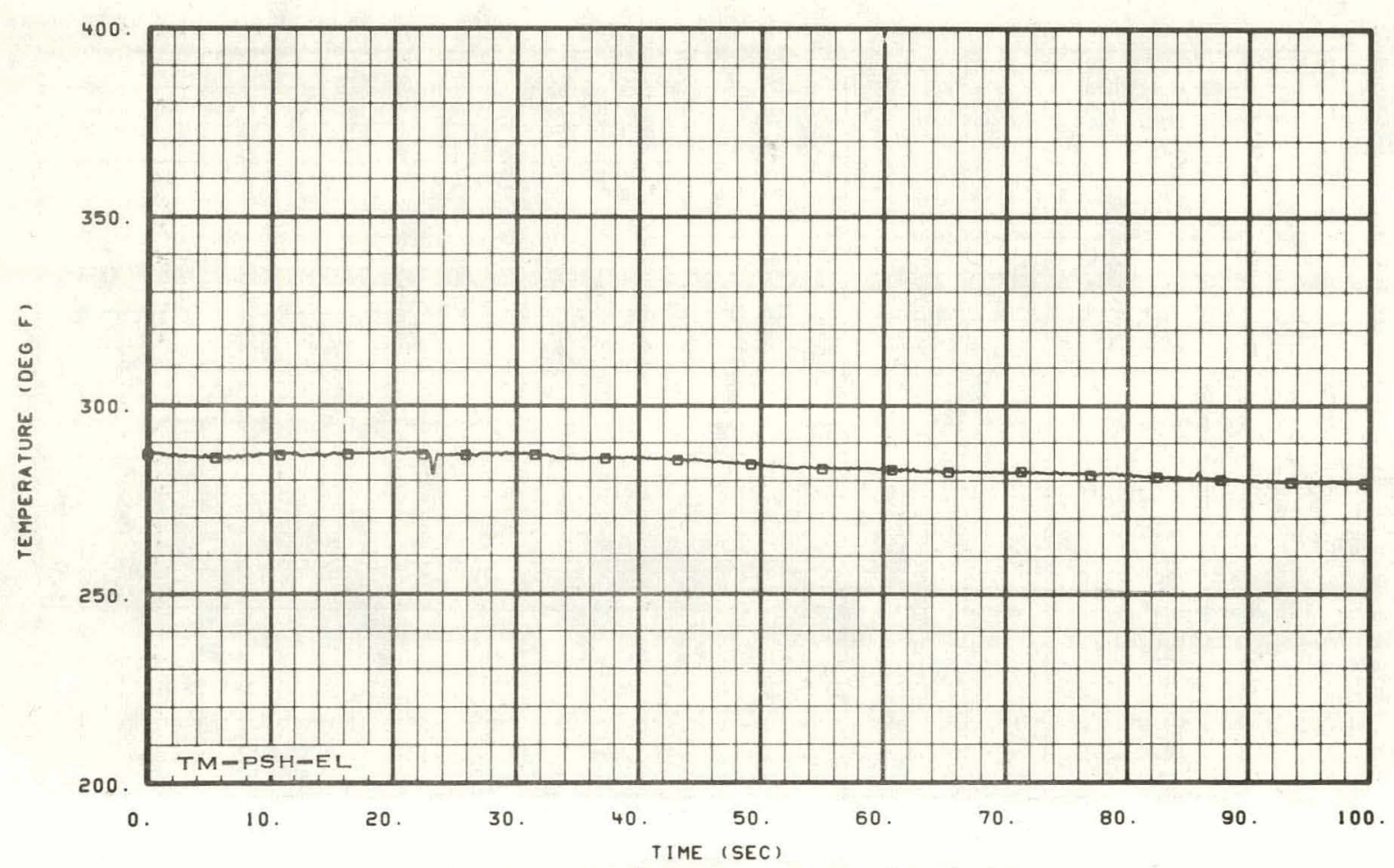

Fig. 85 Metal temperatures in pressure suppression system -- Test 15.1. 


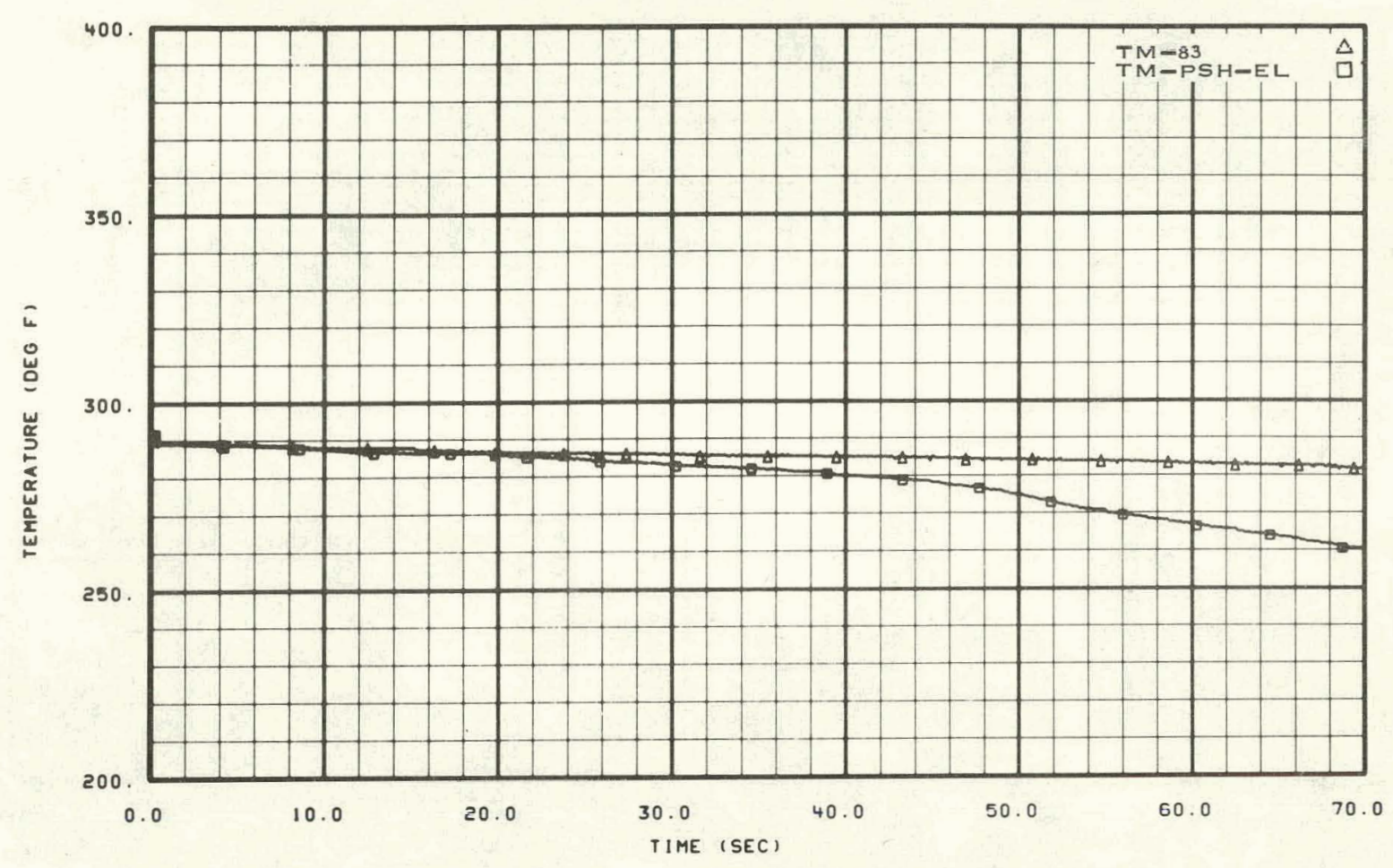

Fig. 86 Metal temperatures in pressure suppression system -- Test 15.2.

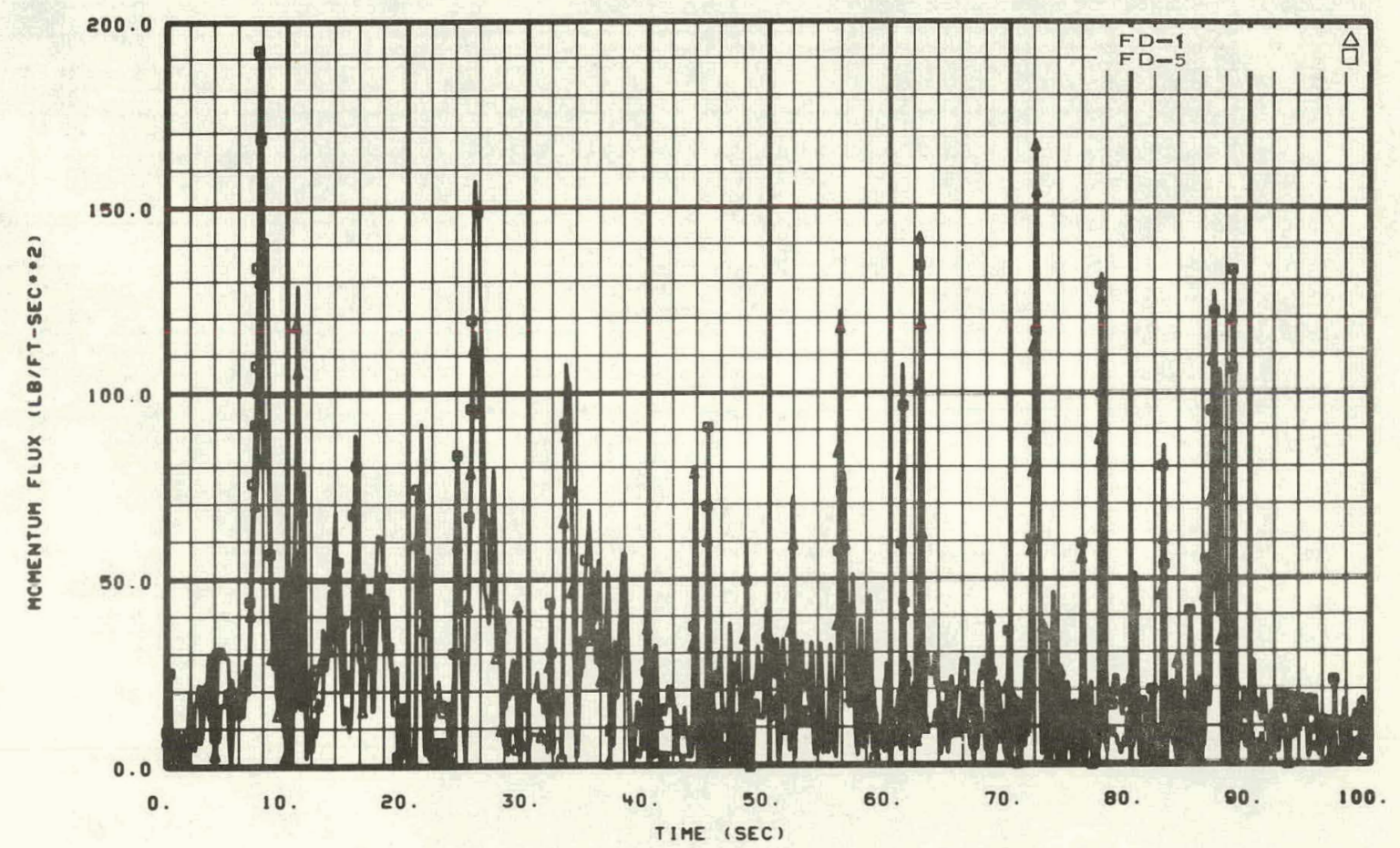

Fig. 87 Momentum flux from drag discs in operating loop hot leg -- Test 15.1 . 


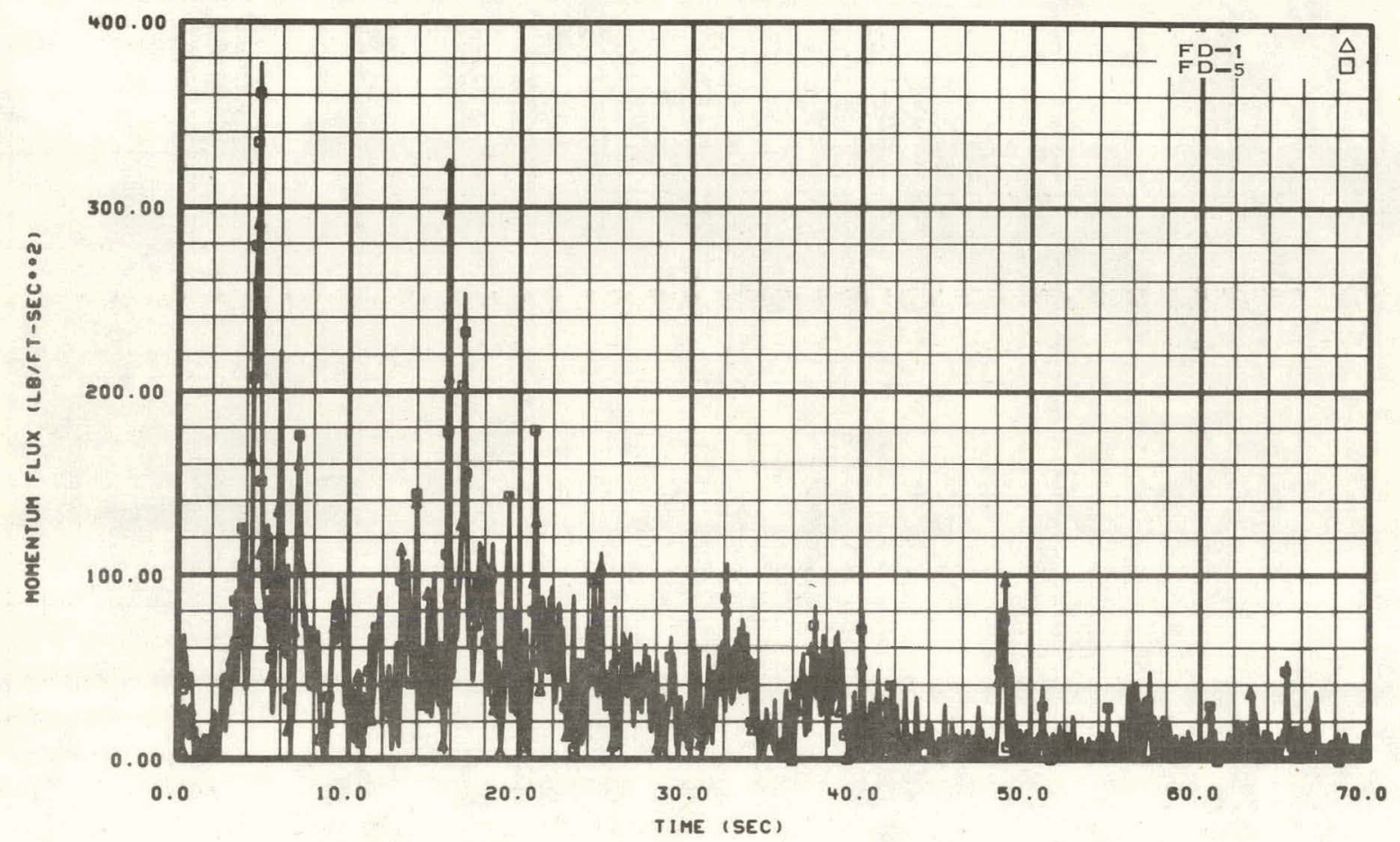

Fig. 88 Momentum flux from drag discs in operating loop hot leg -- Test 15.2 .

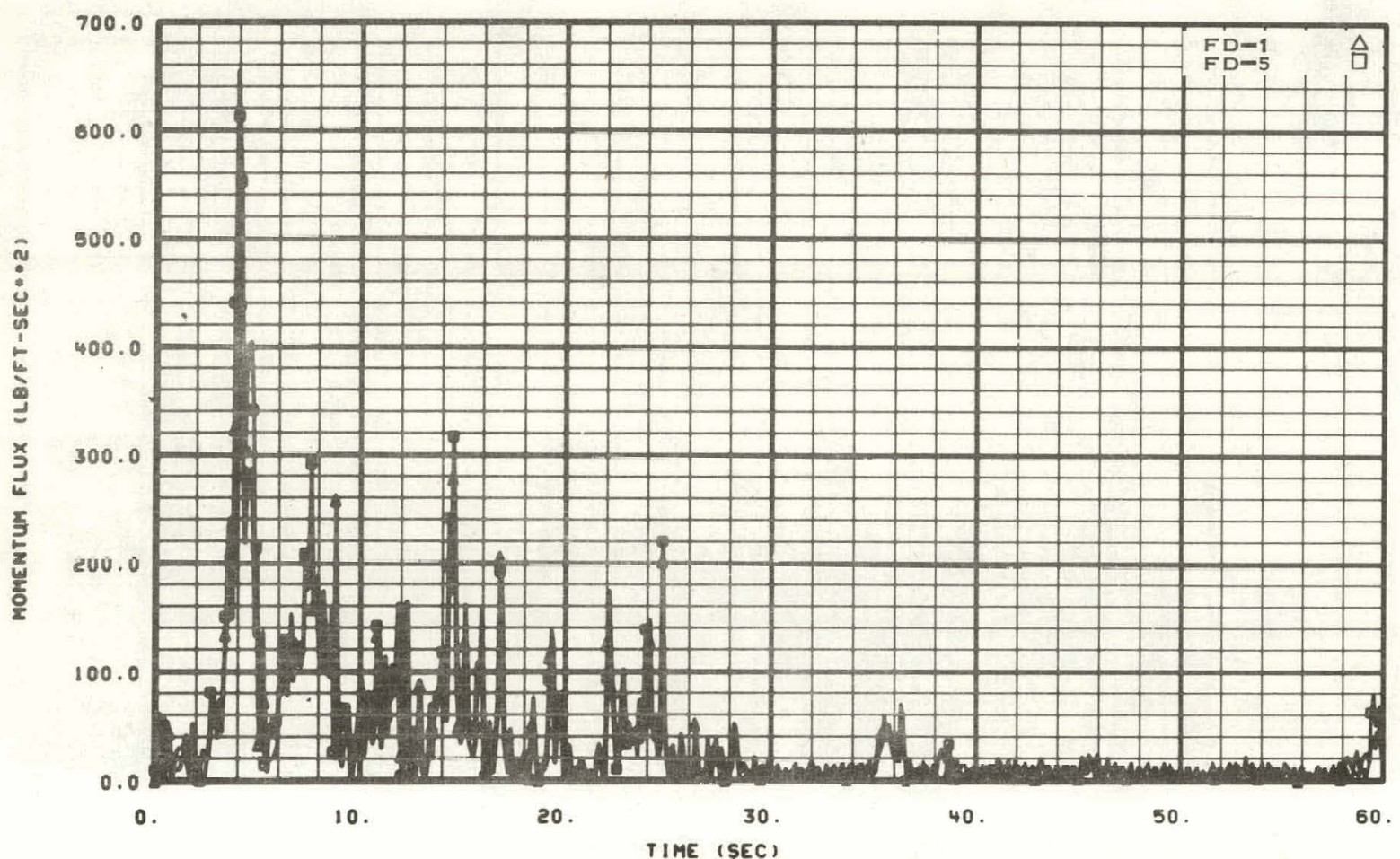

Fig. 89 Momentum flux from drag discs in operating loop hot leg -- Test 15.3 . 


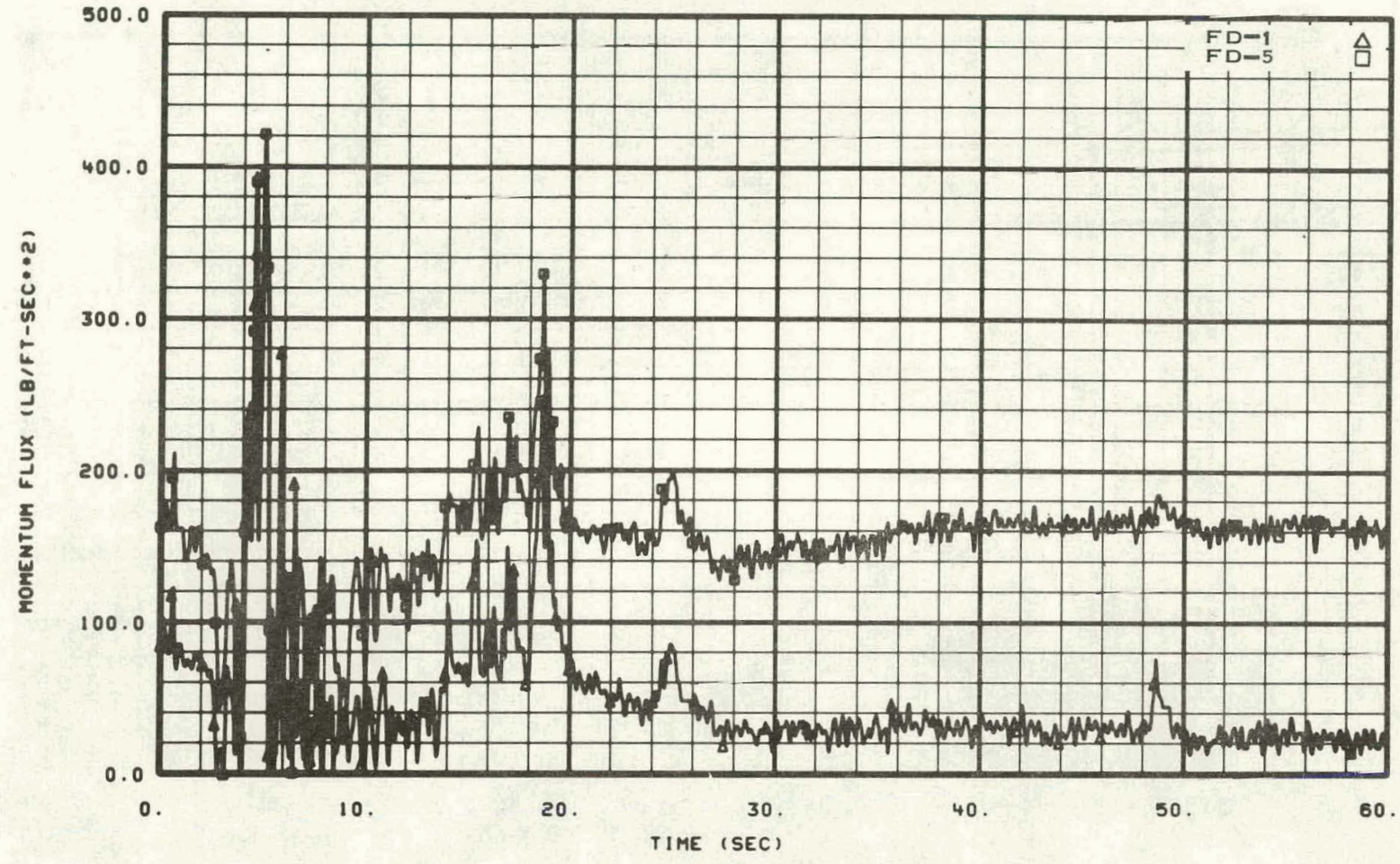

Fig. 90 Momentum flux from drag discs in operating loop hot 1eg -- Test 15.4 .

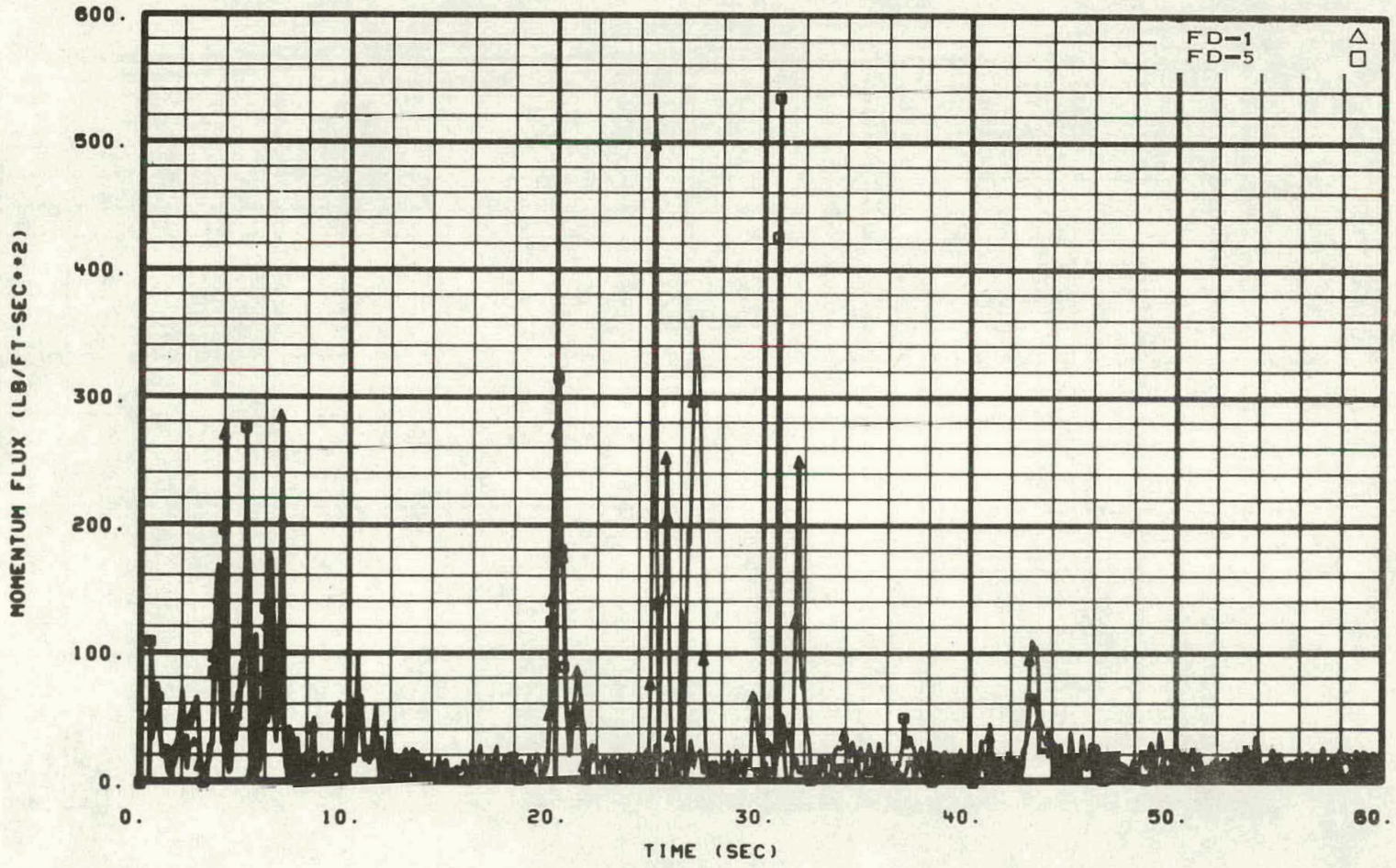

Fig. 91 Momentum flux from drag discs in operating loop hot leg -- Test 15.7 . 


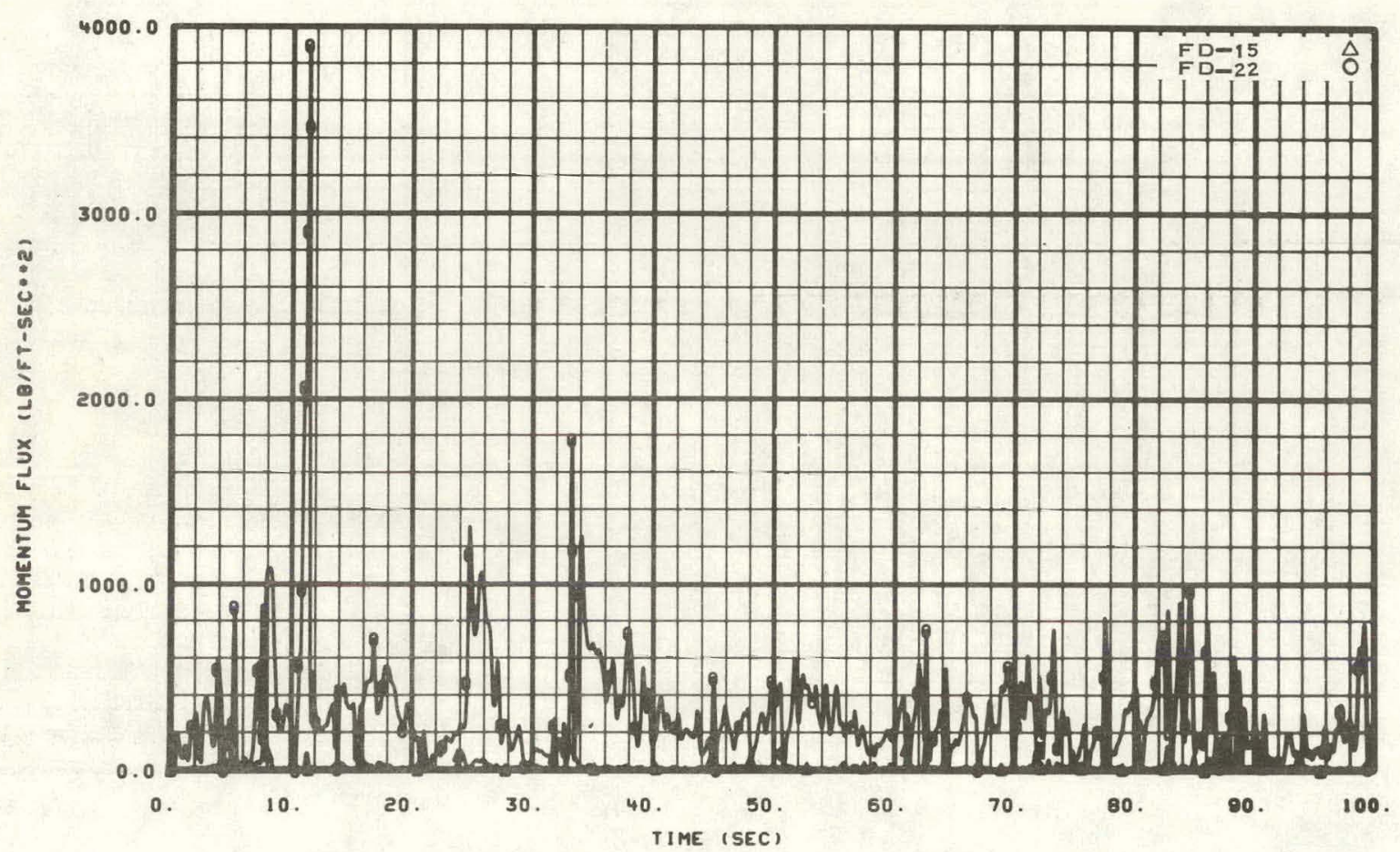

Fig. 92 Momentum flux from drag discs in operating loop cold leg -- Test 15.1 .

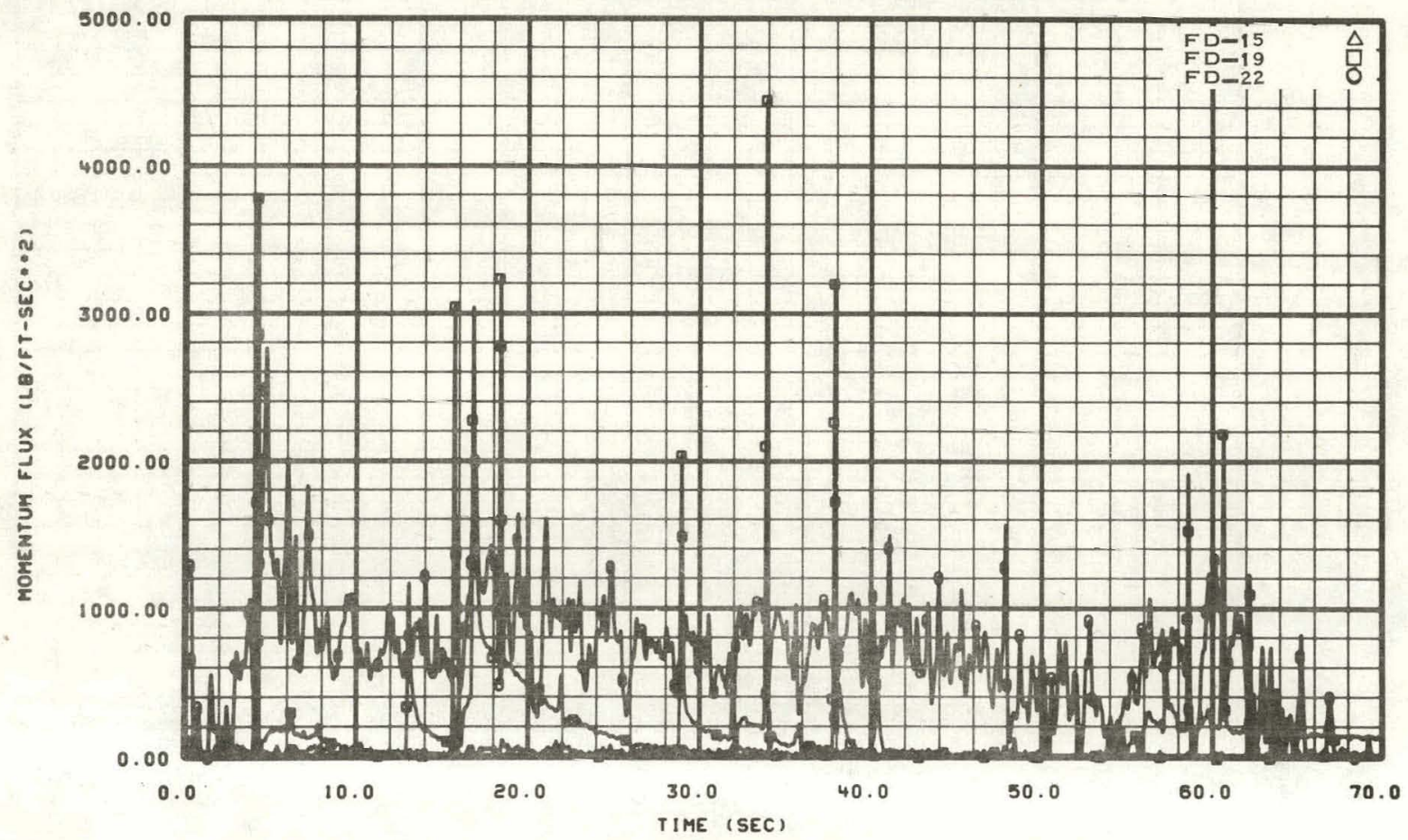

Fig. 93 Momentum flux from drag discs in operating loop cold leg -- Test 15.2 . 


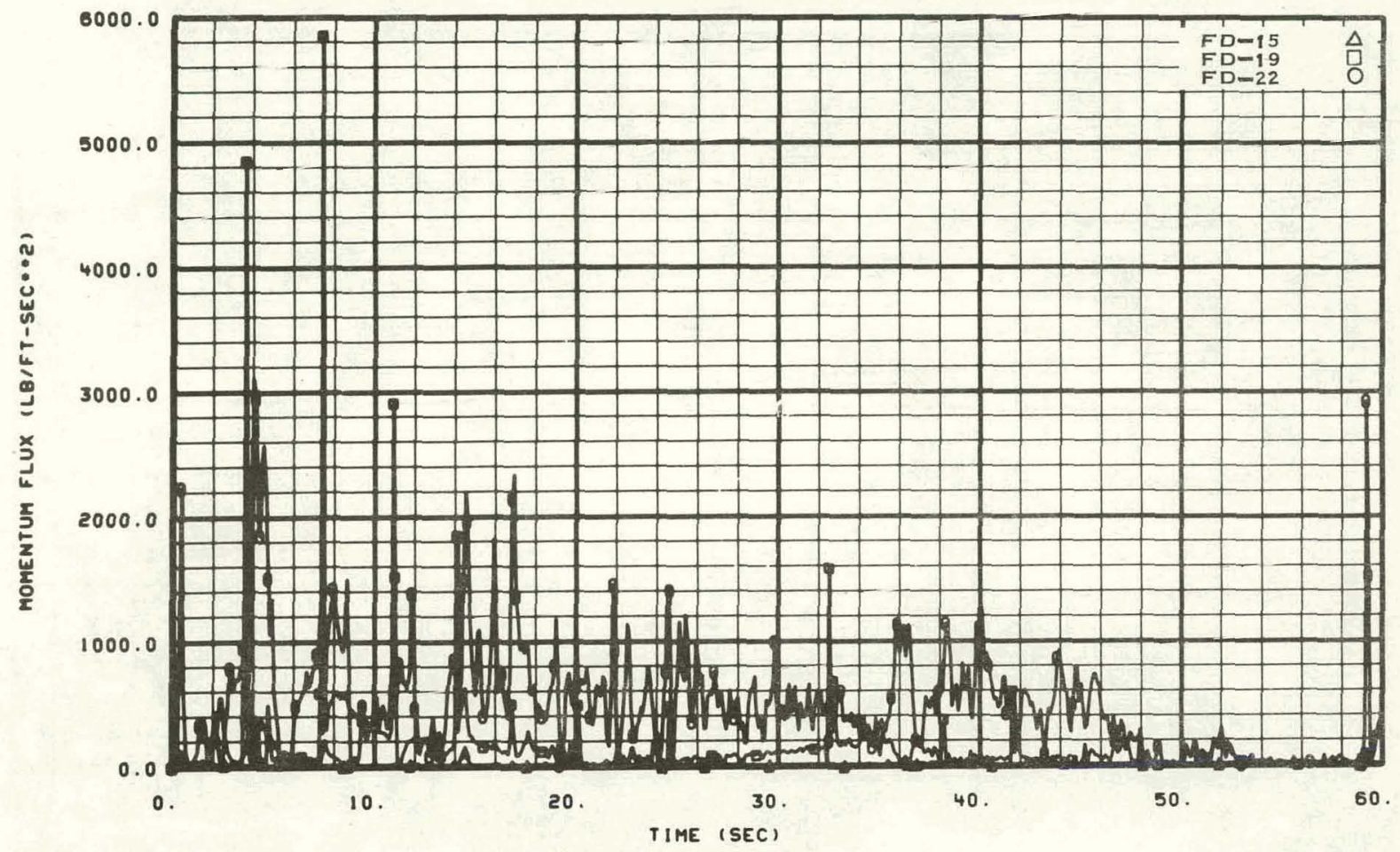

Fig. 94 Momentum flux from drag discs in operating loop cold leg -- Test 15.3.

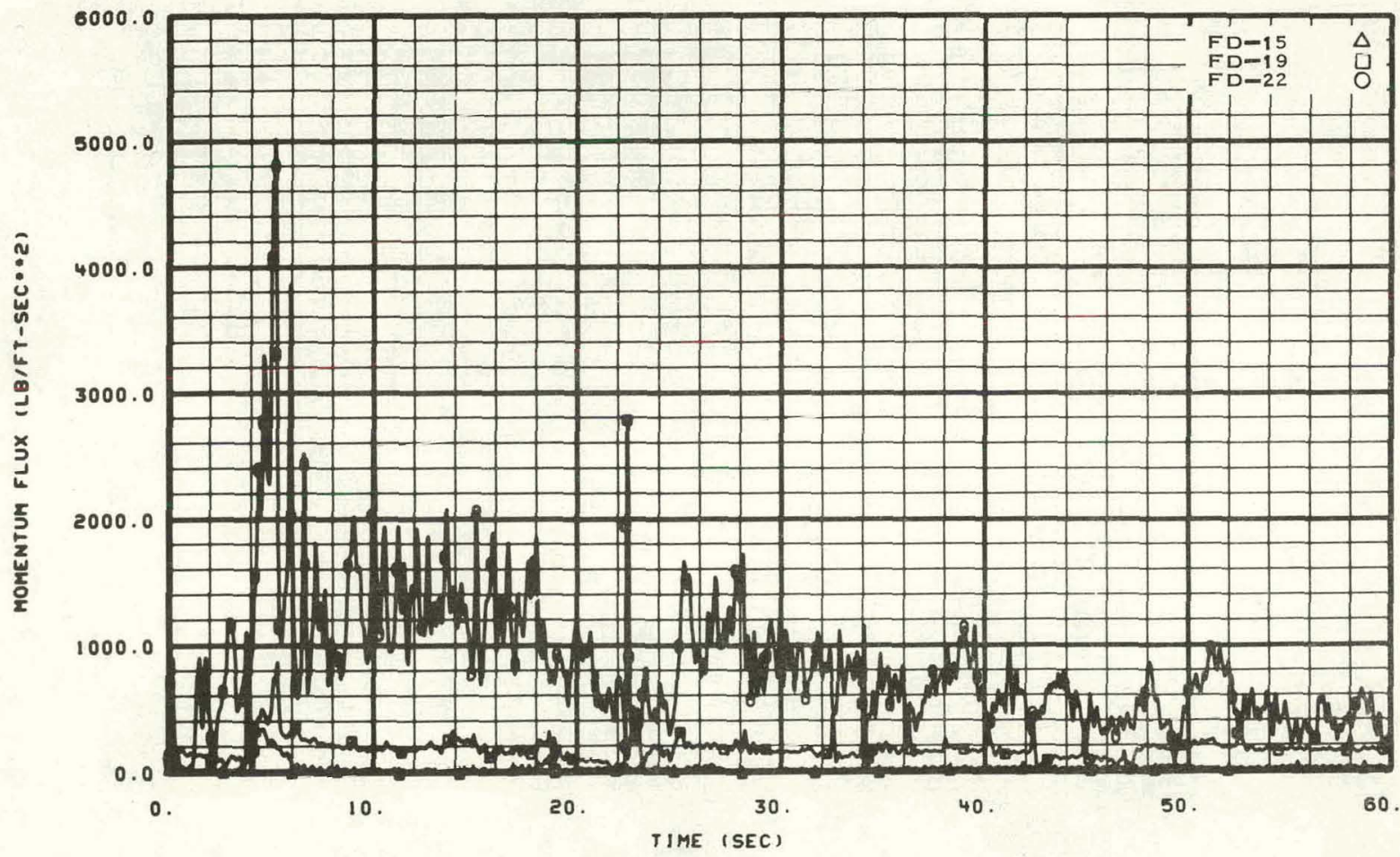

Fig. 95 Momentum flux from drag disce in uperating loop cold leg -- Test 15.4 . 


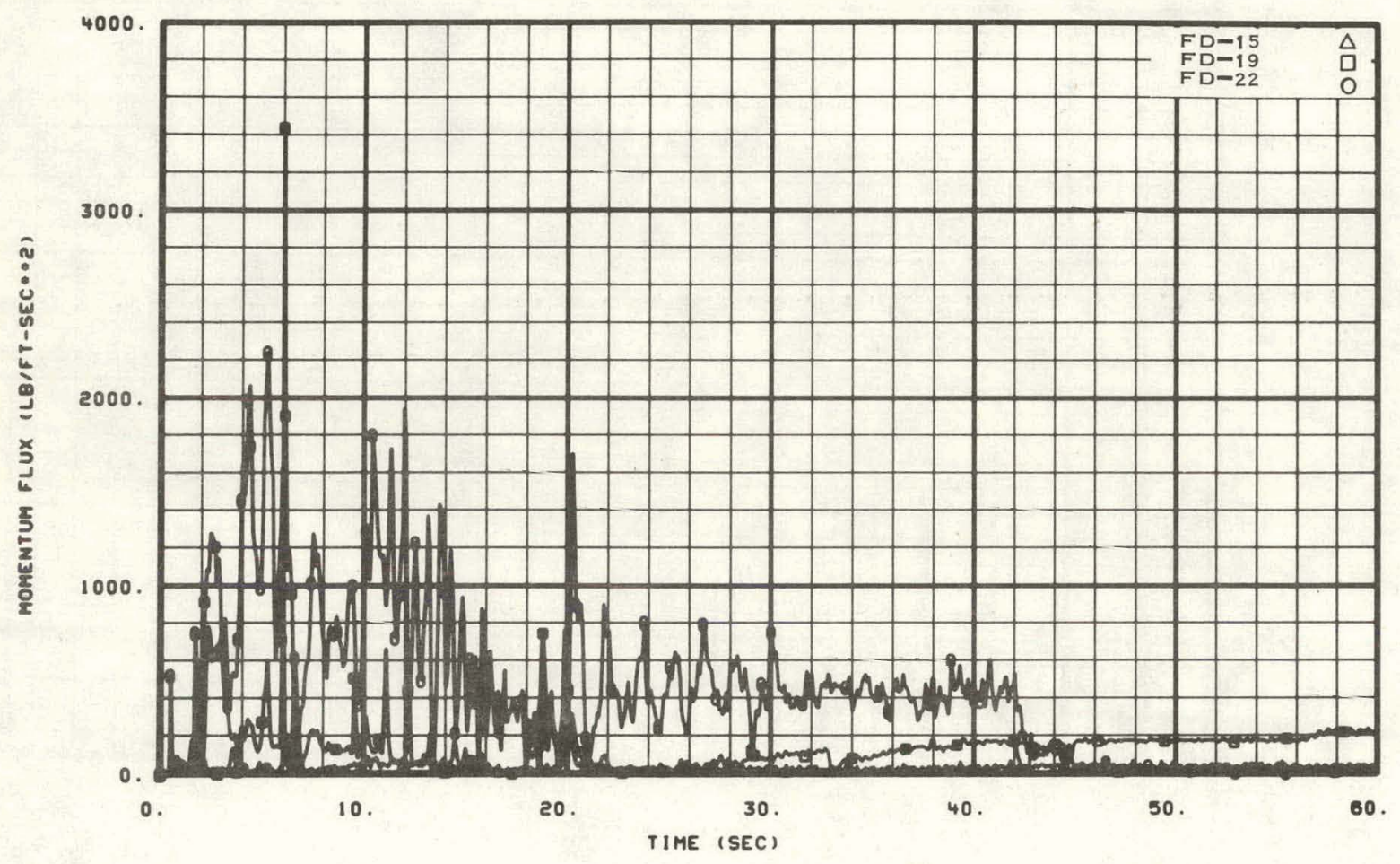

Fig. 96 Momentum flux from drag discs in operating loop cold leg -- Test 15.7 .

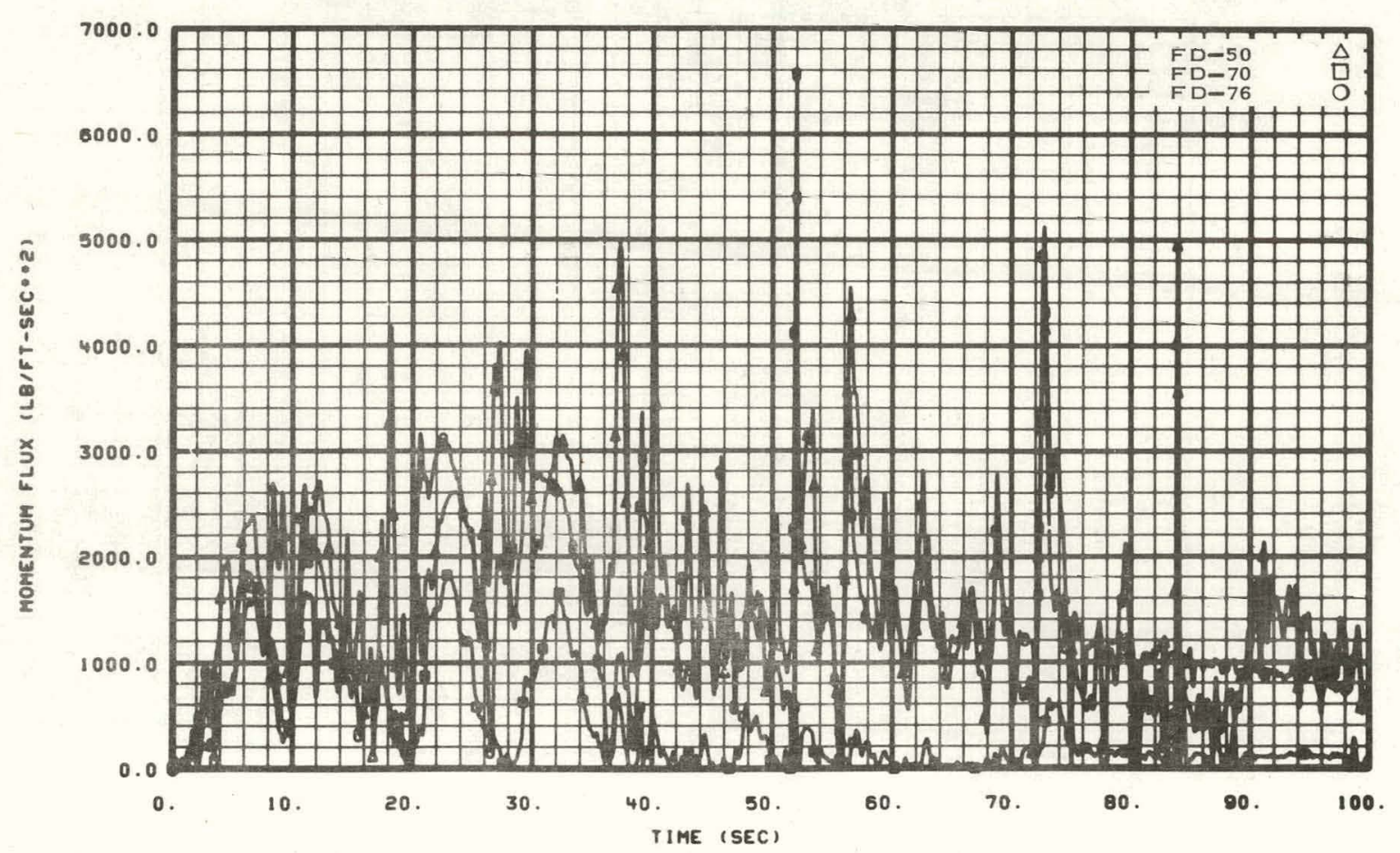

Fig. 97 Momentum flux from drag discs in blowdown loop -- Test 15.1. 


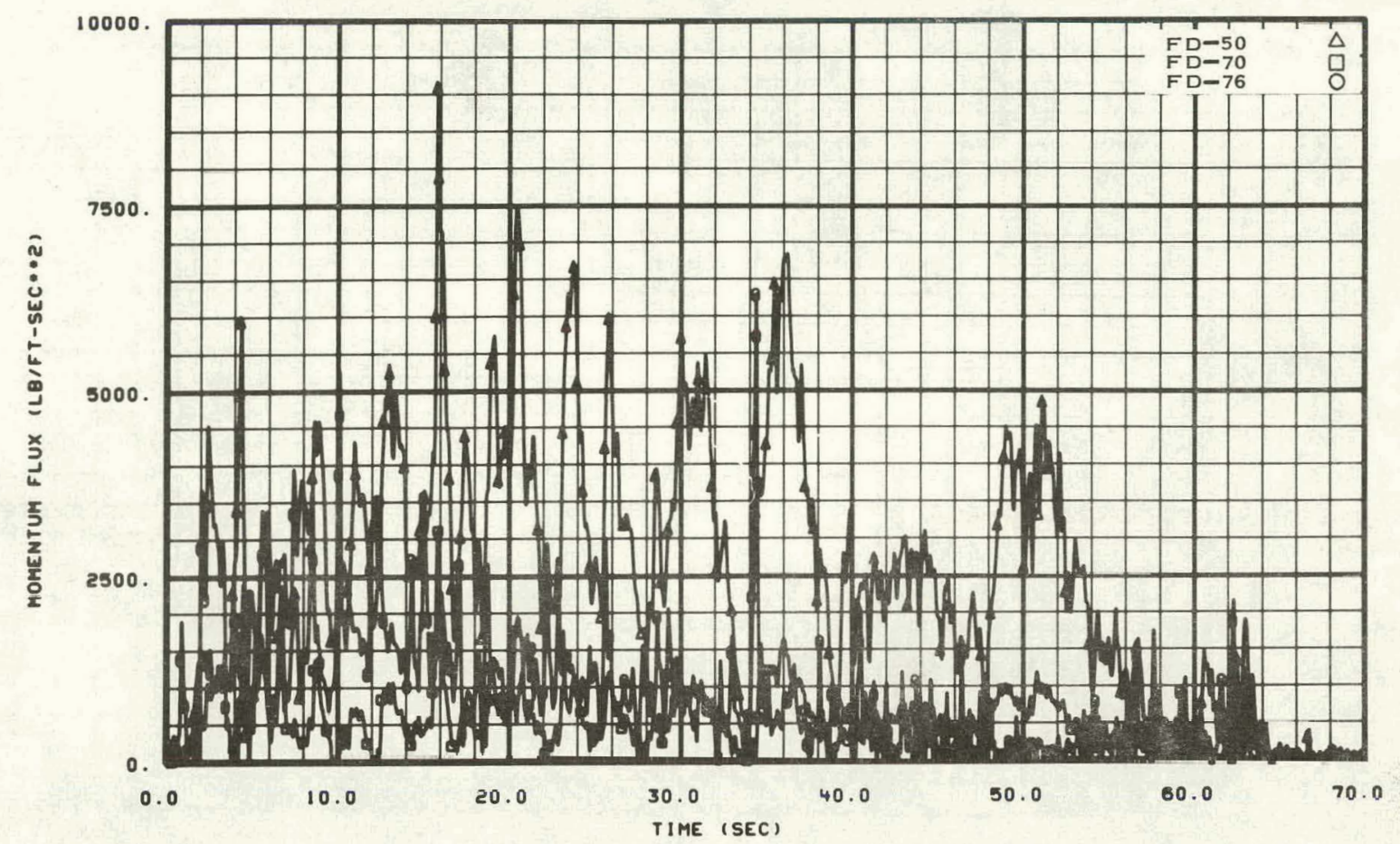

Fig. 98 Momentum flux from drag discs in blowdown loop -- Test 15.2.

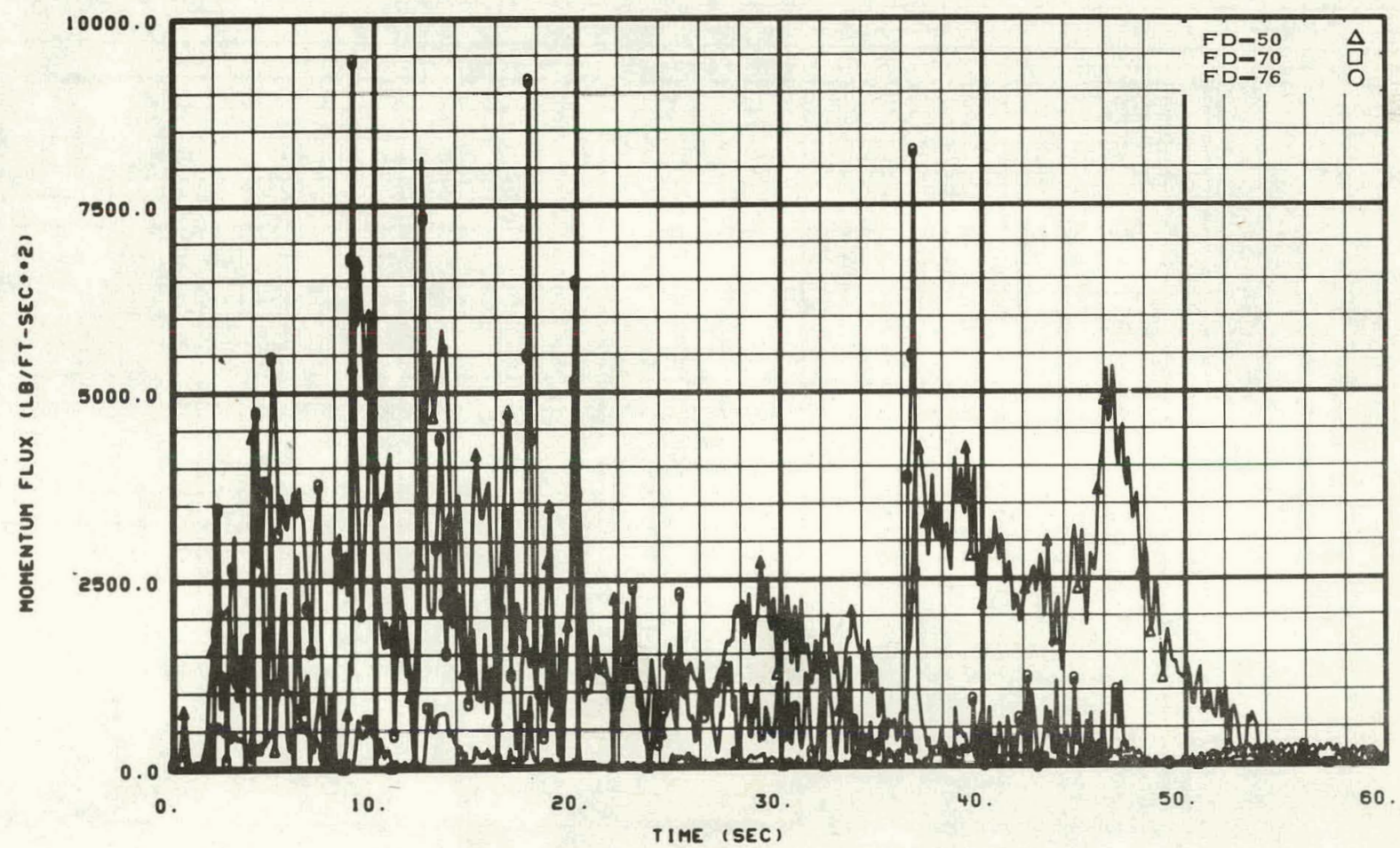

Fig. 99 Momentum flux from drag discs in blowdown loop -- Test 15.3. 


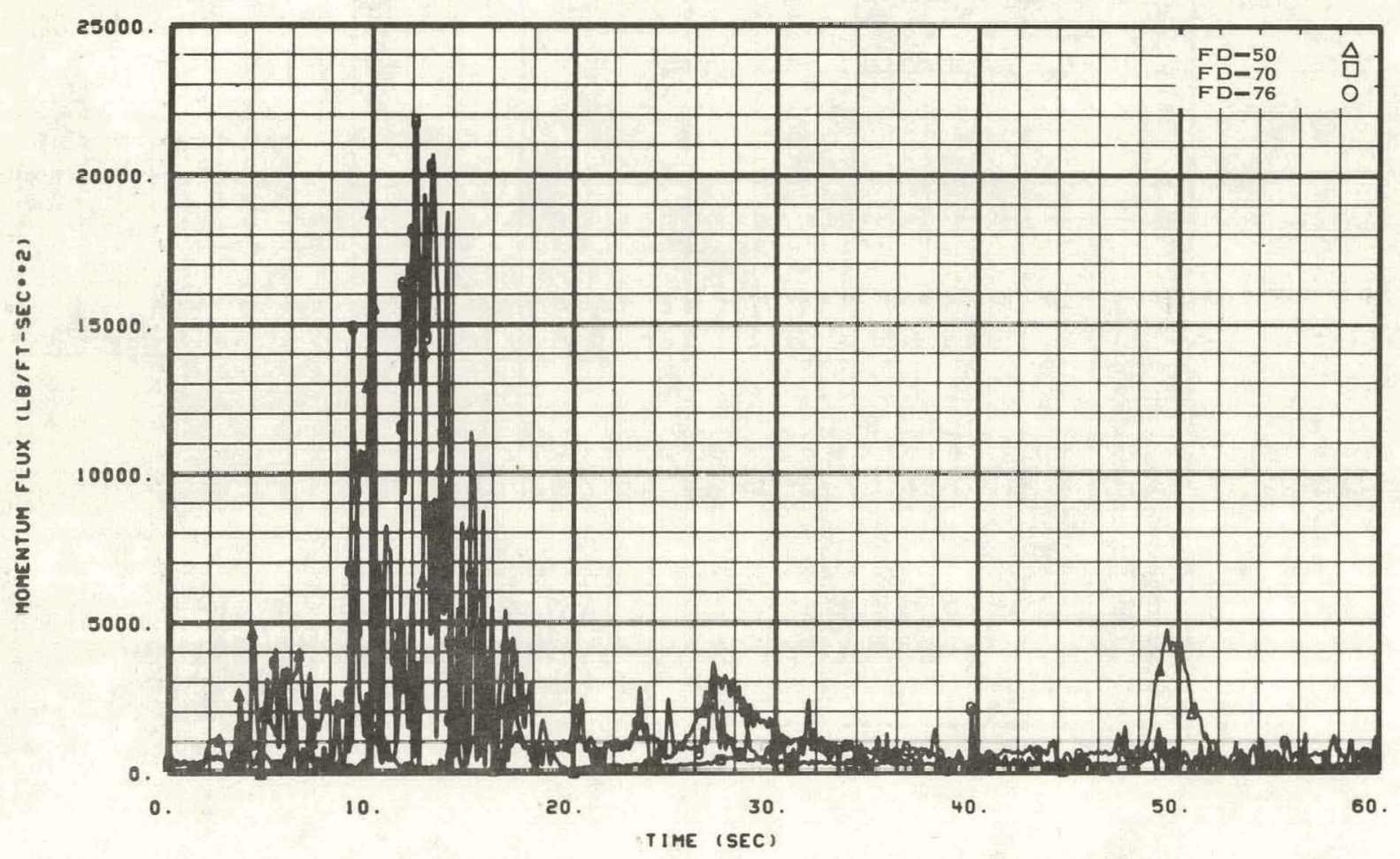

Fig. 100 Momentum flux from drag discs in blowdown loop -- Test 15.4.

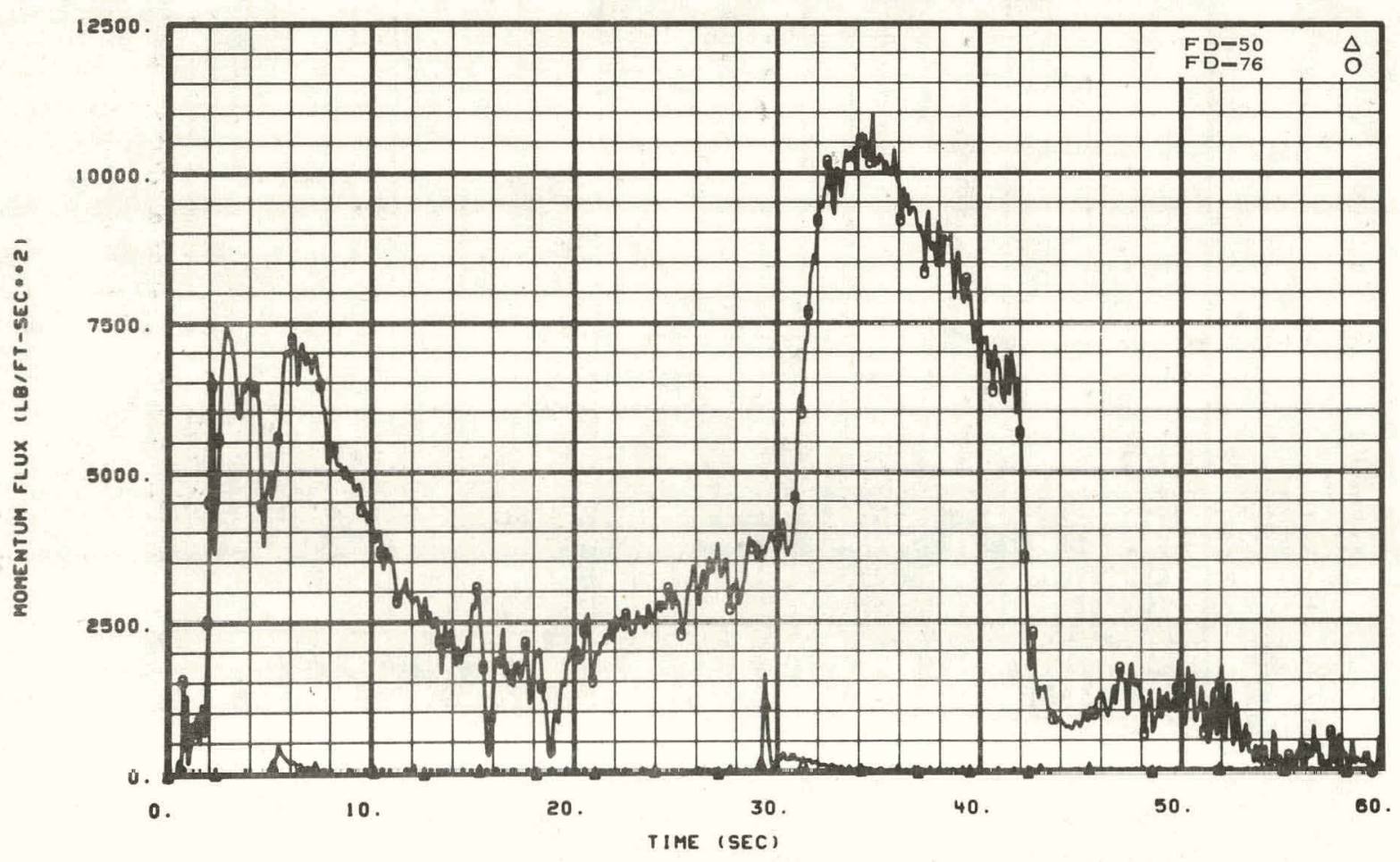

Fig. 101 Momentum flux from drag discs in blowdown loop -- Test 15.7. 


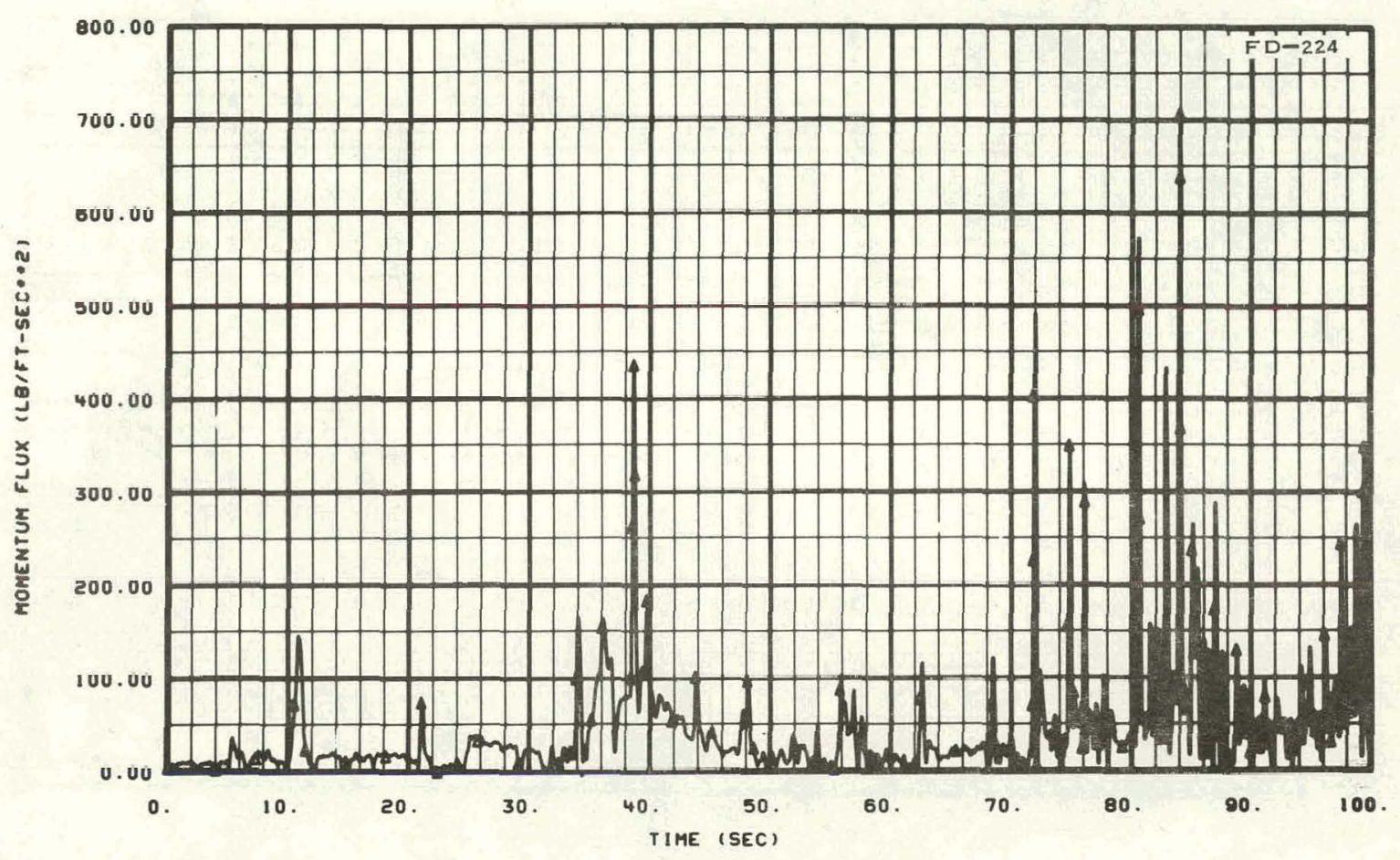

Fig. 102 Momentum flux from drag discs at core barrel inlet -- Test 15.1.

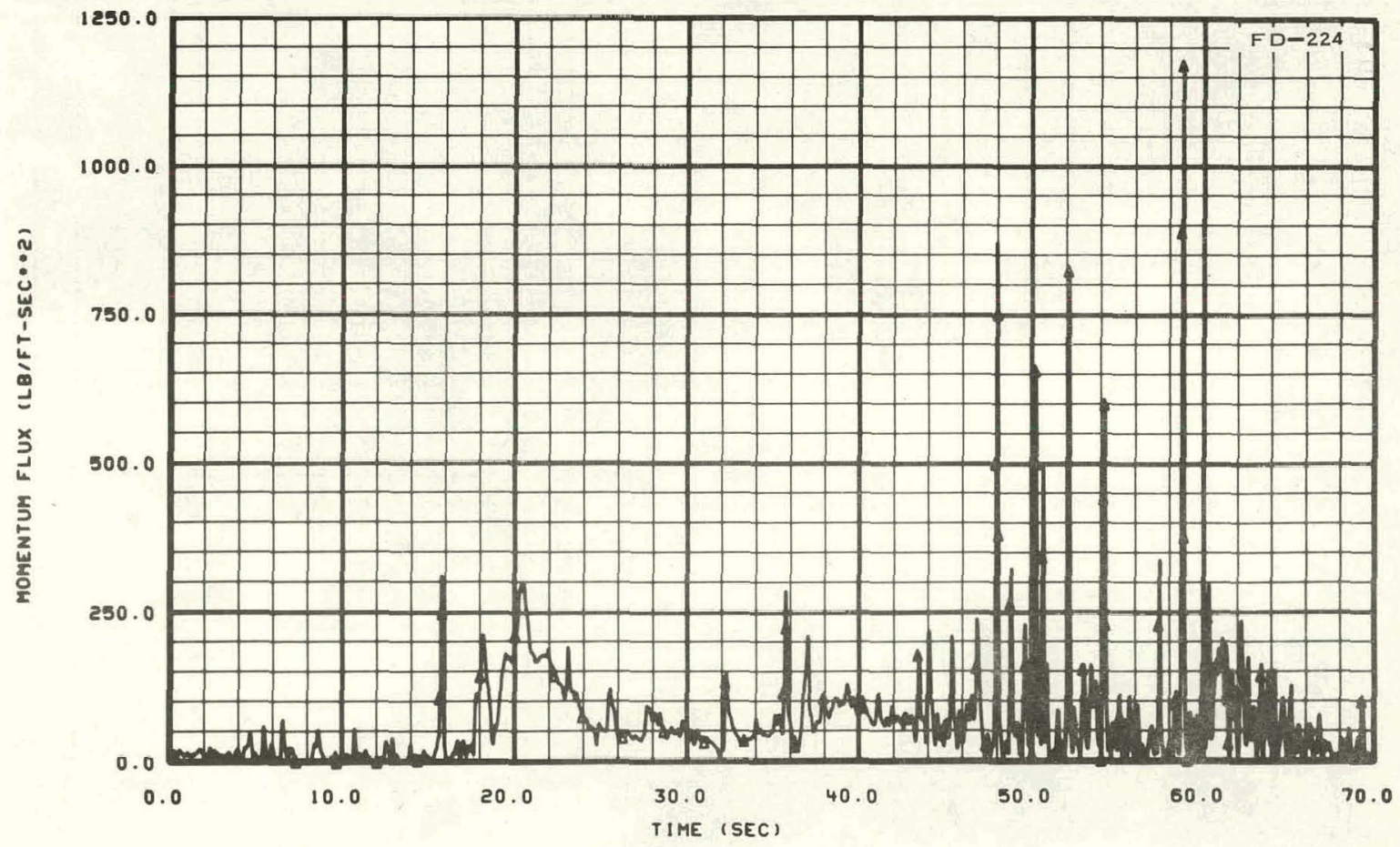

Fig. 103 Momentum flux from drag discs at core barrel inlet -- Test 15.2. 


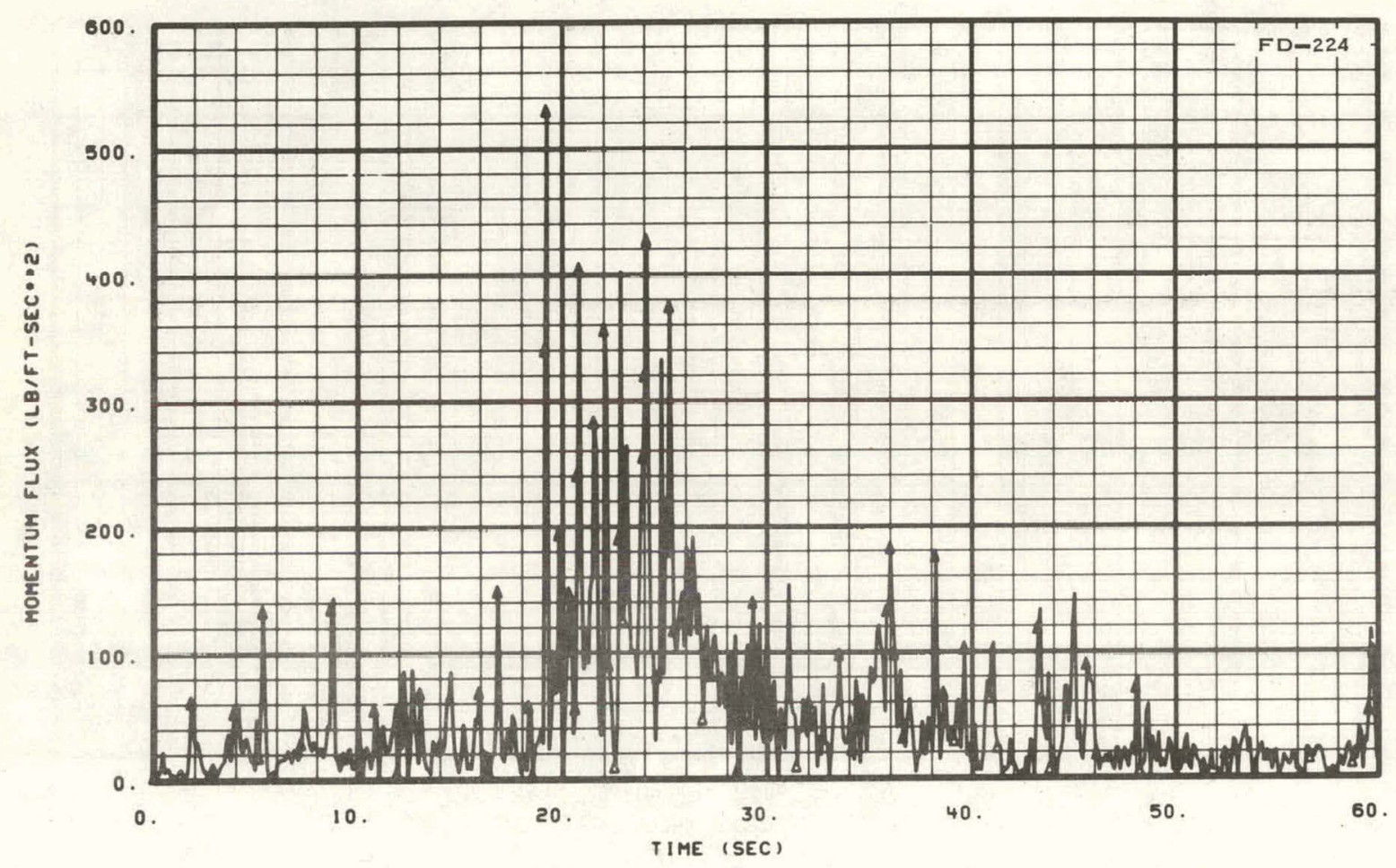

Fig. 104 Momentum flux from drag discs at core barrel inlet -- Test 15.3.

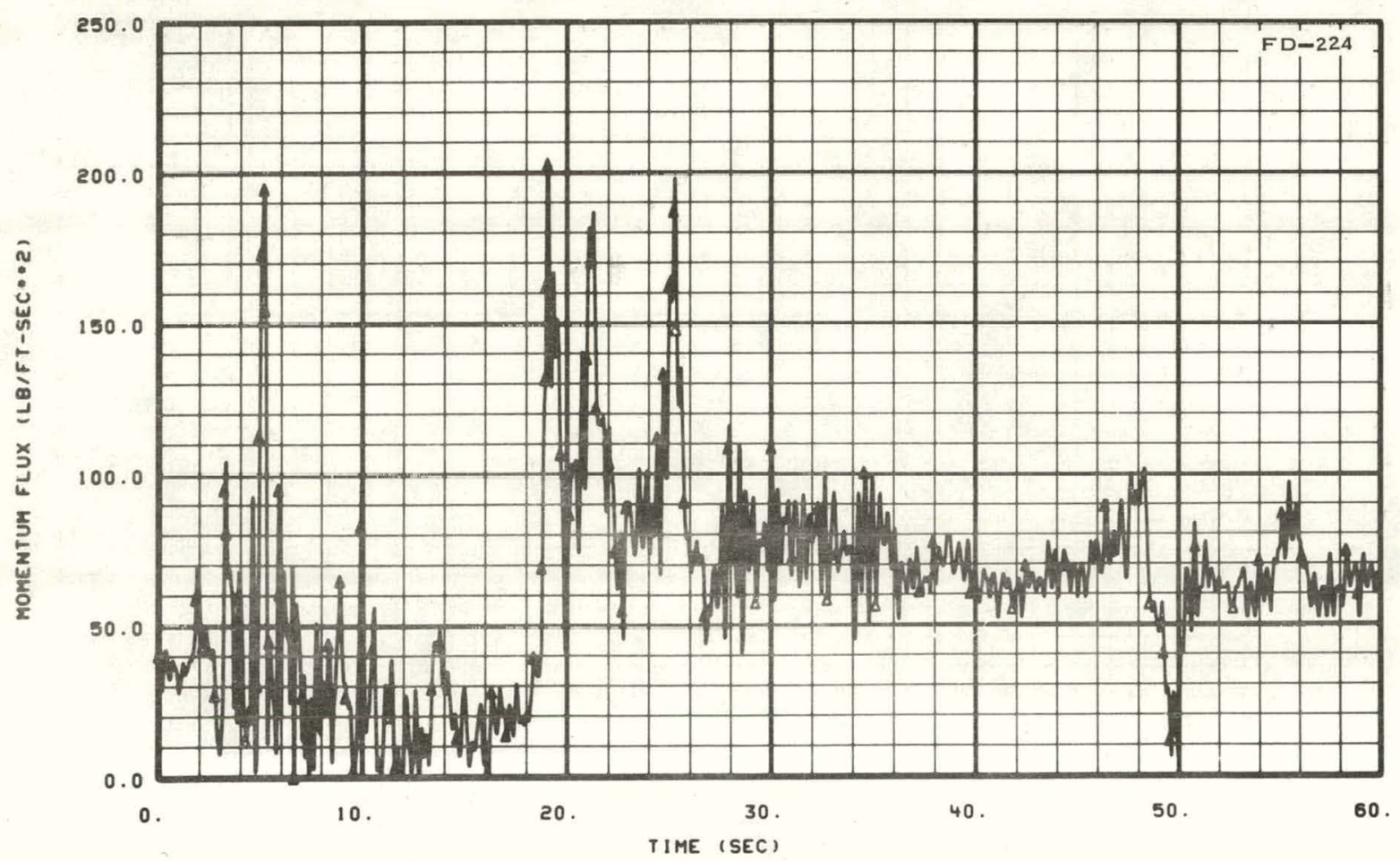

Fig. 105 Momentum flux from drag discs at core barrel inlet -- Test 15.4. 


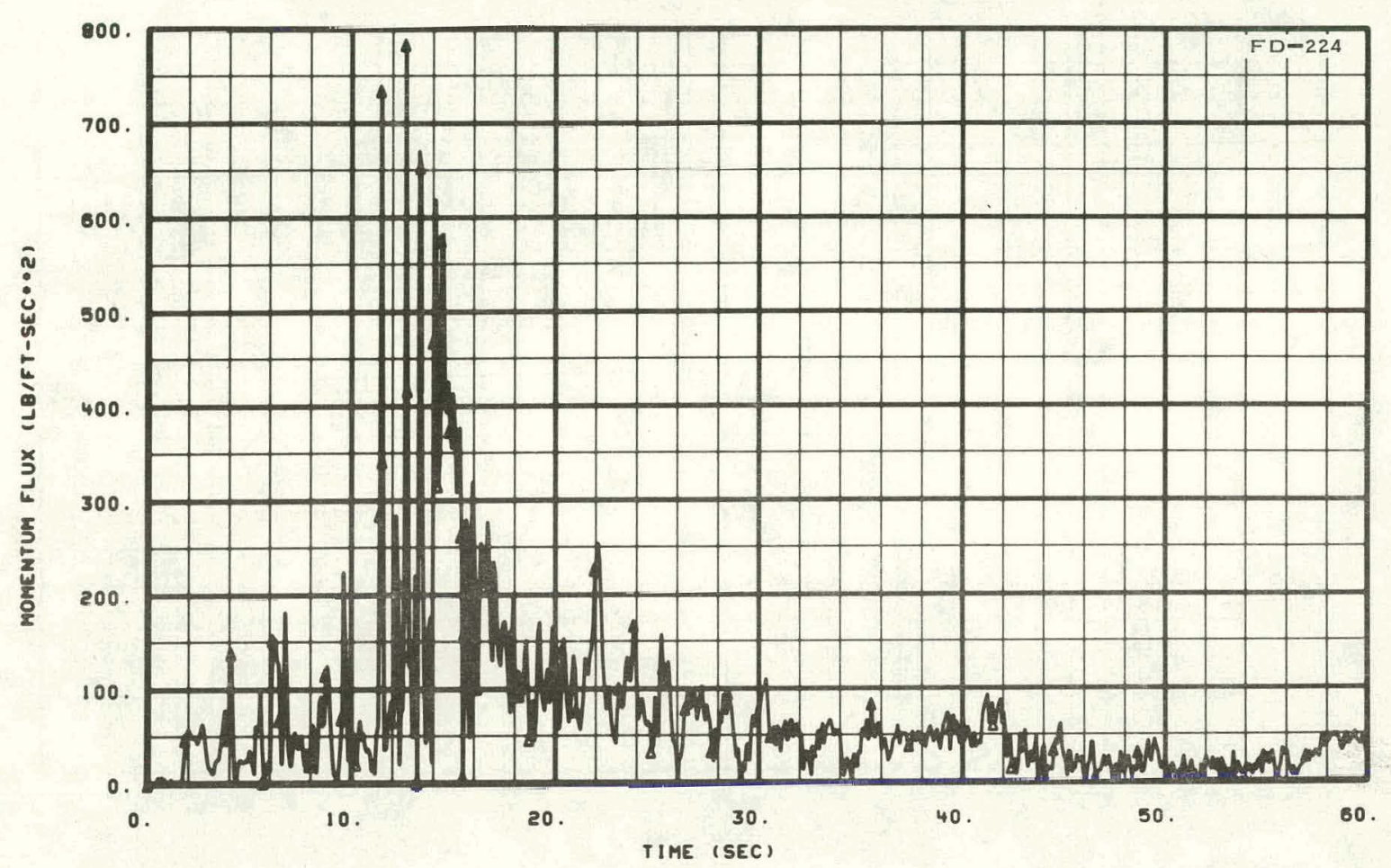

Fig. 106 Momentum flux from drag discs at core barrel inlet -- Test 15.7.

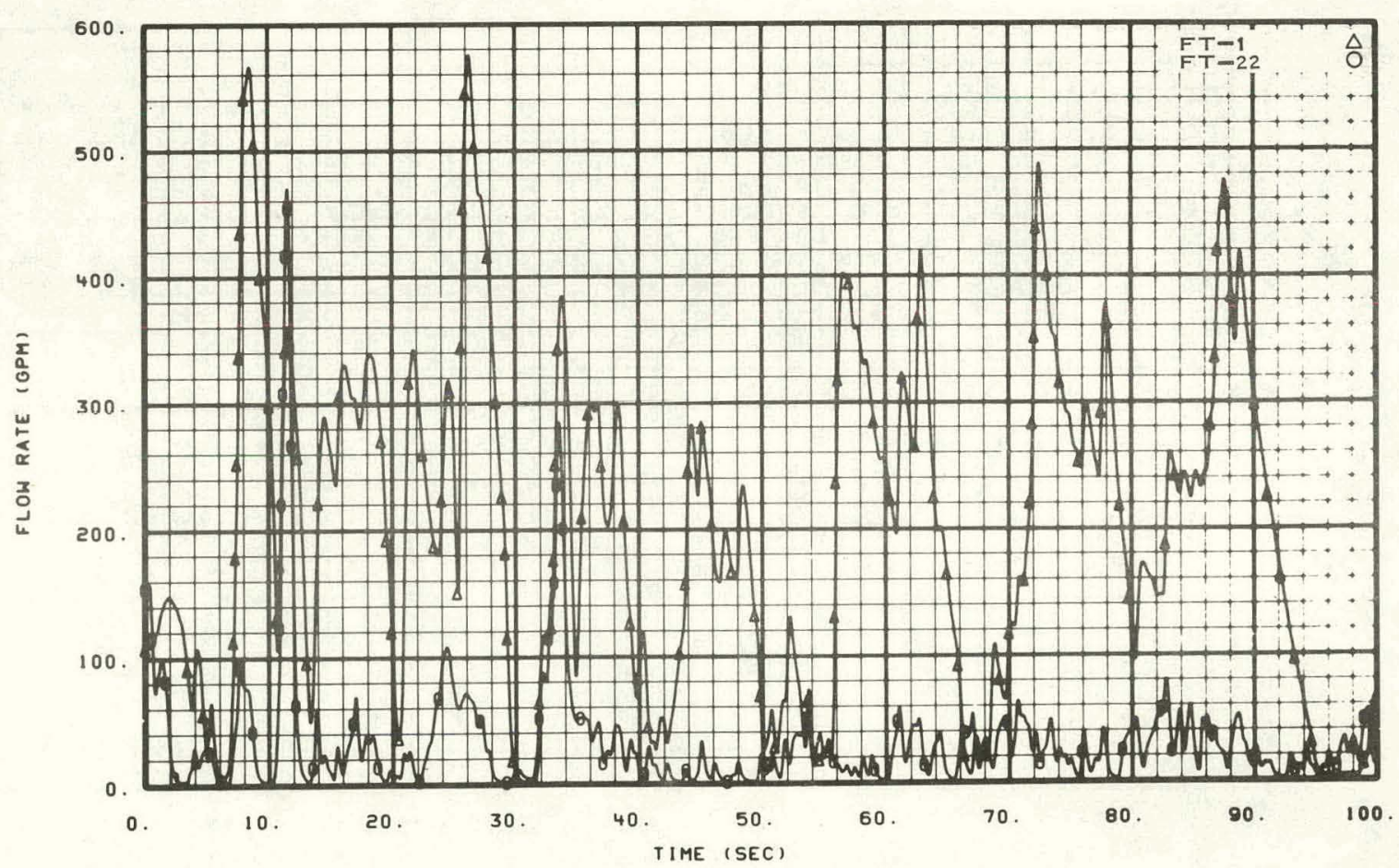

Fig. 107 Volumetric flow rate trom turbine meters in operating loop -Test 15.1 . 


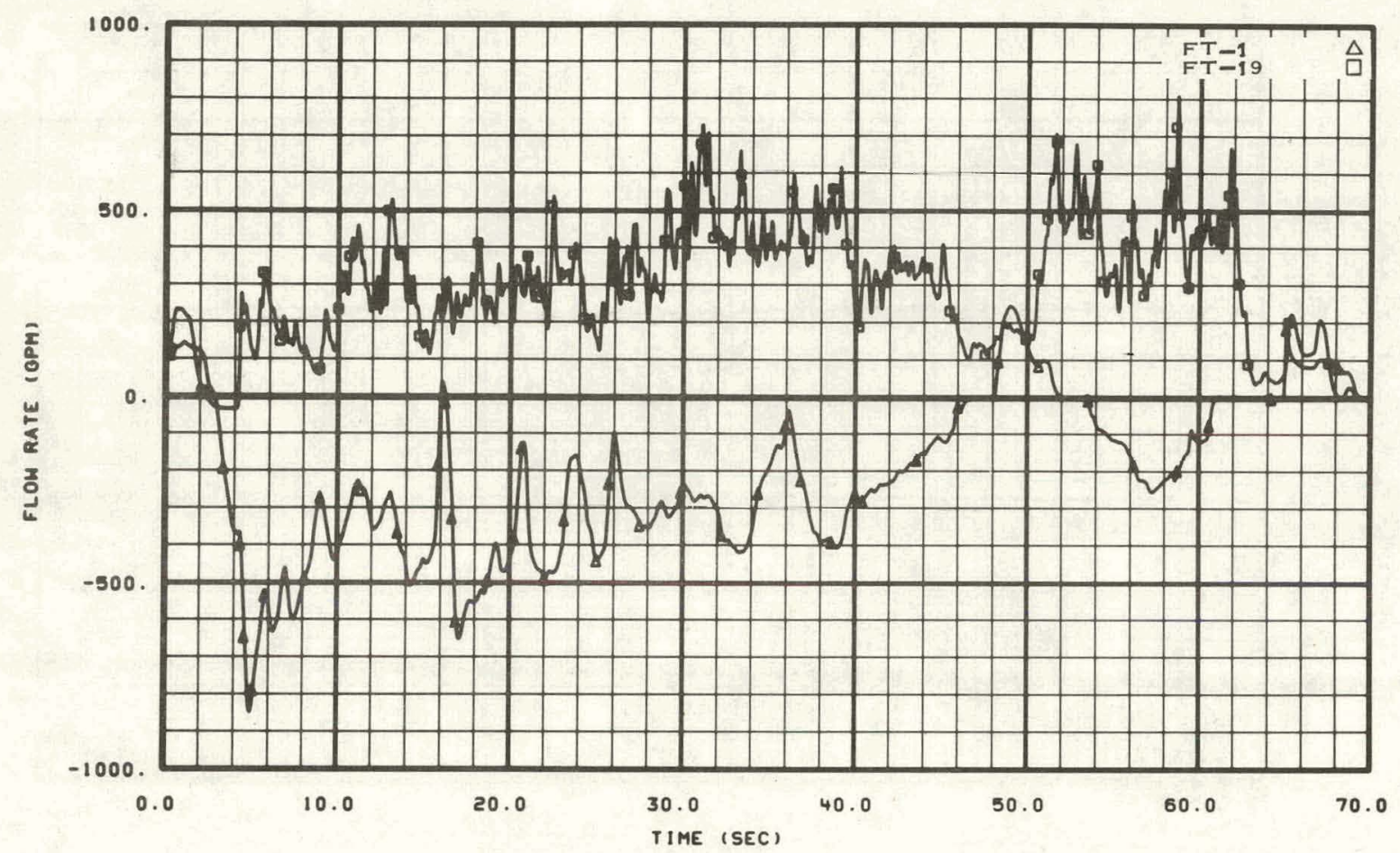

Fig. 108 Volumetric flow rate from turbine meters in operating loop -Test 15.2.

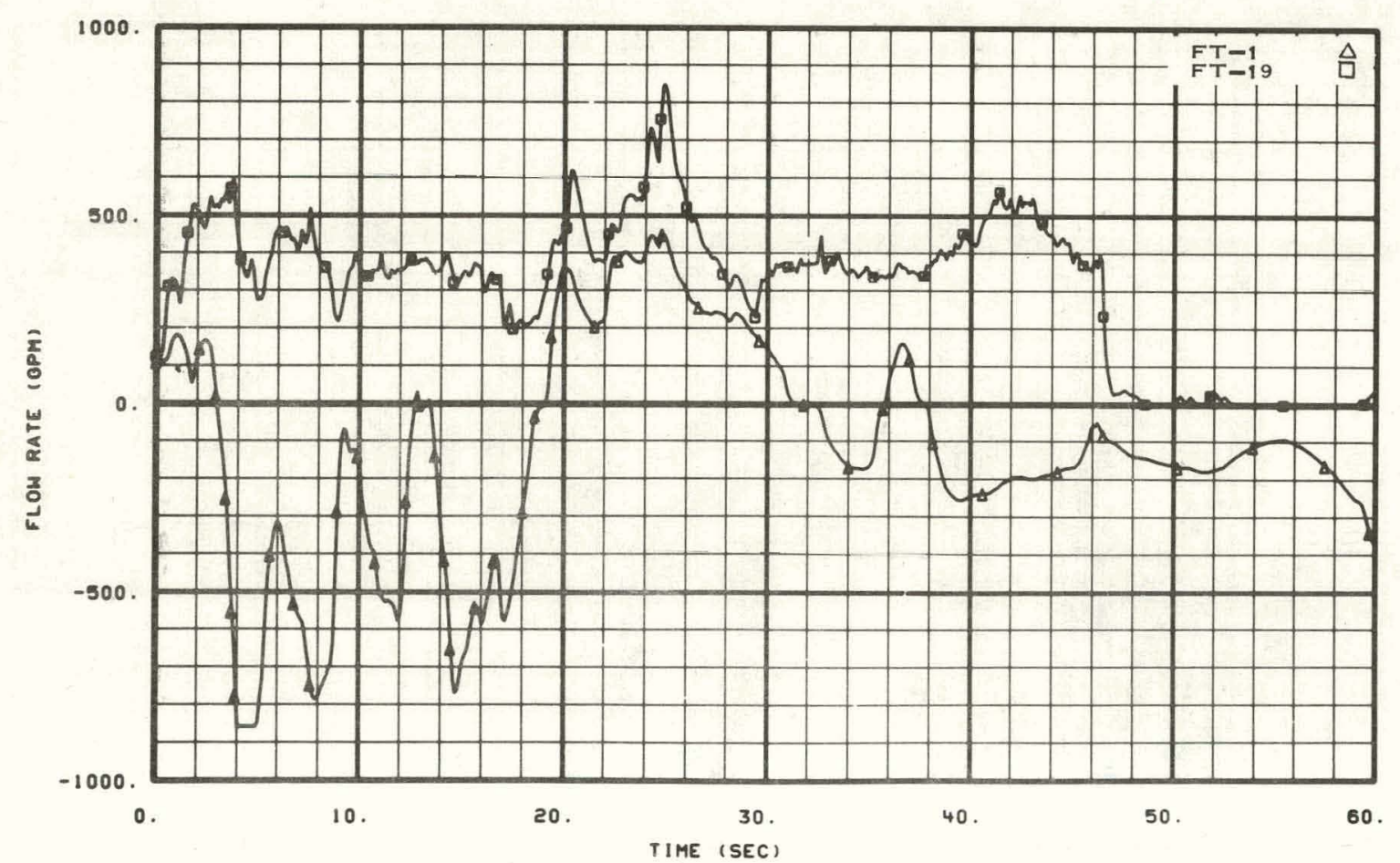

Fig. 109 Volumetric flow rate from turbine meters in operating loop -Test 15.3 . 


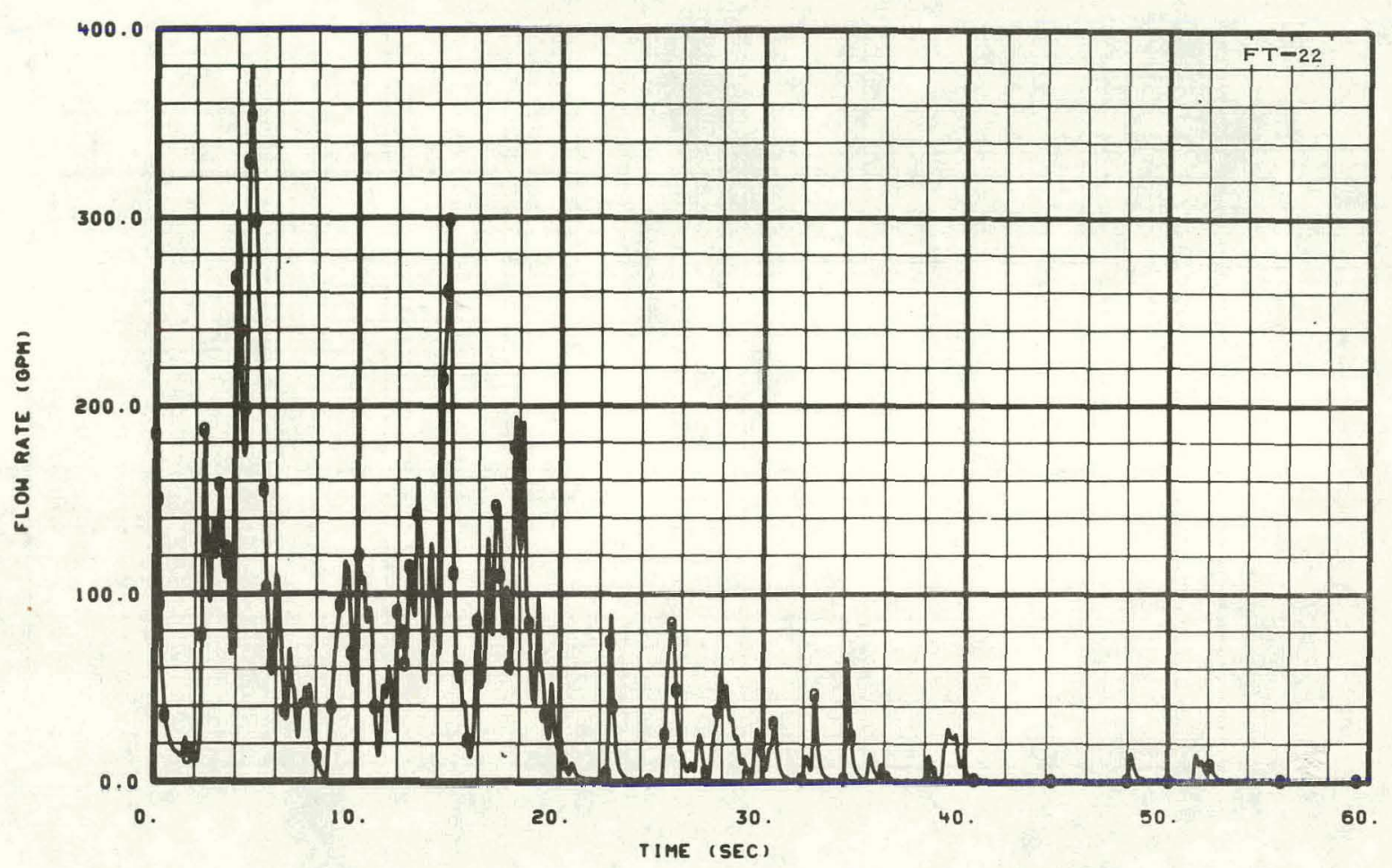

Fig. 110 Volumetric flow rate from turbine meters in operating loop -Test 15.4 .

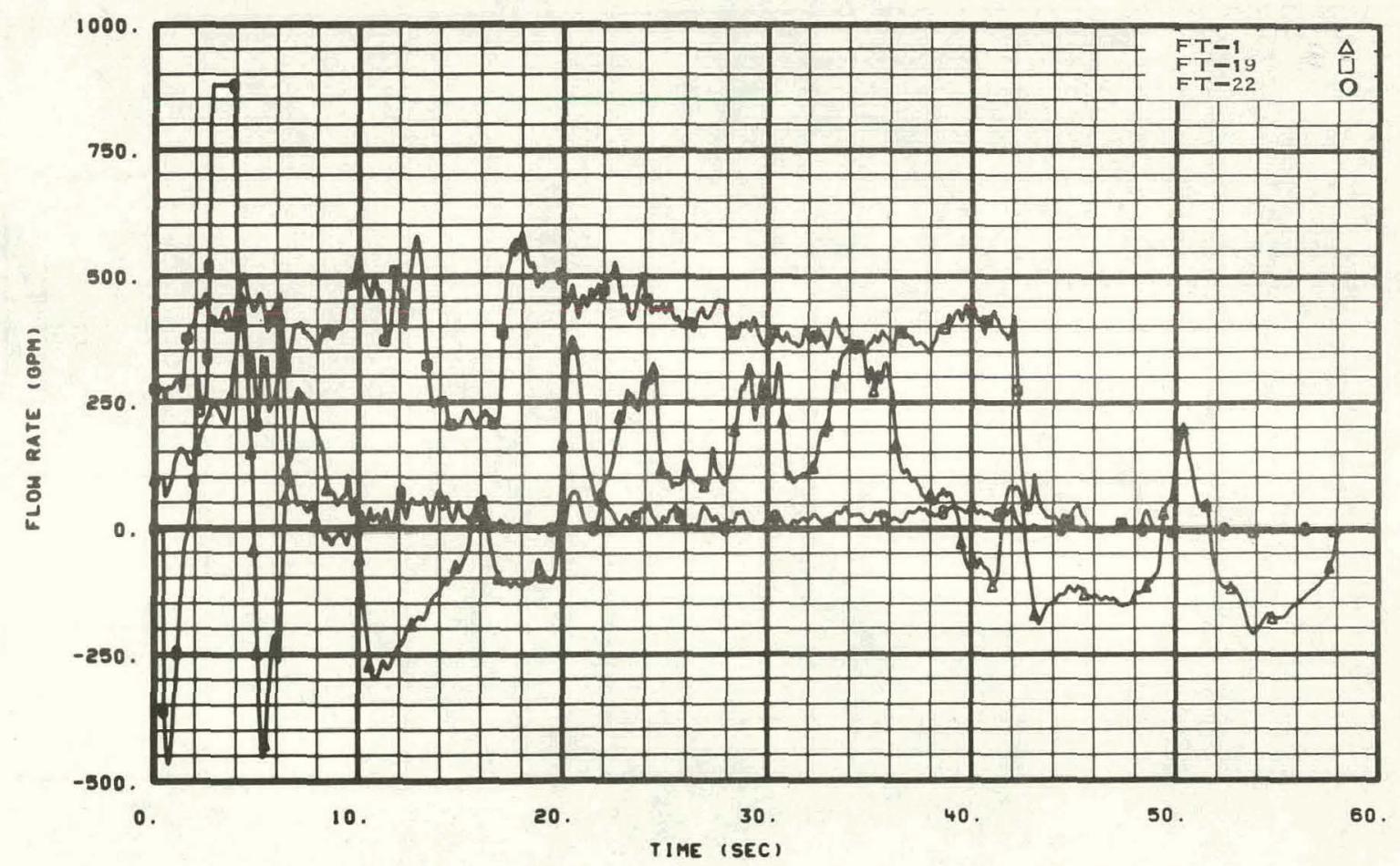

Fig. 111 Volumetric flow rate from turbine meters in operating loop -Test 15.7 . 


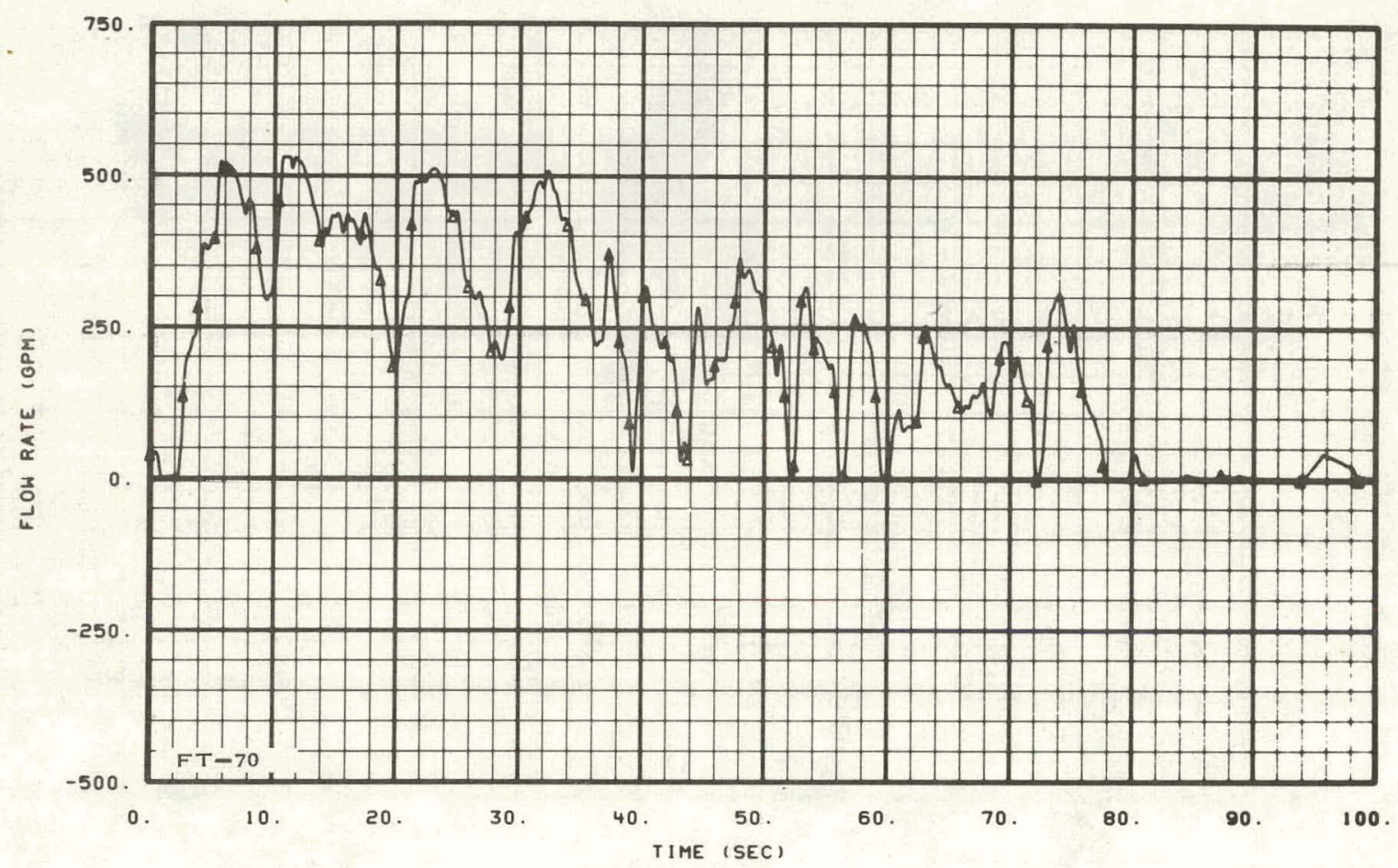

Fig. 112 Volumetric flow rate from turbine meter in blowdown loop hot leg -- Test 15.1.

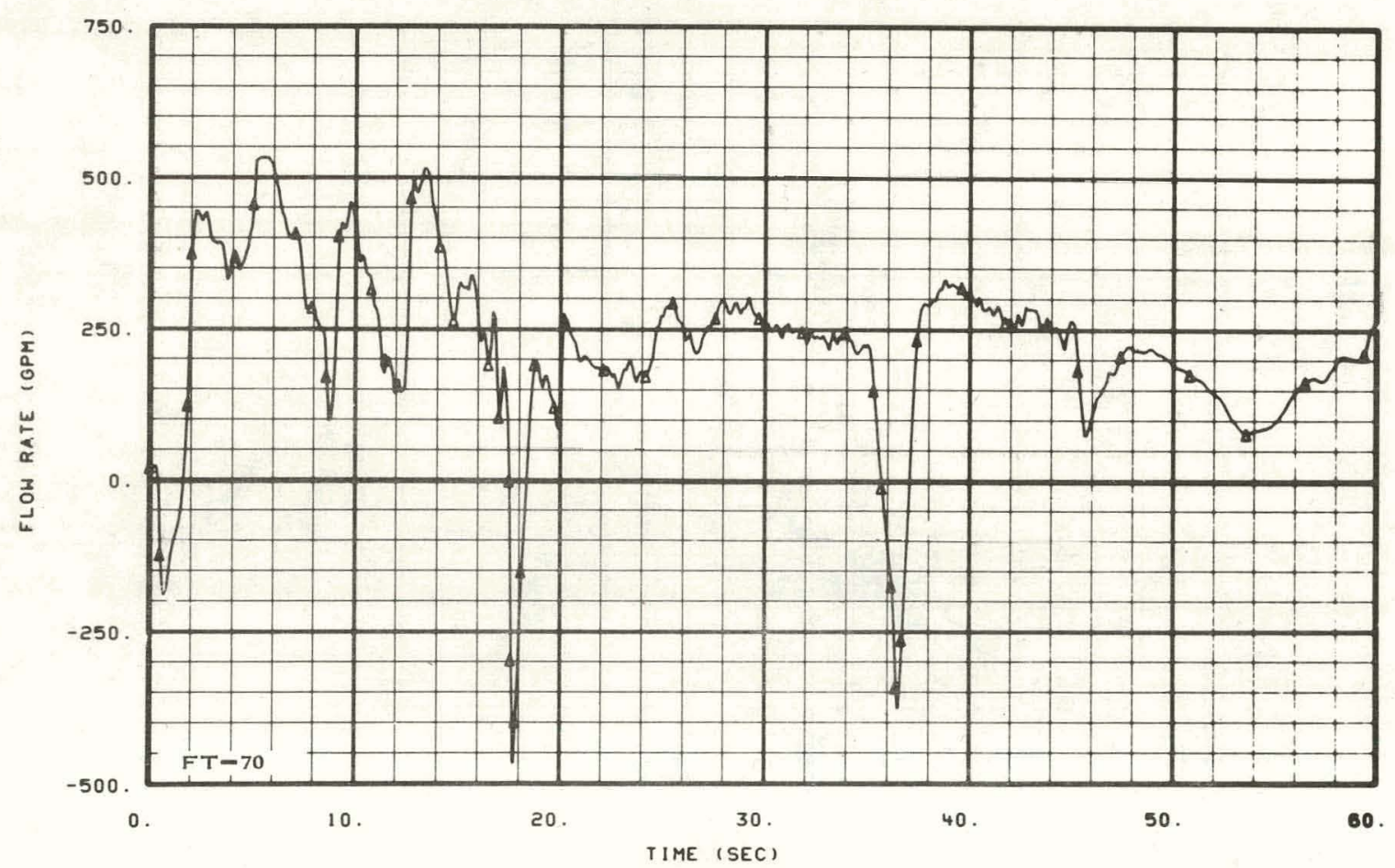

Fig. 113 Volumetric flow rate from turbine meter in blowdown loop hot leg -- Test 15.3 . 


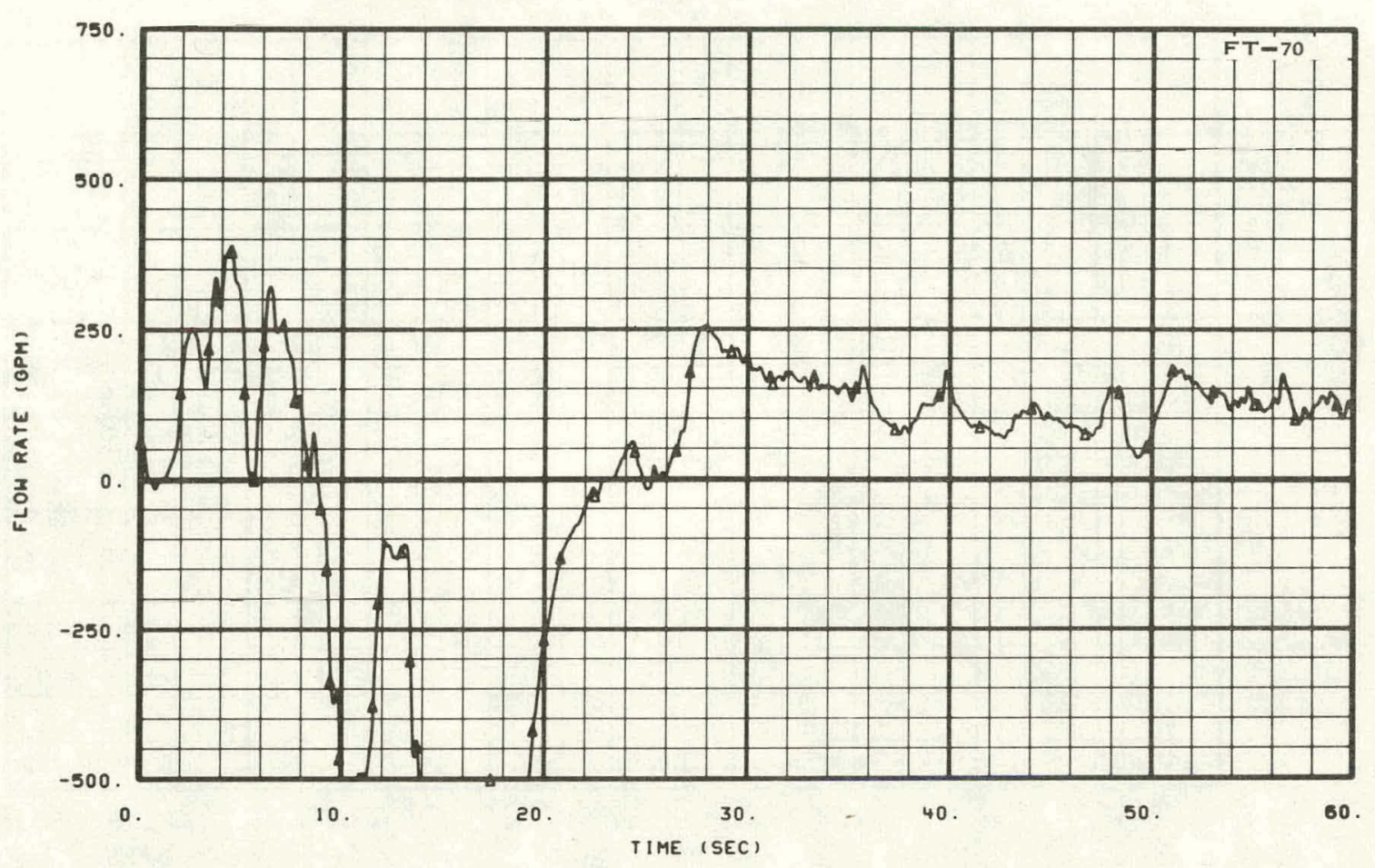

Fig. 114 Volumetric flow rate from turbine meter in blowdown loop hot leg -- Test 15.4.

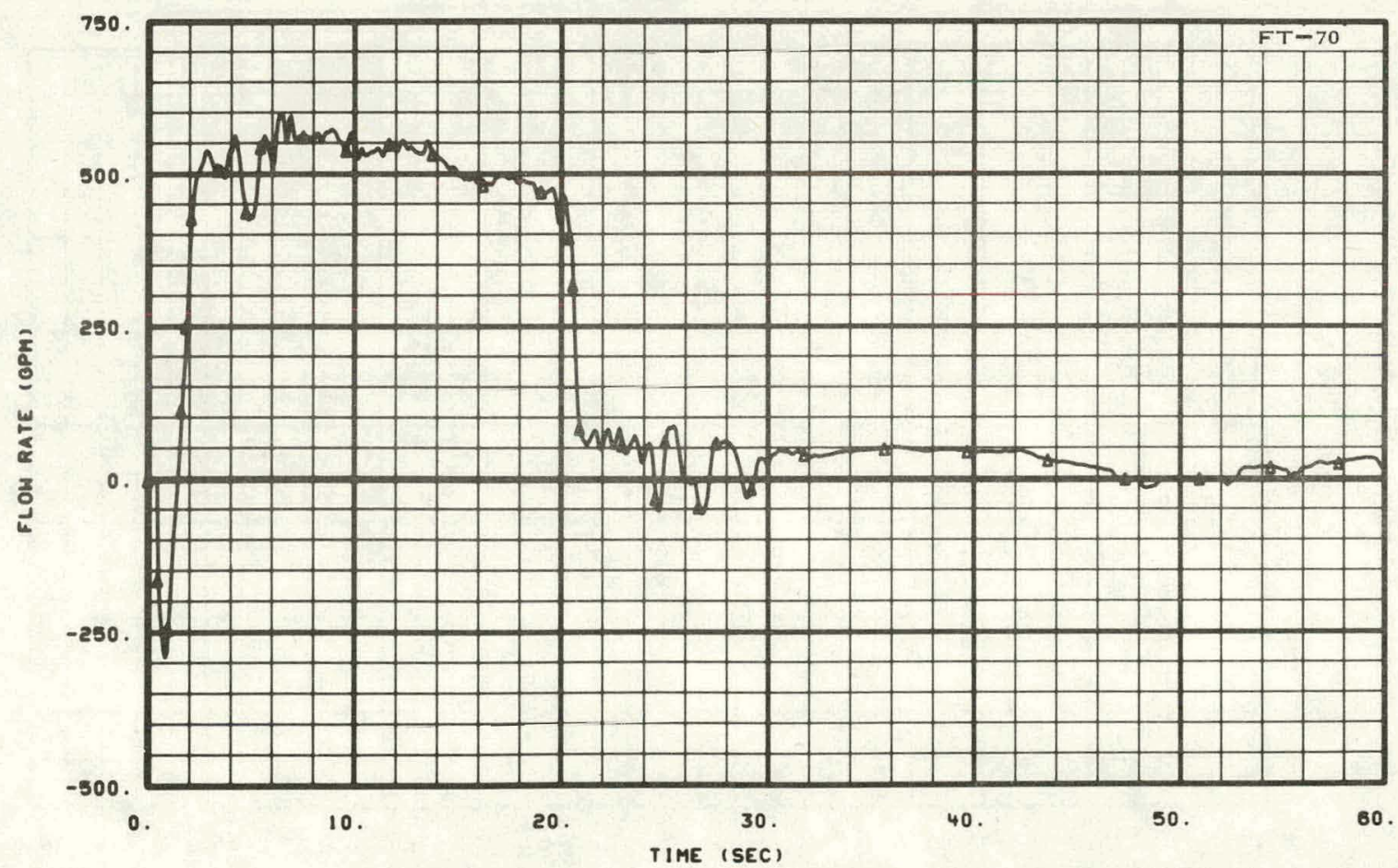

Fig. 115 Volumetric flow rate from turbine meter in blowdown loop hot leg -- Test 15.7 . 


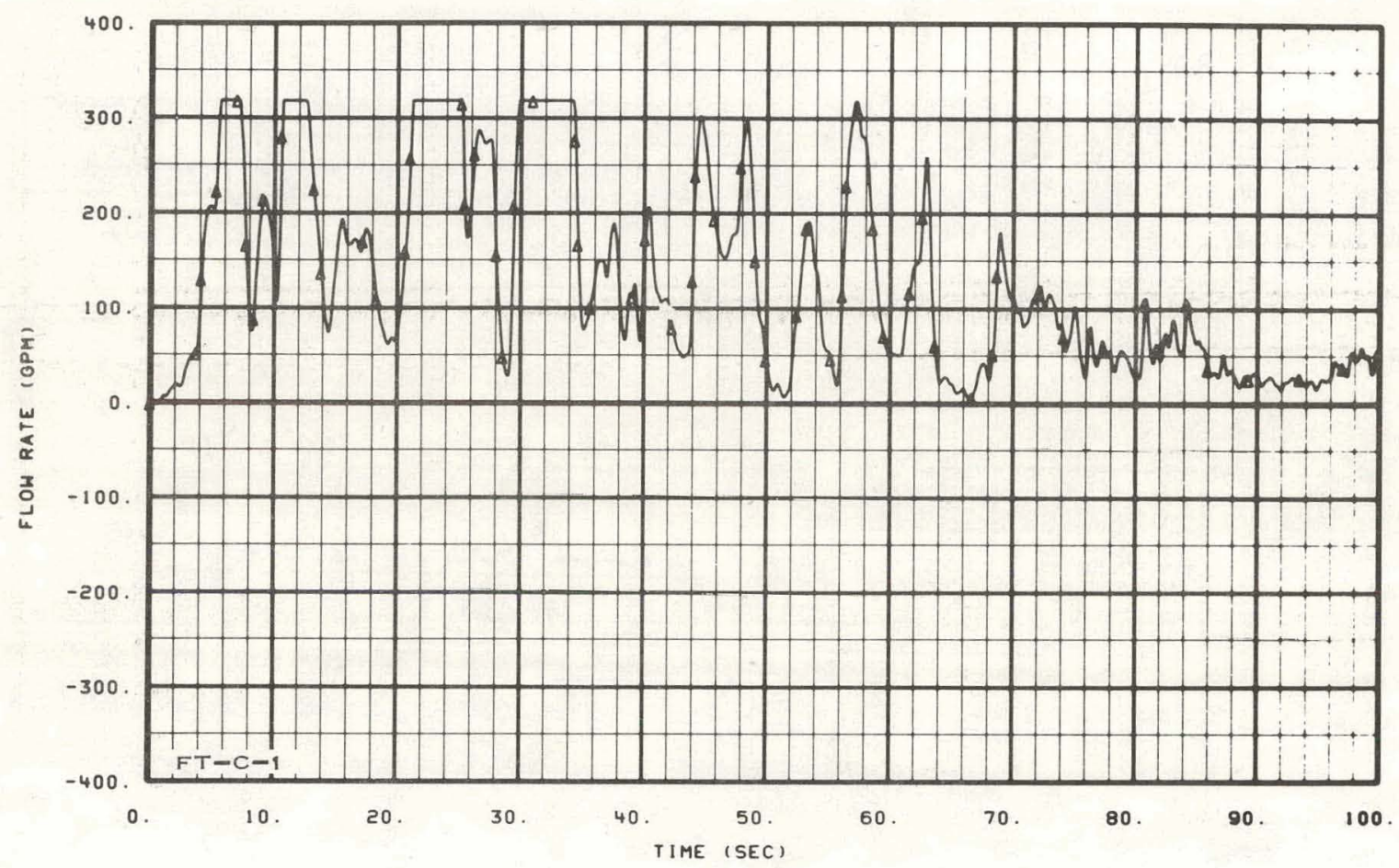

Fig. 116 Volumetric flow rate from turbine meter at core barrel inlet -Test 15.1.

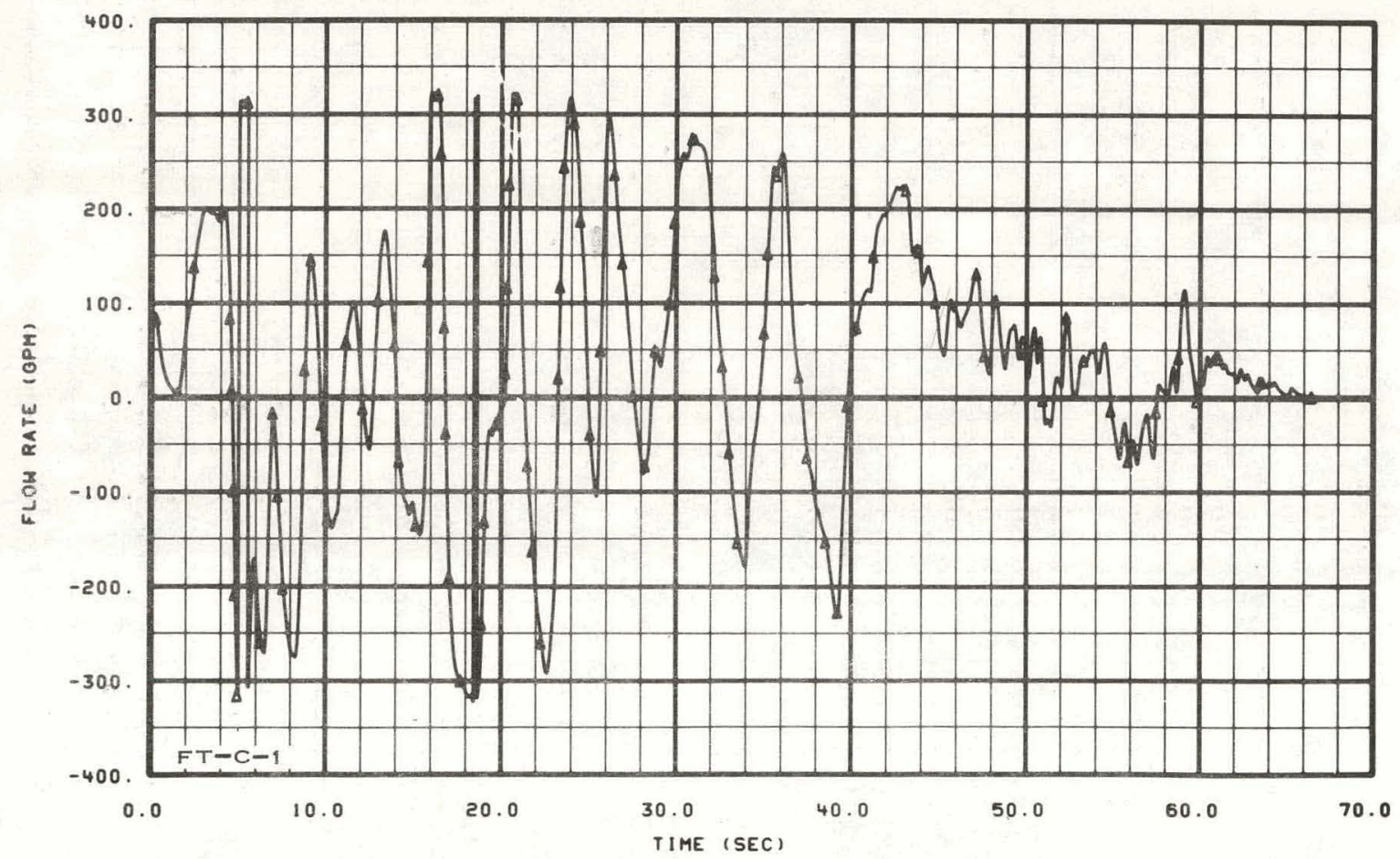

Fig. 117 Volumetric flow rate from turbine meter at core barrel inlet -Test 15.2. 


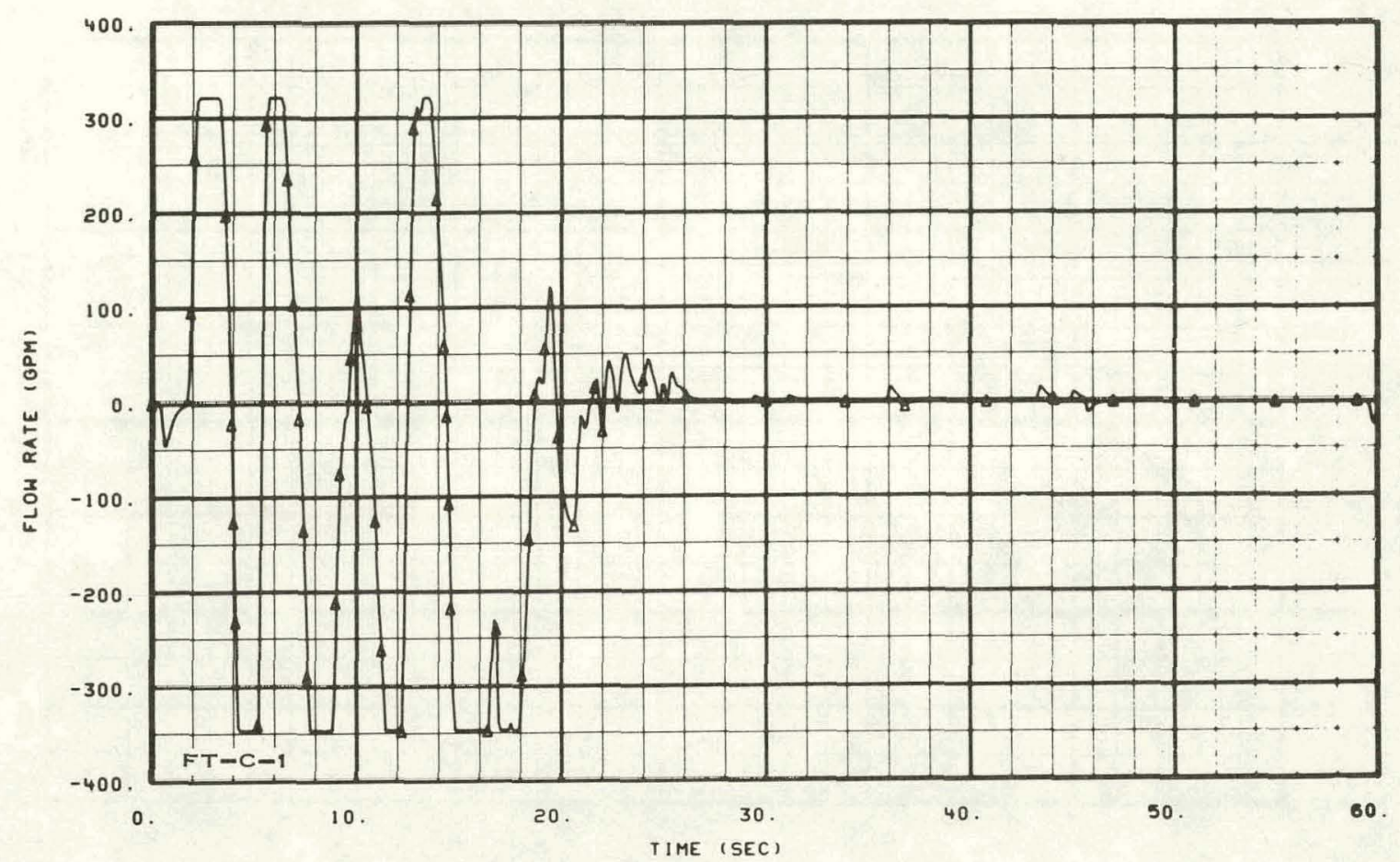

Fig. 118 Volumetric flow rate from turbine meter at core barrel inlet -Test 15.3 .

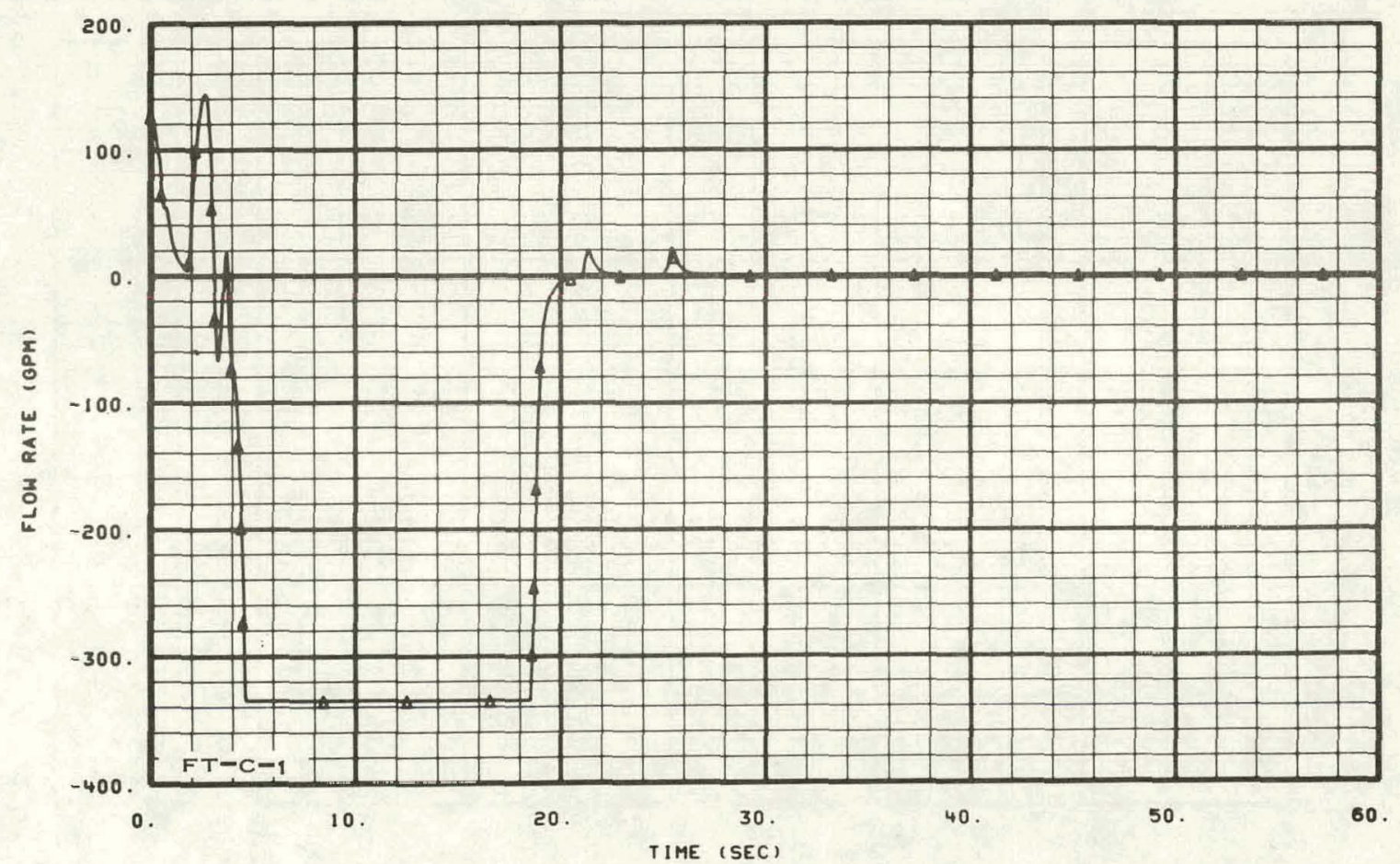

Fig. 119 Volumetric flow rate from turbine meter at core barrel inlet -Test 15.4 . 


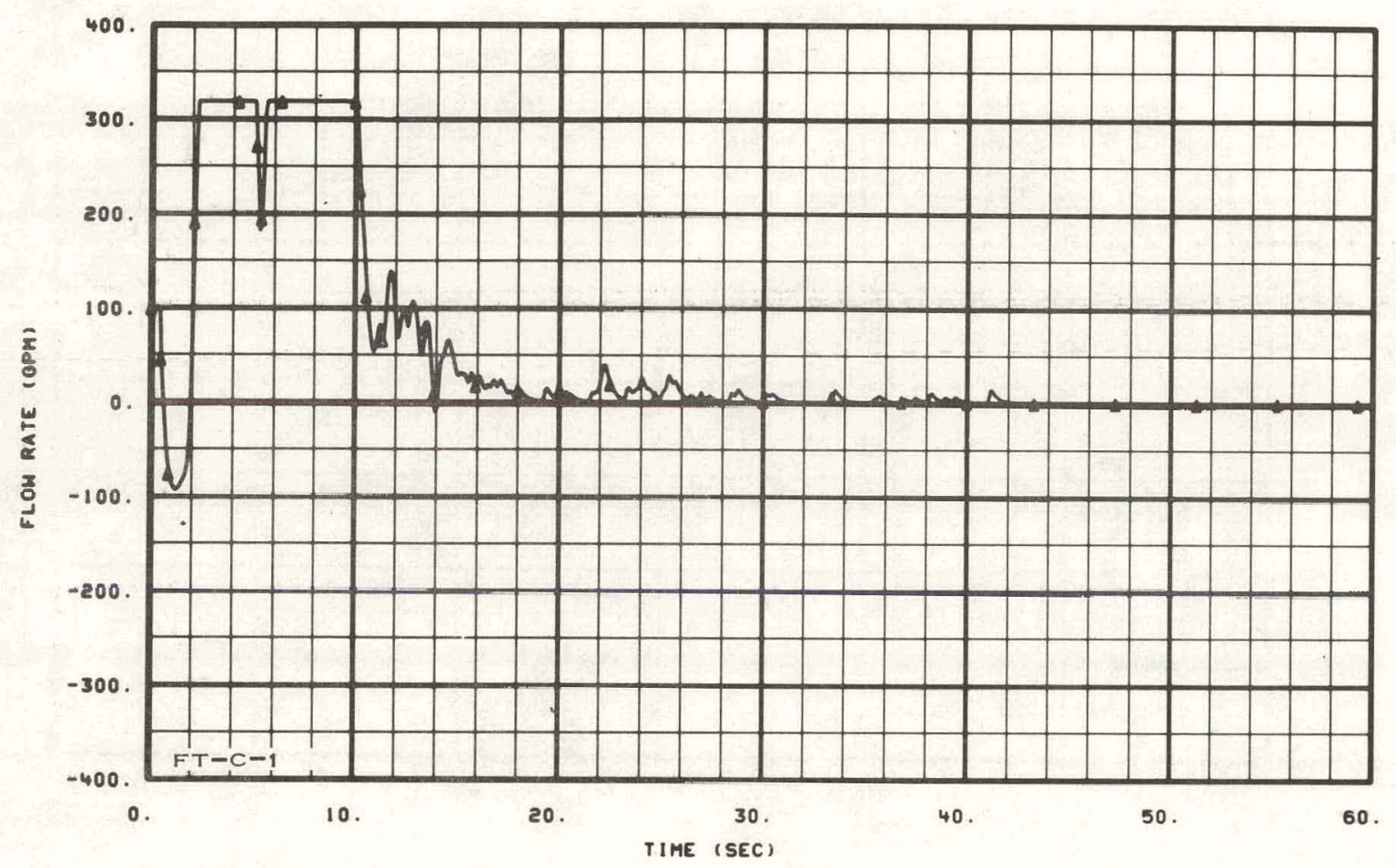

Fig. 120 Volumetric flow rate from turbine meter at core barrel inlet -Test 15.7 .

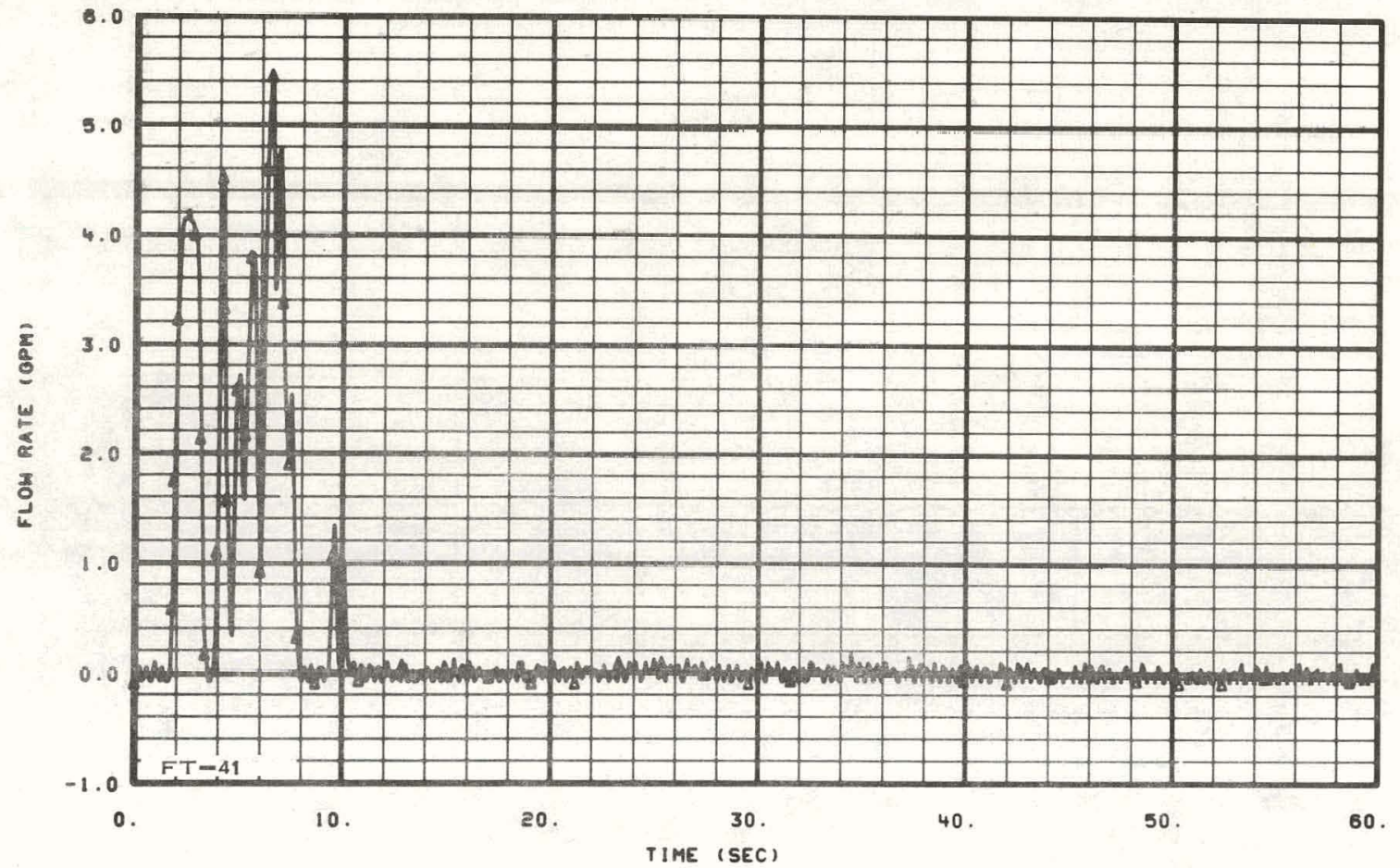

Fig. 121 Volumetric flow rate from turbine meter at pressurizer outlet -Test 15.7 . 


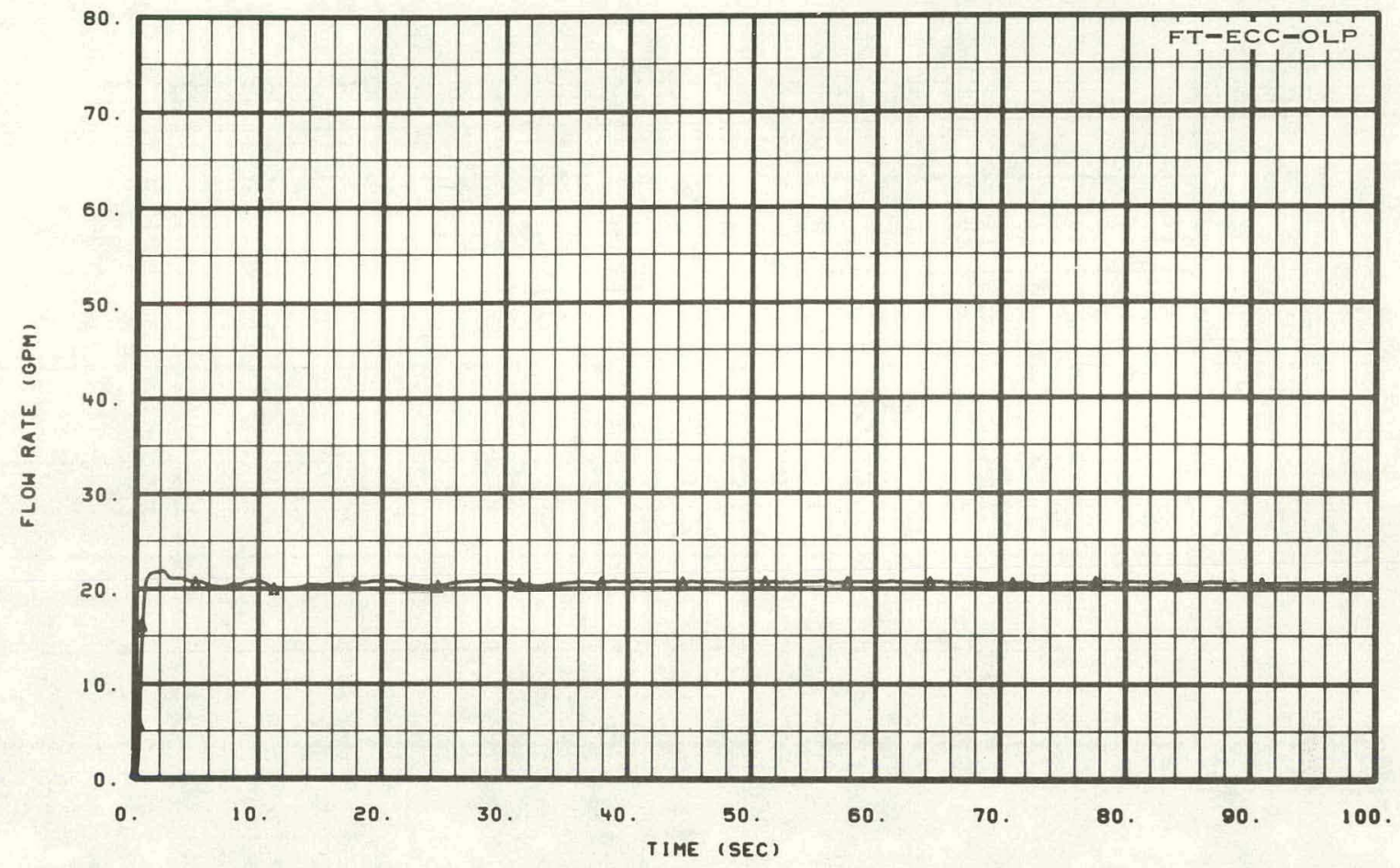

Fig. 122 Volumetric flow rate from ECC injection pumps in operating and blowdown loops (turbine meters) -- Test 15.1.

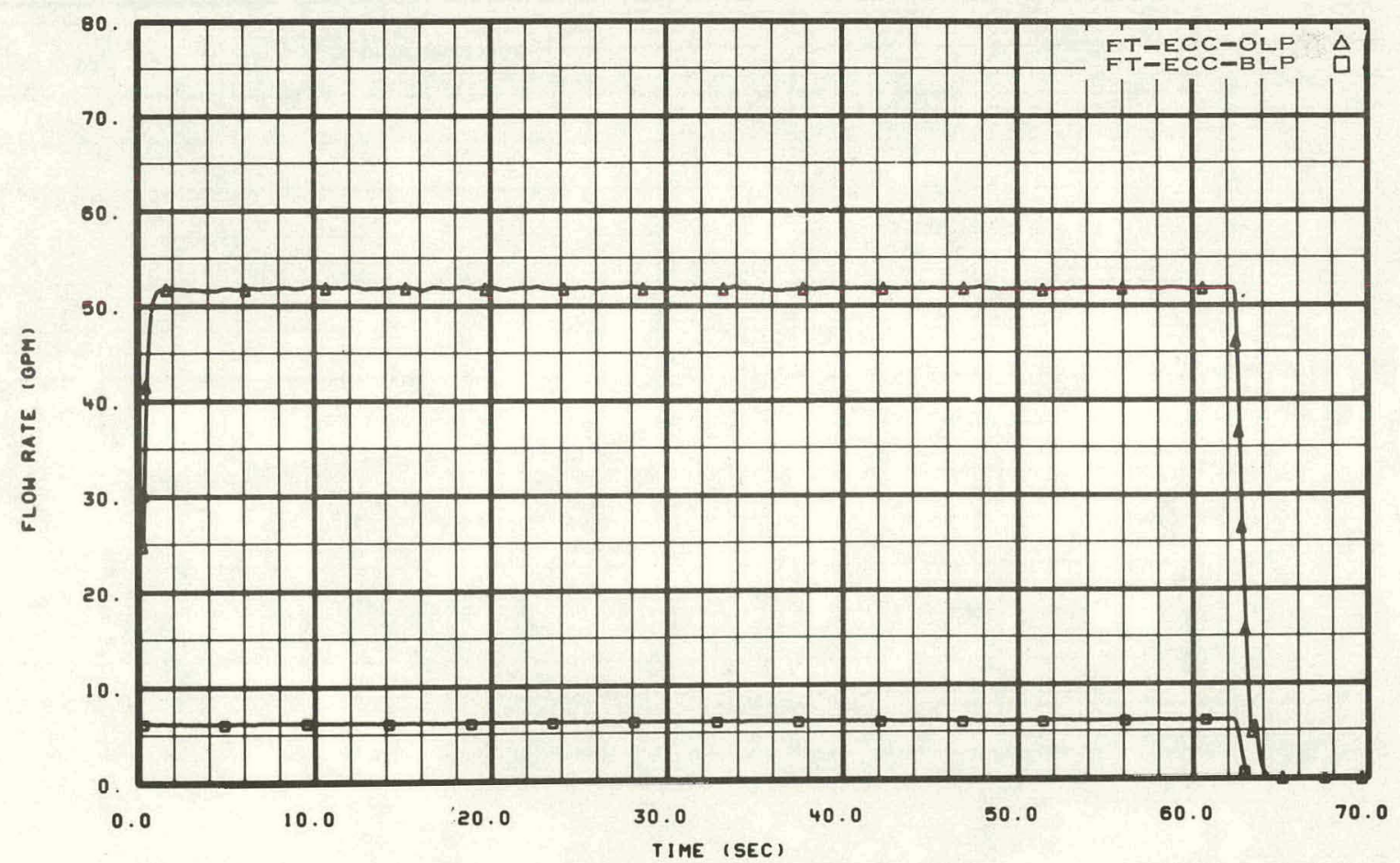

Fig. 123 Volumetric flow rate from ECC injection pumps in operating and blowdown loops (turbine meters) -- Test 15.2. 


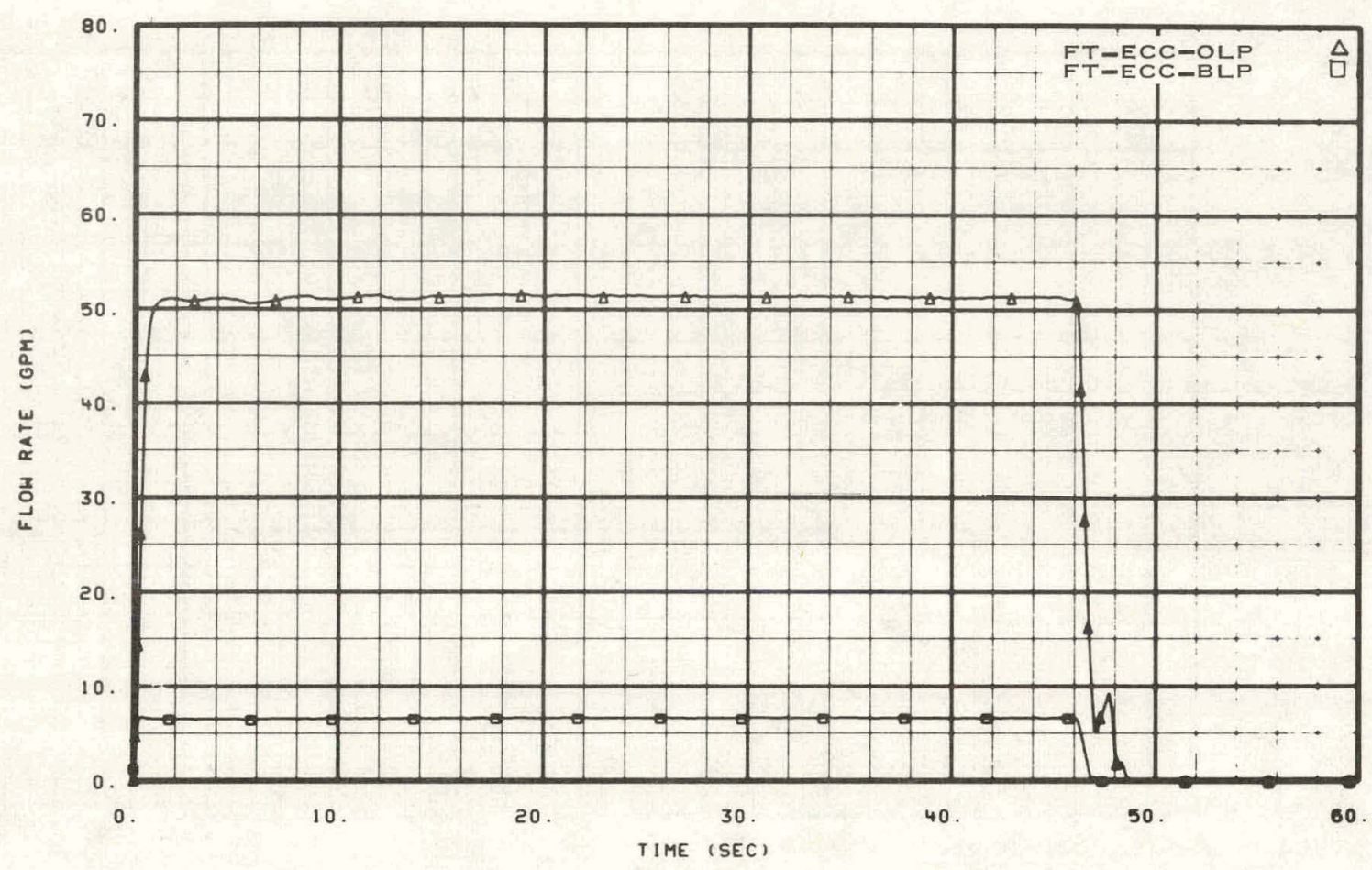

Fig. 124 Volumetric flow rate from ECC injection pumps in operating and blowdown loops (turbine meters) -- Test 15.3.

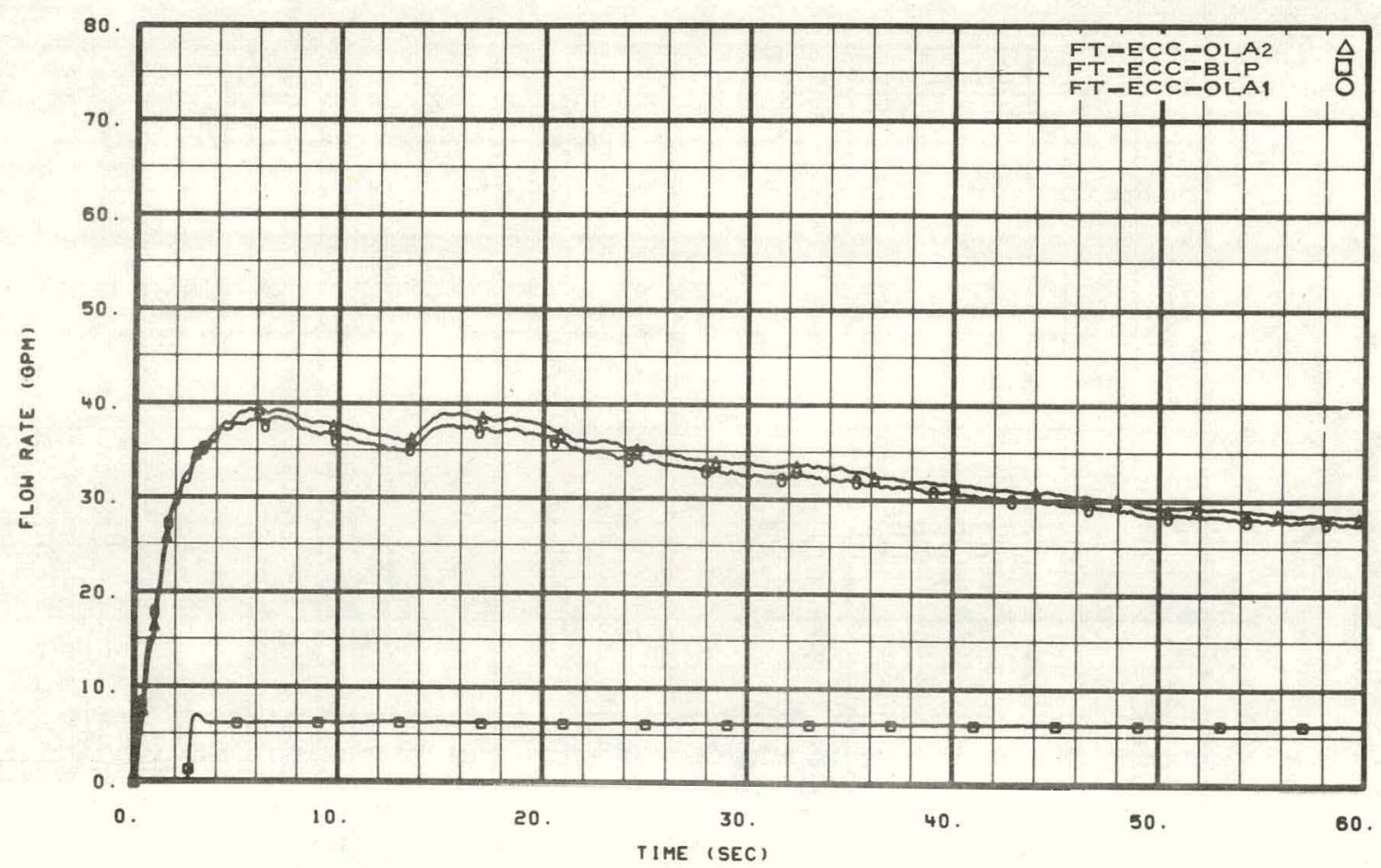

Fig. 125 Volumetric flow rate from ECC injection pump in blowdown loop and ECC accumulators in operating loop (turbine meters) -- Test 15.4. 


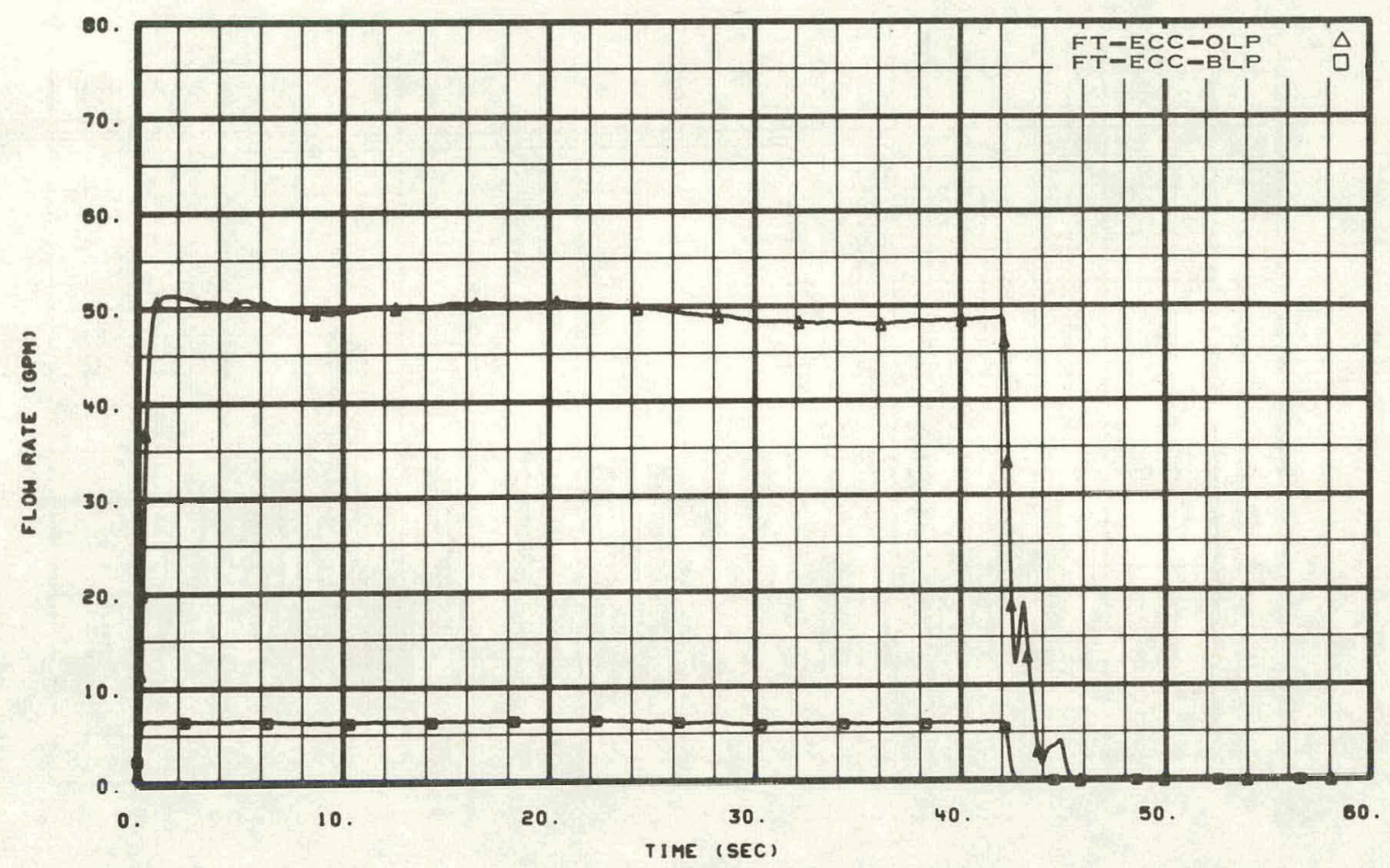

Fig. 126 Volumetric flow rate from ECC injection pumps in operating and blowdown loops (turbine meters) -- Test 15.7 .

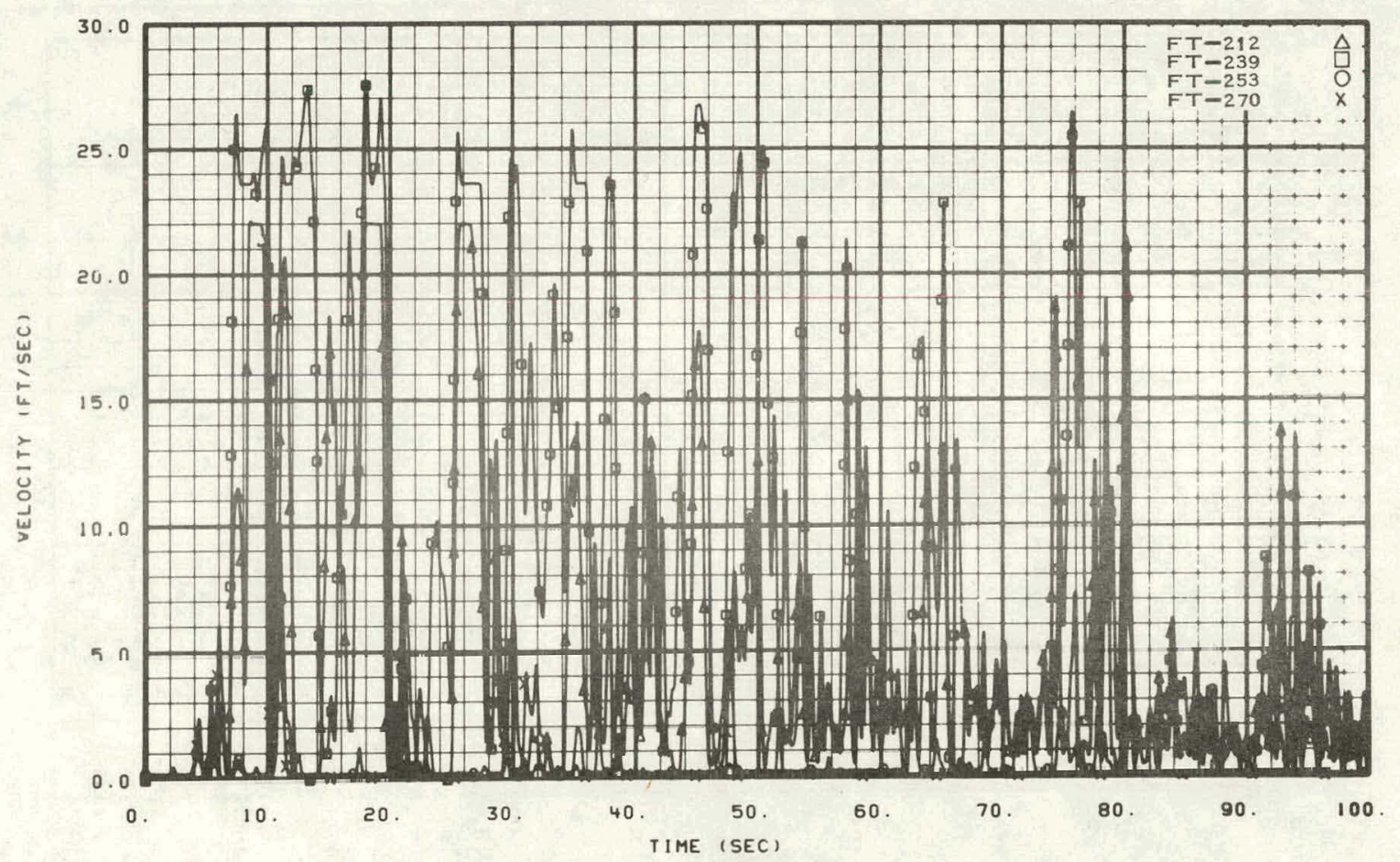

Fig. 127 Fluid velocity from turbine meters in downcomer gap -- Test 15.1. 


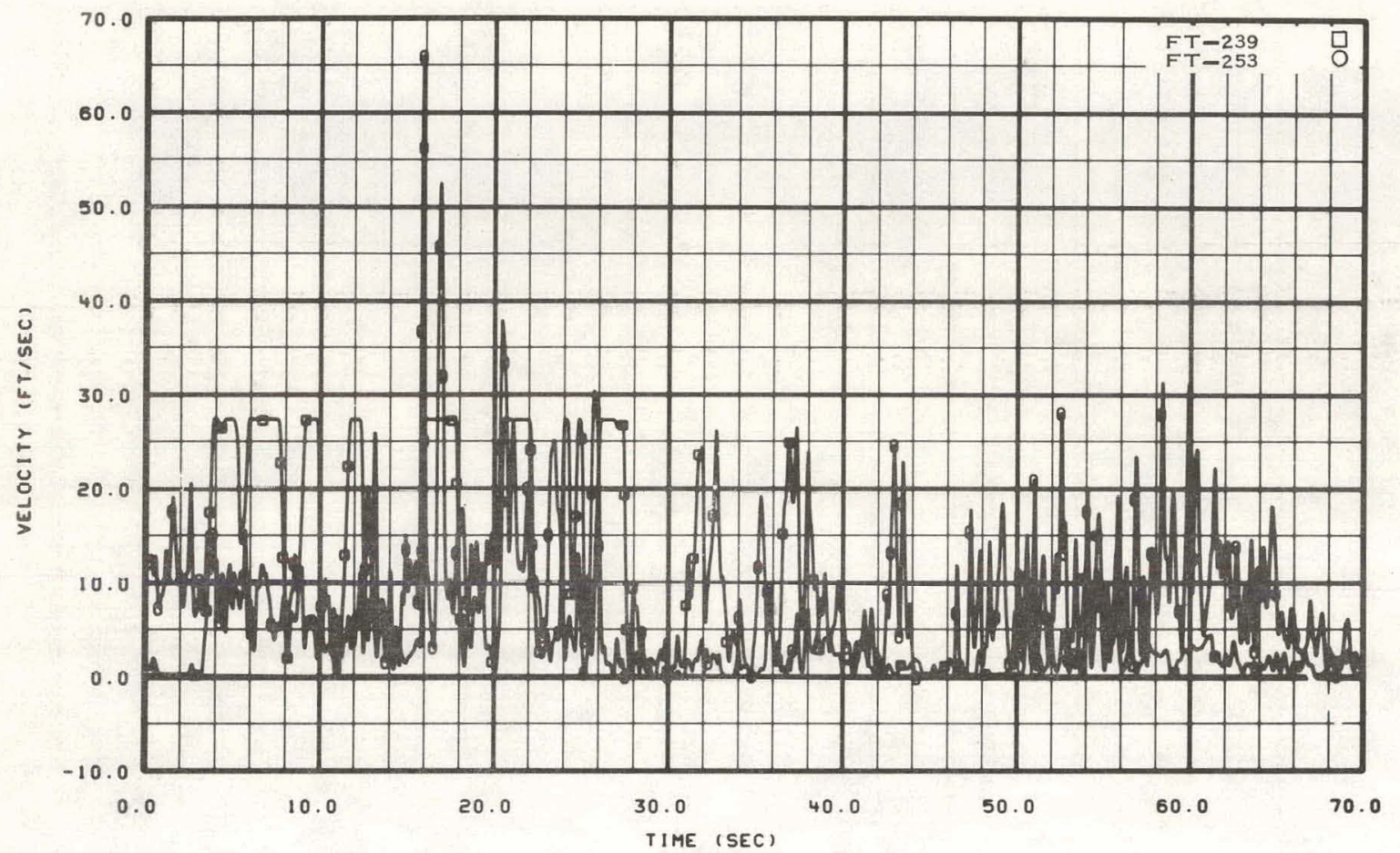

Fig. 128 Fluid velocity from turbine meters in downcomer gap -- Test 15.2.

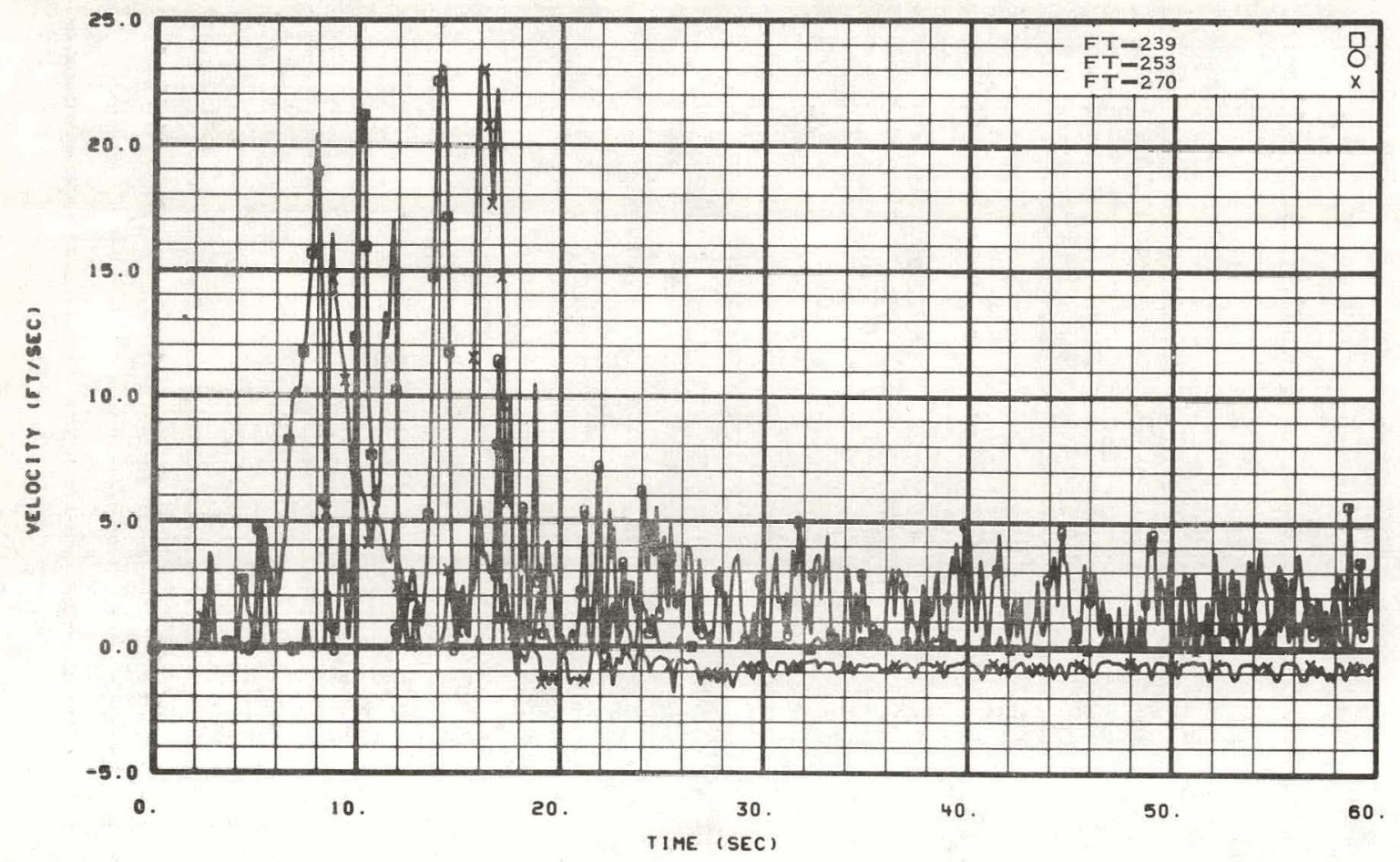

Fig. 129 Fluid velocity from turbine meters in downcomer gap -- Test 15.3. 


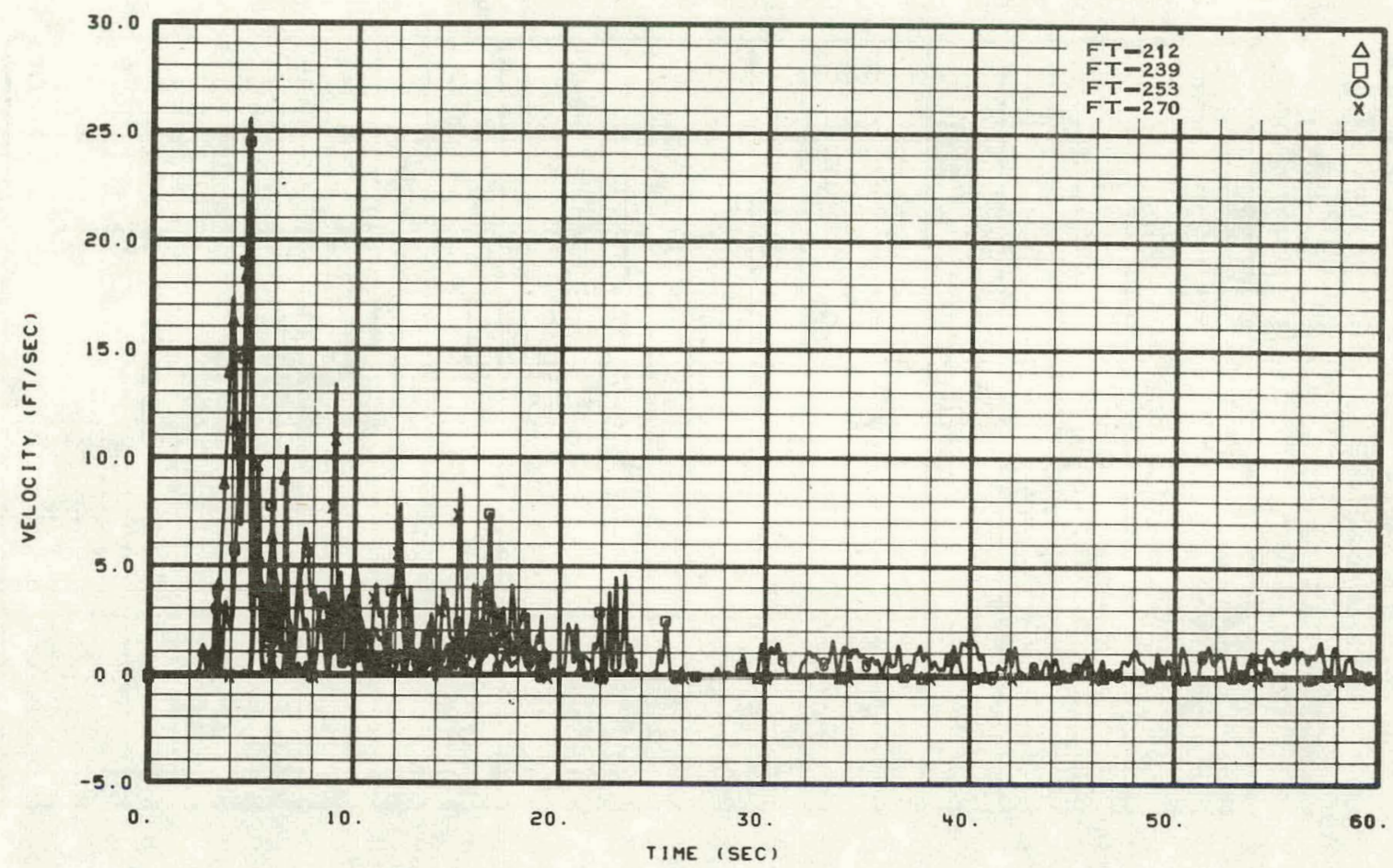

Fig. 130 Fluid velocity from turbine meters in downcomer gap -- Test 15.4 .

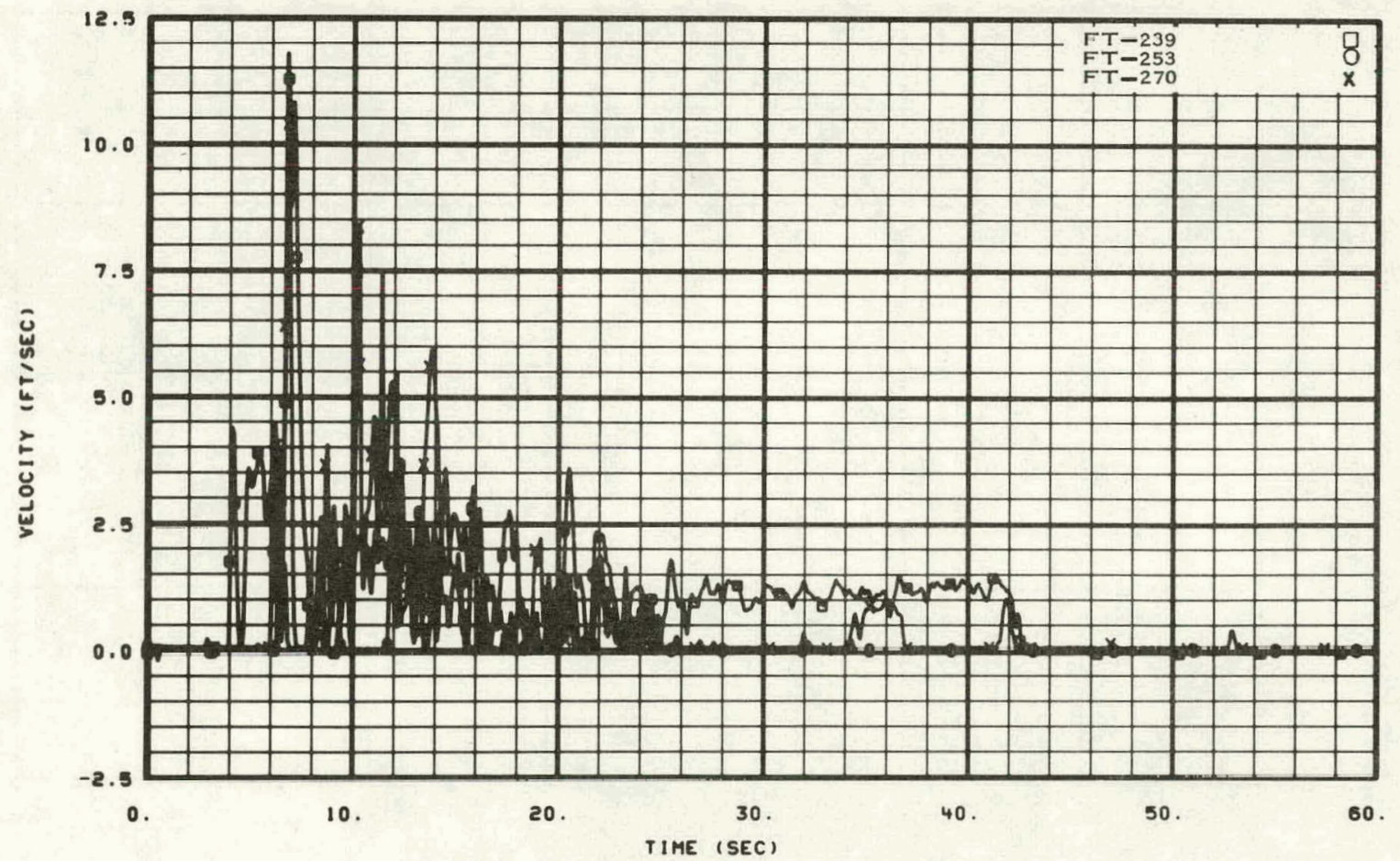

Fig. 131 Fluid velocity from turbine meters in downcomer gap -- Test 15.7. 


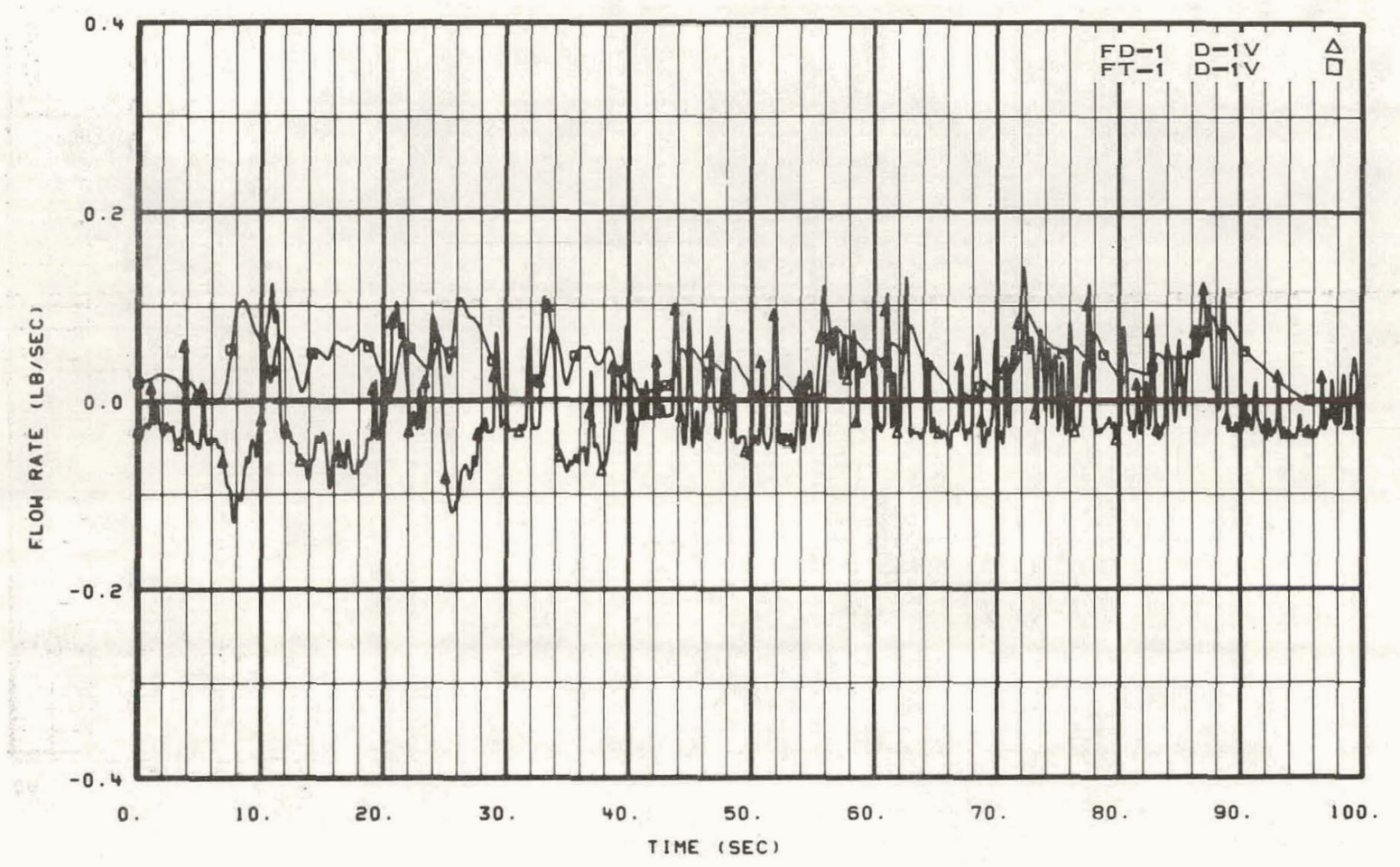

Fig. 132 Mass flow rate in operating loop hot leg Spool 1 -- Test 15.1.

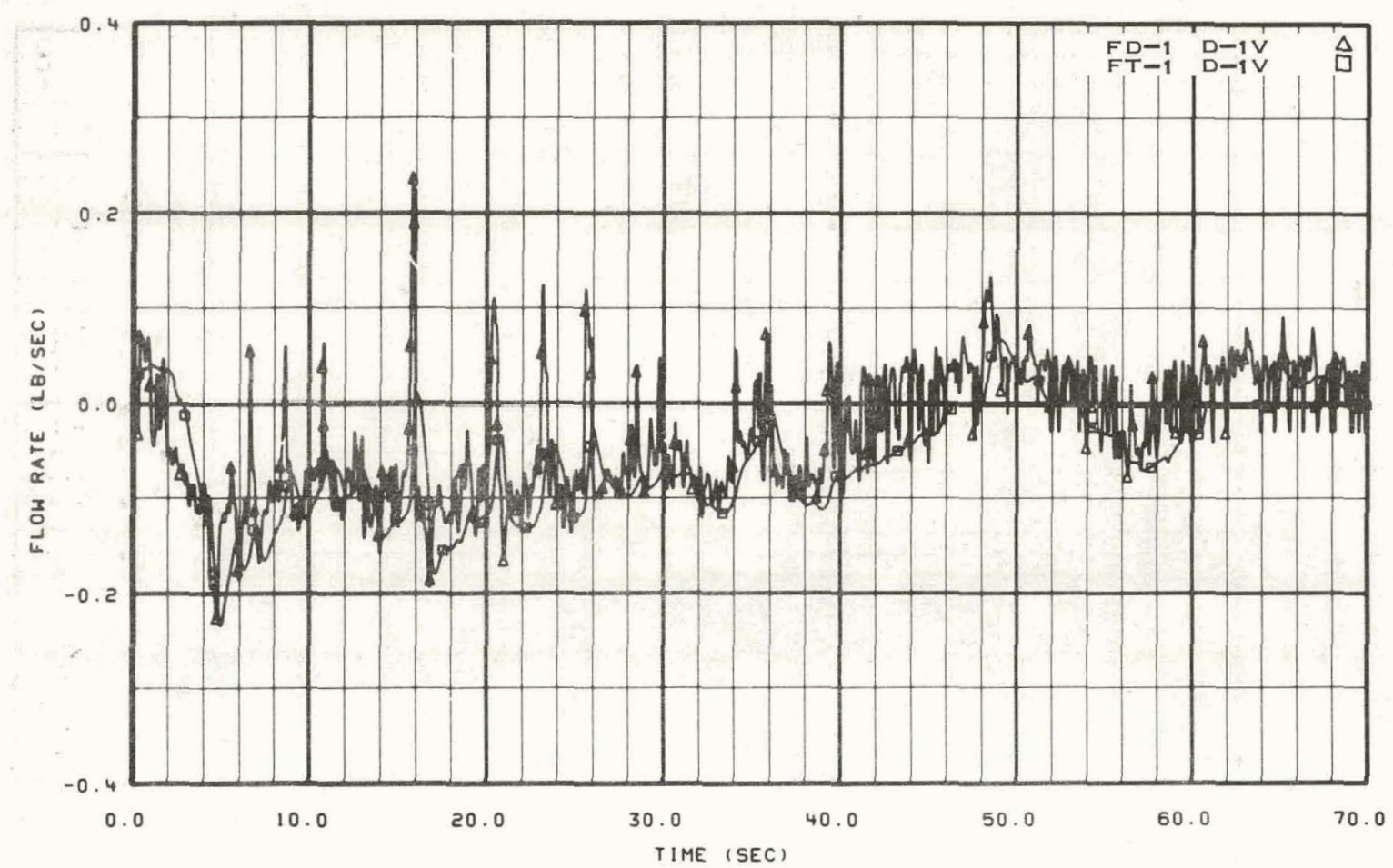

Fig. 133 Mass flow rate in operating loop hot leg Spool 1 -- Test 15.2. 


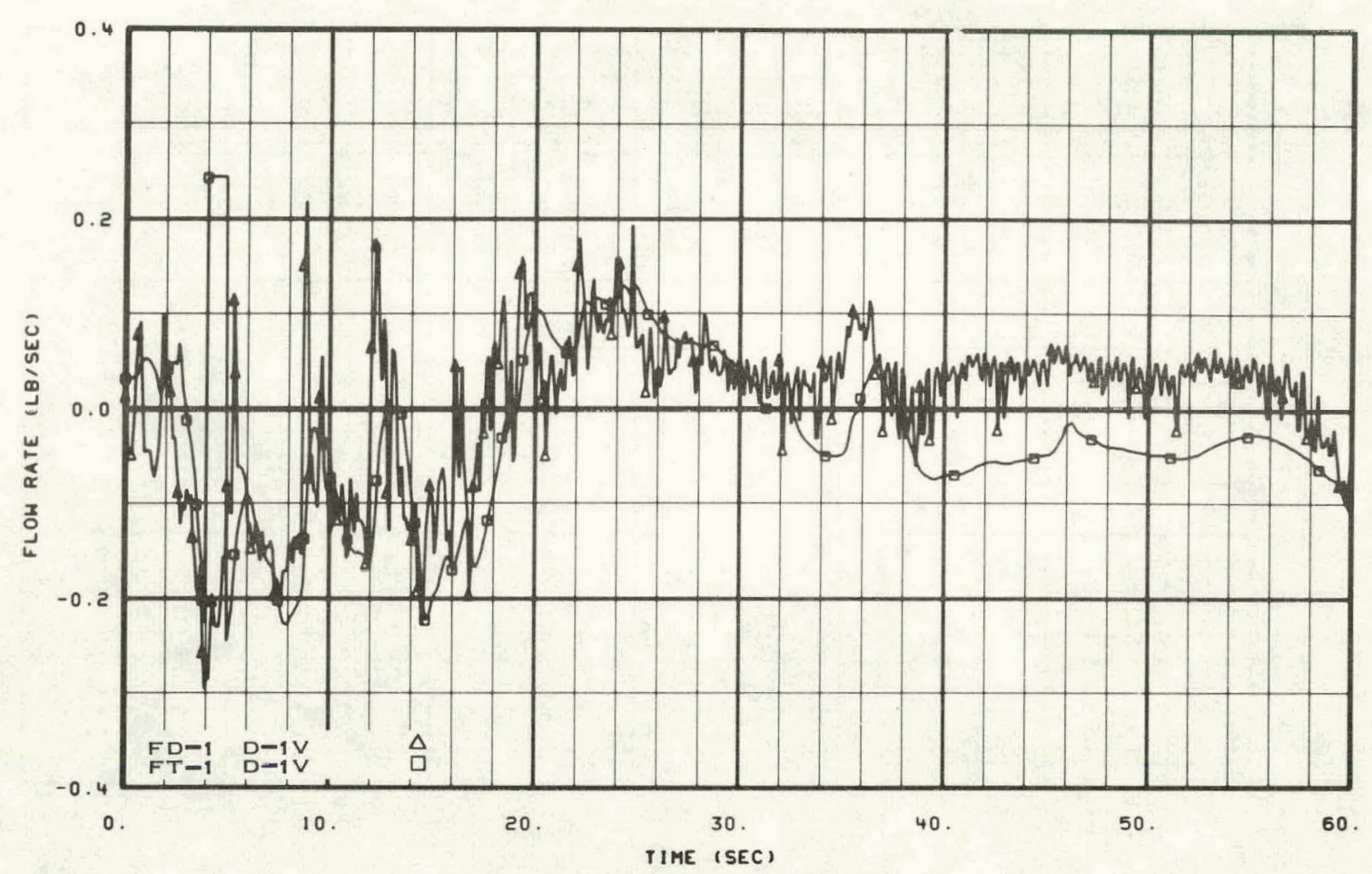

Fig. 134 Mass flow rate in operating loop hot leg Spool 1 -- Test 15.3.

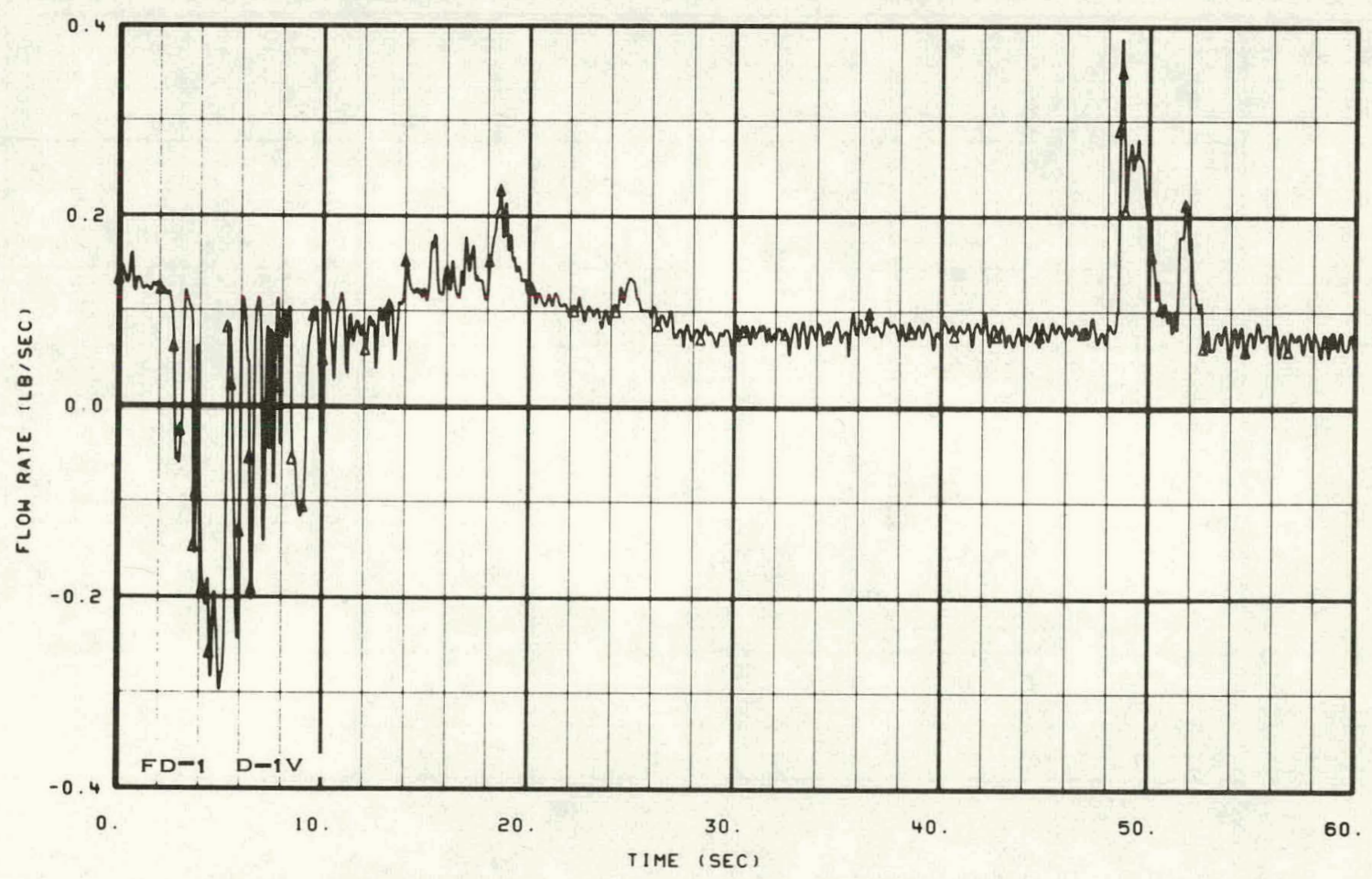

Fig. 135 Mass flow rate in operating loop hot leg Spoo1 1 -- Test 15.4. 


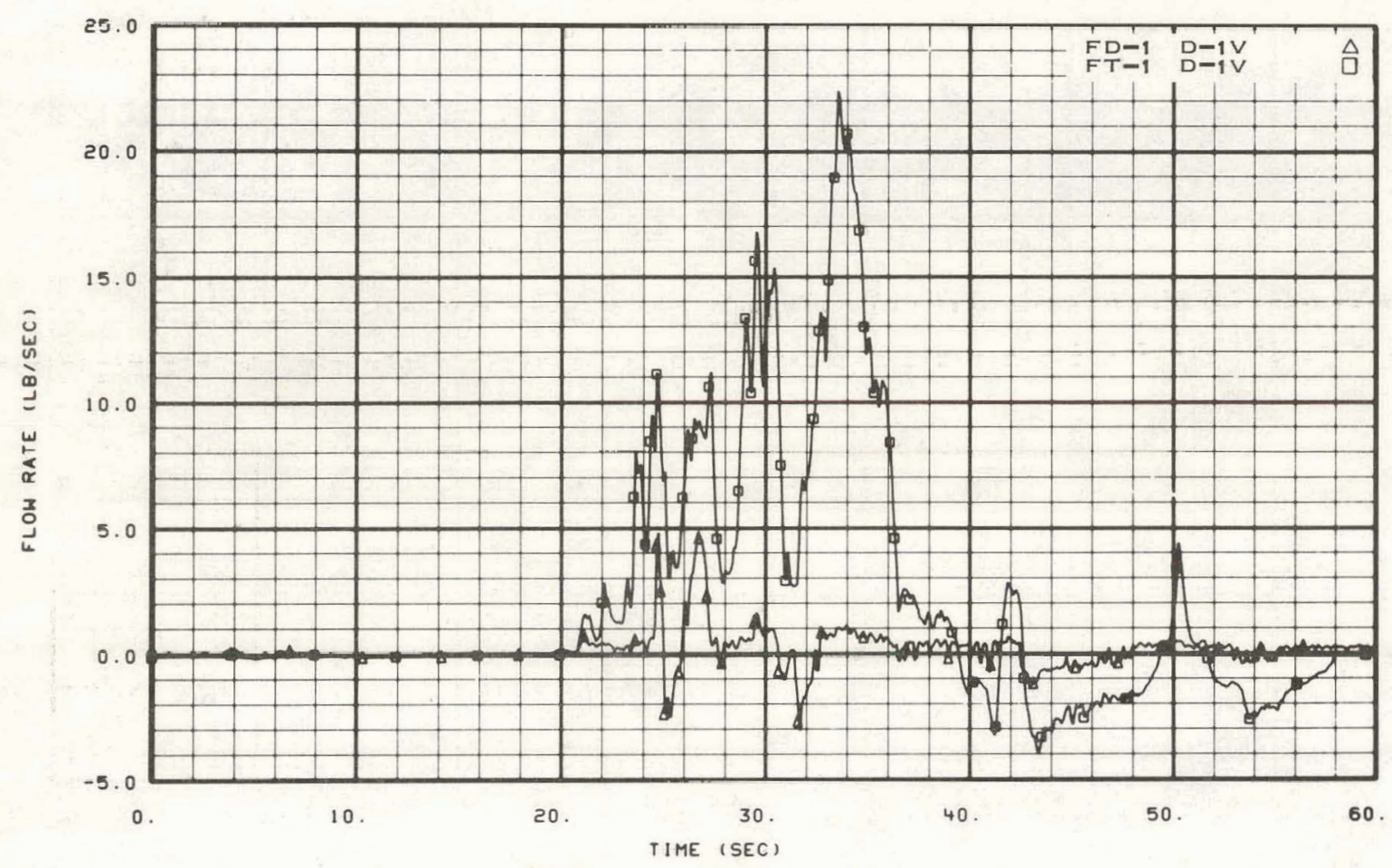

Fig. 136 Mass flow rate in operating loop hot leg Spool 1 -- Test 15.7.

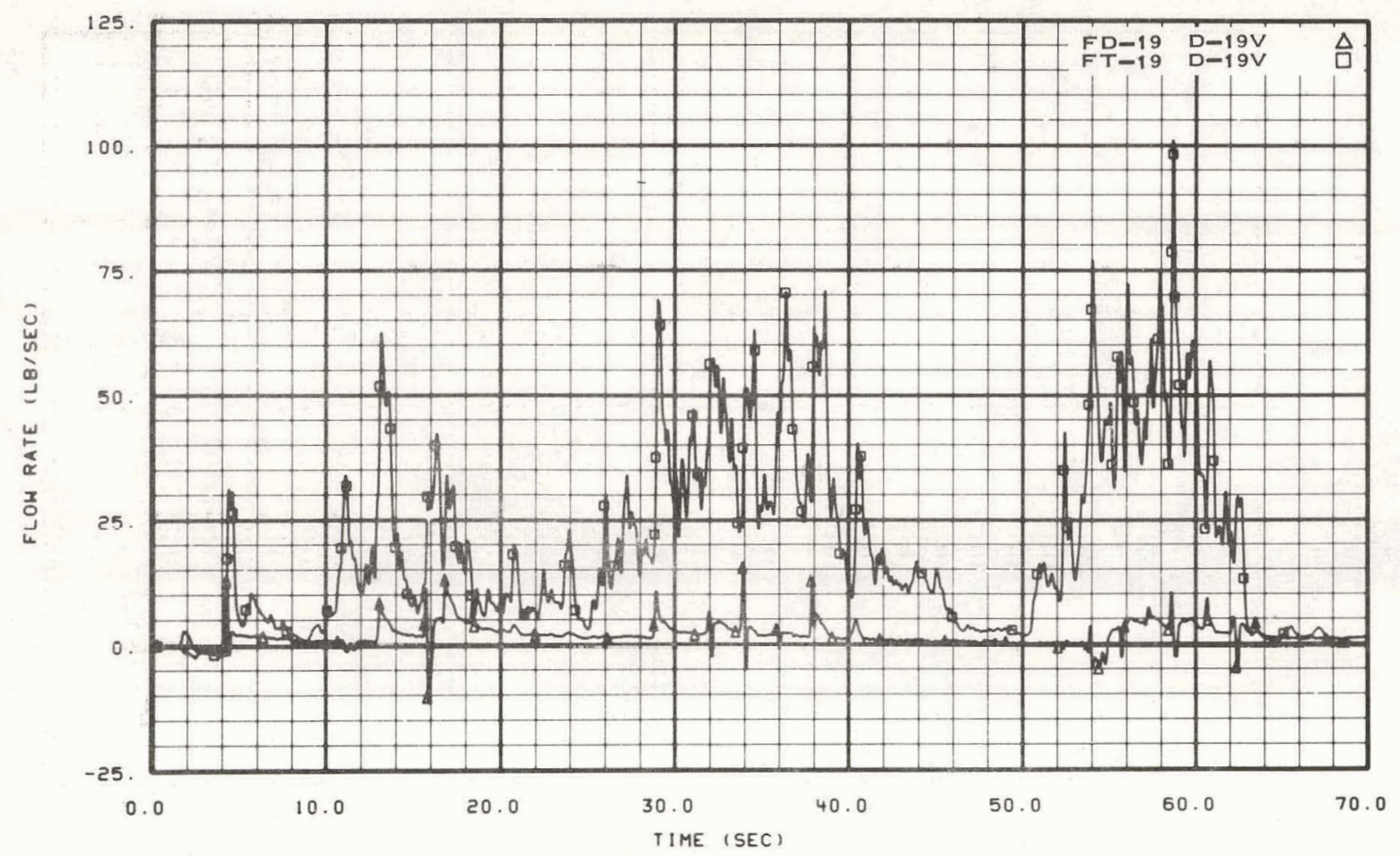

Fig. 137 Mass flow rate in operating loop at pump discharge (Spool 19) -Test 15.2 . 


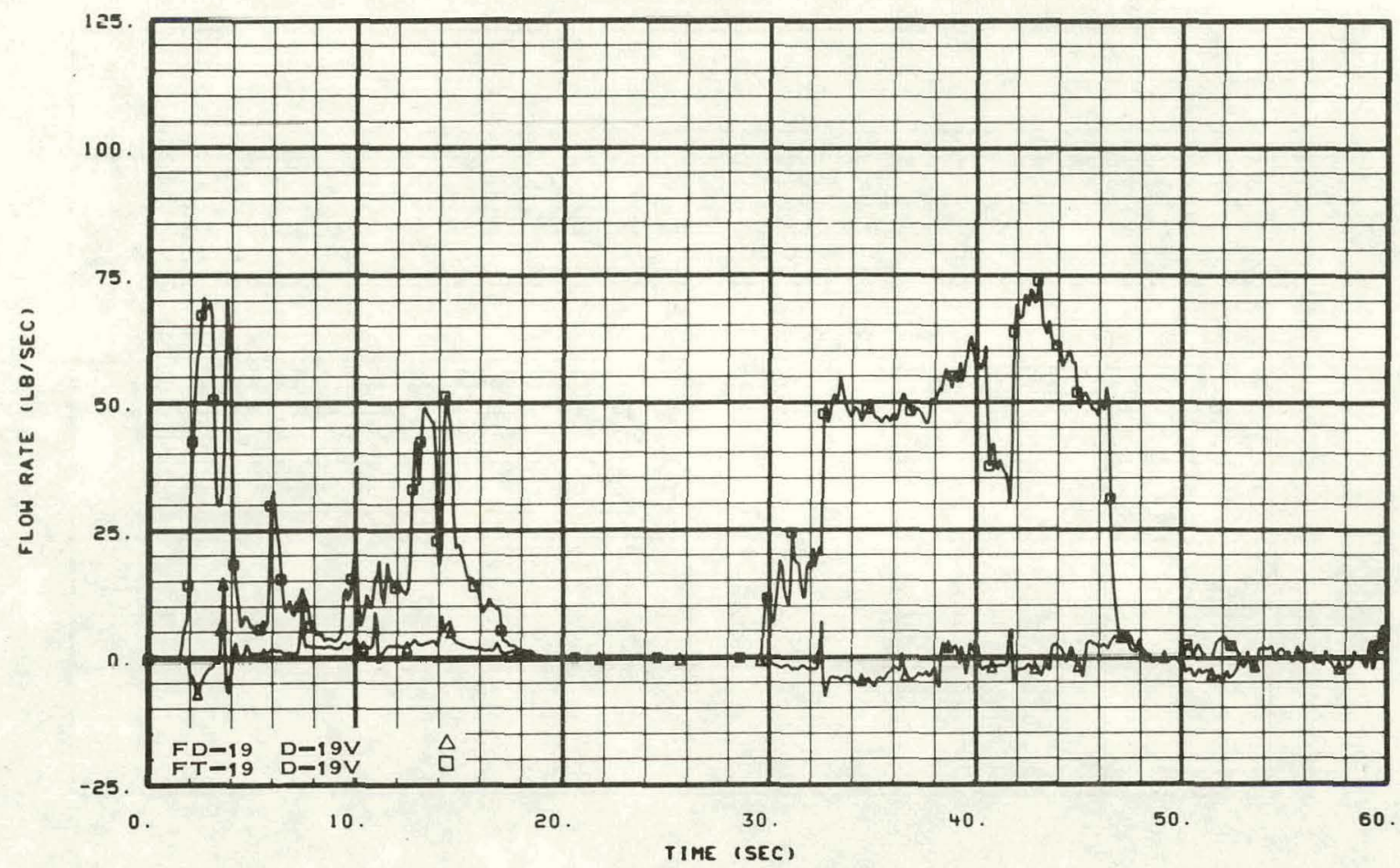

Fig. 138 Mass flow rate in operating loop at pump discharge (Spoo1 19) -Test 15.3 .

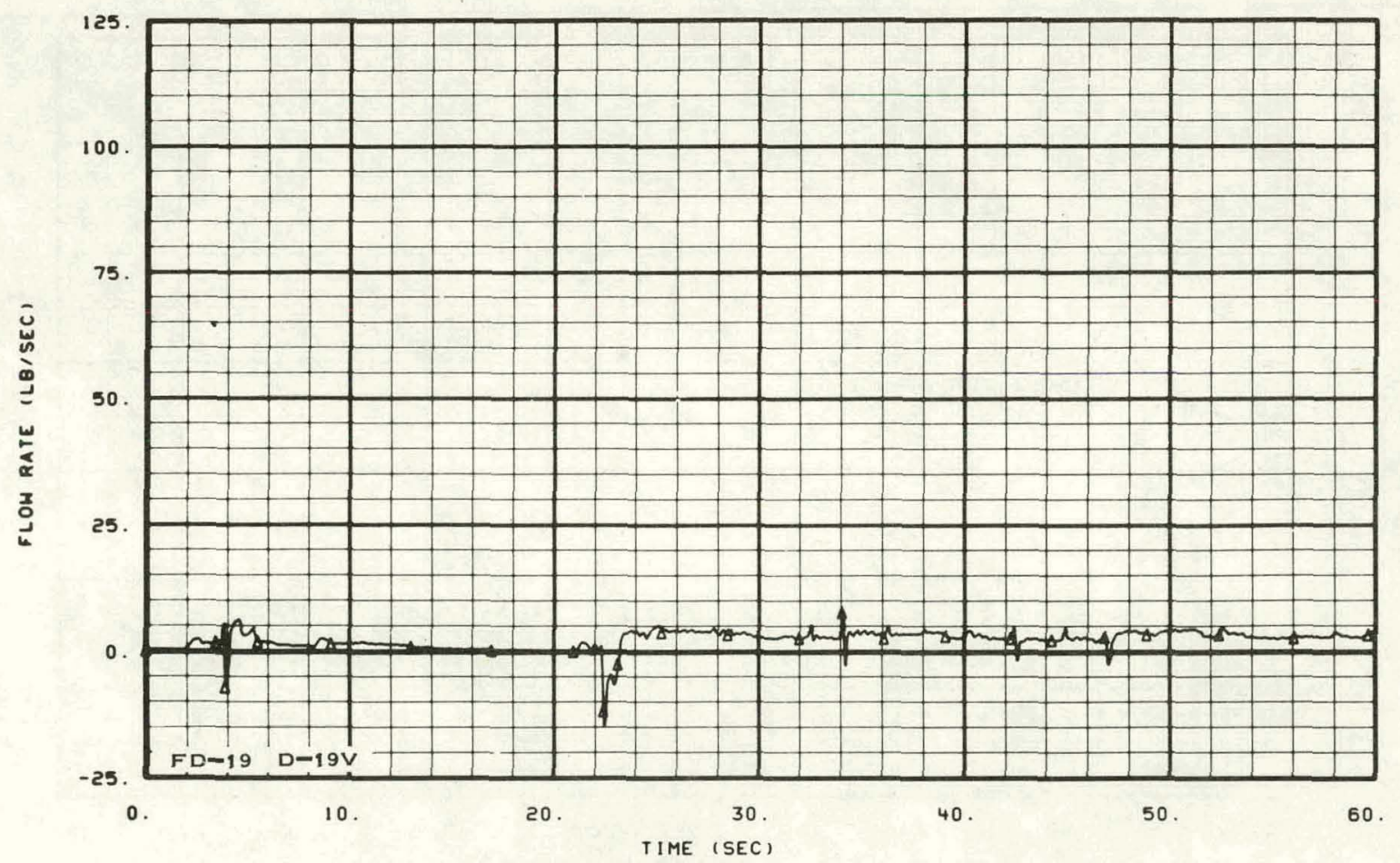

Fig. 139 Mass flow rate in operating loop at pump discharge (Spool 19) -Test 15.4 . 


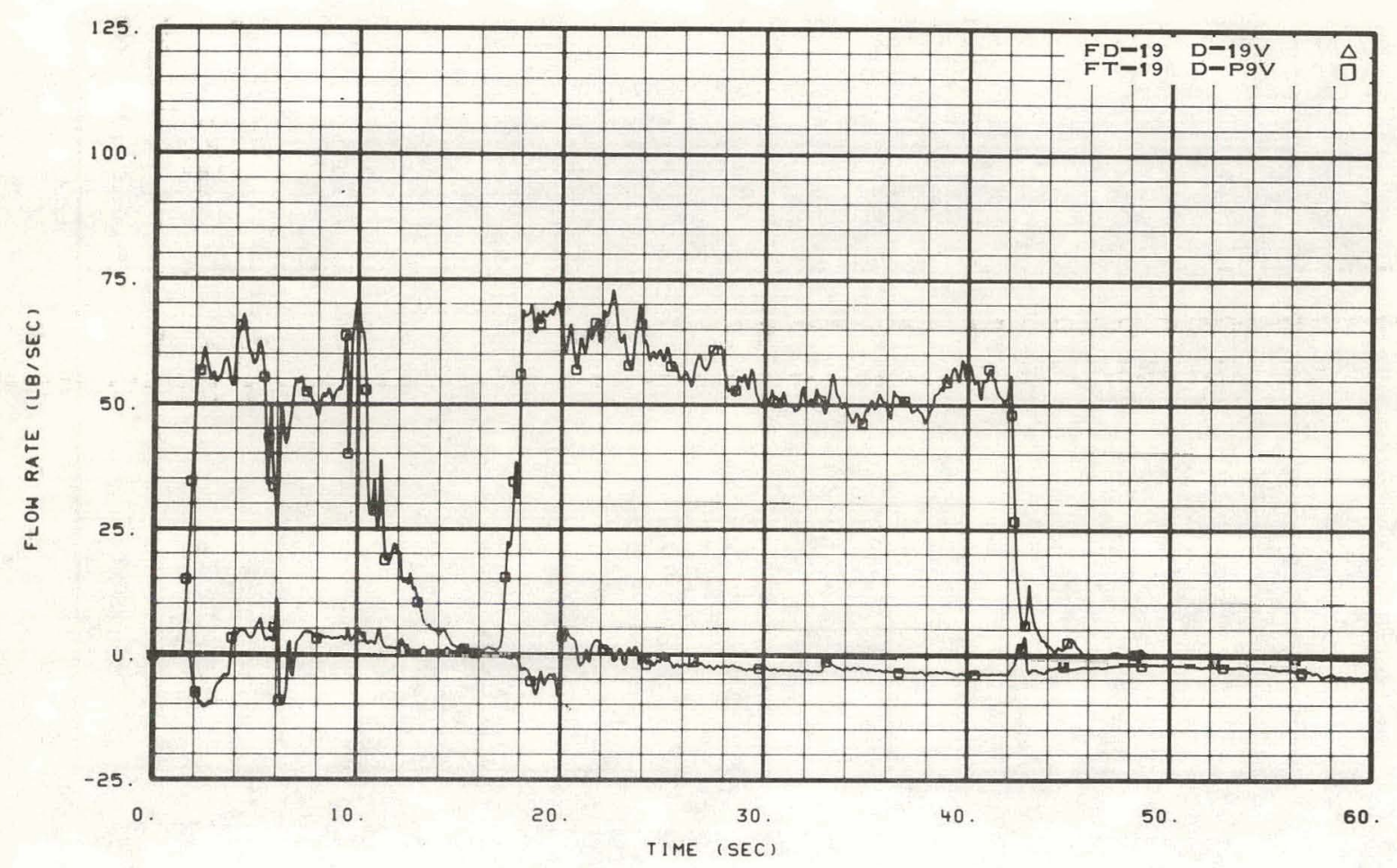

Fig. 140 Mass flow rate in operating loop at pump discharge (Spool 1.9) -Test 15.7 .

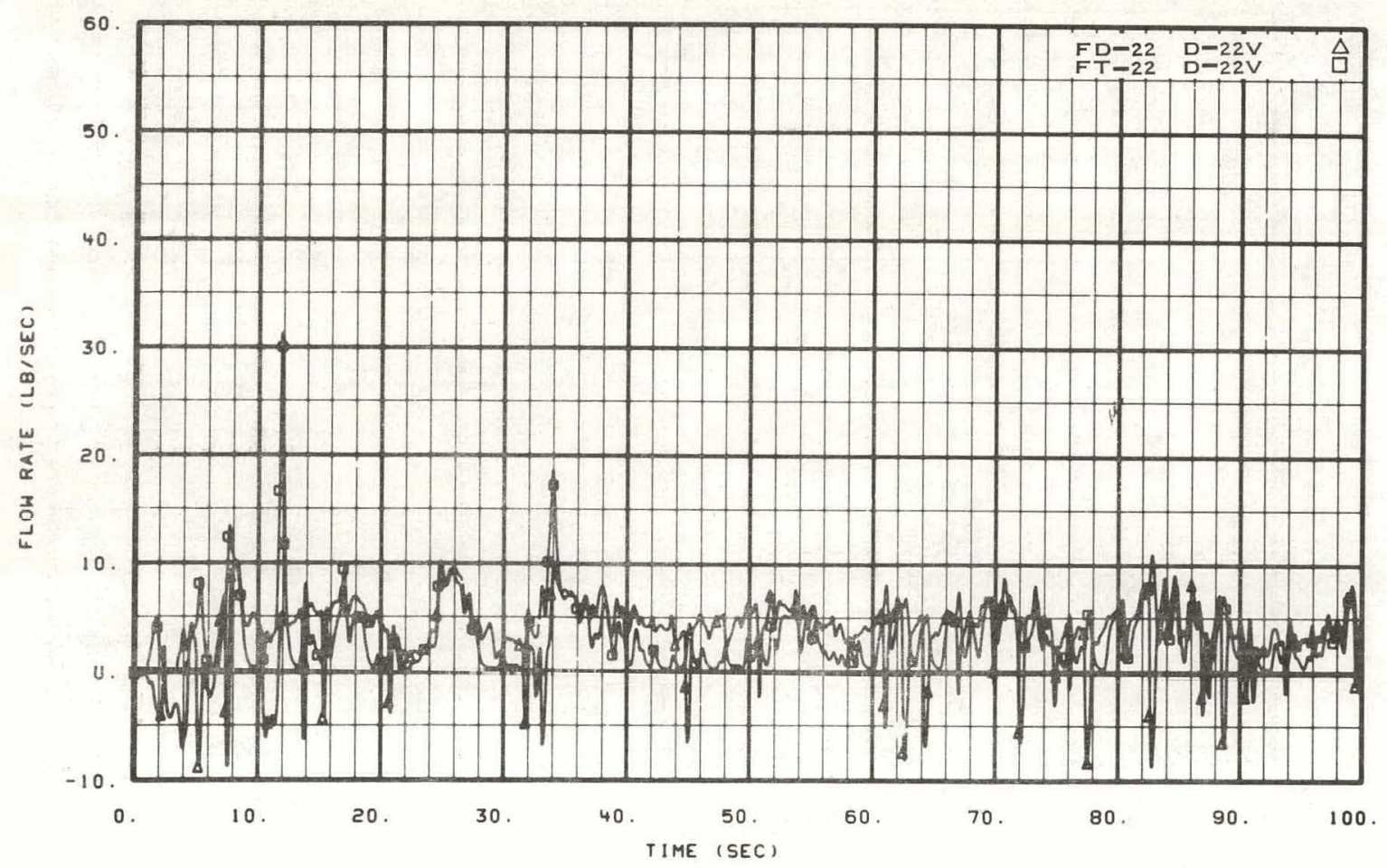

Fig. 141 Mass flow rate in operating loop cold leg Spool 22 -- Test 15.1. 


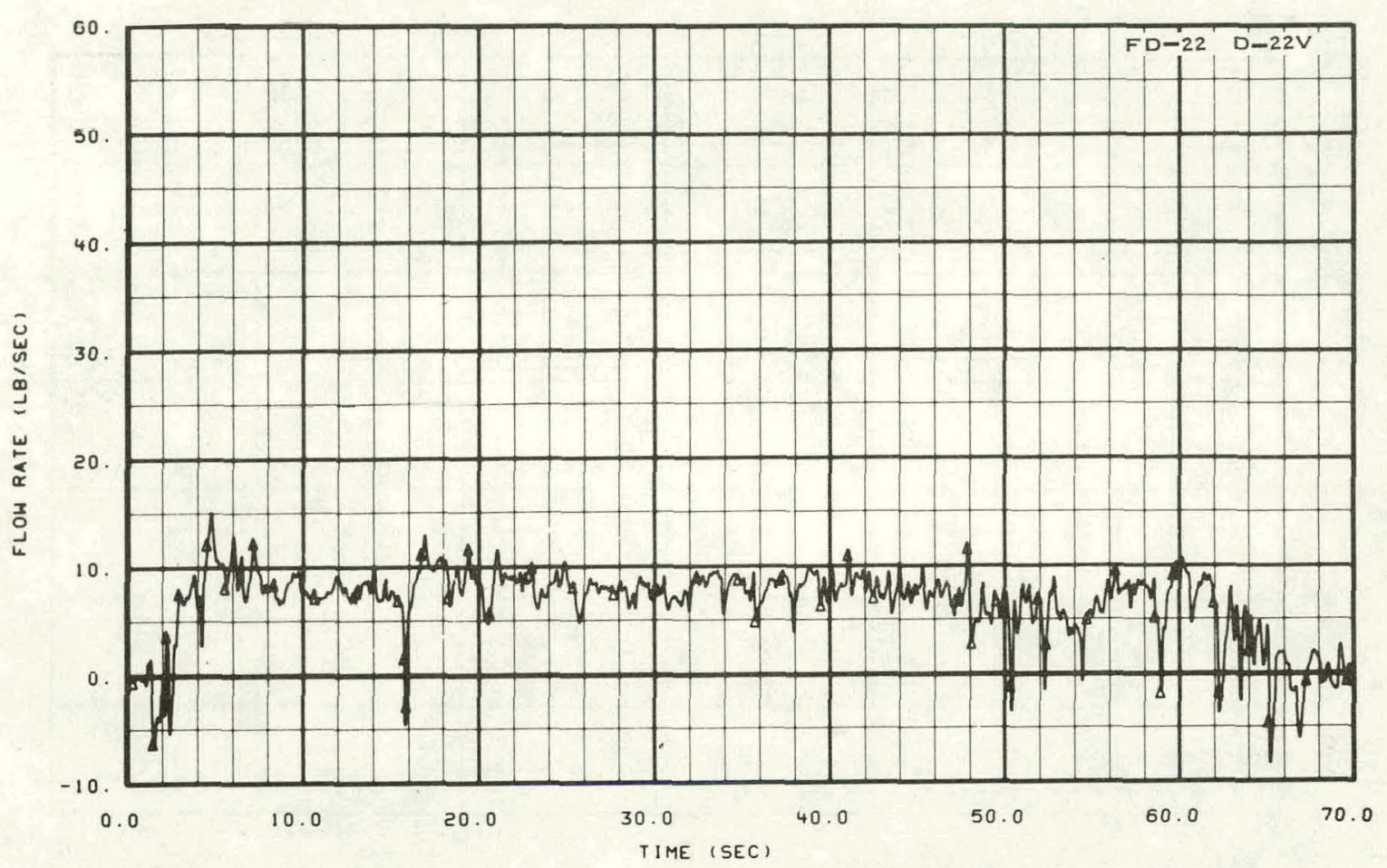

Fig. 142 Mass flow rate in operating loop cold leg Spool 22 -- Test 15.2.

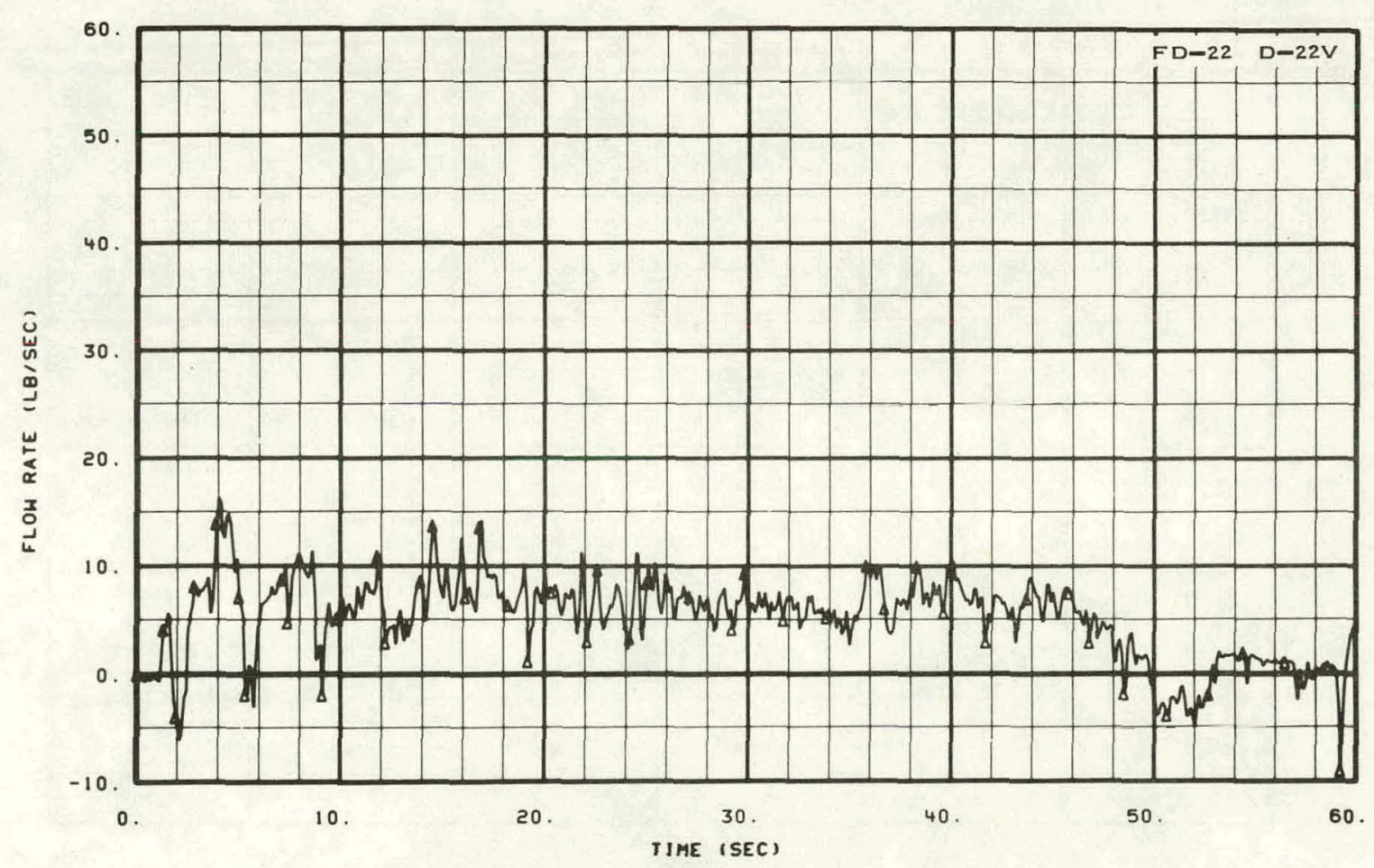

F1g. 143 Mass flow rate in operating loop cold leg Spool 22 -- Test 15.3. 


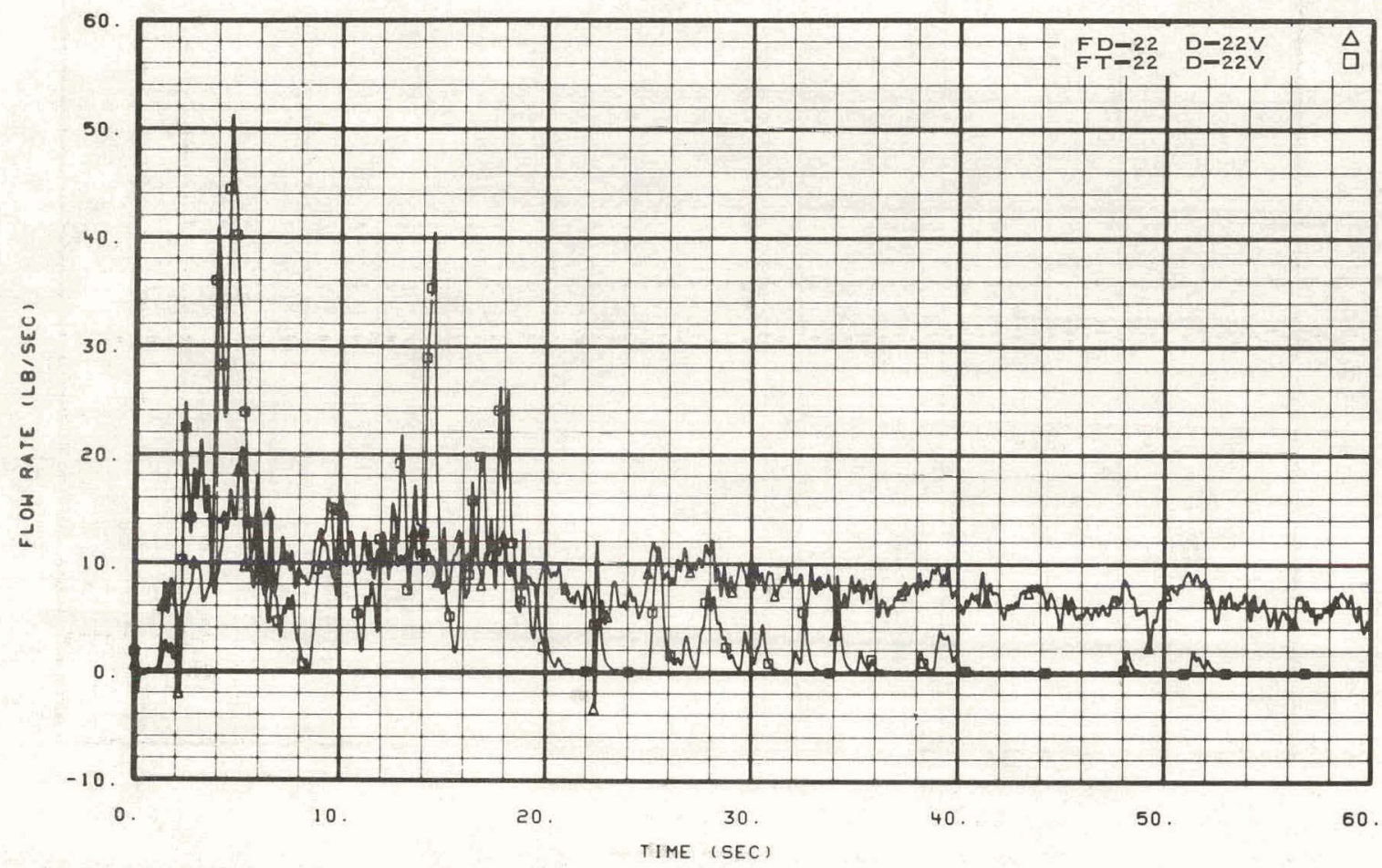

Fig. 144 Mass flow rate in operating loop cold leg Spool 22 -- Test 15.4 .

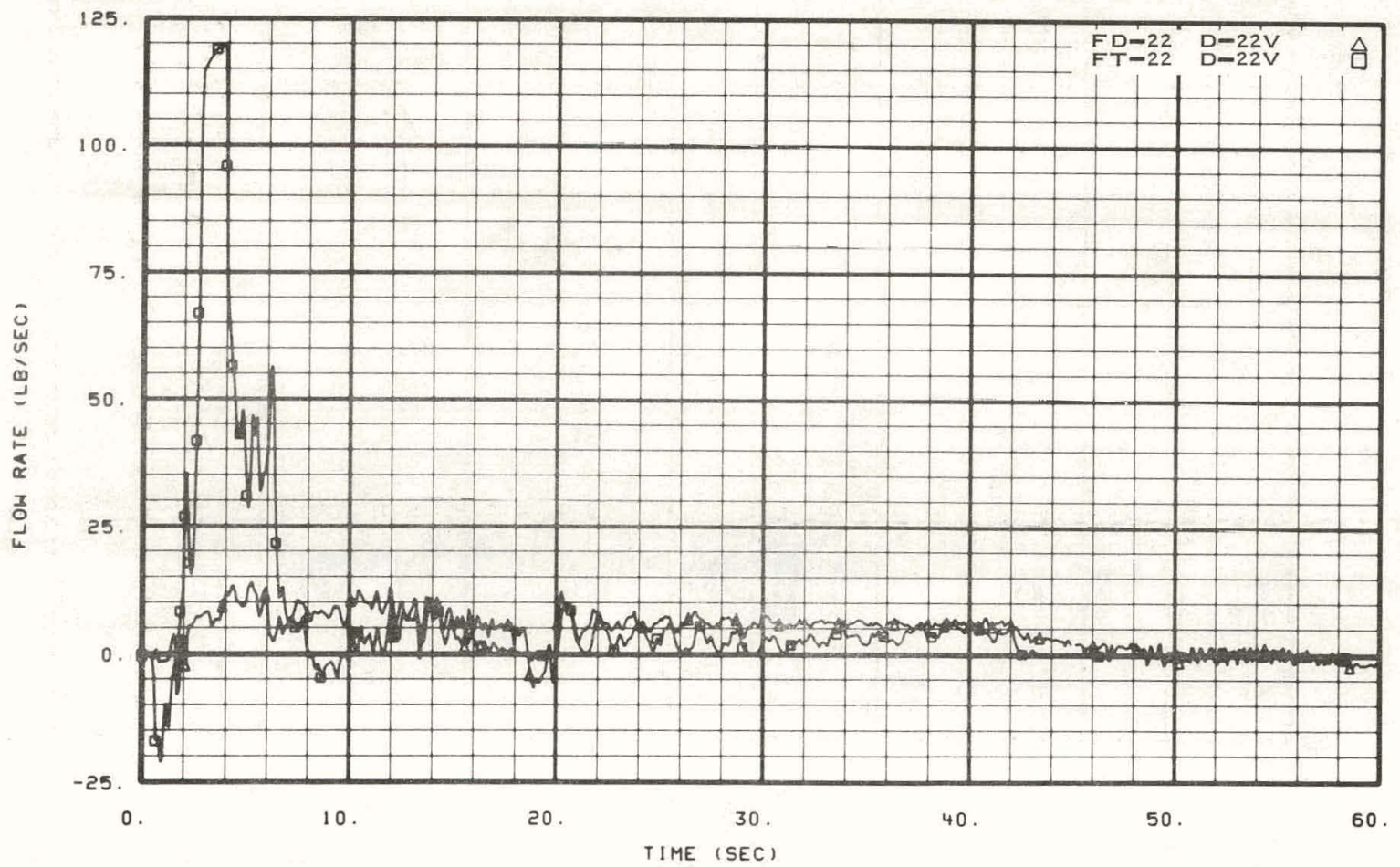

Fig. 145 Mass flow rate in operating loop cold leg Spool 22 -- Test 15.7. 


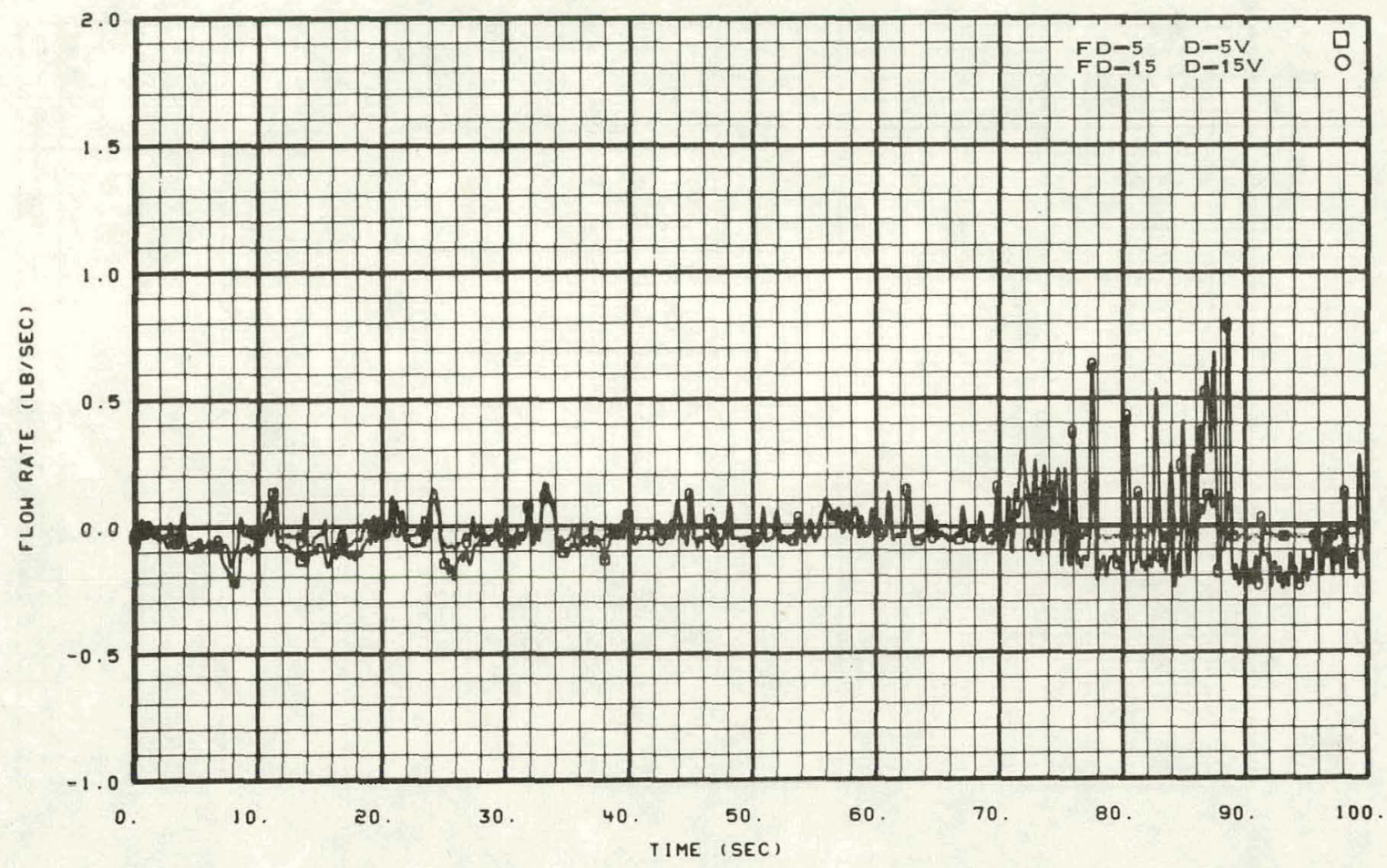

Fig. 146 Mass flow rate in operating loop Spools 5 and 15 -- Test 15.1.

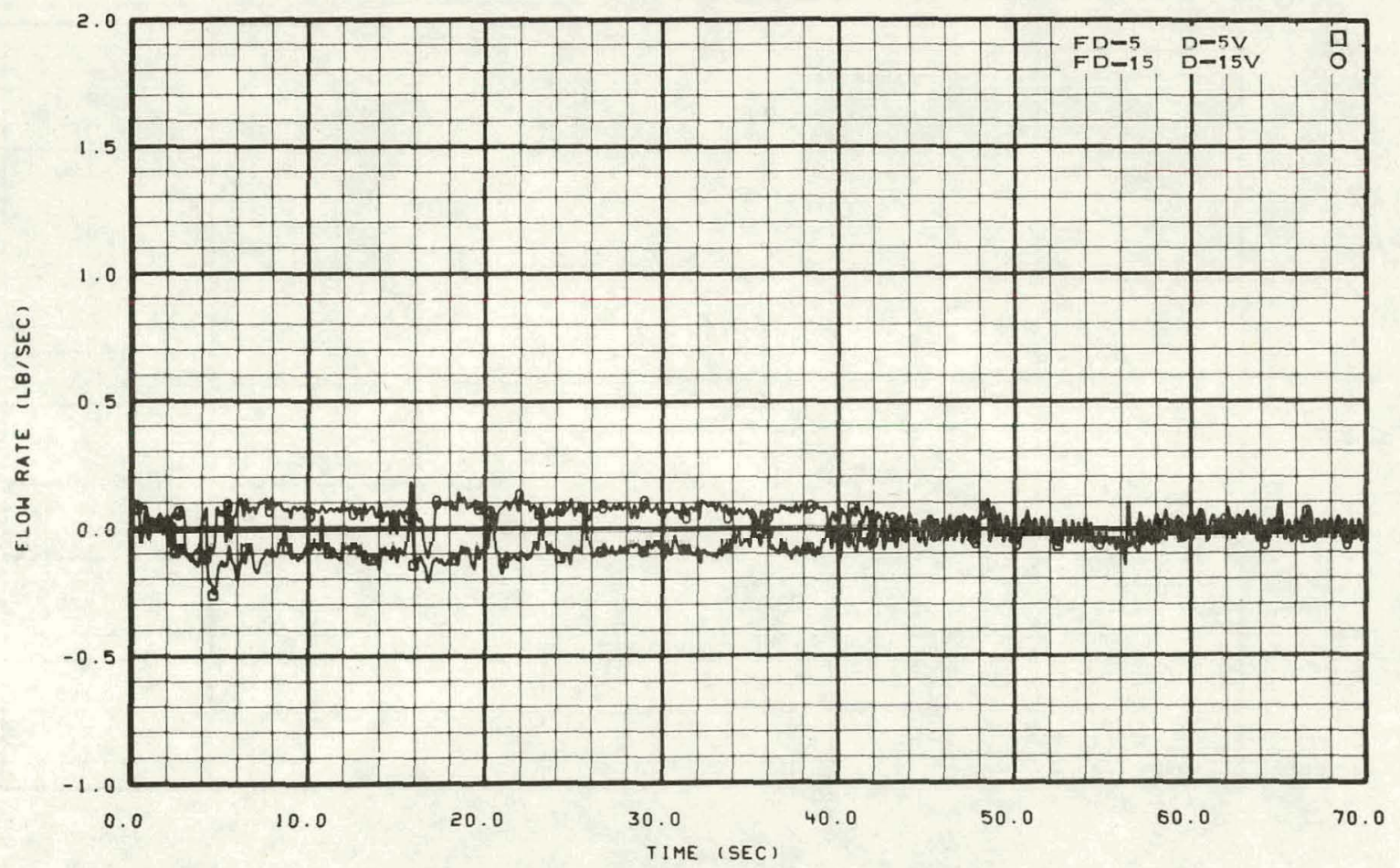

Fig. 147 Mass flow rate in operating loop Spools 5 and 15 -- Test 15.2. 


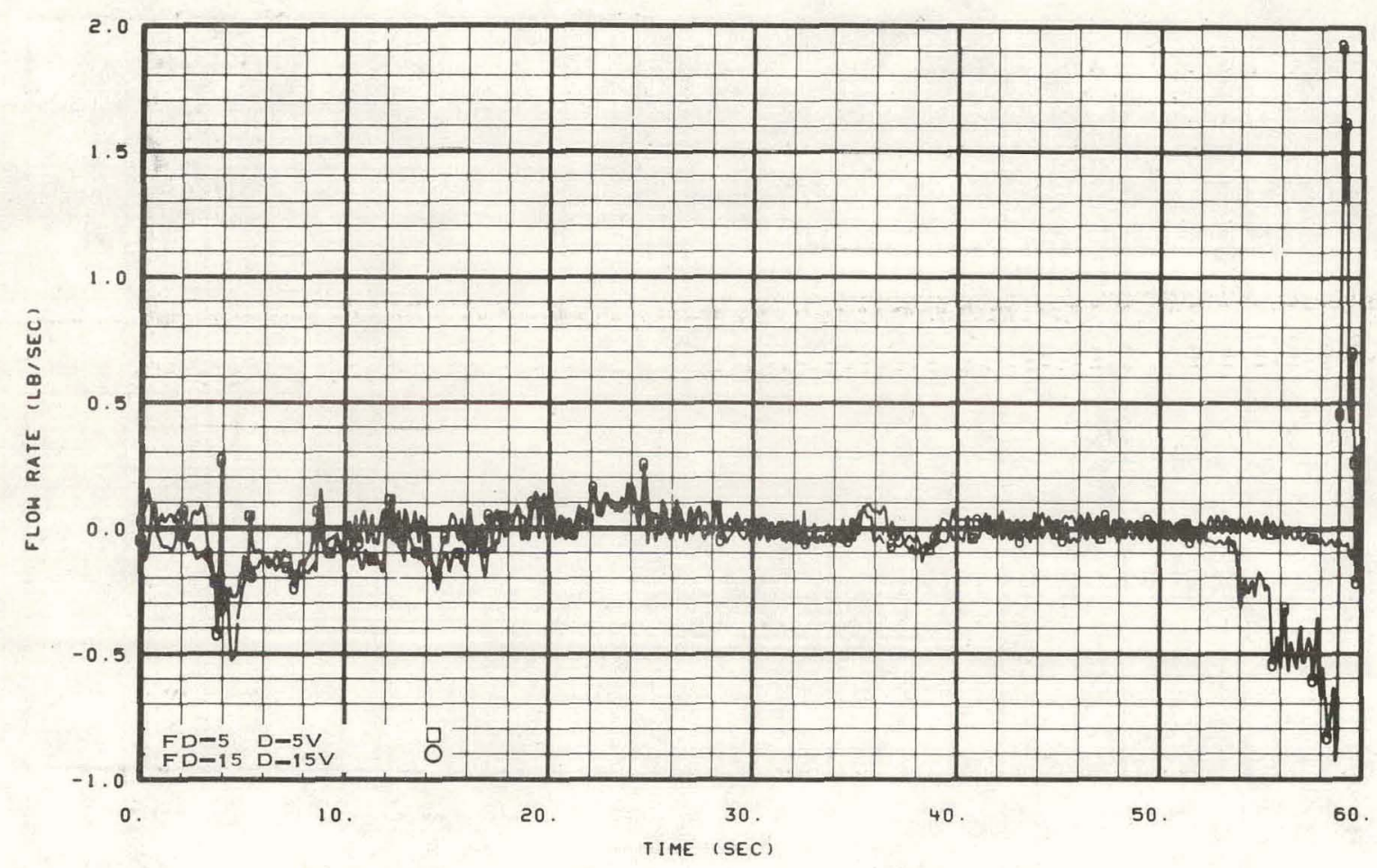

Fig. 148 Mass flow rate in operating loop Spools 5 and 15 -- Test 15.3.

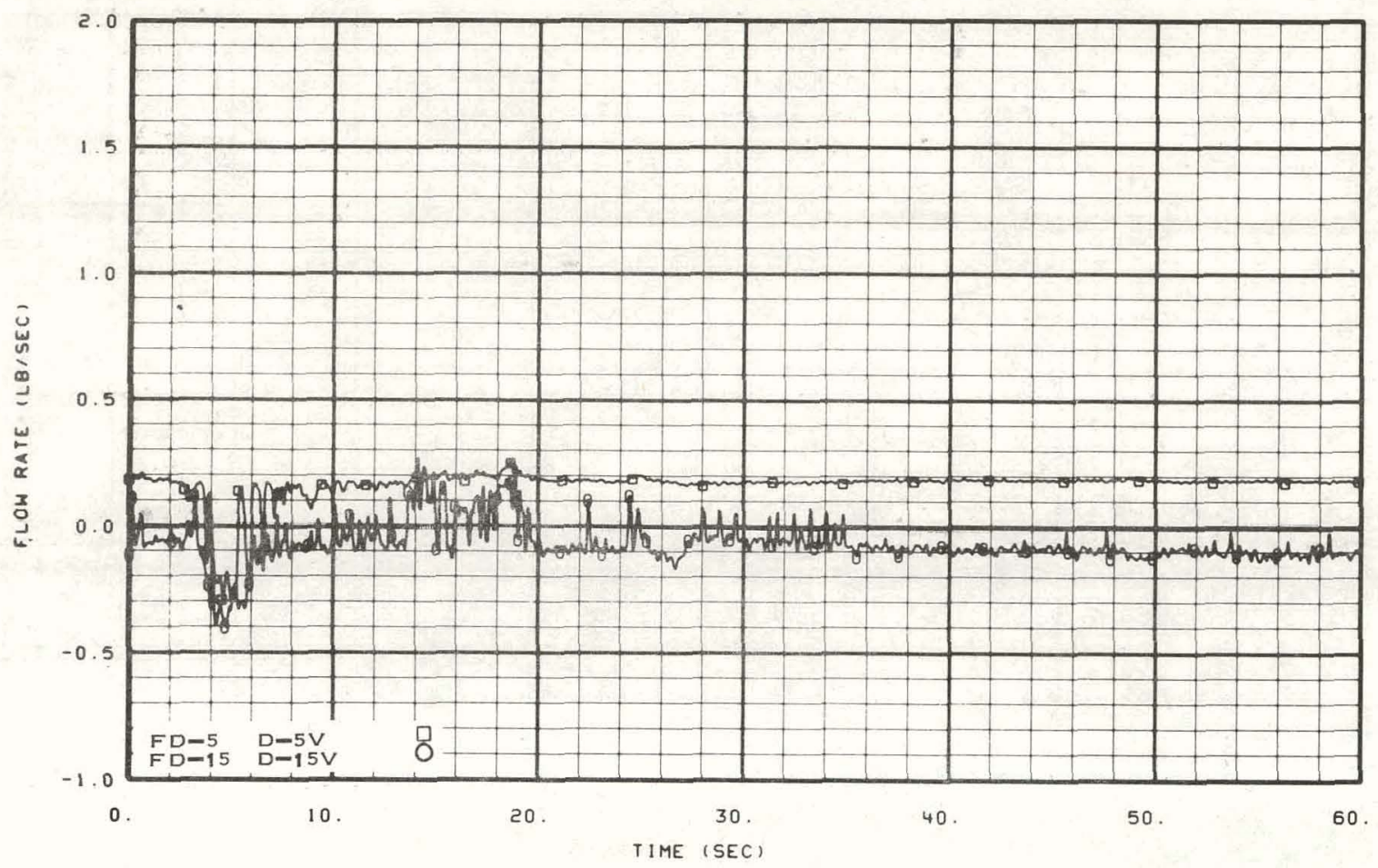

Fig. 149 Mass flow rate in operating loop Spools 5 and 15 -- Test 15.4. 


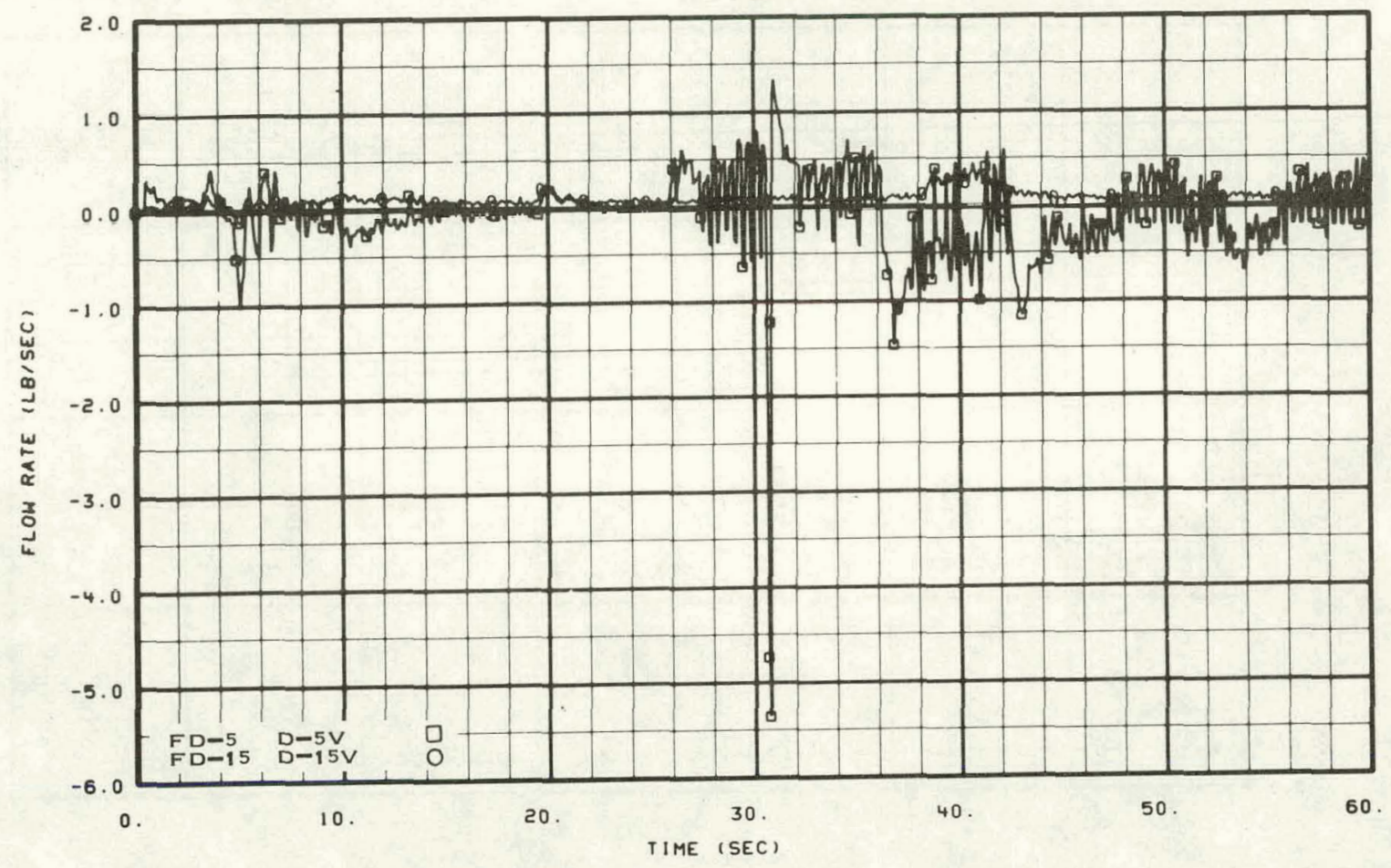

Fig. 150 Mass flow rate in operating loop Spools 5 and 15 -- Test 15.7.

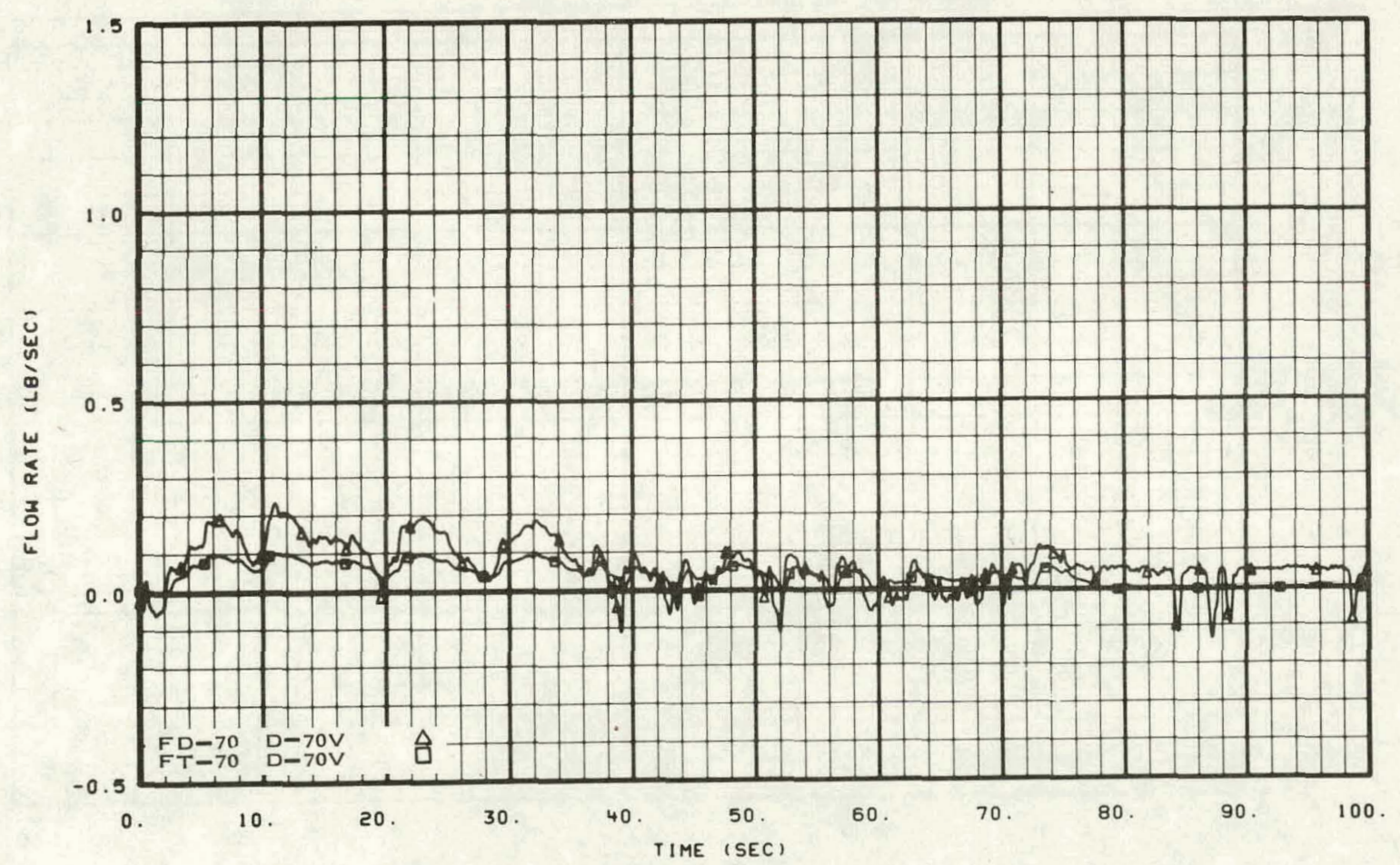

Fig. 151 Mass flow rate in blowdown loop Spool 70 -- Test 15.1. 


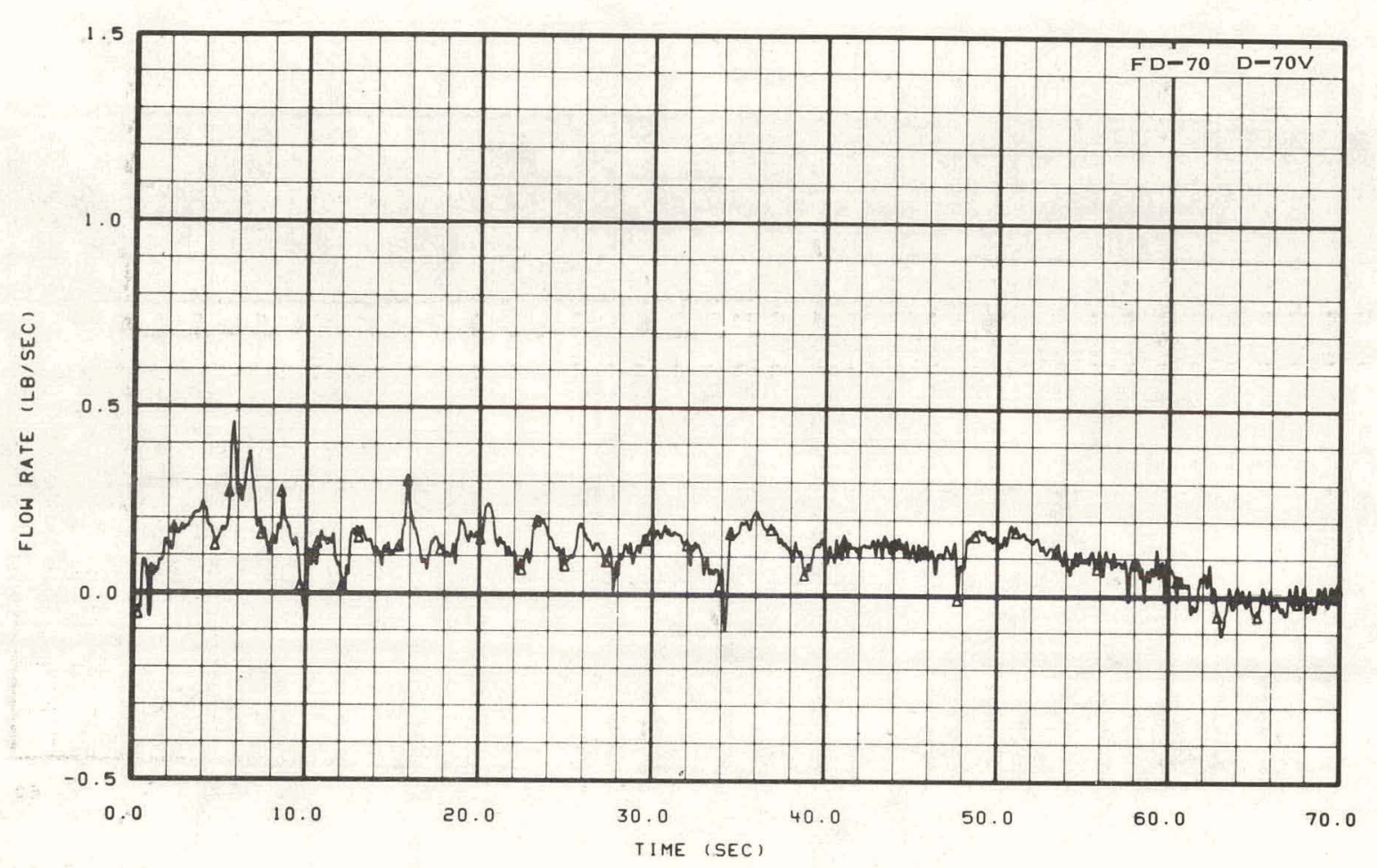

Fig. 152 Mass flow rate in blowdown loop Spool 70 -- Test 15.2.

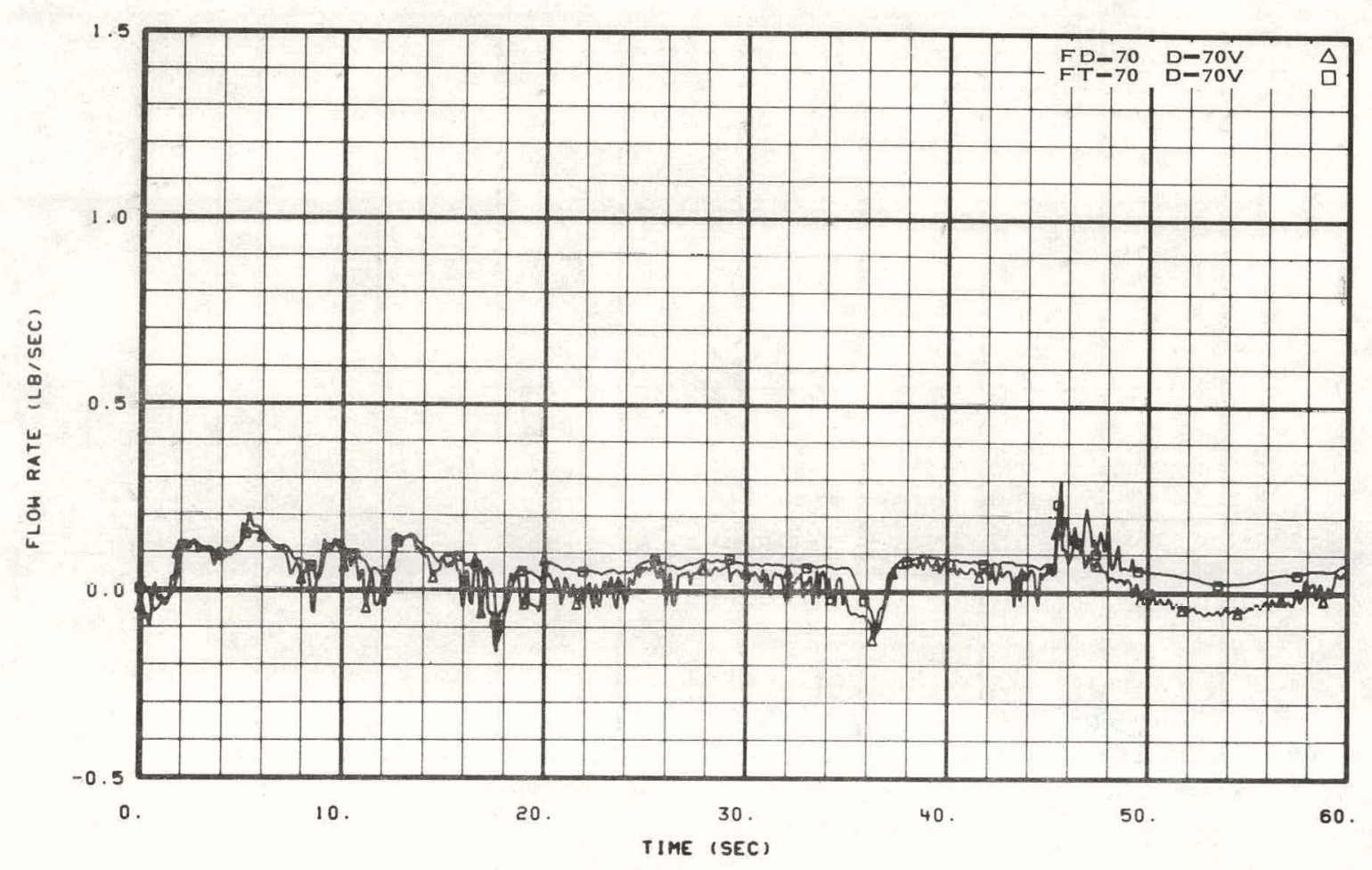

Fig. 153 Mass flow rate in blowdown loop Spool 70 -- Test 15.3. 


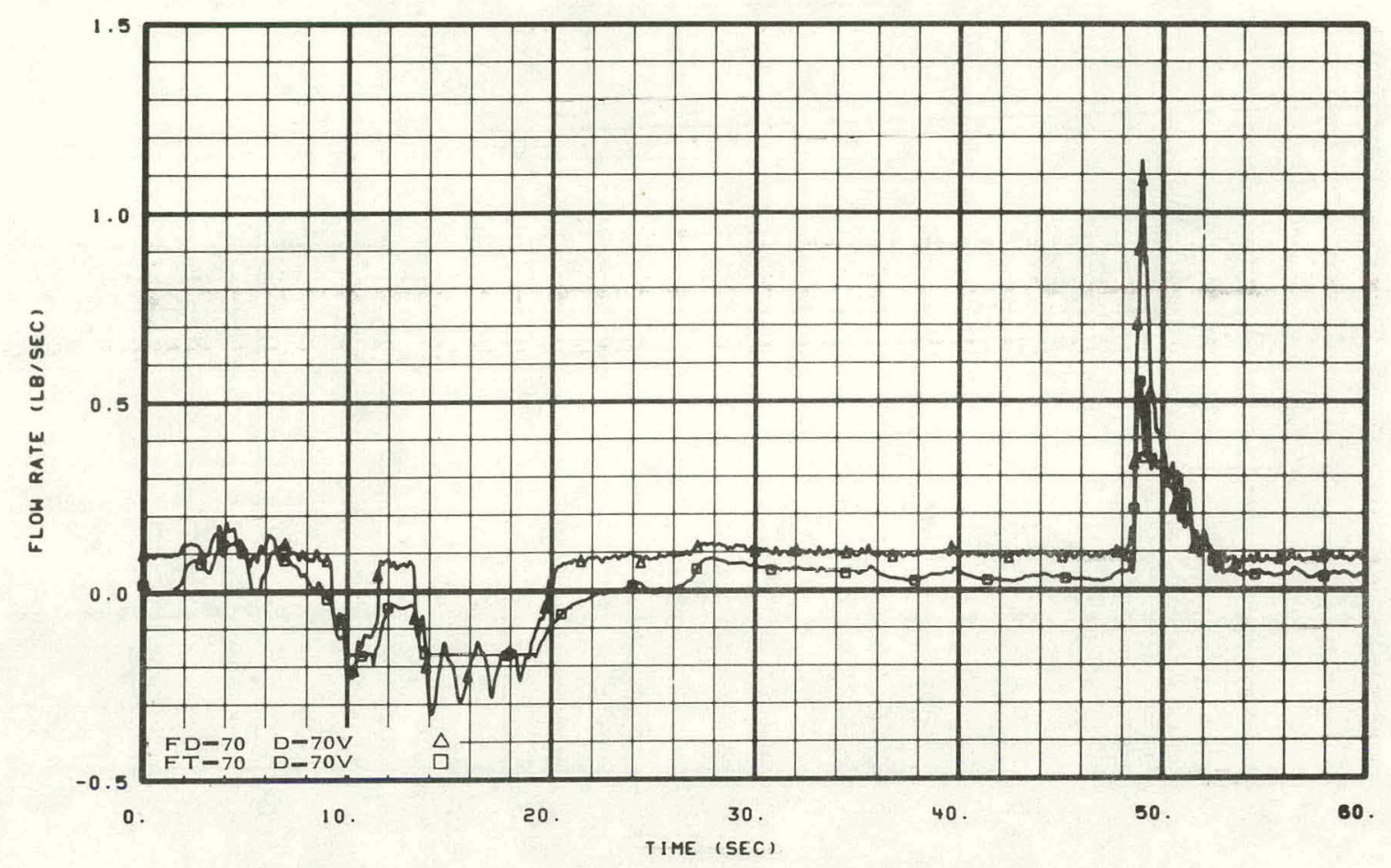

Fig. 154 Mass flow rate in blowdown loop Spool 70 -- Test 15.4.

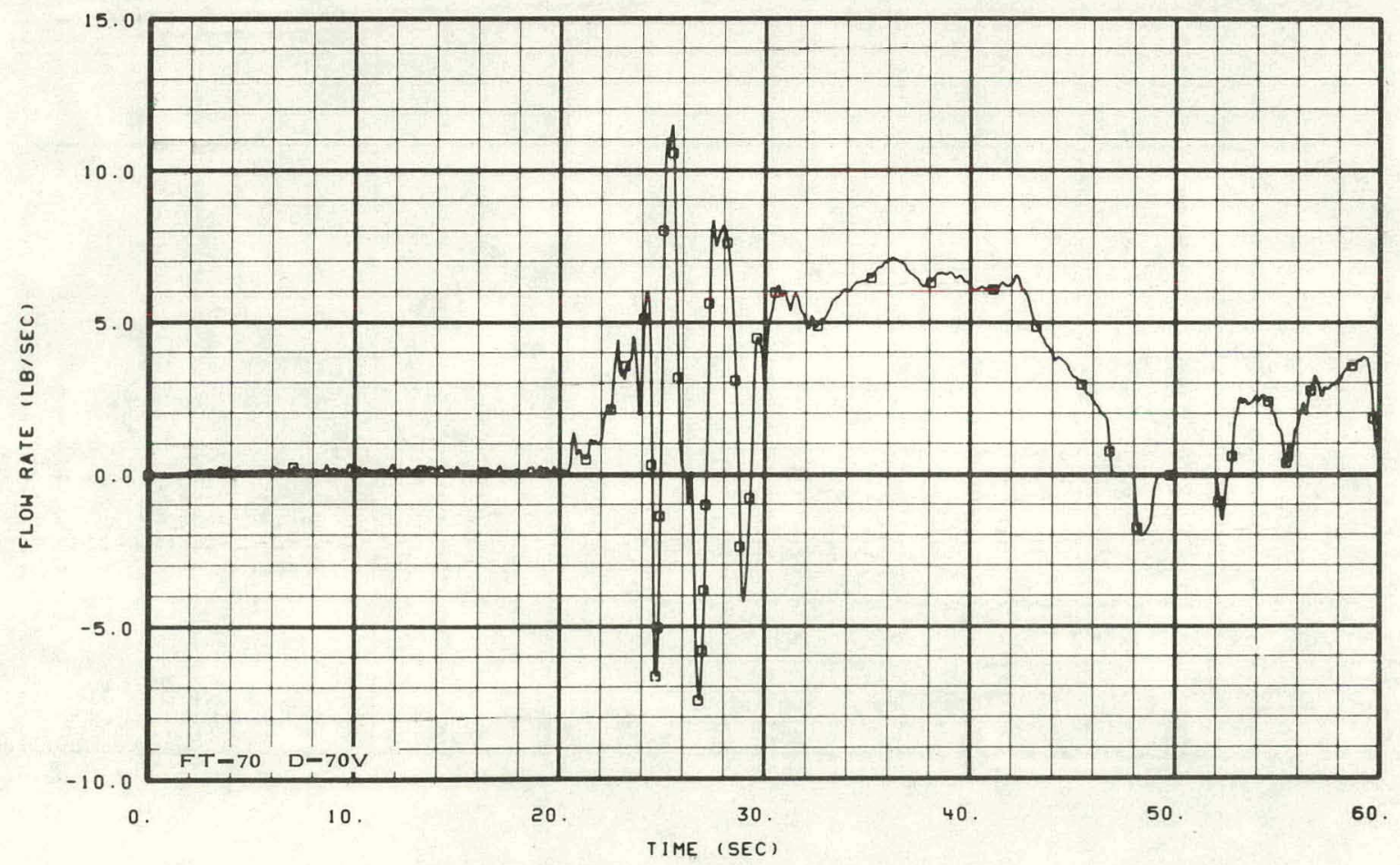

Fig. 155 Mass flow rate in blowdown loop Spool 70 -- Test 15.7 . 


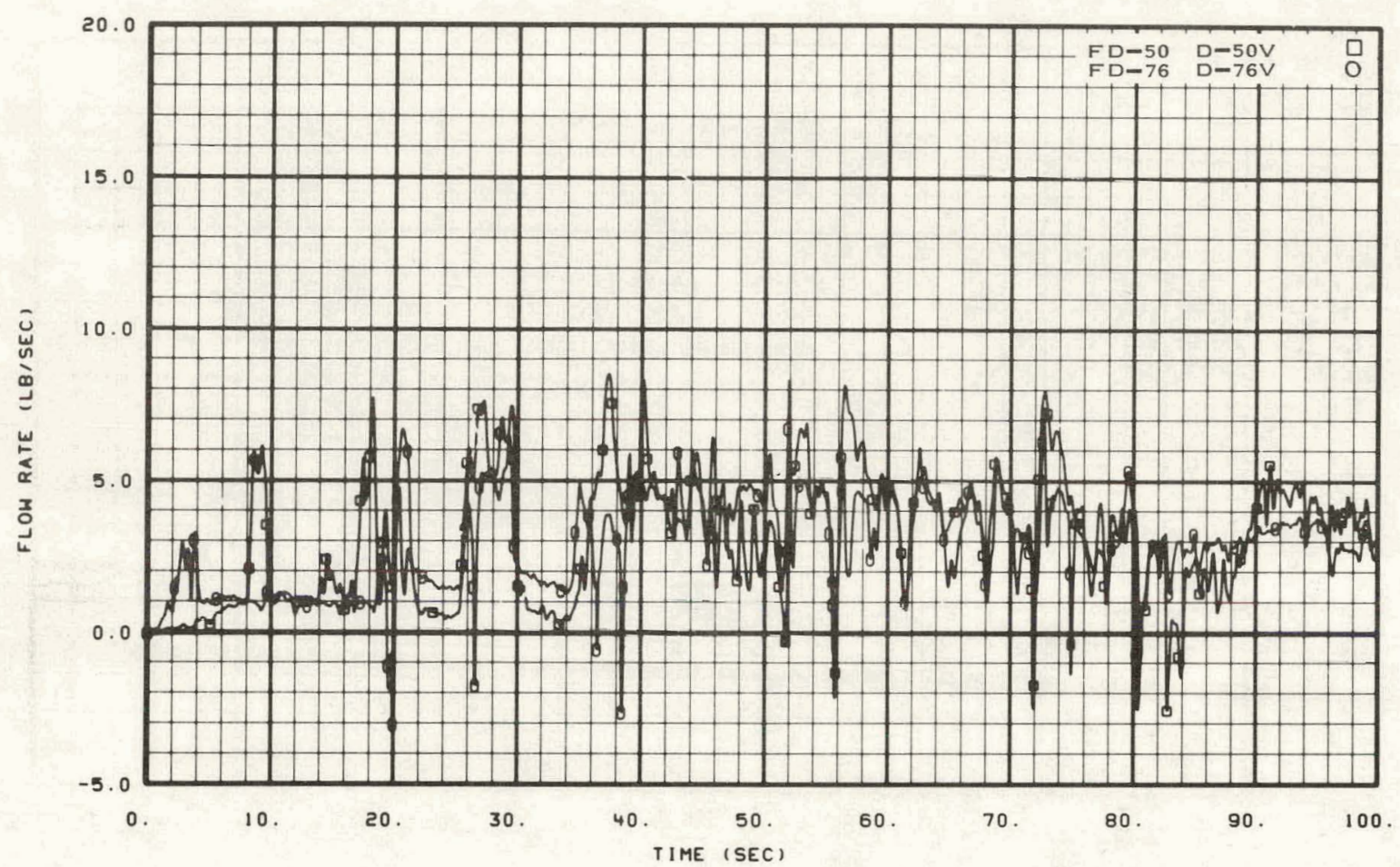

Fig. 156 Mass flow rate in blowdown loop Spools 50 and 76 -- Test 15.1.

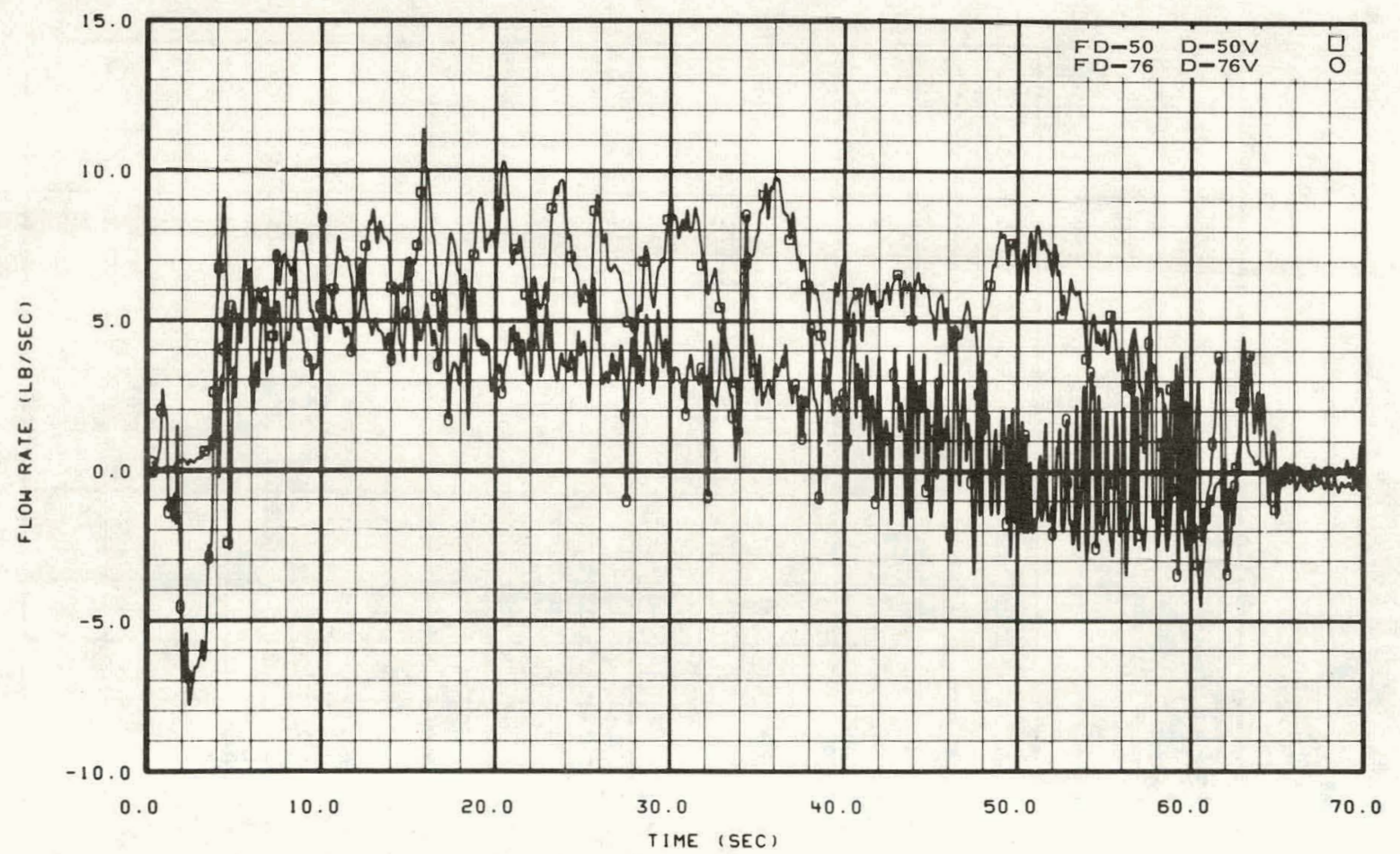

Fig. 157 Mass flow rate in blowdown loop Spools 50 and 76 -- Test 15.2. 


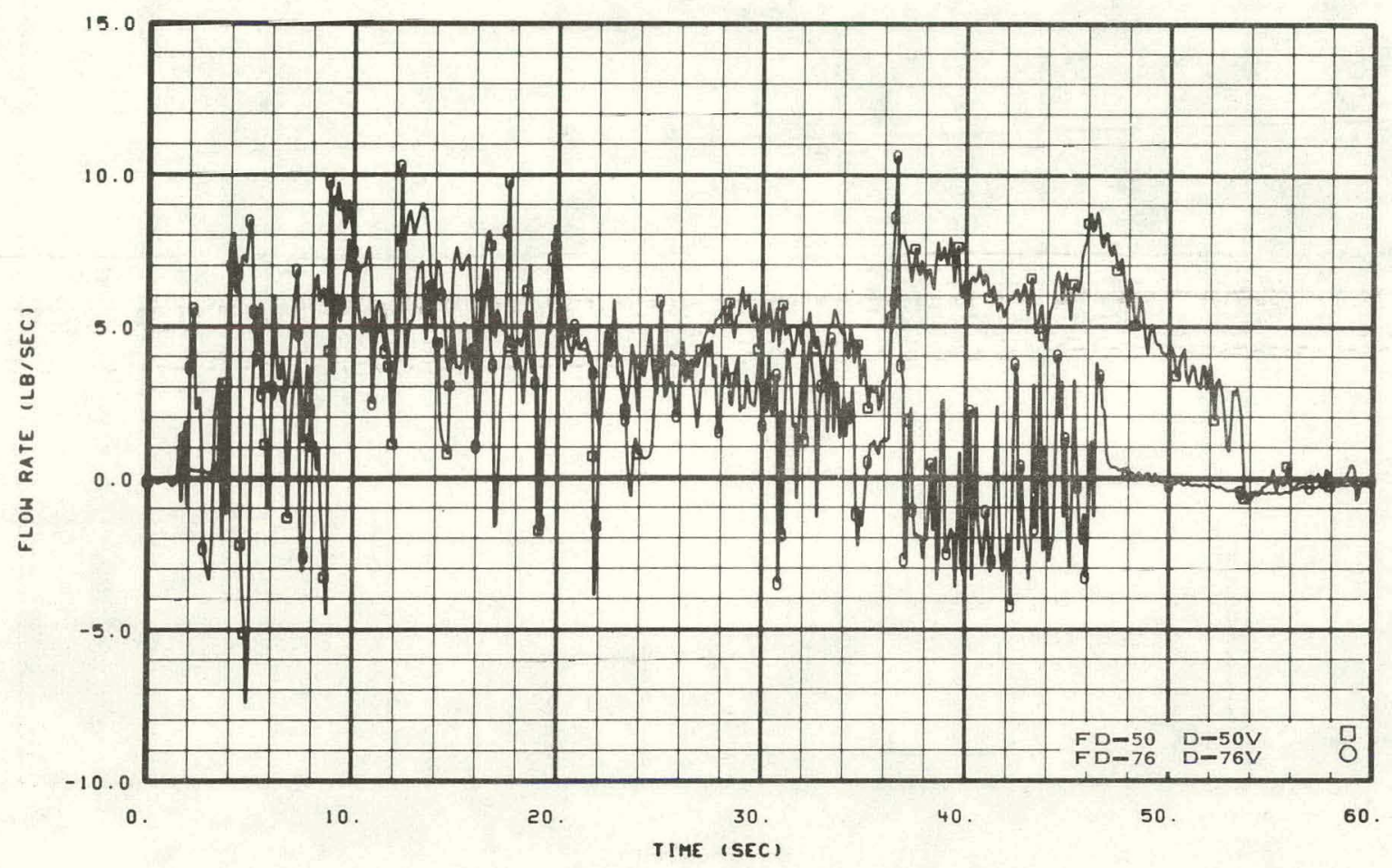

Fig. 158 Mass flow rate in blowdown loop Spools 50 and 76 -- Test 15.3.

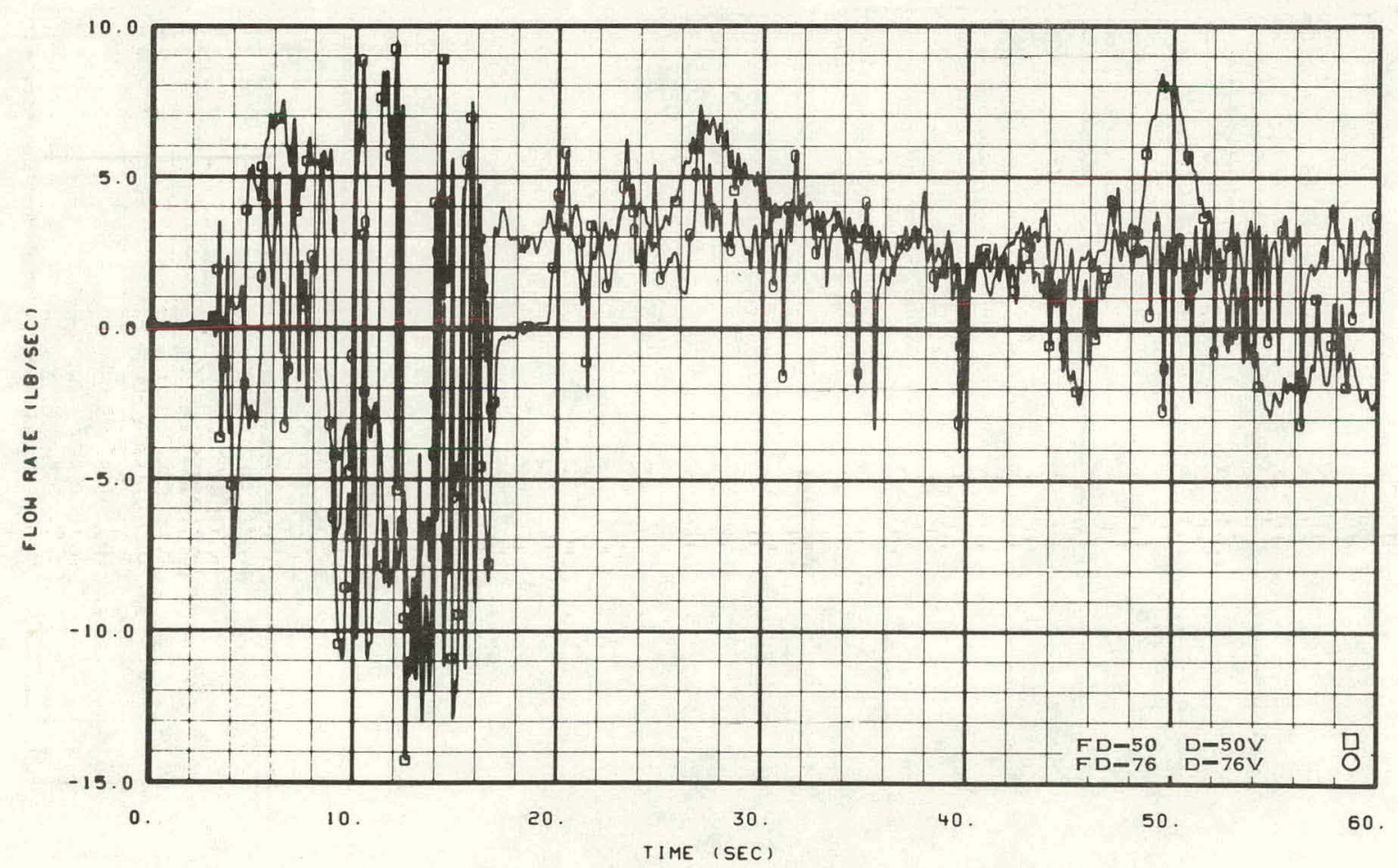

Fig. 159 Mass flow rate in blowdown loop Spools 50 and 76 -- Test 15.4. 


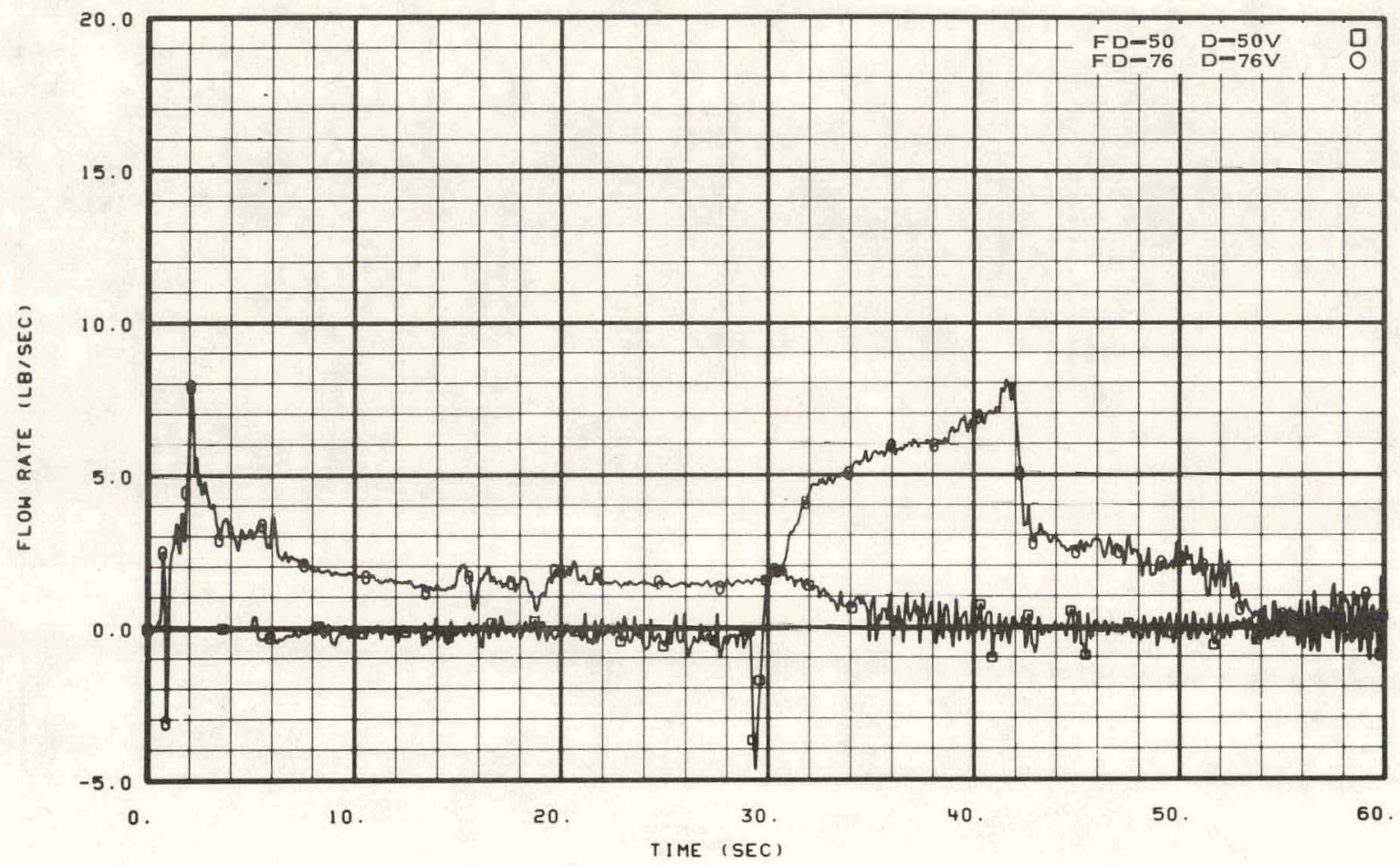

Fig. 160 Mass flow rate in blowdown loop Spools 50 and 76 -- Test 15.7.

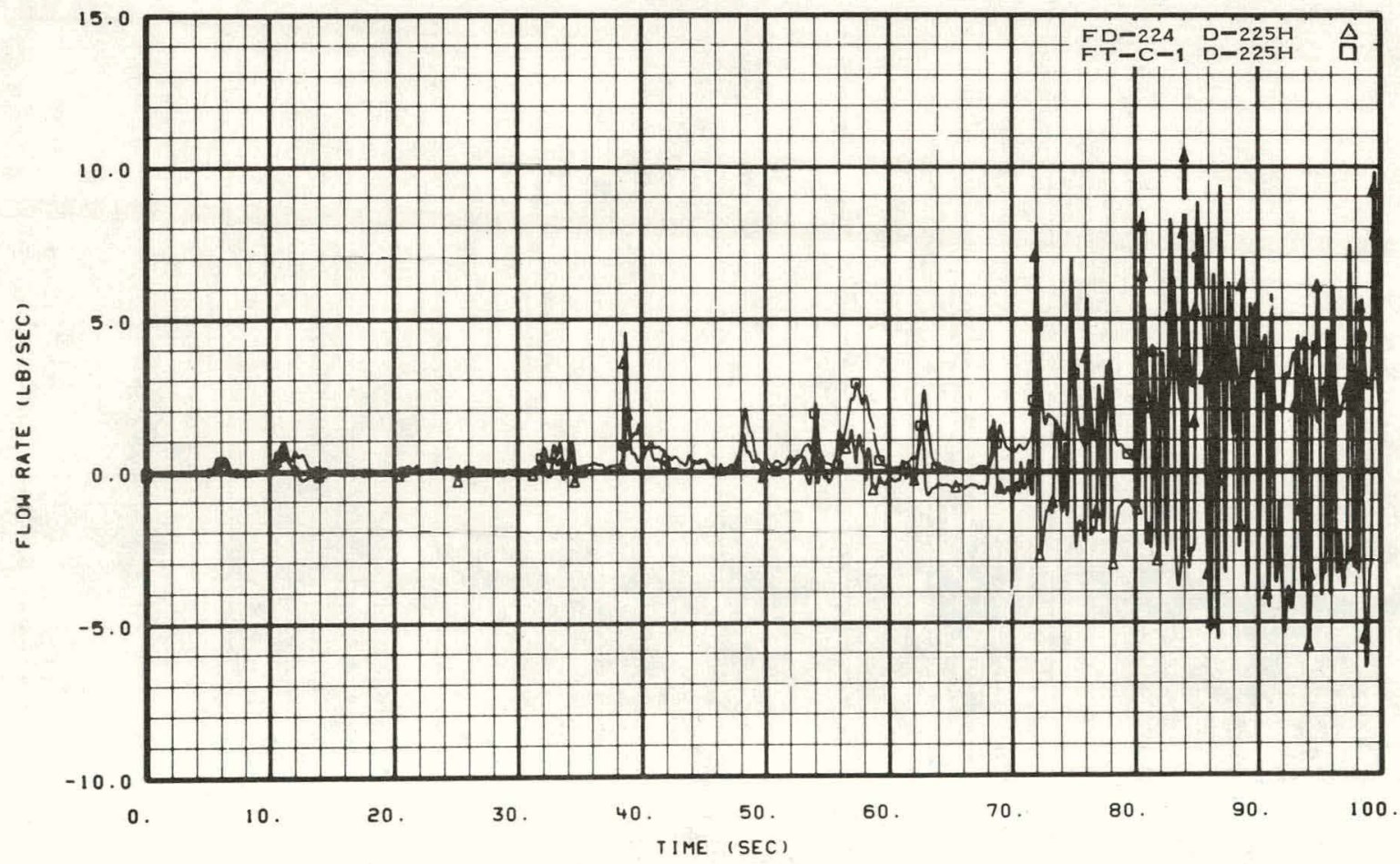

Fig. 161 Mass flow rate at core barrel inlet -- Test 15.1. 


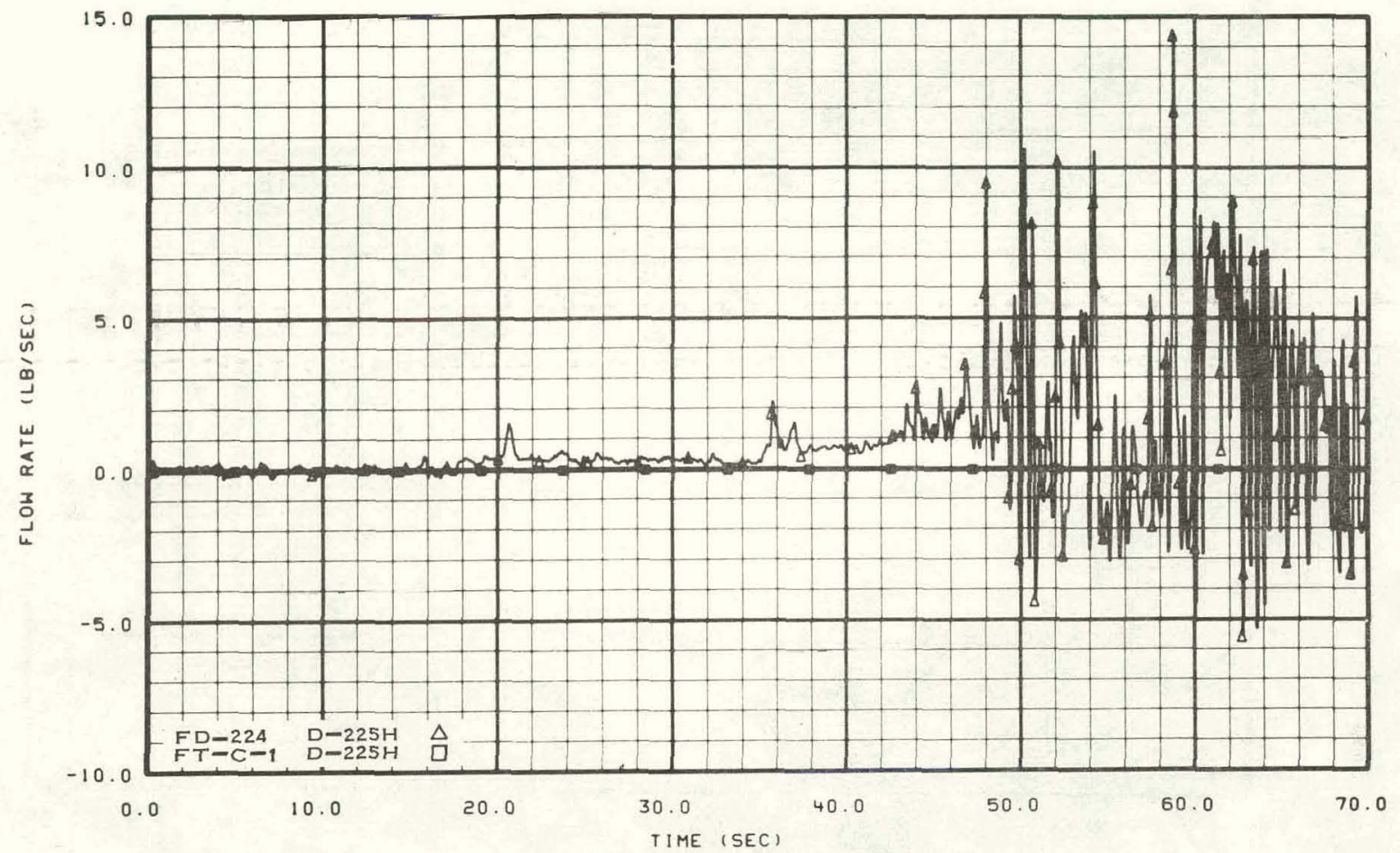

Fig. 162 Mass flow rate at core barrel inlet -- Test 15.2.

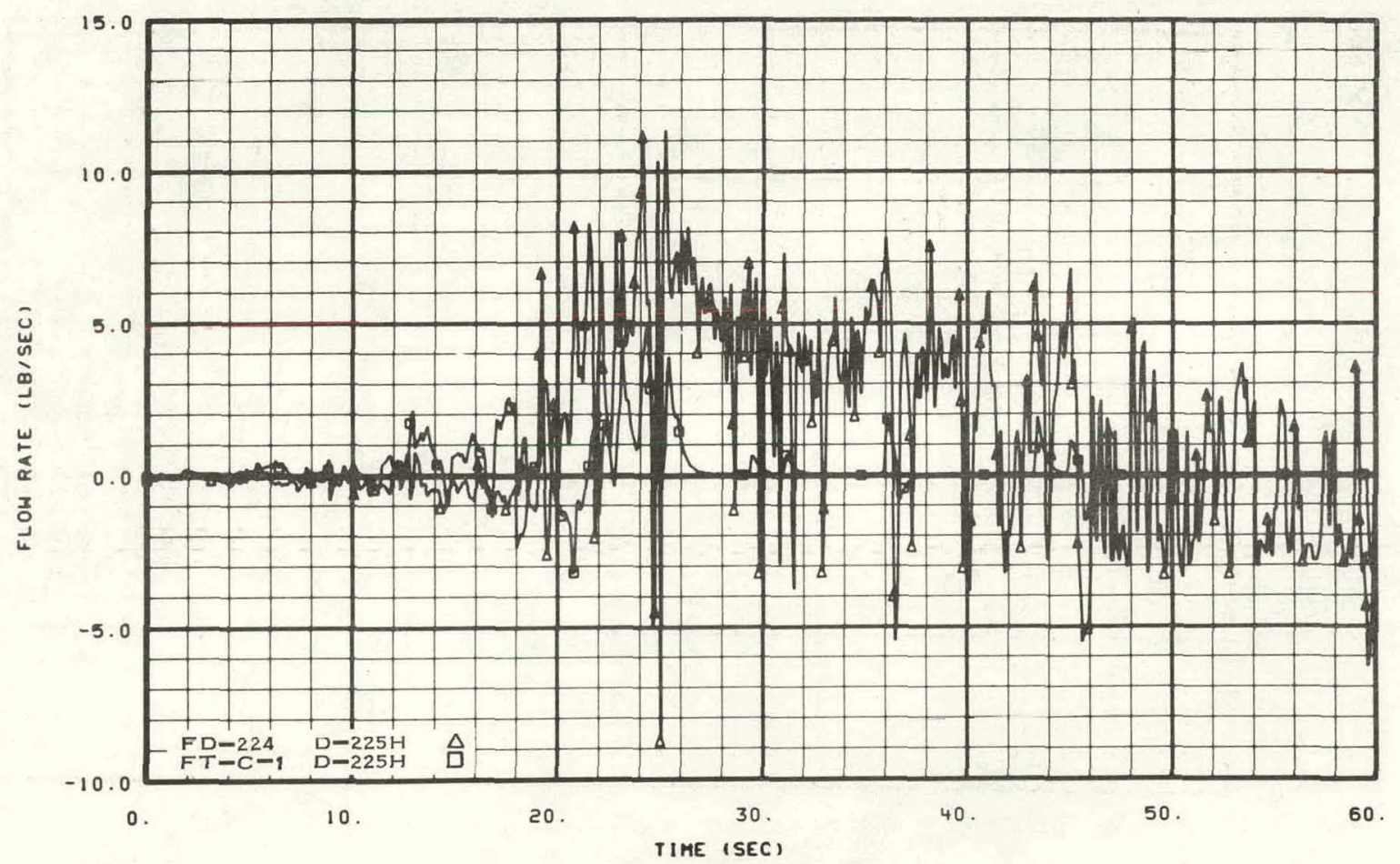

Fig. 163 Mass flow rate at core barrel inlet -- Test 15.3. 


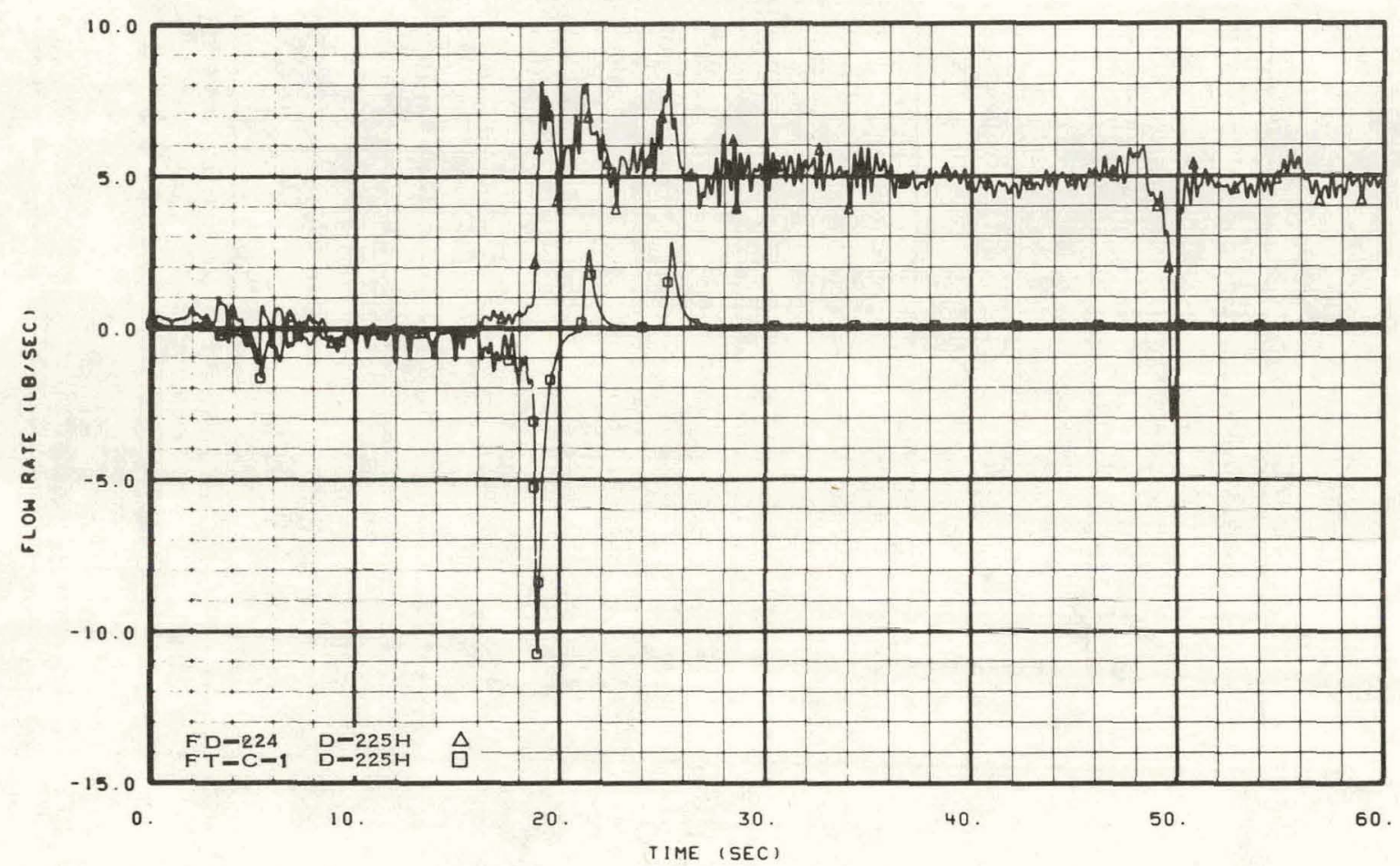

Fig. 164 Mass flow rate at core barrel inlet -- Test 15.4.

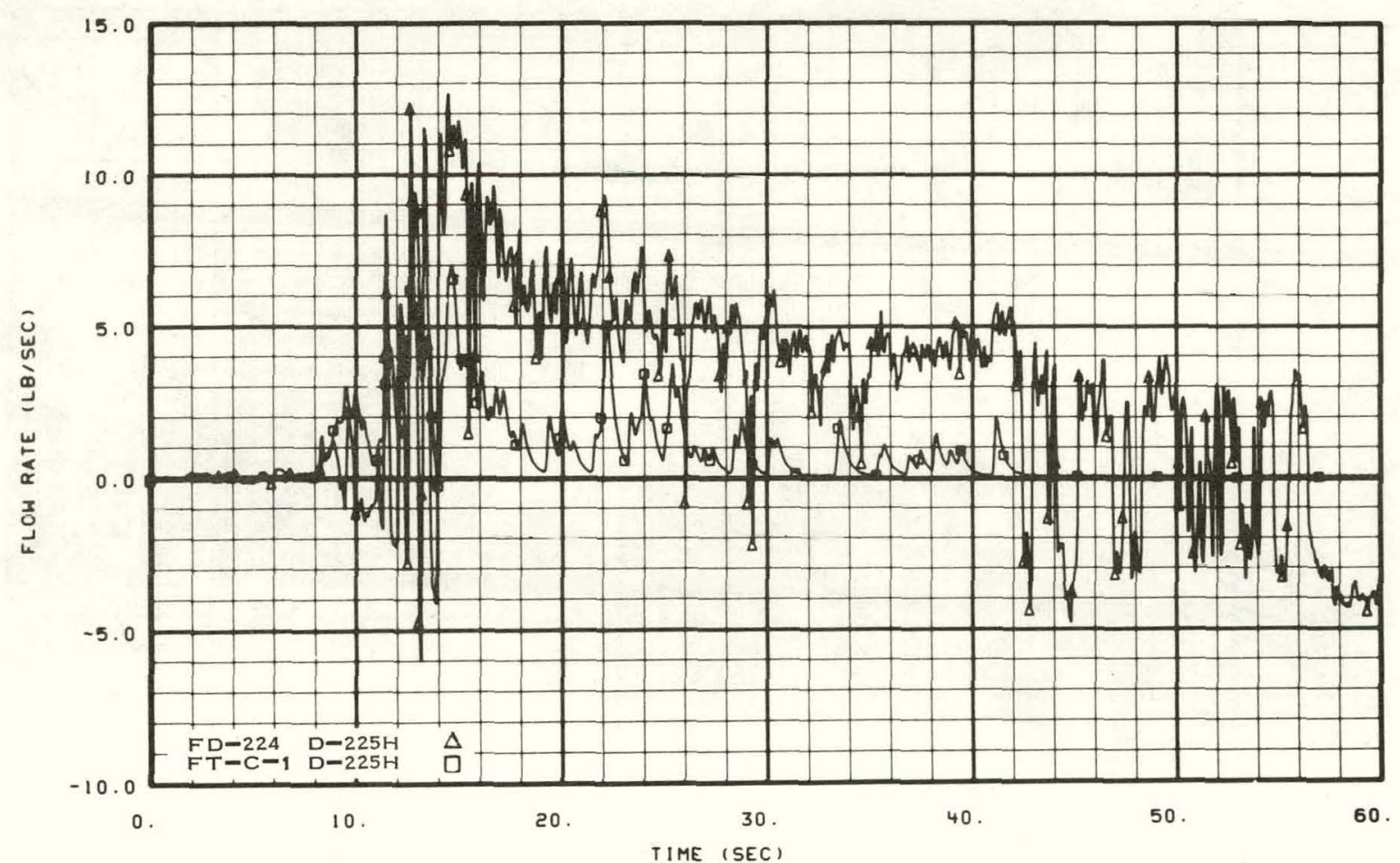

Fig. 165 Mass flow rate at core barrel inlet -- Test 15.7. 


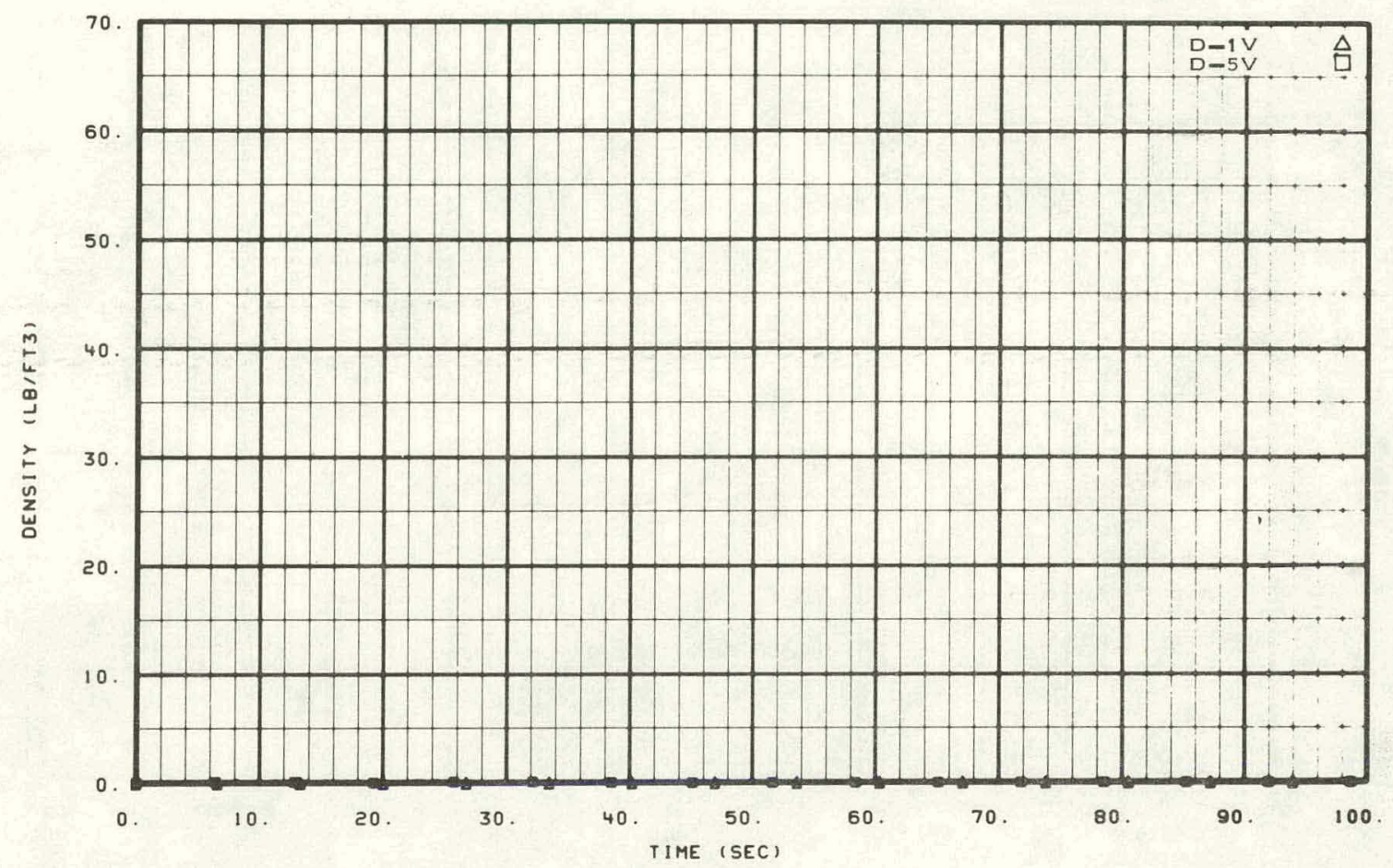

Fig. 166 Fluid density in operating loop hot leg -- Test 15.1.

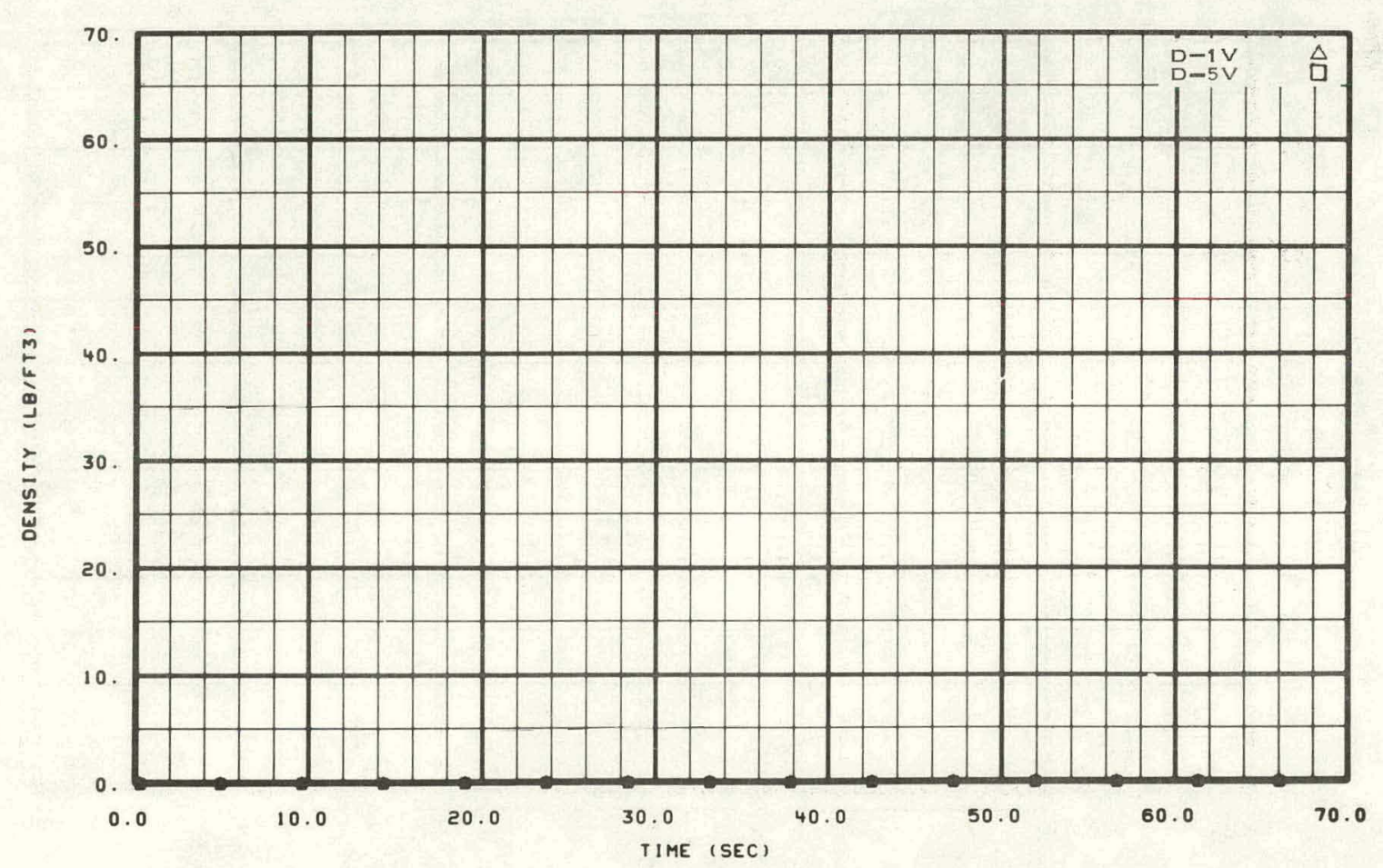

Fig. 167 Fluid density in operating loop hot leg -- Test 15.2. 


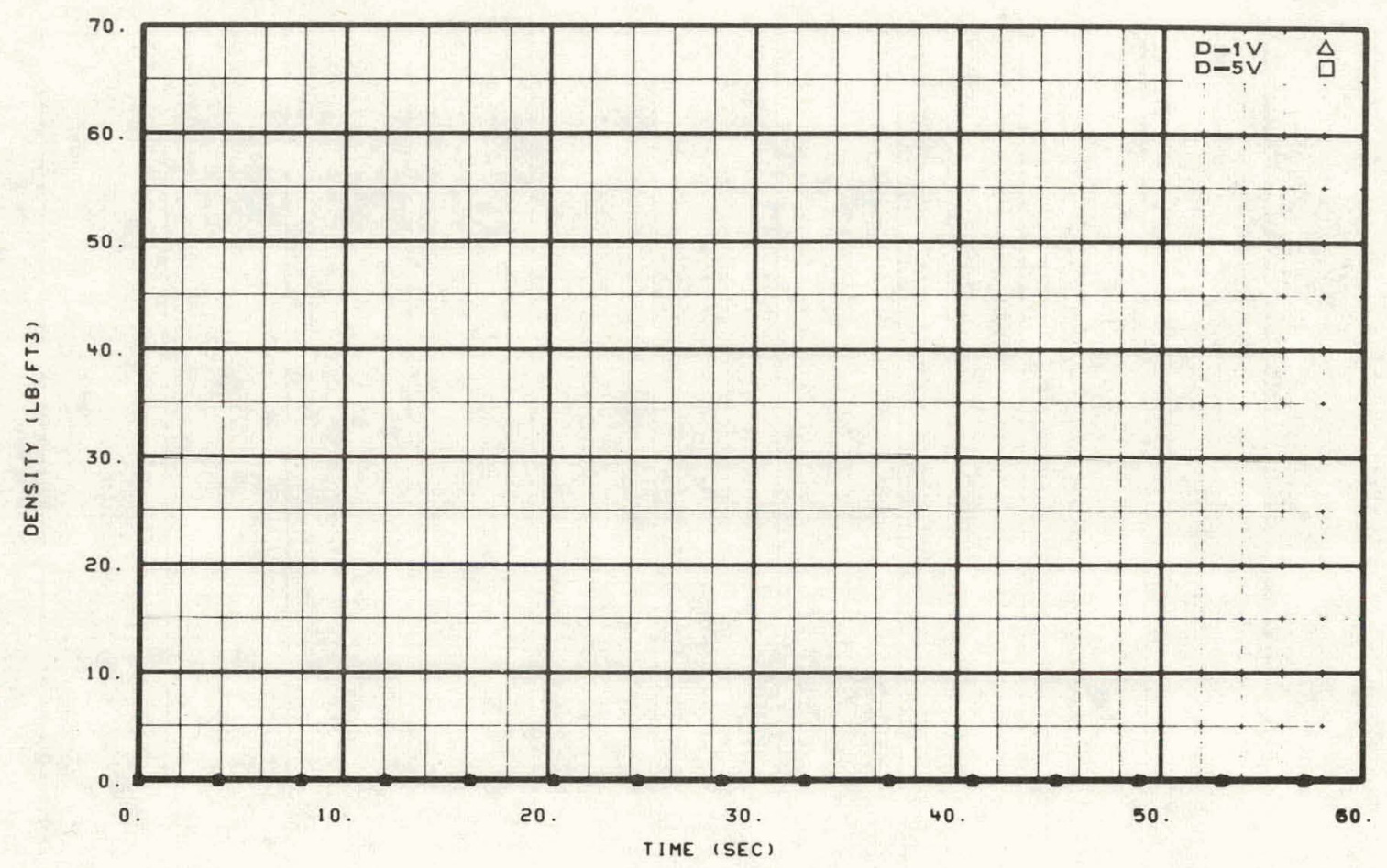

Fig. 168 Fluid density in operating loop hot leg -- Test 15.3.

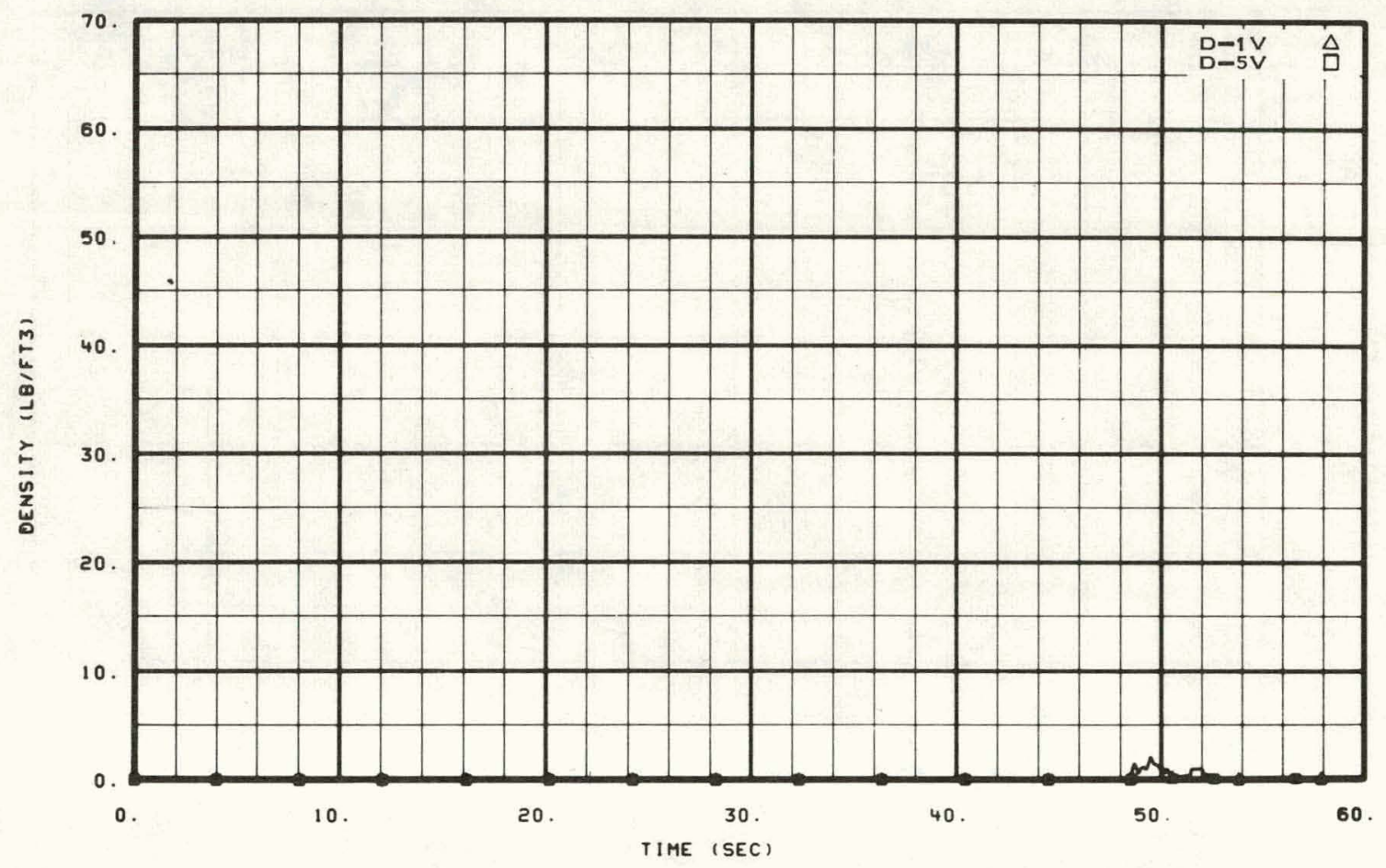

Fig. 169 Fluid density in operating loop hot leg -- Test 15.4. 


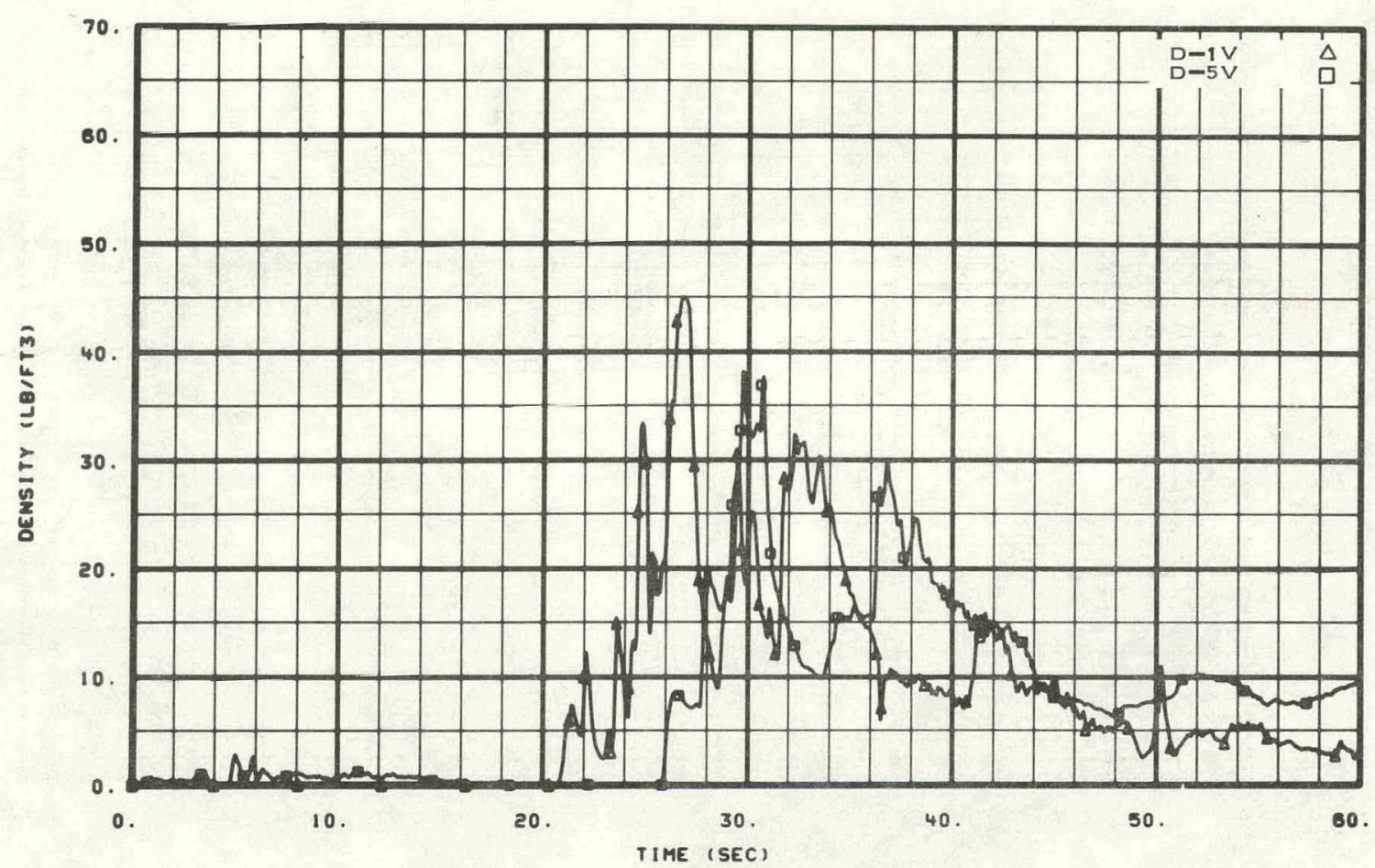

Fig. 170 Fluid density in operating loop hot leg -- Test 15.7.

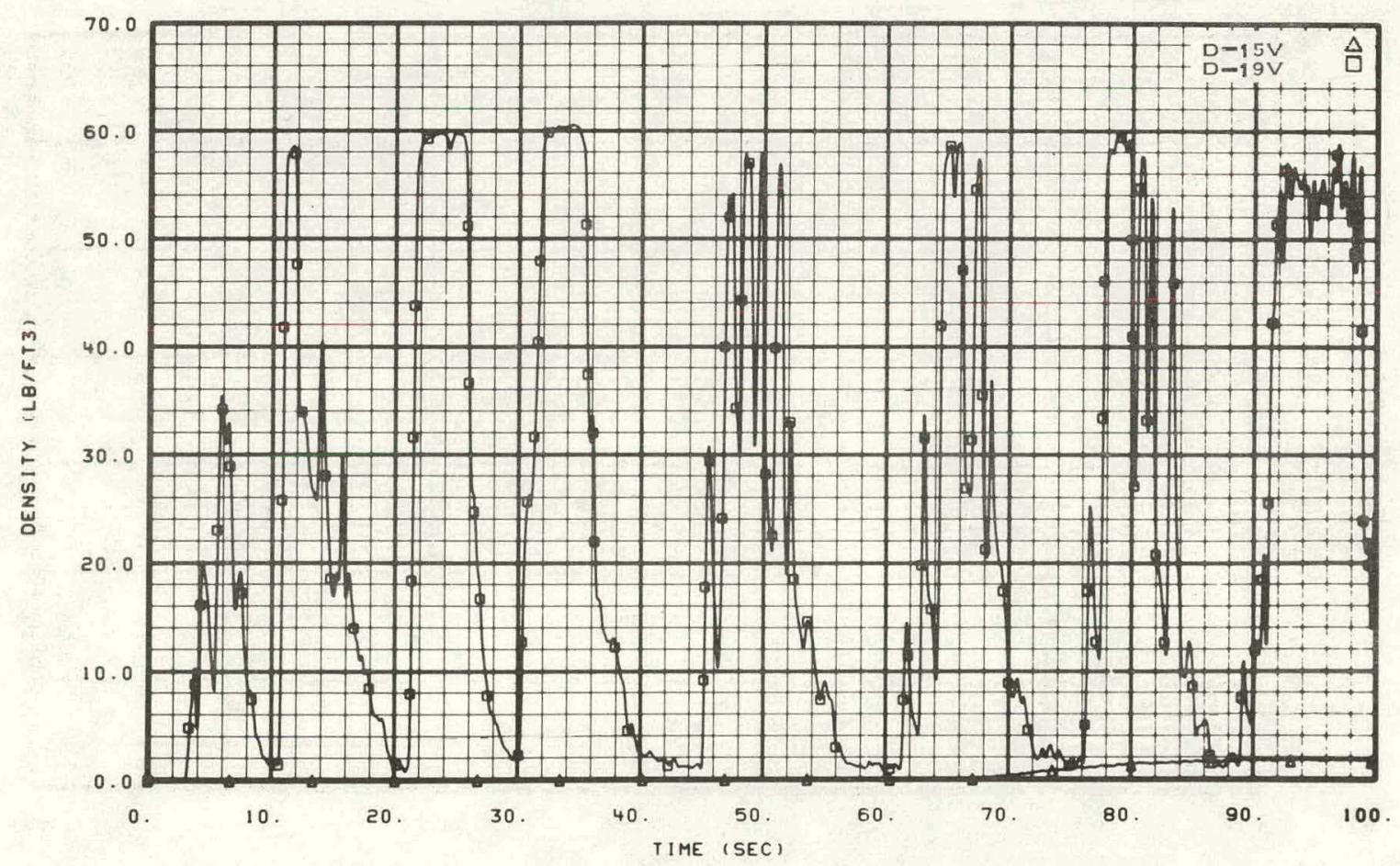

Fig. 171 Fluid density at operating loop pump inlet and outlet -- Test 15.1 . 


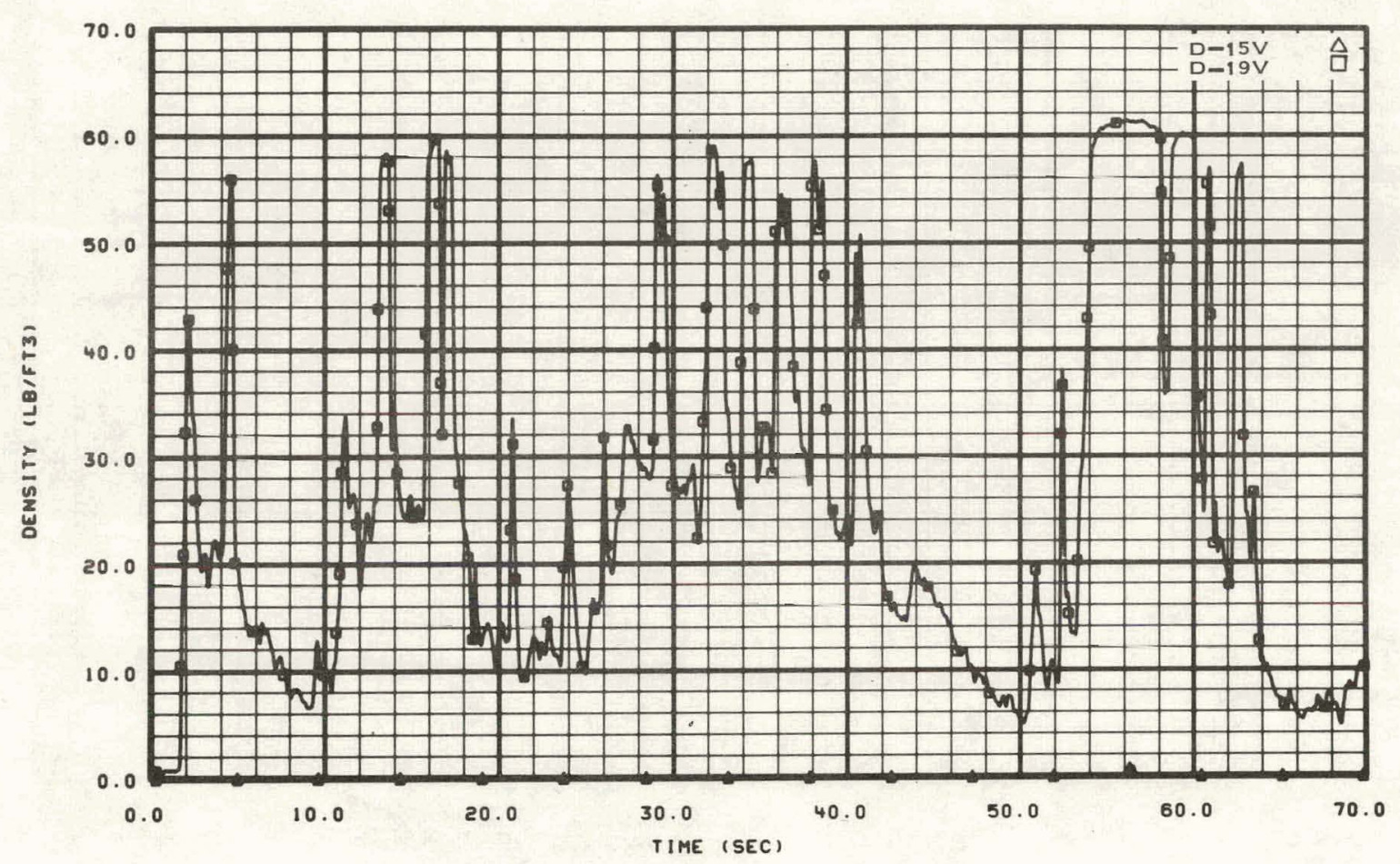

Fig. 172 Fluid density at operating loop pump inlet and outlet -- Test 15.2 .

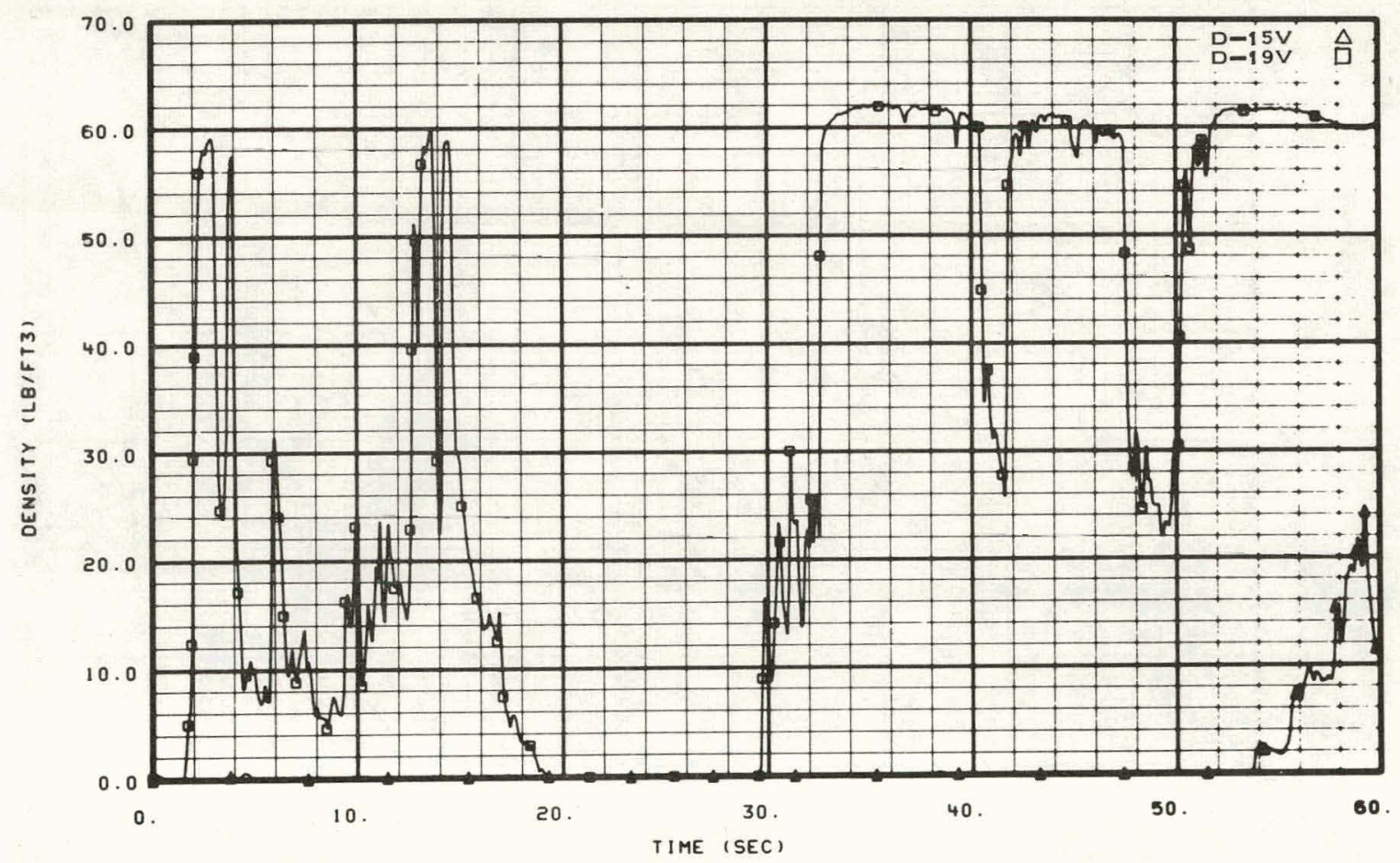

Fig. 173 Fluid density at operating loop pump inlet and outlet -- Test 15.3 . 


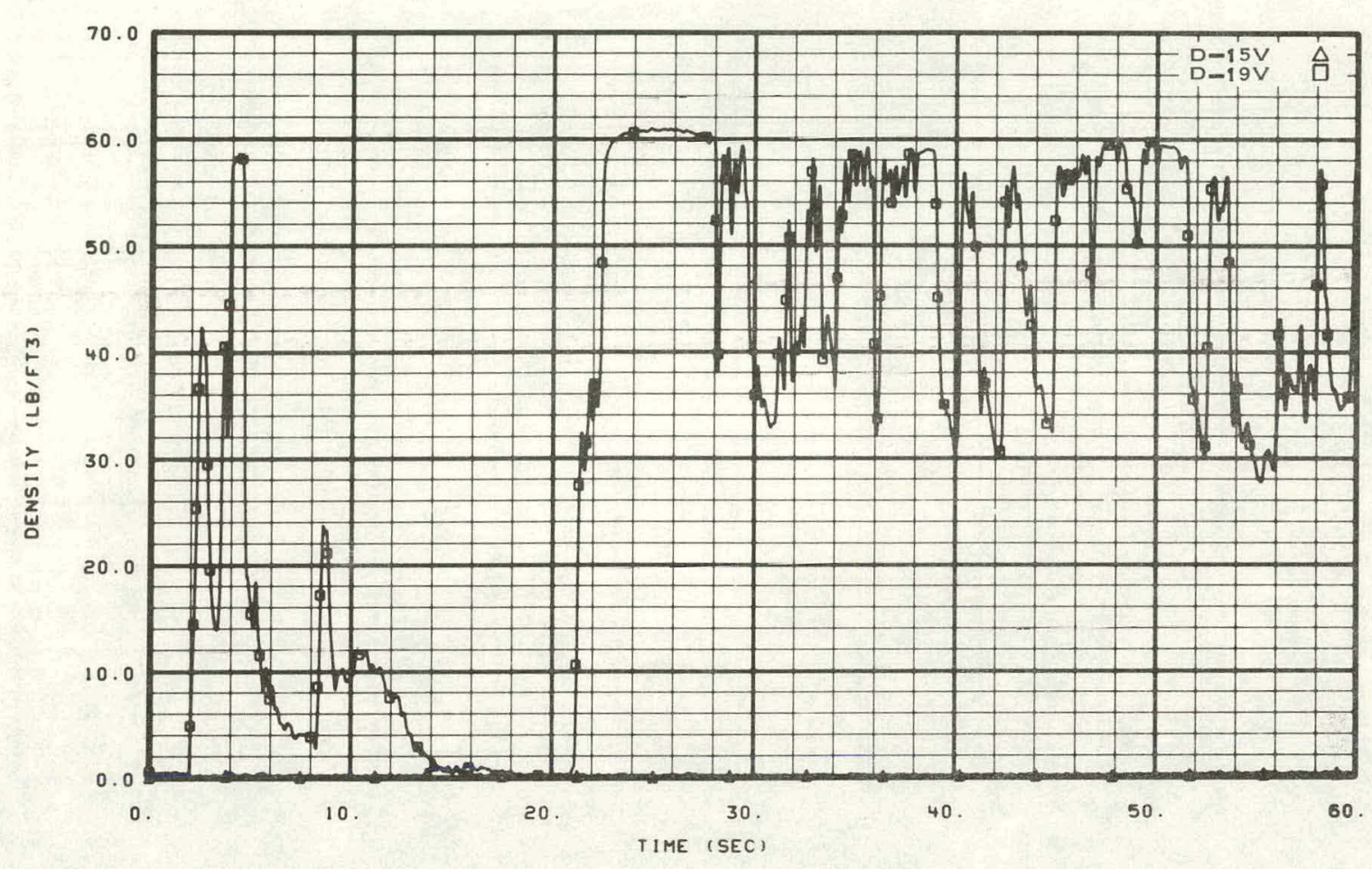

Fig. 174 Fluid density at operating loop pump inlet and outlet -- Test 15.4 .

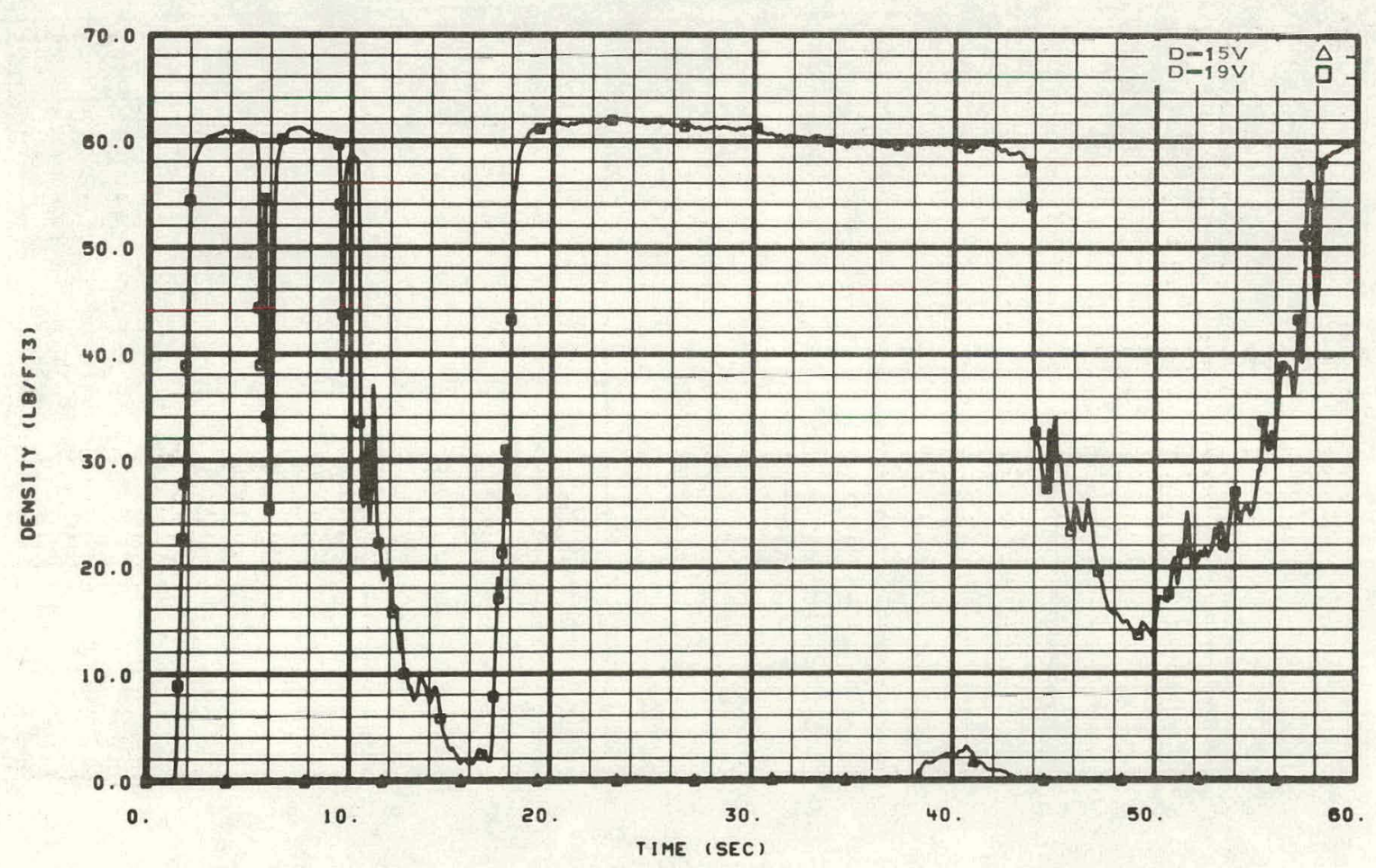

Fig. 175 Fluid density at operating loop pump inlet and outlet -- Test 15.7 . 


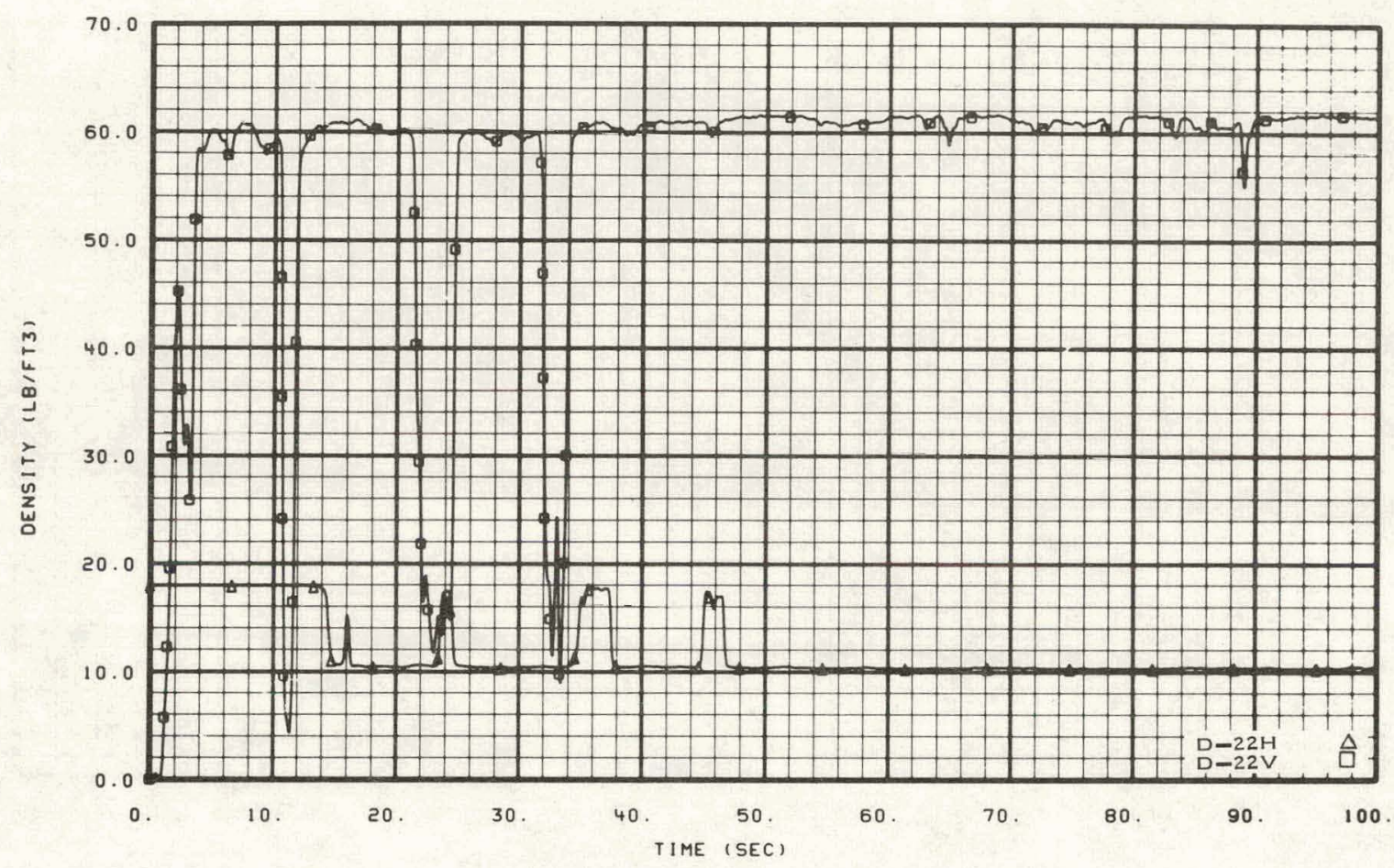

Fig. 176 Fluid density in operating loop cold leg -- Test 15.1.

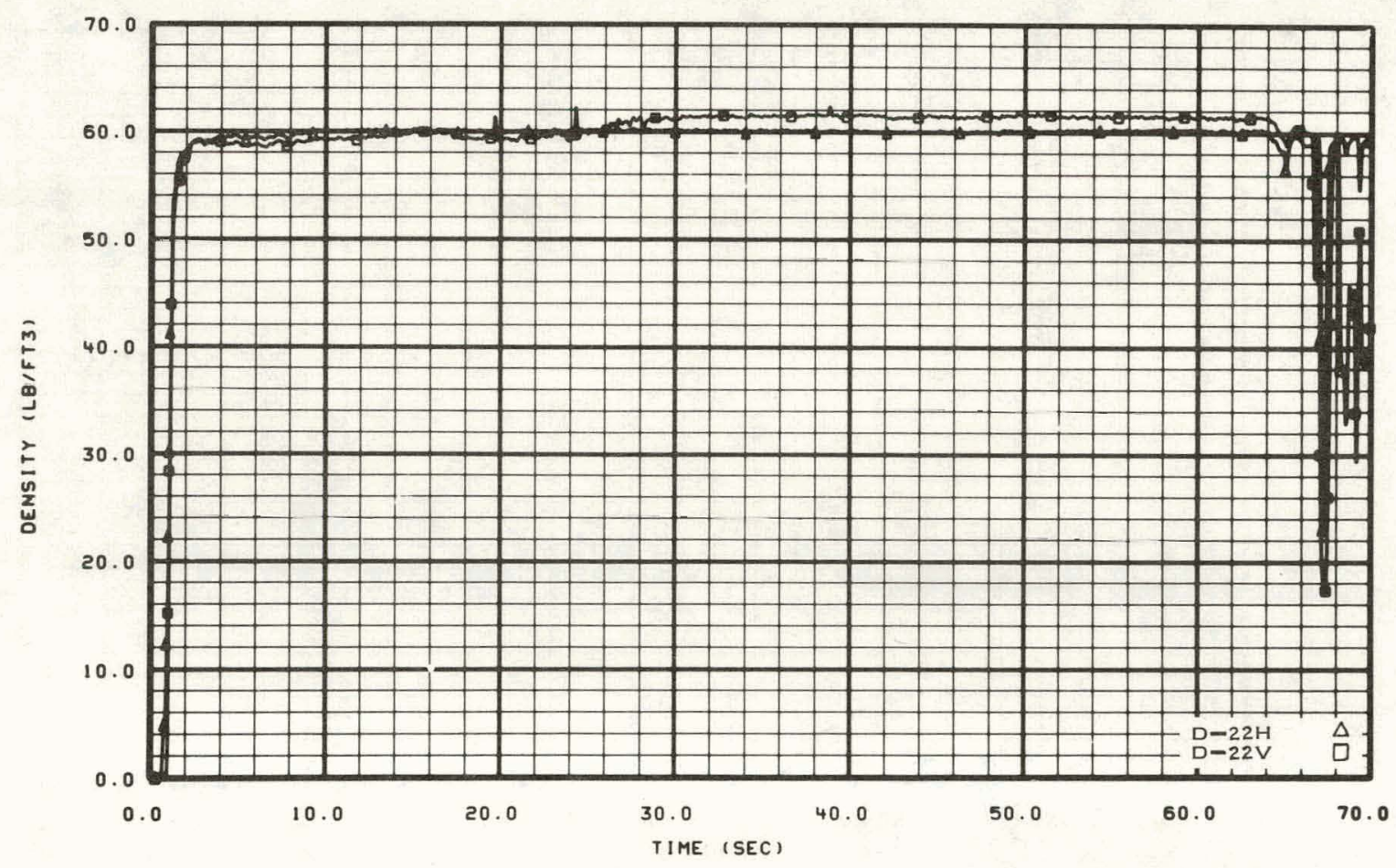

Fig. 177 Fluid density in operating loop cold leg -- Test 15.2. 


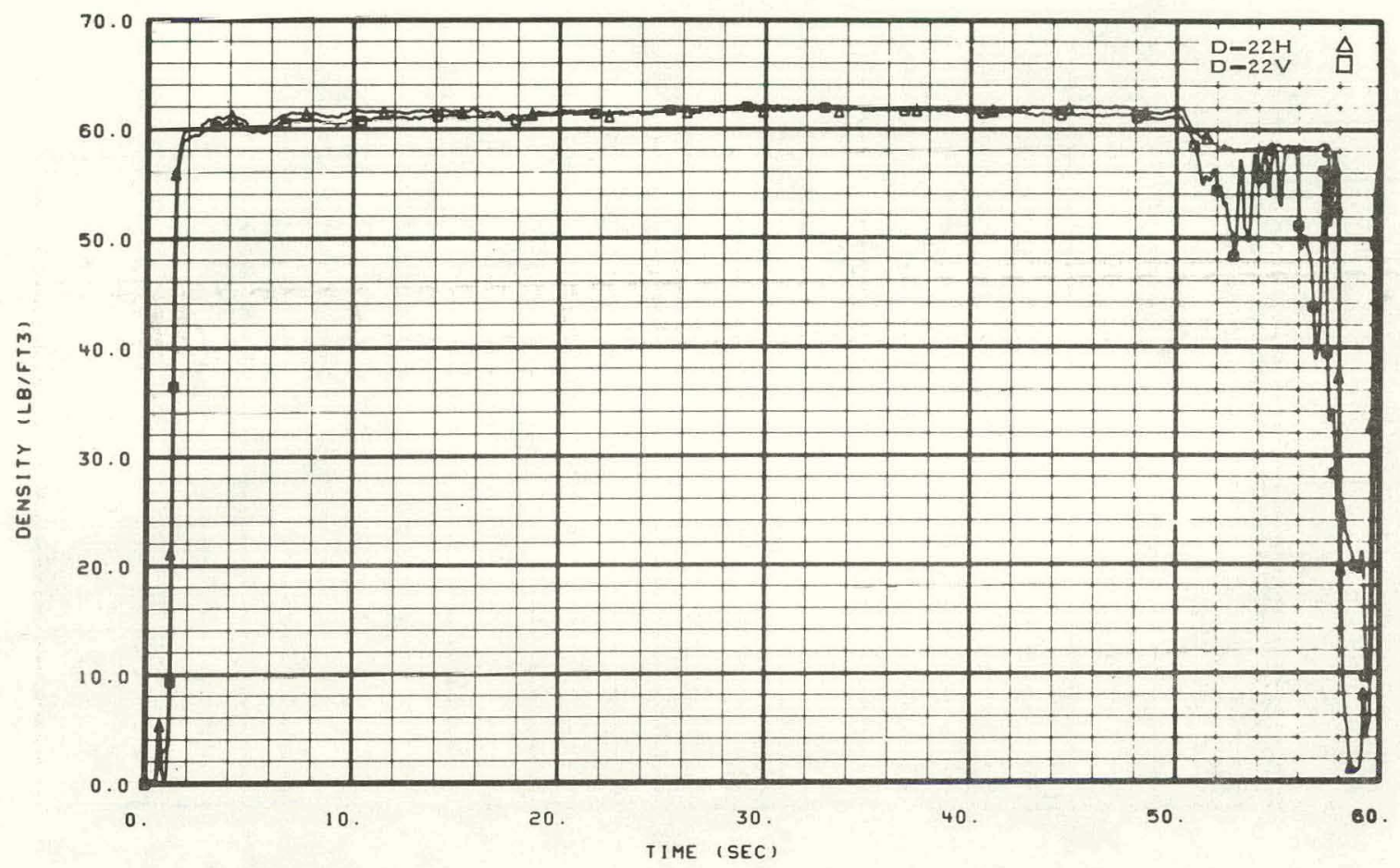

Fig. 178 Fluid density in operating loop cold leg -- Test 15.3.

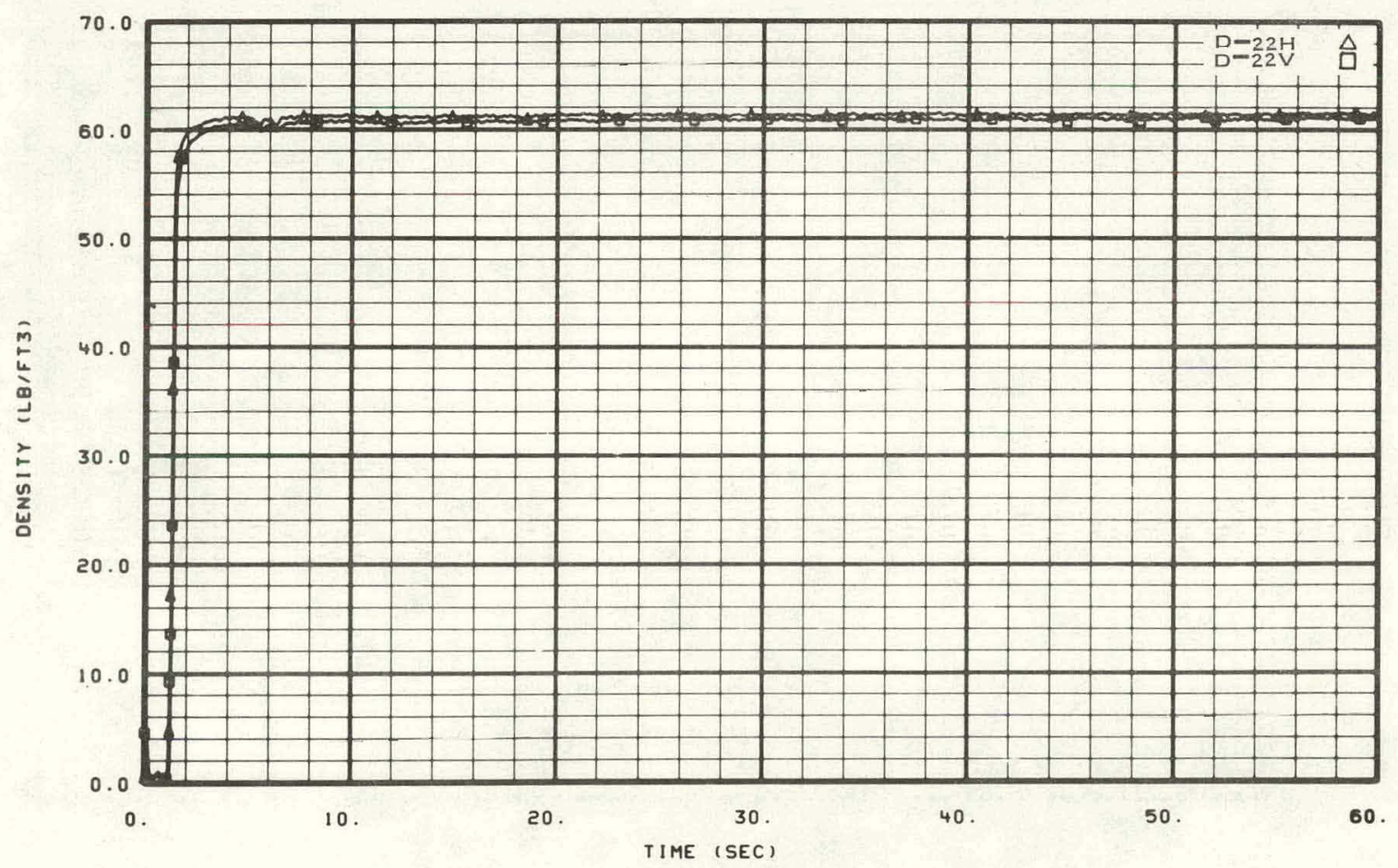

Fig. 179 Fluid density in operating loop cold leg -- Test 15.4. 


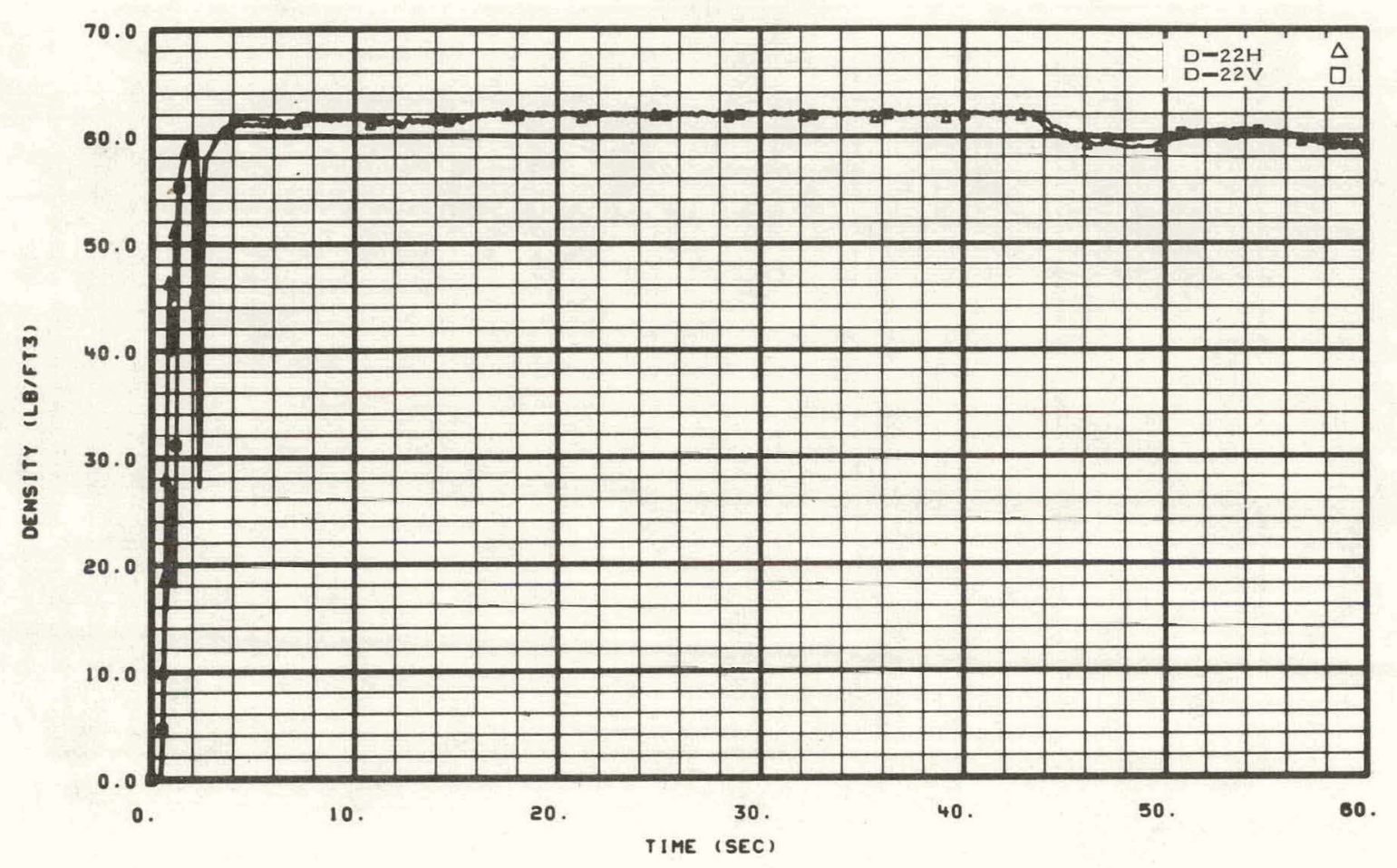

Fig. 180 Fluid density in operating loop cold leg -- Test 15.7.

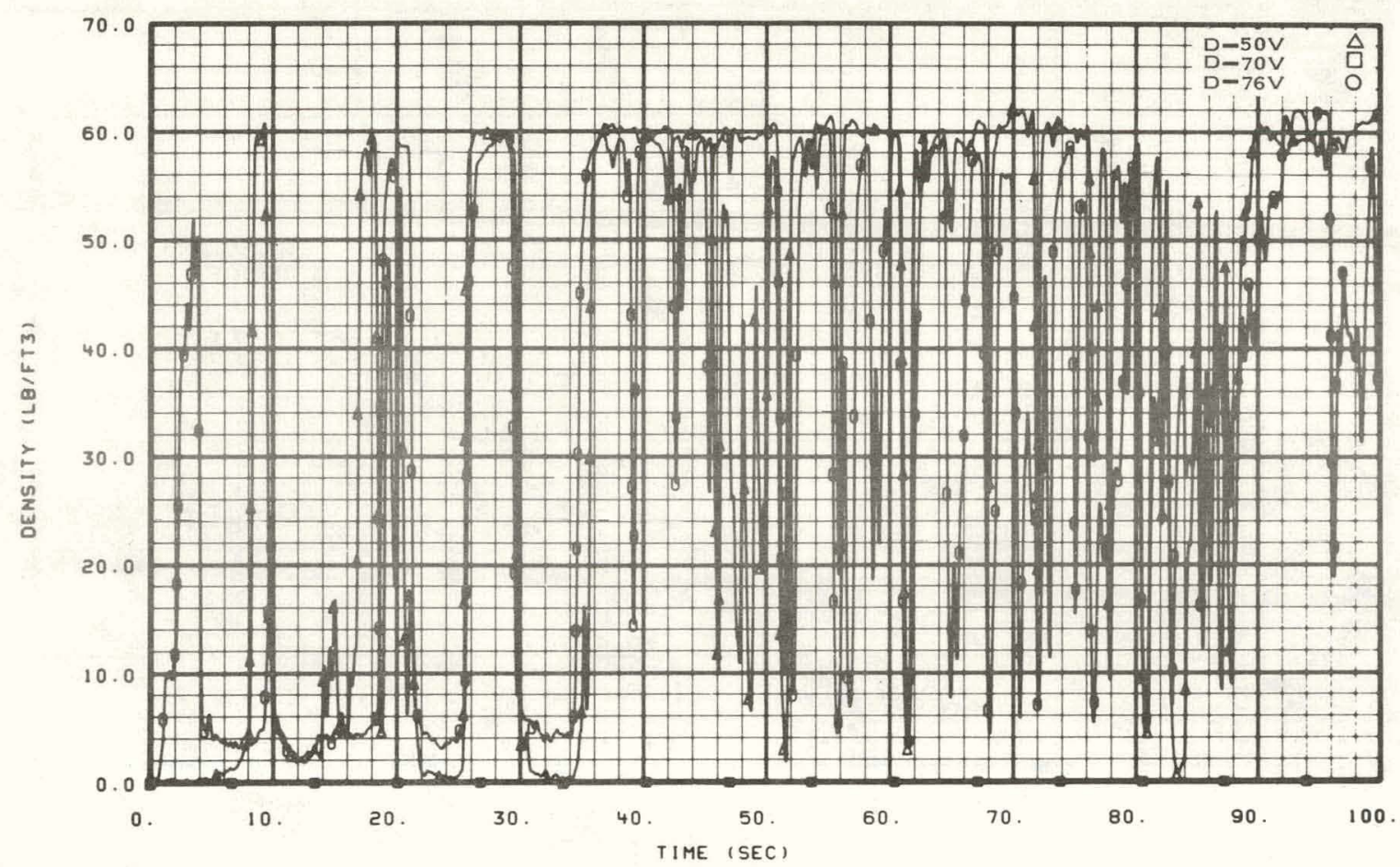

Fig. 181 Fluid density in blowdown loop -- Test 15.1. 


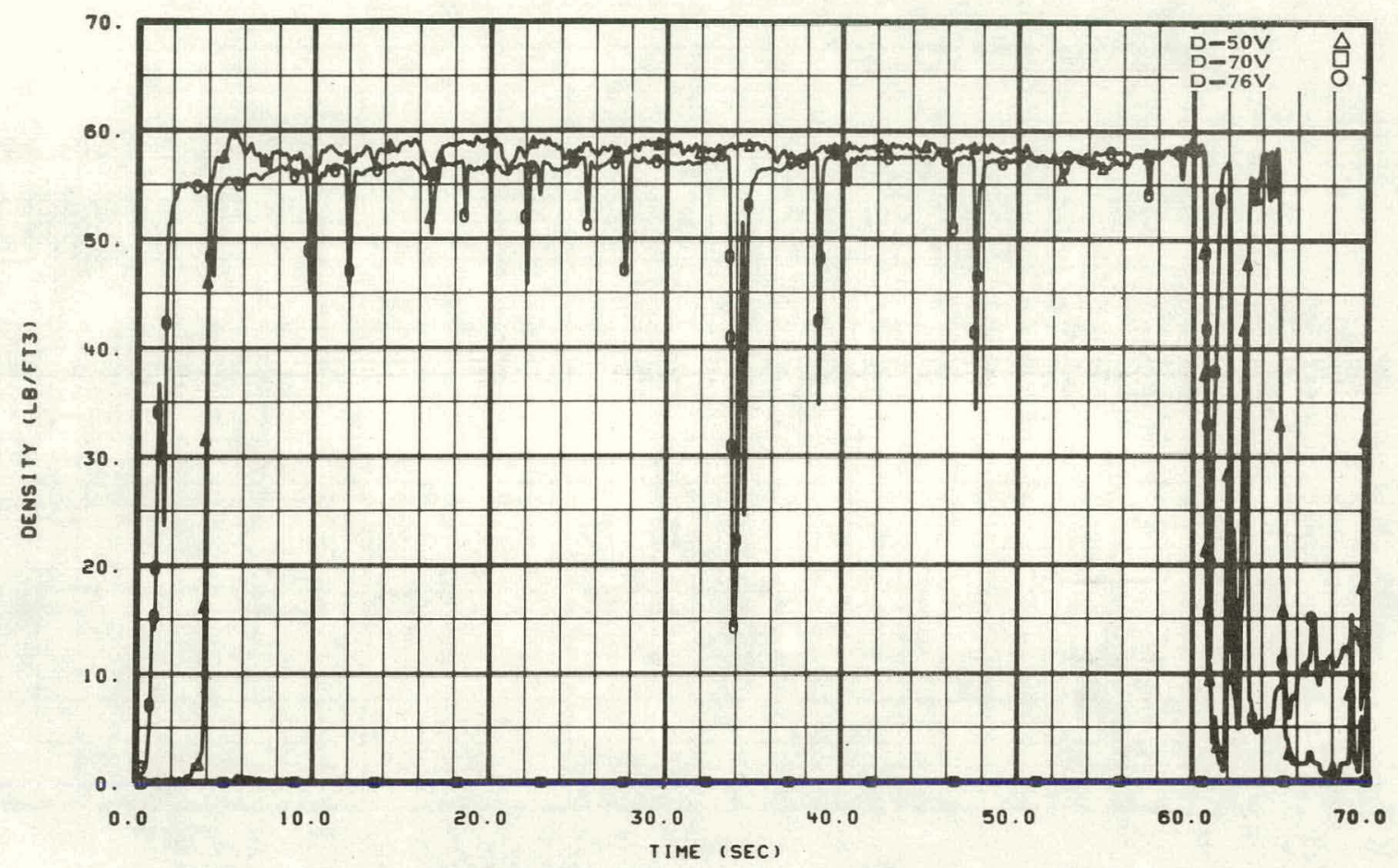

Fig. 182 Fluid density in blowdown loop -- Test 15.2.

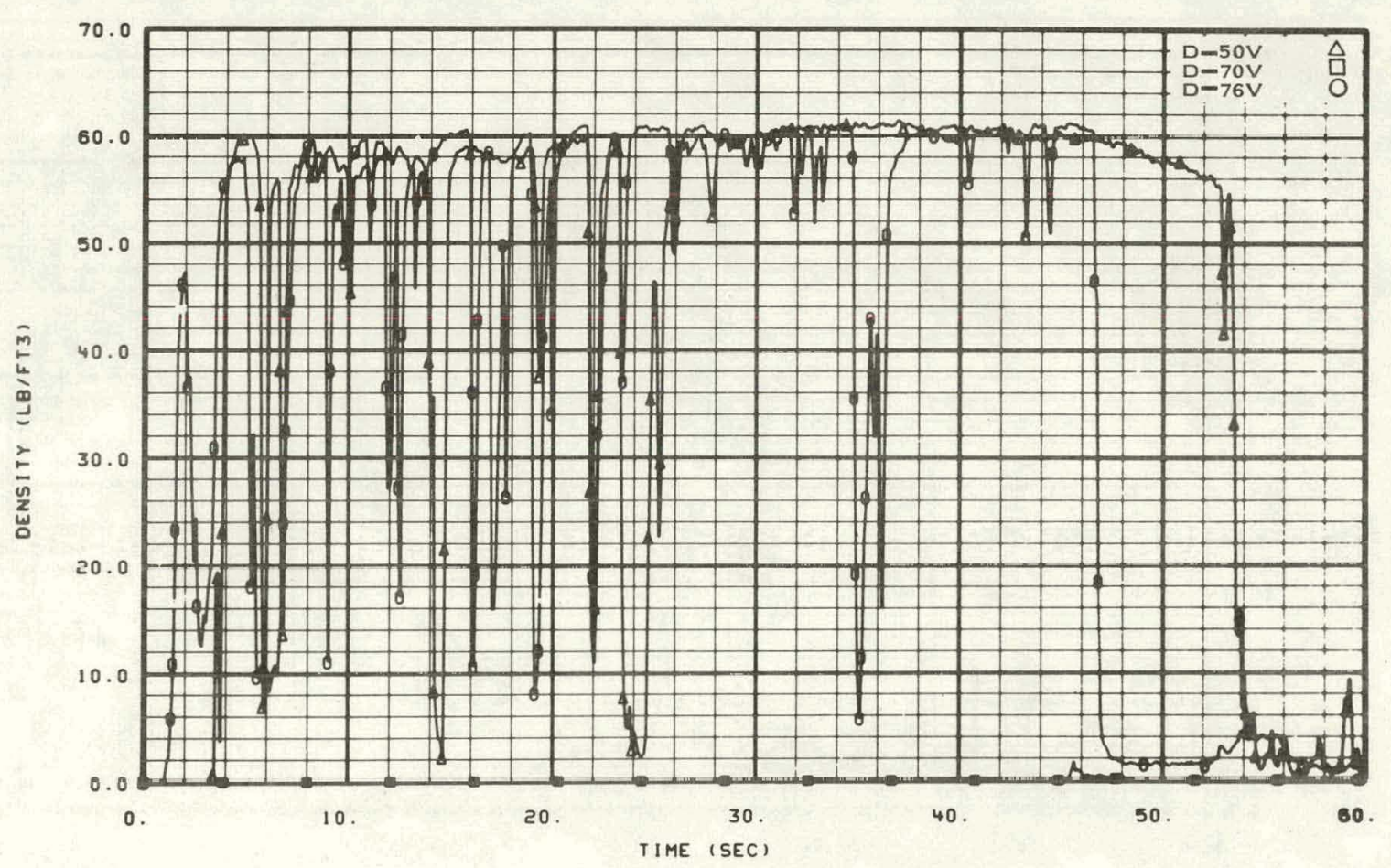

Fig. 183 Fluid density in blowdown loop -- Test 15.3. 


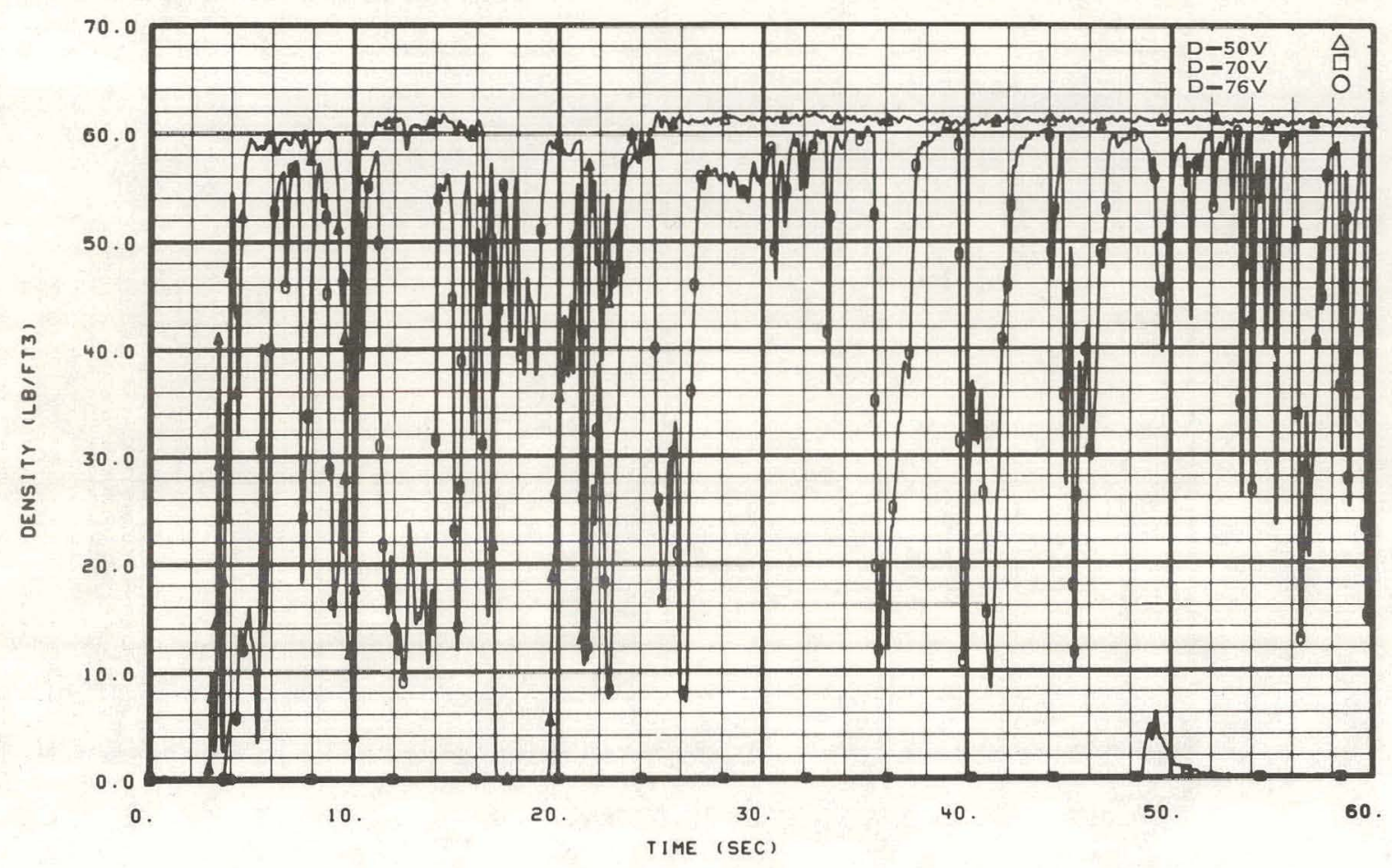

Fig. 184 Fluid density in blowdown loop -- Test 15.4 .

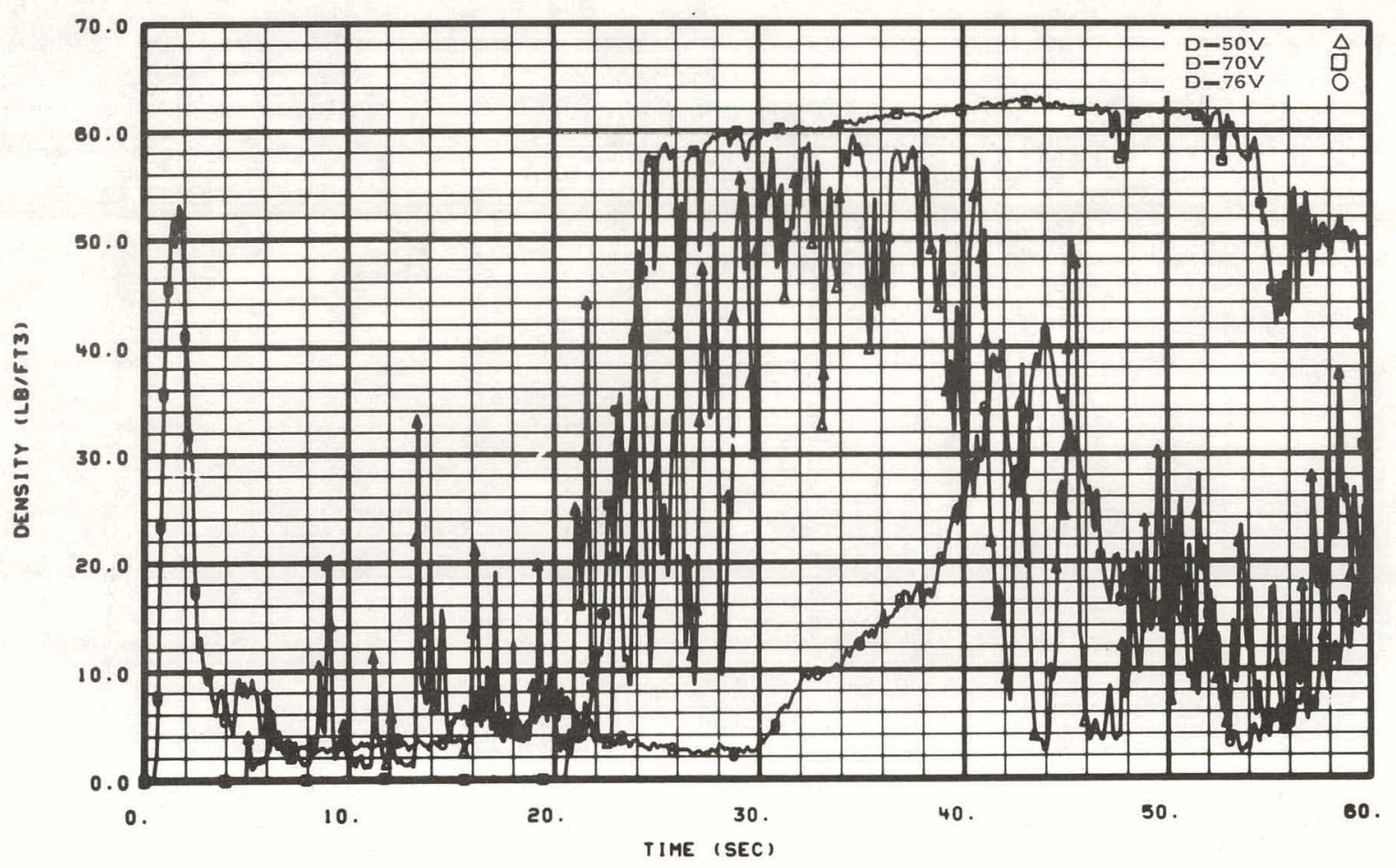

Fig. 185 Fluid density in blowdown loop -- Test 15.7. 


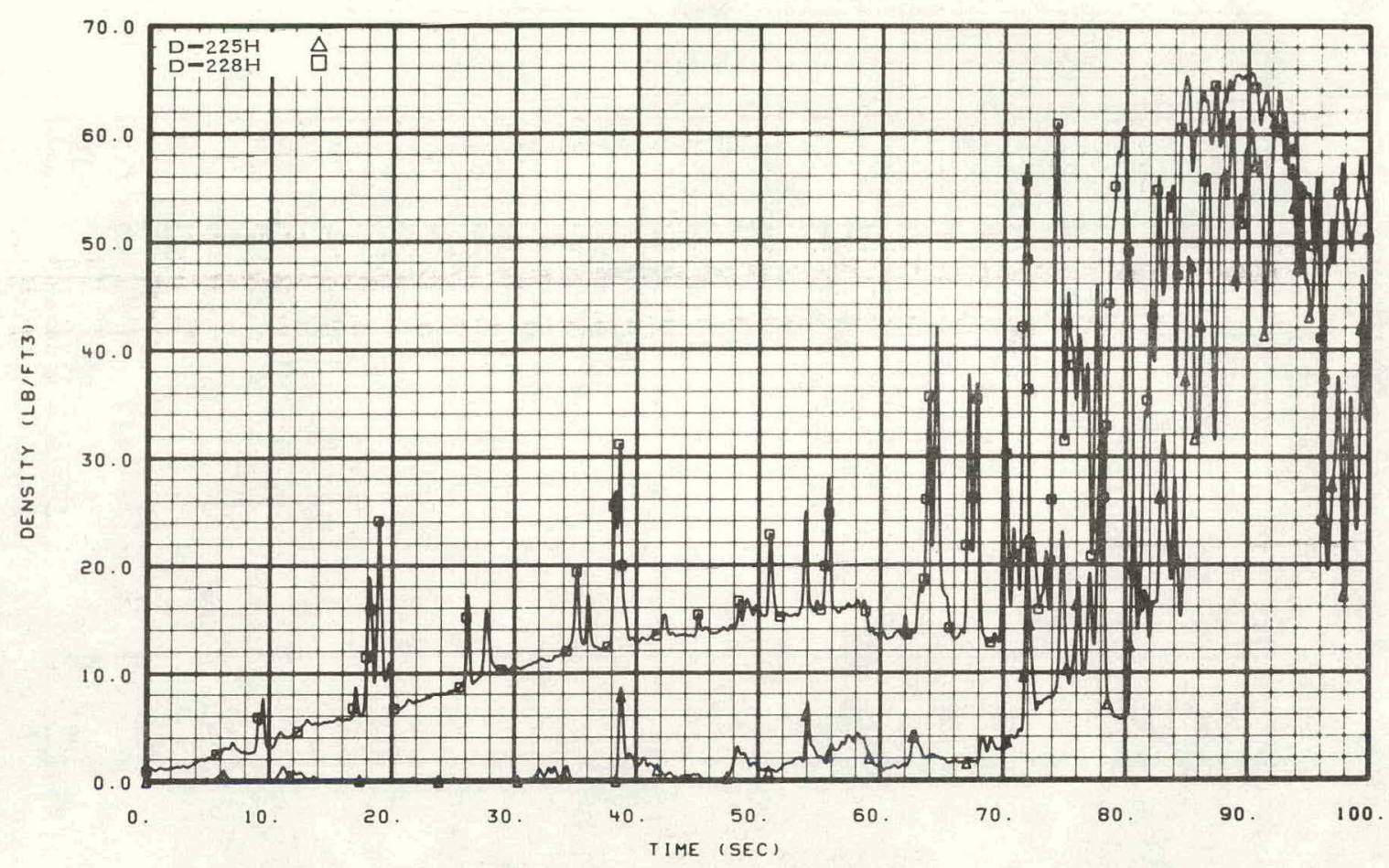

Fig. 186 Fluid density in vesse1 -- Test 15.1.

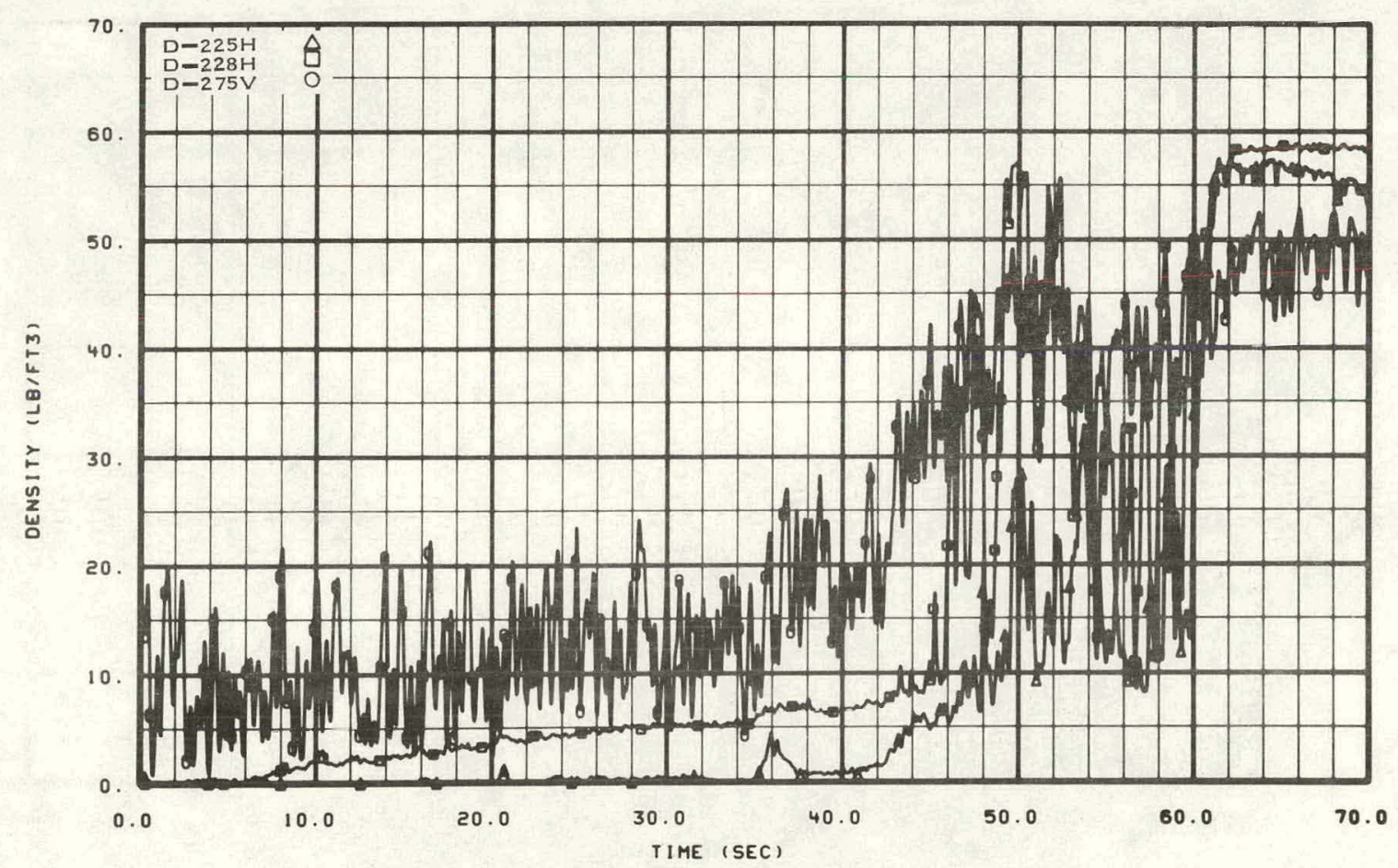

Fig. 187 Fluid density in vessel -- Test 15.2 . 


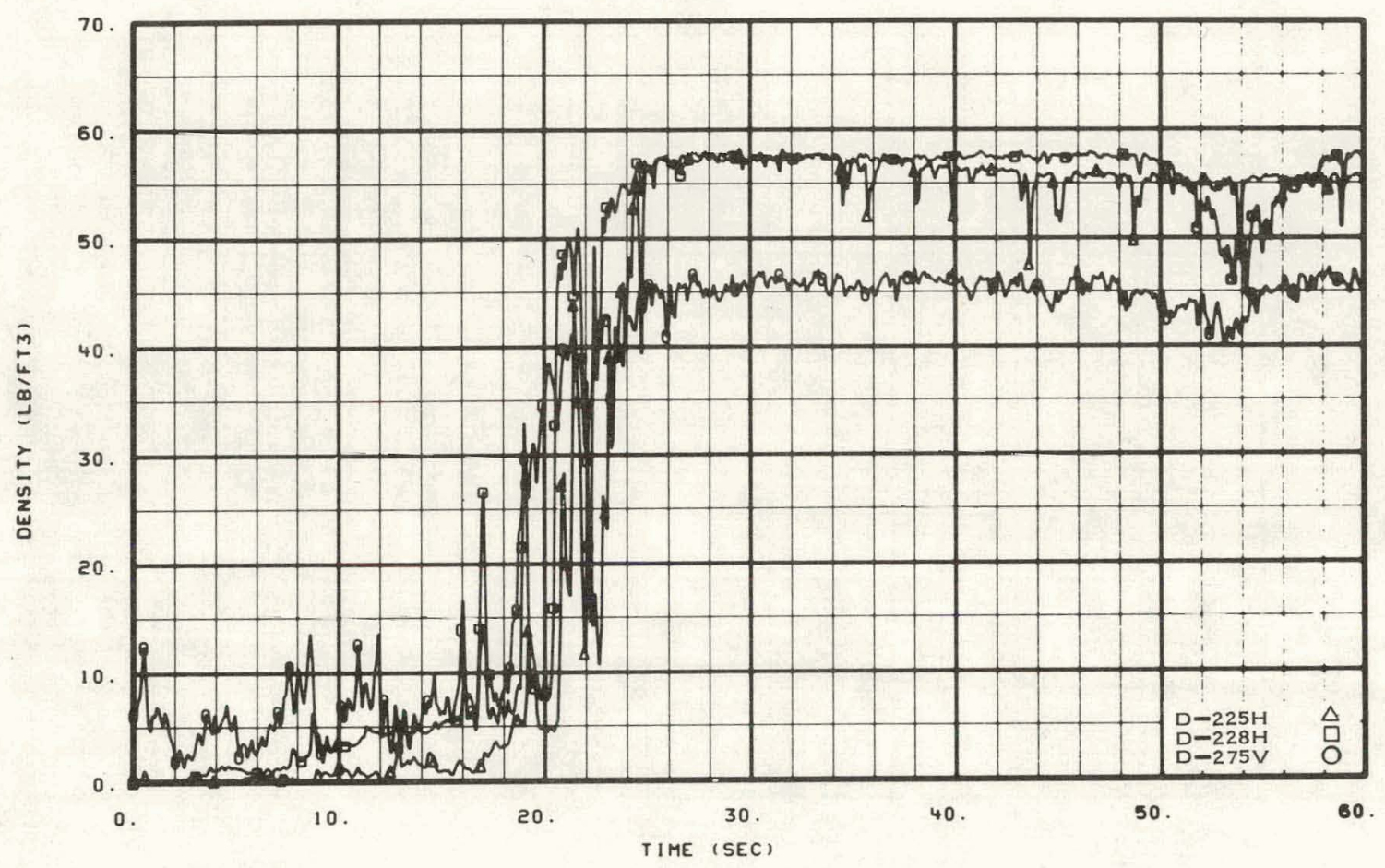

Fig. 188 Fluid density in vesse1 -- Test 15.3.

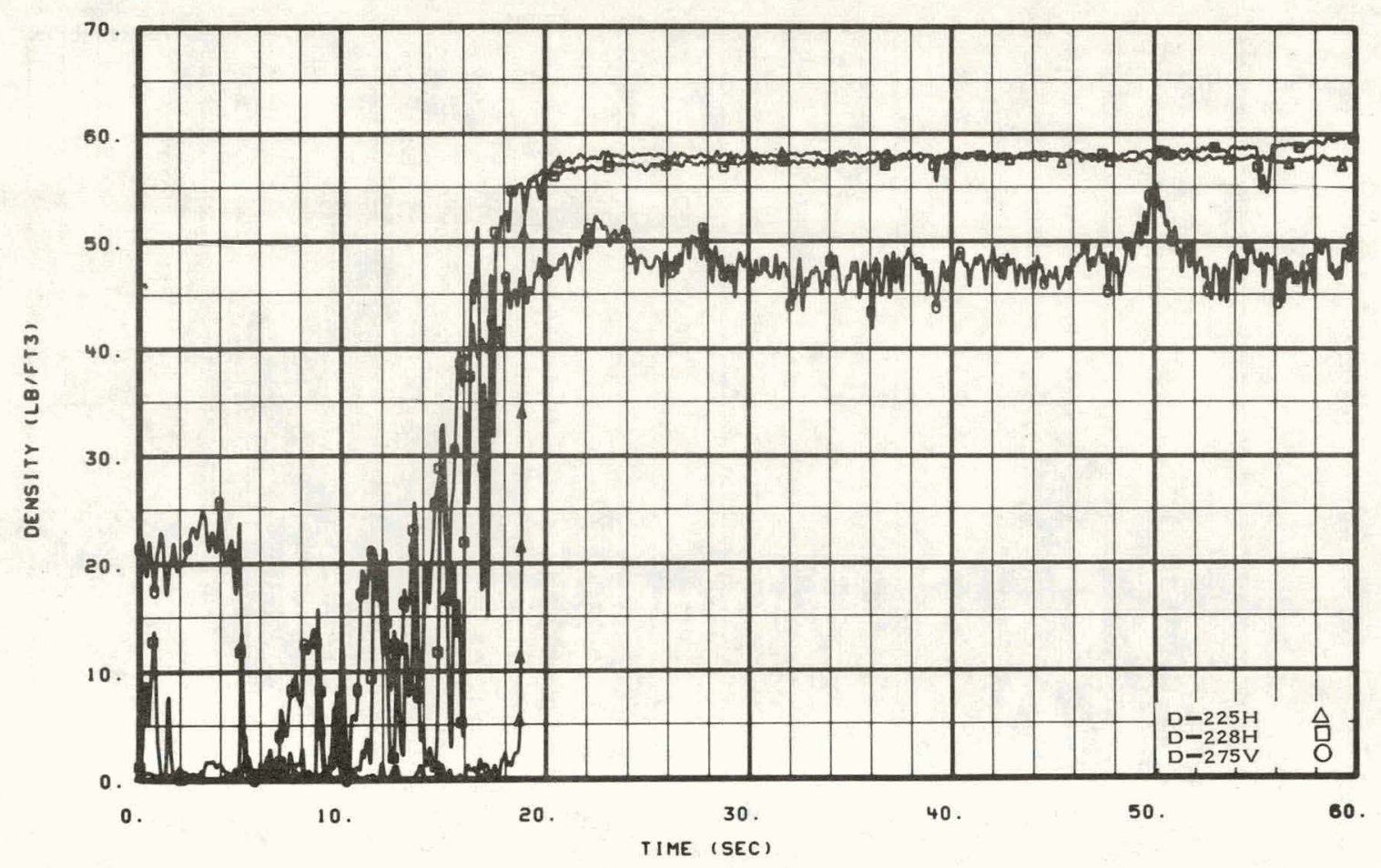

Fig. 189 Fluid density in vesse1 -- Test 15.4 . 


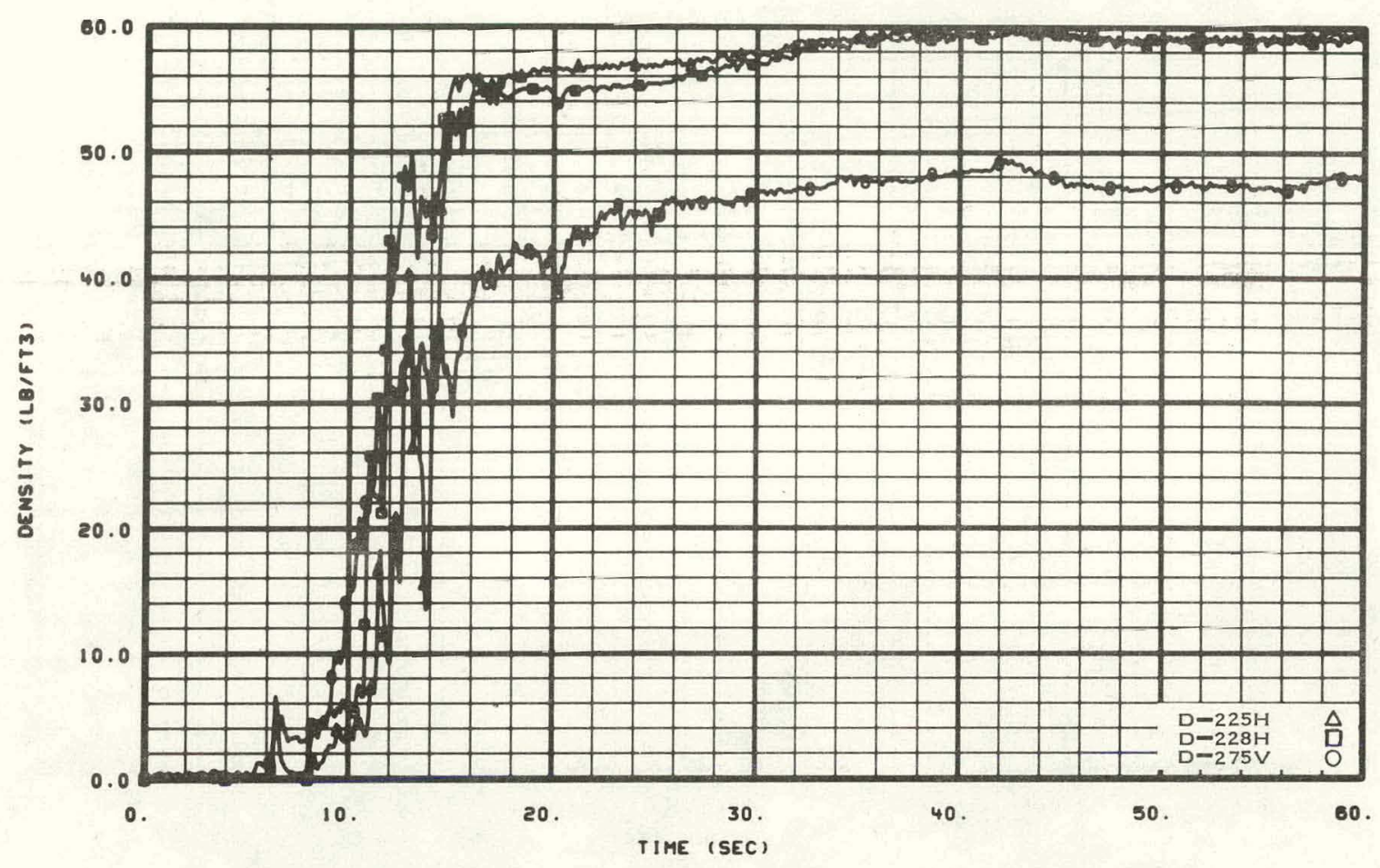

Fig. 190 Fluid density in vessel -- Test 15.7.

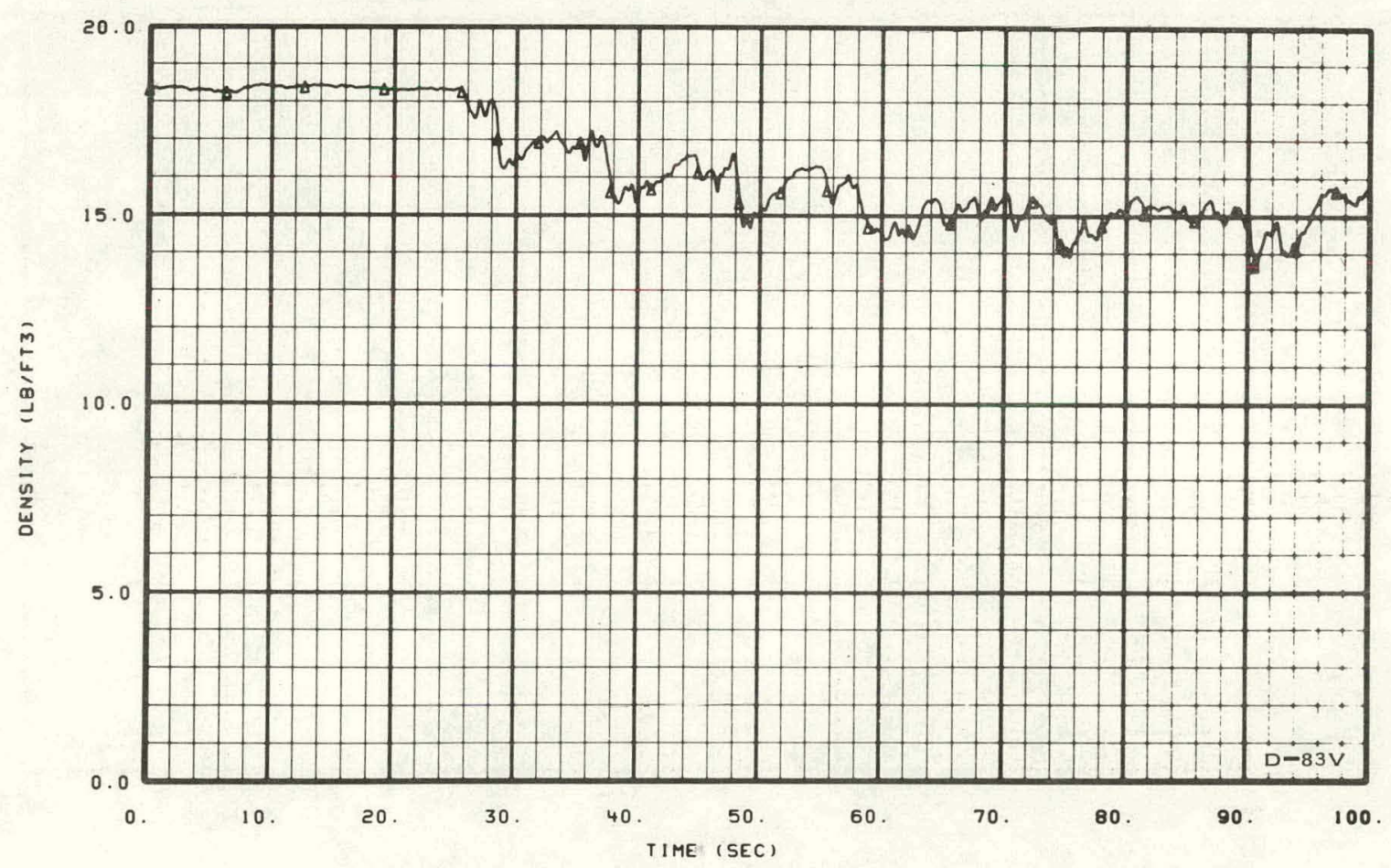

Fig. 191 Fluid density in pressure suppression header -- Test 15.1. 


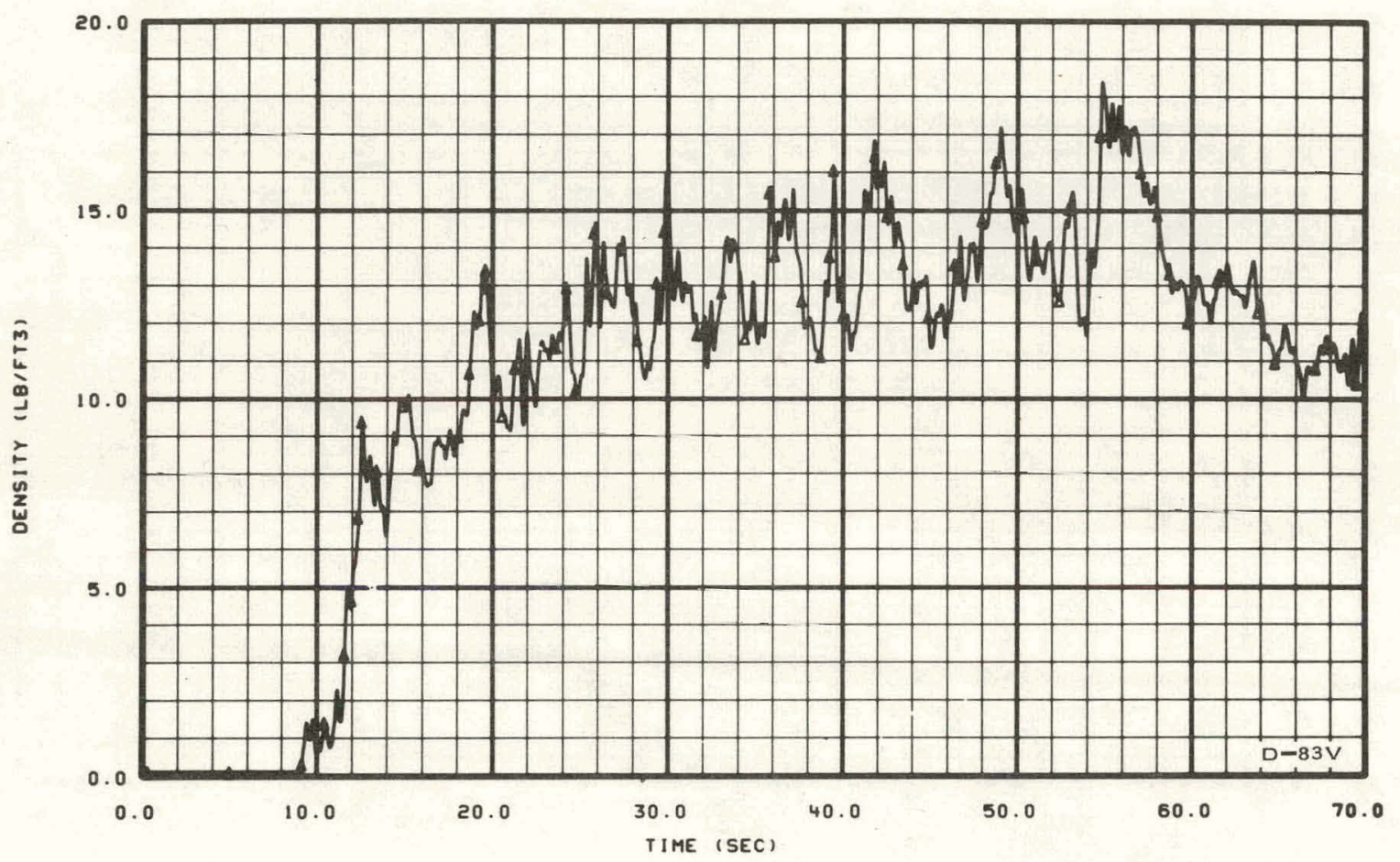

Fig. 192 Fluid density in pressure suppression header -- Test 15.2.

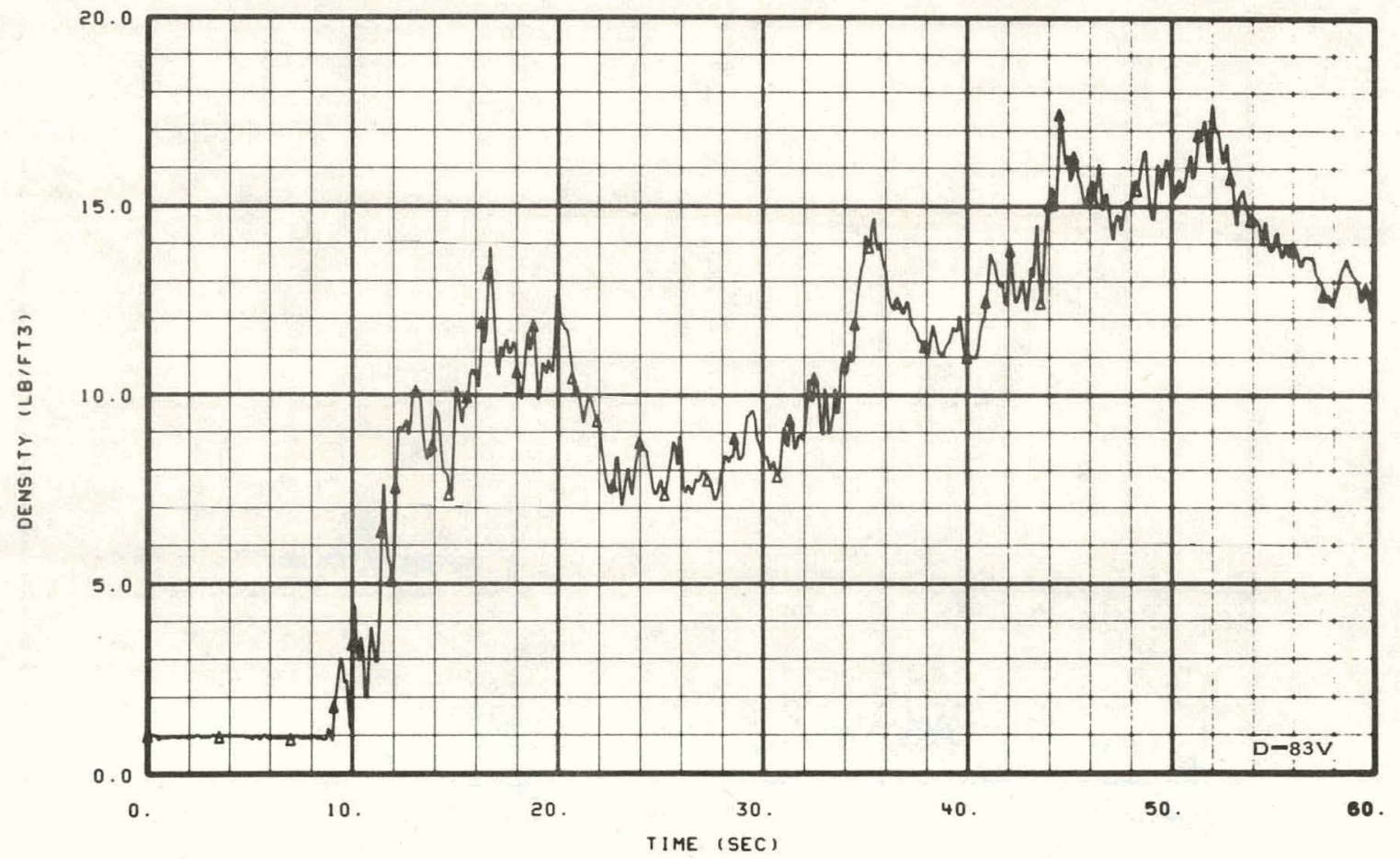

Fig. 193 Fluid density in pressure suppression header -- Test 15.3. 


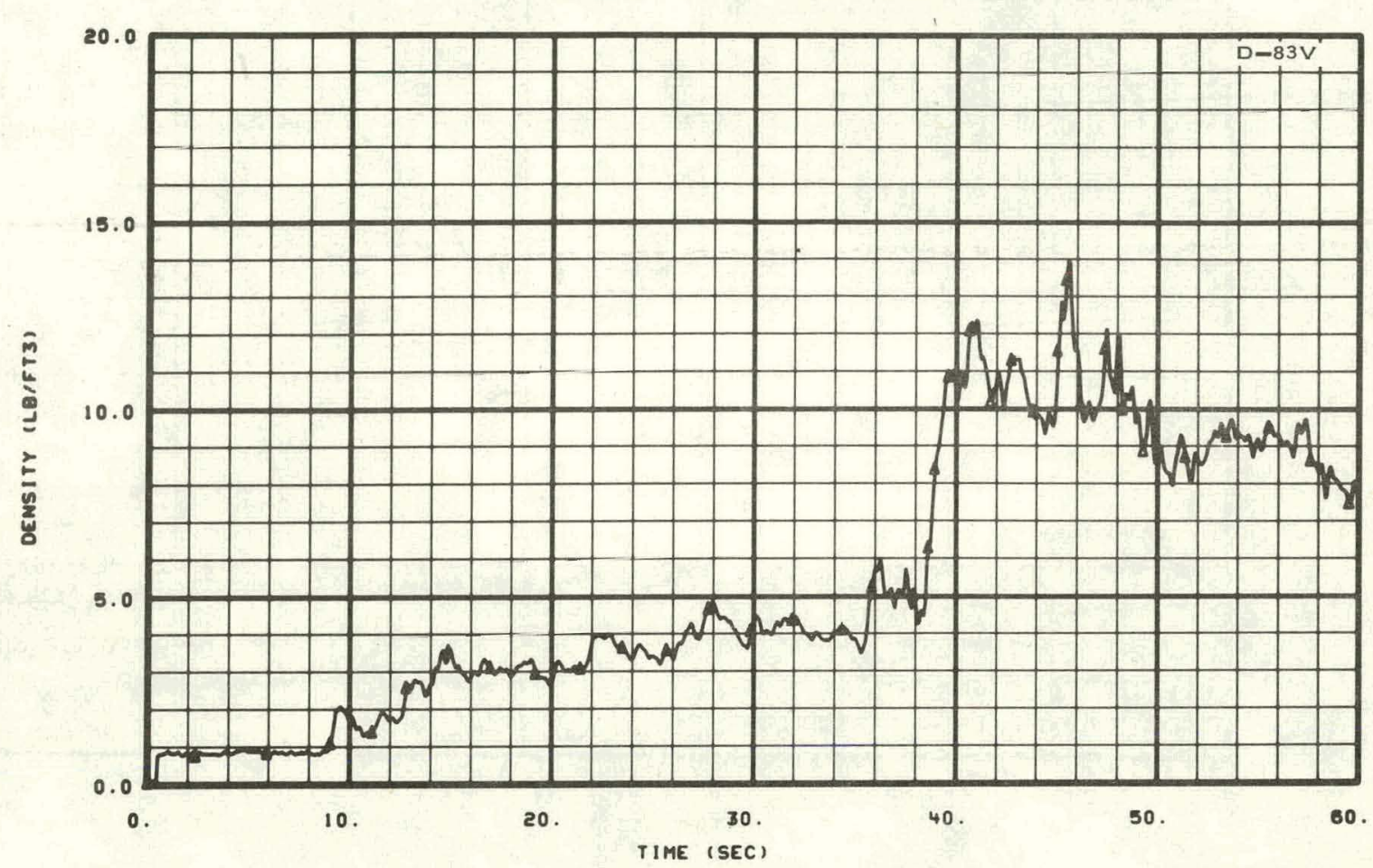

Fig. 194 Fluid density in pressure suppression header -- Test 15.7.

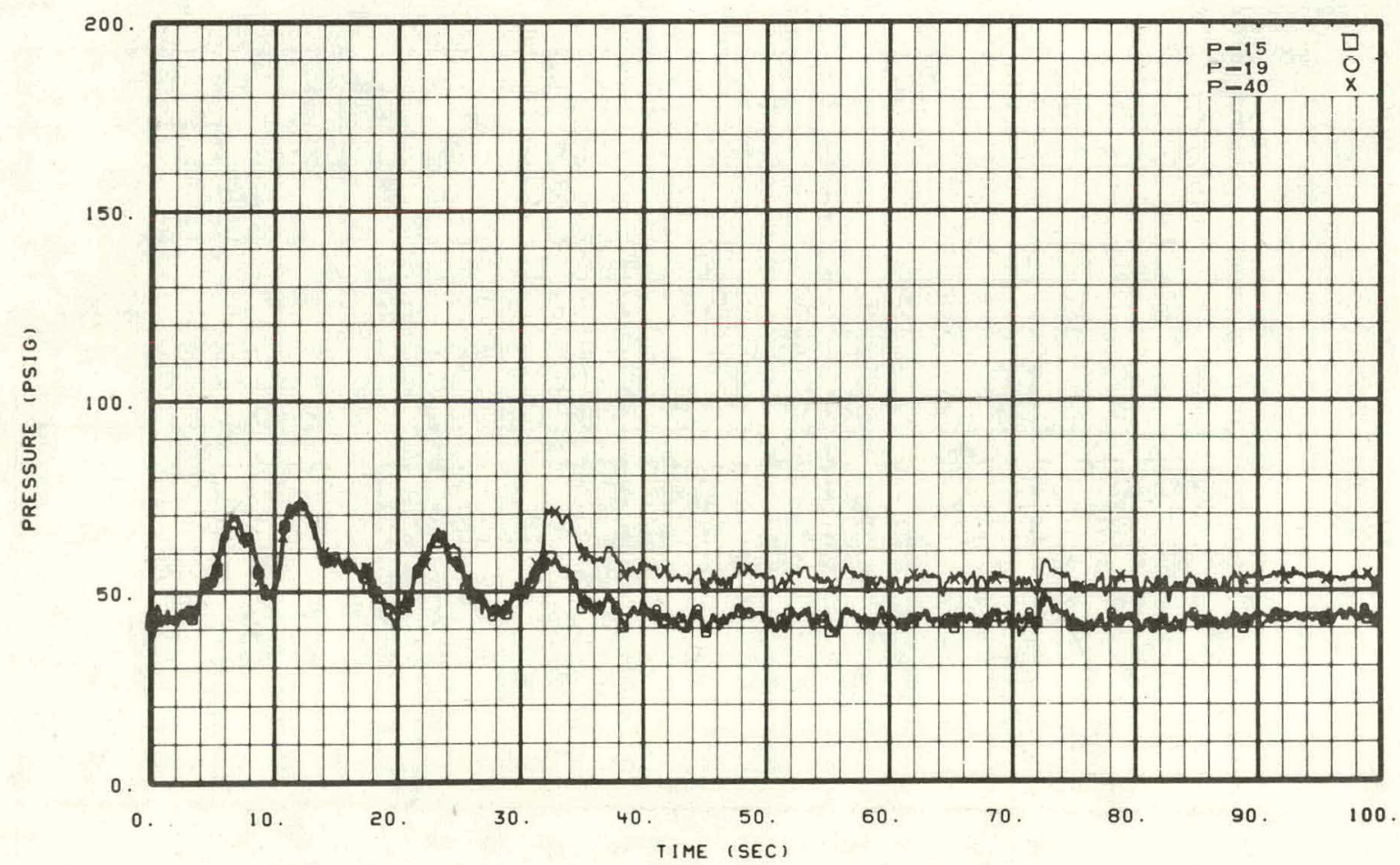

Fig. 195 Pressure in operating loop -- Test 15.1. 


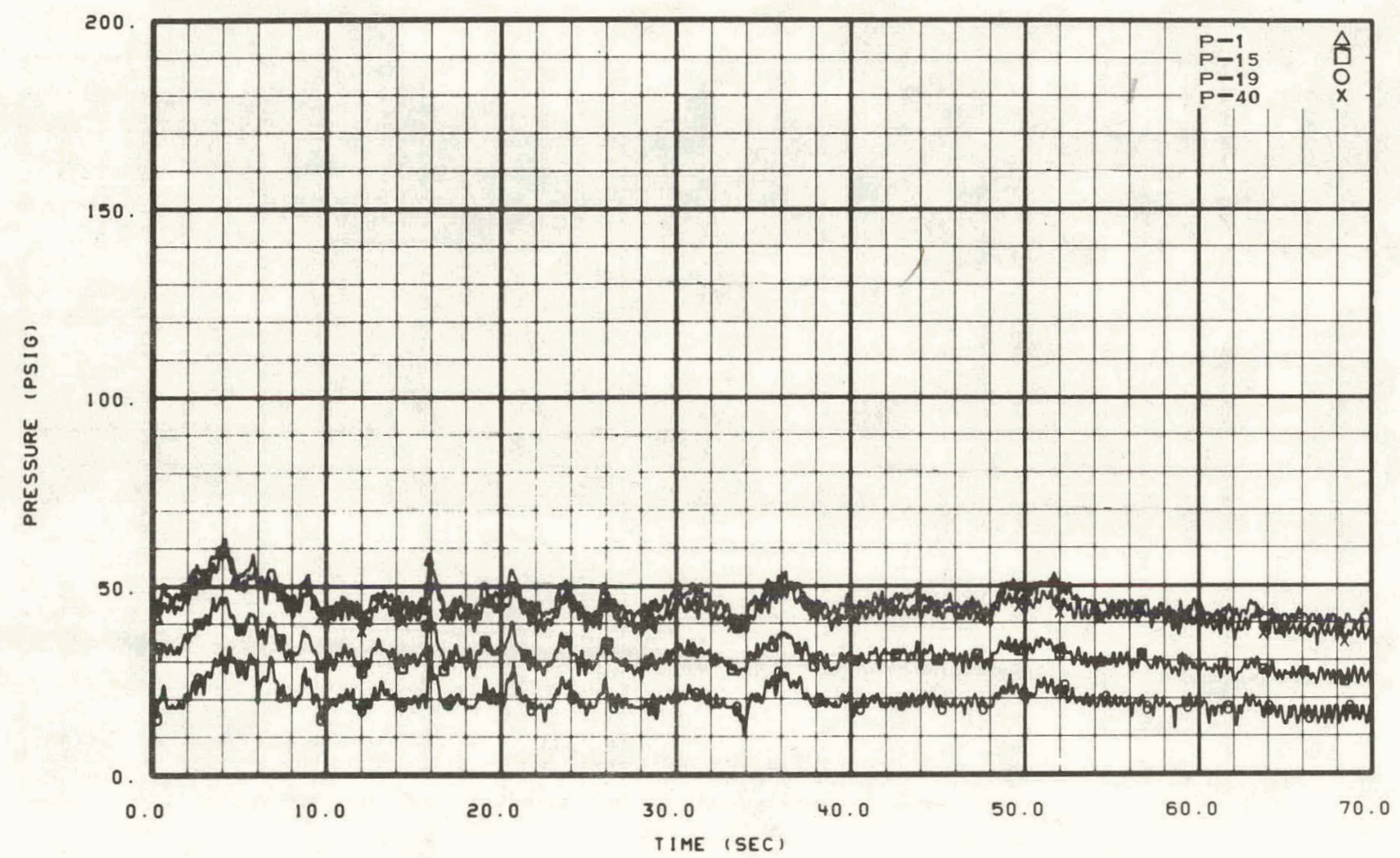

Fig. 196 Pressure in operating loop -- Test 15.2.

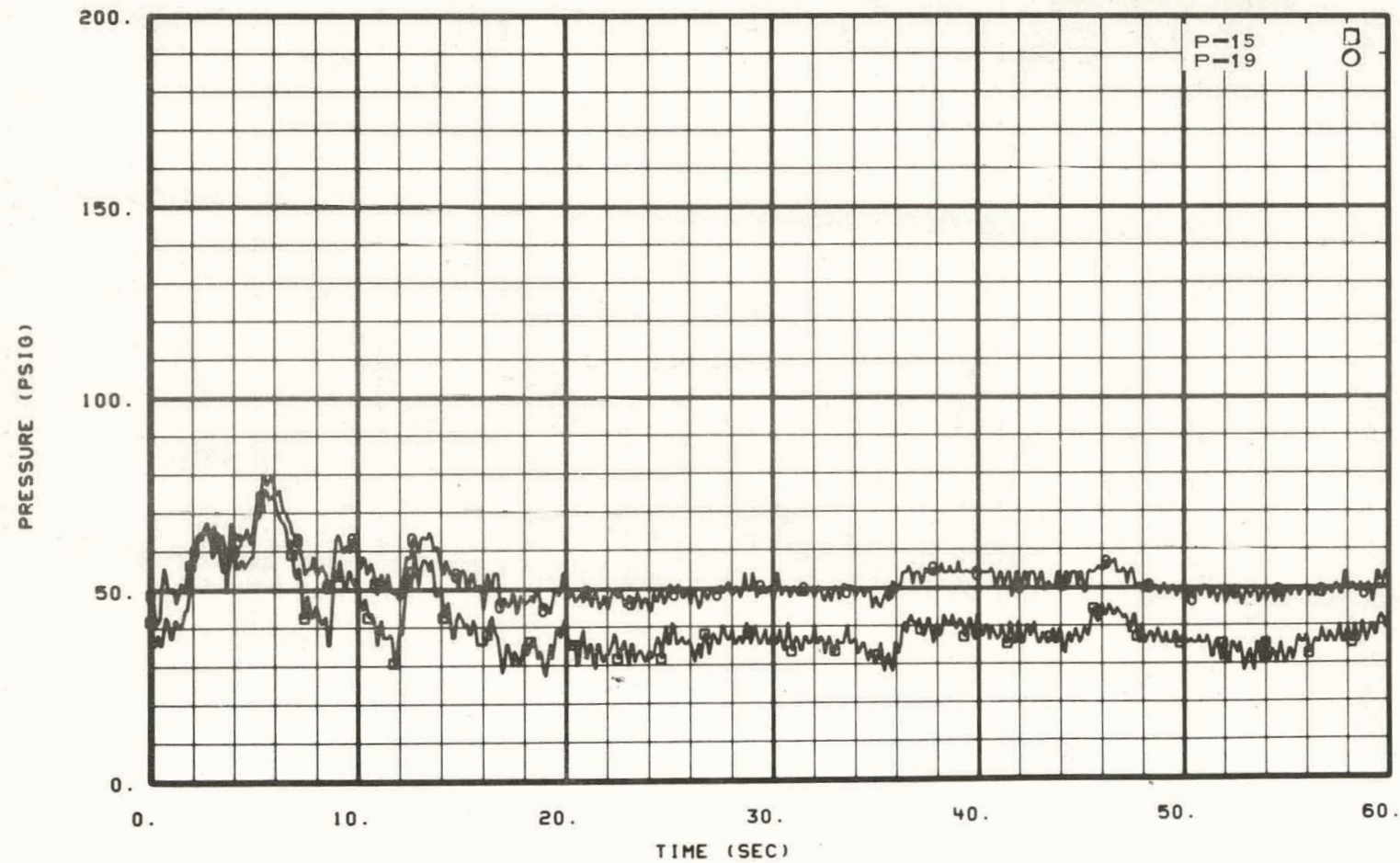

Fig. 197 Pressure in operating loop -- Test 15.3. 


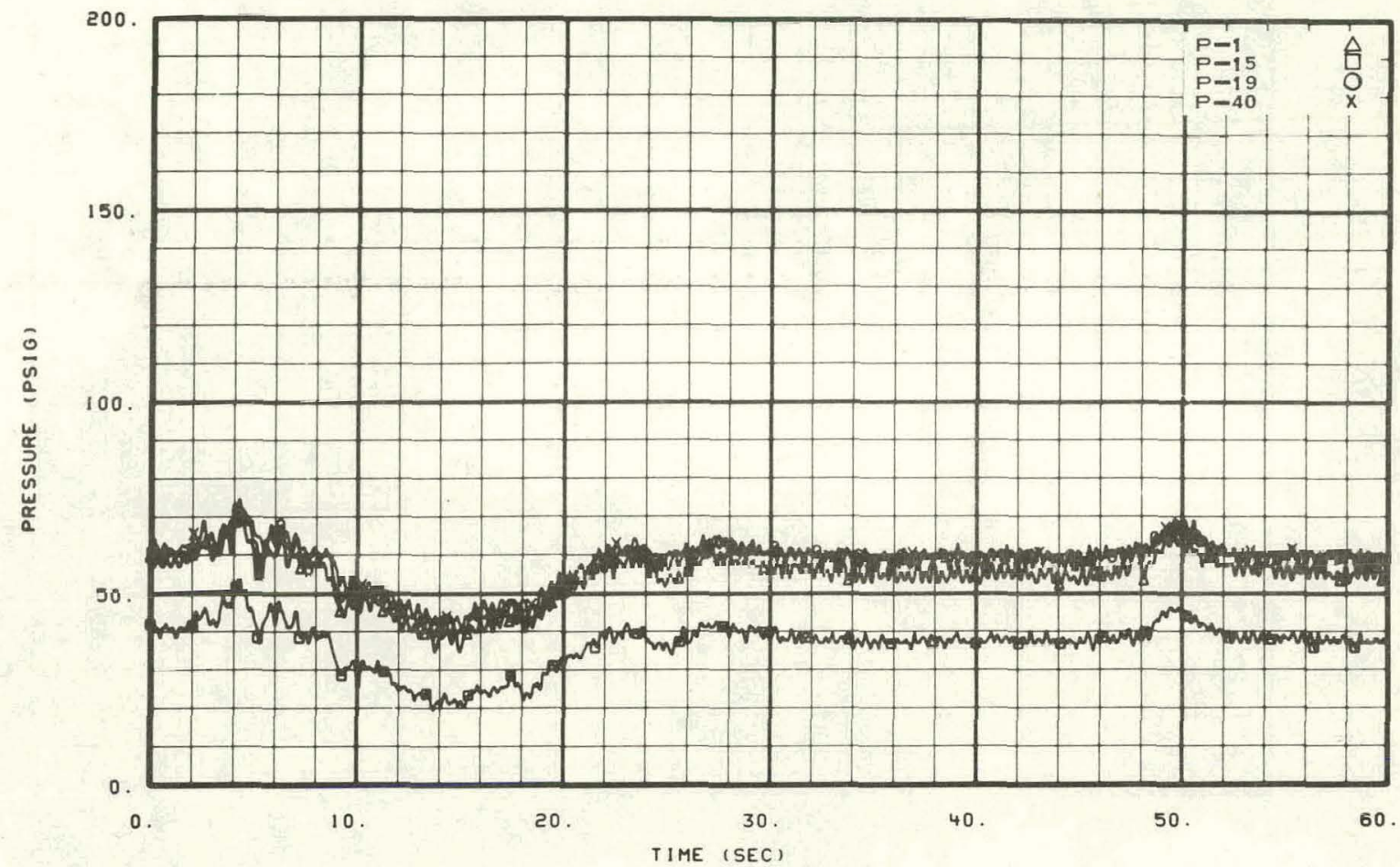

Fig. 198 Pressure in operating loop -- Test 15.4.

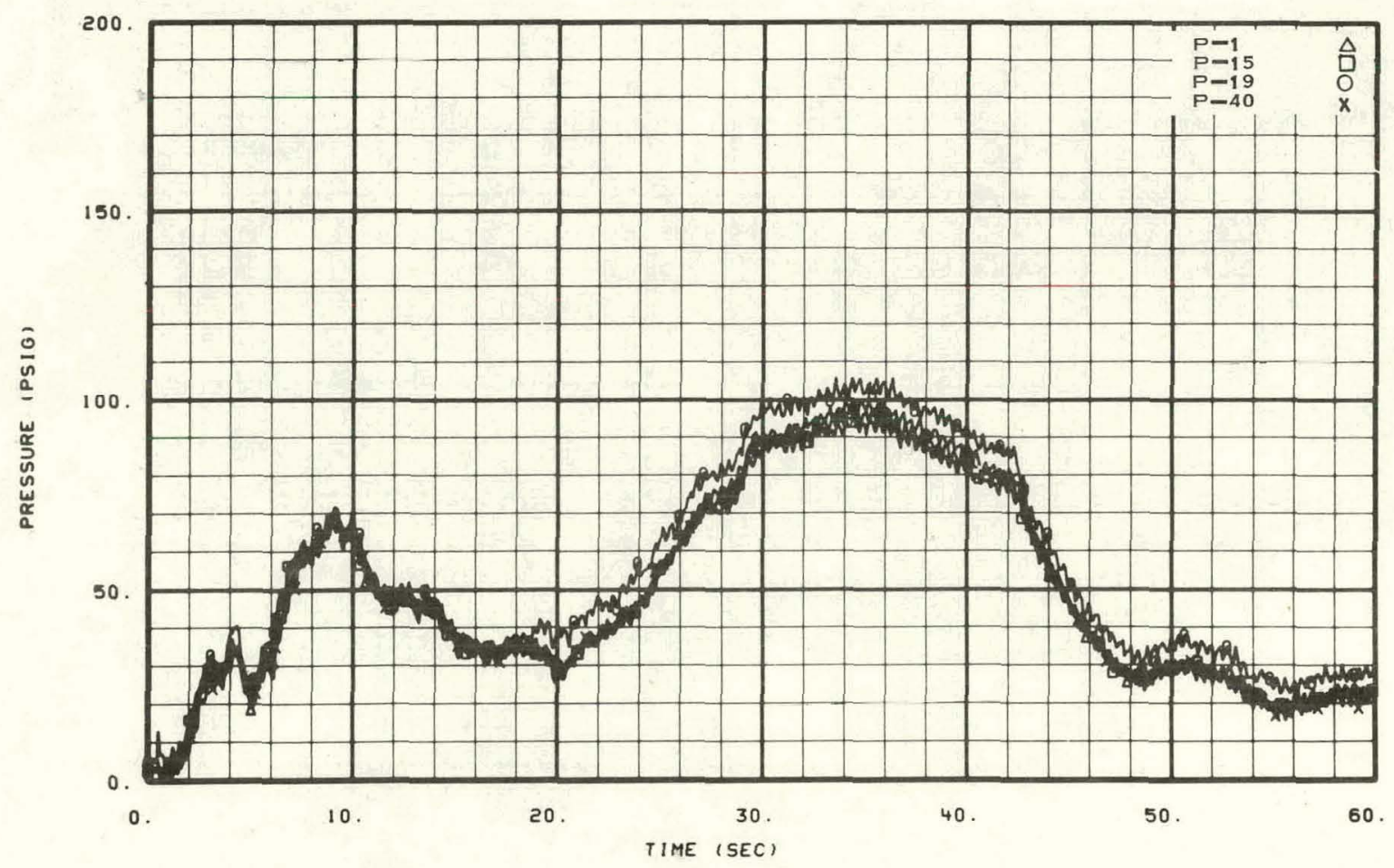

Fig. 199 Pressure in operating loop -- Test 15.7. 


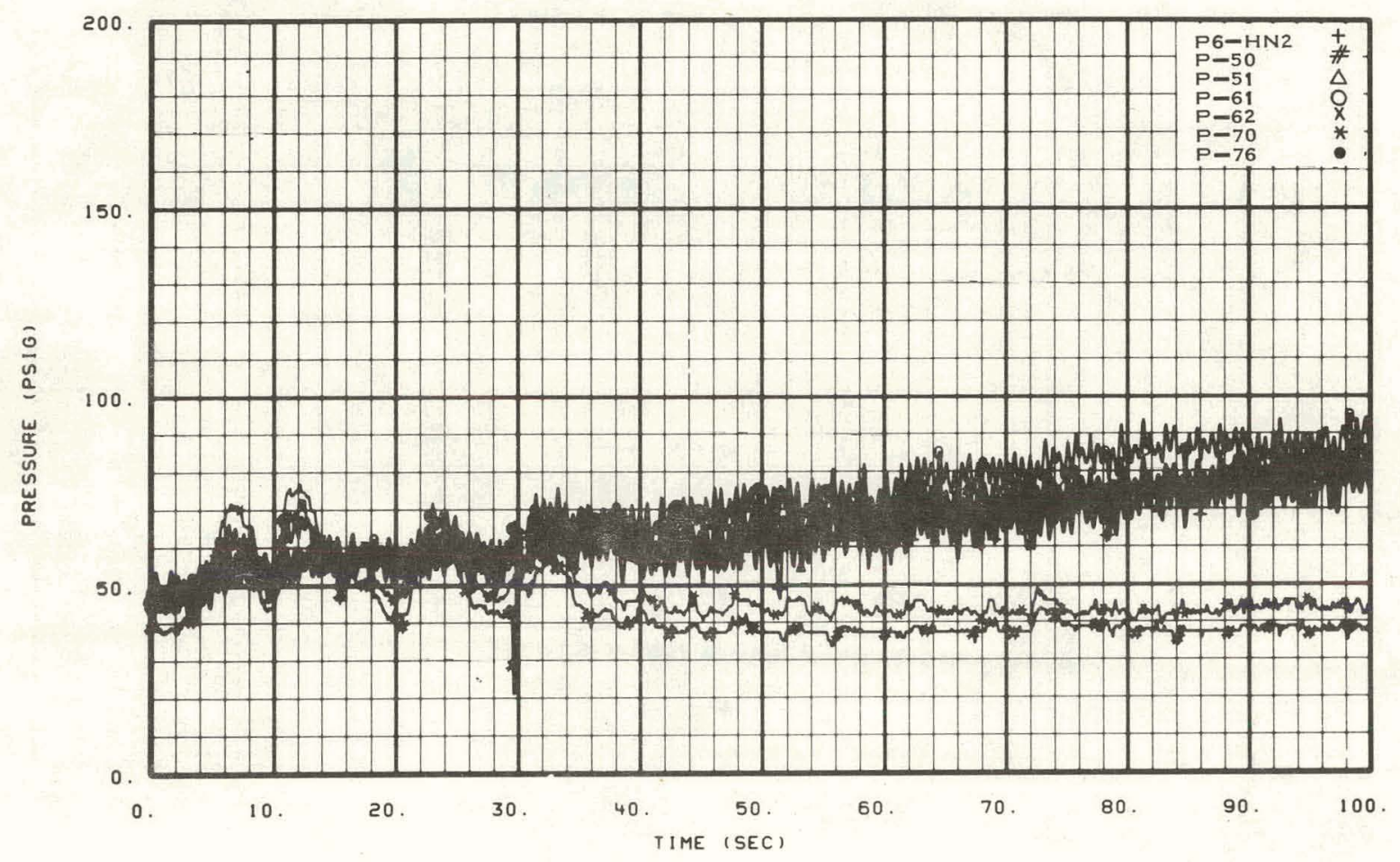

Fig. 200 Pressure in blowdown loop -- Test 15.1.

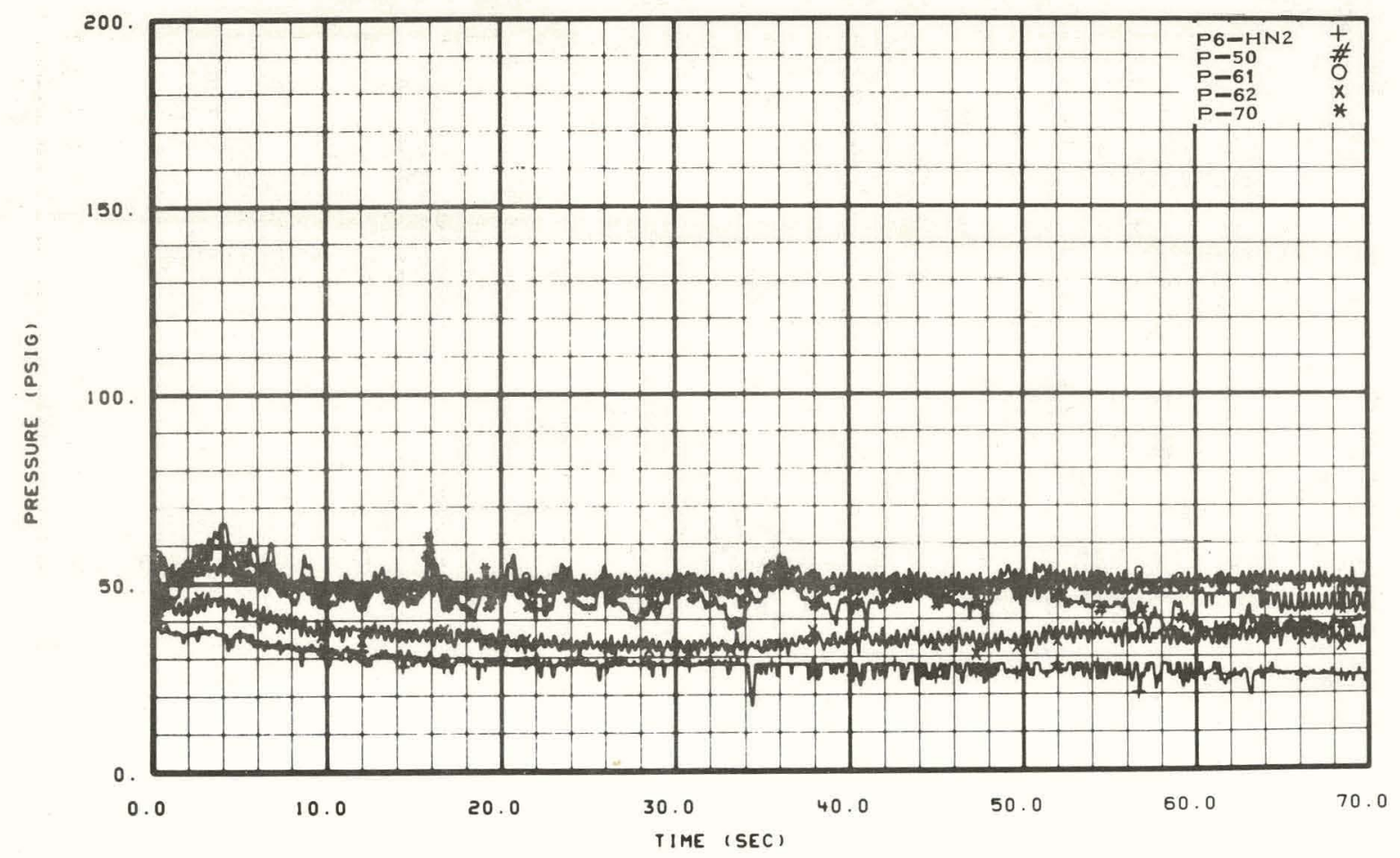

Fig. 201 Pressure in blowdown loop -- Test 15.2. 


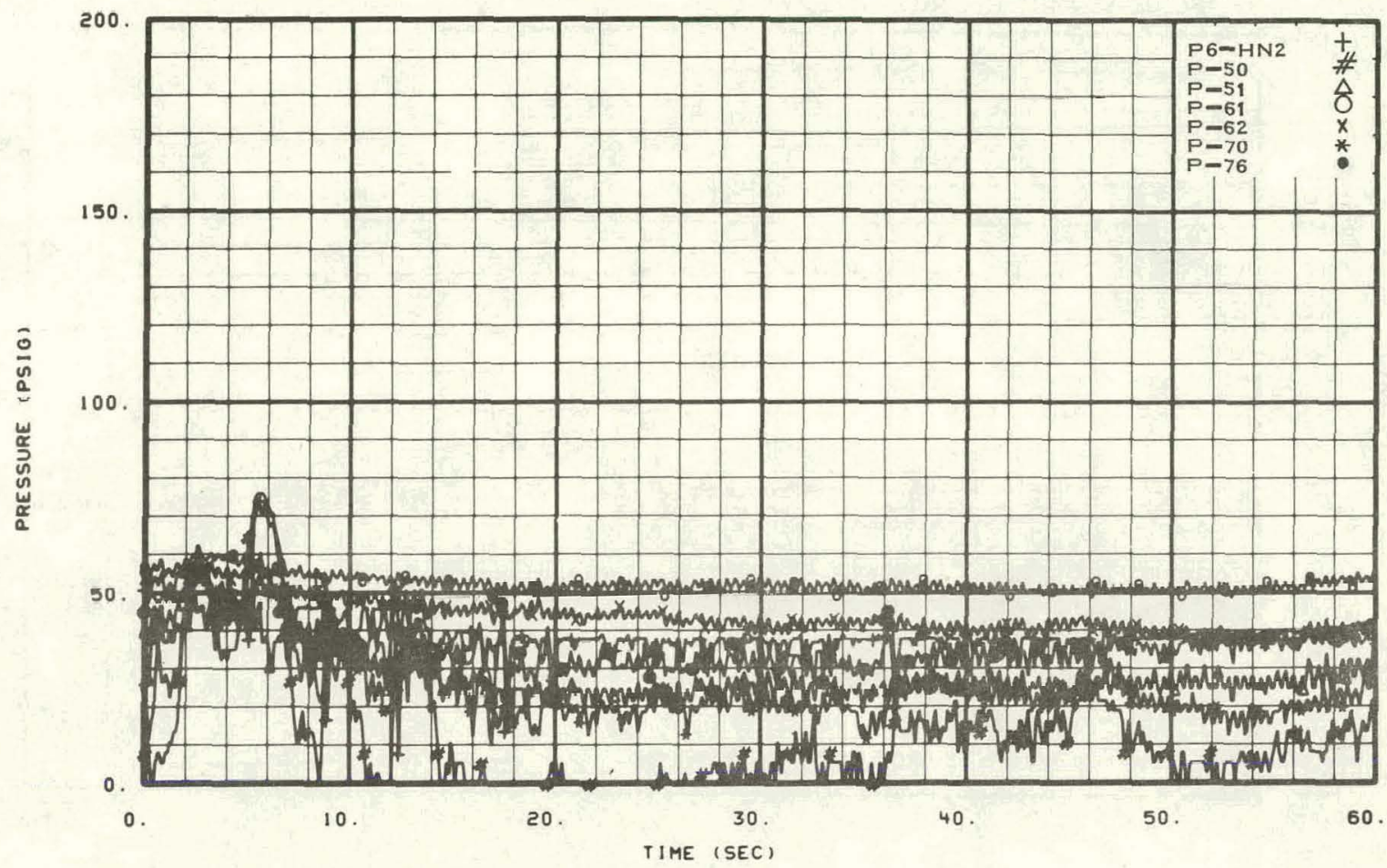

Fig. 202 Pressure in blowdown loop -- Test 15.3.

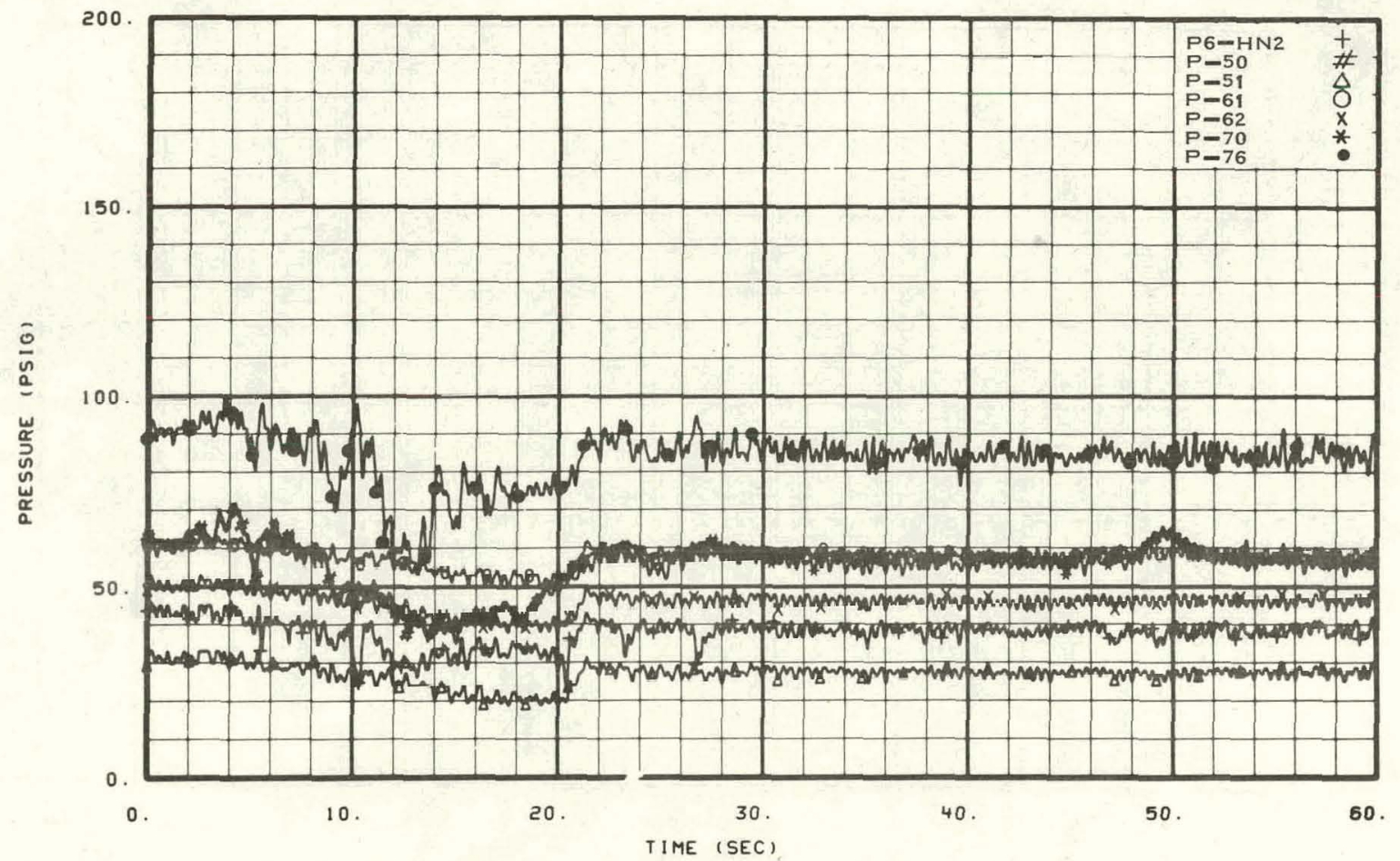

Fig. 203 Pressure in blowdown loop -- Test 15.4 . 


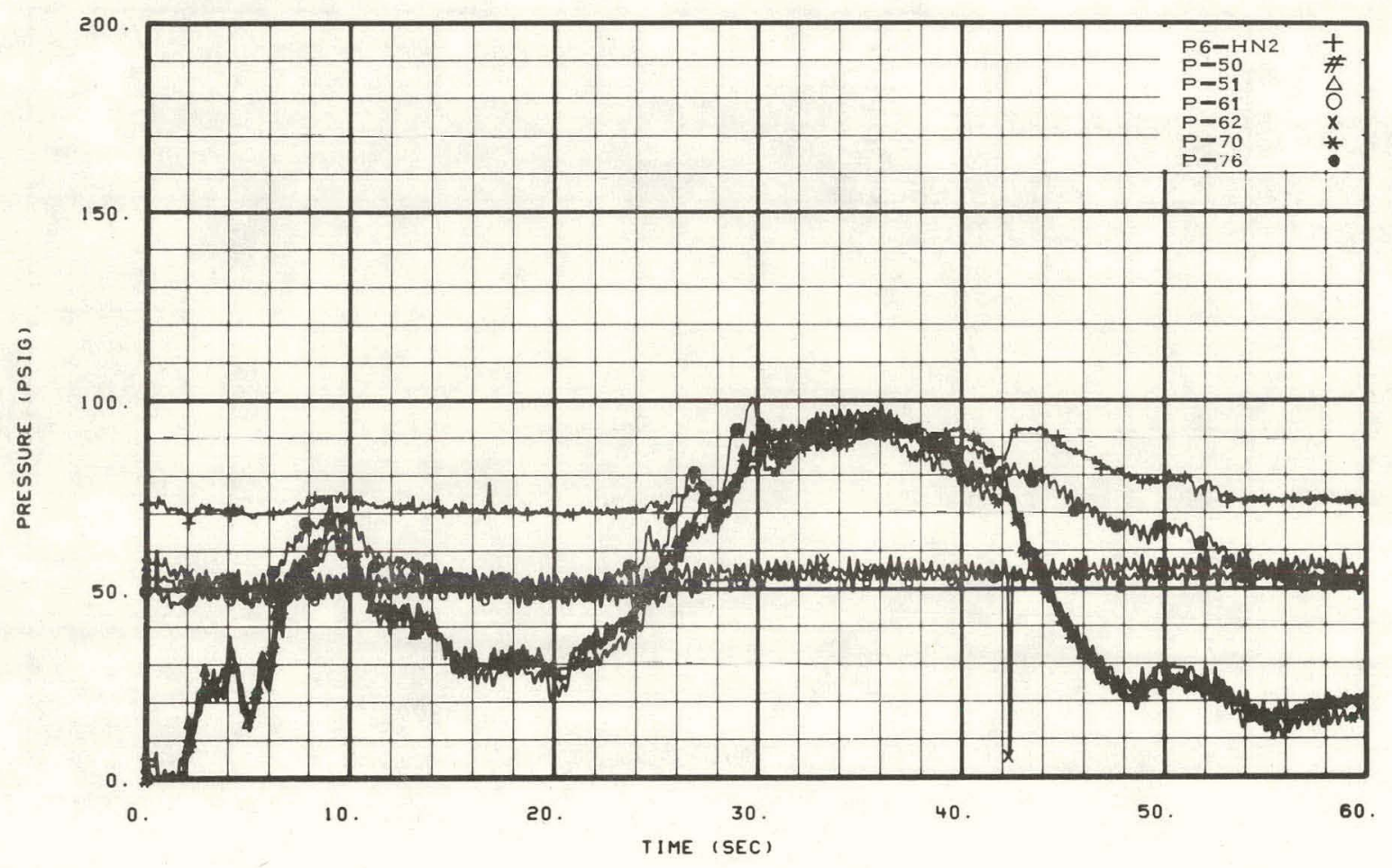

Fig. 204 Pressure in blowdown loop -- Test 15.7.

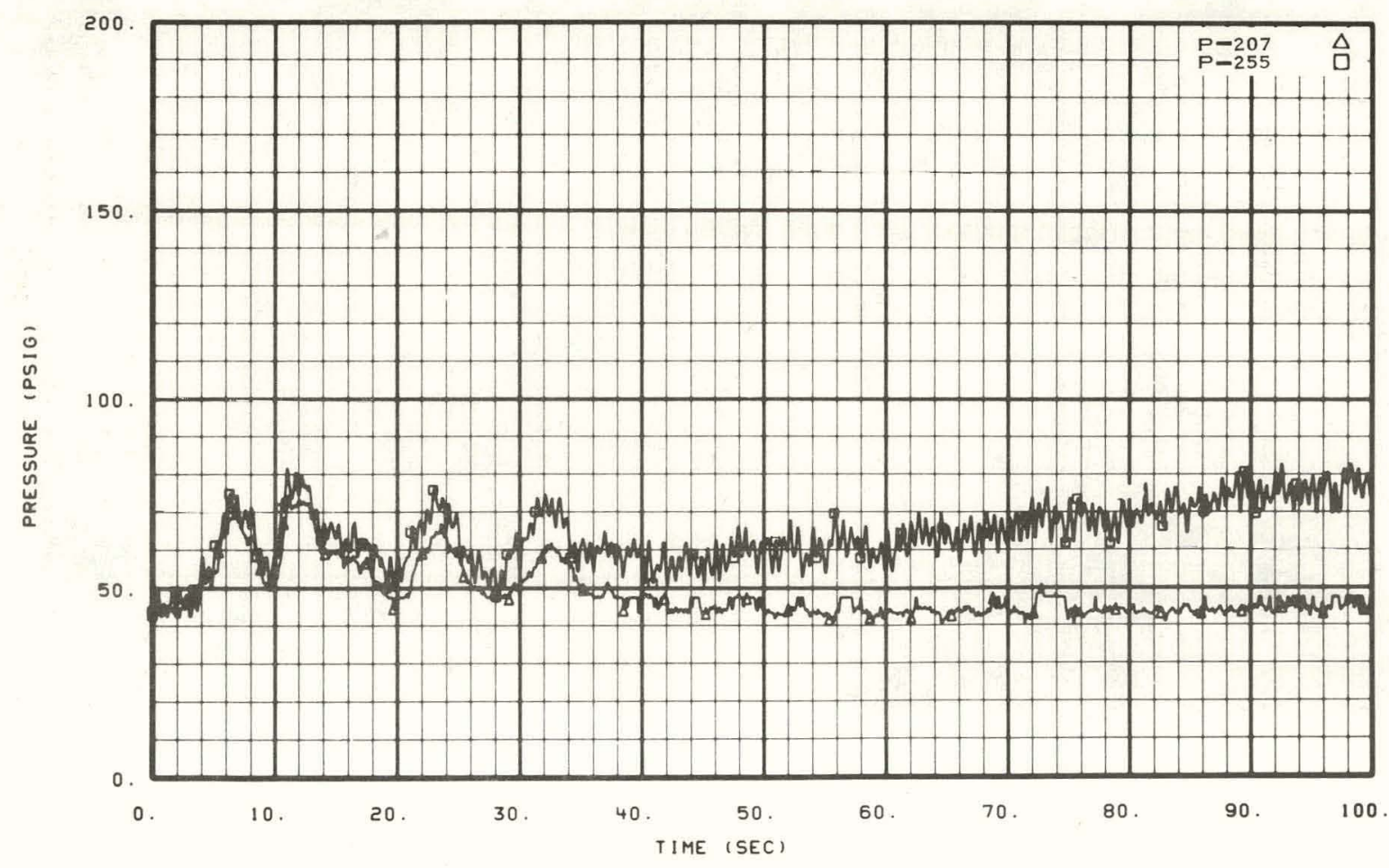

Fig. 205 Pressure in vessel -- Test 15.1. 


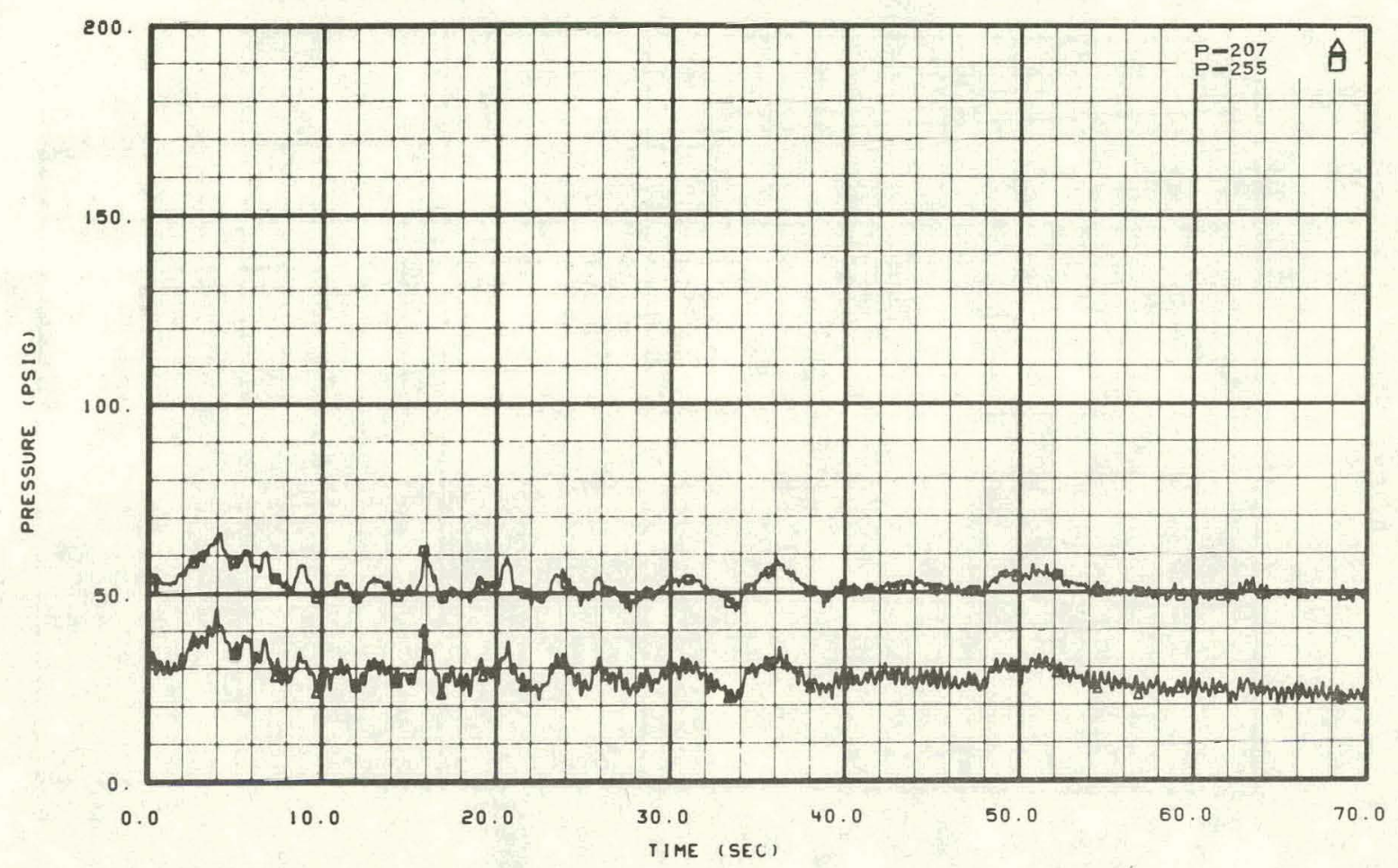

Fig. 206 Pressure in vesse1 -- Test 15.2.

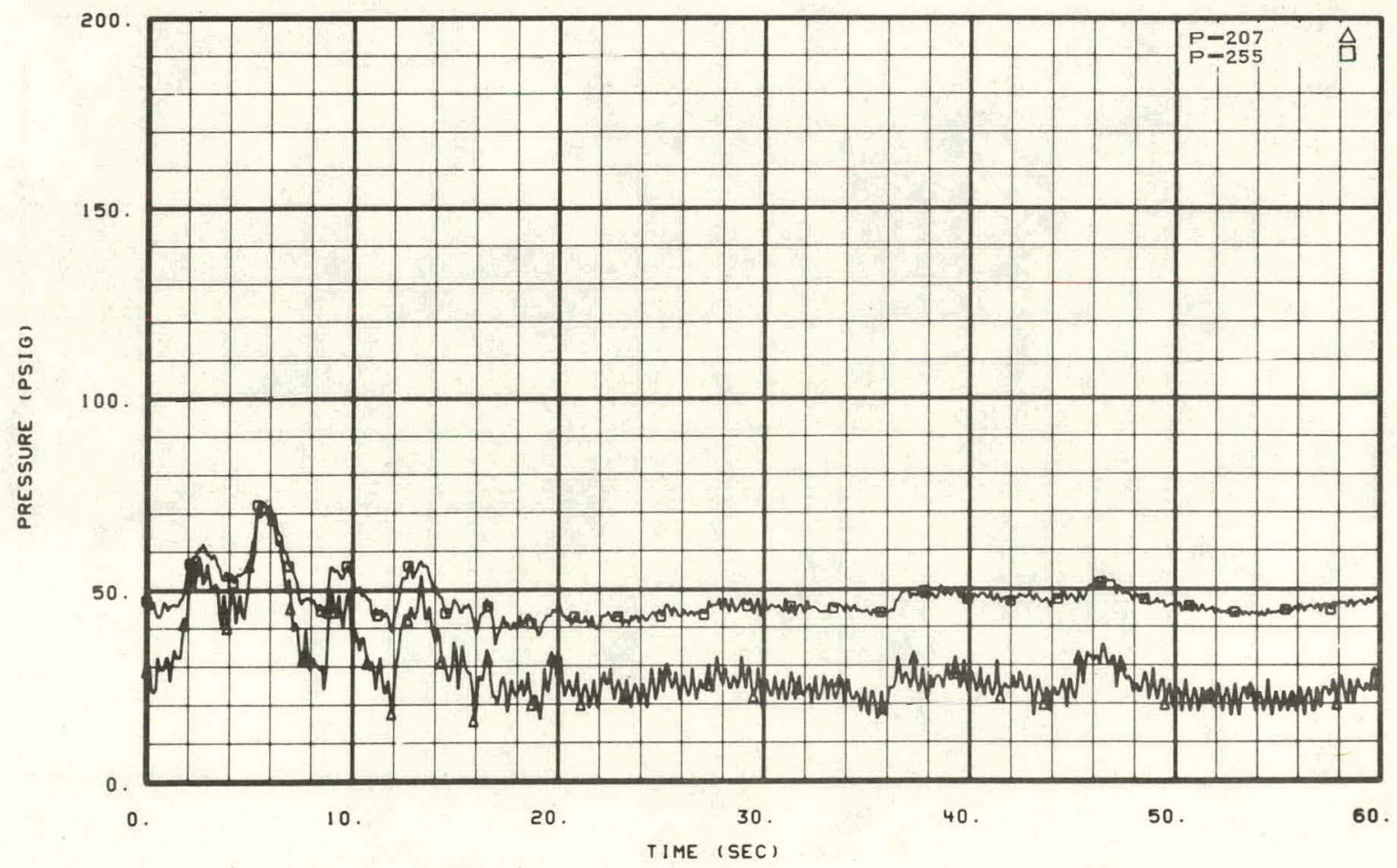

Fig. 207 Pressure in vesse1 -- Test 15.3. 


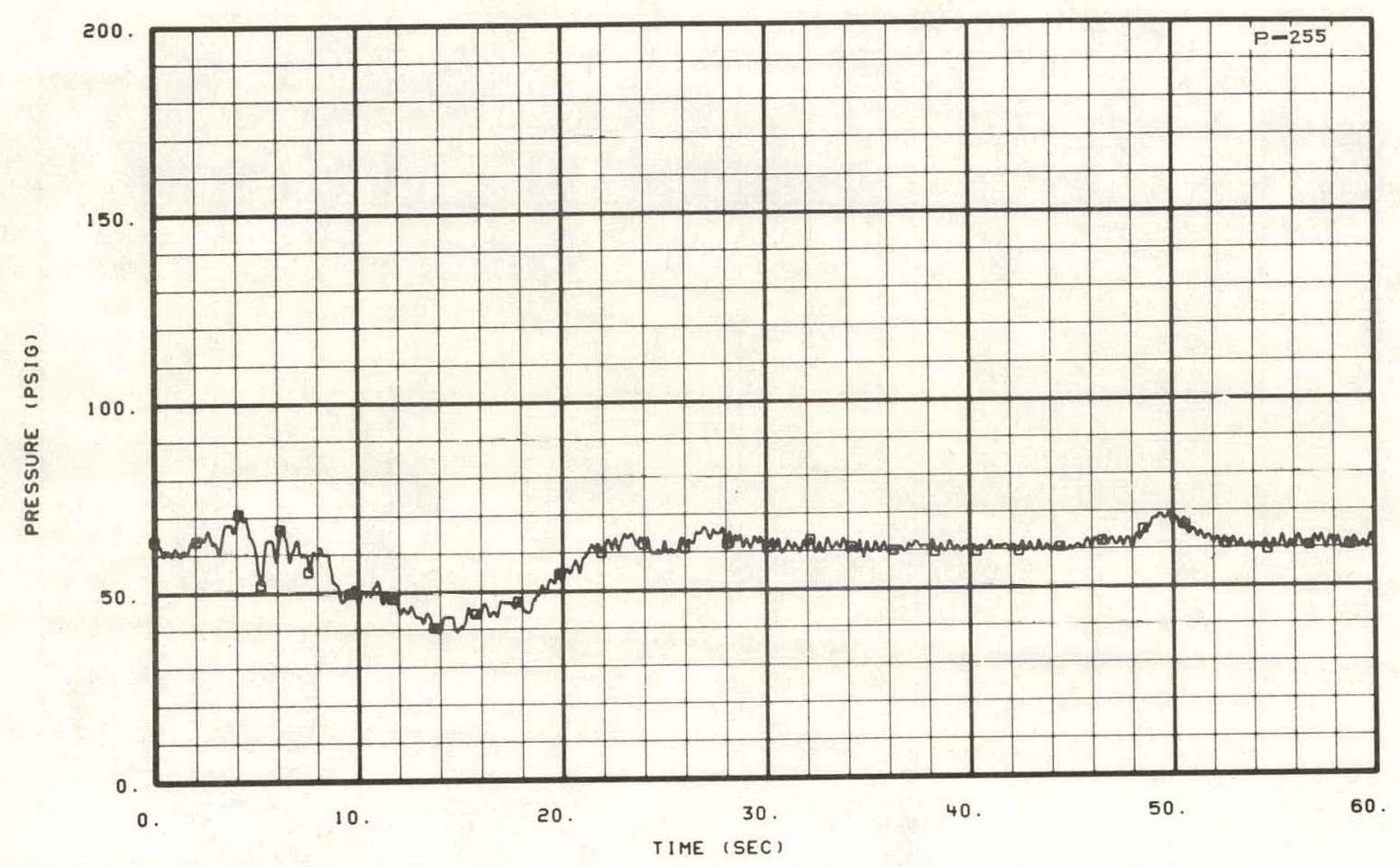

Fig. 208 Pressure in vesse1 -- Test 15.4.

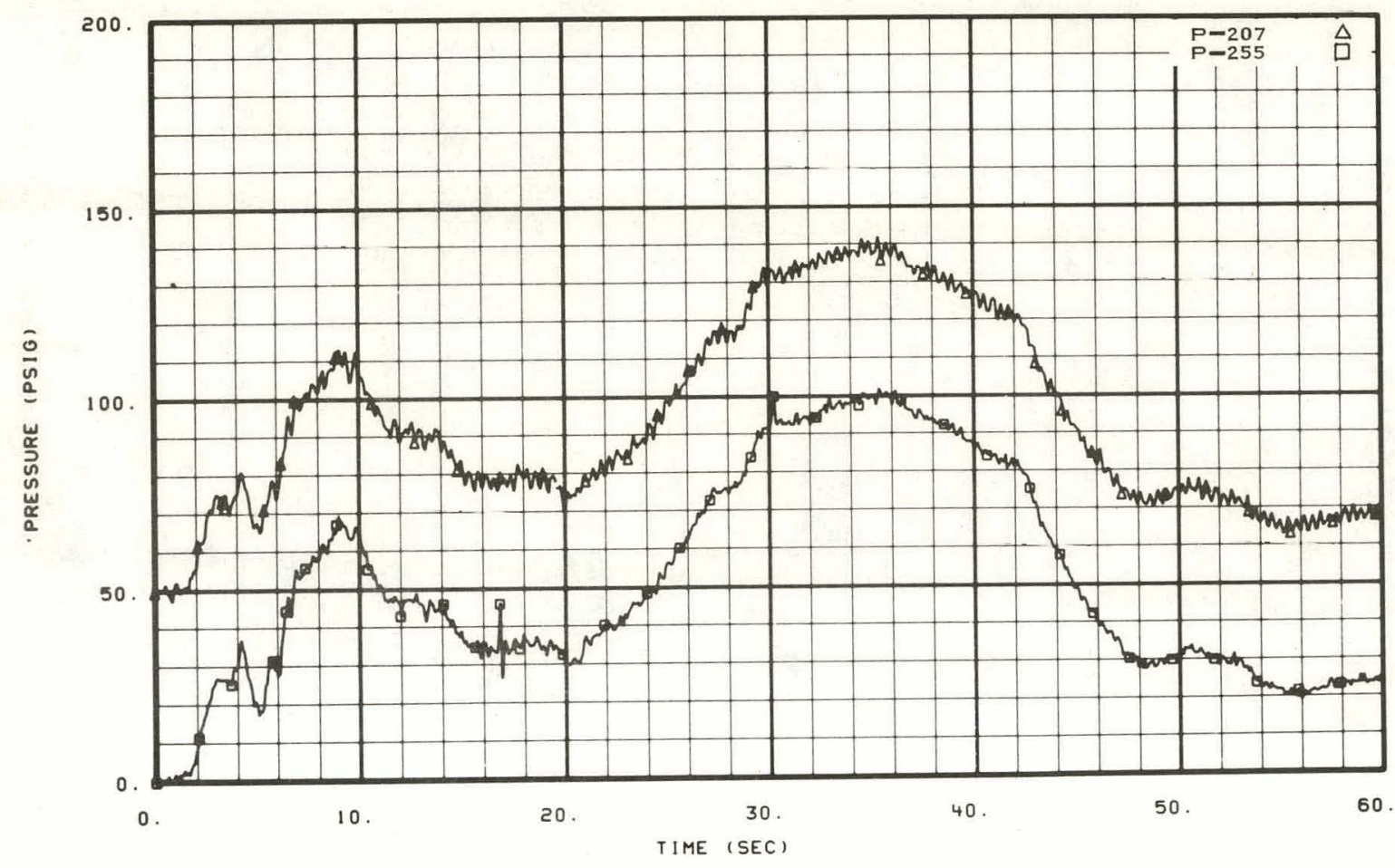

Fig. 209 Pressure in vesse1 -- Test 15.7. 


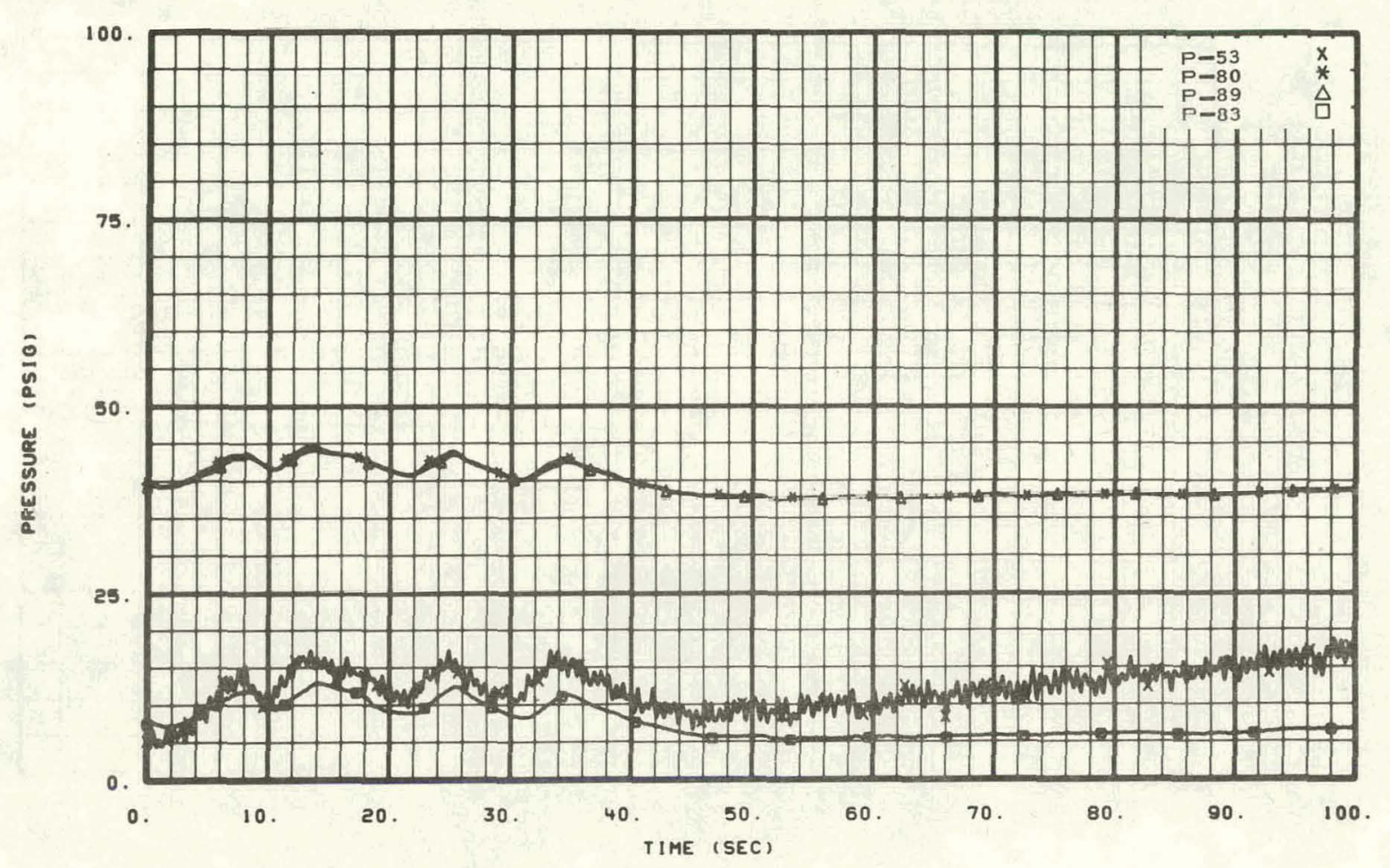

Fig. 210 Pressure in pressure suppression system -- Test 15.1.

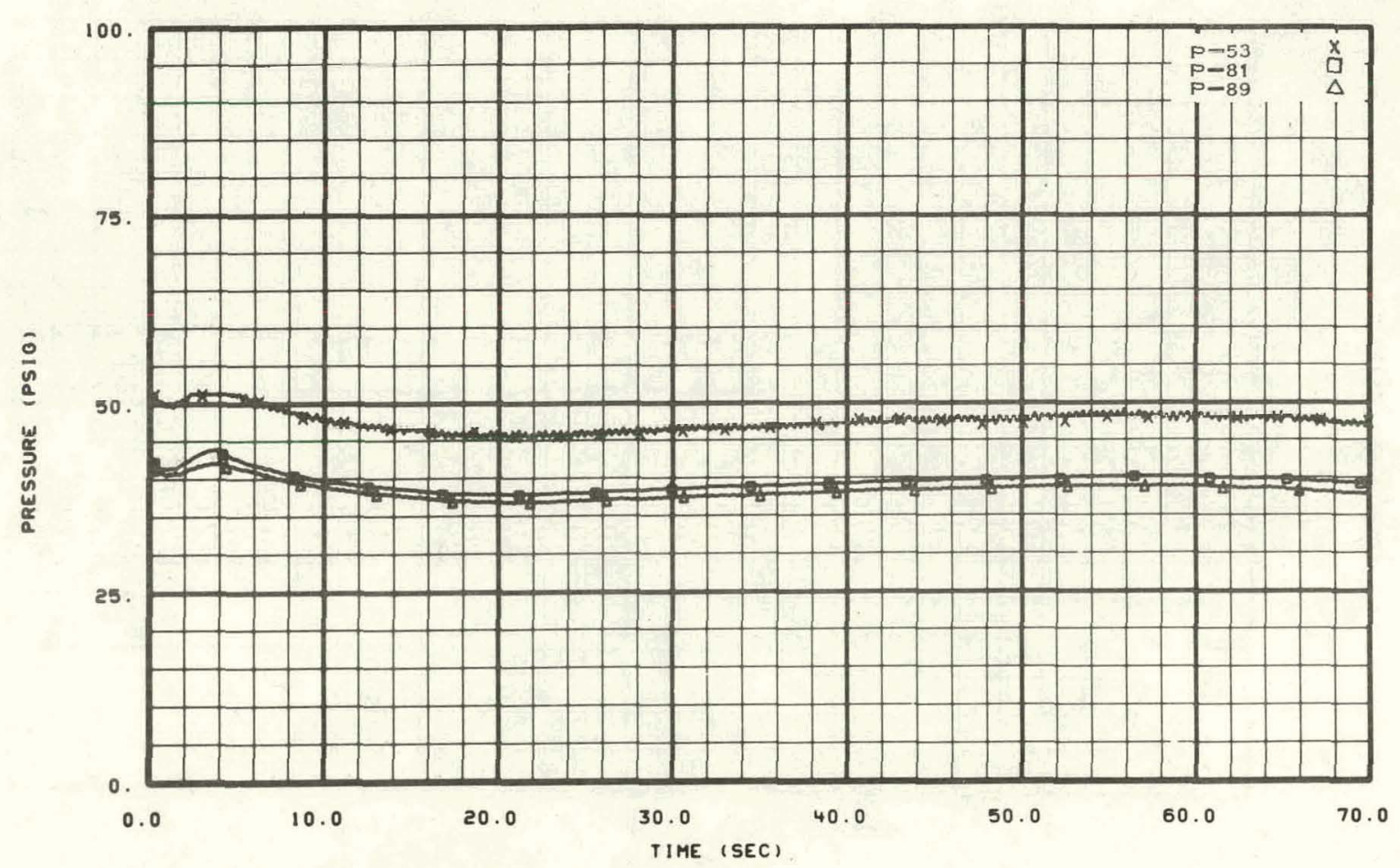

Fig. 211 Pressure in pressure suppression system -- Test 15.2. 


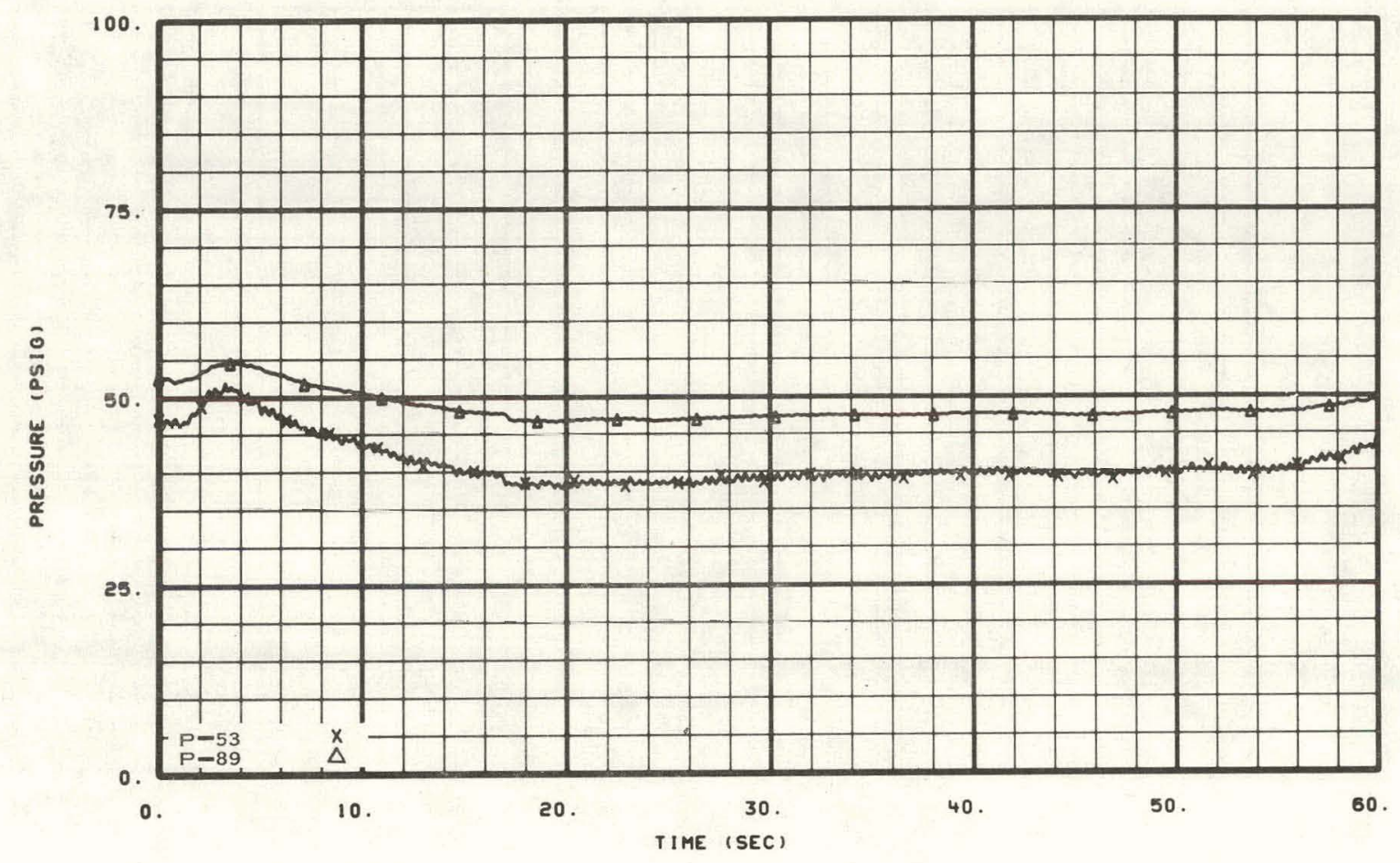

Fig. 212 Pressure in pressure suppression system -- Test 15.3.

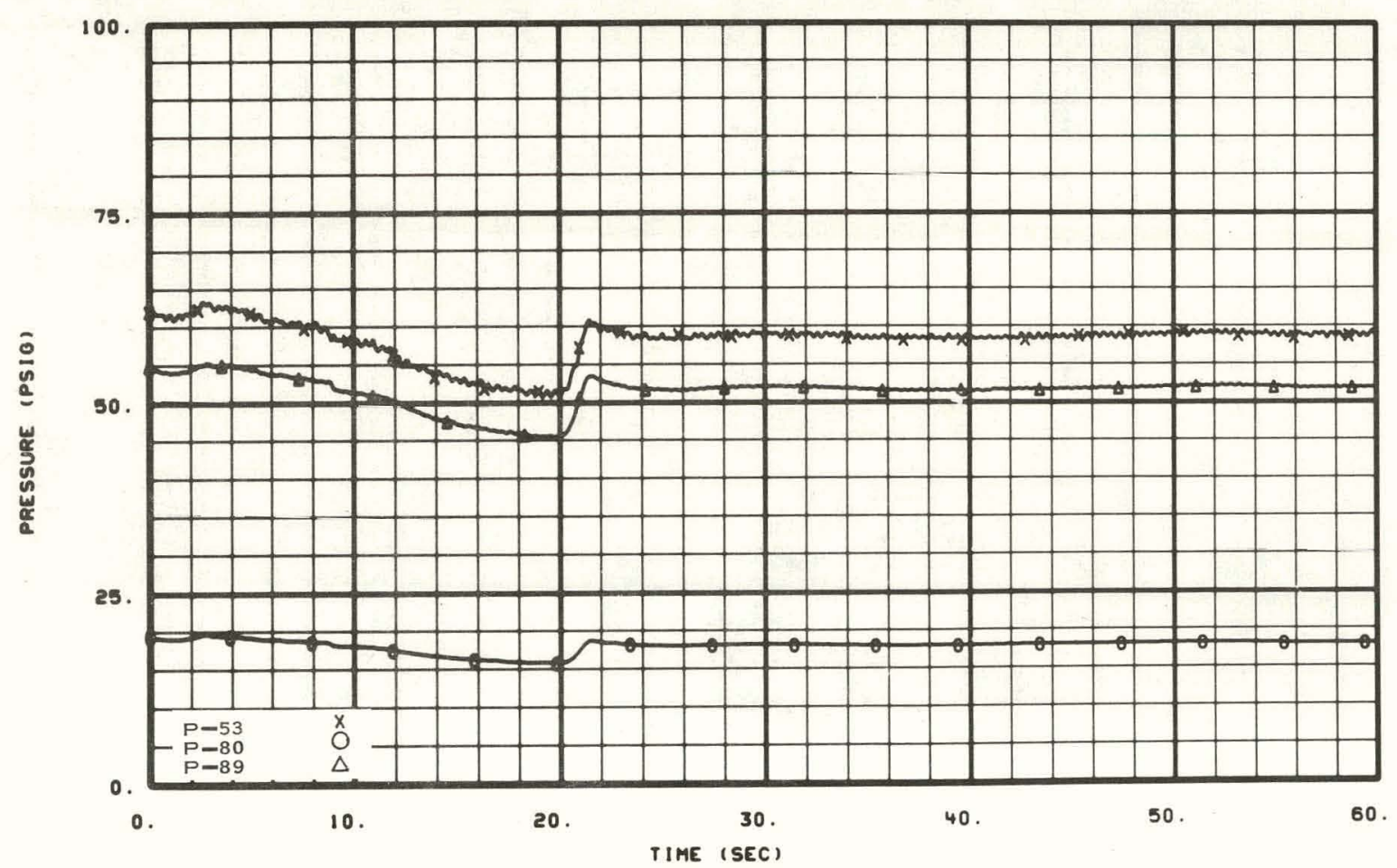

Fig. 213 Pressure in pressure suppression system -- Test 15.4. 


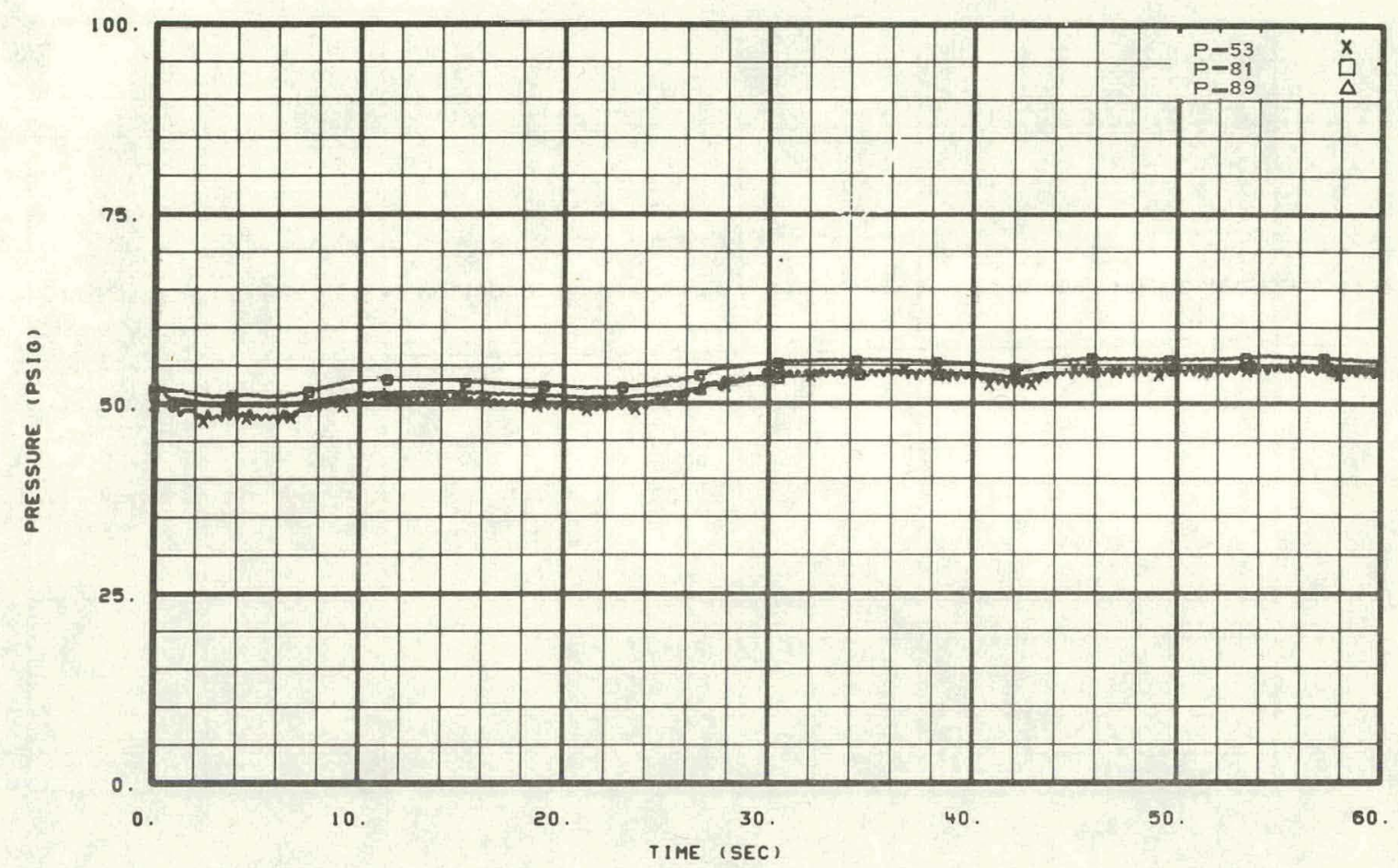

Fig. 214 Pressure in pressure suppression system -- Test 15.7.

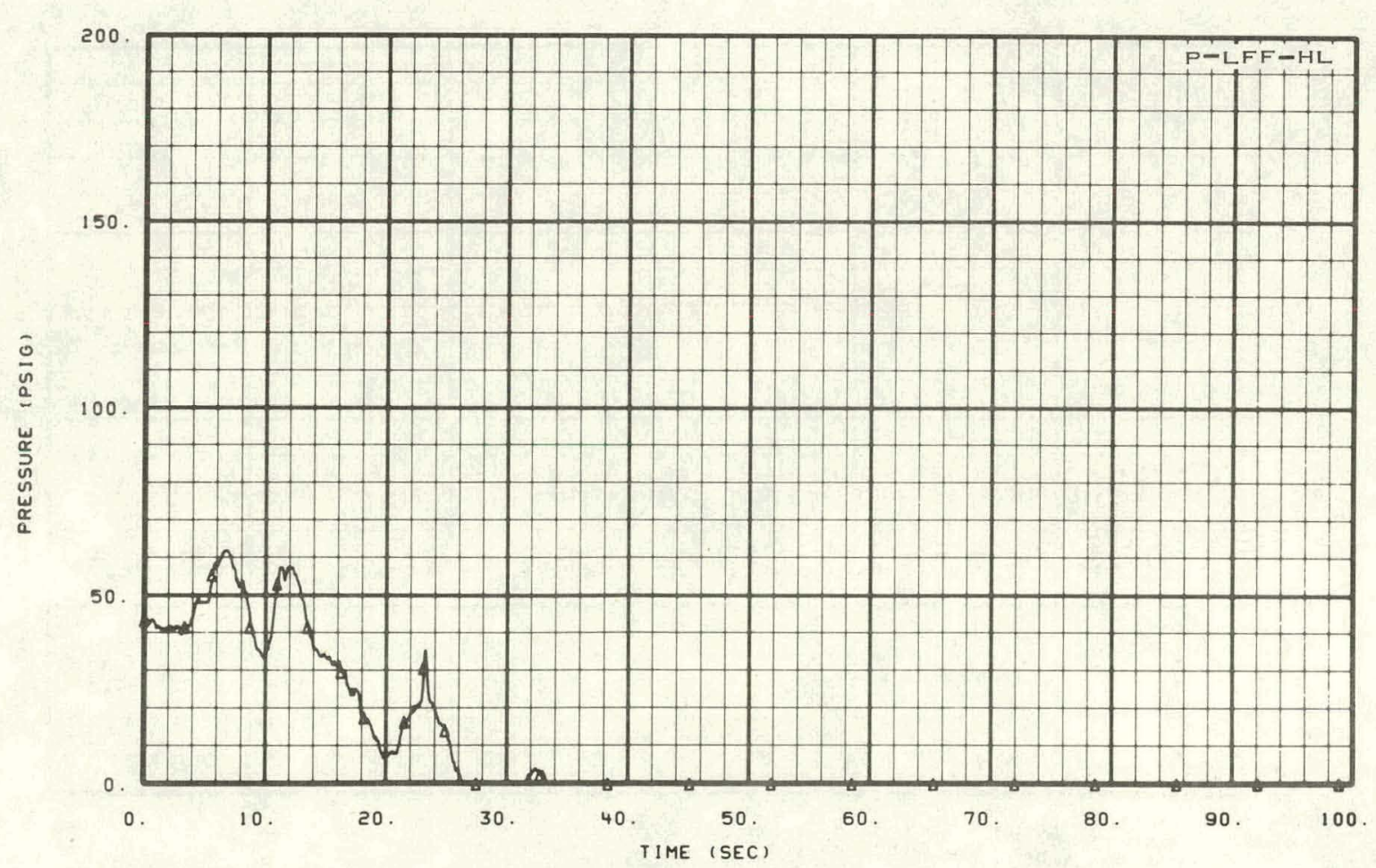

Fig. 215 Pressure at hot leg stub in upper plenum (LOFT free field pressure transducer) -- Test 15.1. 


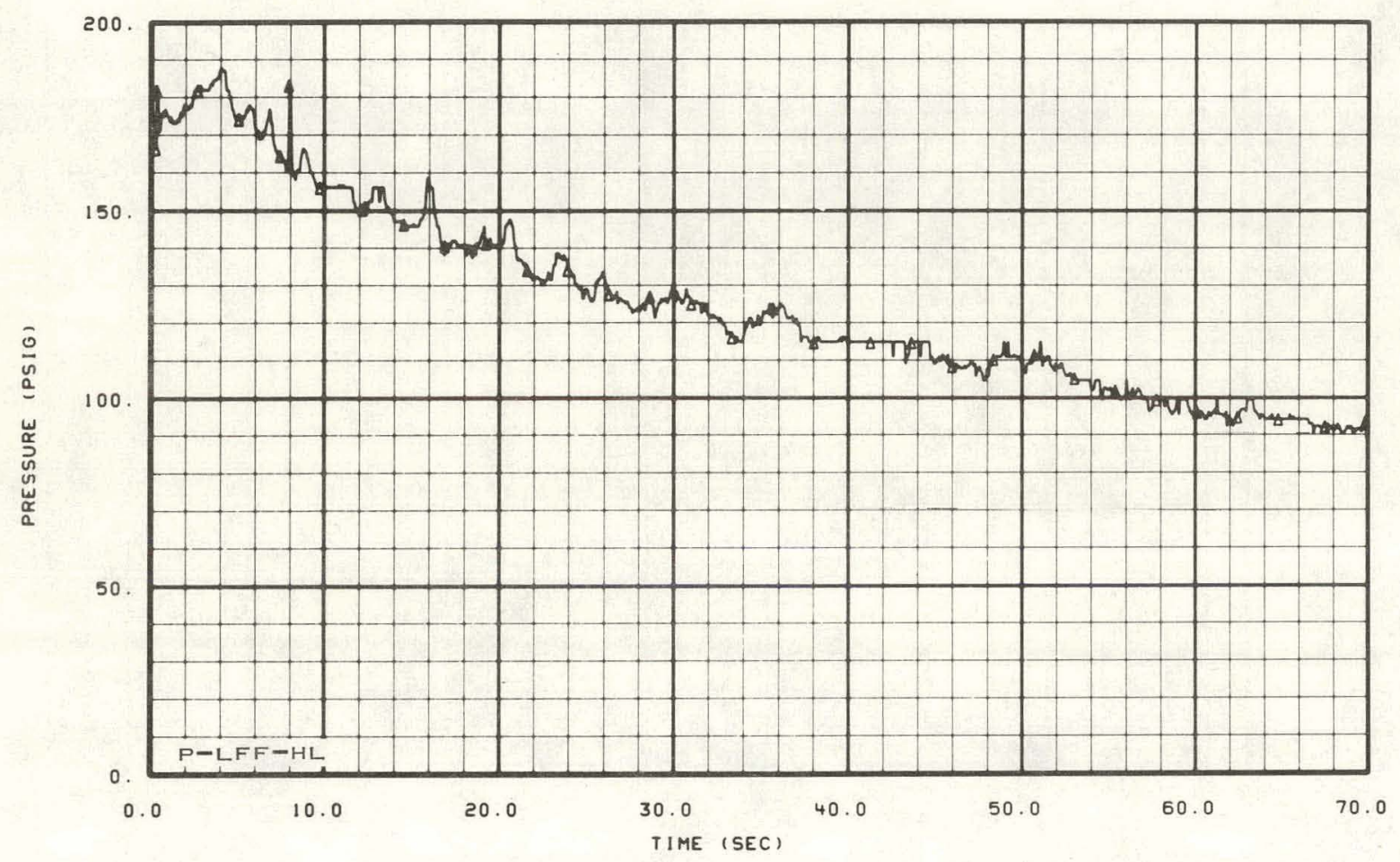

Fig. 216 Pressure at hot leg stub in upper plenum (LOFT free field pressure transducer) -- Test 15.2 .

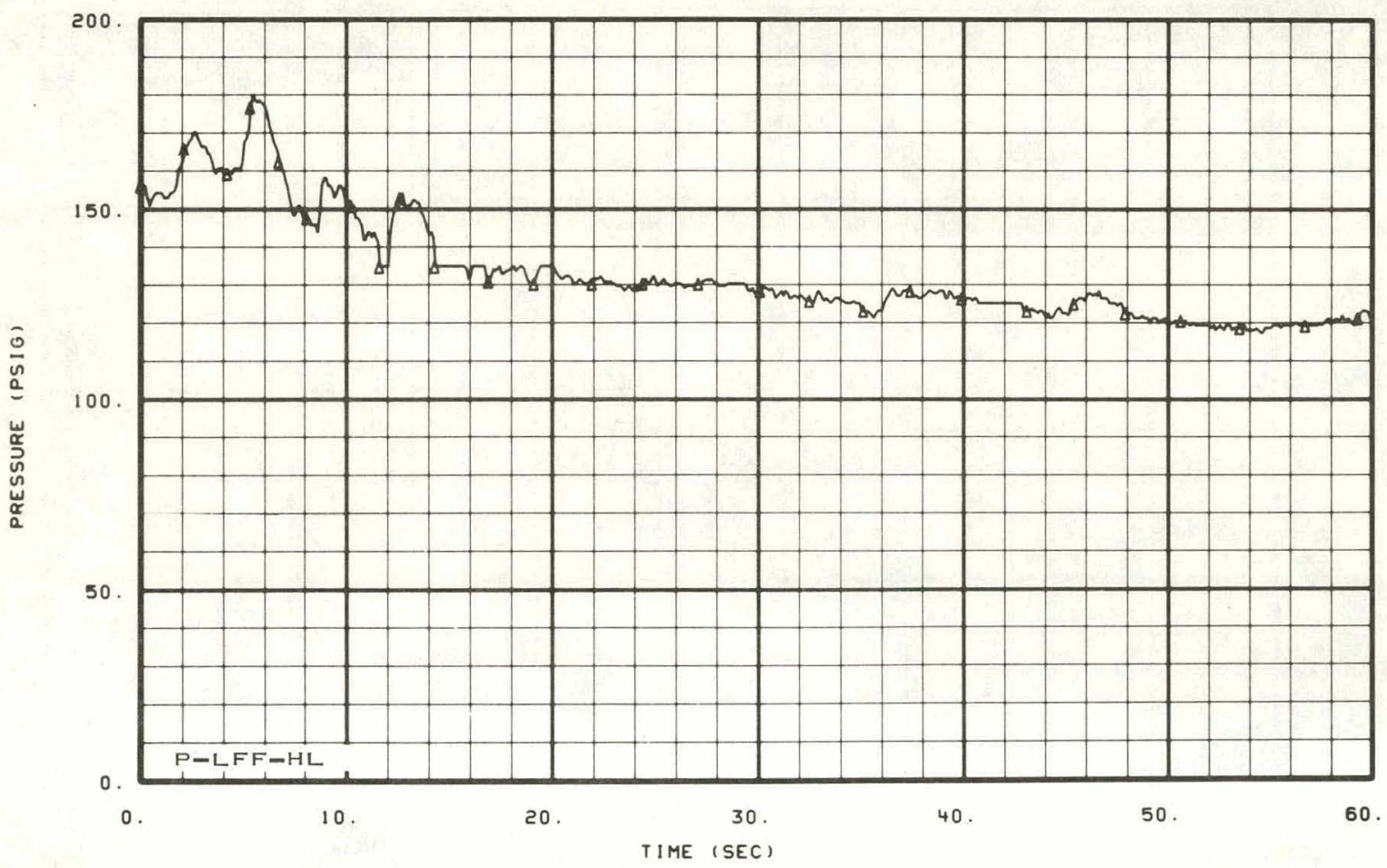

Fig. 217 Pressure at hot leg stub in upper plenum (LOFT free field pressure transducer) -- Test 15.3. 


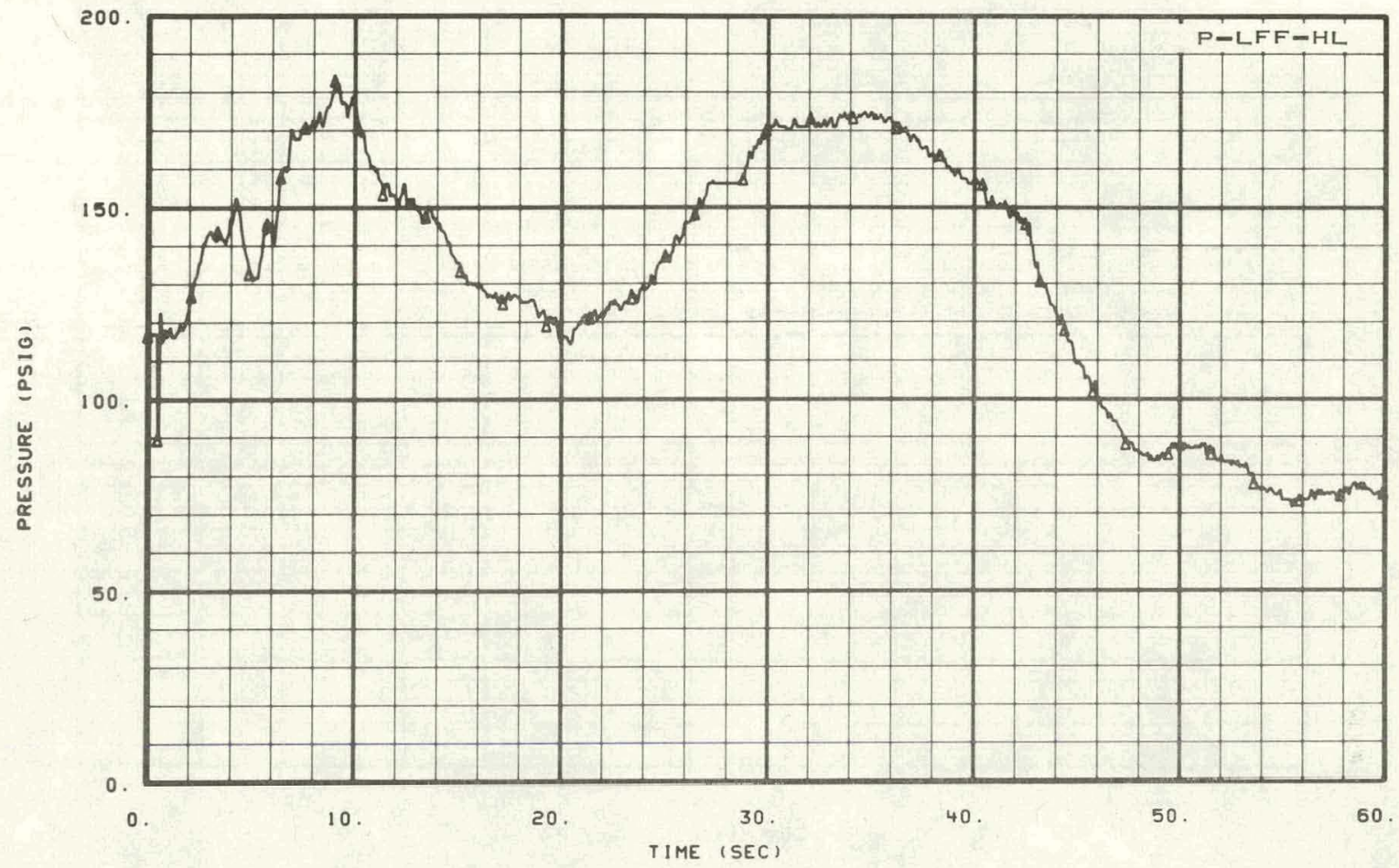

Fig. 218 Pressure at hot leg stub in upper plenum (LOFT free field pressure transducer) -- Test 15.7 .

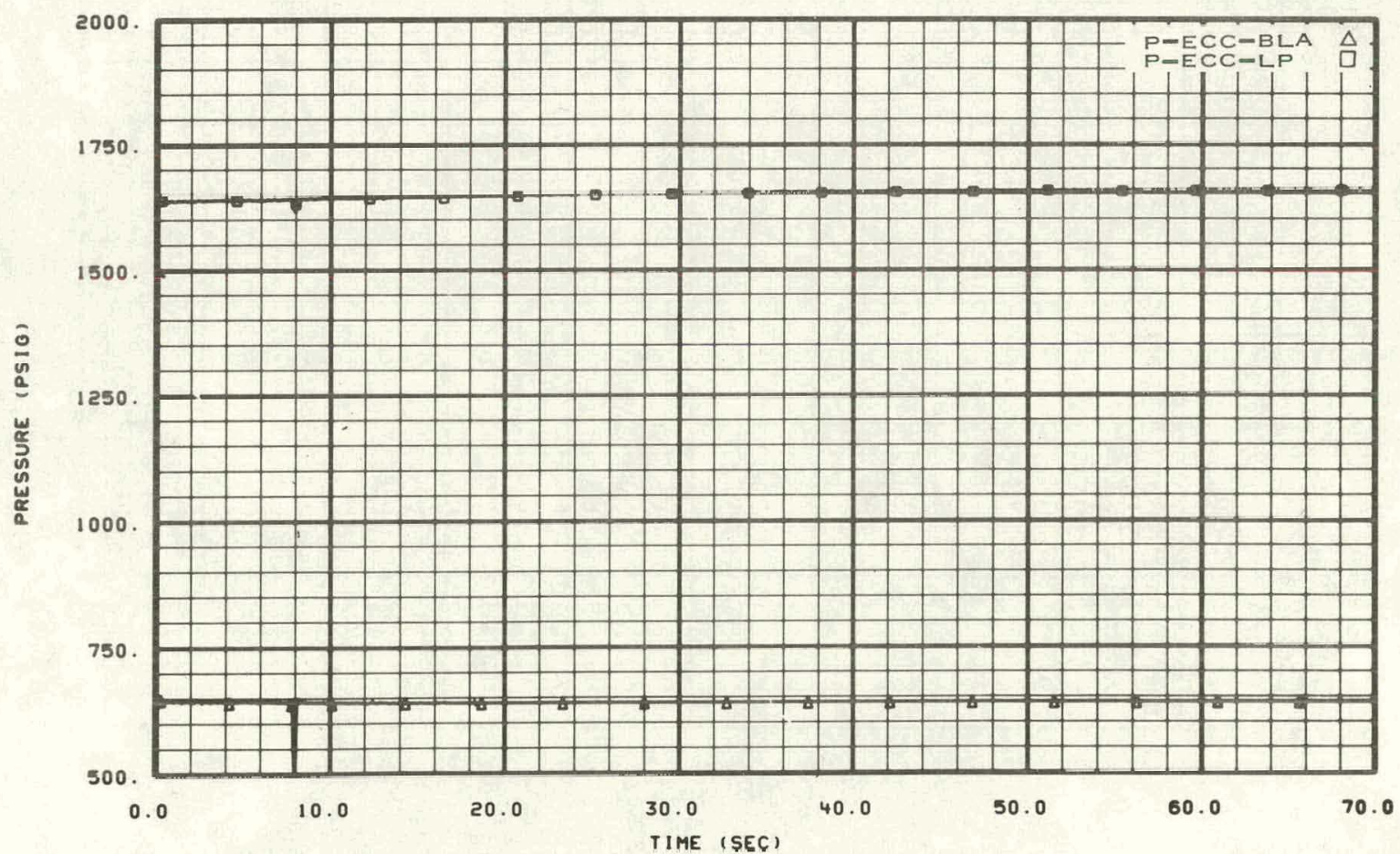

Fig. 219 Pressure of ECC in accumulators -- Test 15.2. 


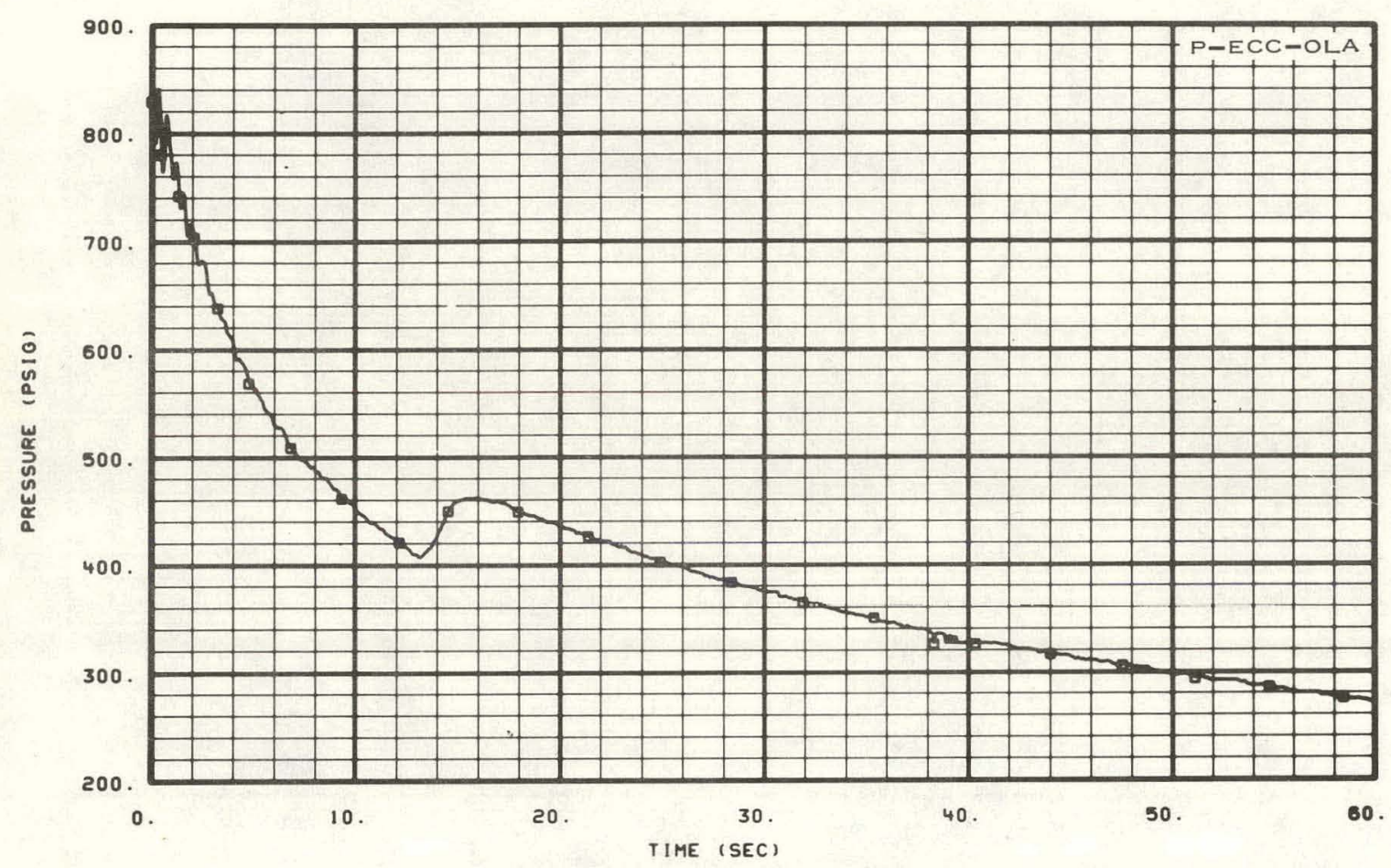

Fig. 220 Pressure of ECC in accumulators -- Test 15.4 .

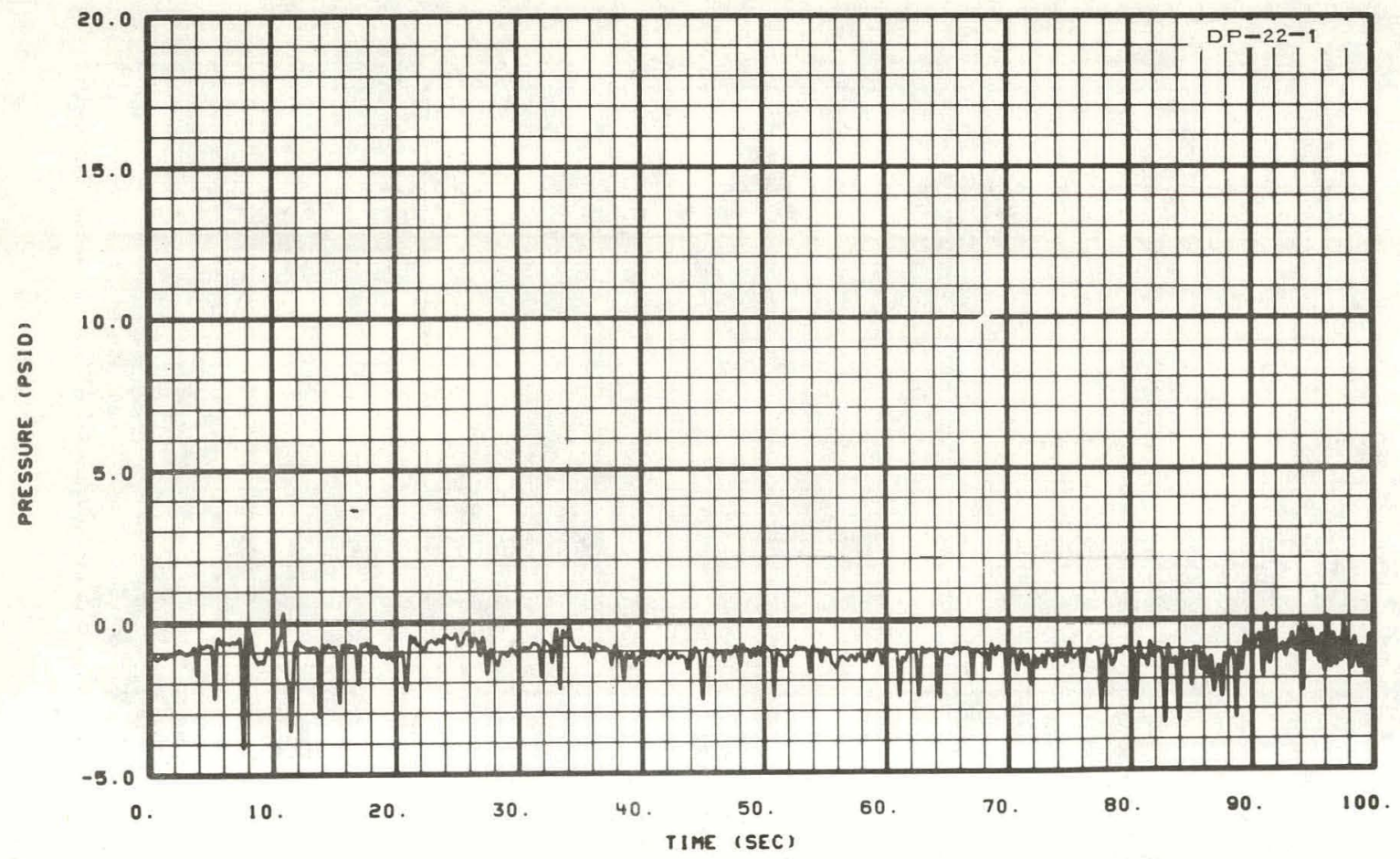

Fig. 221 Differential pressure across operating 1oop (DP-22-1) -- Test 15.1. 


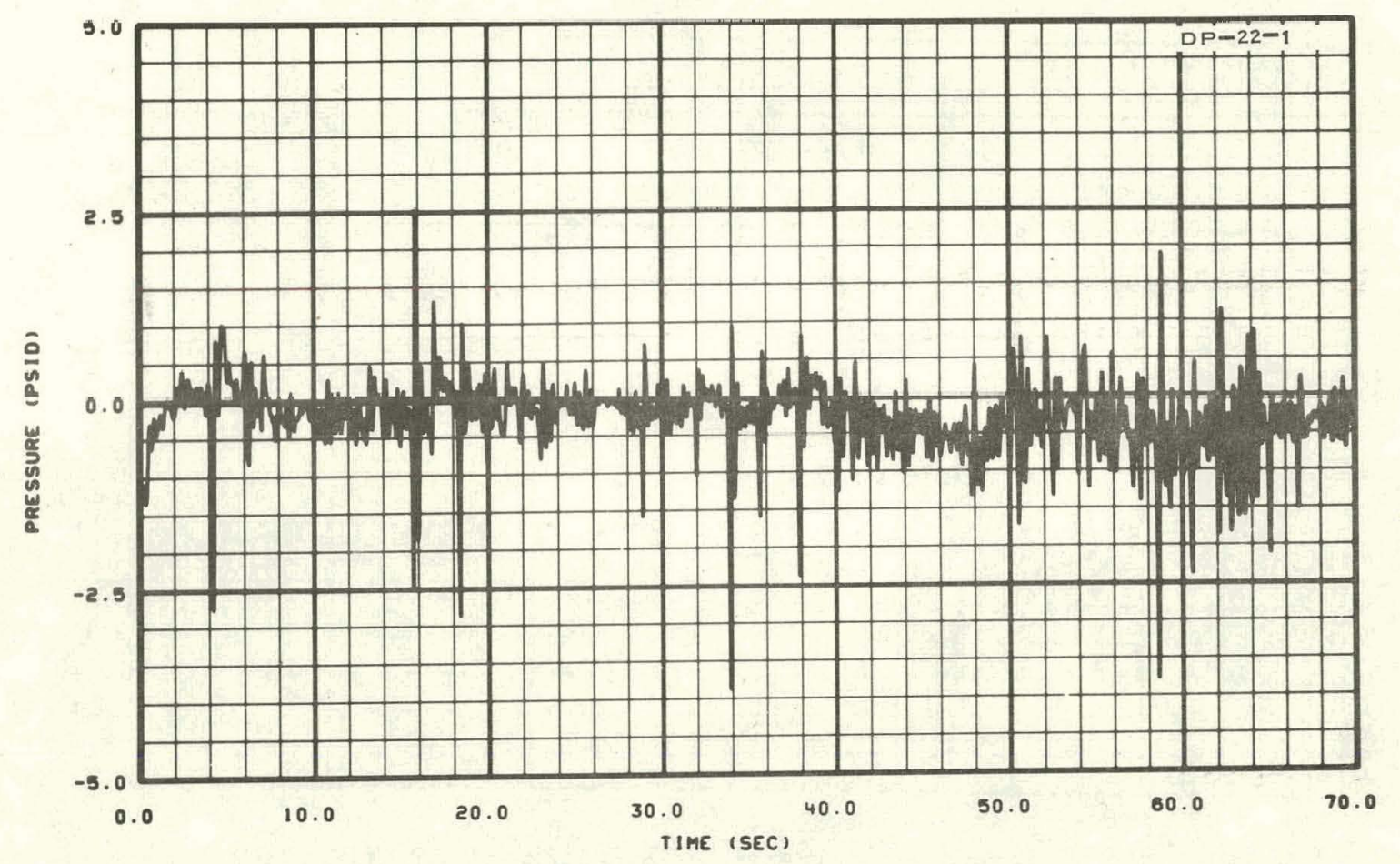

Fig. 222 Differential pressure across operating 1oop (DP-22-1) -- Test 15.2.

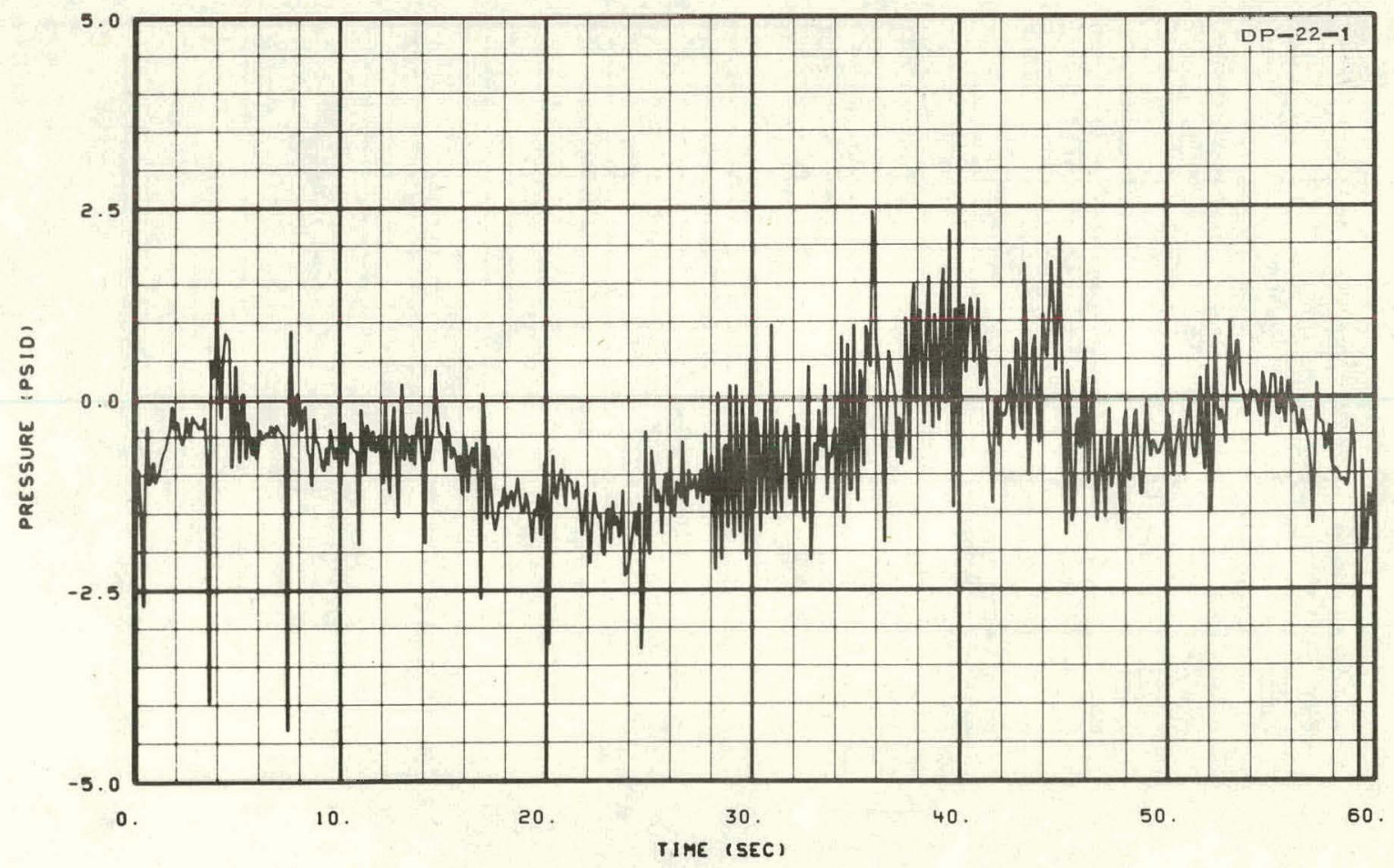

Fig. 223 Differential pressure across operating loop (DP-22-1) -- Test 15.3. 


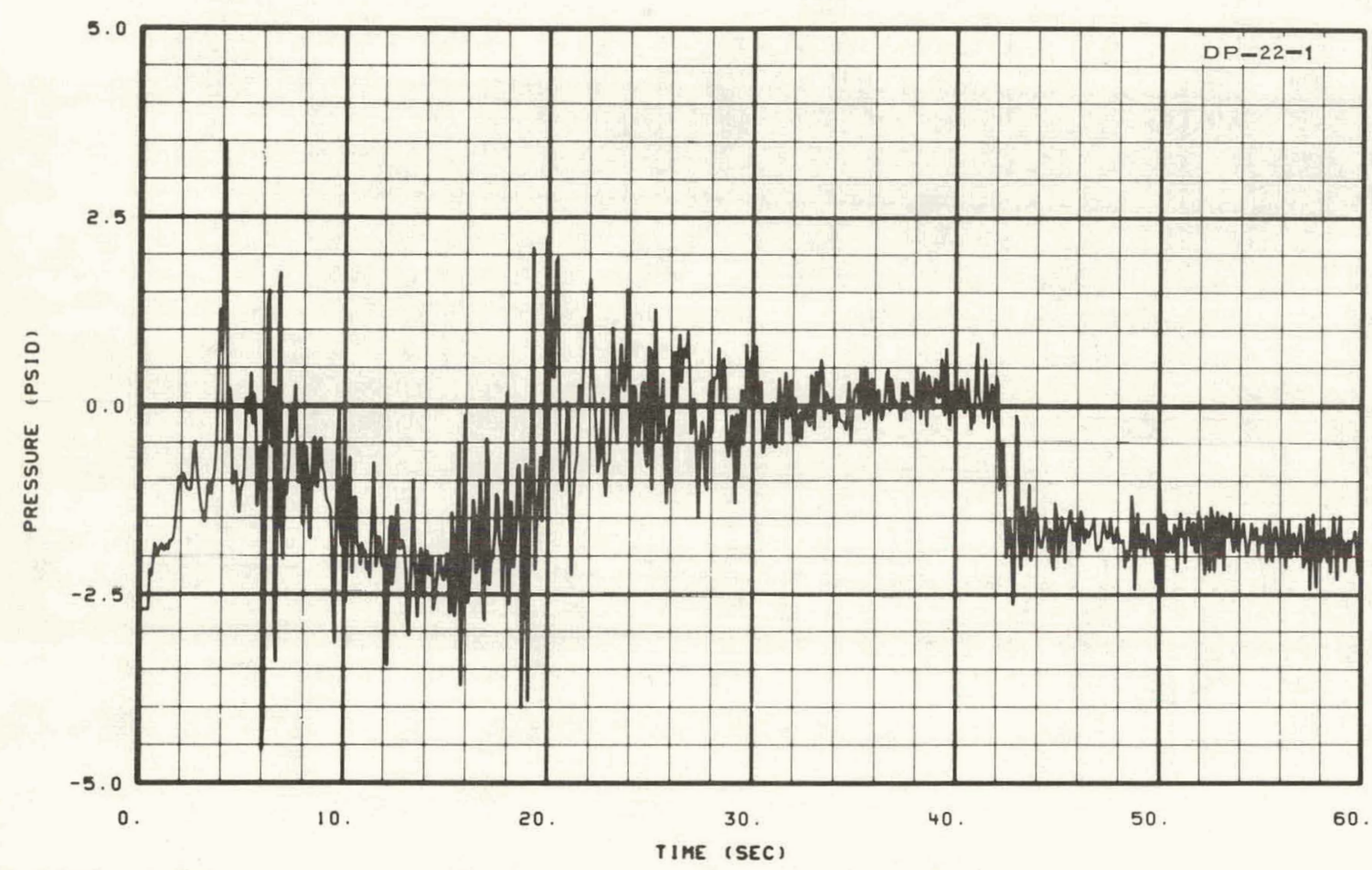

Fig. 224 Differential pressure across operating loop (DP-22-1) -- Test 15.7.

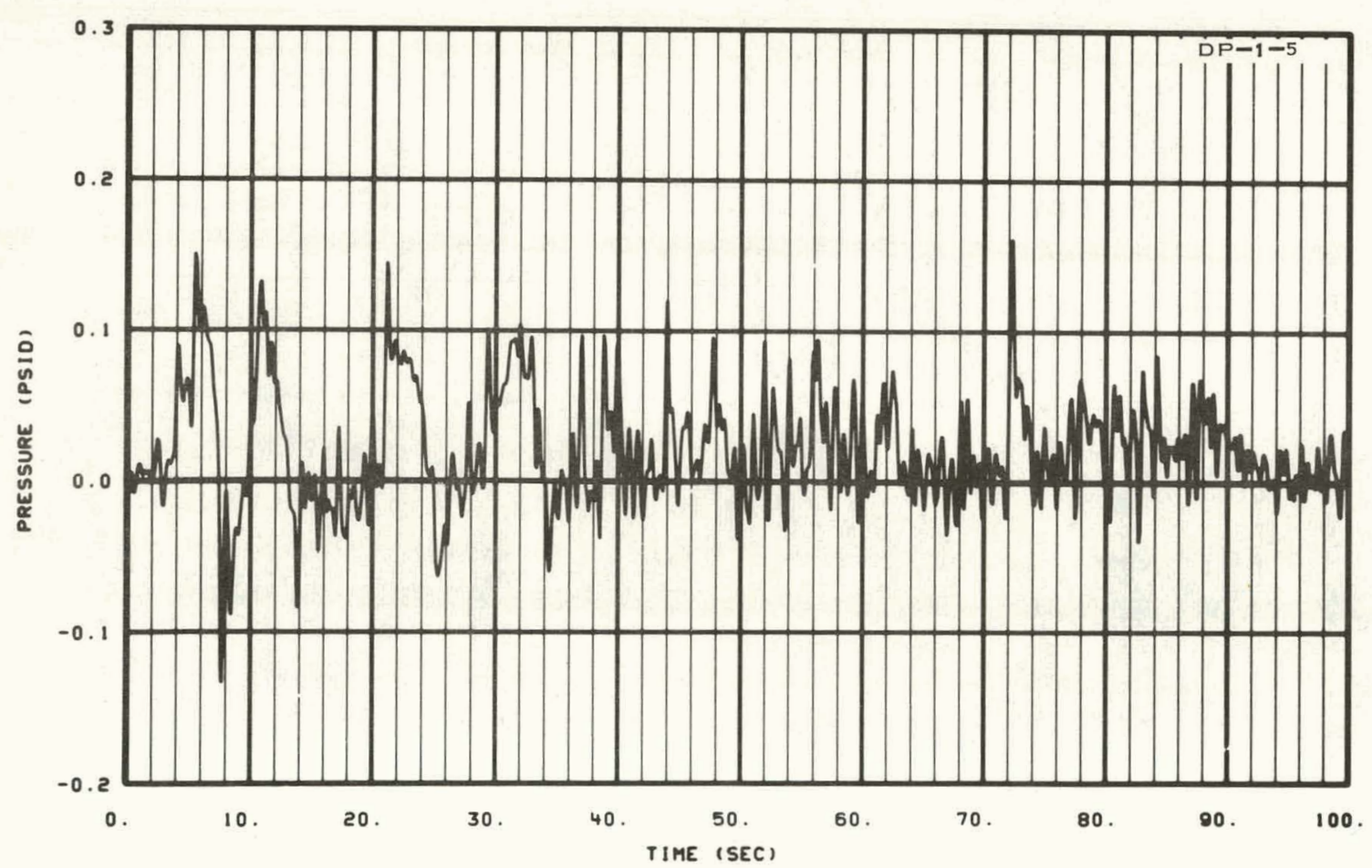

Fig. 225 Differential pressure, operating loop hot leg (DP-1-5) -- Test 15.1 . 


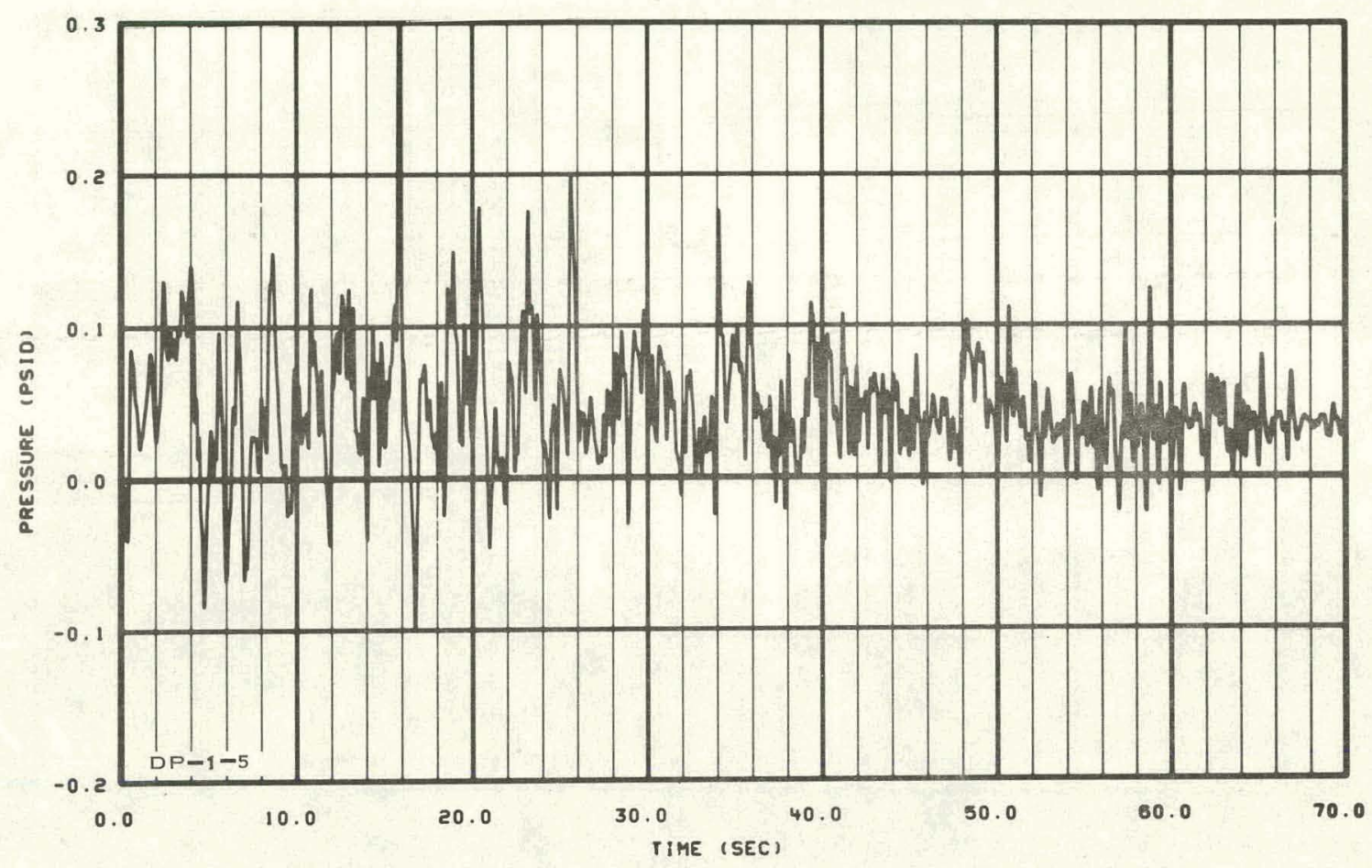

Fig. 226 Differential pressure, operating loop hot leg (DP-1-5) -- Test 15.2 .

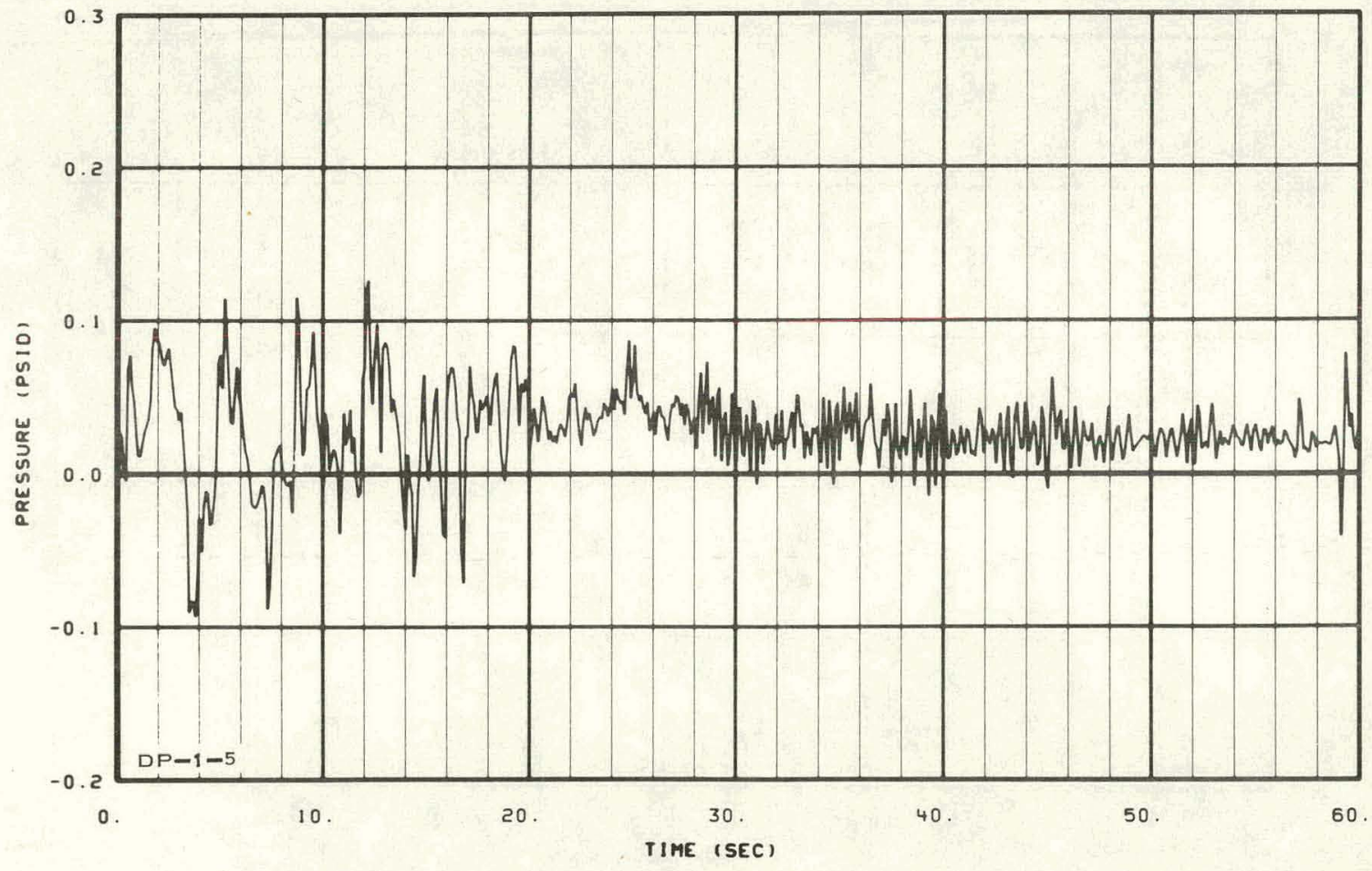

Fig. 227 Differential pressure, operating loop hot leg (DP-1-5) -- Test 15.3 . 


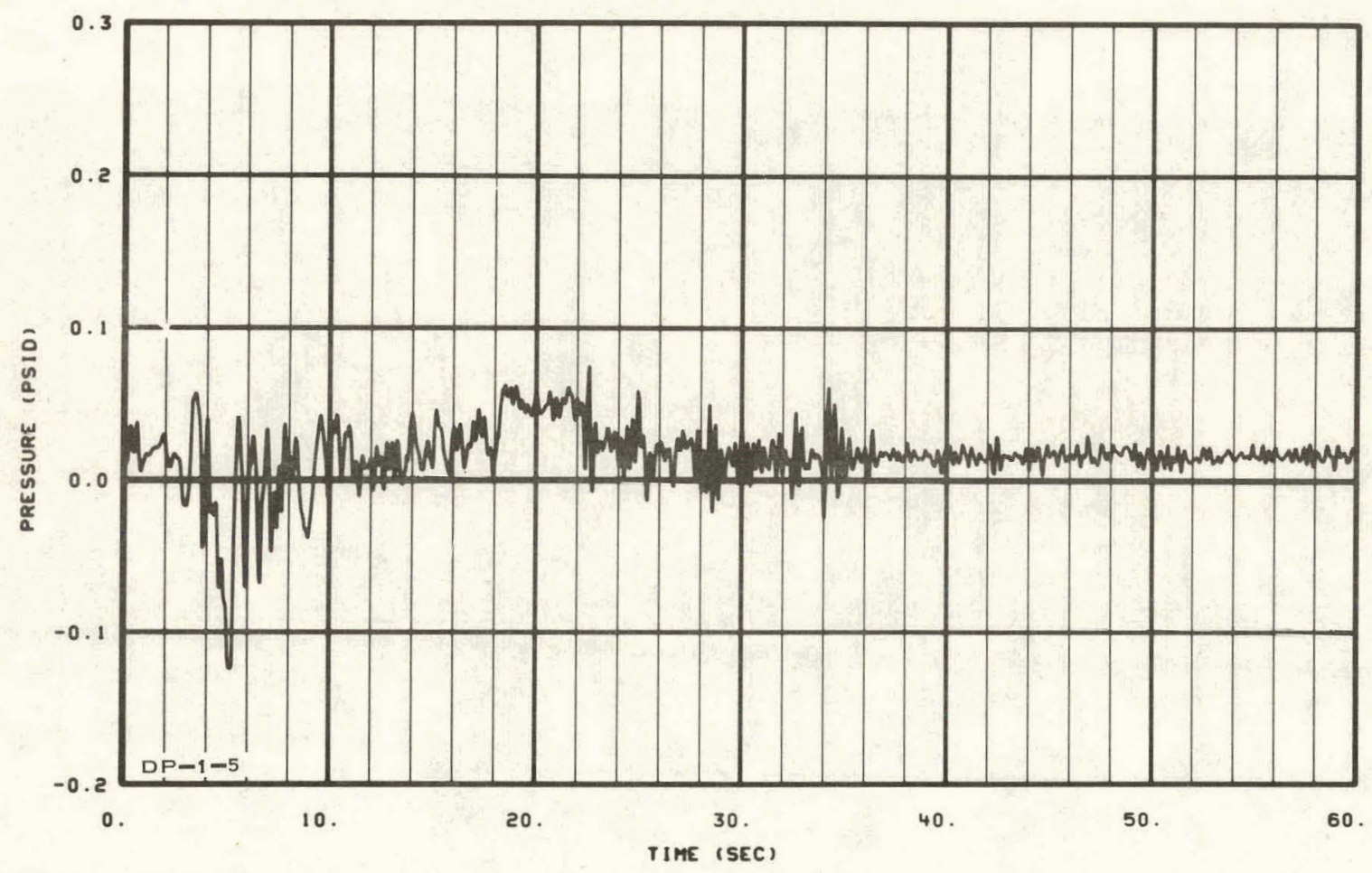

Fig. 228 Differential pressure, operating loop hot 1eg (DP-1-5) -- Test 15.4 .

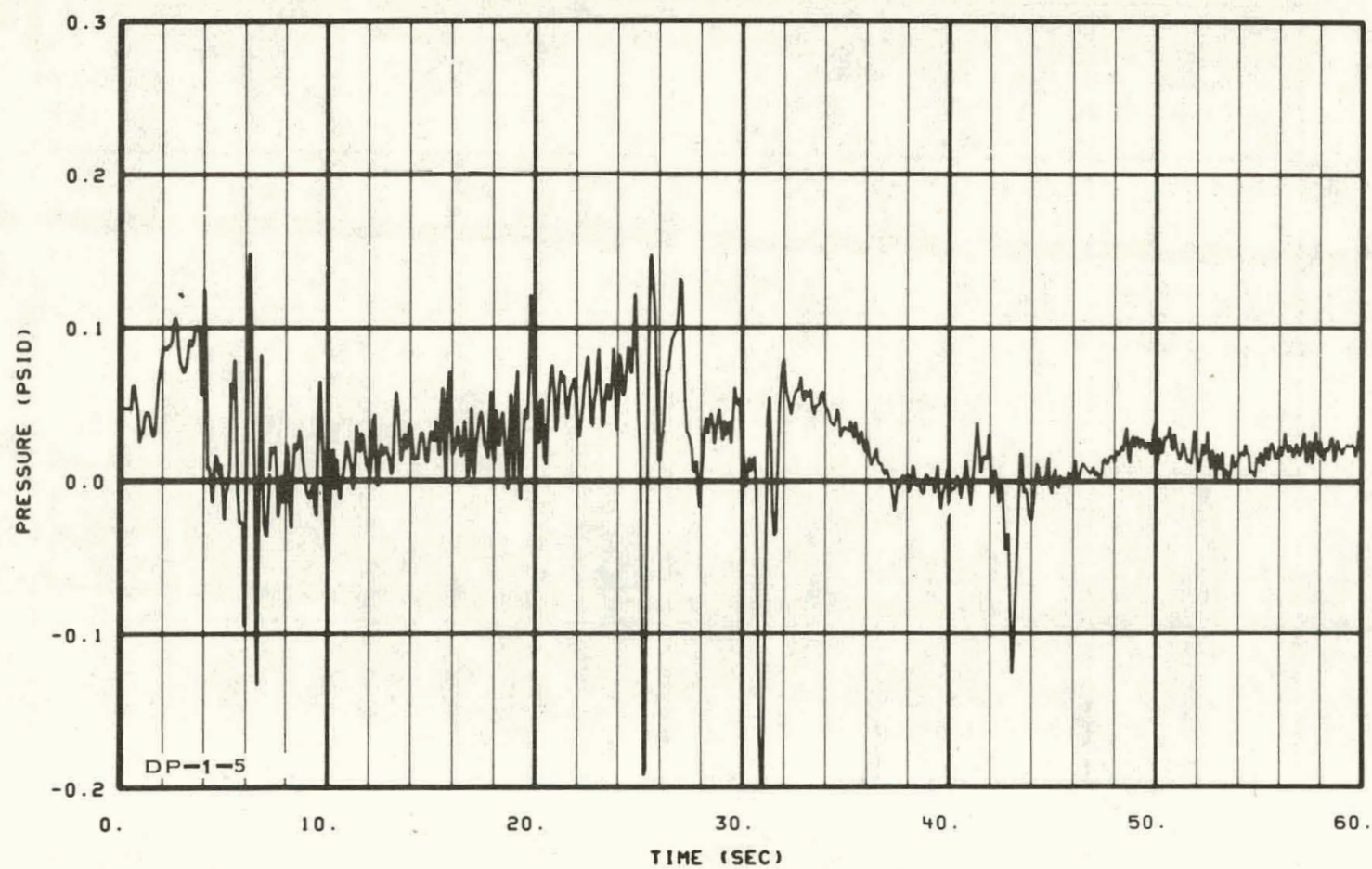

Fig. 229 Differential pressure, operating loop hot leg (DP-1-5) -- Test 15.7 . 


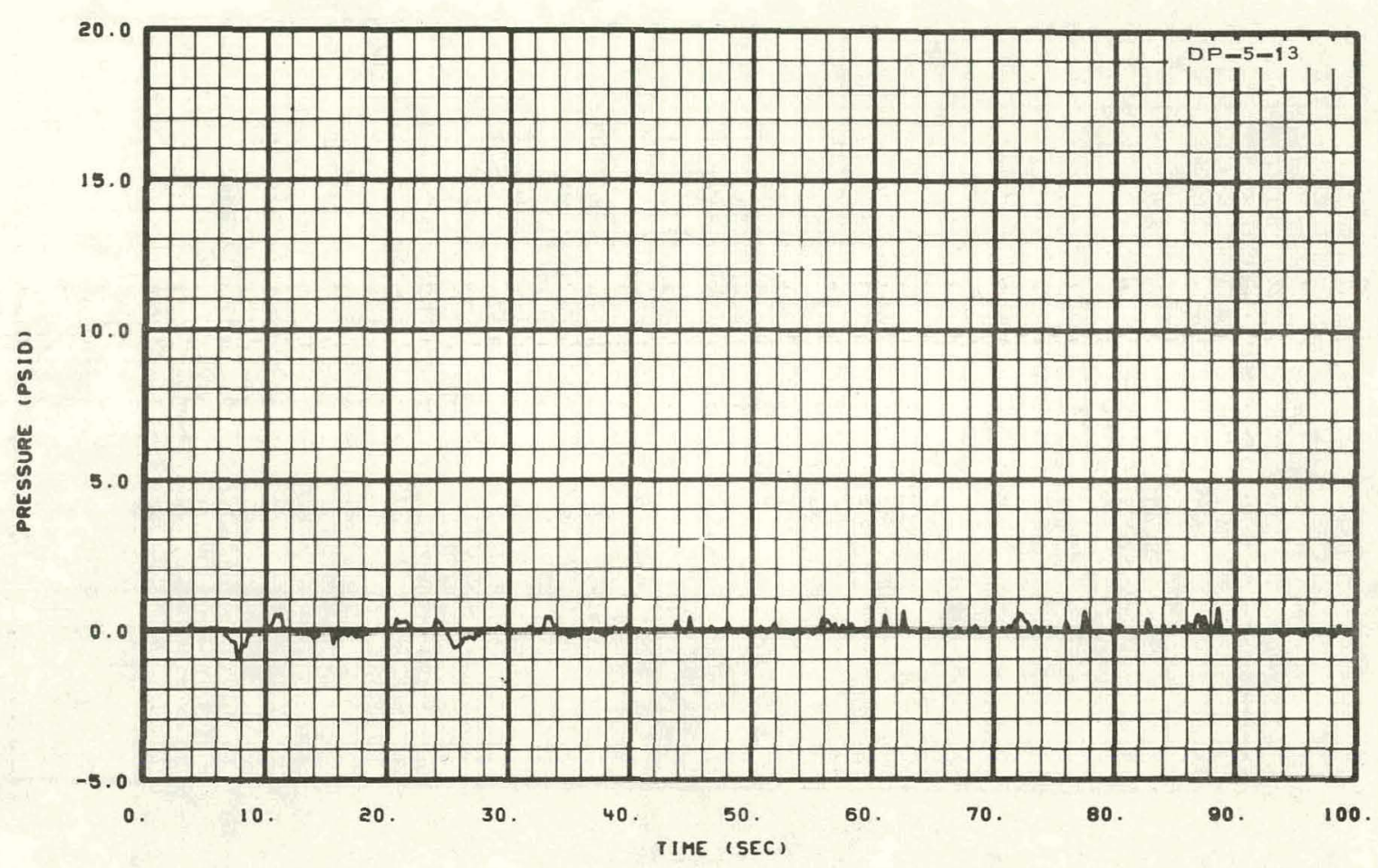

Fig. 230 Differential pressure across steam generator (DP-5-13) -- Test 15.1 .

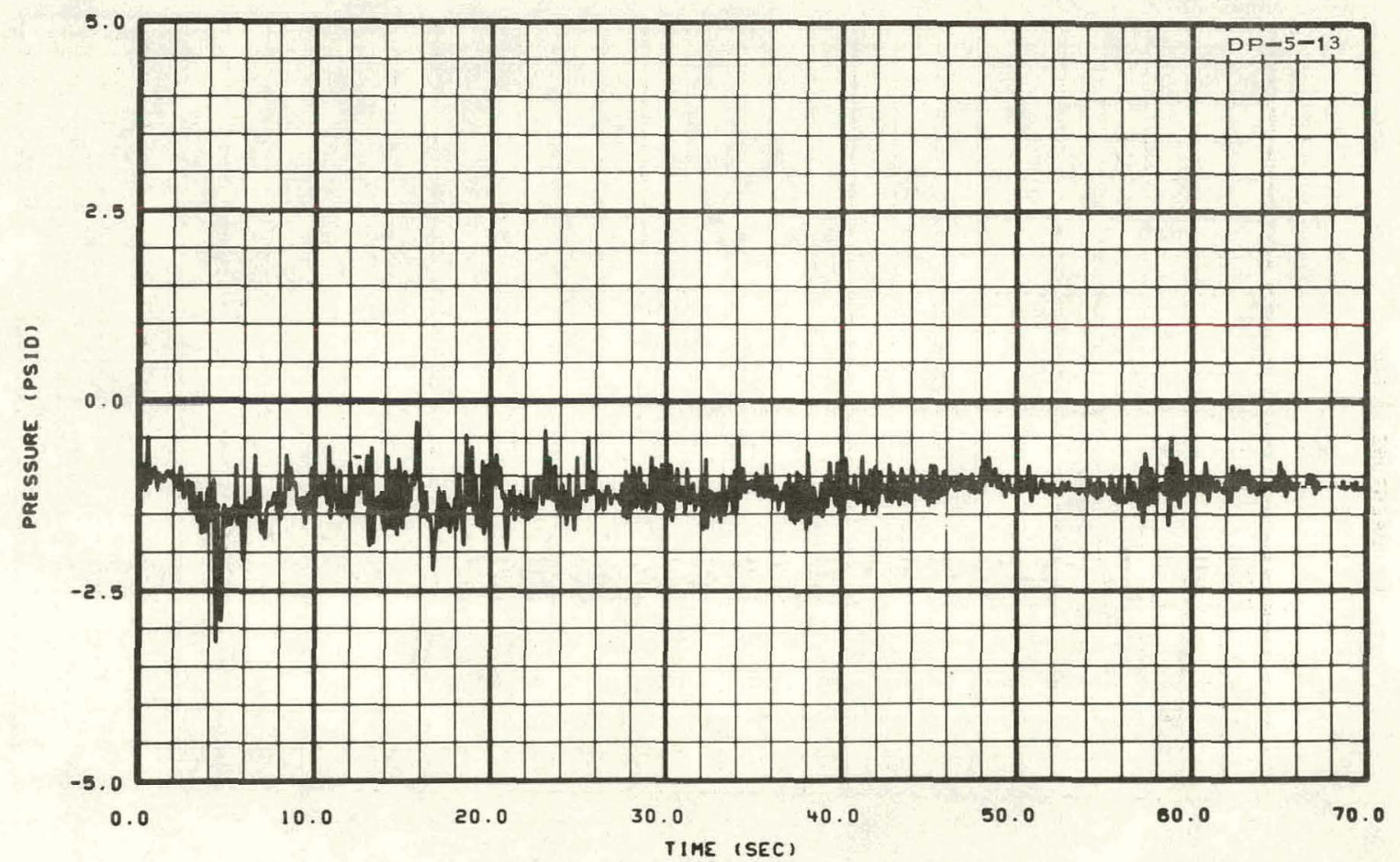

Fig. 231 Differential pressure across steam generator (DP-5-13) -- Test 15.2 . 


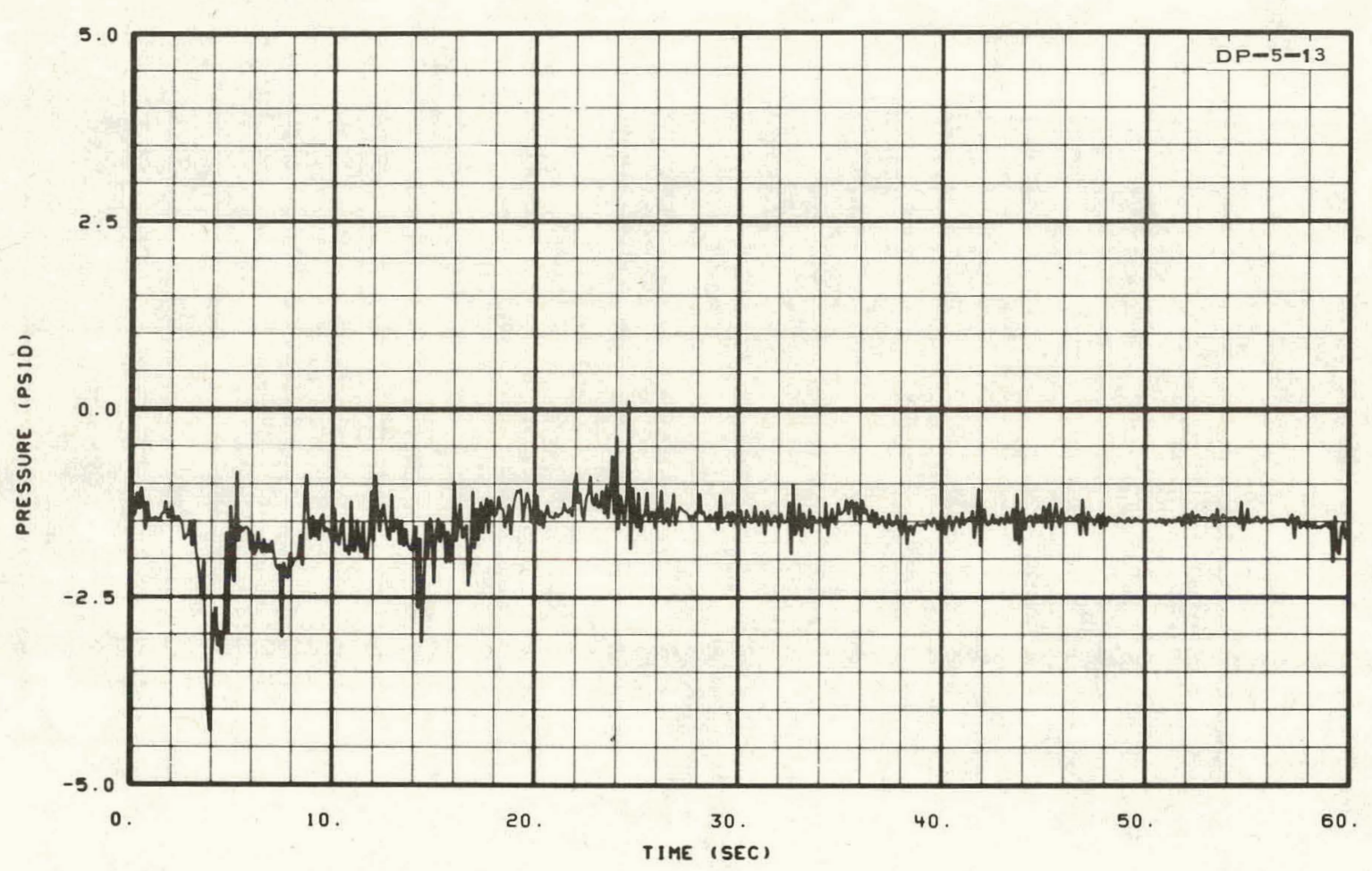

Fig. 232 Differential pressure across steam generator (DP-5-13) -- Test 15.3 .

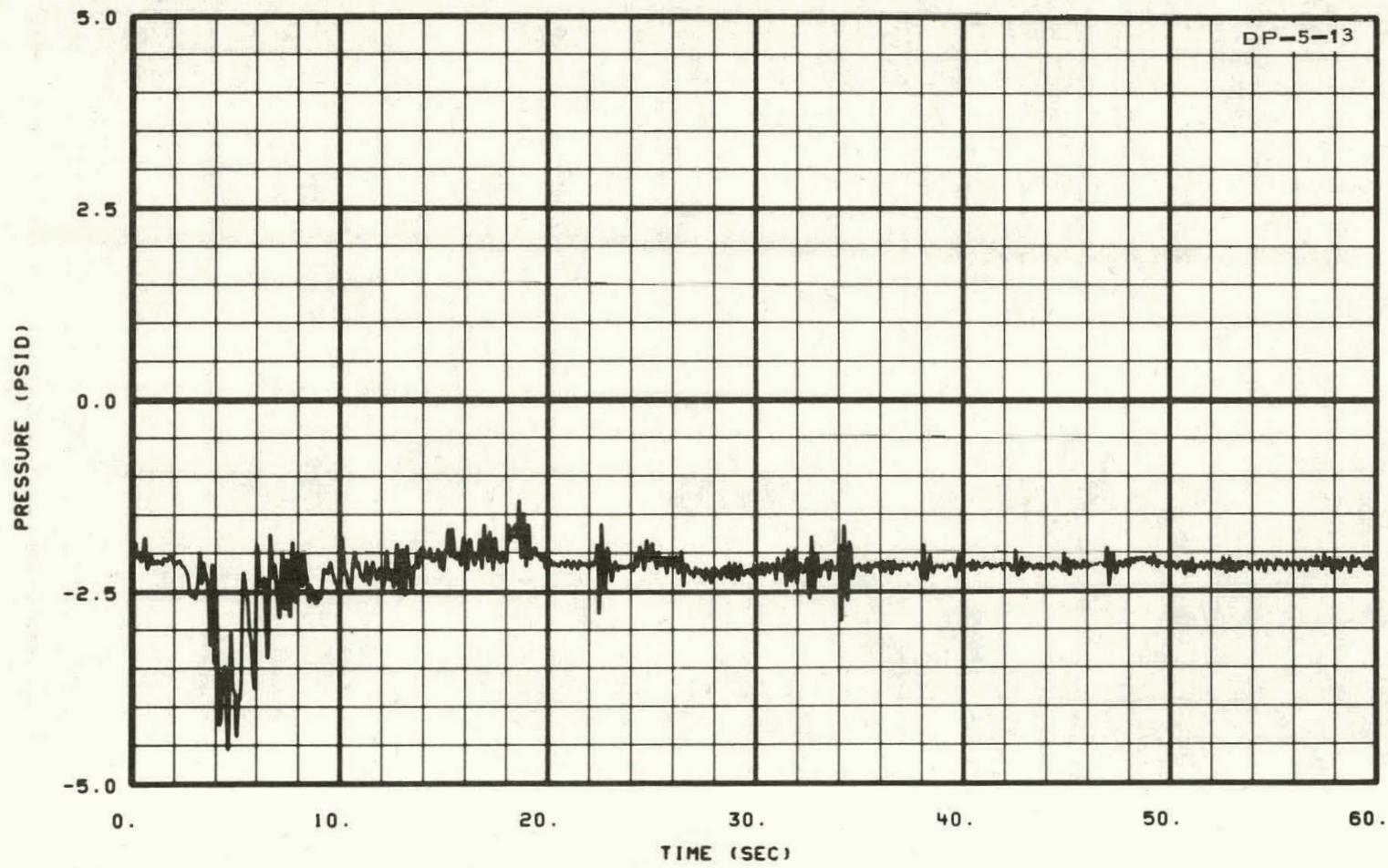

Fig. 233 Differential pressure across steam generator (DP-5-13) -- Test 15.4 . 


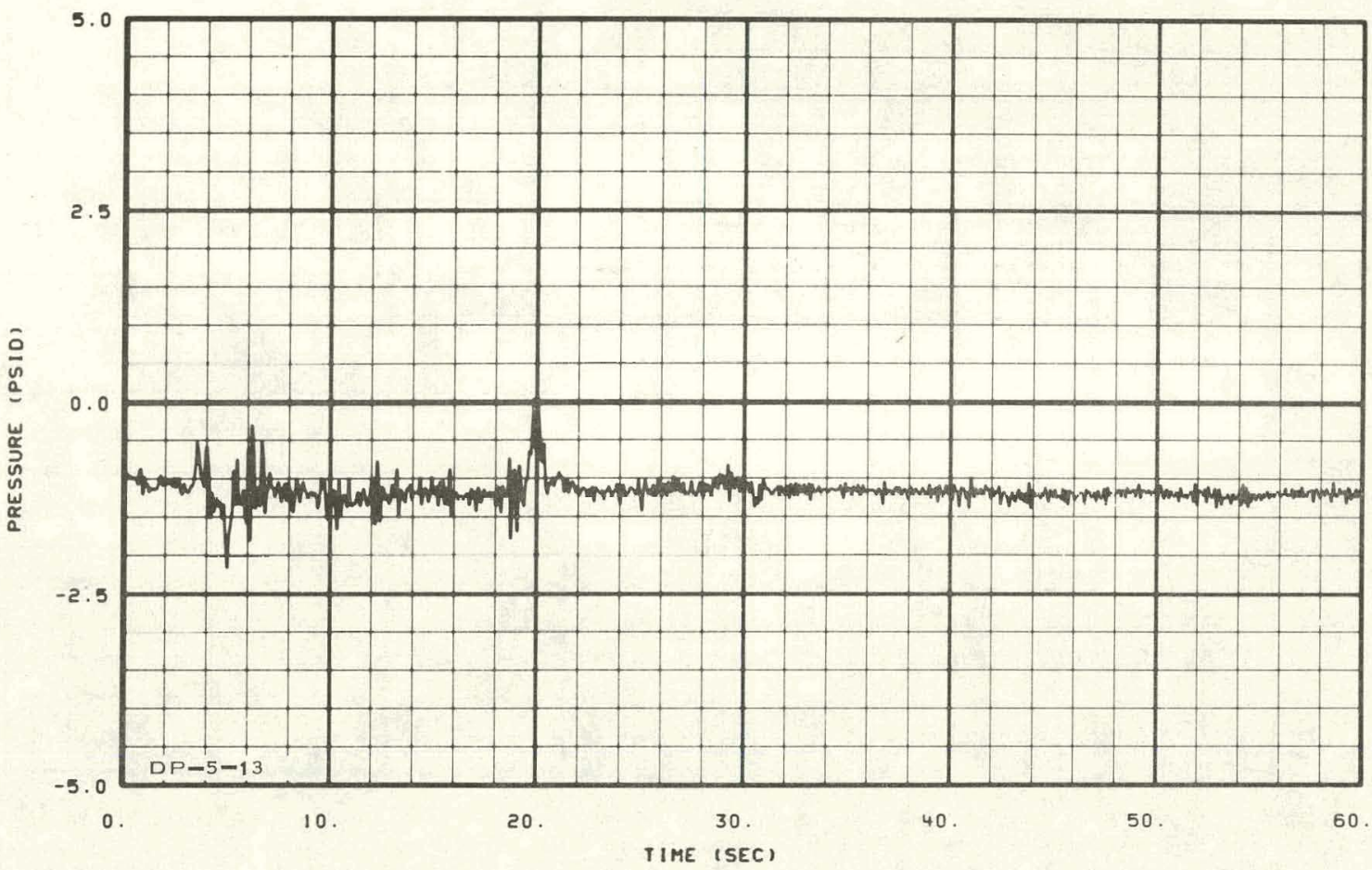

Fig. 234 Differential pressure across steam generator (DP-5-13) -- Test 15.7 .

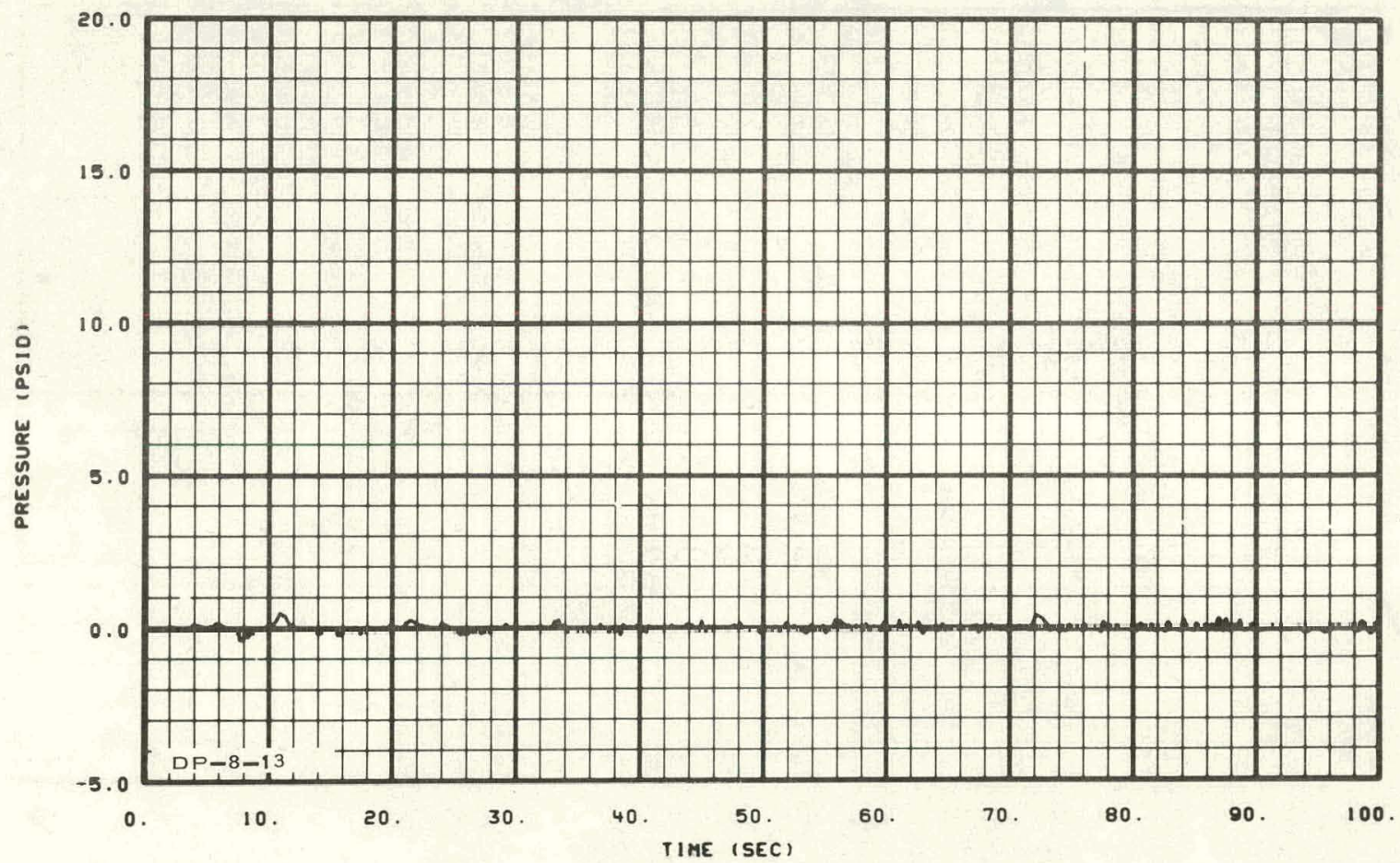

Fig. 235 Differential pressure across pump suction orifice (DP-8-13) -Test 15.1 . 


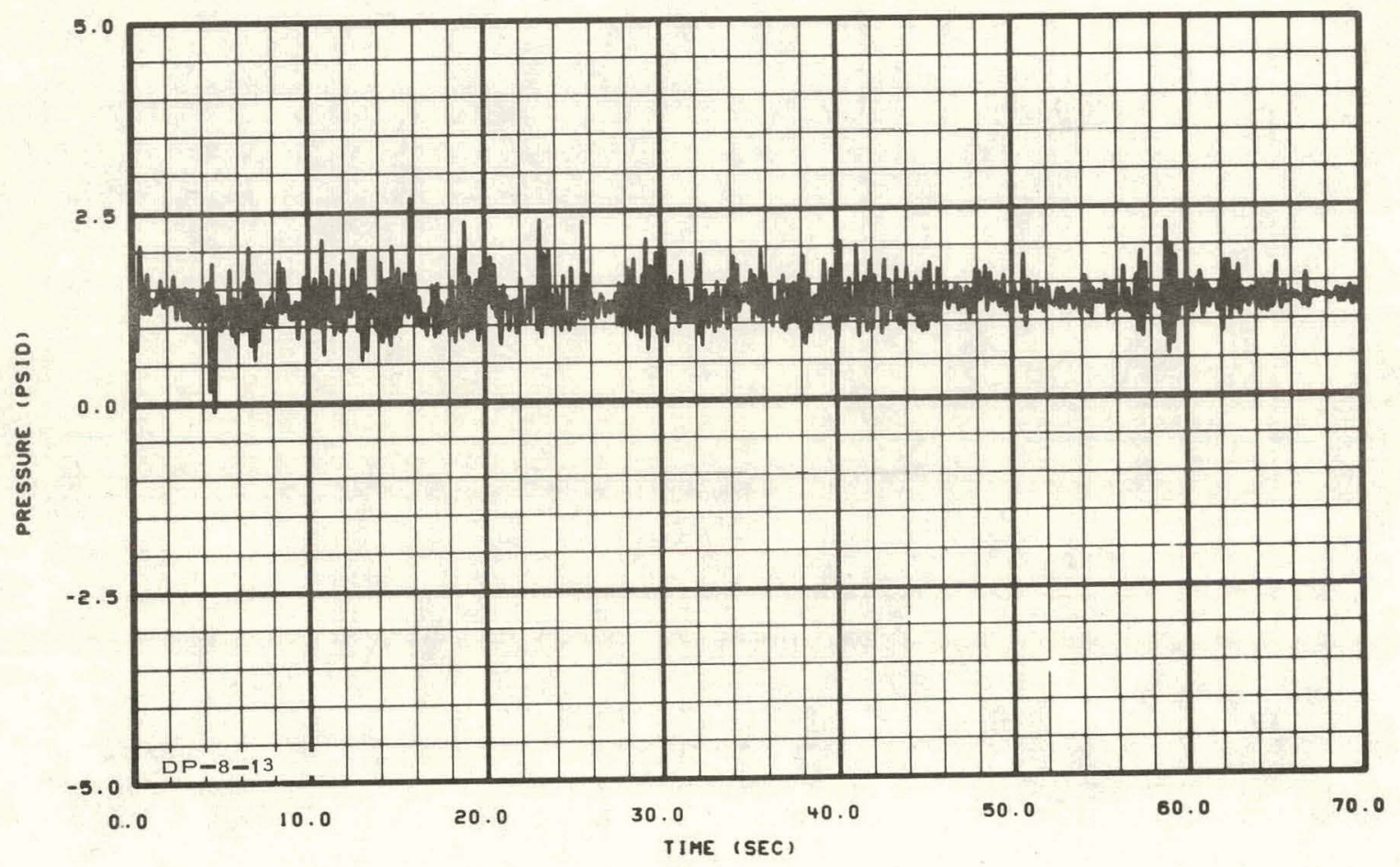

Fig. 236 Differential pressure across pump suction orifice (DP-8-13) -Test 15.2 .

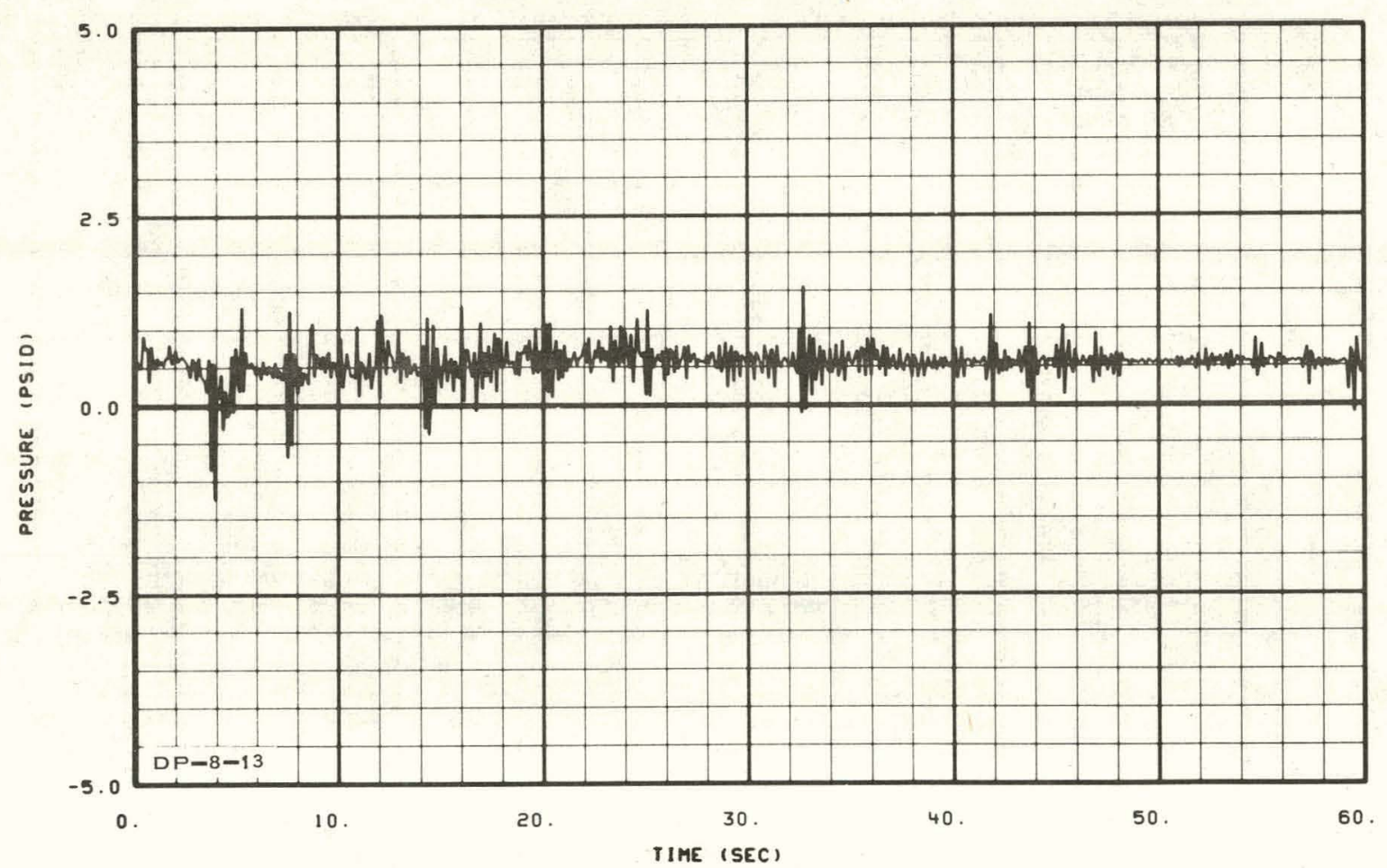

Fig. 237 Differential pressure across pump suction orifice (DP-8-13) -Test 15.3 . 


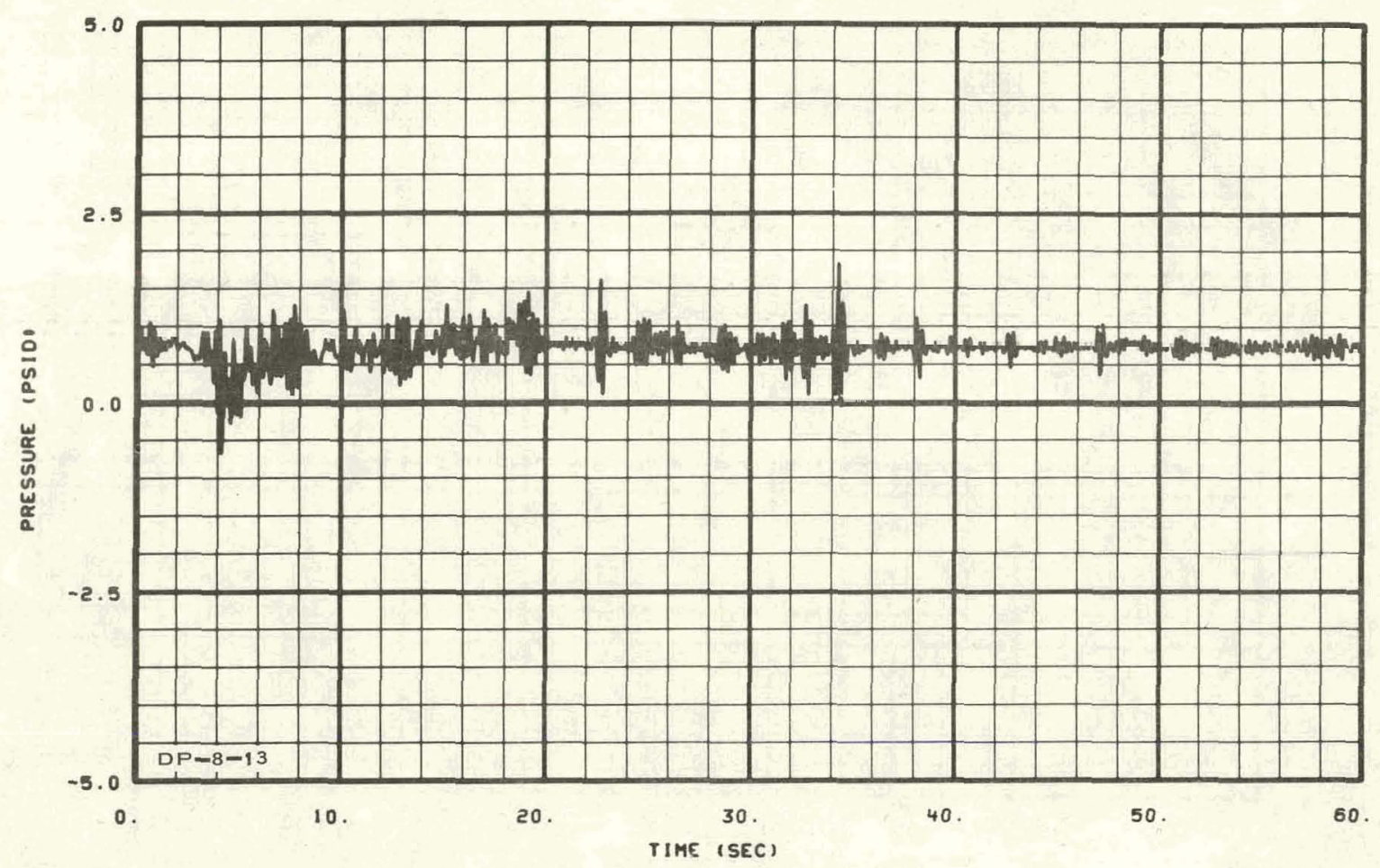

Fig. 238 Differential pressure across pump suction orifice (DP-8-13) -Test 15.4 .

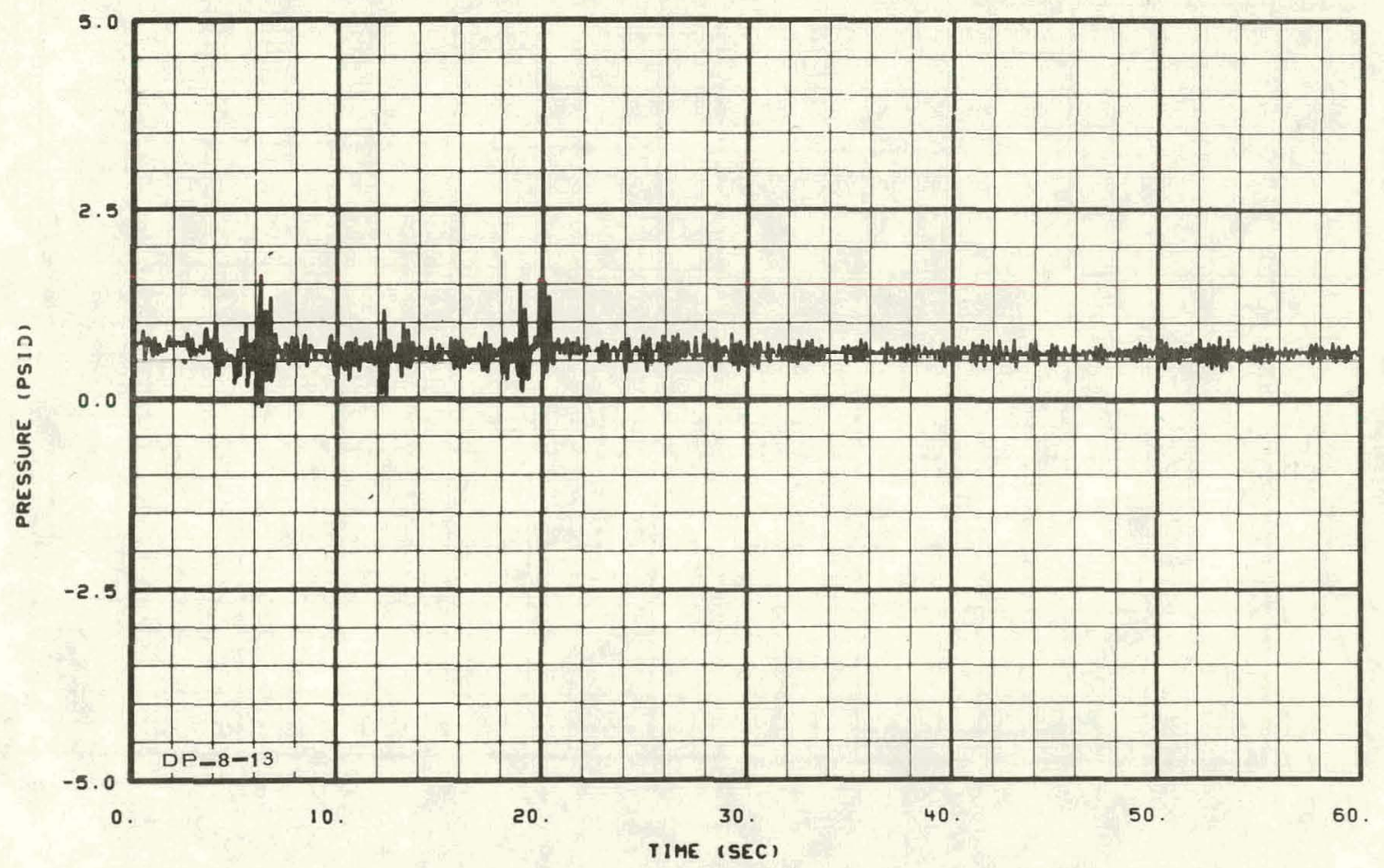

Fig. 239 Differential pressure across pump suction orifice (DP-8-13) -Test 15.7 . 


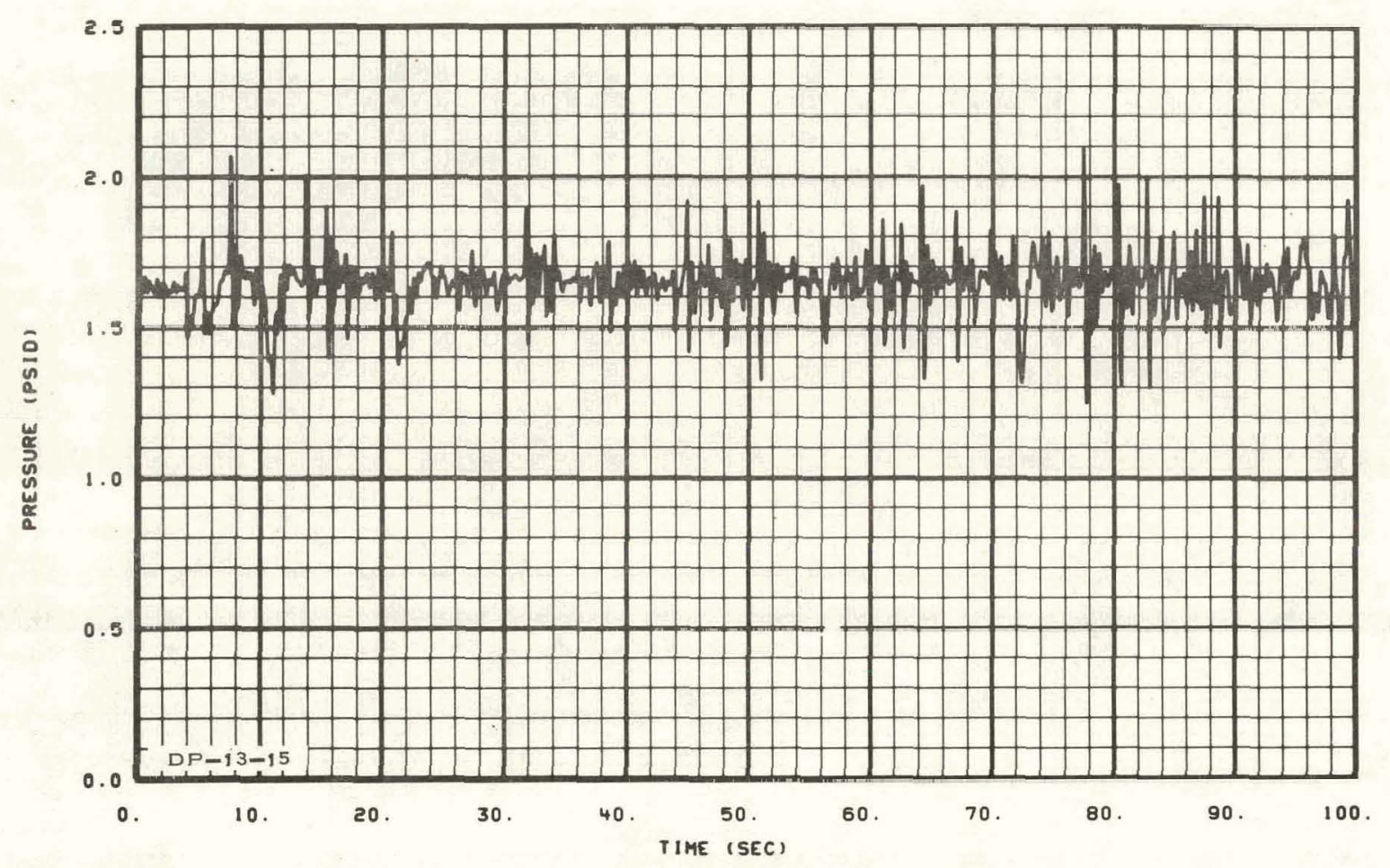

Fig. 240 Differential pressure across operating loop pump inlet (DP-1315) -- Test 15.1.

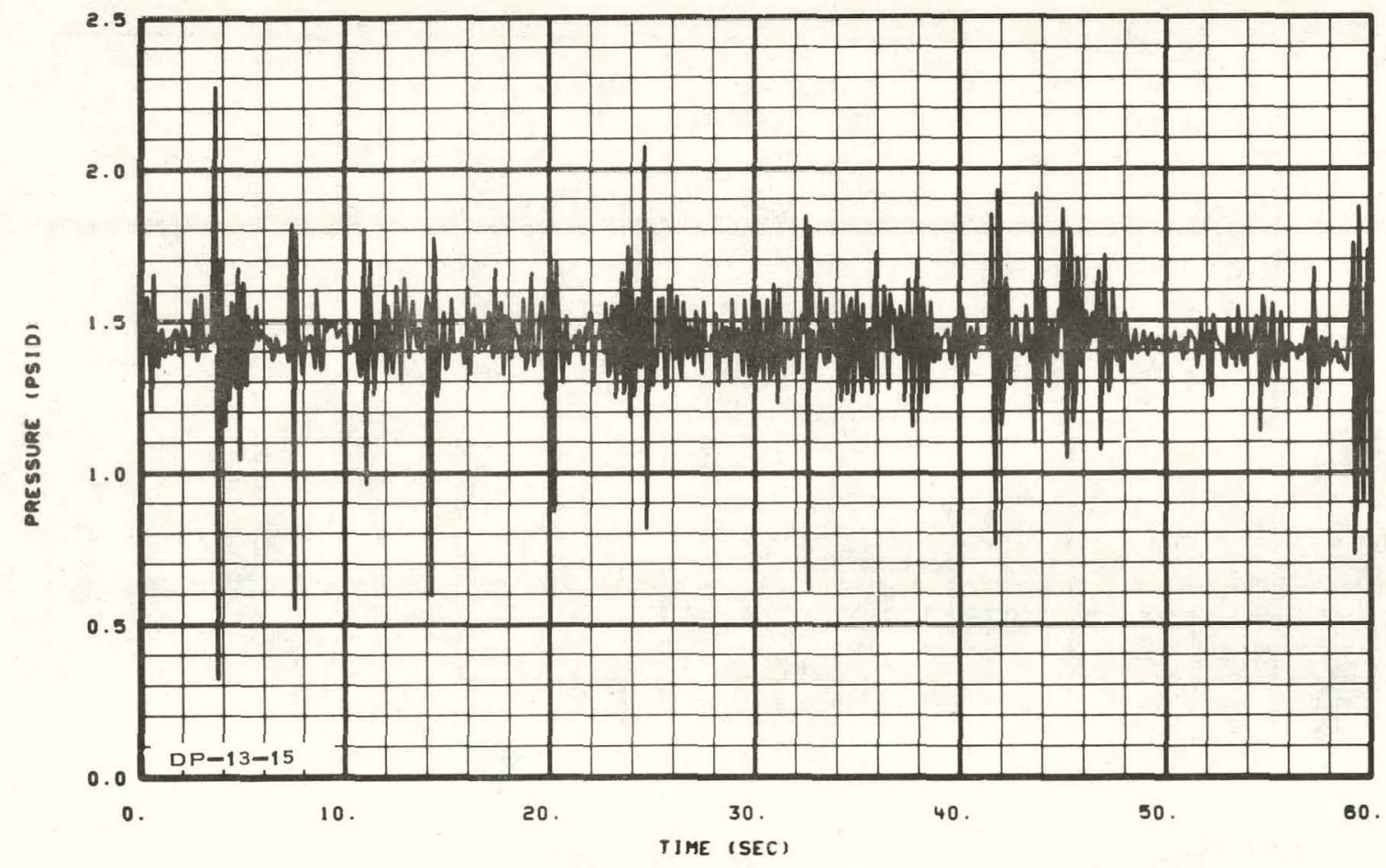

Fig. 241 Differential pressure across operating 1oop pump inlet (DP-1315) -- Test 15.3. 


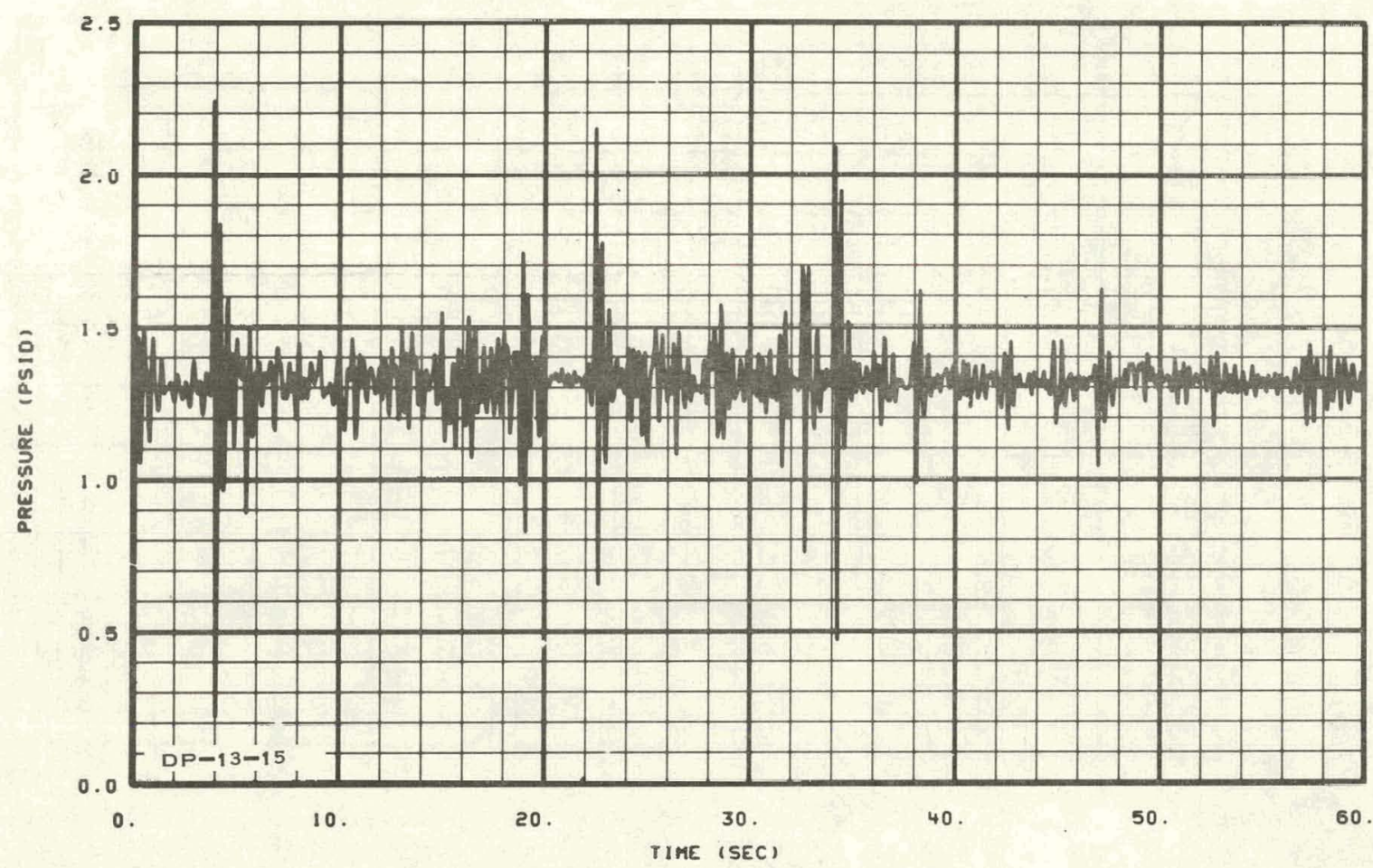

Fig. 242 Differential pressure across operating loop pump inlet (DP-1315) -- Test 15.4 .

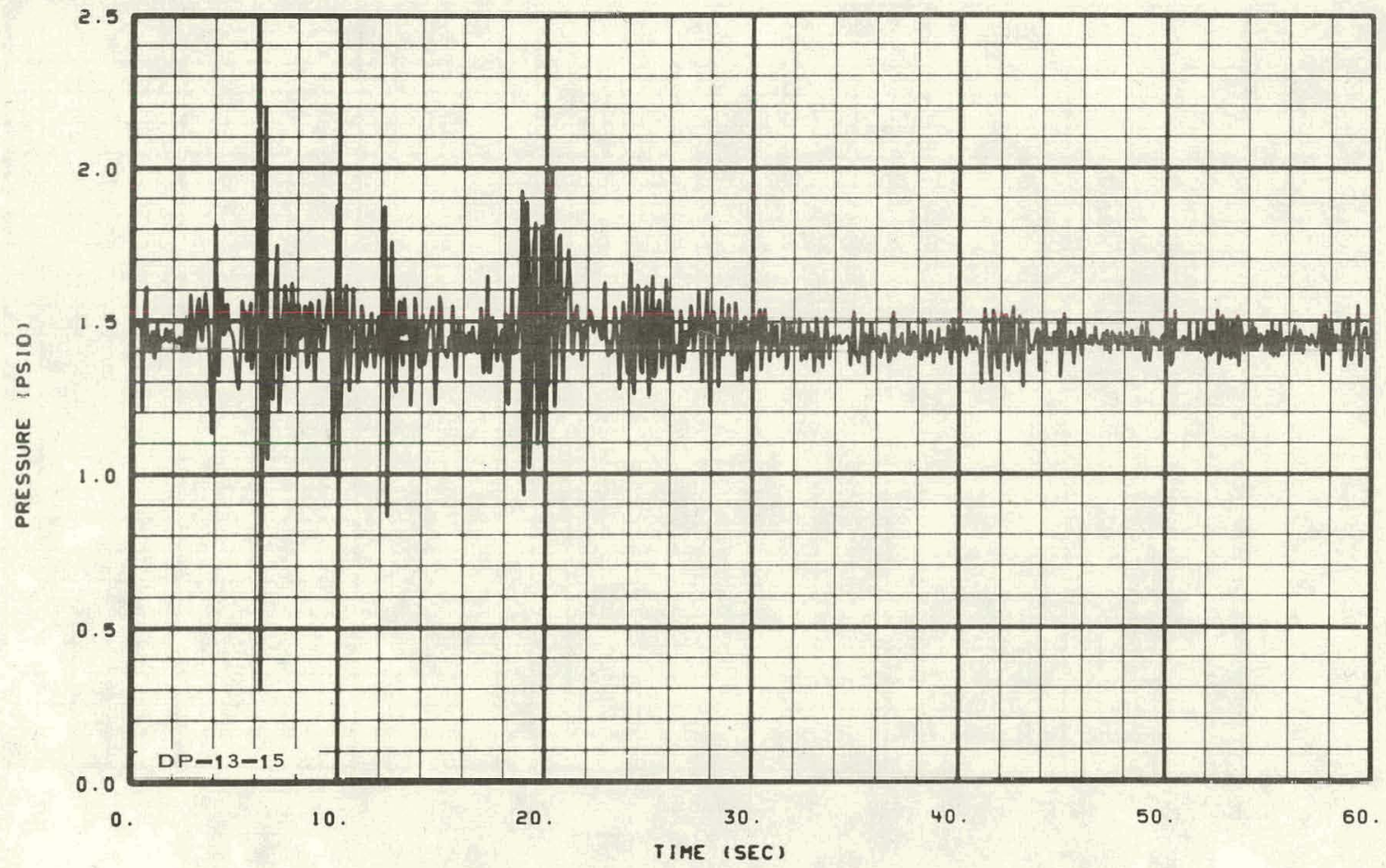

Fig. 243 Differential pressure across operating loop pump inlet (DP-1315) -- Test 15.7. 


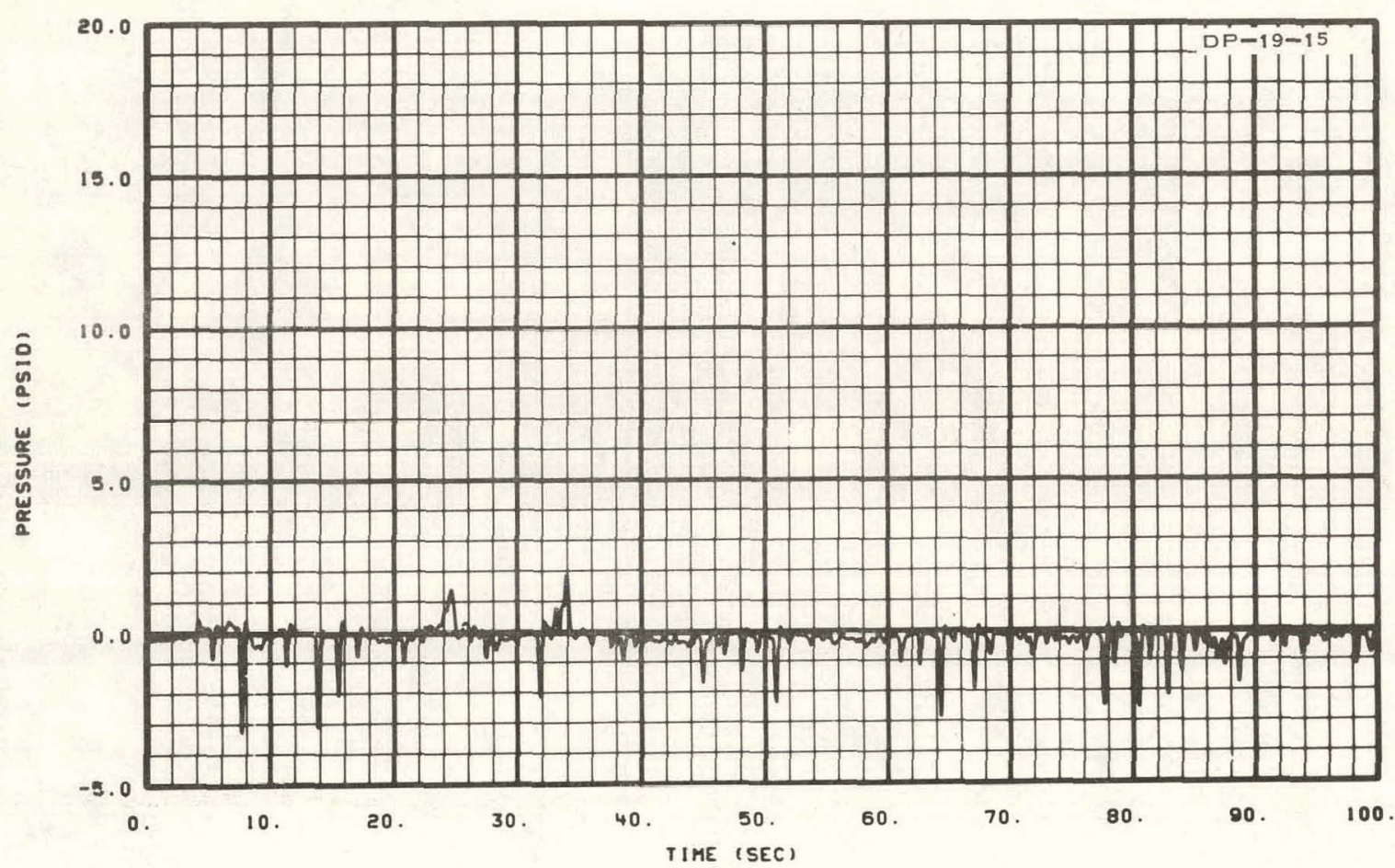

Fig. 244 Differential pressure across operating loop pump (DP-19-15) -Test 15.1.

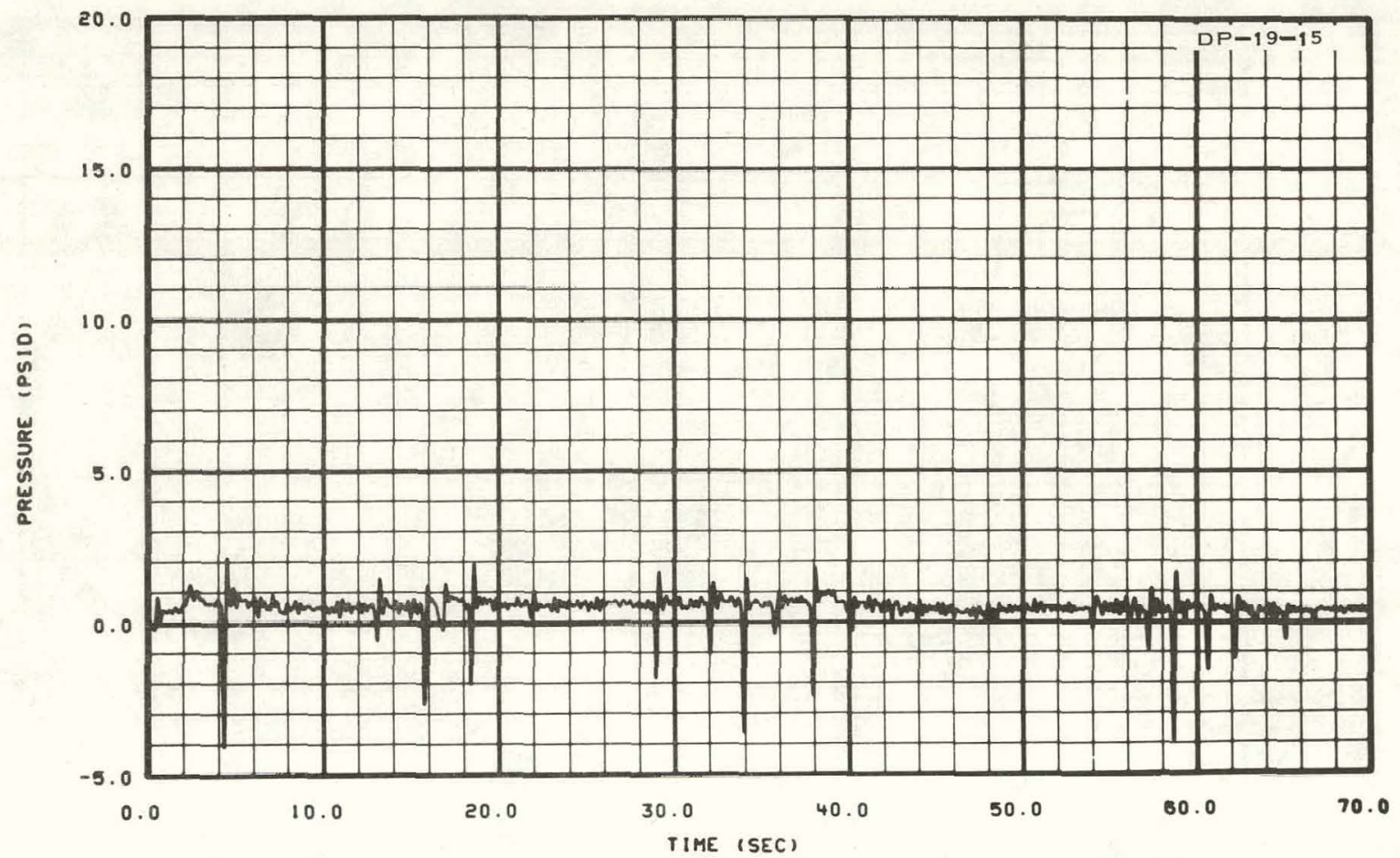

Fig. 245 Differential pressure across operating loop pump (DP-19-15) -Test 15.2. 


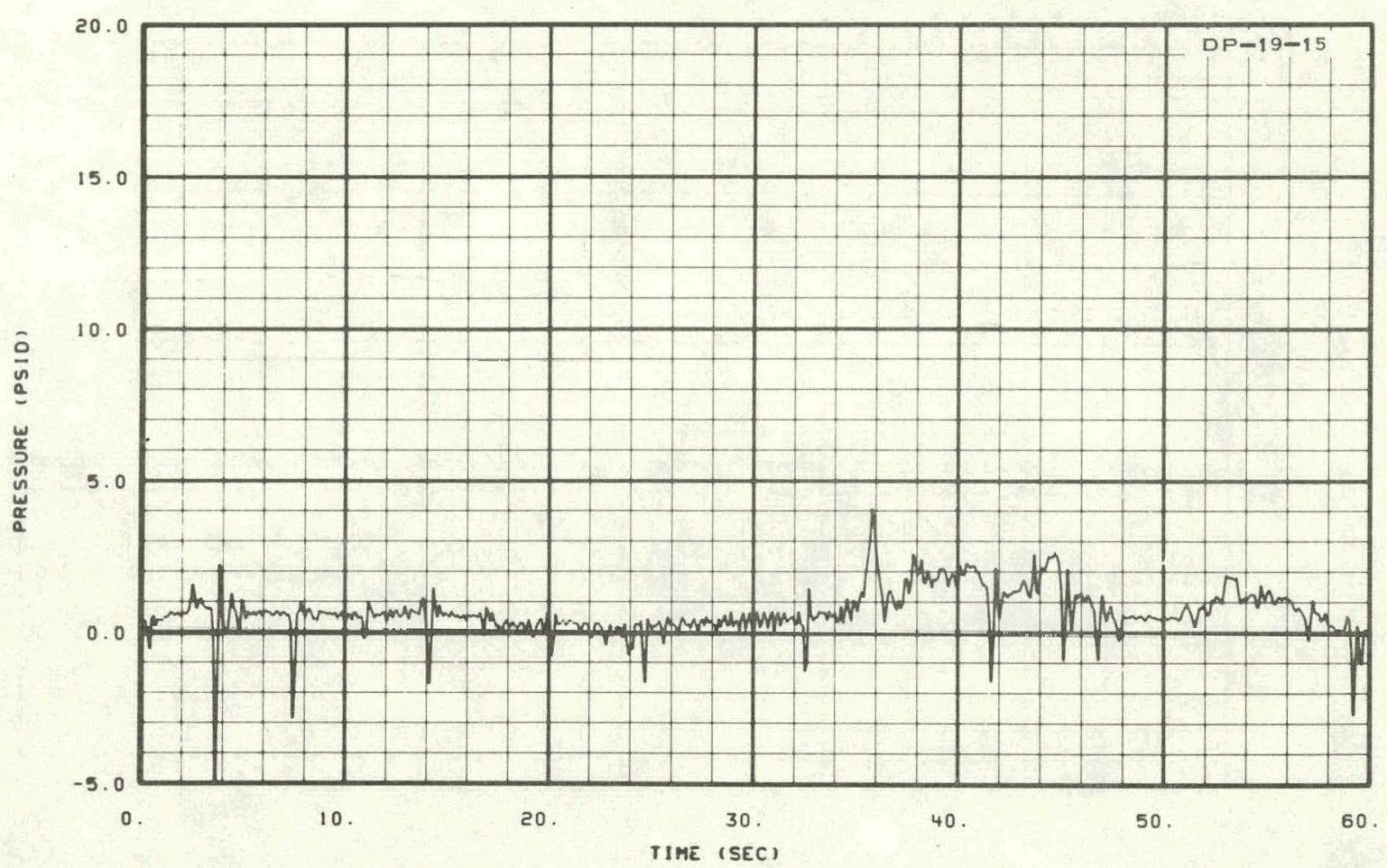

Fig. 246 Differential pressure across operating loop pump (DP-19-15) -Test 15.3 .

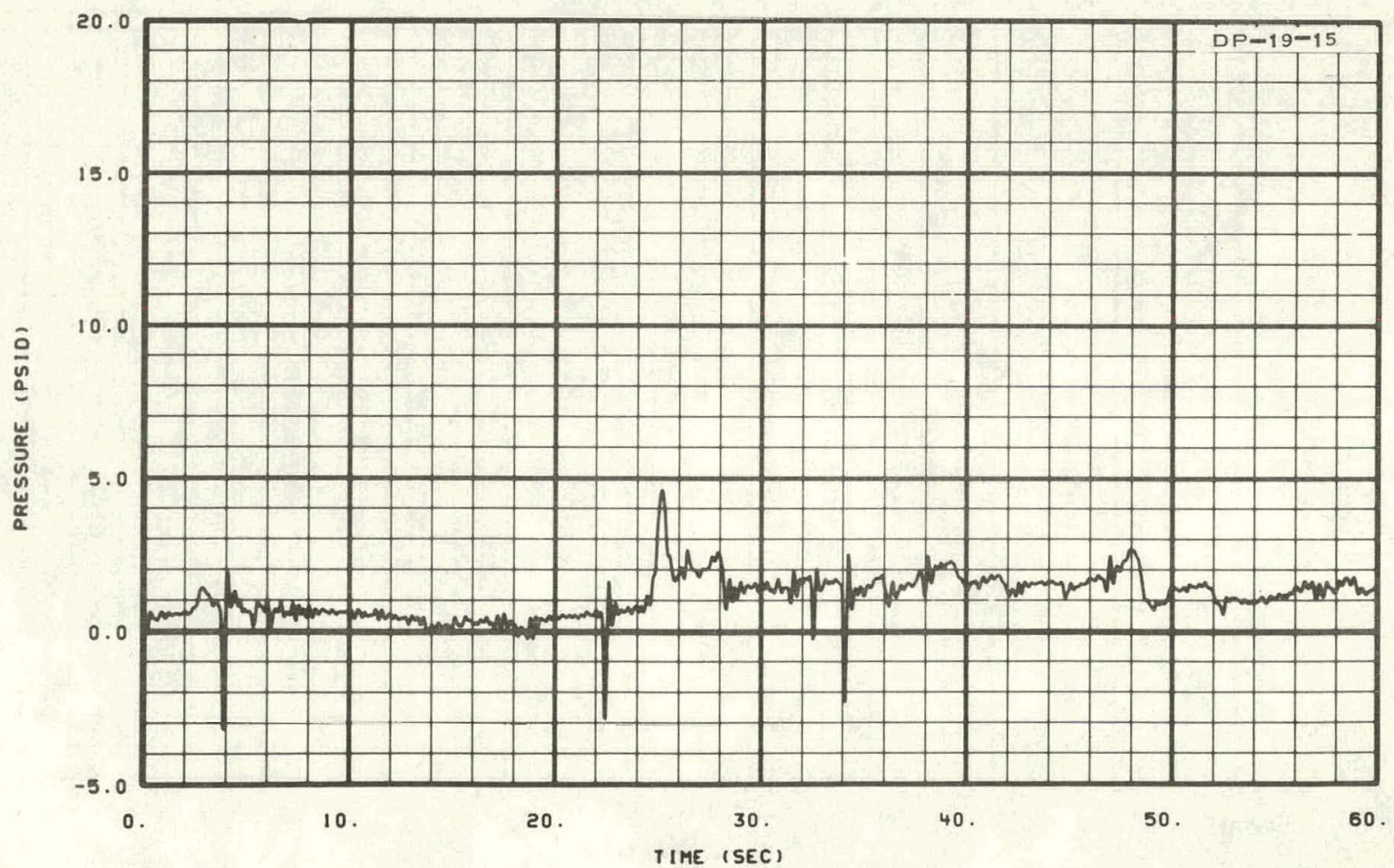

Fig. 247 Differential pressure across operating loop pump (DP-19-15) -Test 15.4 . 


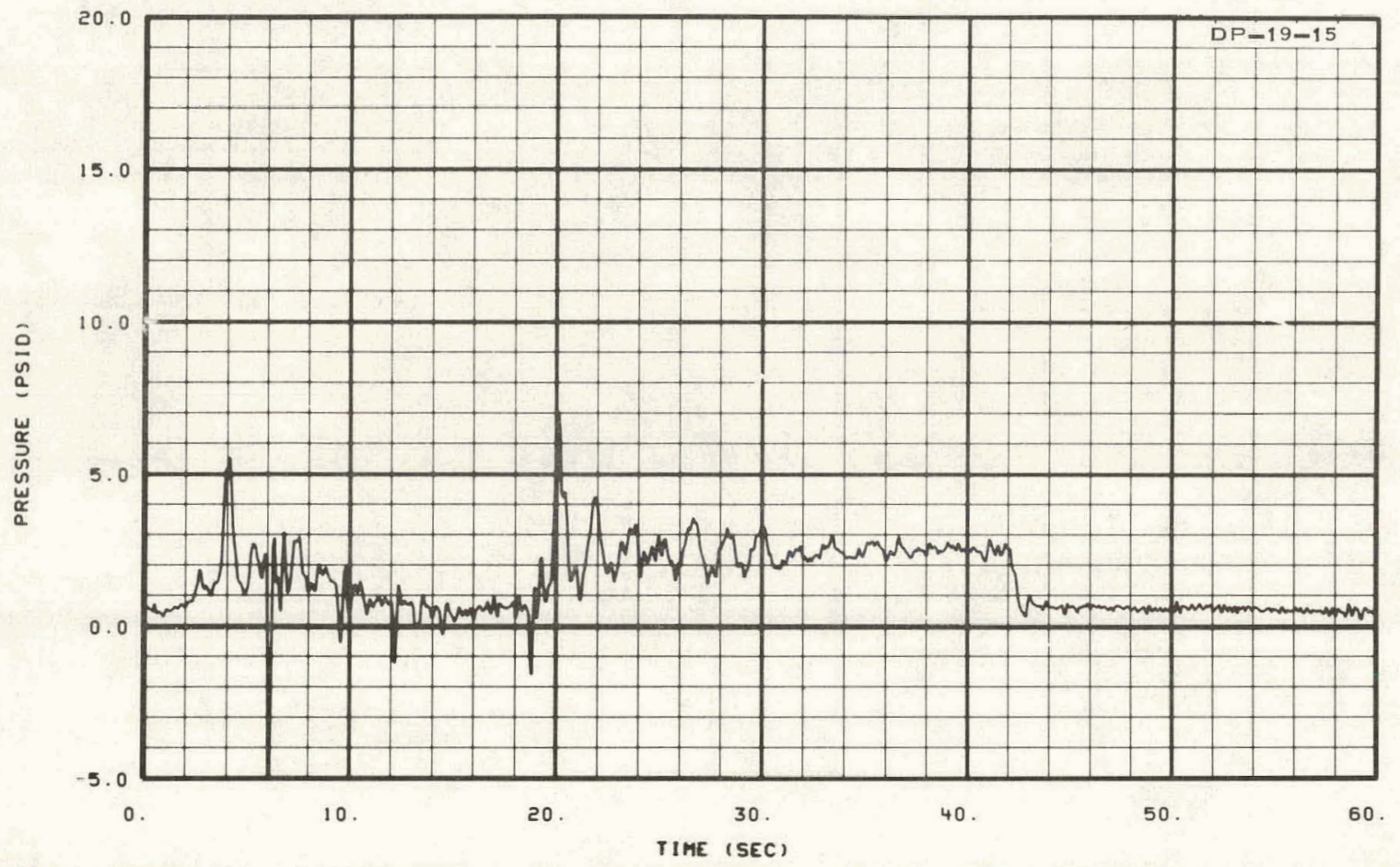

Fig. 248 Differential pressure across operating loop pump (DP-19-15) -Test 15.7 .

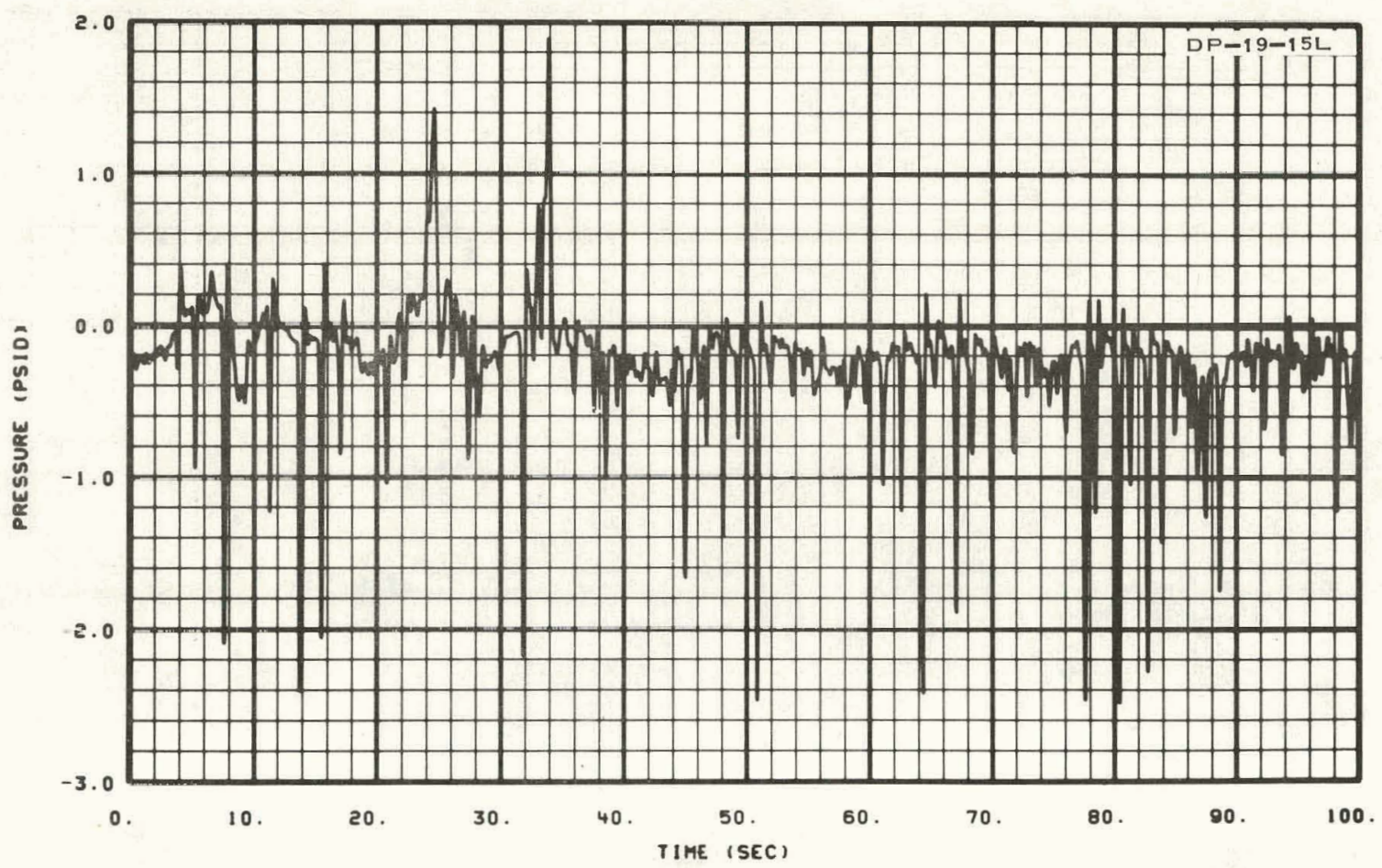

Fig. 249 Differential pressure across operating loop pump, low range (DP-19-15L) -- Test 15.1. 


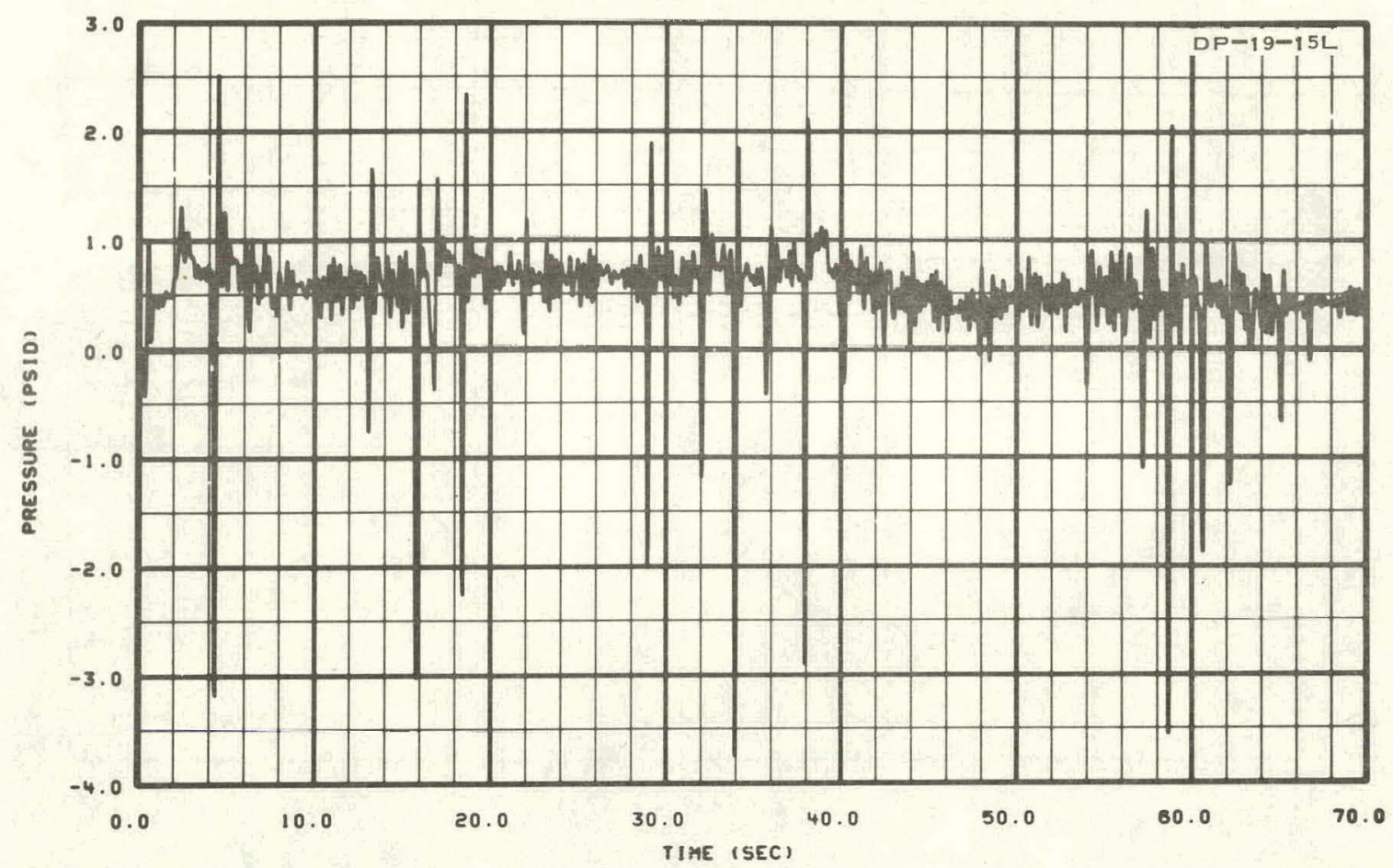

Fig. 250 Differential pressure across operating loop pump, low range (DP-19-15L) -- Test 15.2.

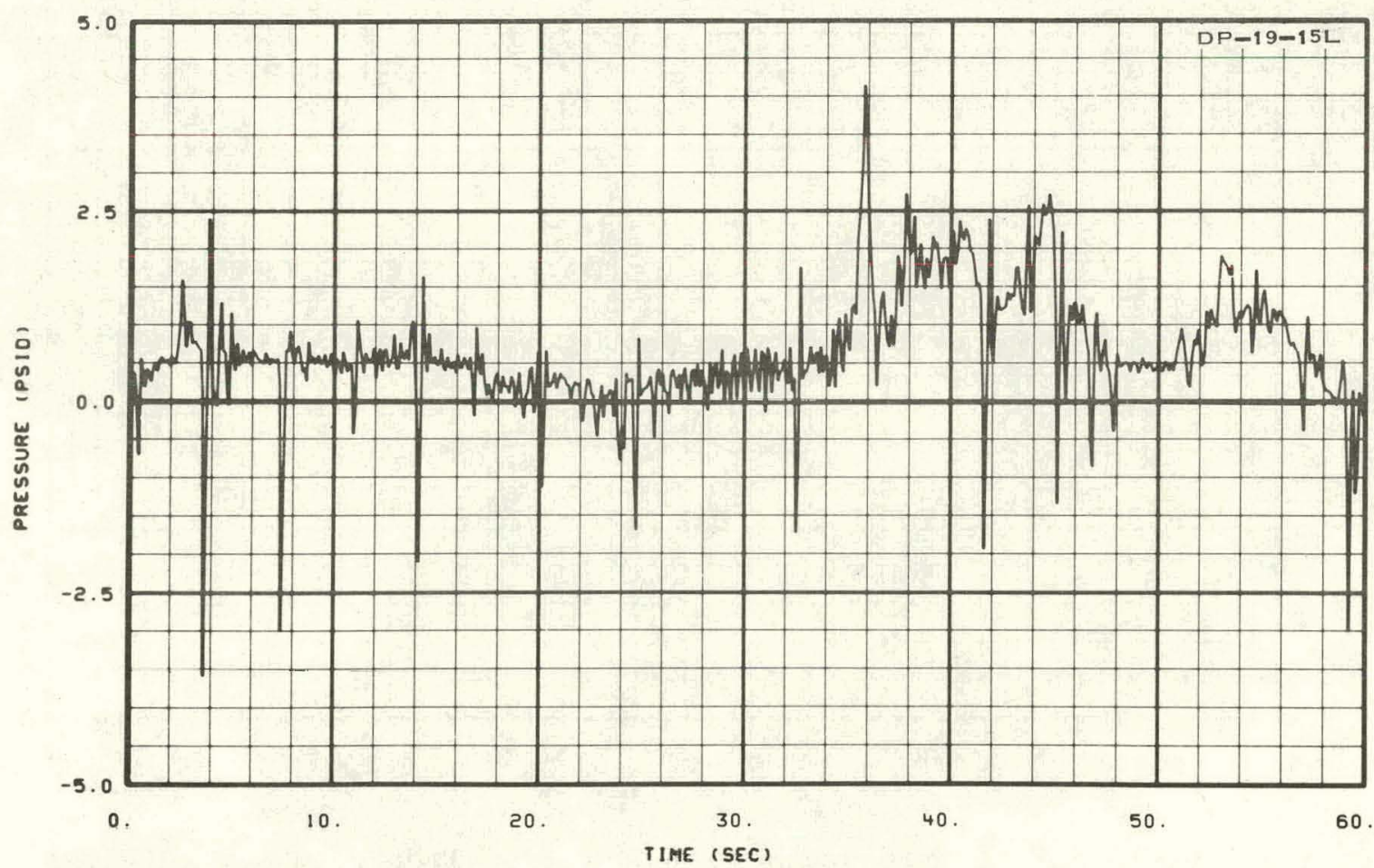

Fig. 251 Differential pressure across operating loop pump, low range (DP-19-15L) -- Test 15.3. 


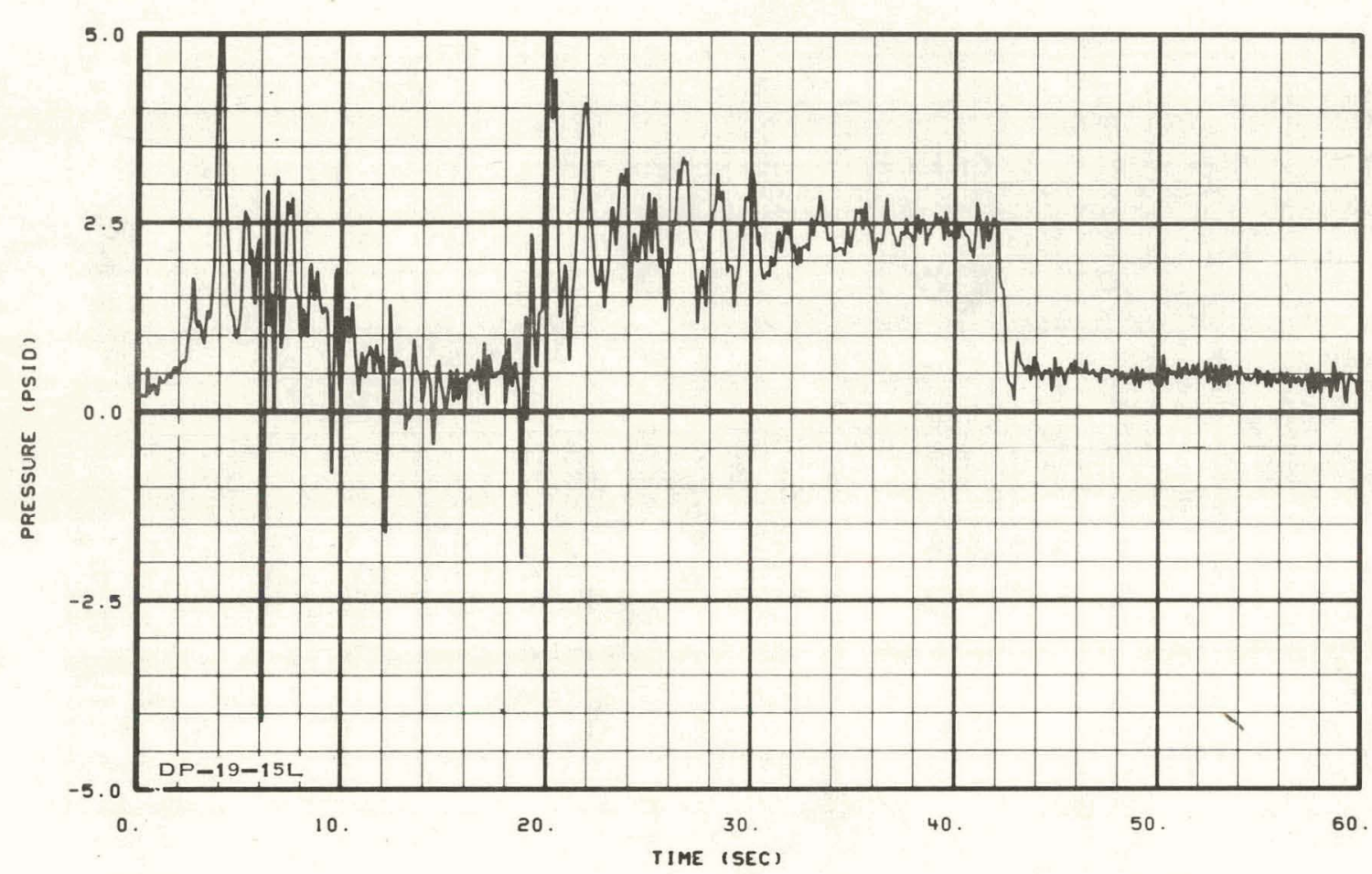

Fig. 252 Differential pressure across operating loop pump, low range (DP-19-15L) -- Test 15.7.

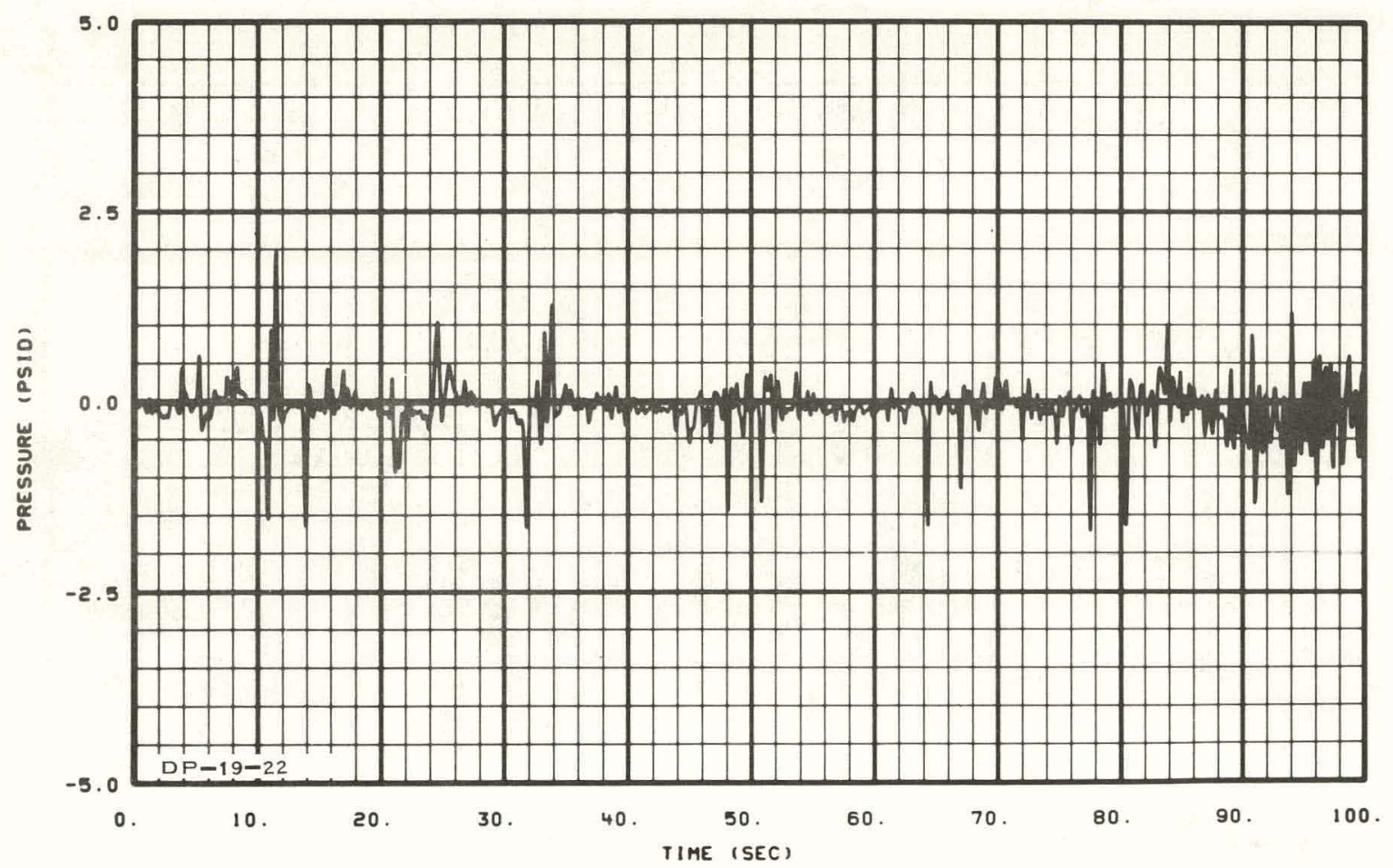

Fig. 253 Differential pressure across operating 1oop cold 1eg (DP-19-22) -Test 15.1 . 


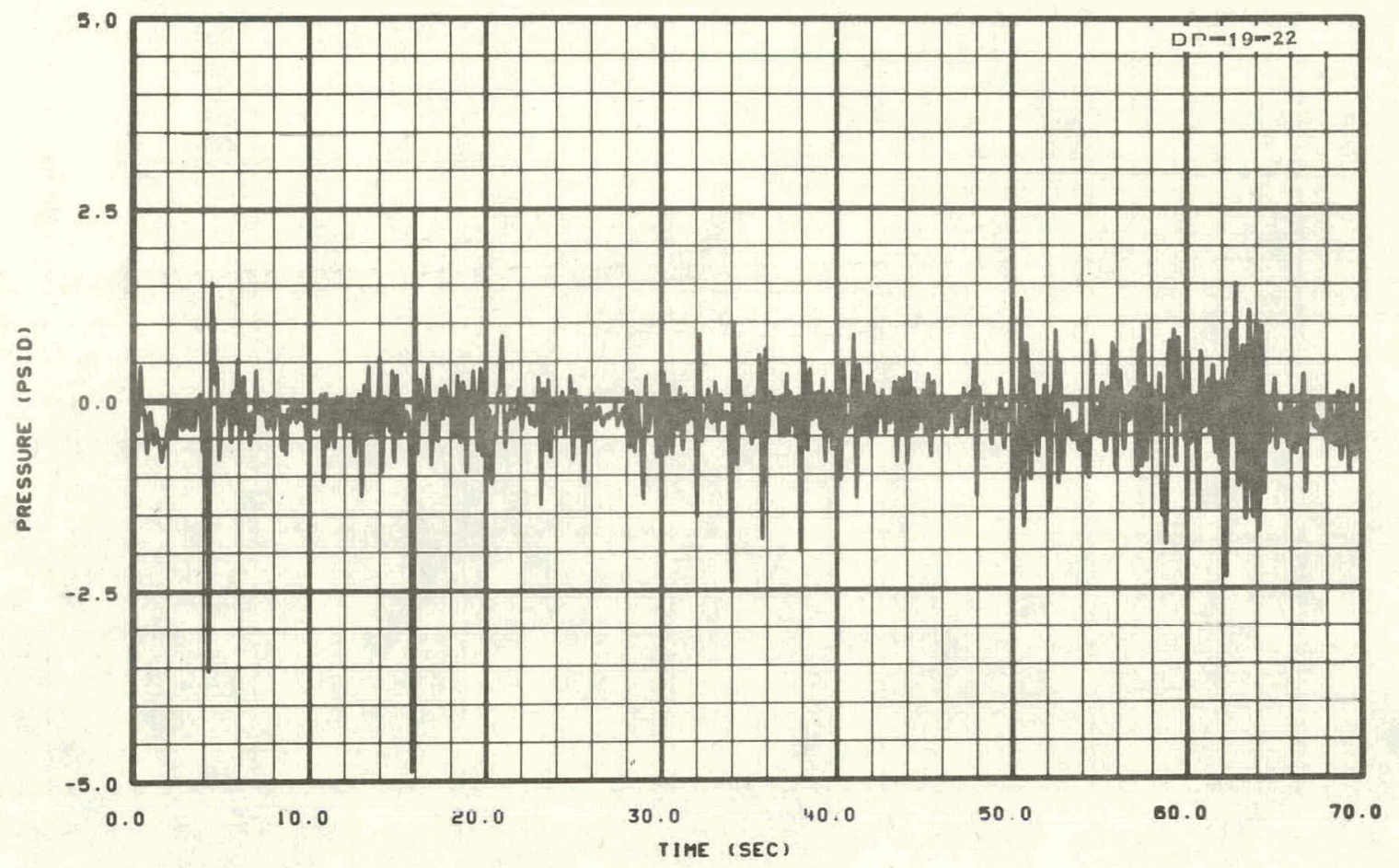

Fig. 254 Differential pressure across operating loop cold leg (DP-19-22) -Test 15.2 .

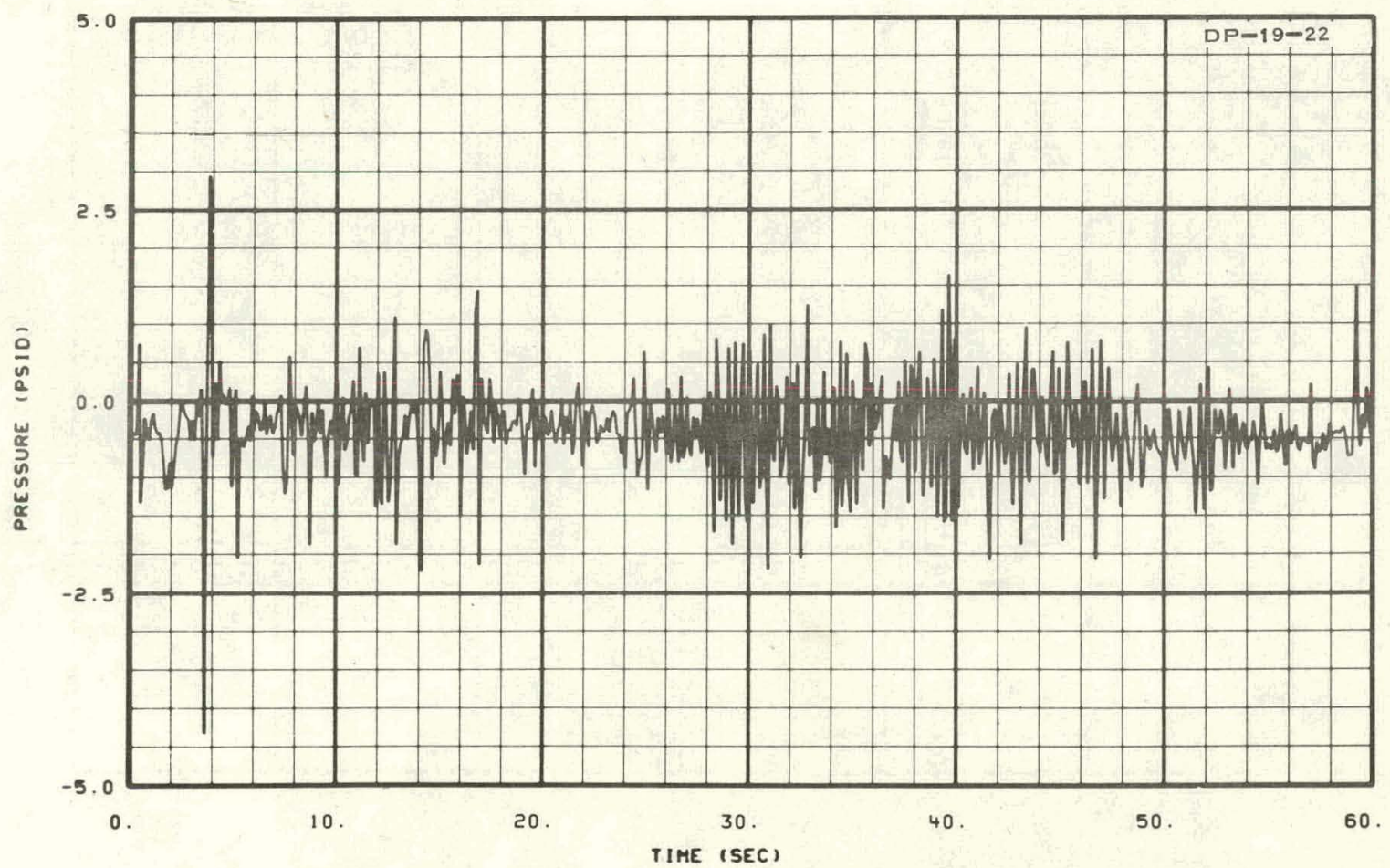

Fig. 255 Differential pressure across operating loop cold leg (DP-19-22) -Test 15.3 . 


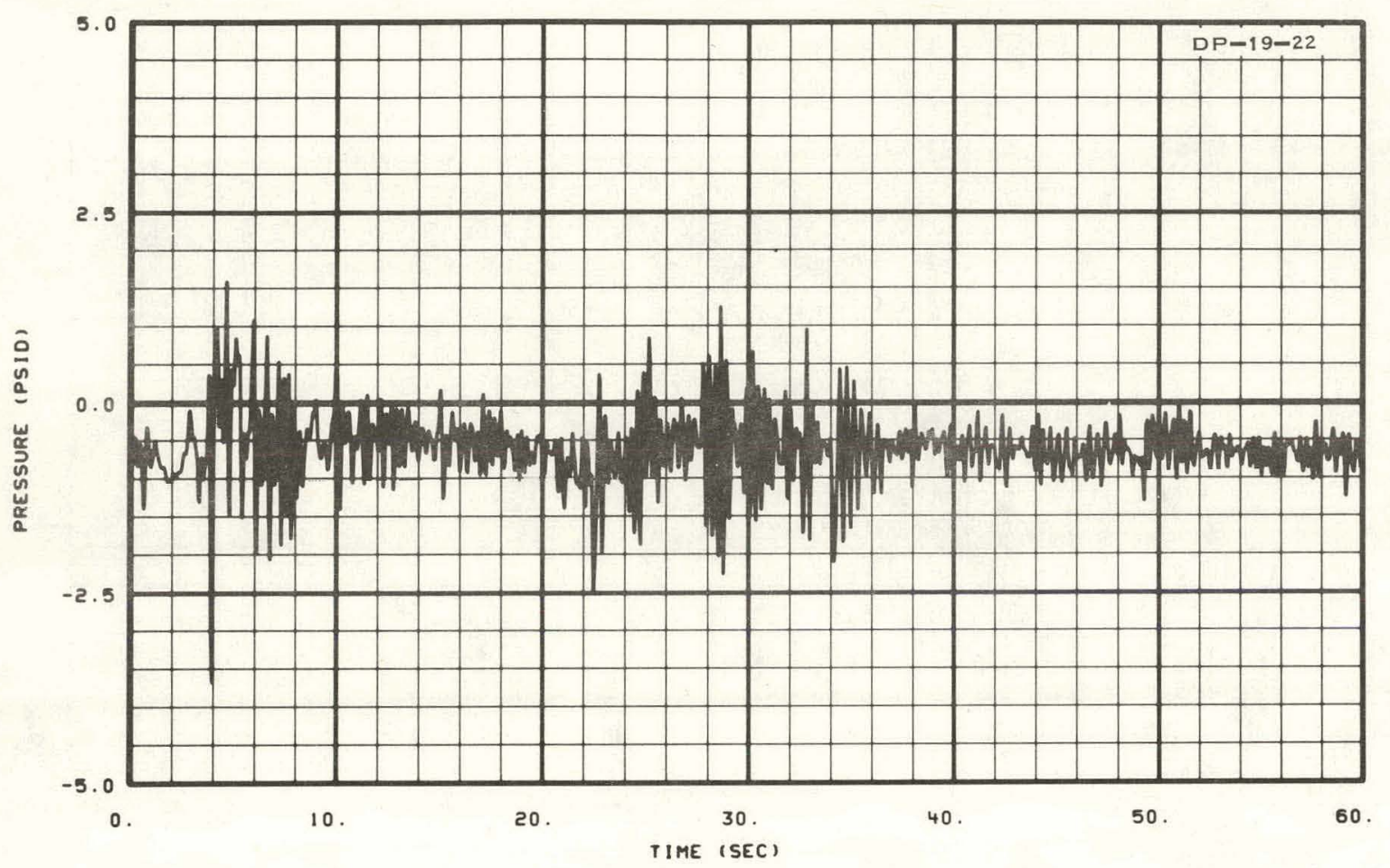

Fig. 256 Differential pressure across operating loop cold leg (DP-19-22) -Test 15.4.

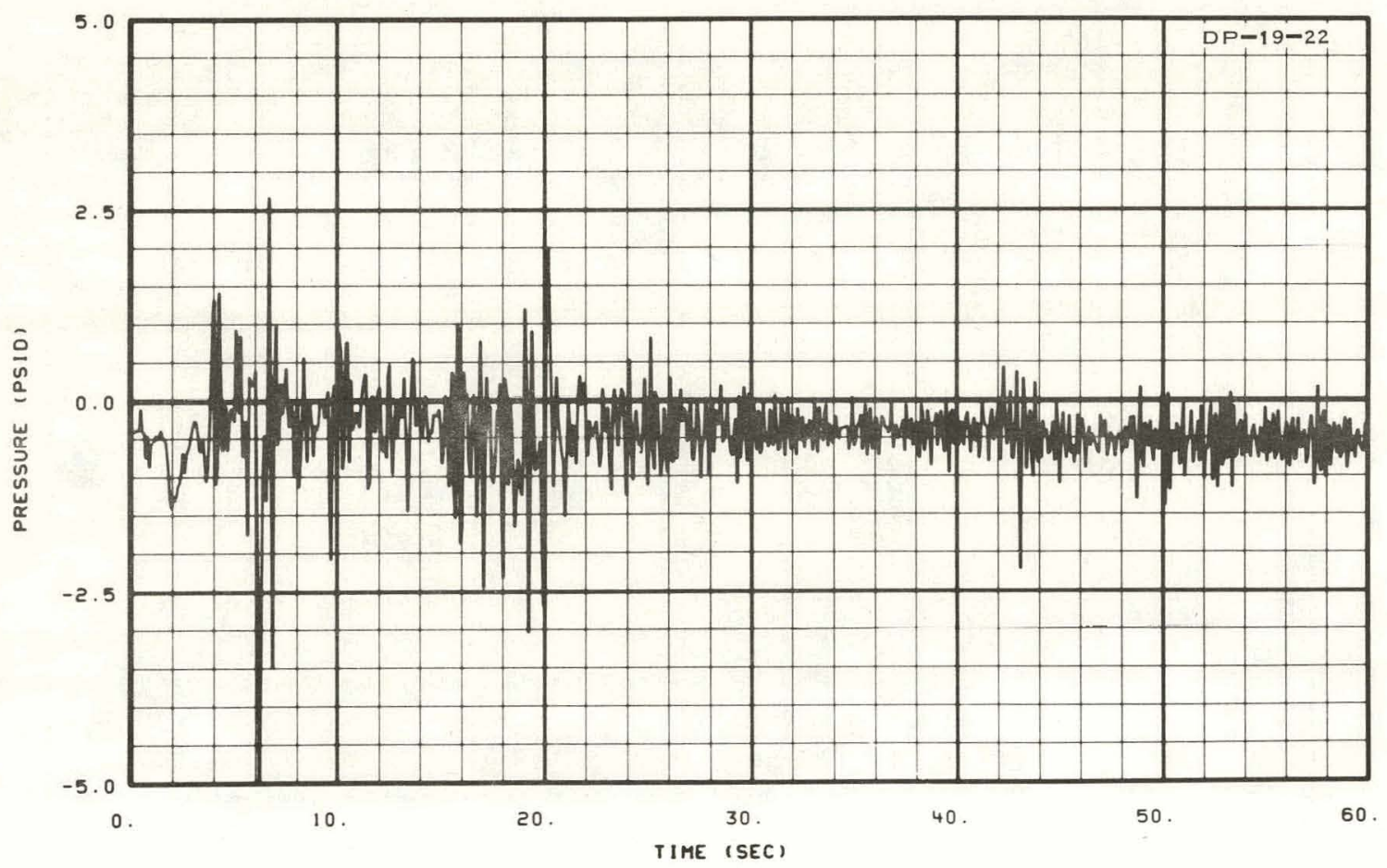

Fig. 257 Differential pressure across operating loop cold leg (DP-19-22) -Test 15.7 . 


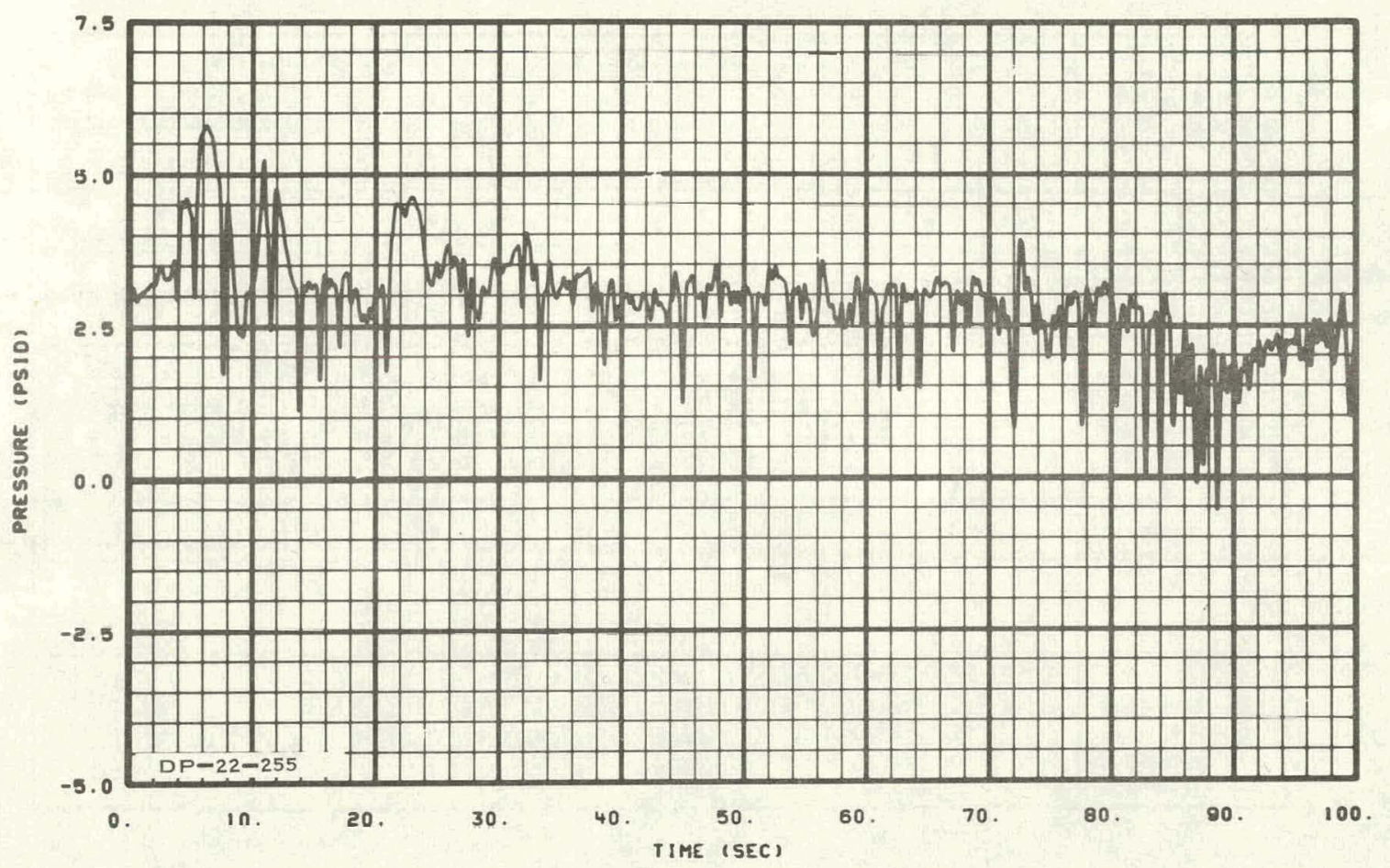

Fig. 258 Differential pressure between cold leg and lower plenum (DP-22255) -- Test 15.1.

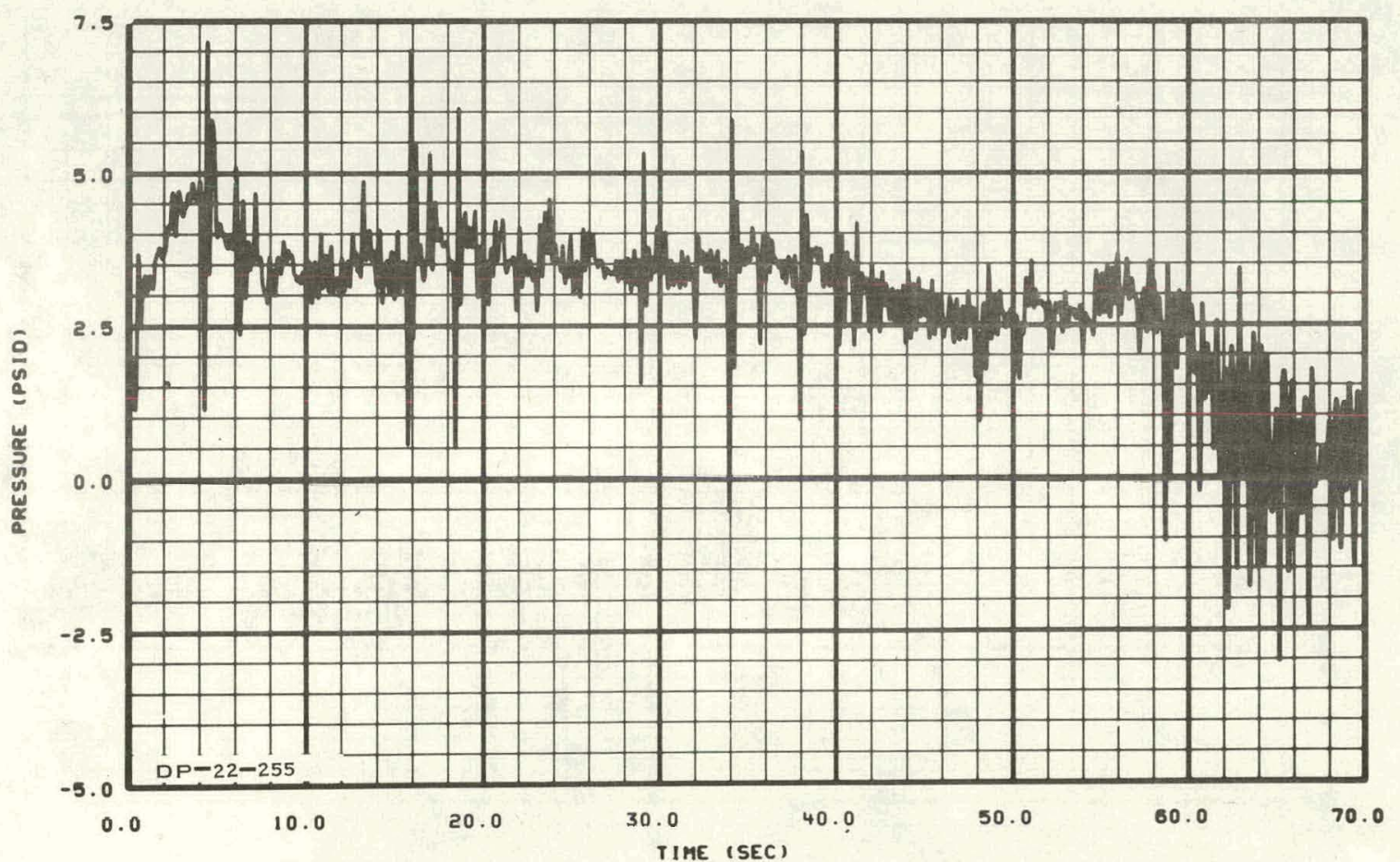

Fig. 259 Differential pressure between cold leg and lower plenum (DP-22255) -- Test 15.2. 


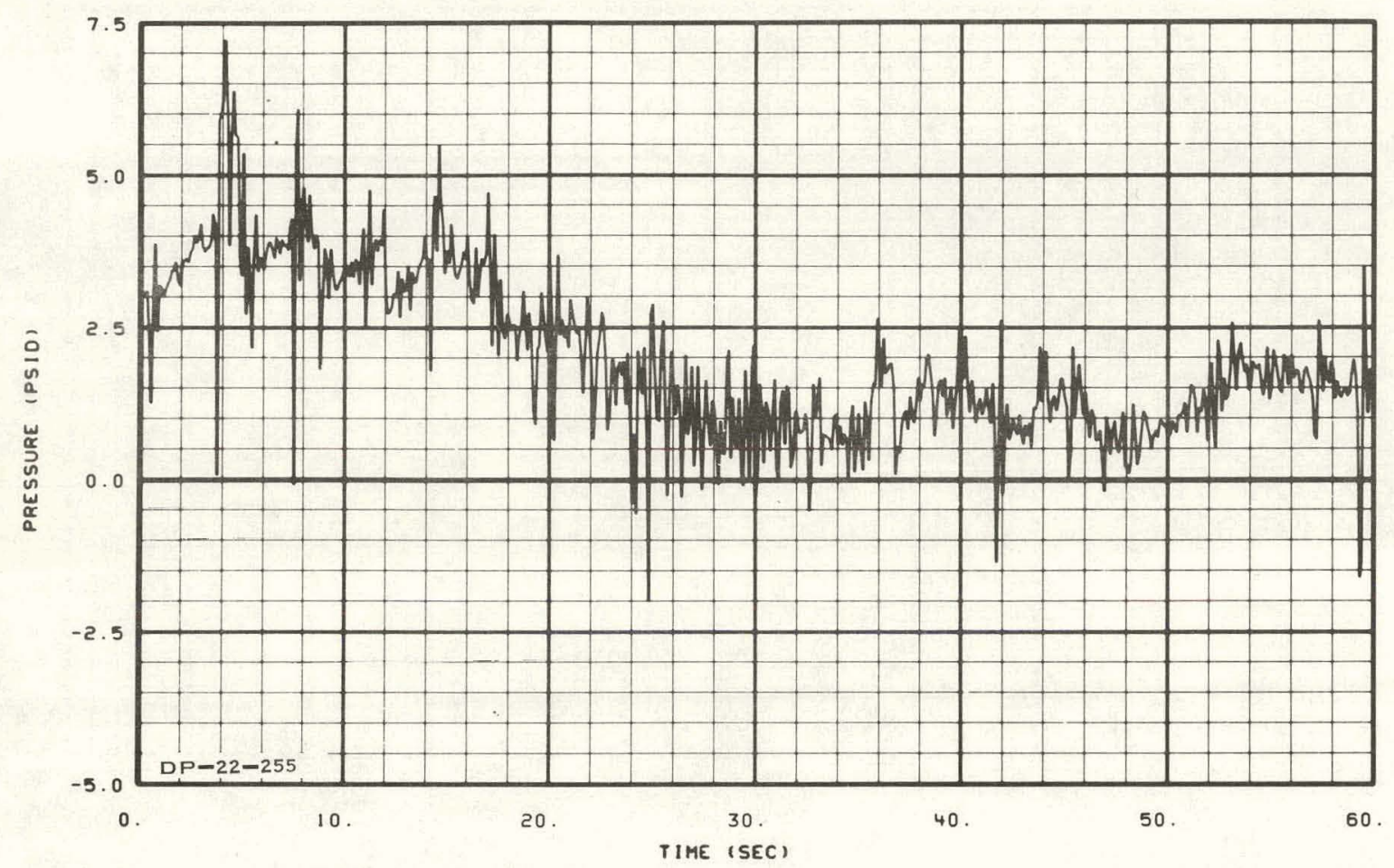

Fig. 260 Differential pressure between cold leg and lower plenum (DP-22255) -- Test 15.3.

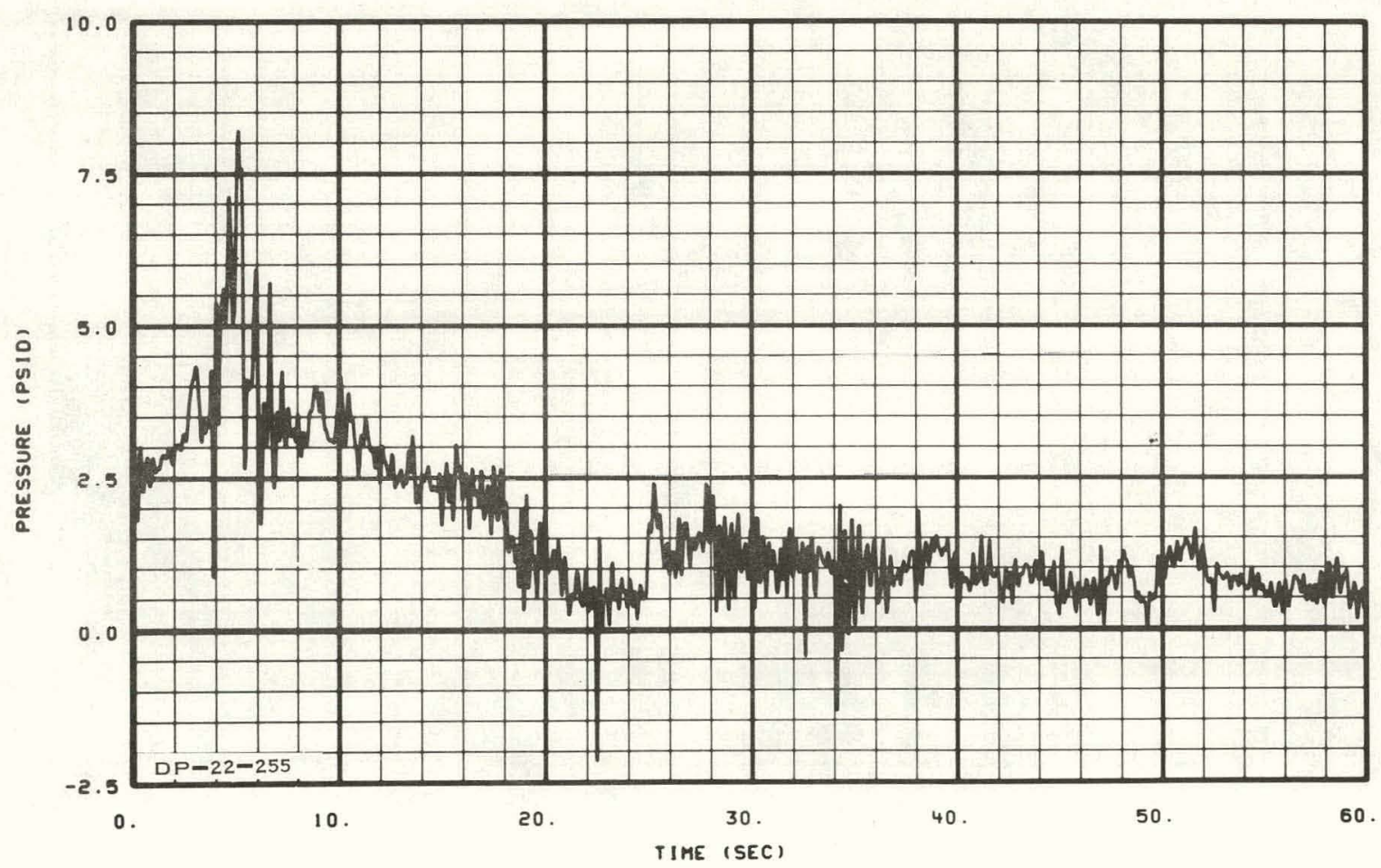

Fig. 261 Differential pressure between cold leg and lower plenum (DP-22255) -- Test 15.4 . 


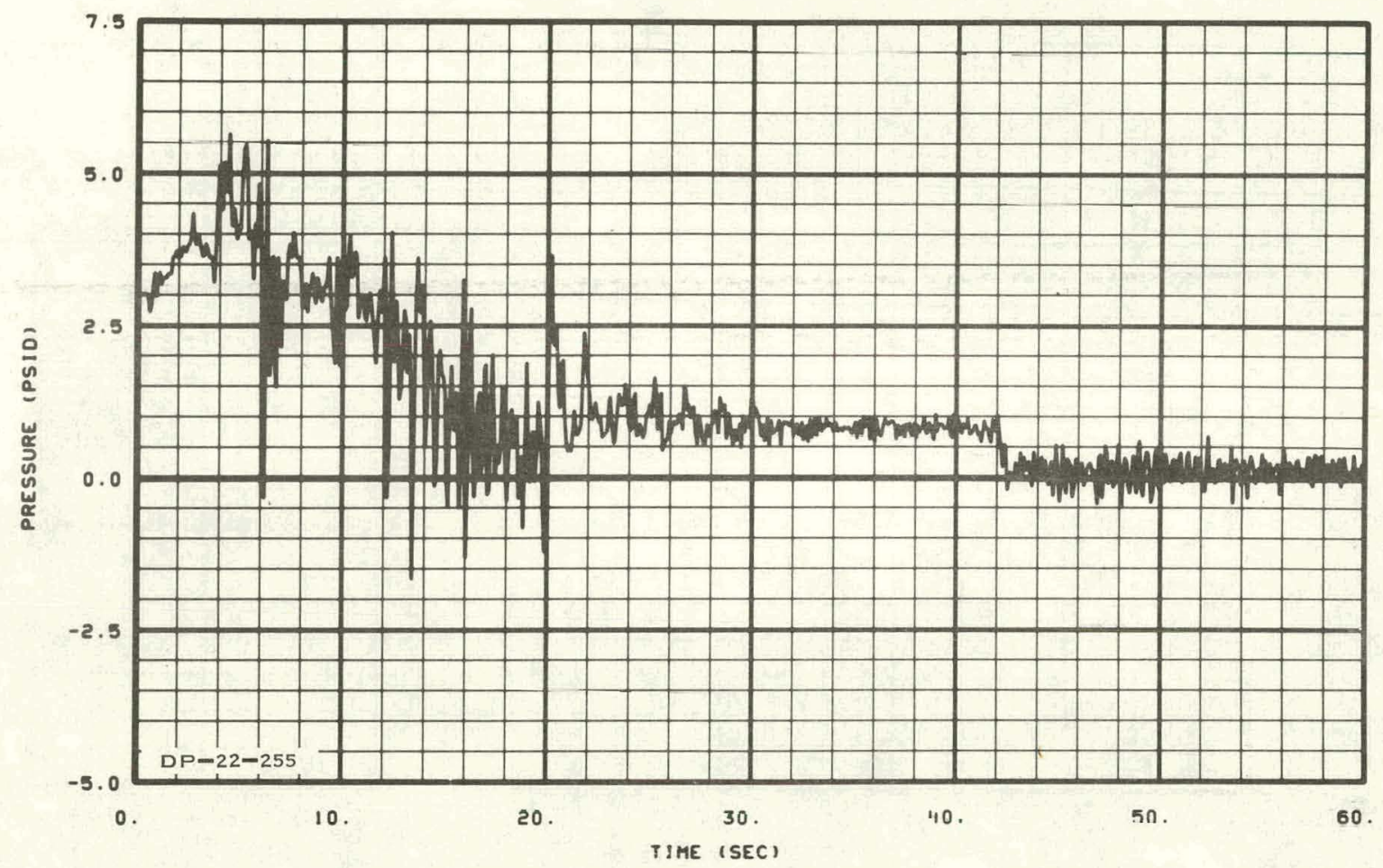

Fig. 262 Differential pressure between cold leg and lower plenum (DP-22255) -- Test 15.7.

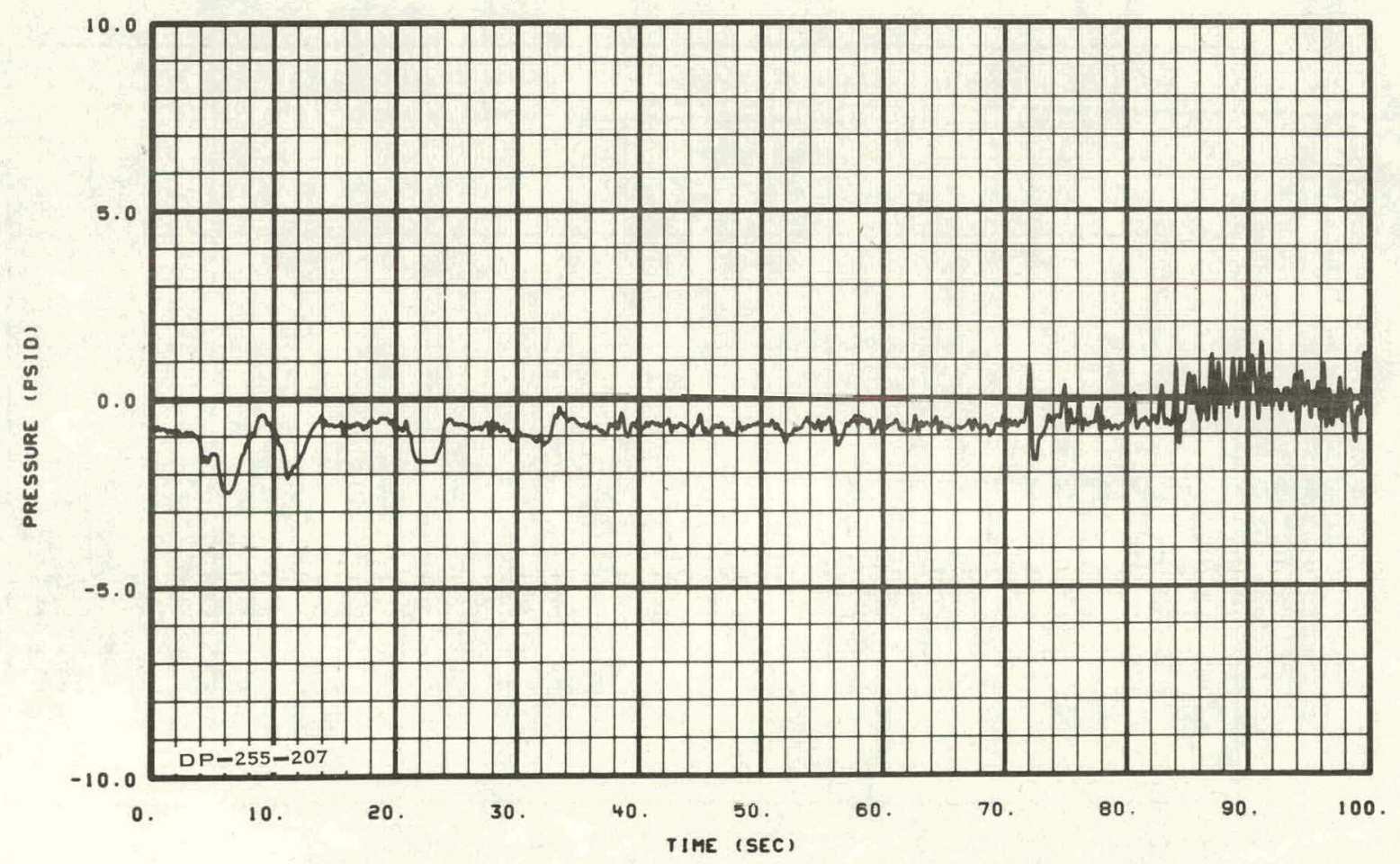

Fig. 263 Differential pressure across core (DP-255-207) -- Test 15.1. 


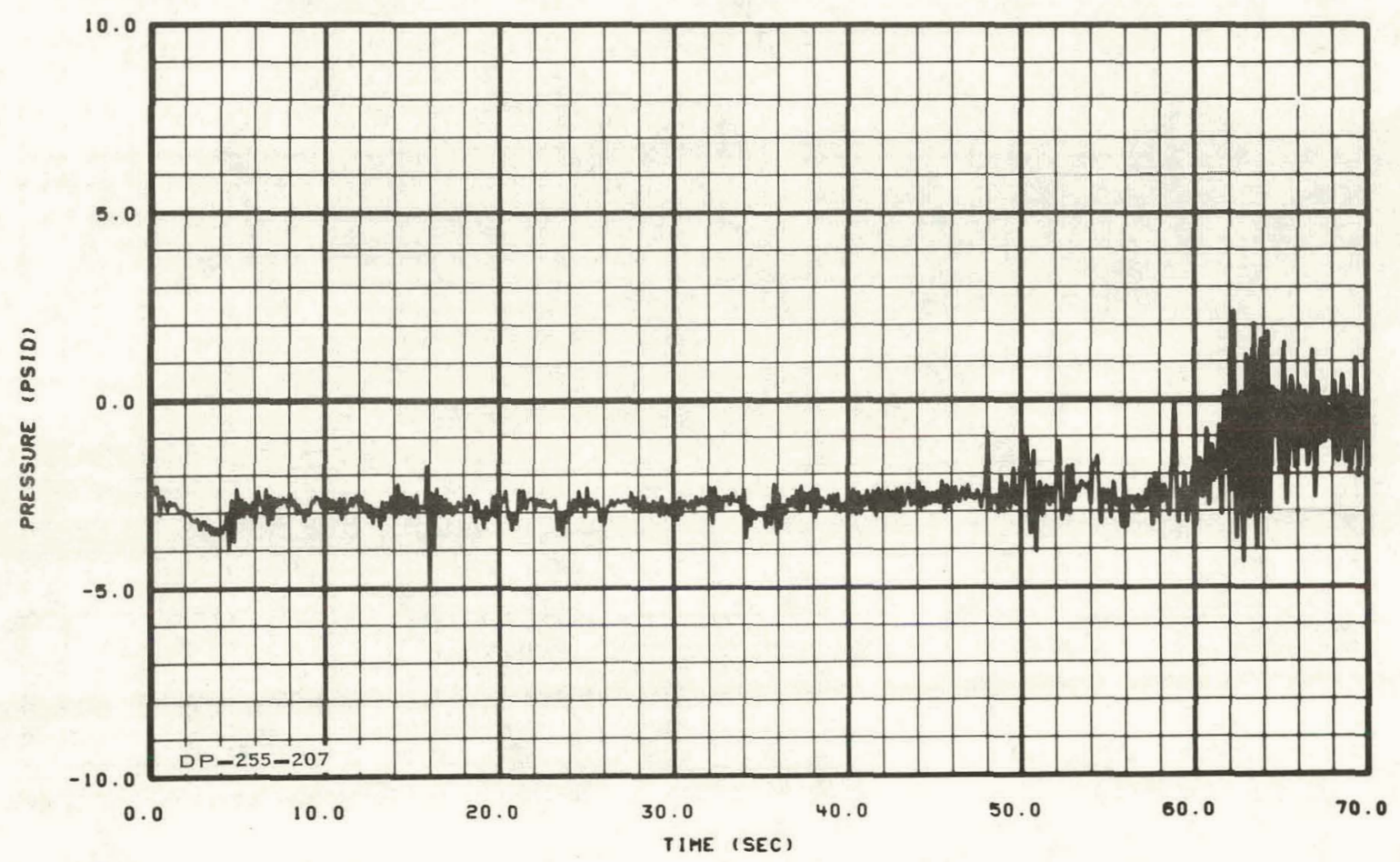

Fig. 264 Differential pressure across core (DP-255-207) -- Test 15.2.

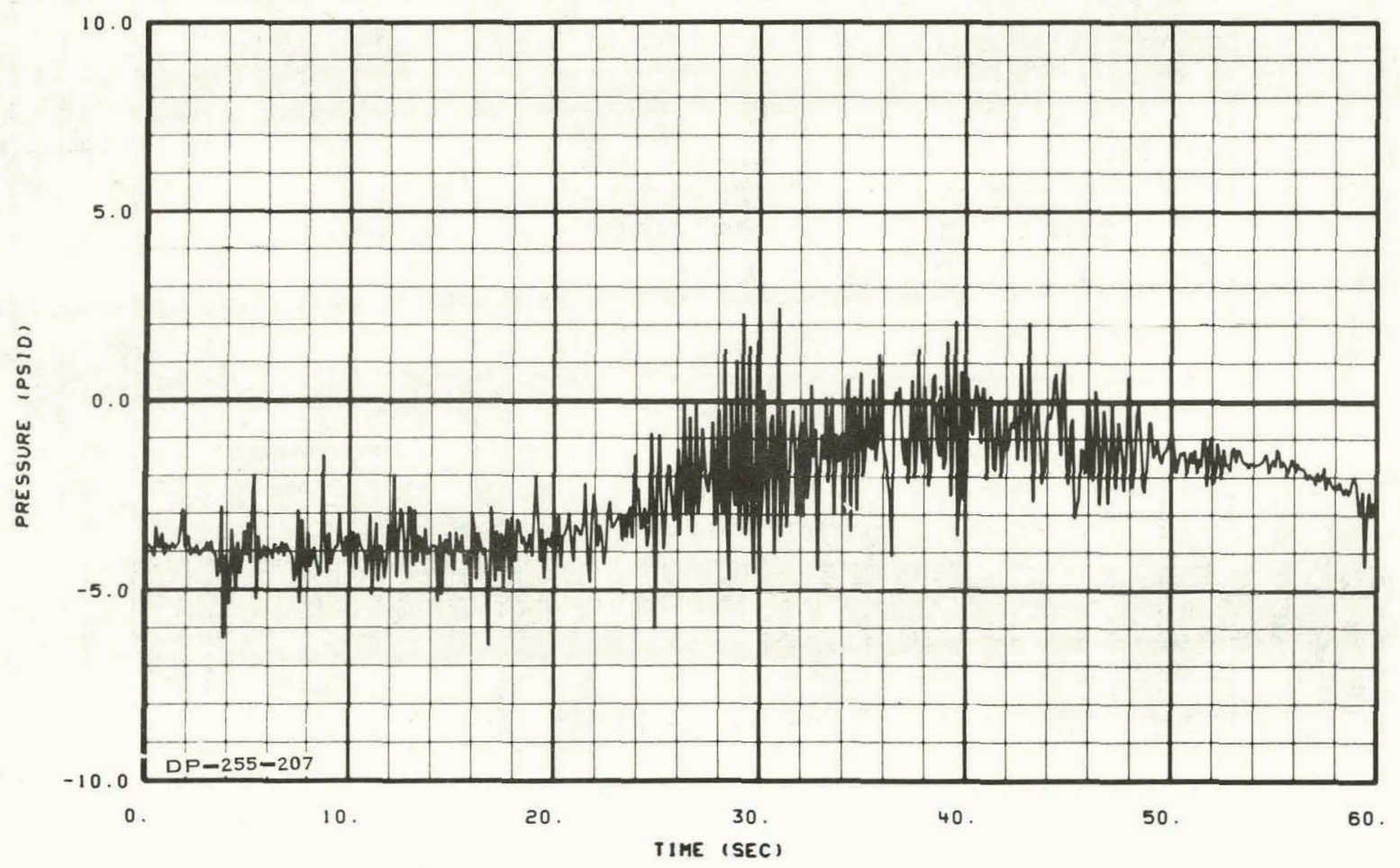

Fig. 265 Differential pressure across core (DP-255-207) -- Test 15.3. 


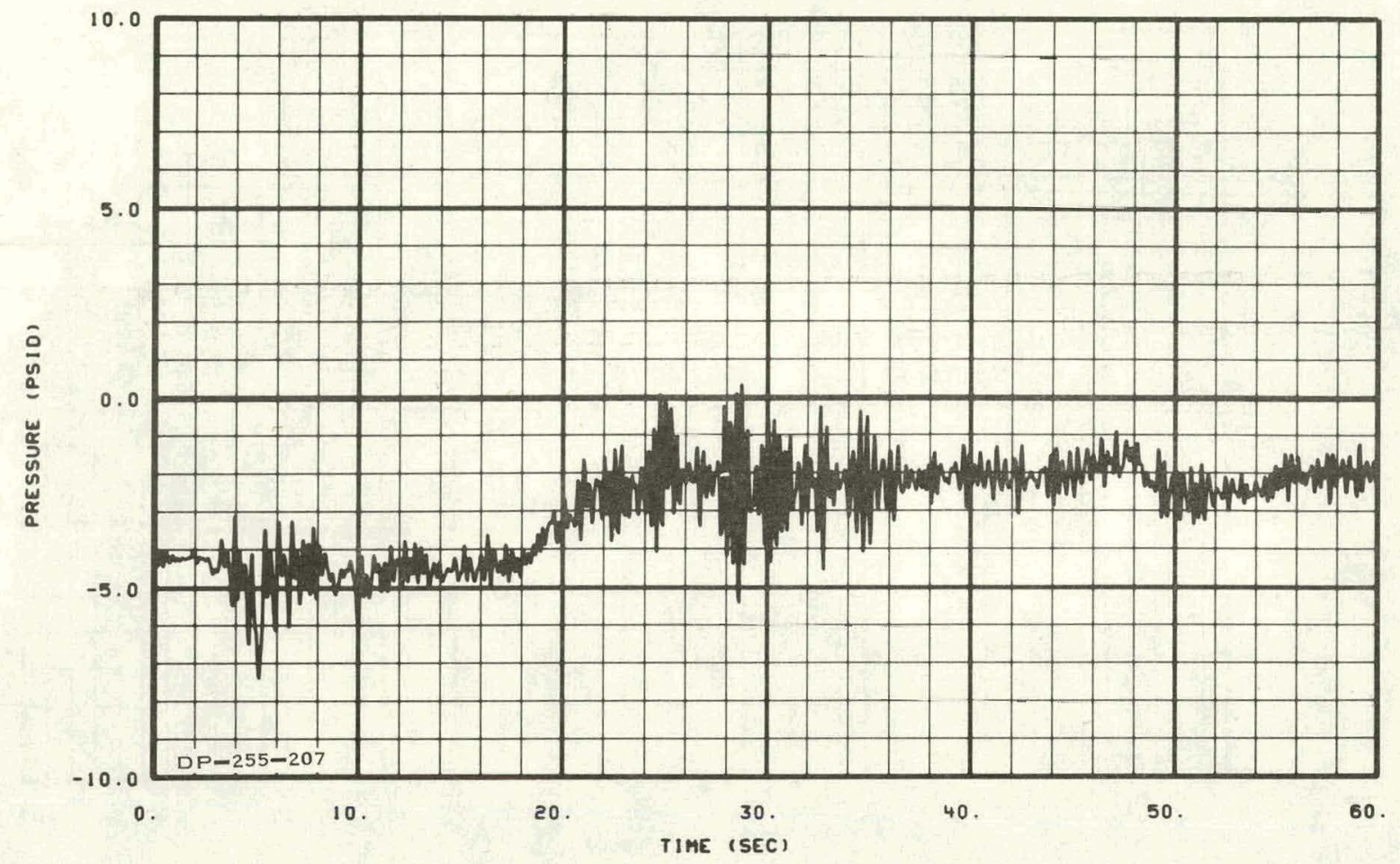

Fig. 266 Differential pressure across core (DP-255-207) -- Test 15.4.

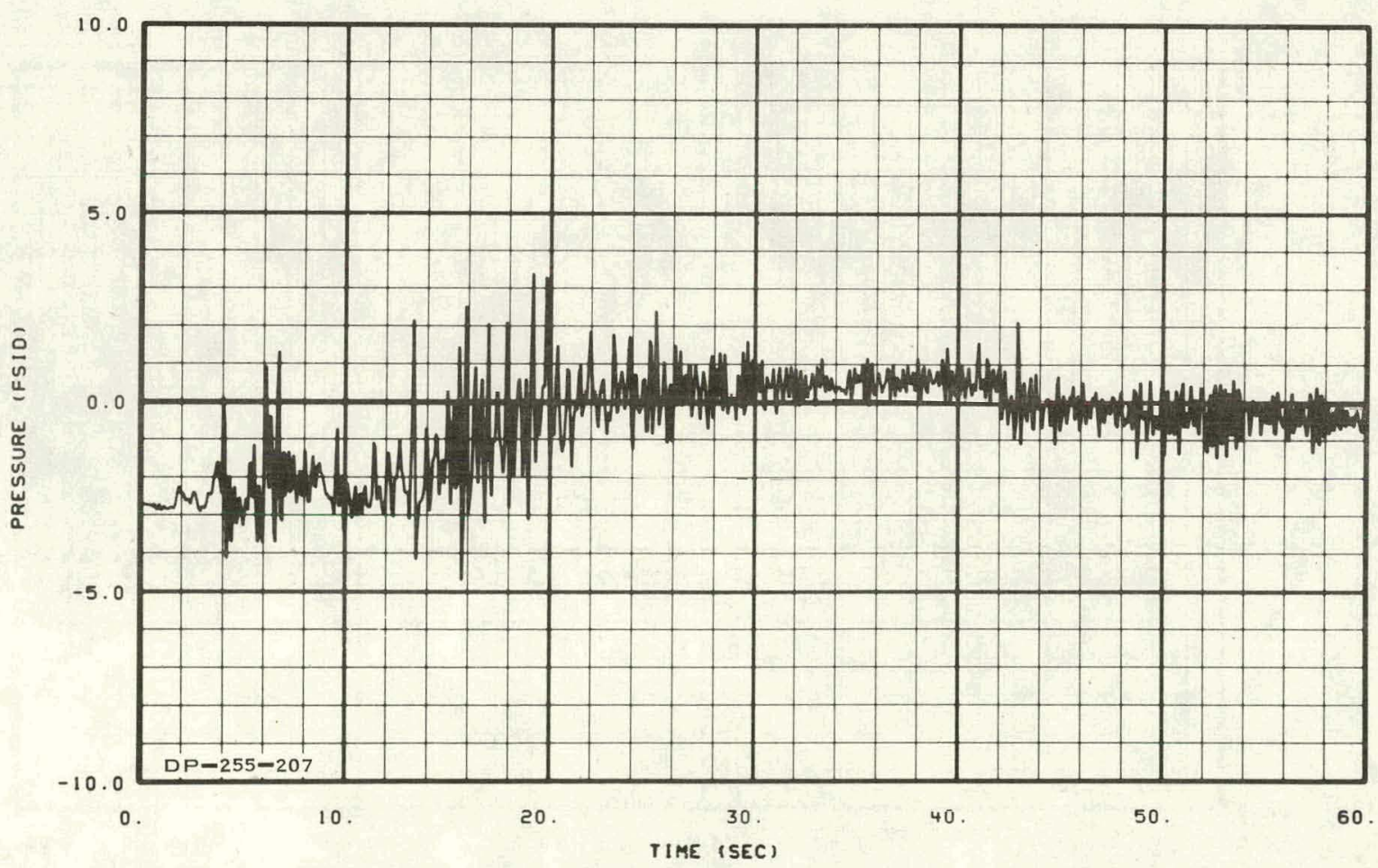

Fig. 267 Differential pressure across core (DP-255-207) -- Test 15.7. 


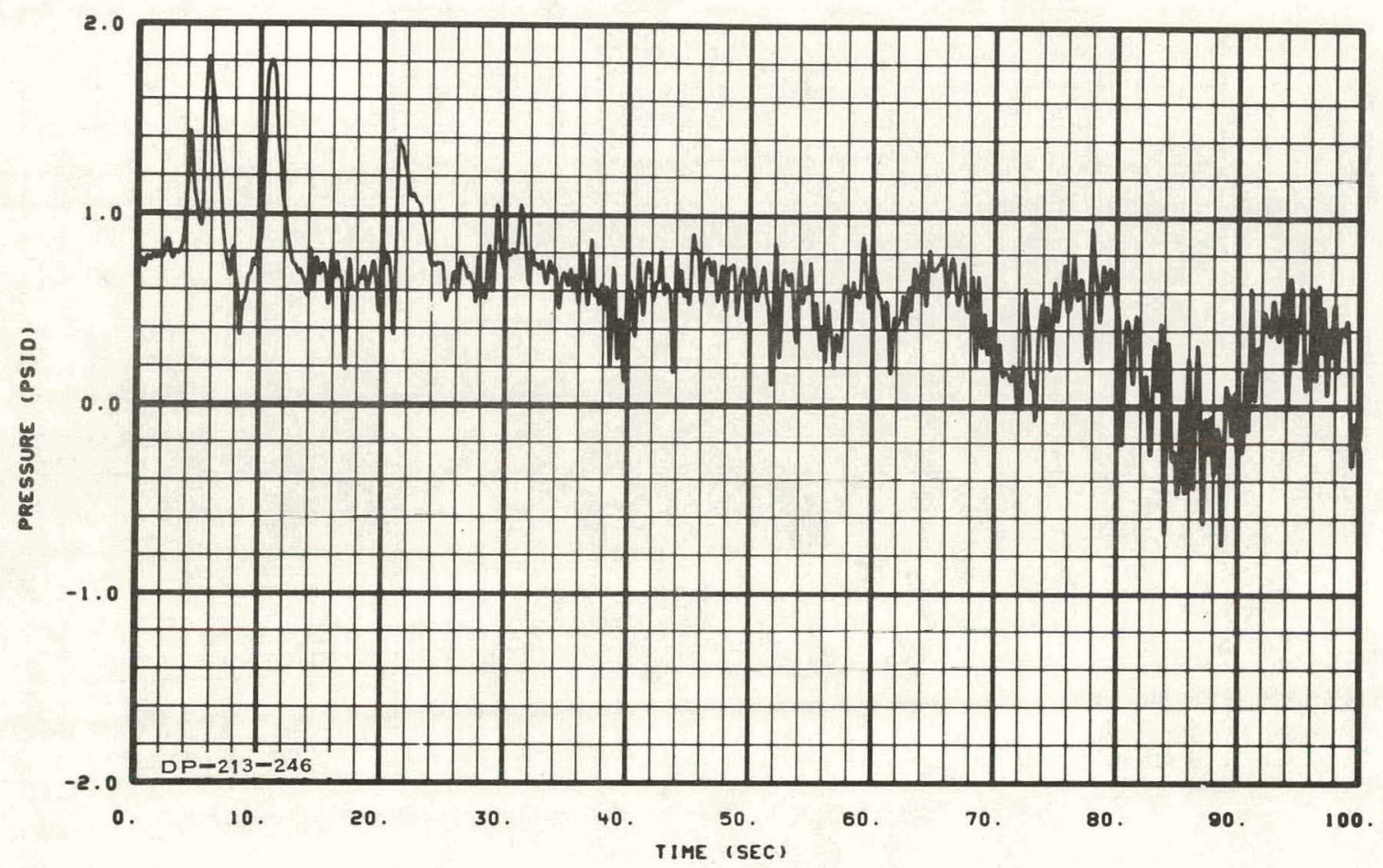

Fig. 268 Differential pressure across upper portion of downcomer (DP-213246) -- Test 15.1.

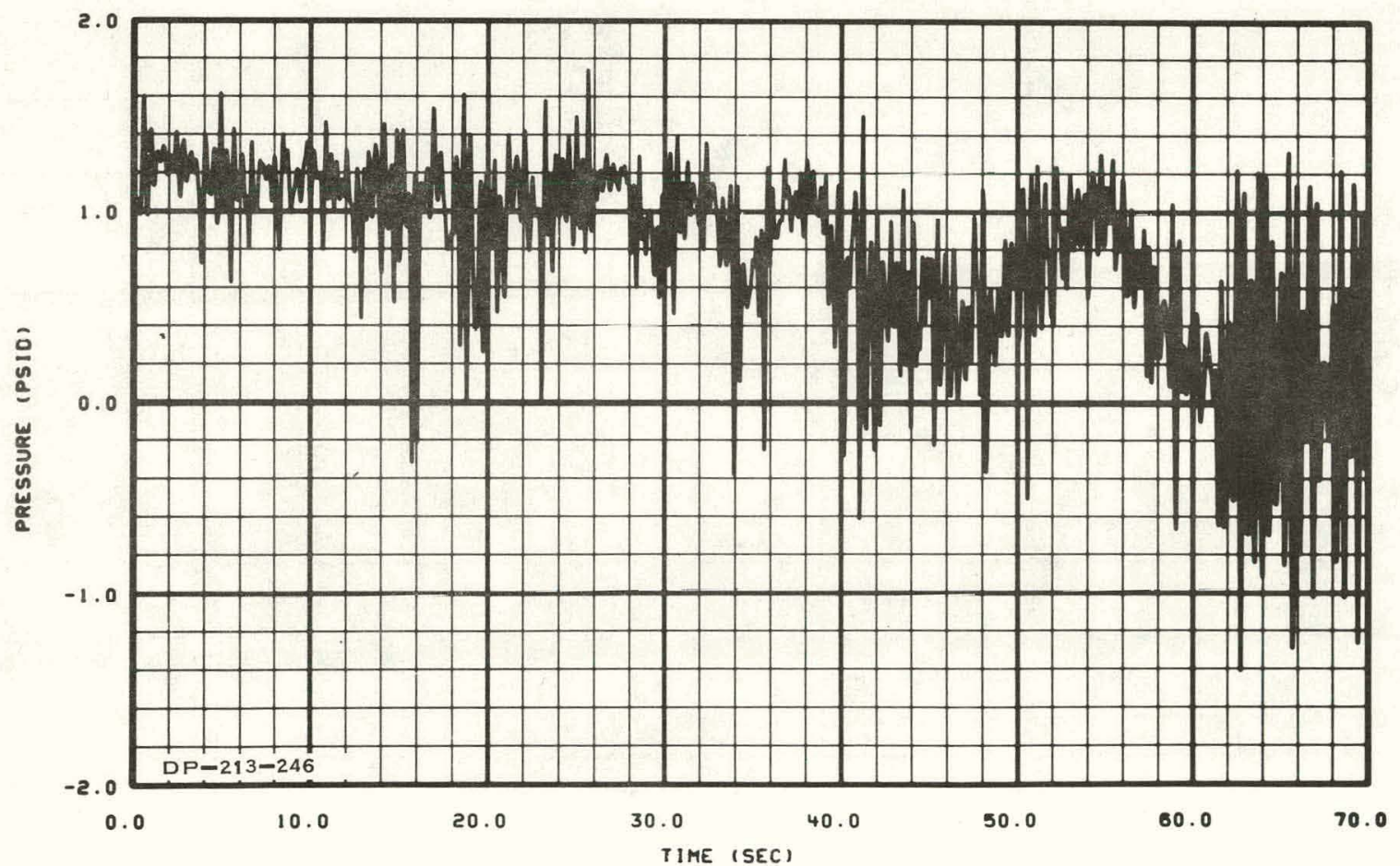

Fig. 269 Differential pressure across upper portion of downcomer (DP-213246) -- Test 15.2. 


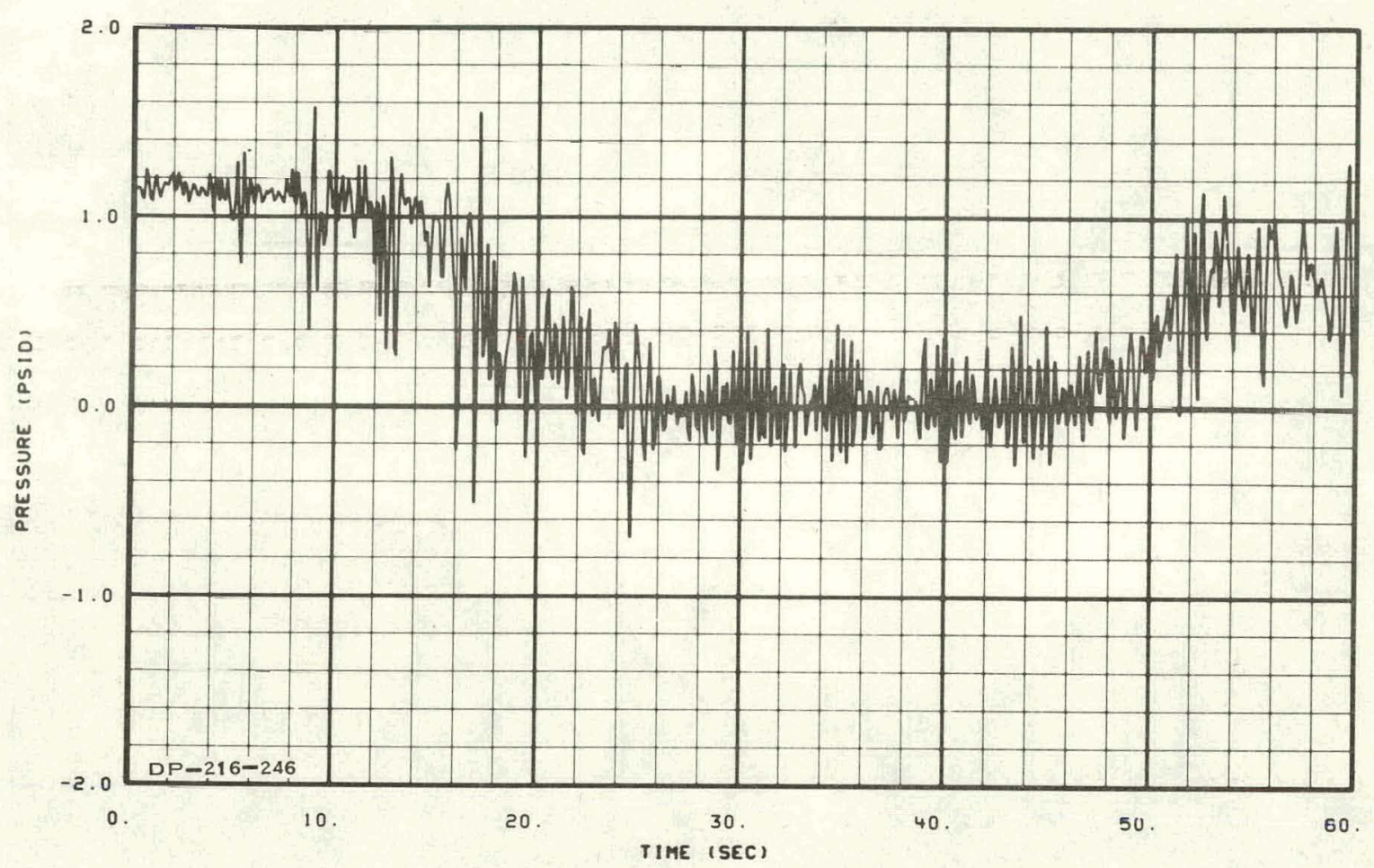

Fig. 270 Differential pressure across upper portion of downcomer (DP-216246) -- Test 15.3.

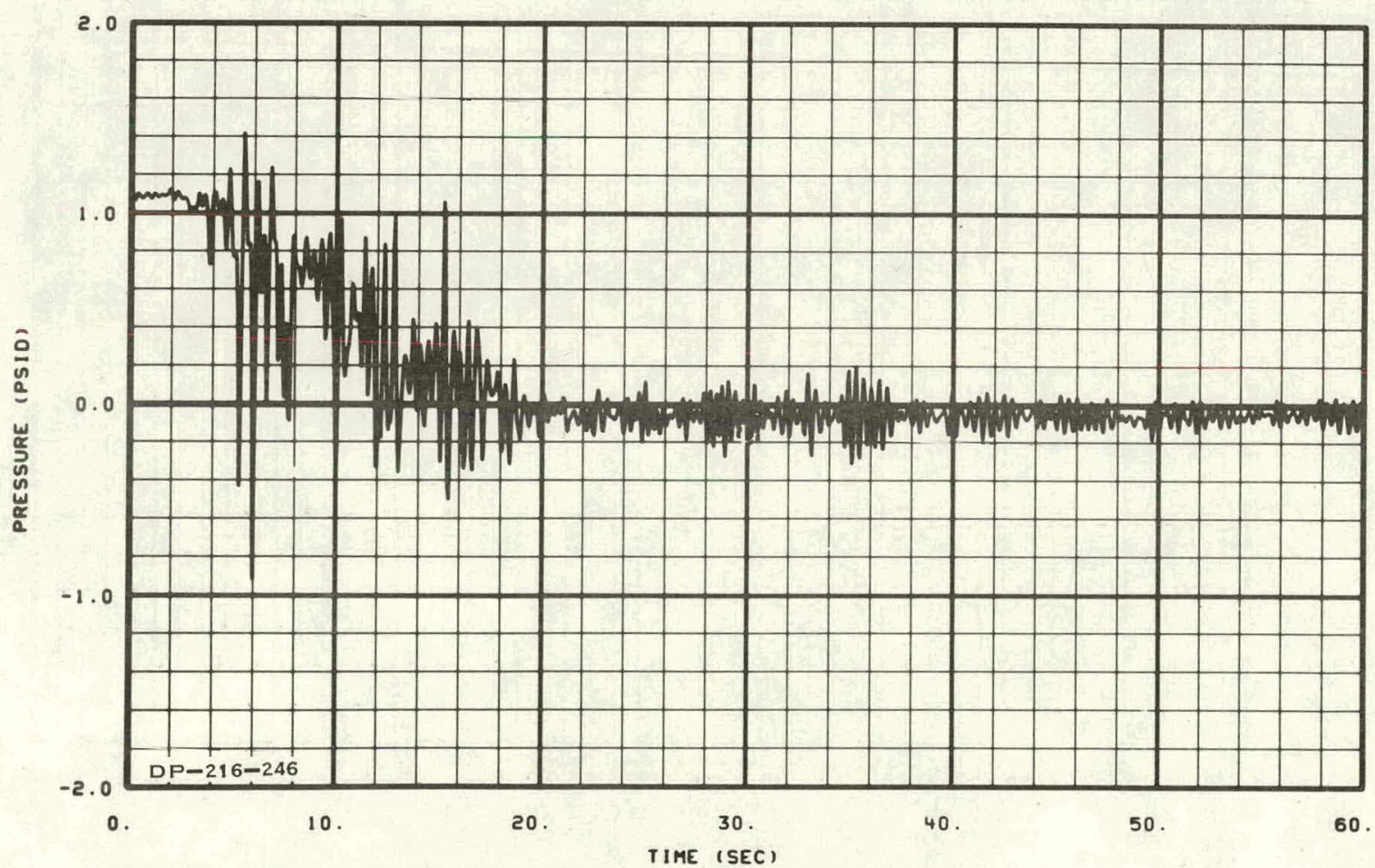

Fig. 271 Differential pressure across upper portion of downcomer (DP-216246) -- Test 15.4 . 


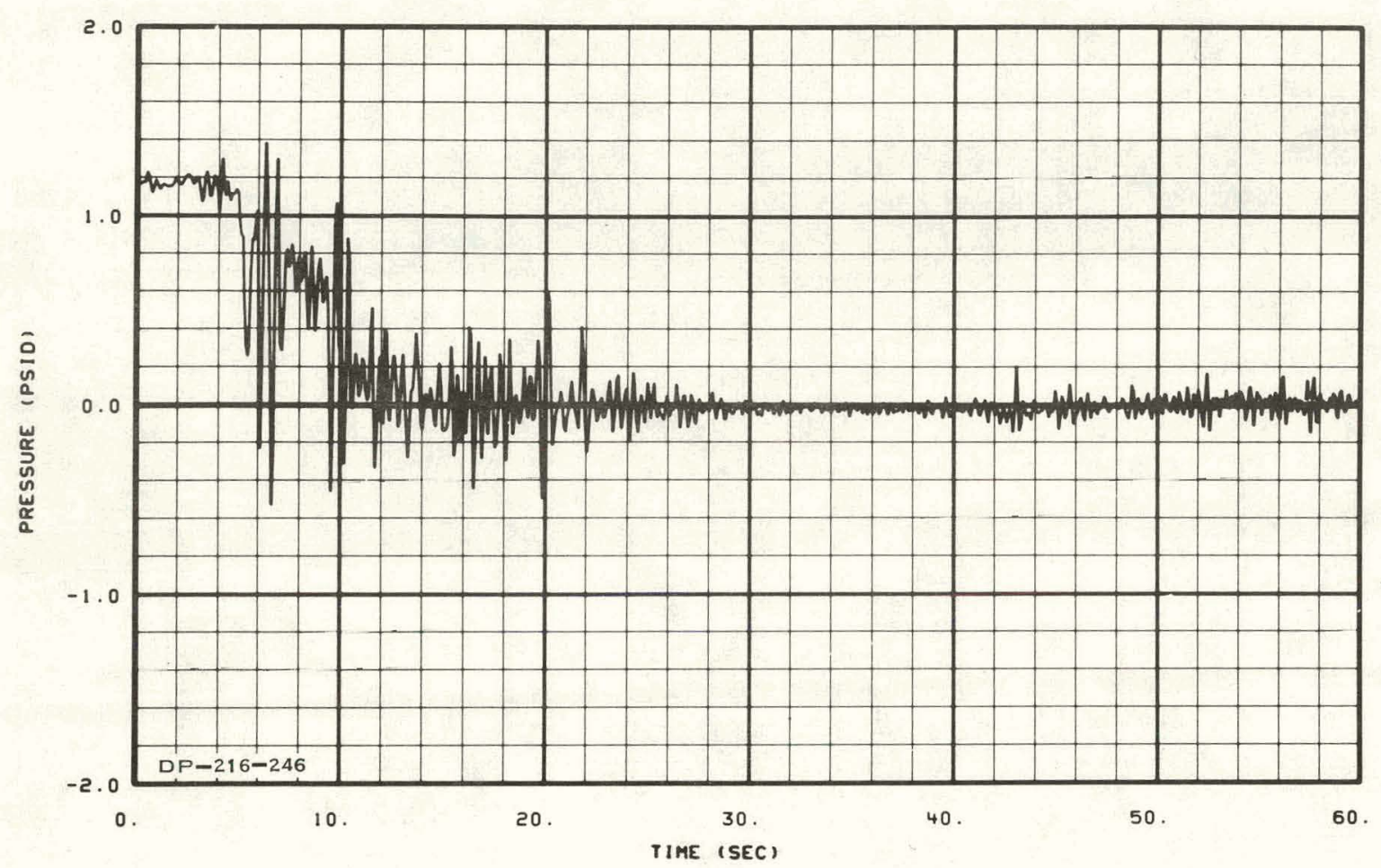

Fig. 272 Differential pressure across upper portion of downcomer (DP-216246) -- Test 15.7 .

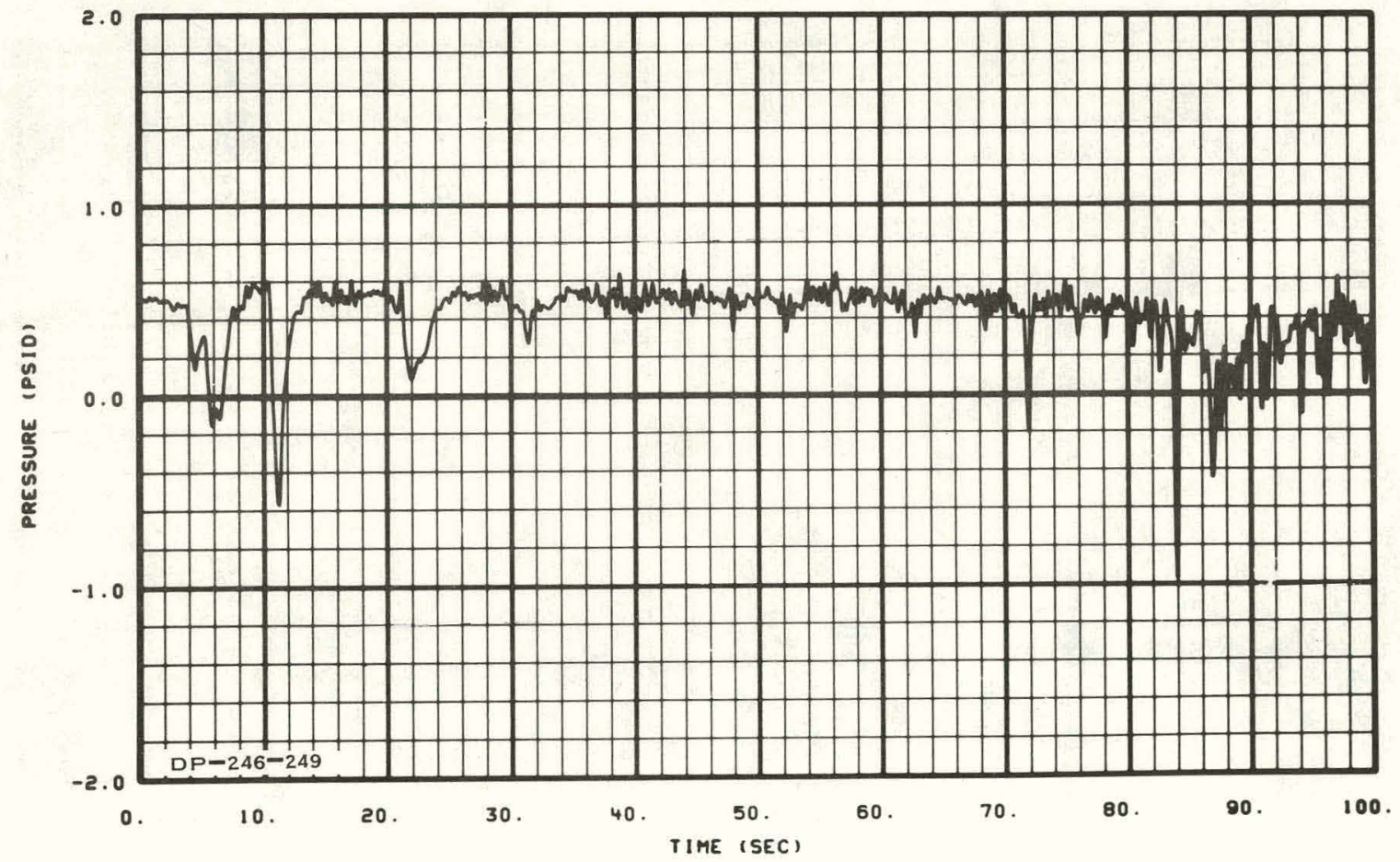

Fig. 273 Differential pressure across middle portion of downcomer (DP-246249) -- Test 15.1. 


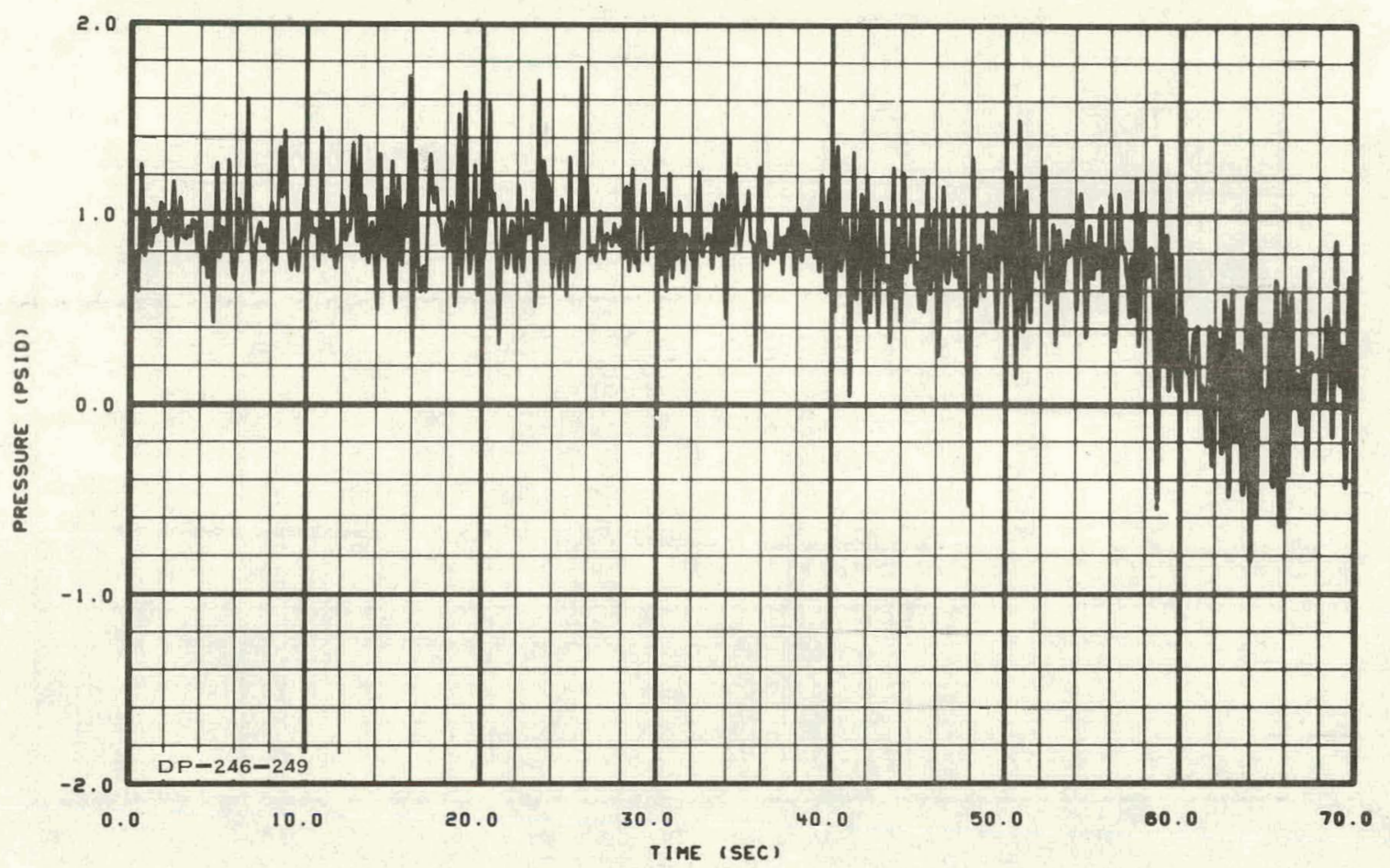

Fig. 274 Differential pressure across middle portion of downcomer (DP-246249) -- Test 15.2 .

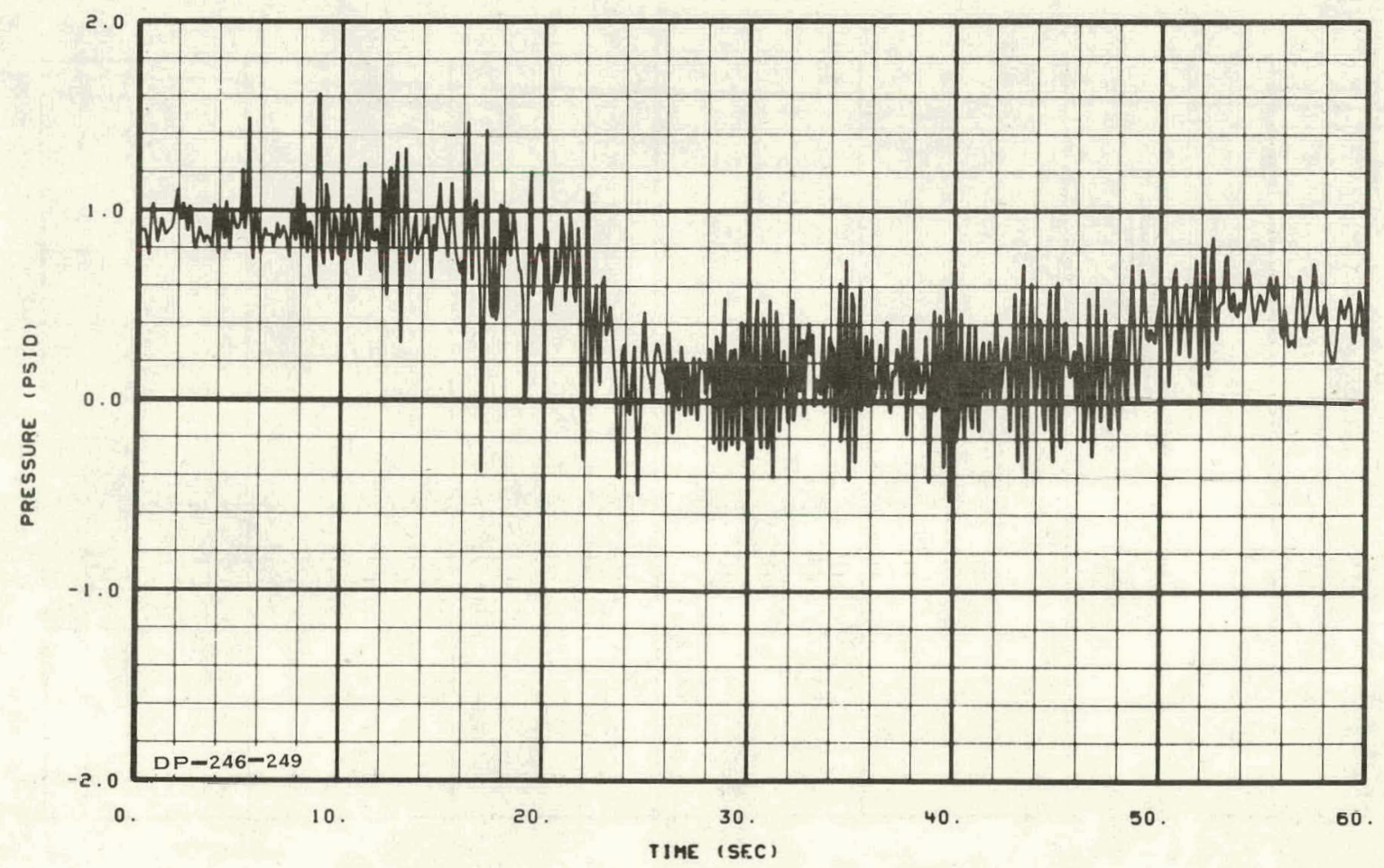

Fig. 275 Differential pressure across middle portion of downcomer (DP-246 249) -- Test 15.3. 


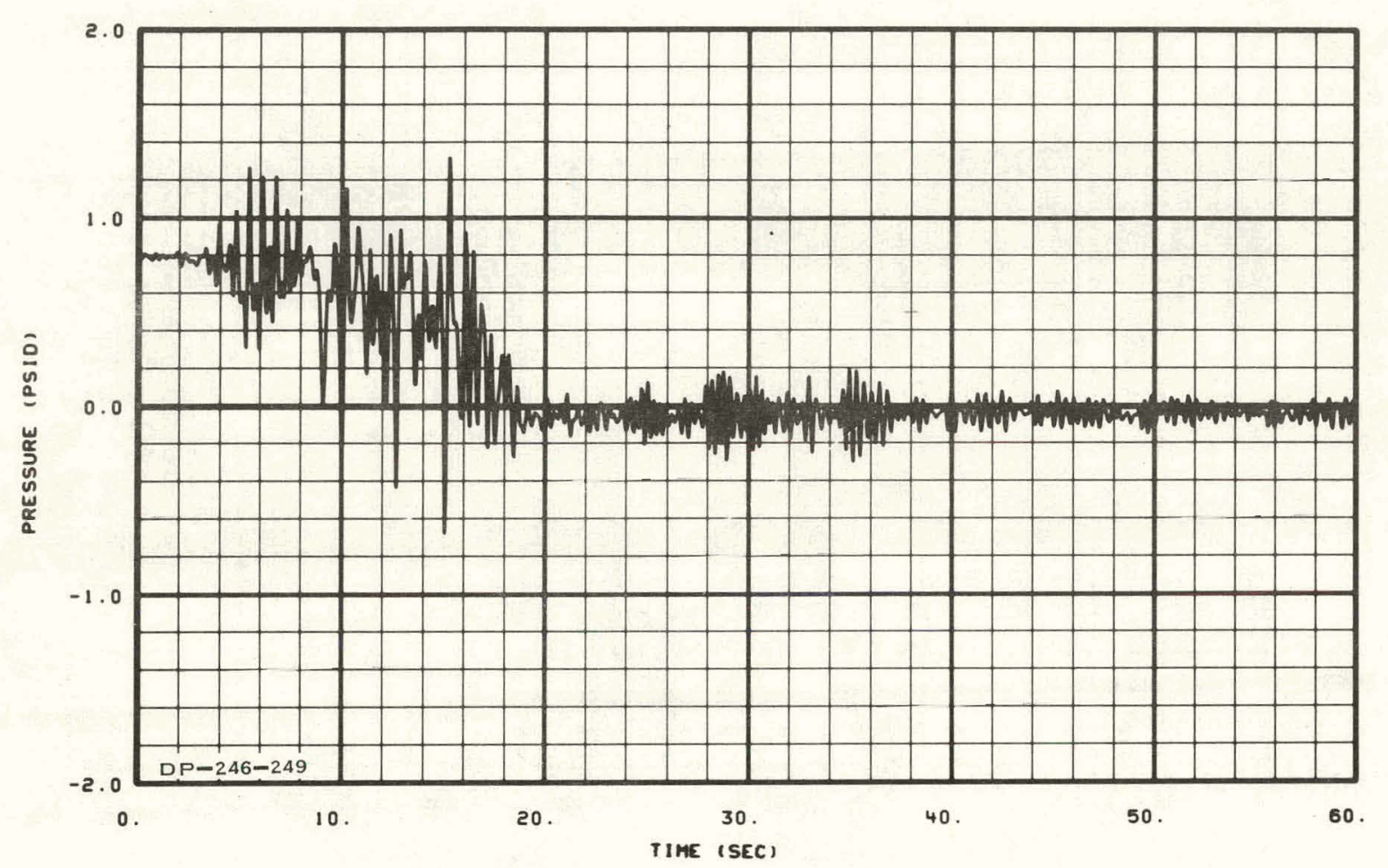

Fig. 276 Differential pressure across middle portion of downcomer (DP-246249) -- Test 15.4 .

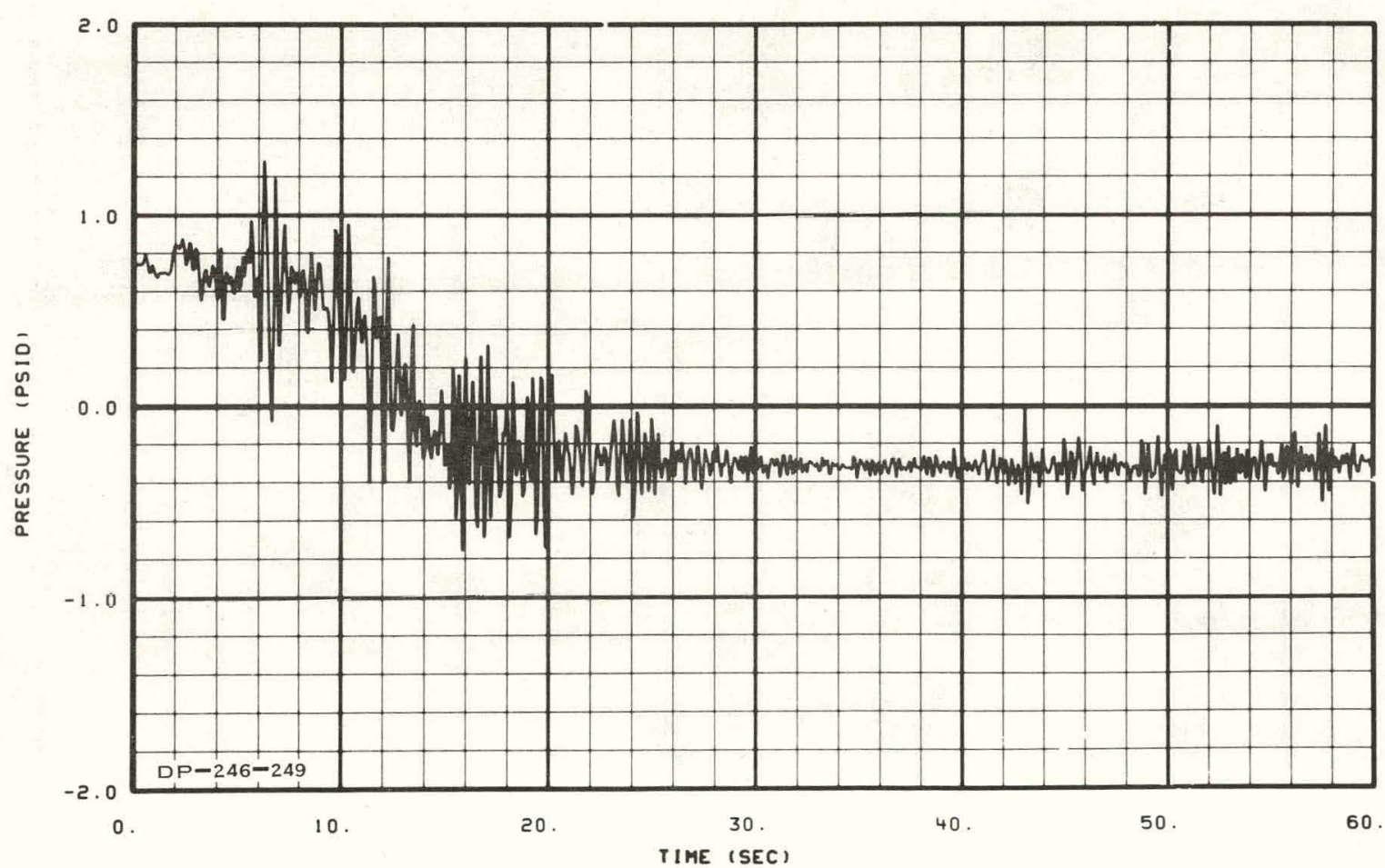

Fig. 277 Differential pressure across middle portion of downcomer (DP-246249) -- Test 15.7. 


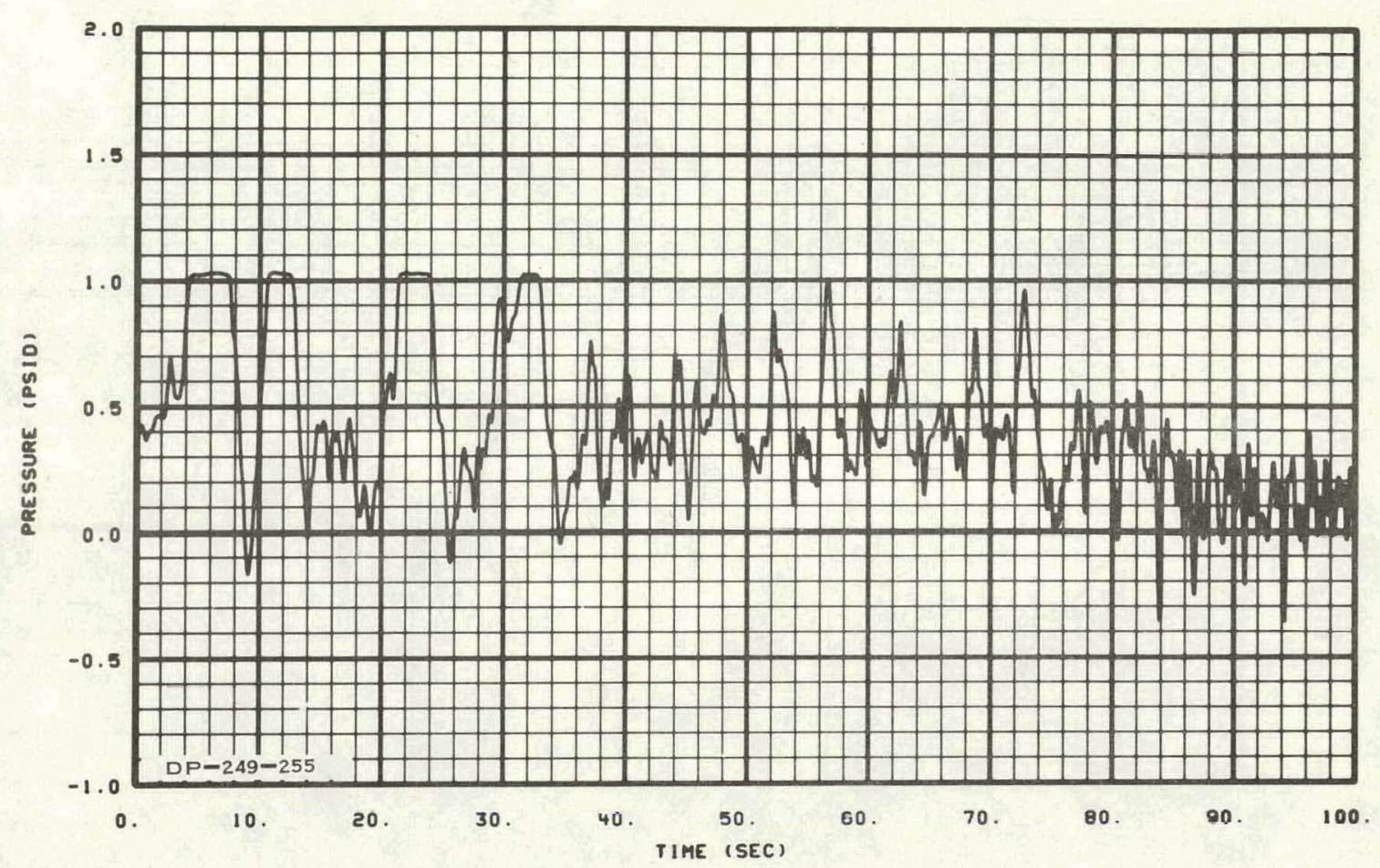

Fig. 278 Differential pressure across lower portion of downcomer (DP-249255) -- Test 15.1.

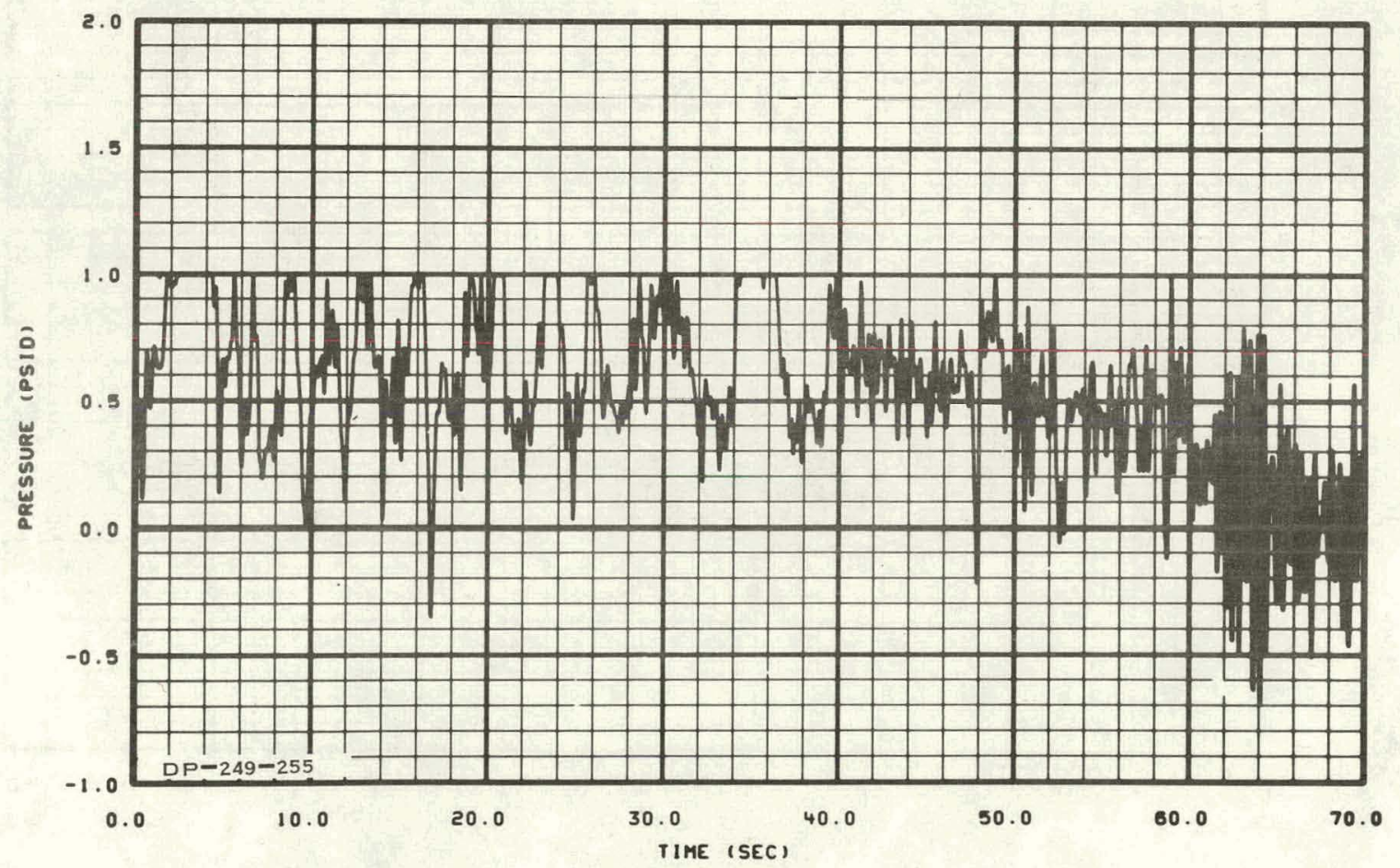

Fig. 279 Differential pressure across lower portion of downcomer (DP-249255) -- Test 15.2. 


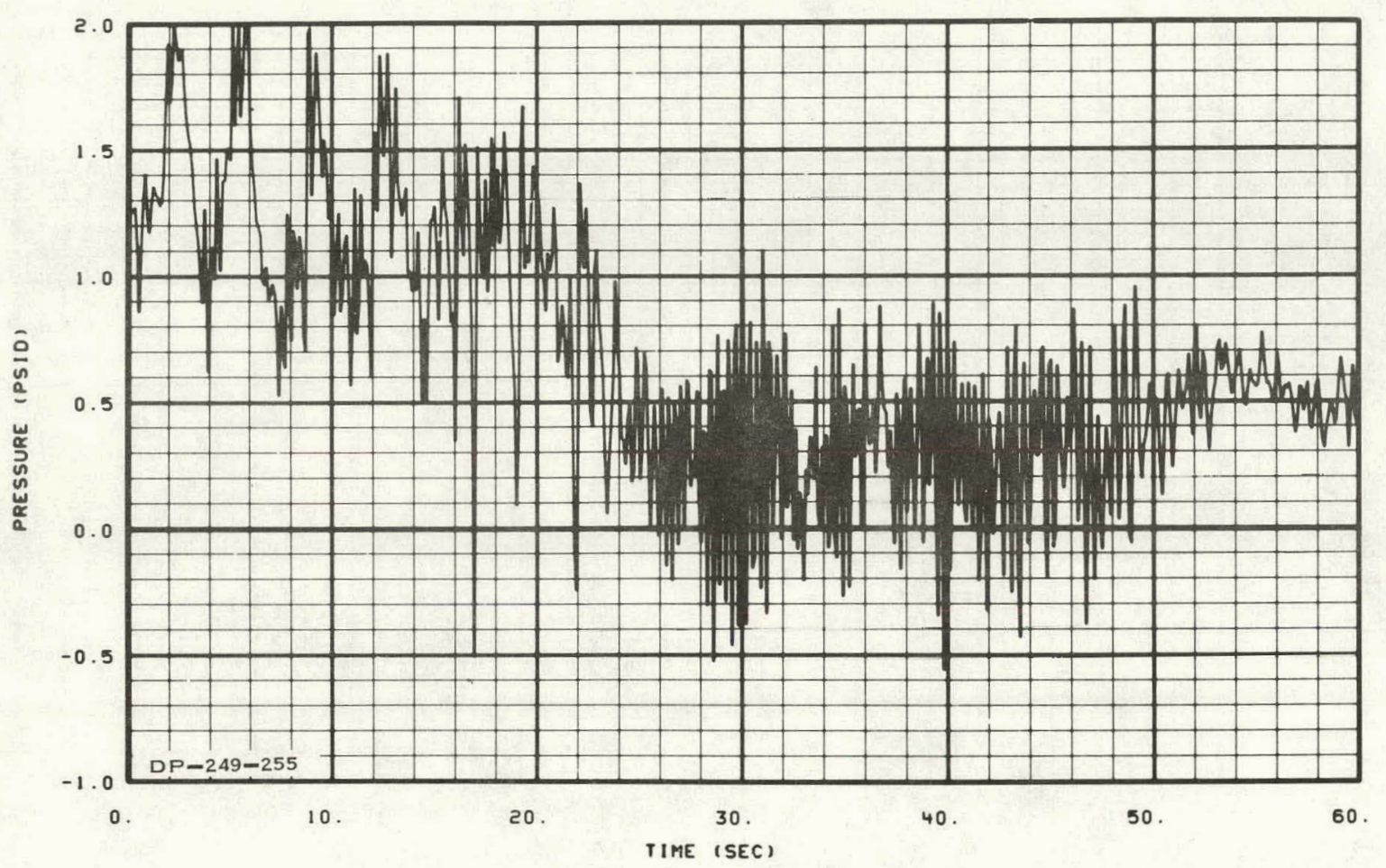

Fig. 280 Differential pressure across lower portion of downcomer (DP-249255) -- Test 15.3.

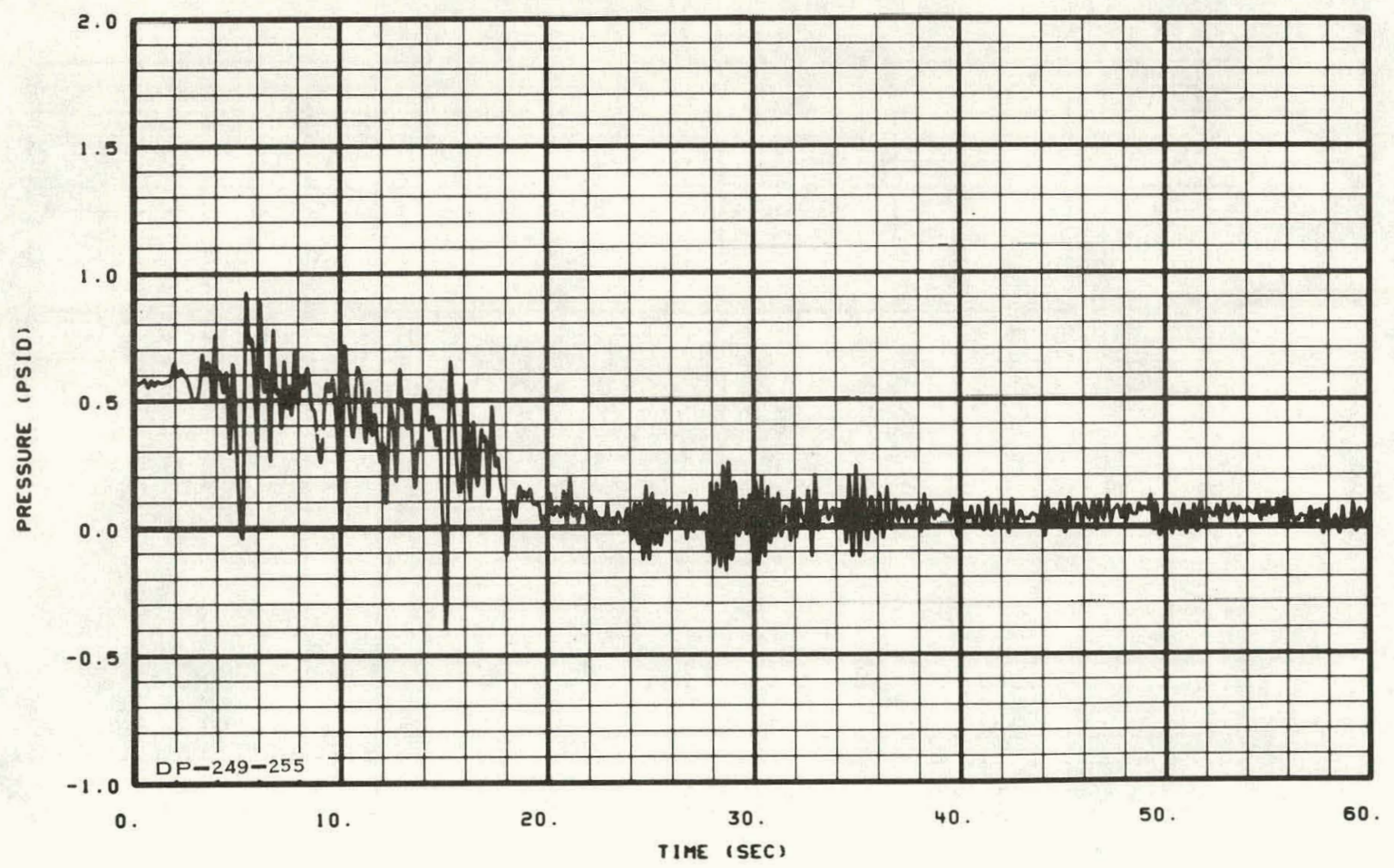

Fig. 281 Differential pressure across lower portion of downcomer (DP-249255) -- Test 15.4 . 


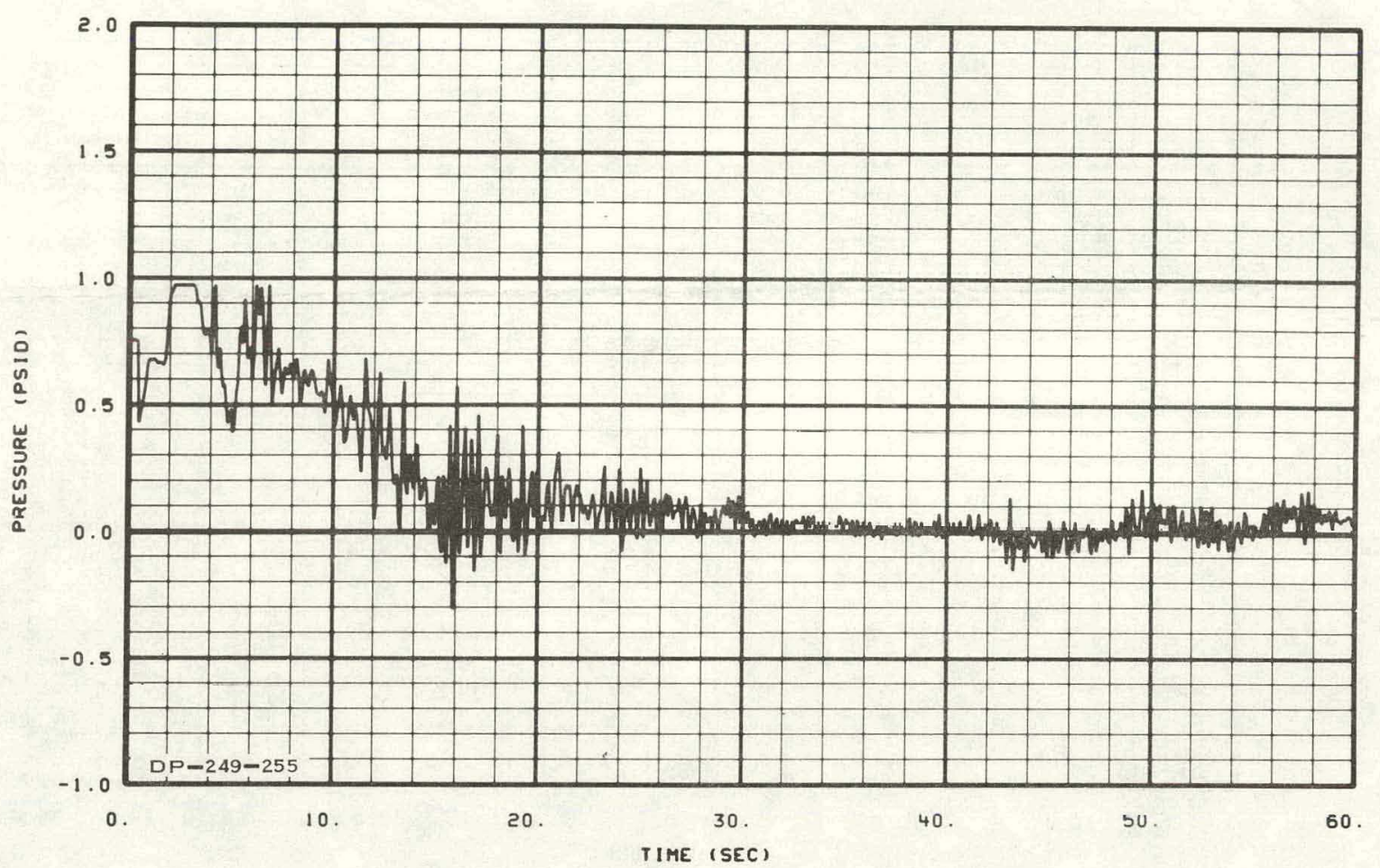

Fig. 282 Differential pressure across lower portion of downcomer (DP-249255) -- Test 15.7.

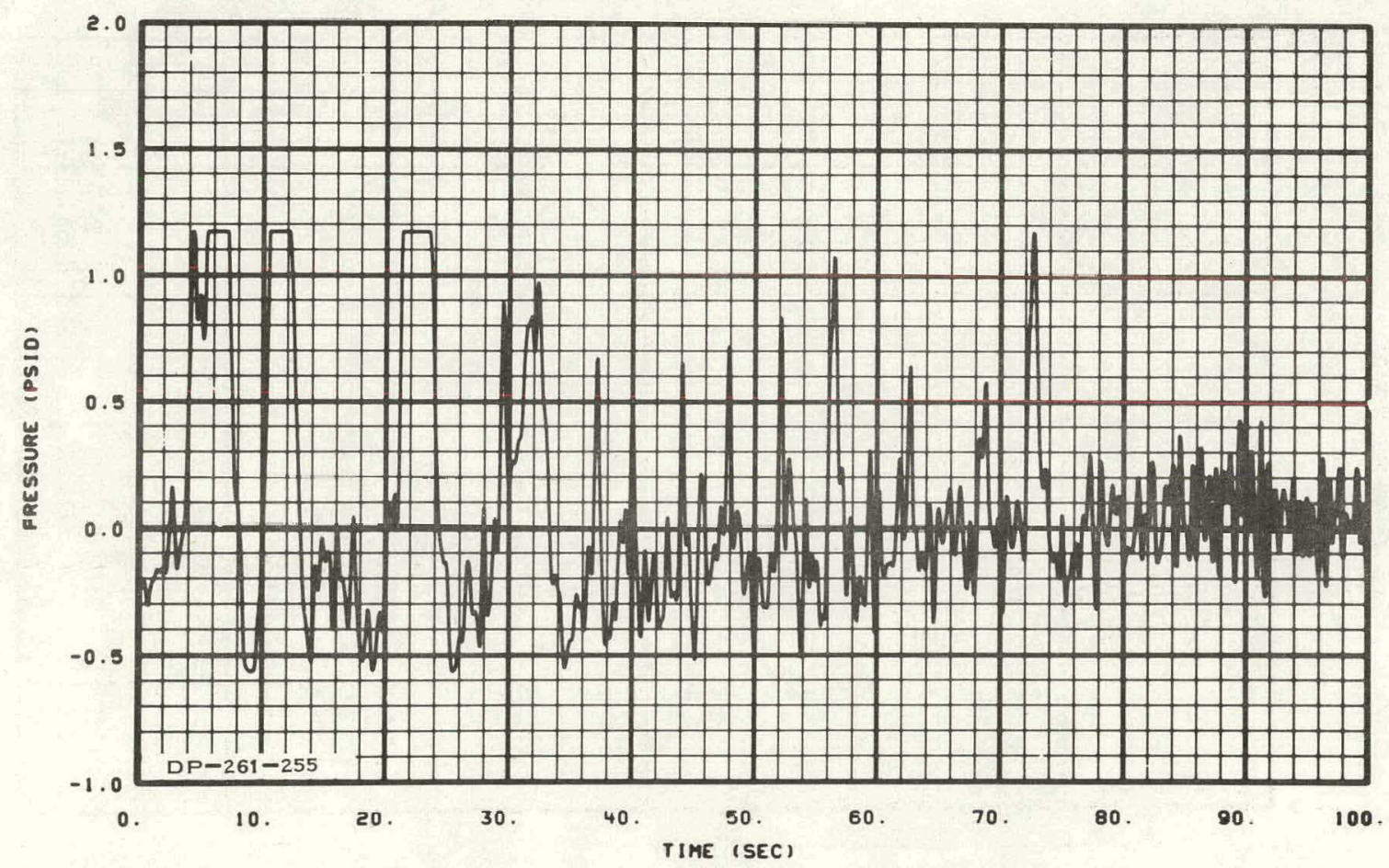

Fig. 283 Differential pressure across lower plenum (DP-261-255) -- Test 15.1 . 


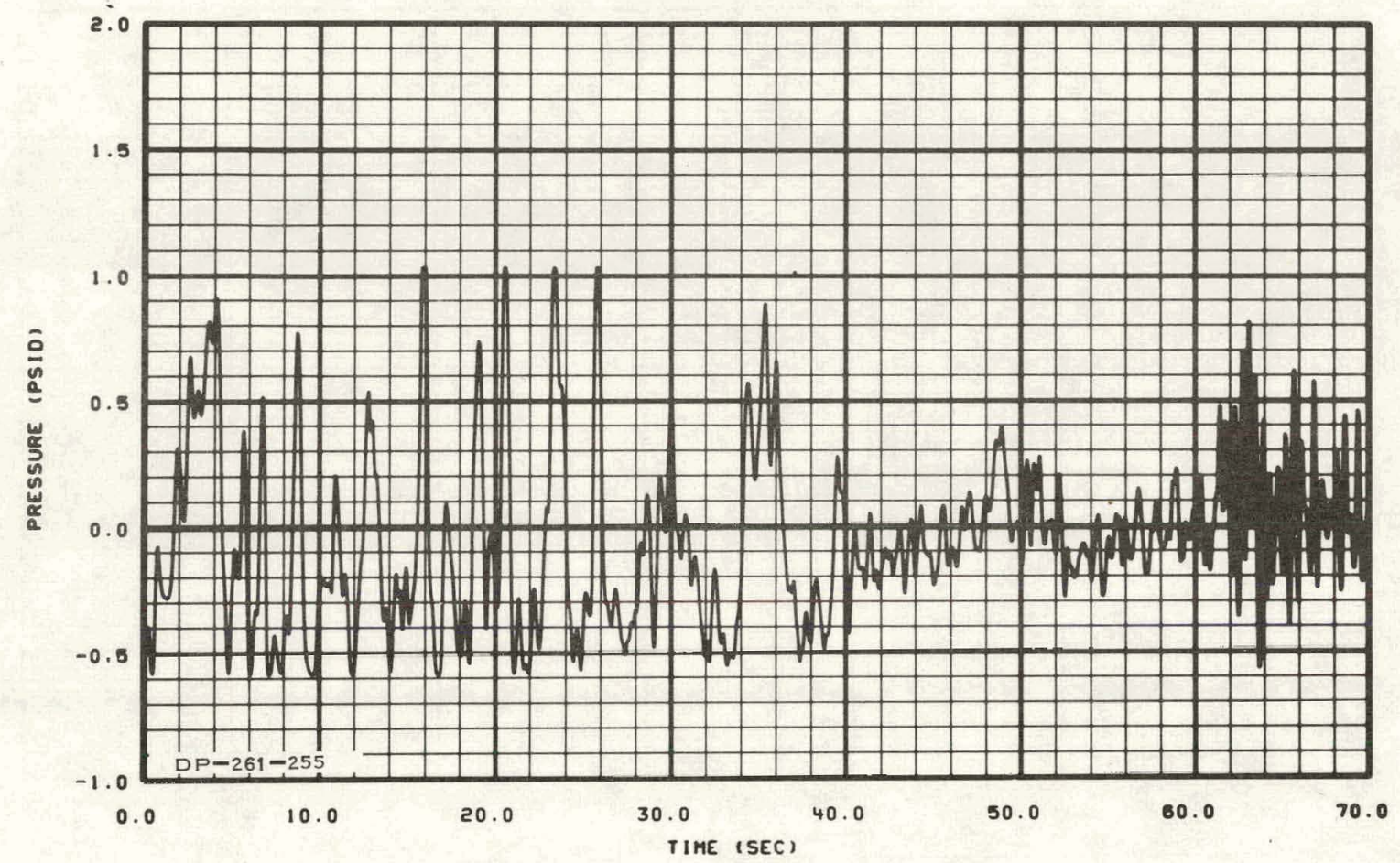

Fig. 284 Differential pressure across lower plenum (DP-261-255) -- Test 15.2 .

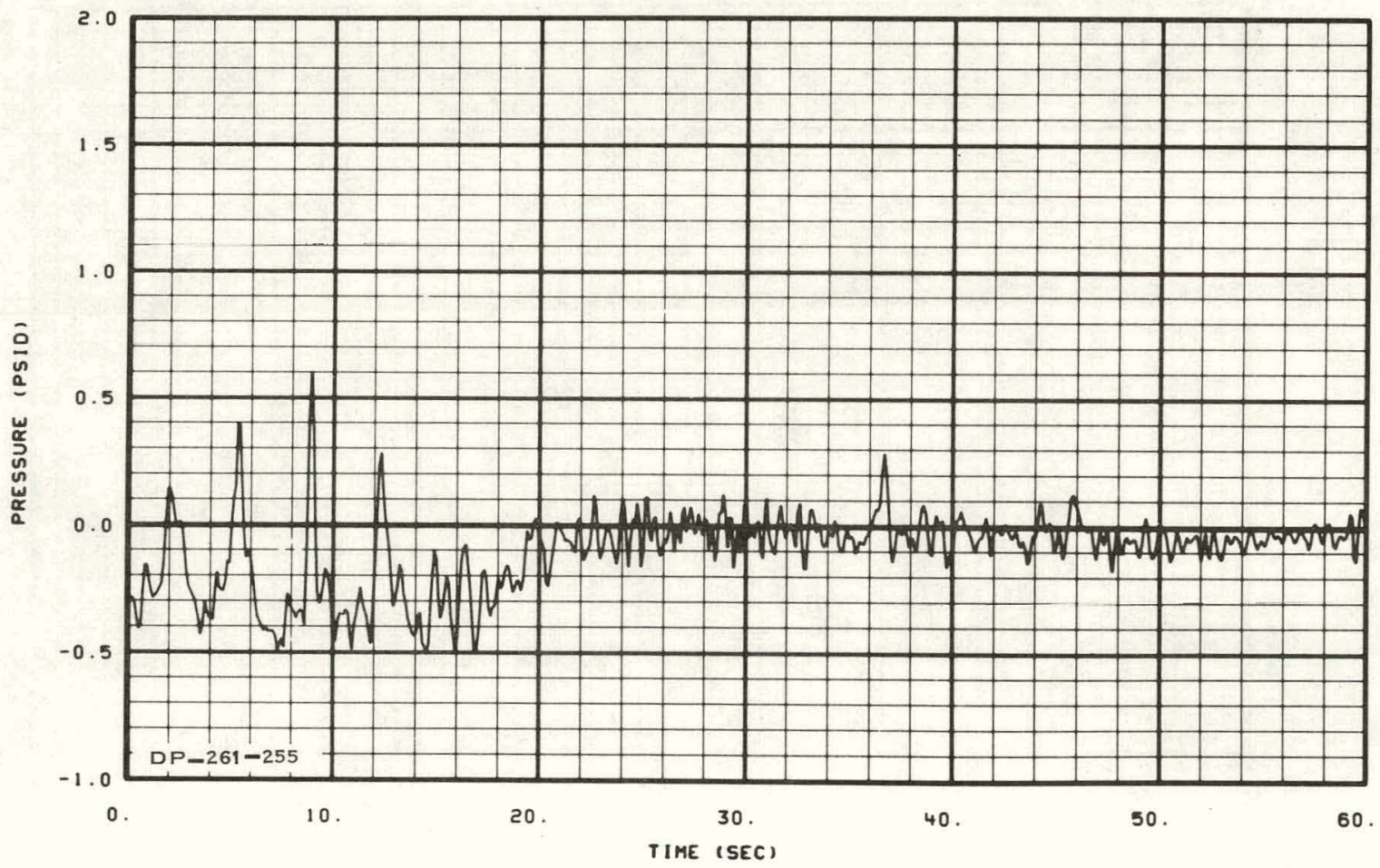

Fig. 285 Differential pressure across lower plenum (DP-261-255) -- Test 15.3 . 


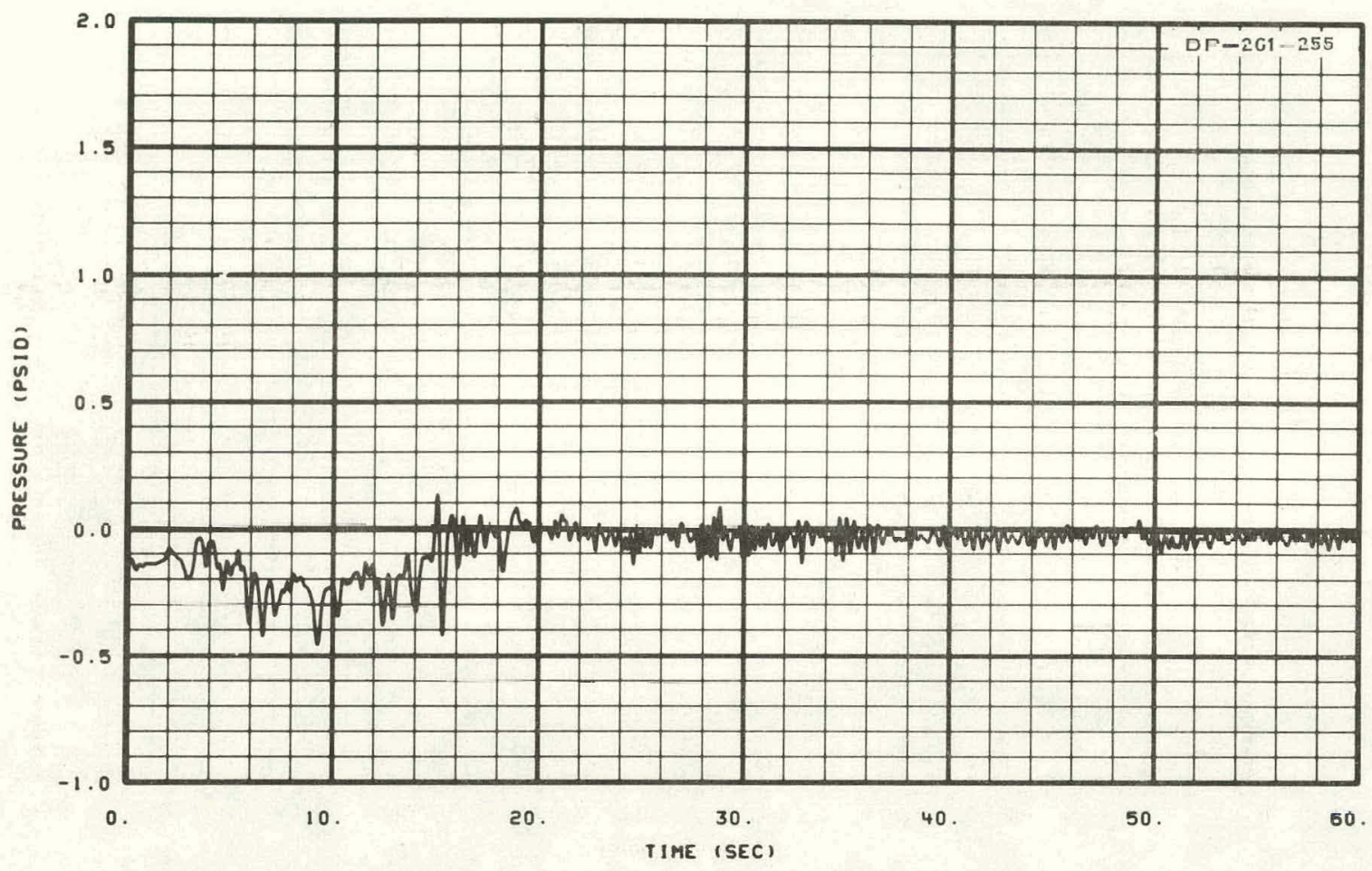

Fig. 286 Differential pressure across lower plenum (DP-261-255) -- Test 15.4 .

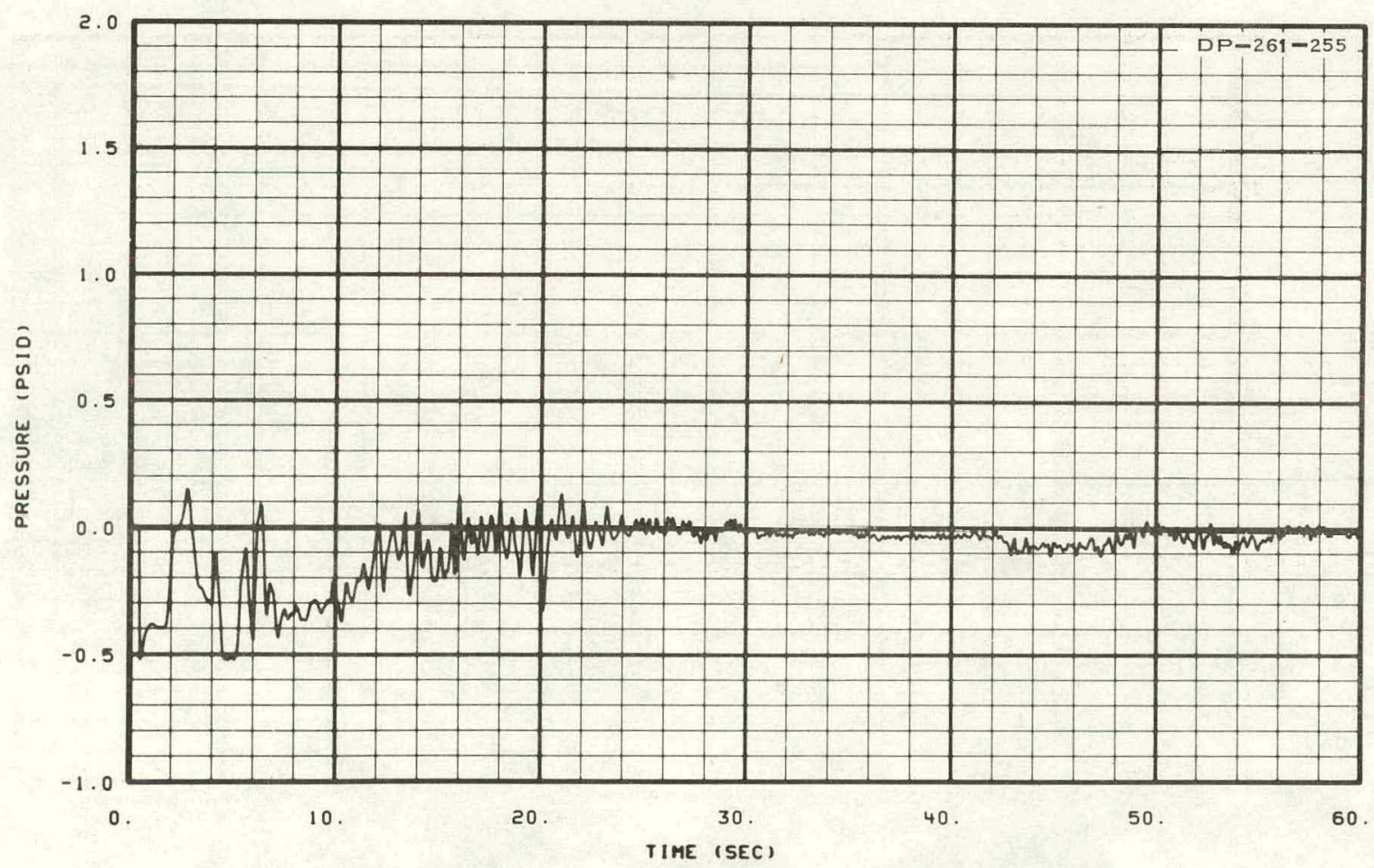

Fig. 287 Differential pressure across lower plenum (DP-261-255) -- Test 15.7 . 


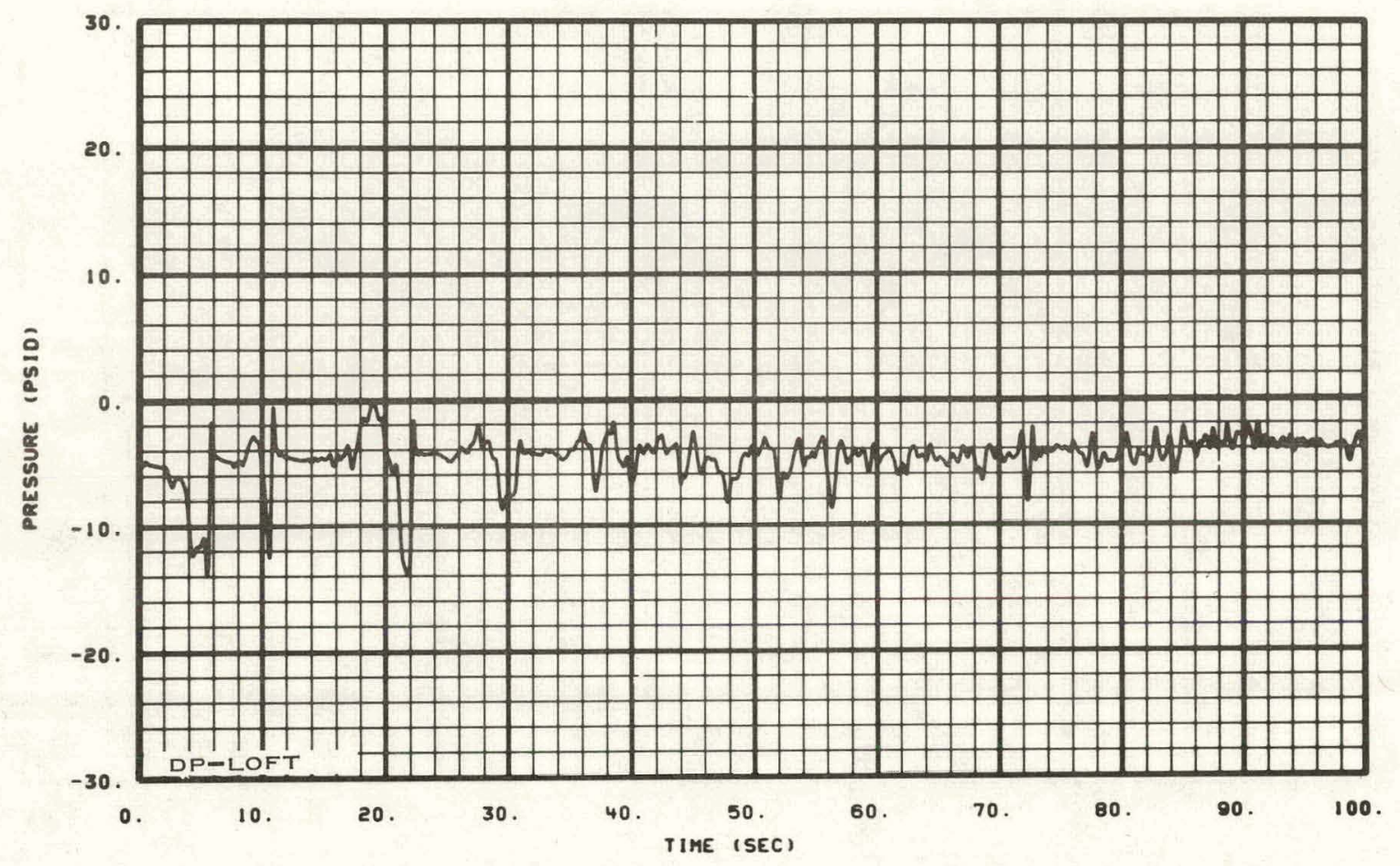

Fig. 288 Differential pressure across vesse1 (DP-LOFT) -- Test 15.1.

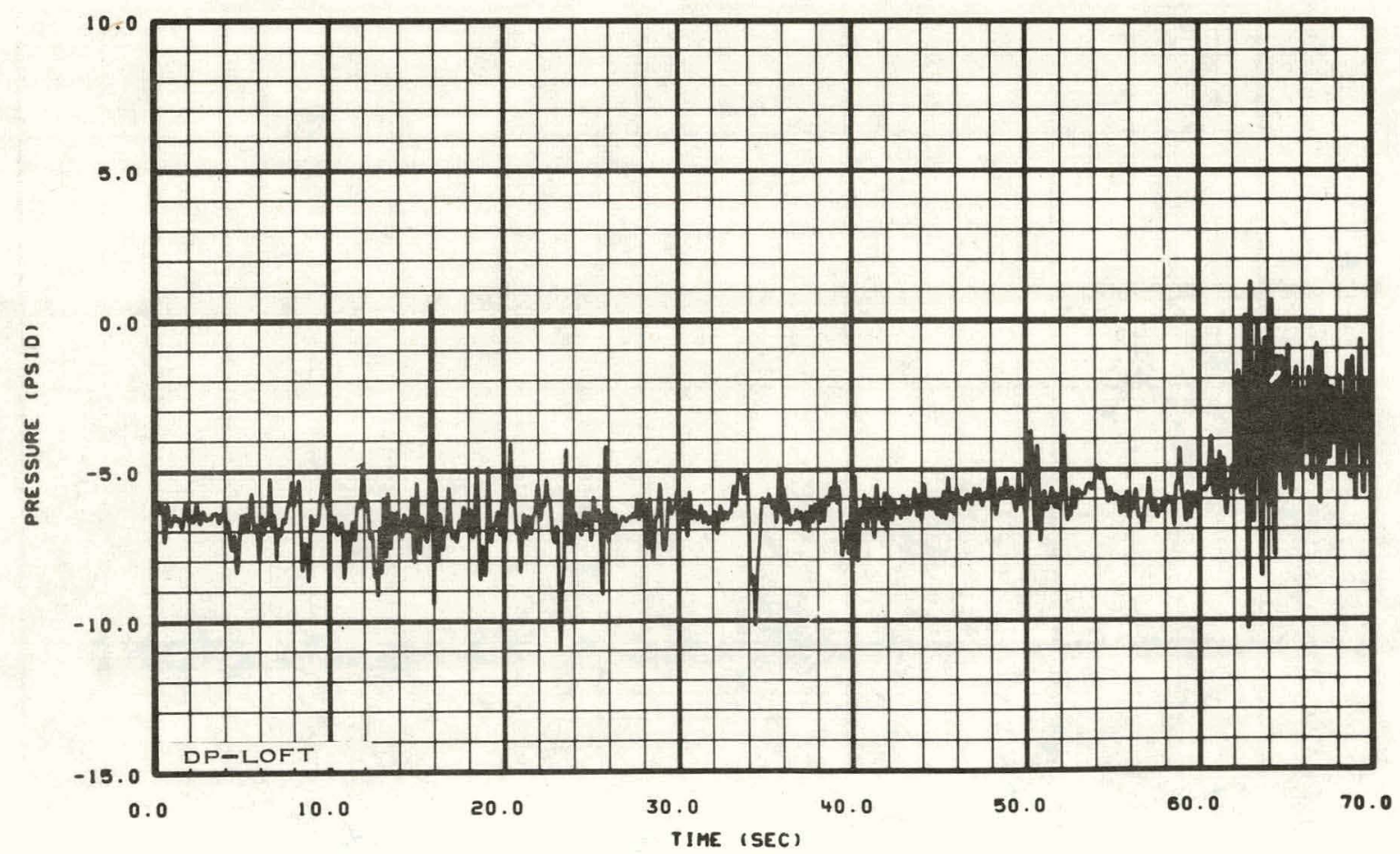

Fig. 289 Differential pressure across vessel (DP-LOFT) -- Test 15.2. 


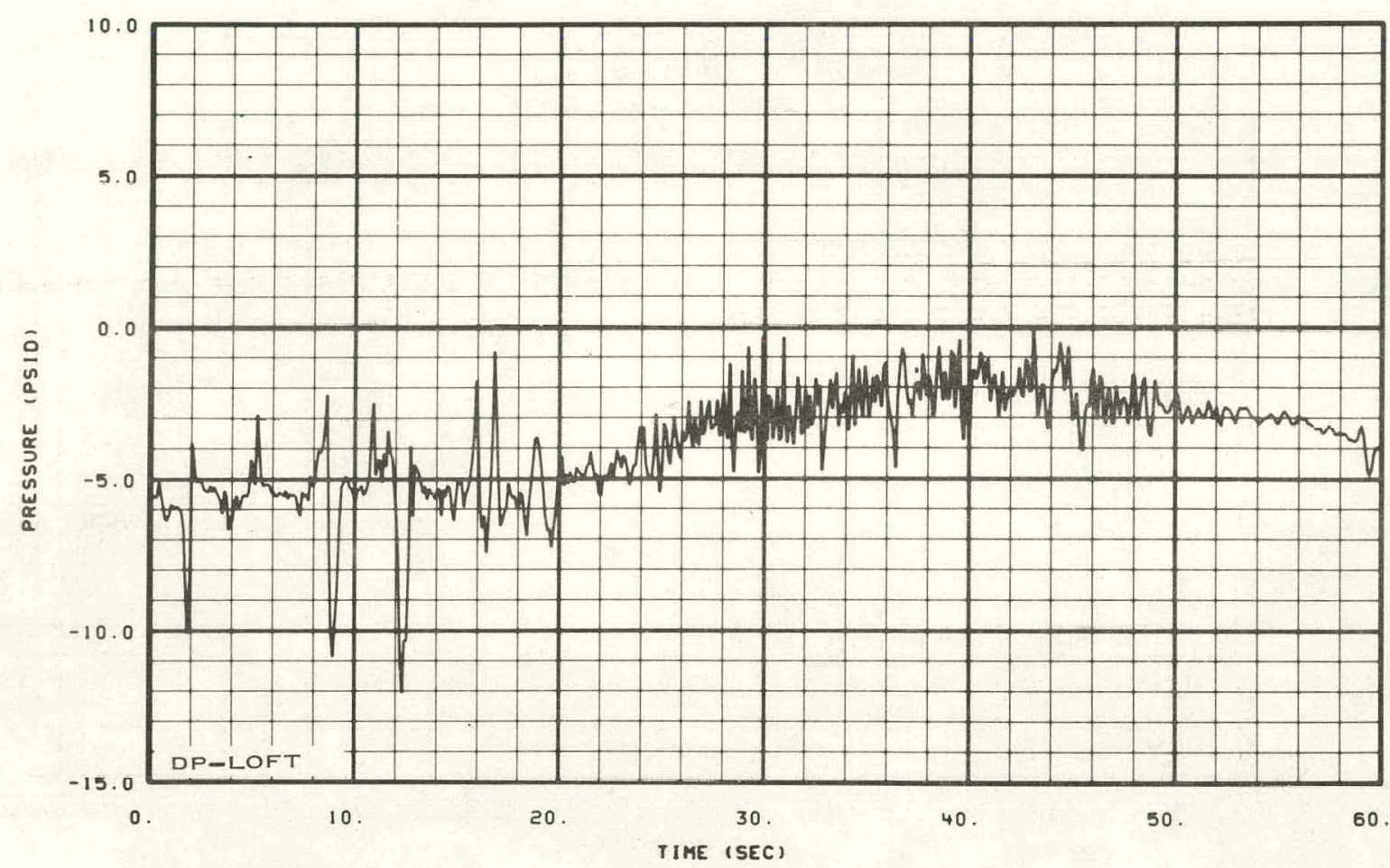

Fig. 290 Differential pressure across vessel (DP-LOFT) -- Test 15.3.

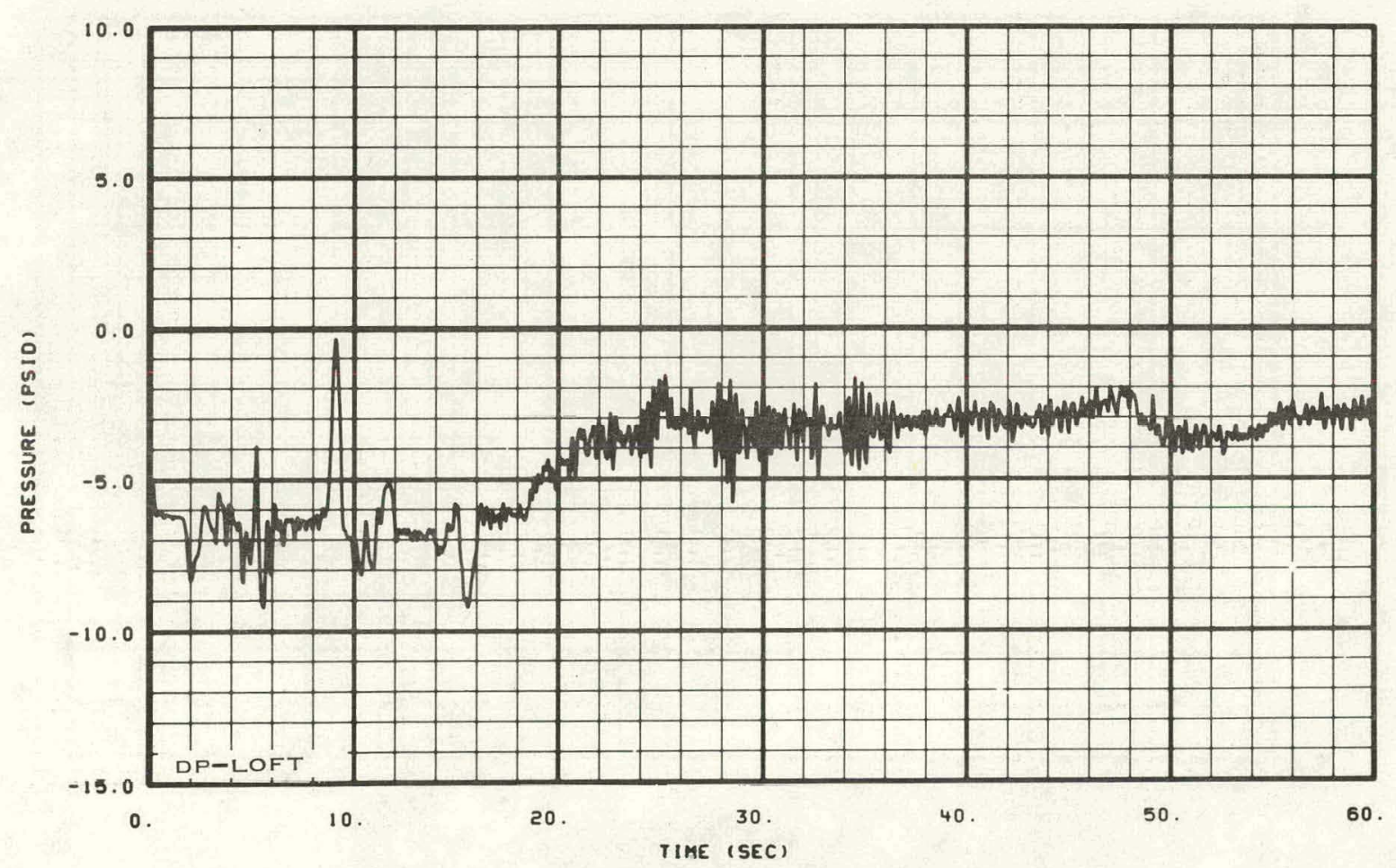

Fig. 291 Differential pressure across vessel (DP-LOFT) -- Test 15.4. 


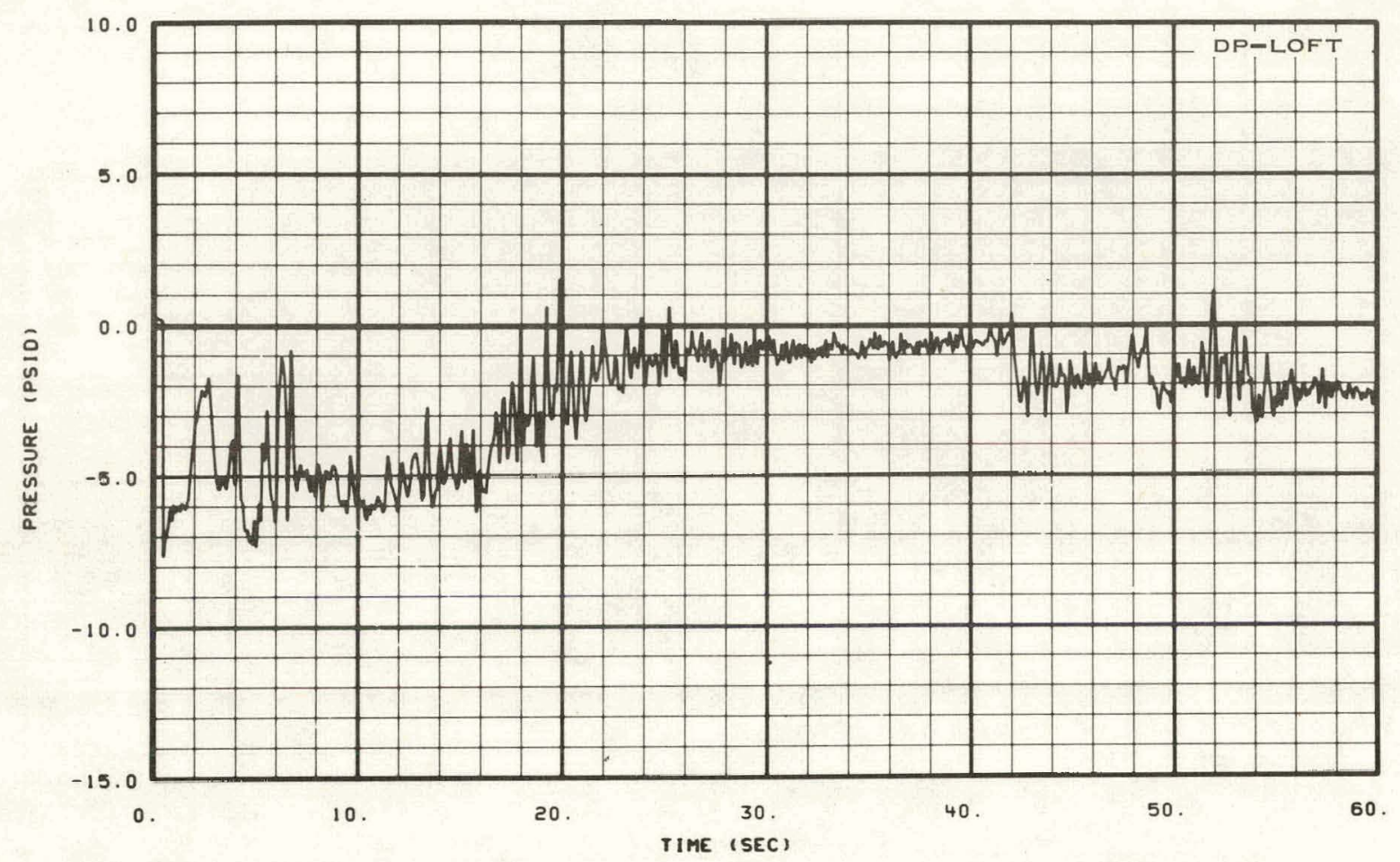

Fig. 292 Differential pressure across vesse1 (DP-LOFT) -- Test 15.7.

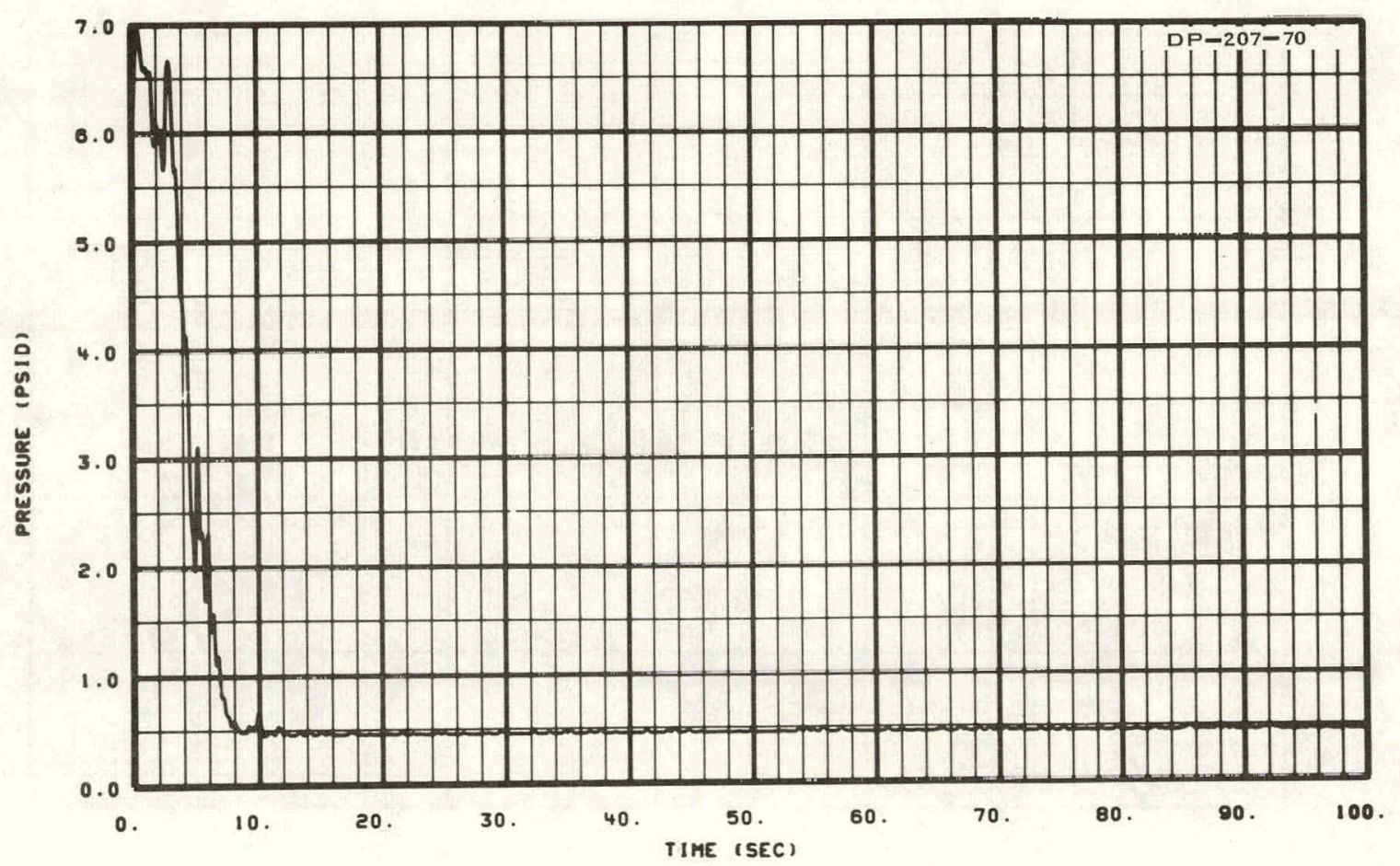

Fig. 293 Differential pressure between vessel upper plenum and blowdown loop hot leg (DP-207-70) -- Test 15.1. 


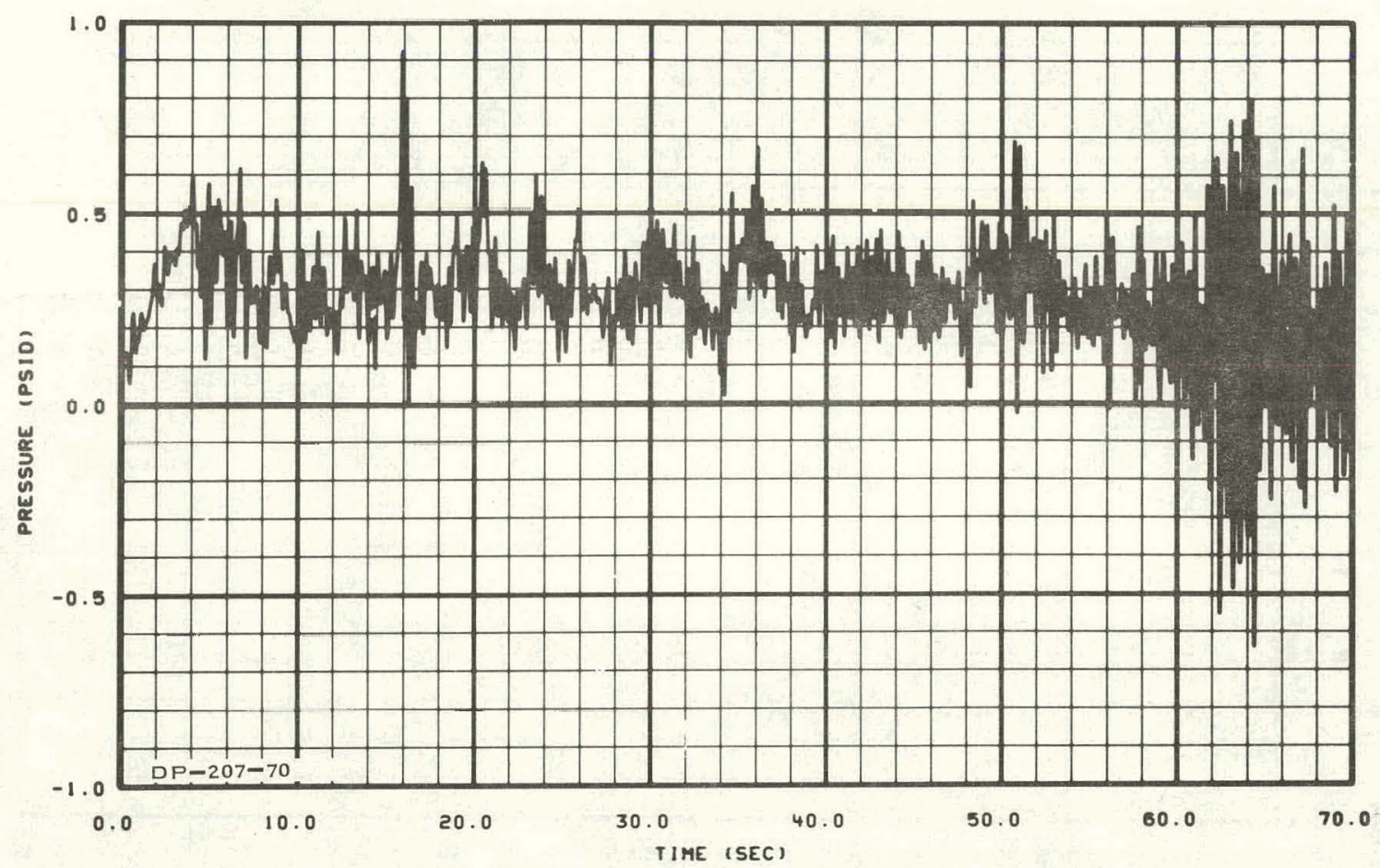

Fig. 294 Differential pressure between vessel upper plenum and blowdown loop hot leg (DP-207-70) -- Test 15.2.

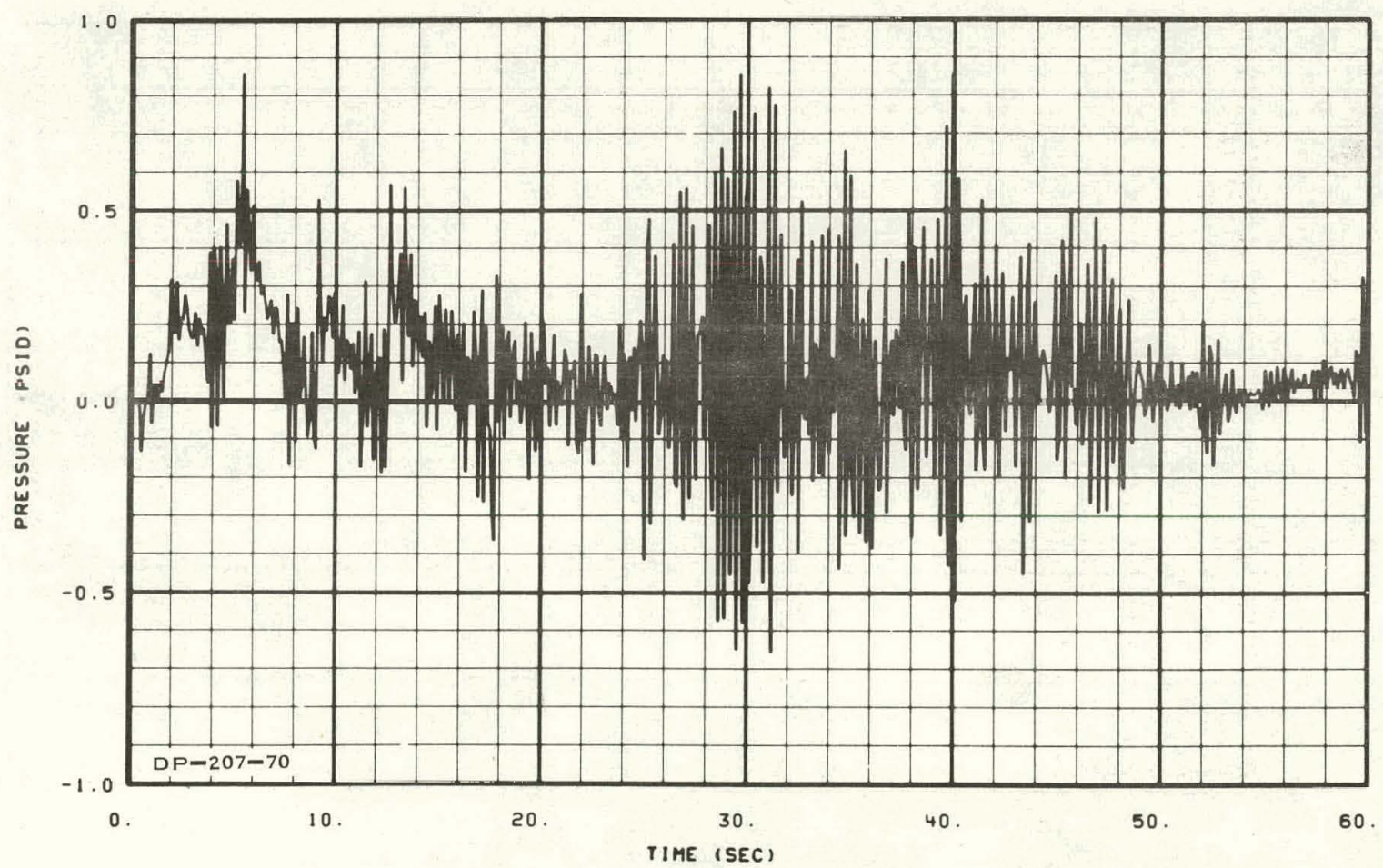

Fig. 295 Differential pressure between vessel upper plenum and blowdown 1onp hat 1Pg (nP-2.07-70) -- Test 15.3. 


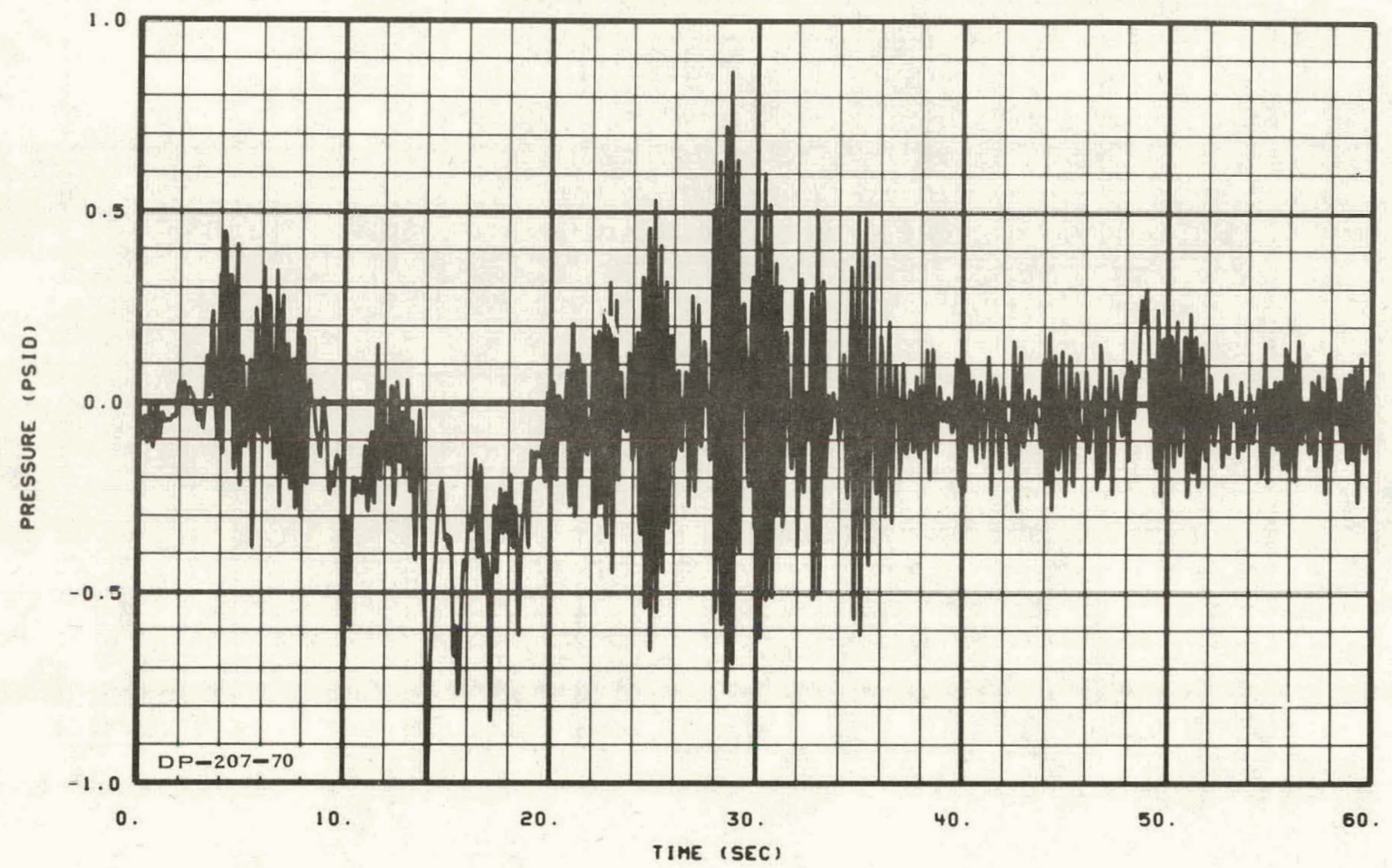

Fig. 296 Differential pressure between vessel upper plenum and blowdown loop hot leg (DP-207-70) -- Test 15.4.

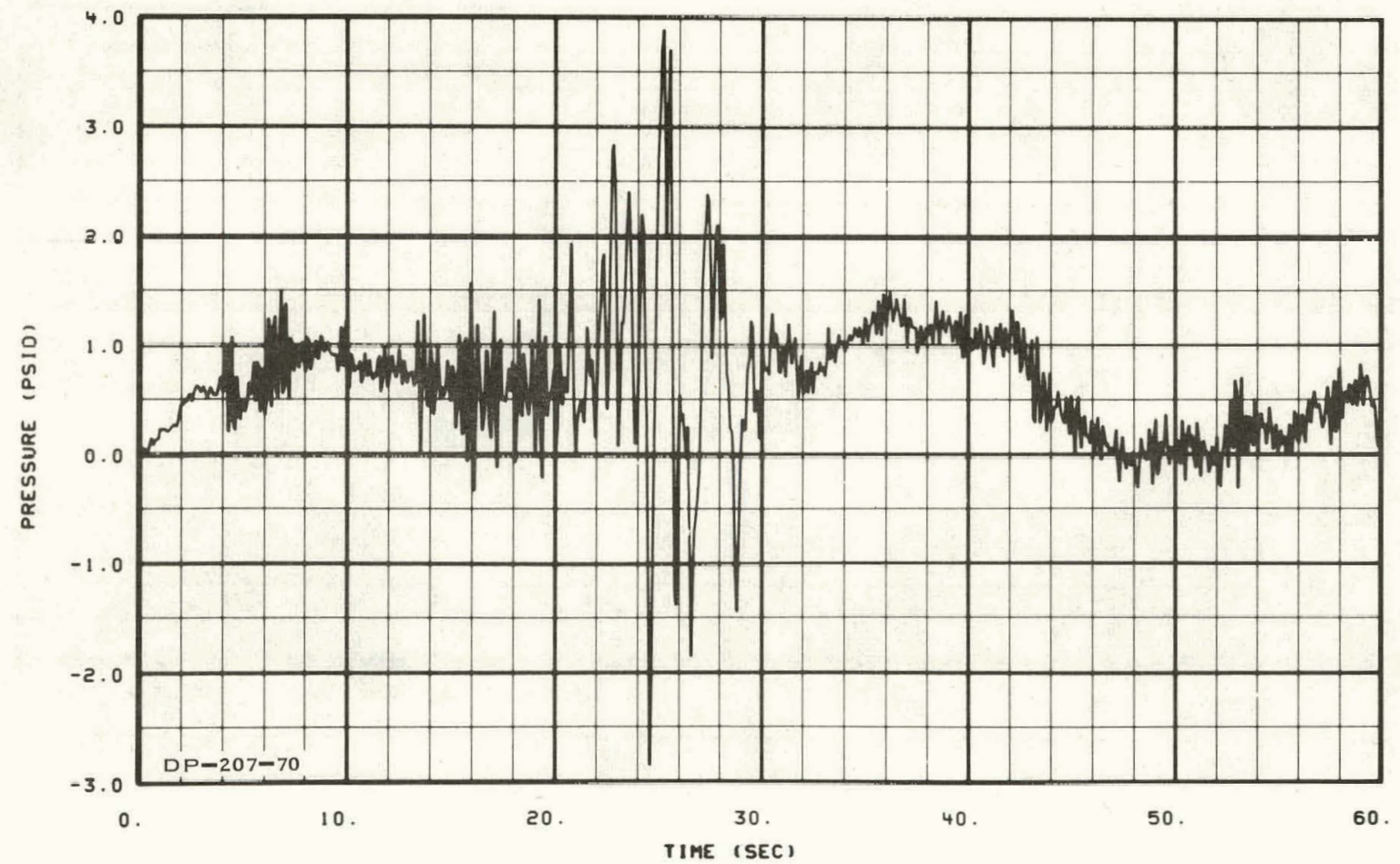

Fig. 297 Differential pressure between vessel upper plenum and blowdown loop hot leg (DP-207-70) -- Test 15.7. 


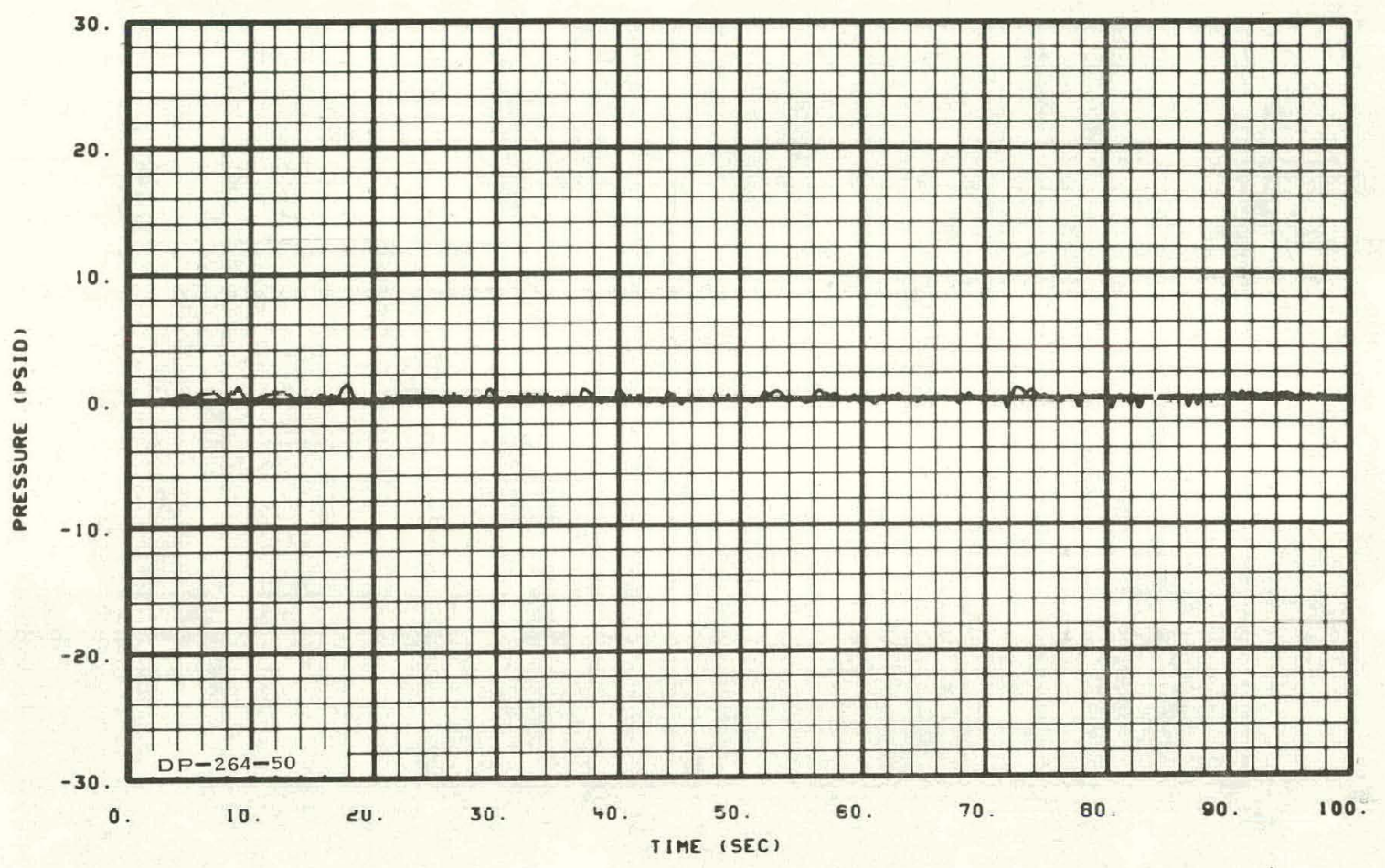

Fig. 298 Differential pressure between vessel inlet annulus and blowdown loop cold leg (DP-264-50) -- Test 15.1 .

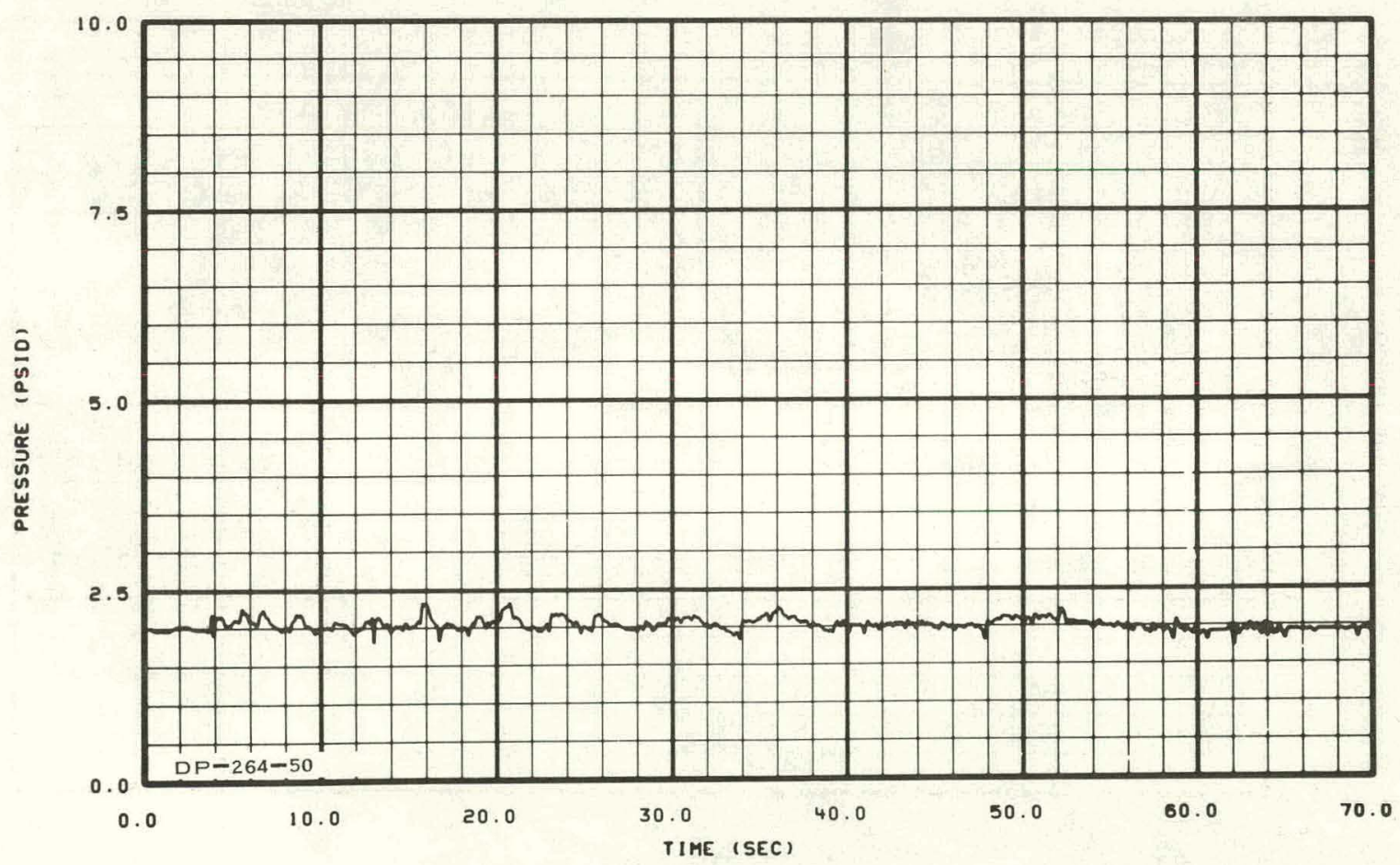

Fig. 299 Differential pressure between vessel inlet annulus and blowdown loop cold leg (DP-264-50) -- Test 15.2 . 


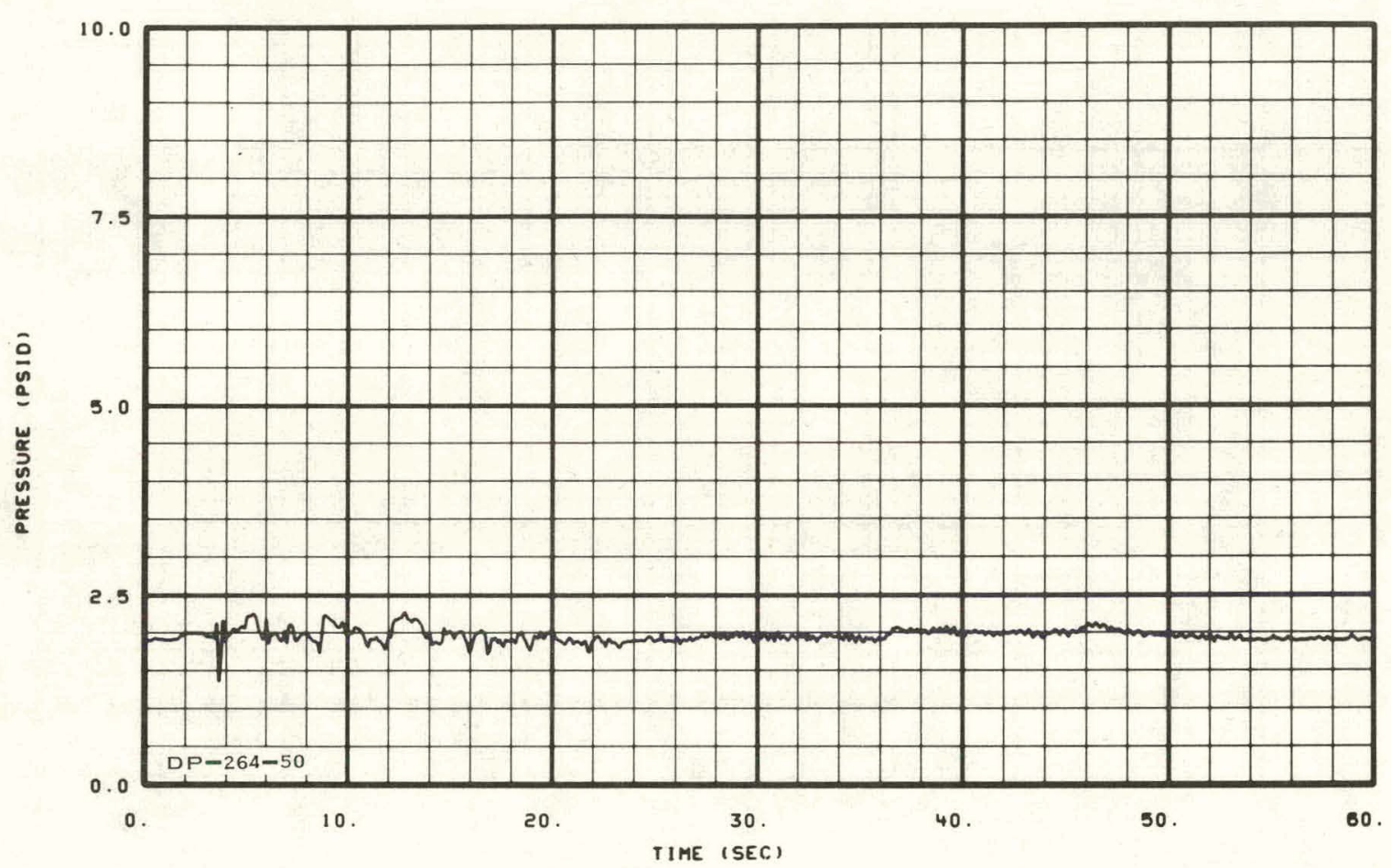

Fig. 300 Differential pressure between vessel inlet annulus and blowdown loop cold leg (DP-264-50) -- Test 15.3.

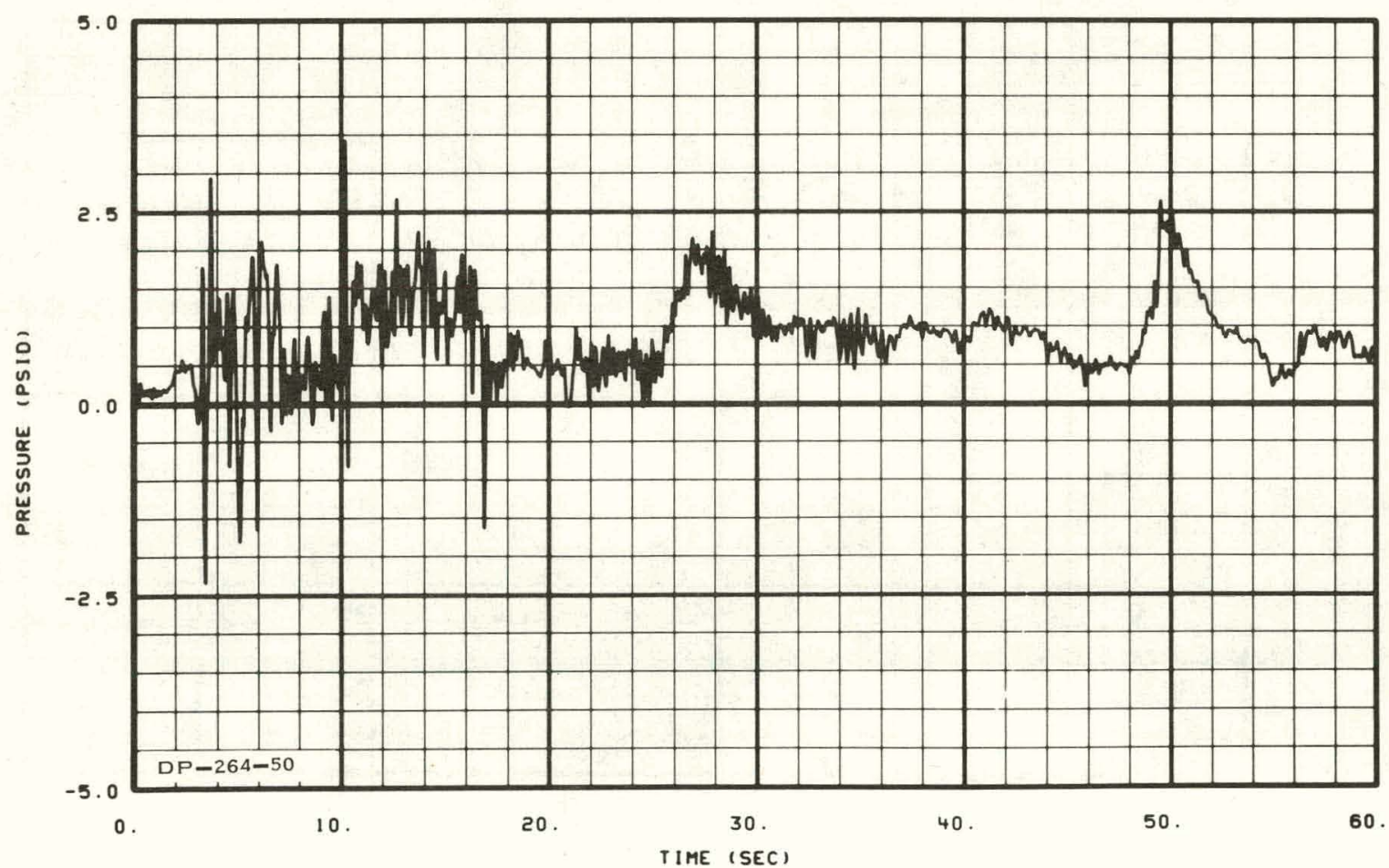

Fig. 301 Differential pressure between vessel inlet annulus and blowdown loop cold leg (DP-264-50) -- Test 15.4. 


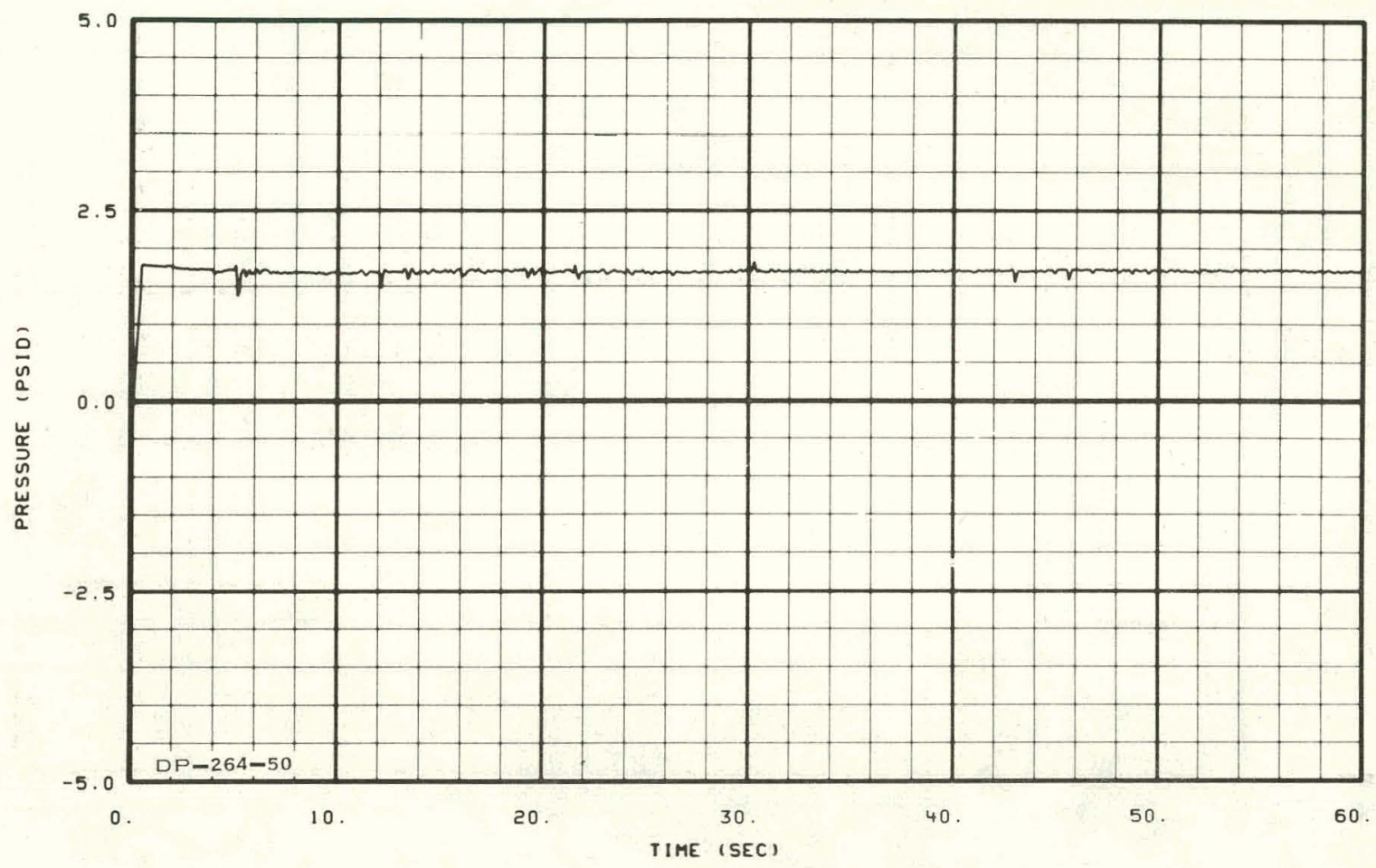

Fig. 302 Differential pressure between vessel inlet annulus and blowdown loop cold leg (DP-264-50) -- Test 15.7 .

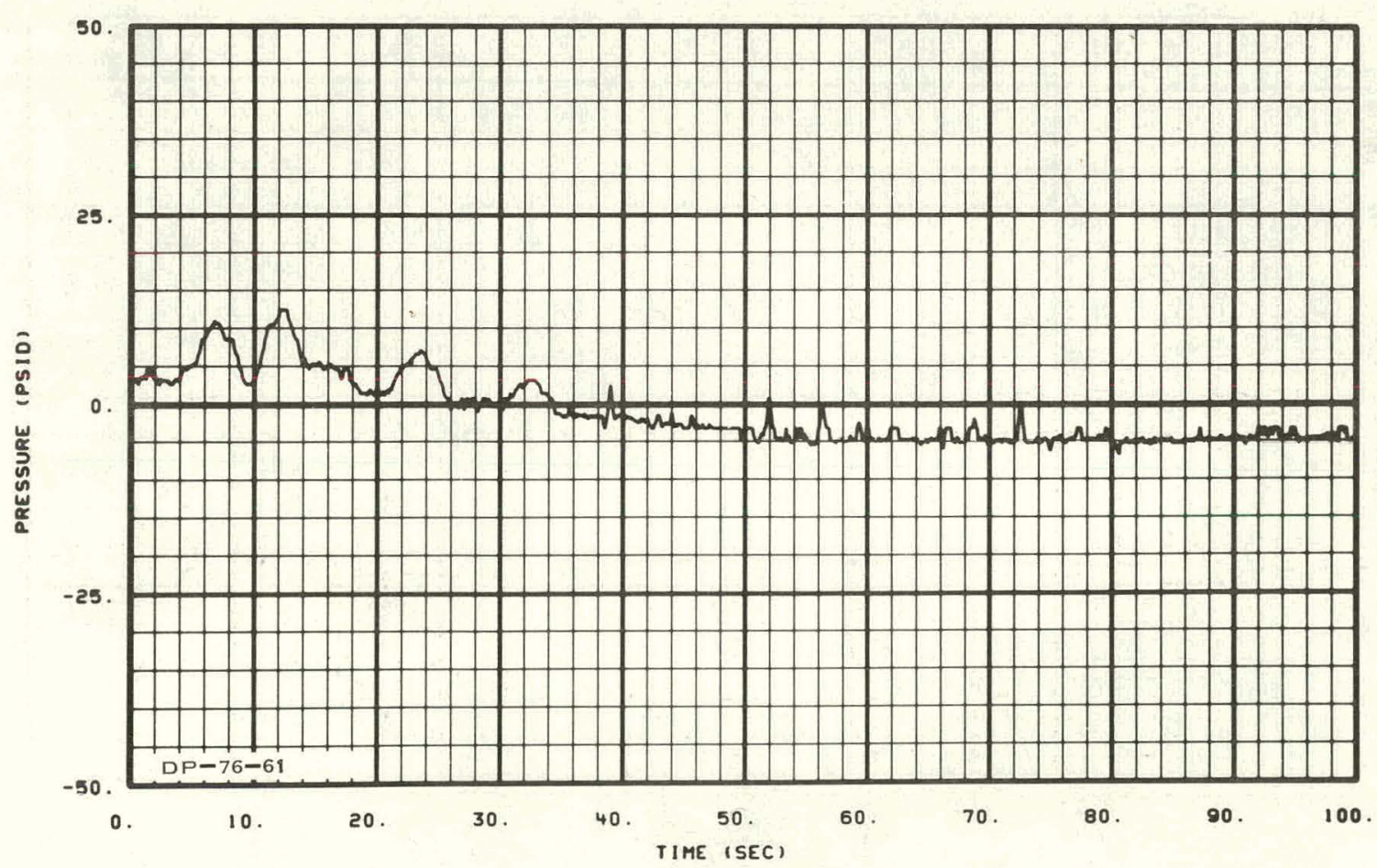

Fig. 303 Differential pressure across blowdown loop hot leg nozzle (DP76-61) -- Test 15.1 . 


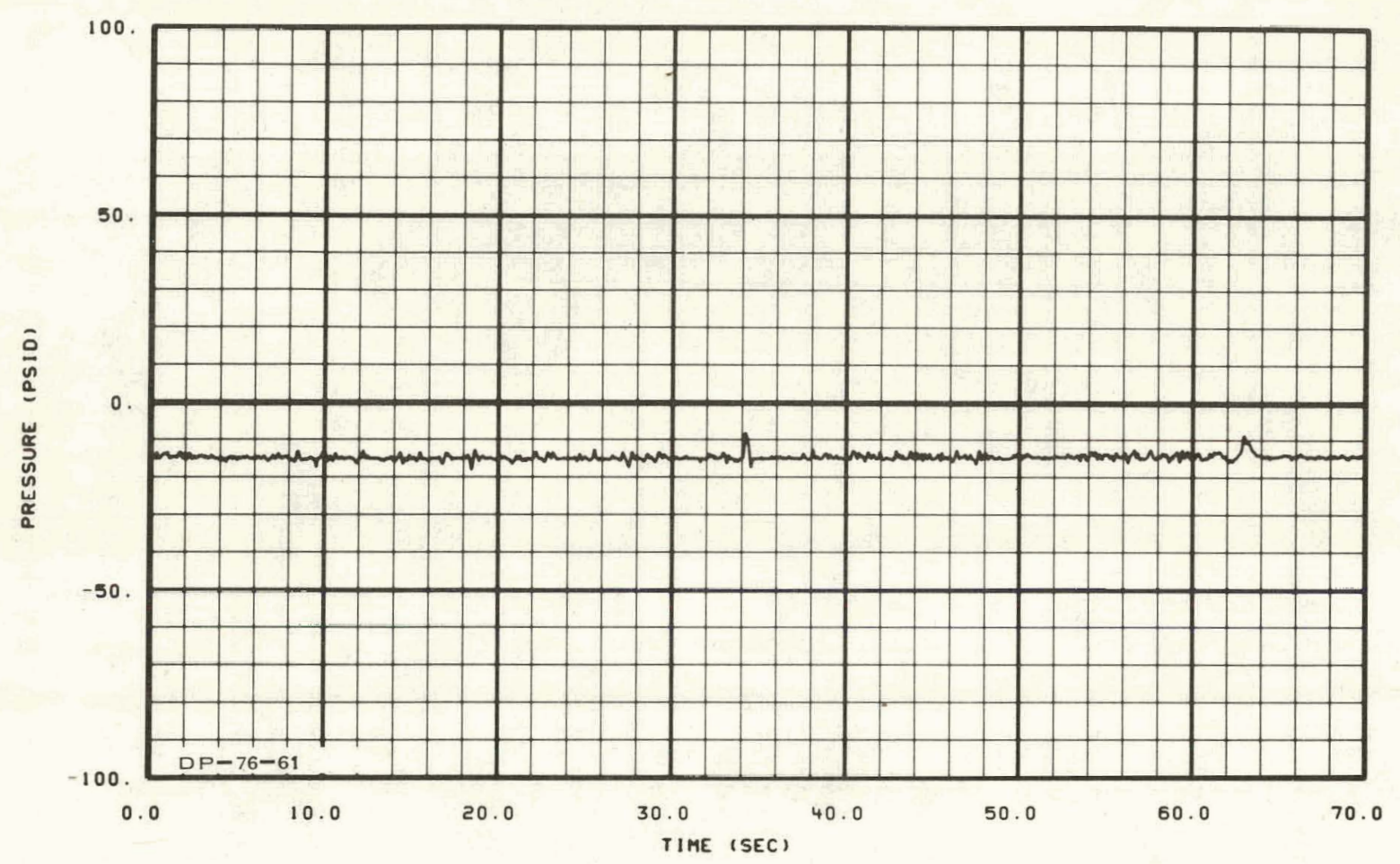

Fig. 304 Differential pressure across blowdown loop hot leg nozzle (DP76-61) -- Test 15.2.

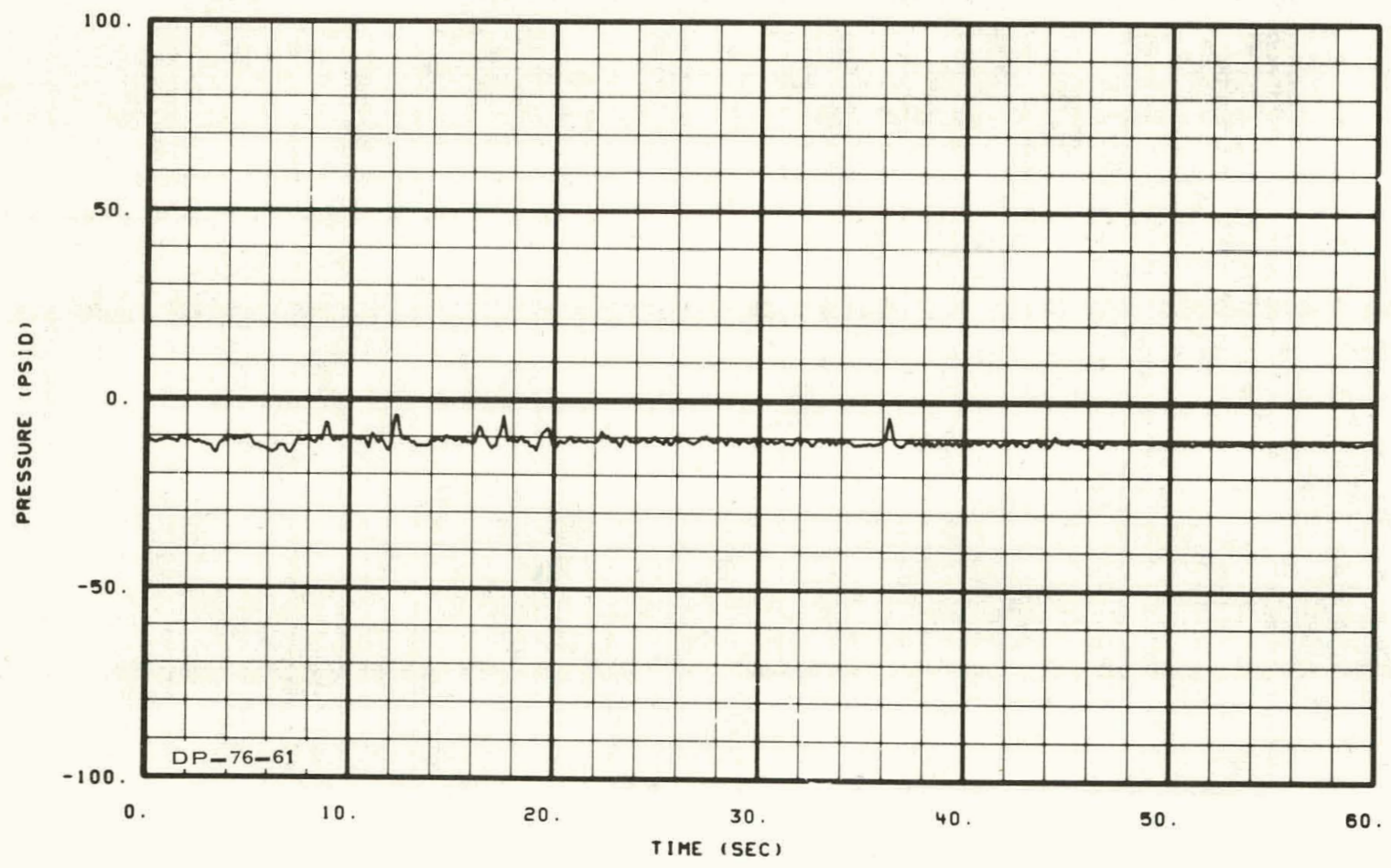

Fig. 305 Differential pressure across blowdown loop hot leg nozzle (DP76-61) -- Test 15.3. 


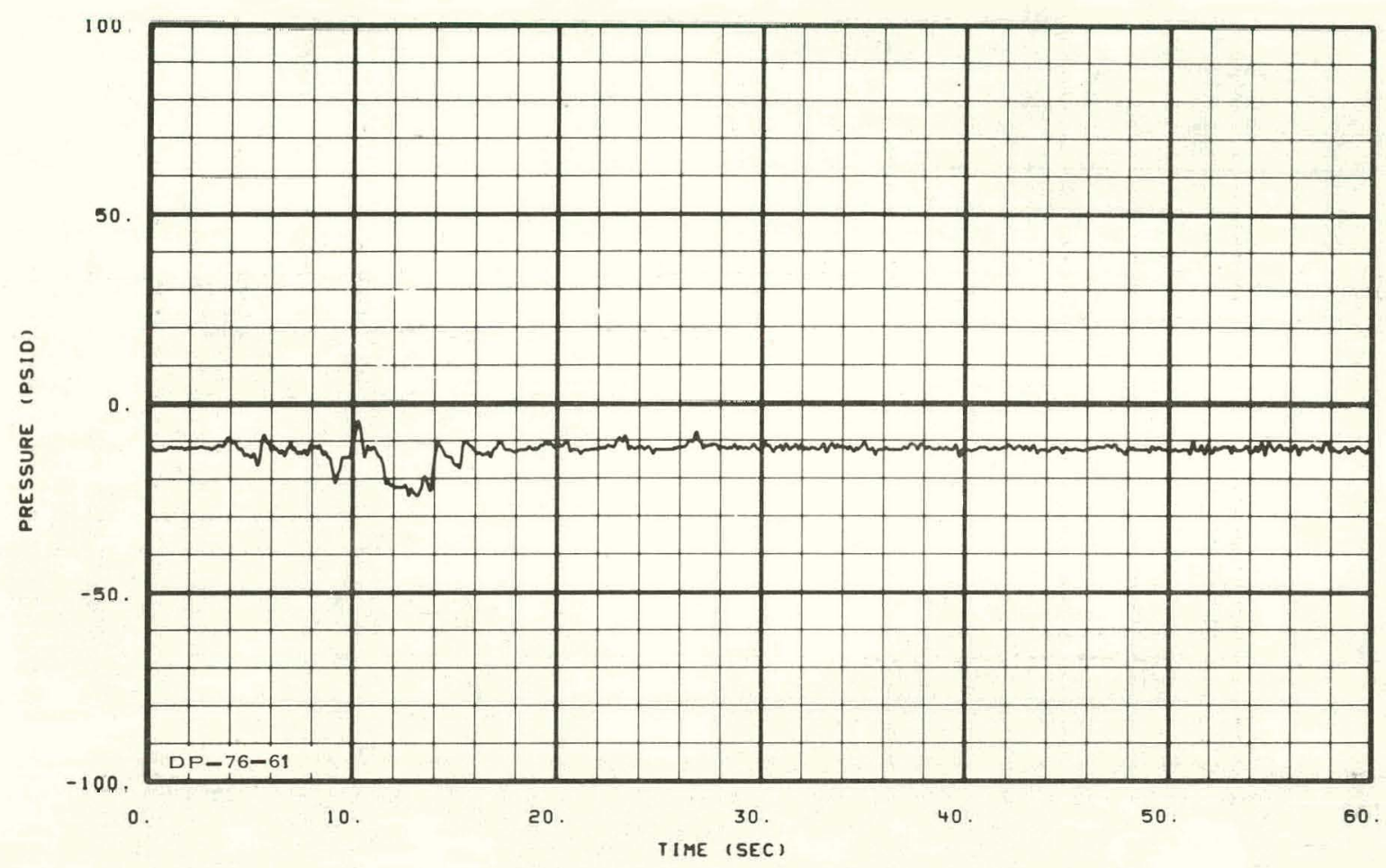

Fig. 306 Differential pressure across blowdown loop hot leg nozzle (DP76-61) -- Test 15.4.

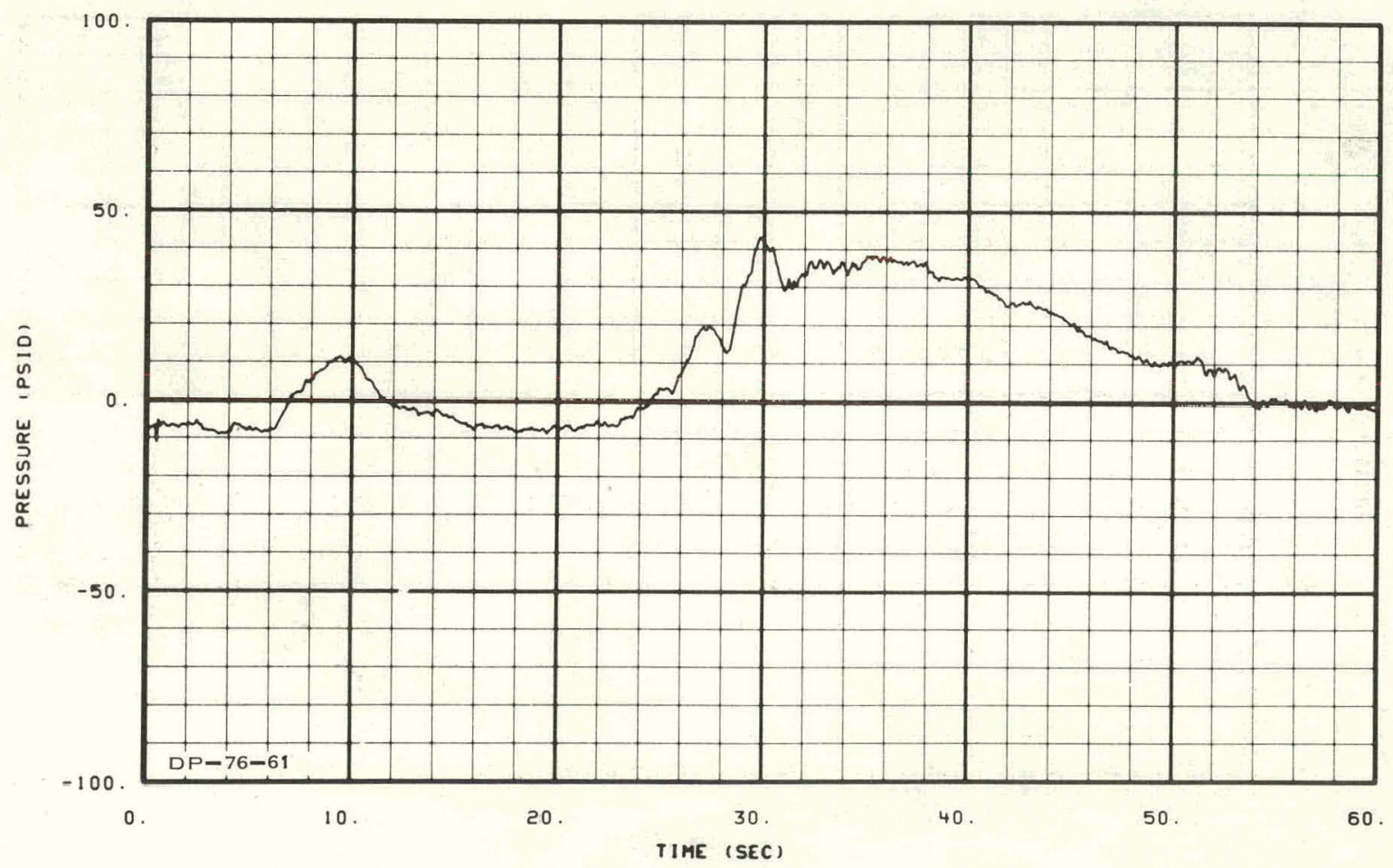

Fig. 307 Differential pressure across blowdown loop hot leg nozzle (DP76-61) -- Test 15.7. 


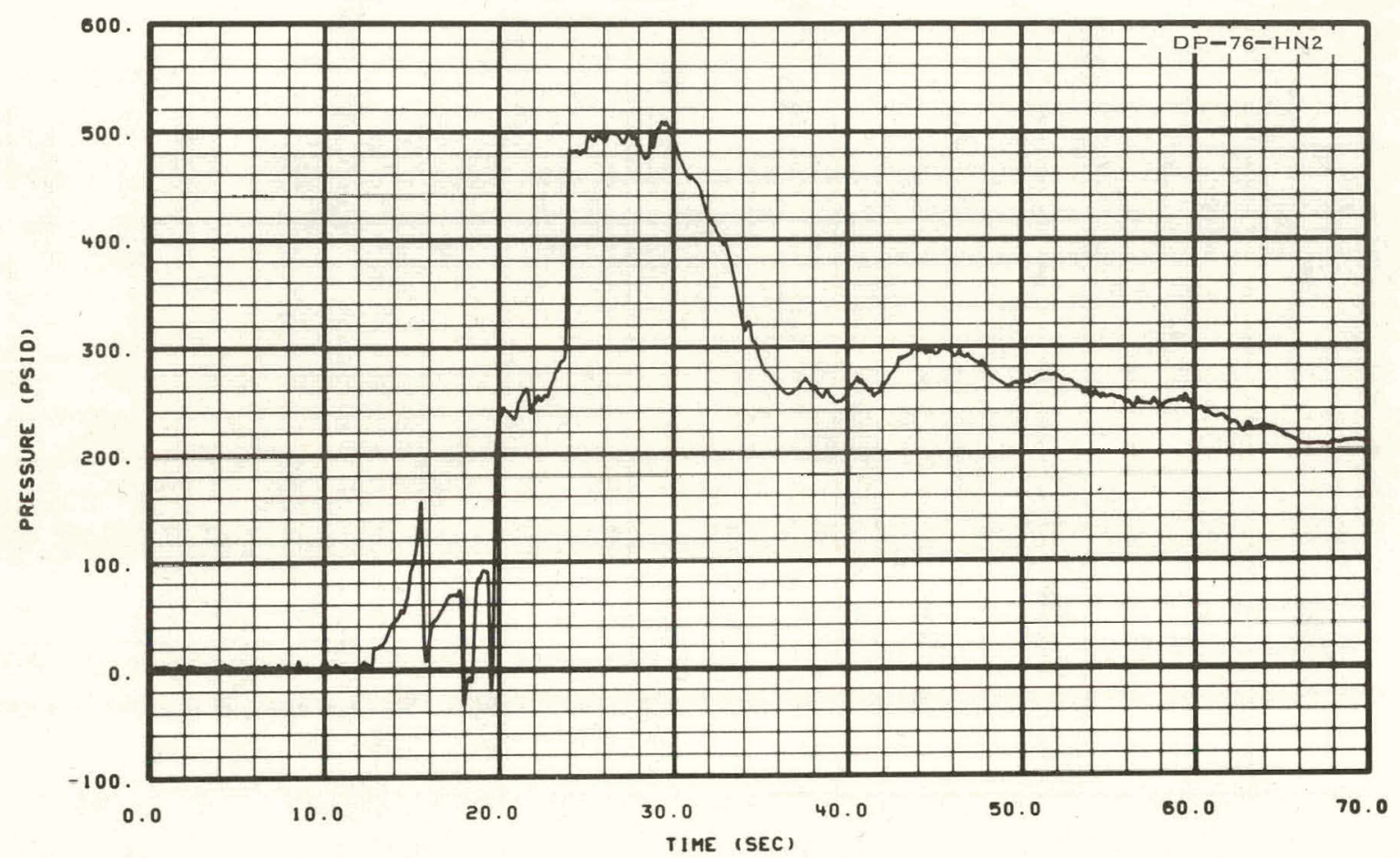

Fig. 308 Differential pressure between simulated pump and throat of blowdown loop hot leg nozzle (DP-76-HN2) -- Test 15.2.

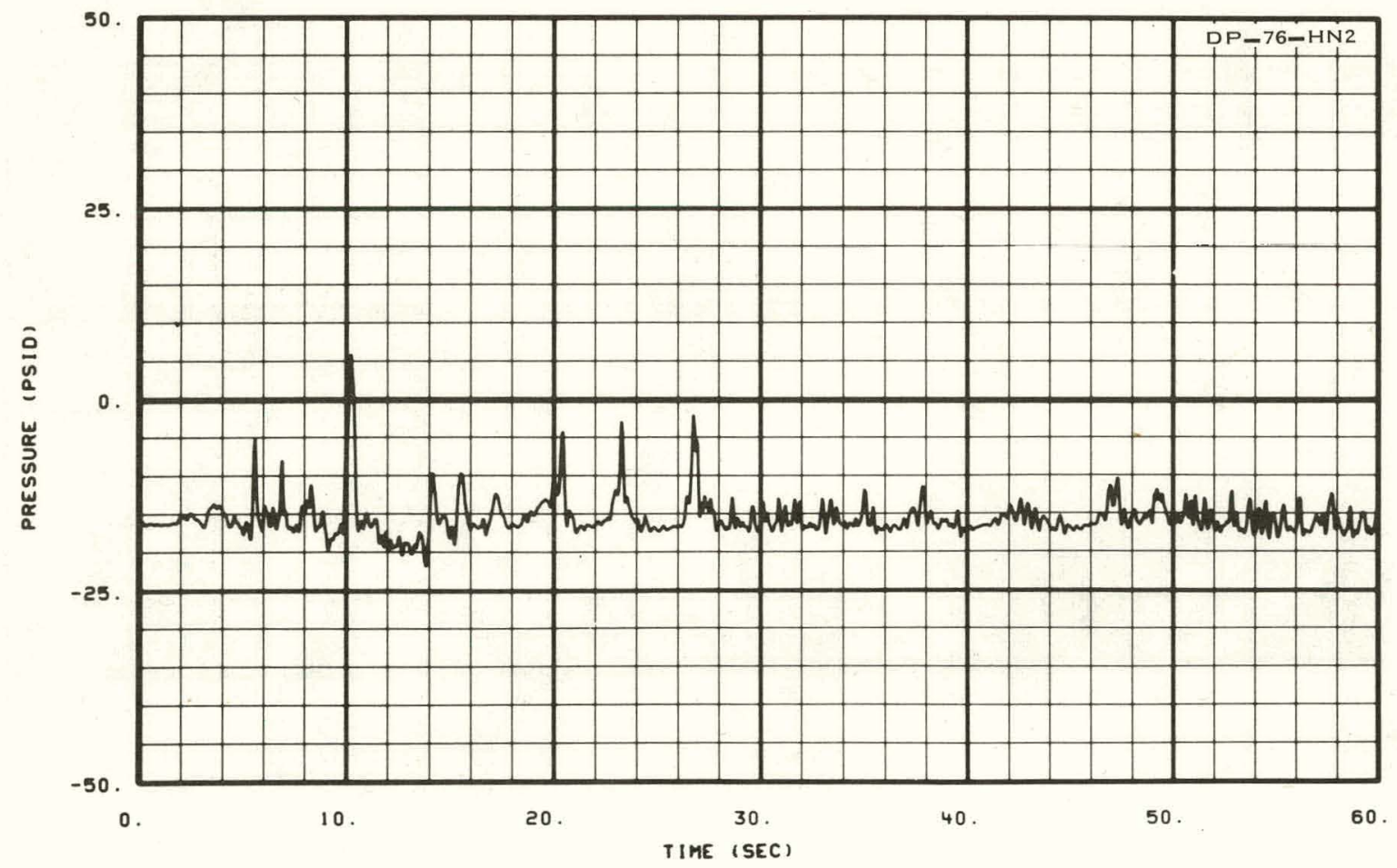

Fig. 309 Differential pressure between simulated pump and throat of blowdown loop hot leg nozzle (DP-76-HN2) -- Test 15.4 . 


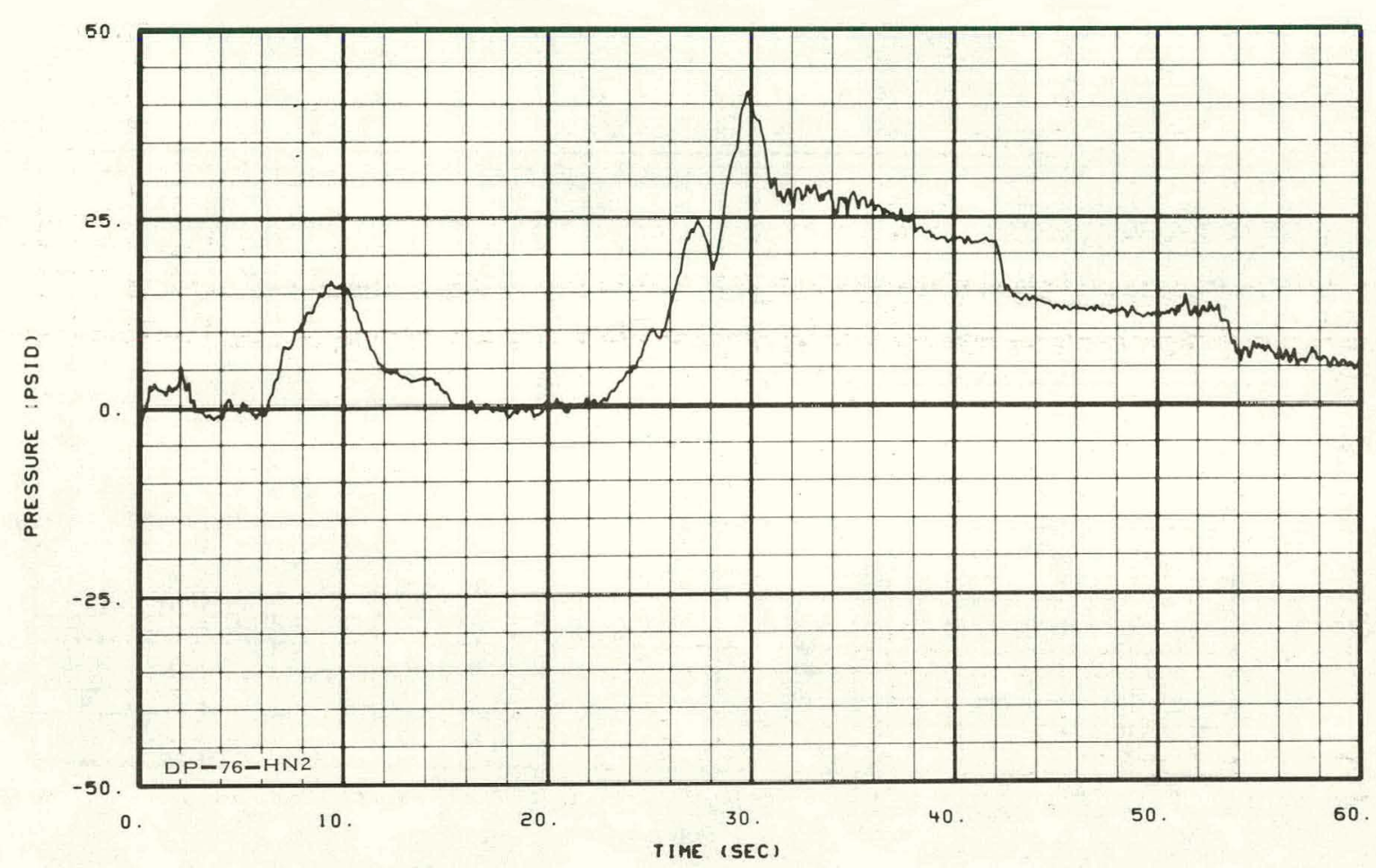

Fig. 310 Differential pressure between simulated pump and throat of blowdown loop hot leg nozzle (DP-76-HN2) -- Test 15.7.

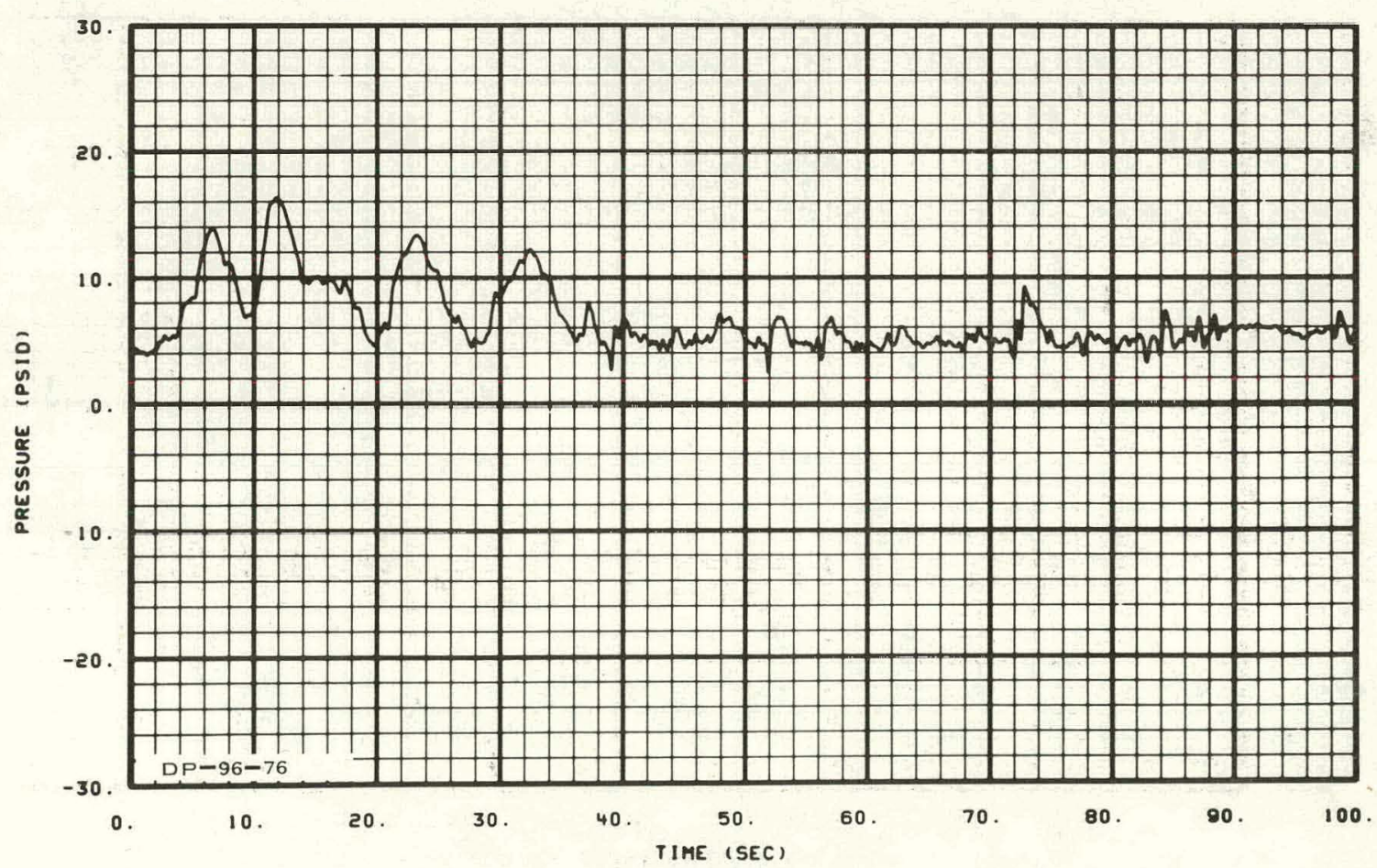

Fig. 311 Differential pressure across simulated pump (DP-96-76) -- Test 15.1 . 


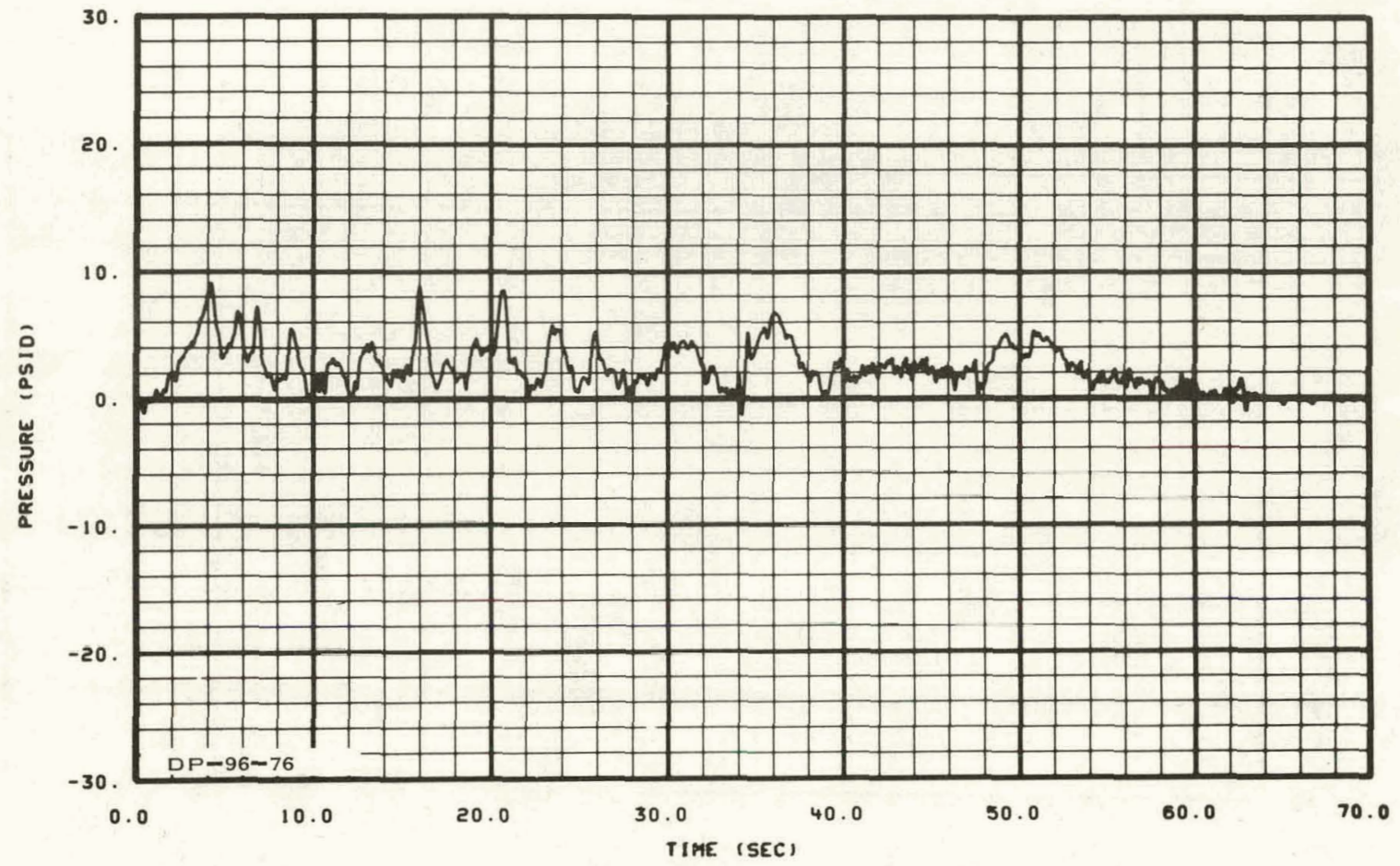

Fig. 312 Differential pressure across simulated pump (DP-96-76) -- Test 15.2 .

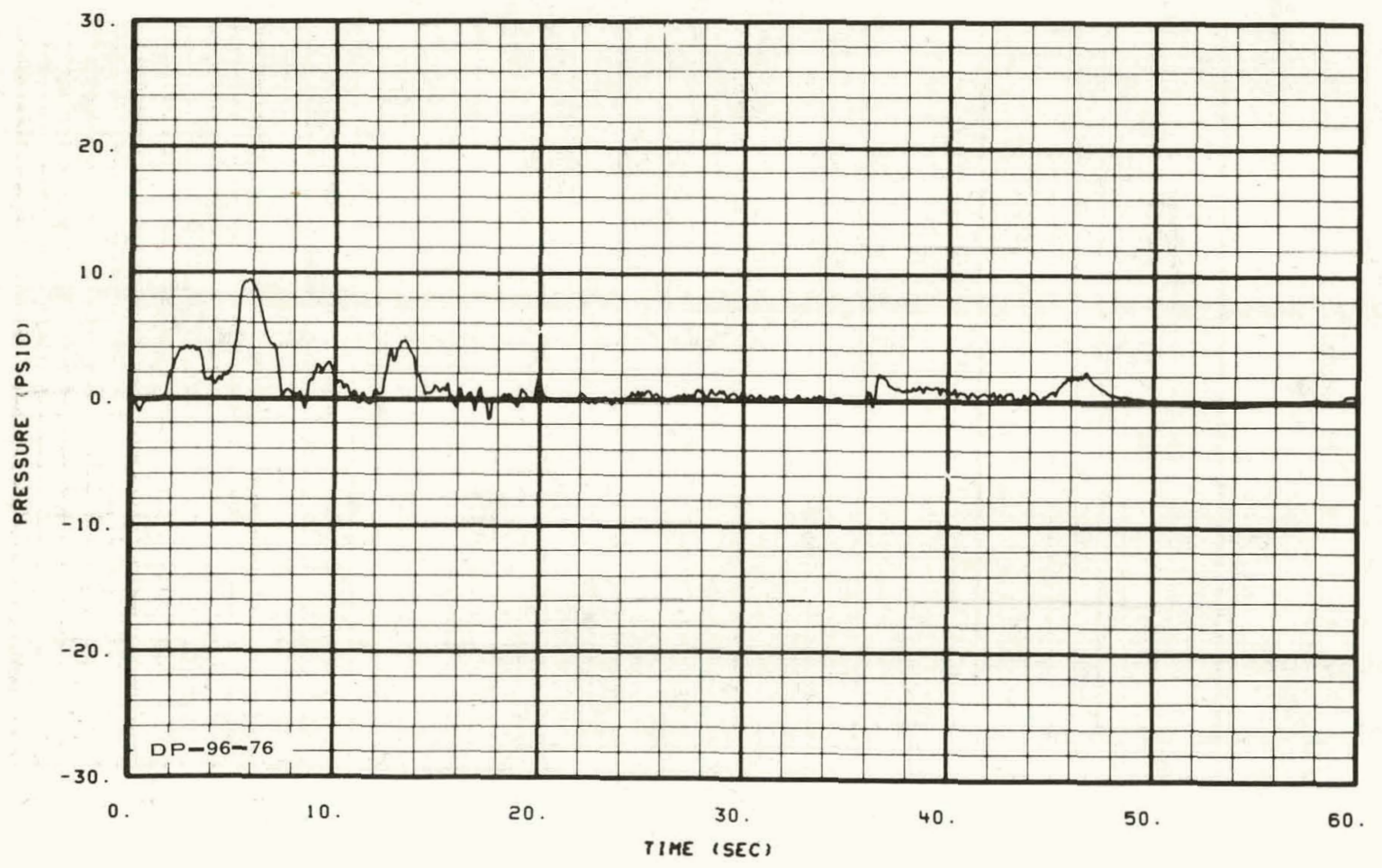

Fig. 313 Differential pressure across simulated pump (DP-96-76) -- Test 15.3 . 


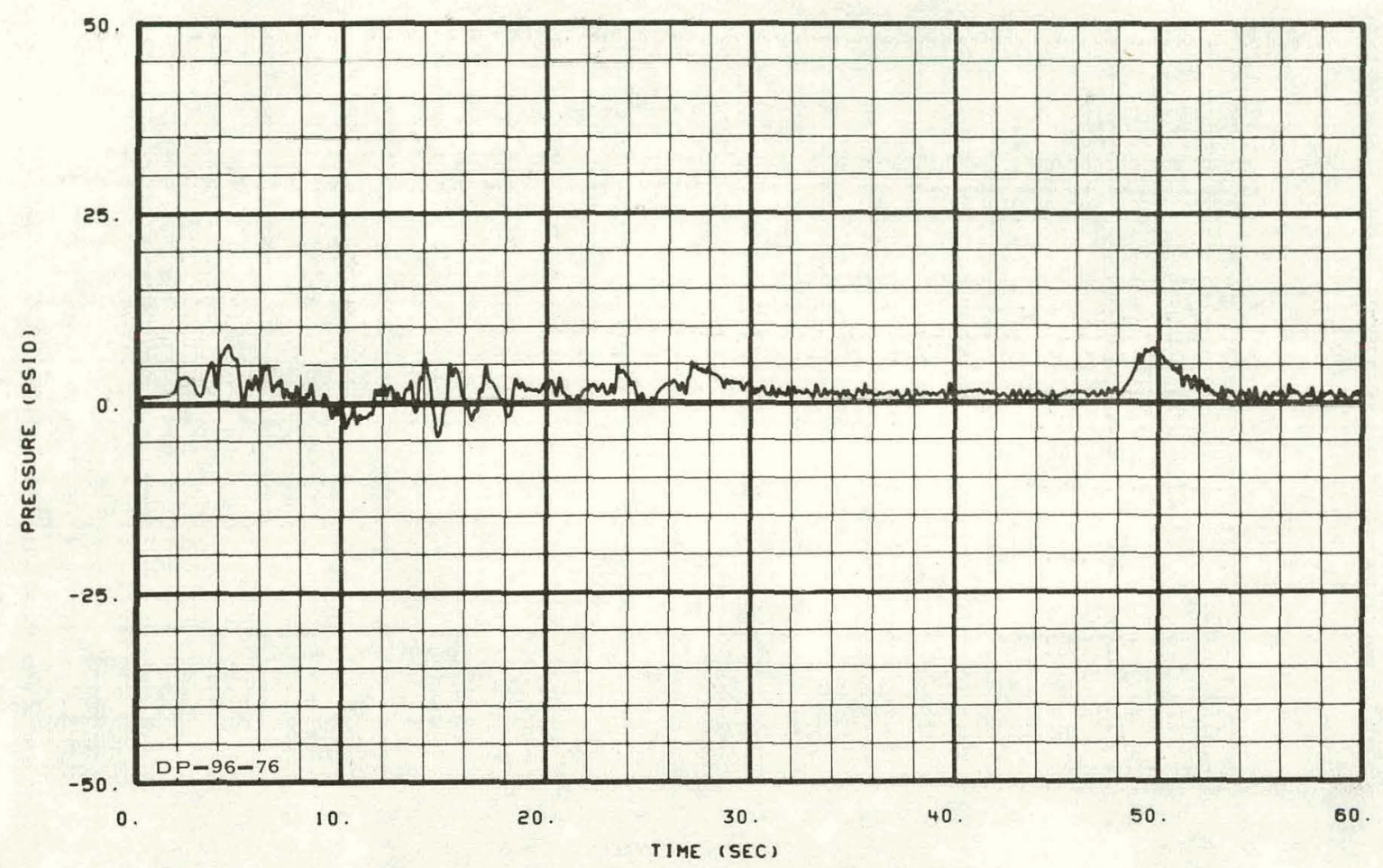

Fig. 314 Differential pressure across simulated pump (DP-96-76) -- Test 15.4 .

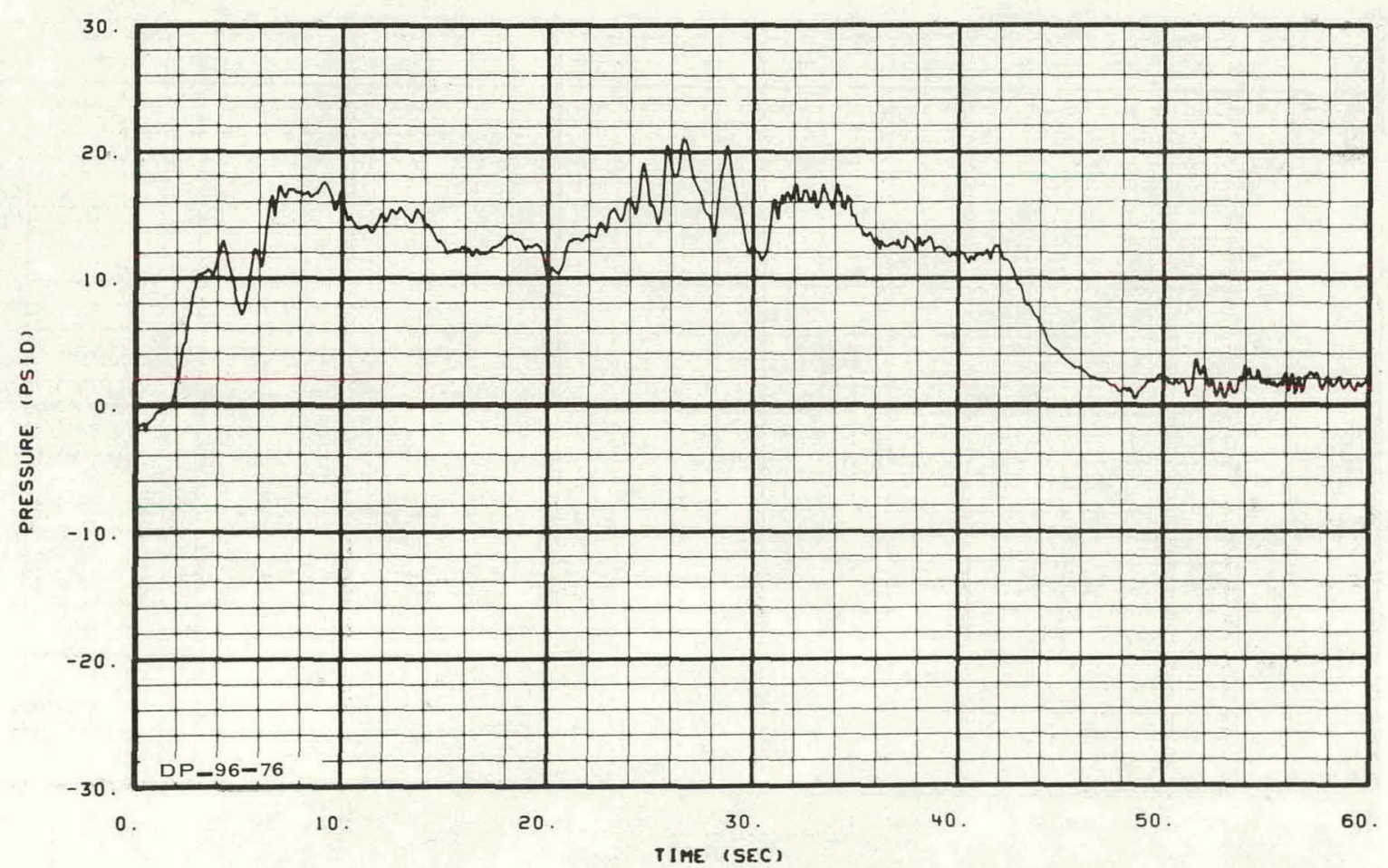

Fig. 315 Differential pressure across simulated pump (DP-96-76) -- Test 15.7 . 


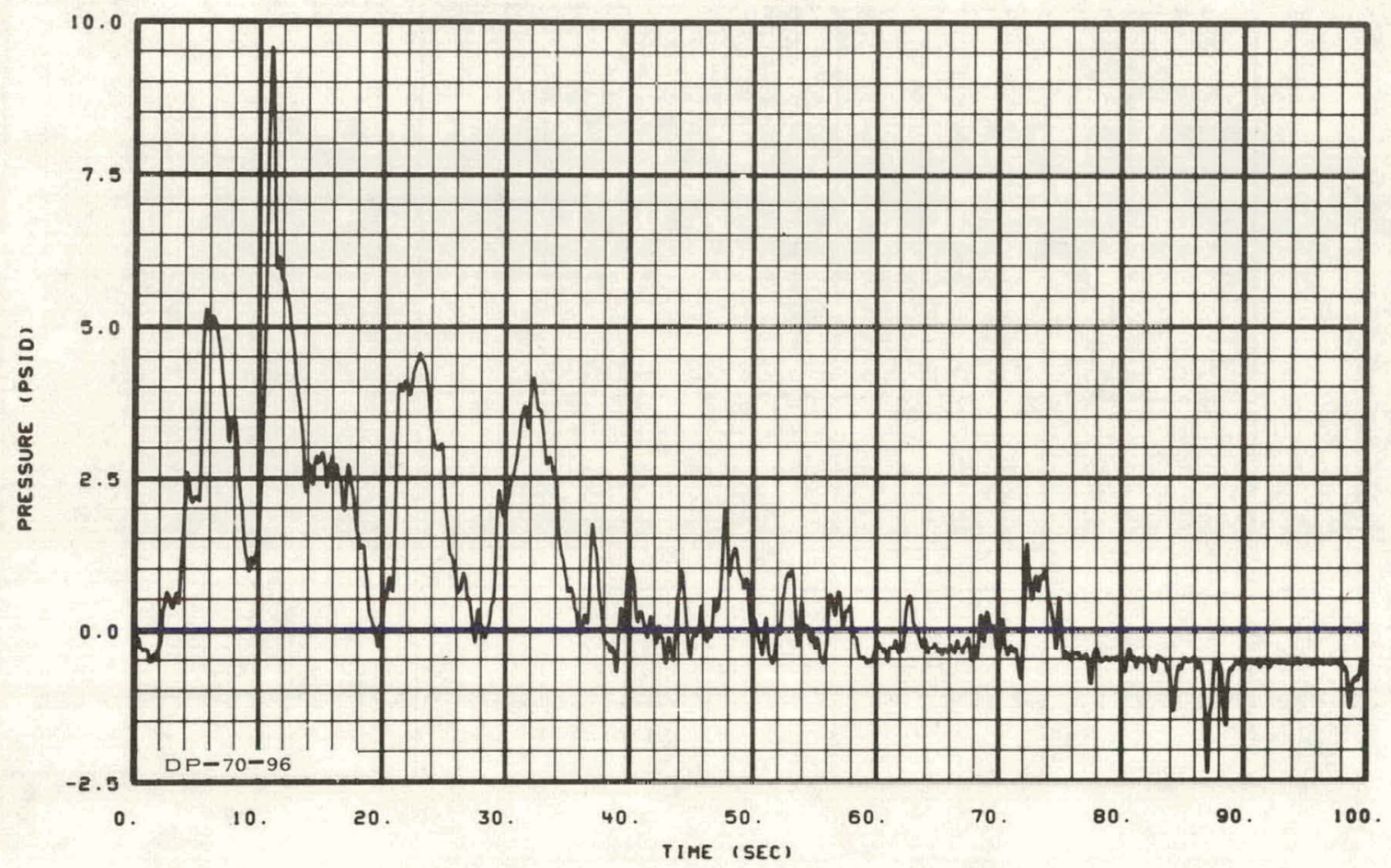

Fig. 316 Differential pressure across simulated steam generator (DP-7096) -- Test 15.1.

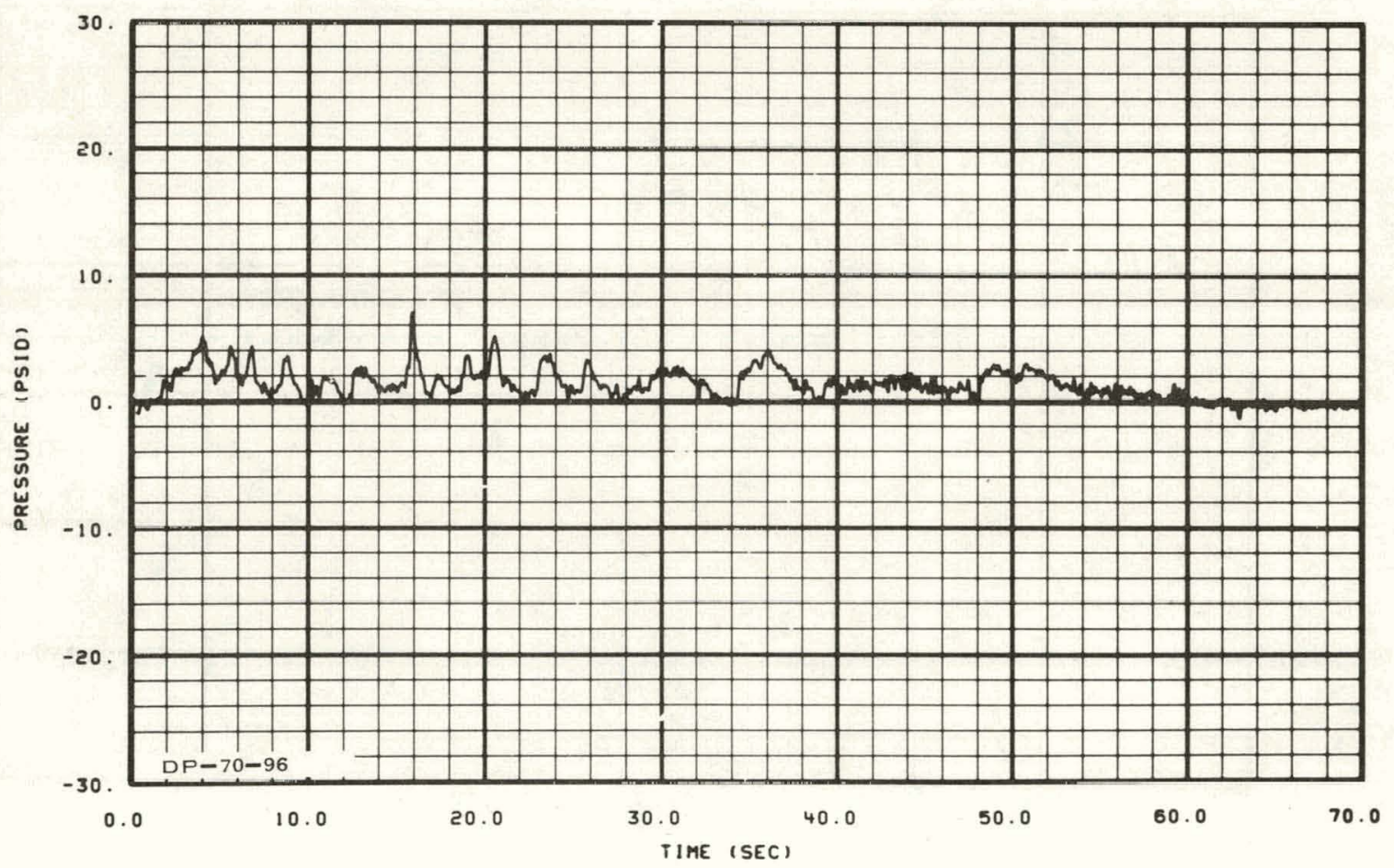

Fig. 317 Differential pressure across simulated steam generator (DP-7096) -- Test 15.2. 


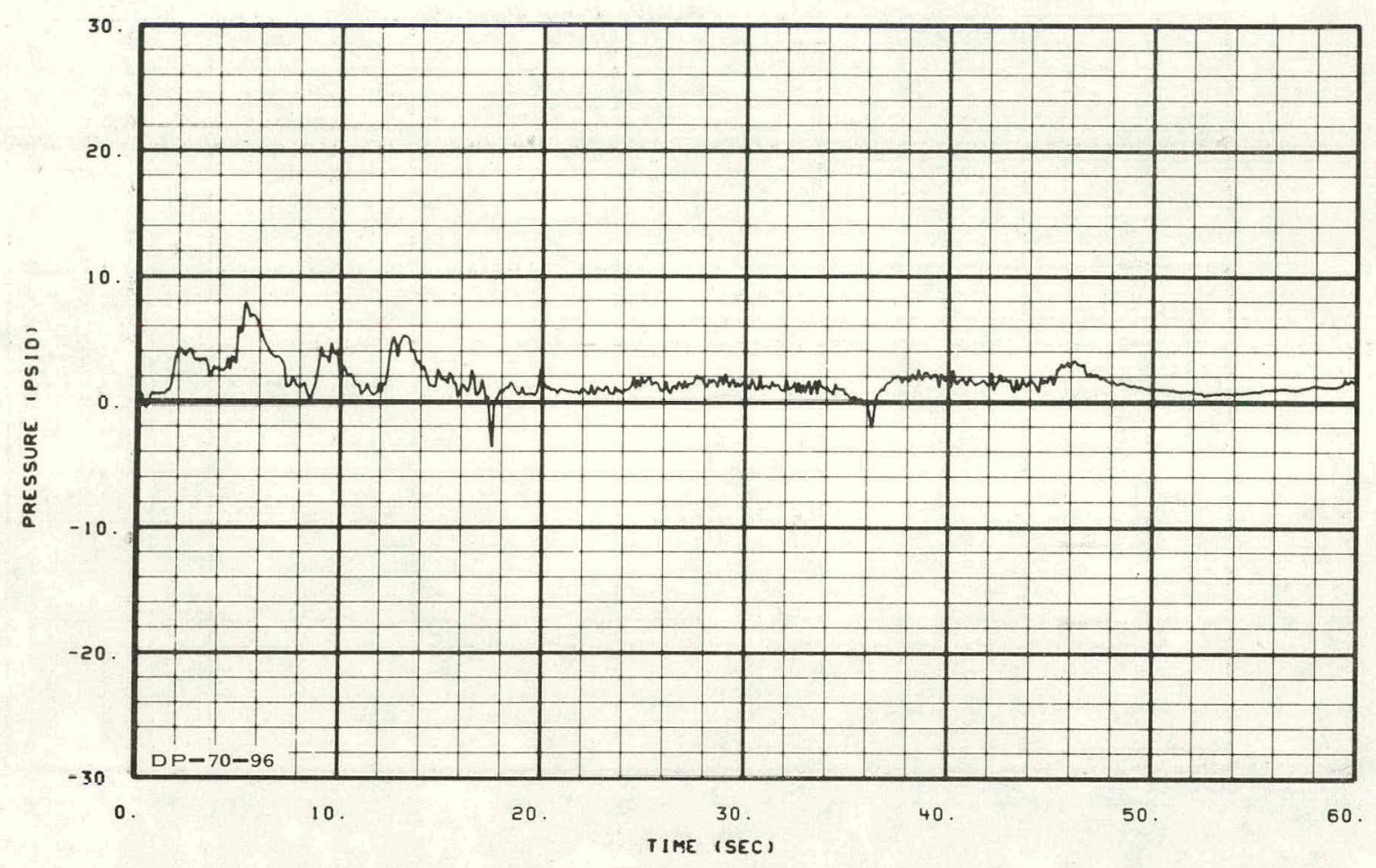

Fig. 318 Differential pressure across simulated steam generator (DP-7096) -- Test 15.3.

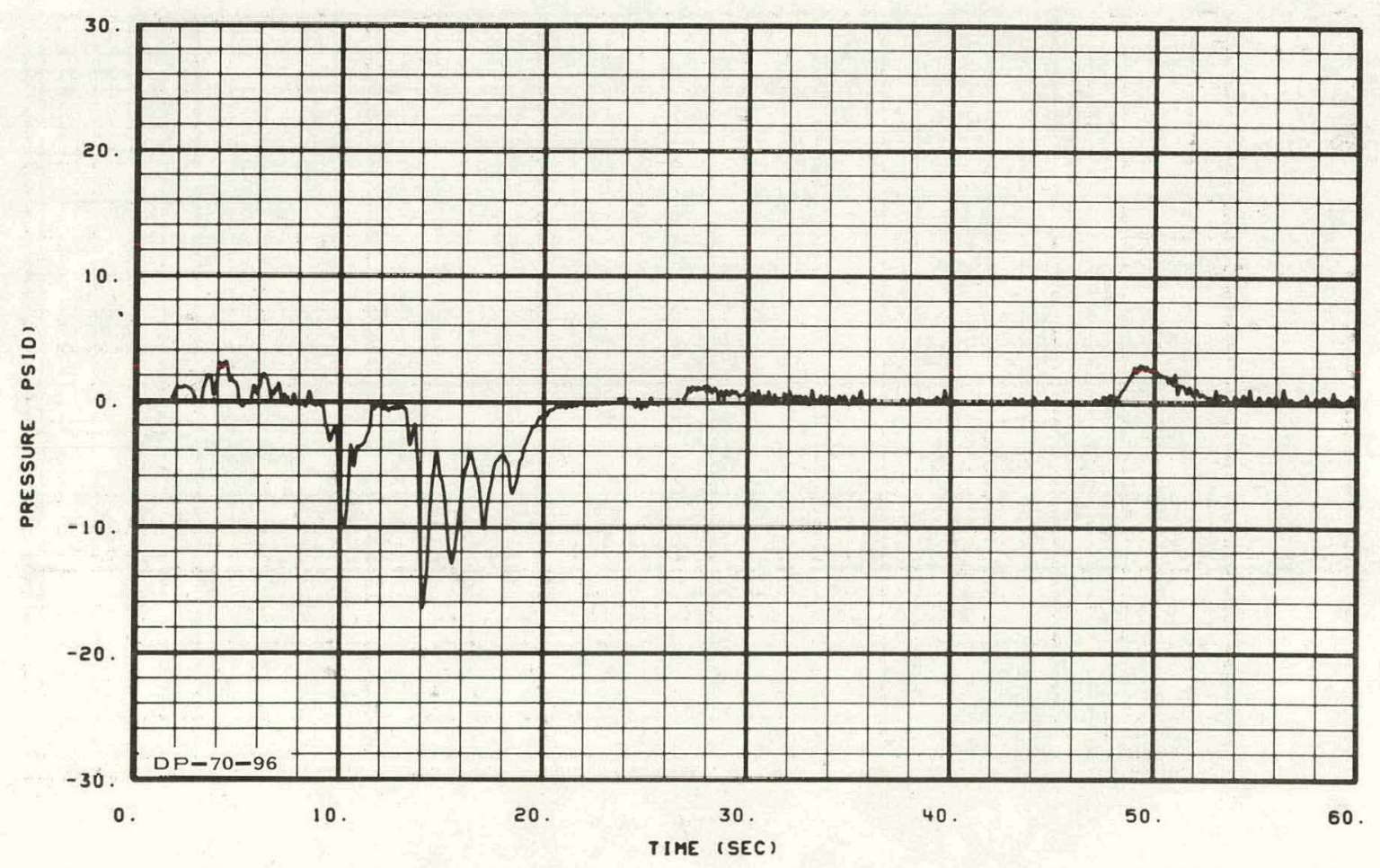

Fig. 319 Differential pressure across simulated steam generator (DP-7096) -- Test 15.4 . 


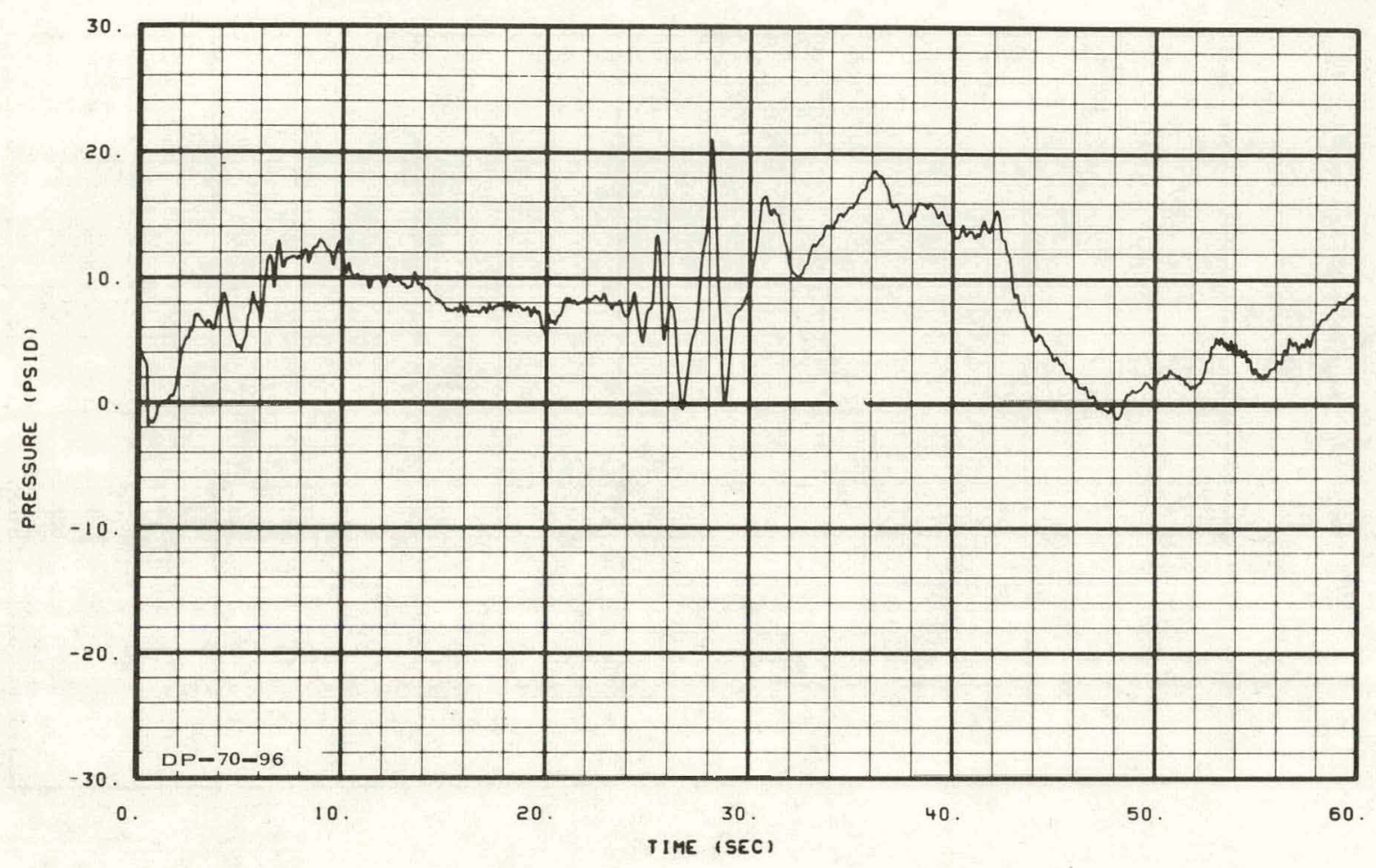

Fig. 320 Differential pressure across simulated steam generator (DP-7096) -- Test 15.7.

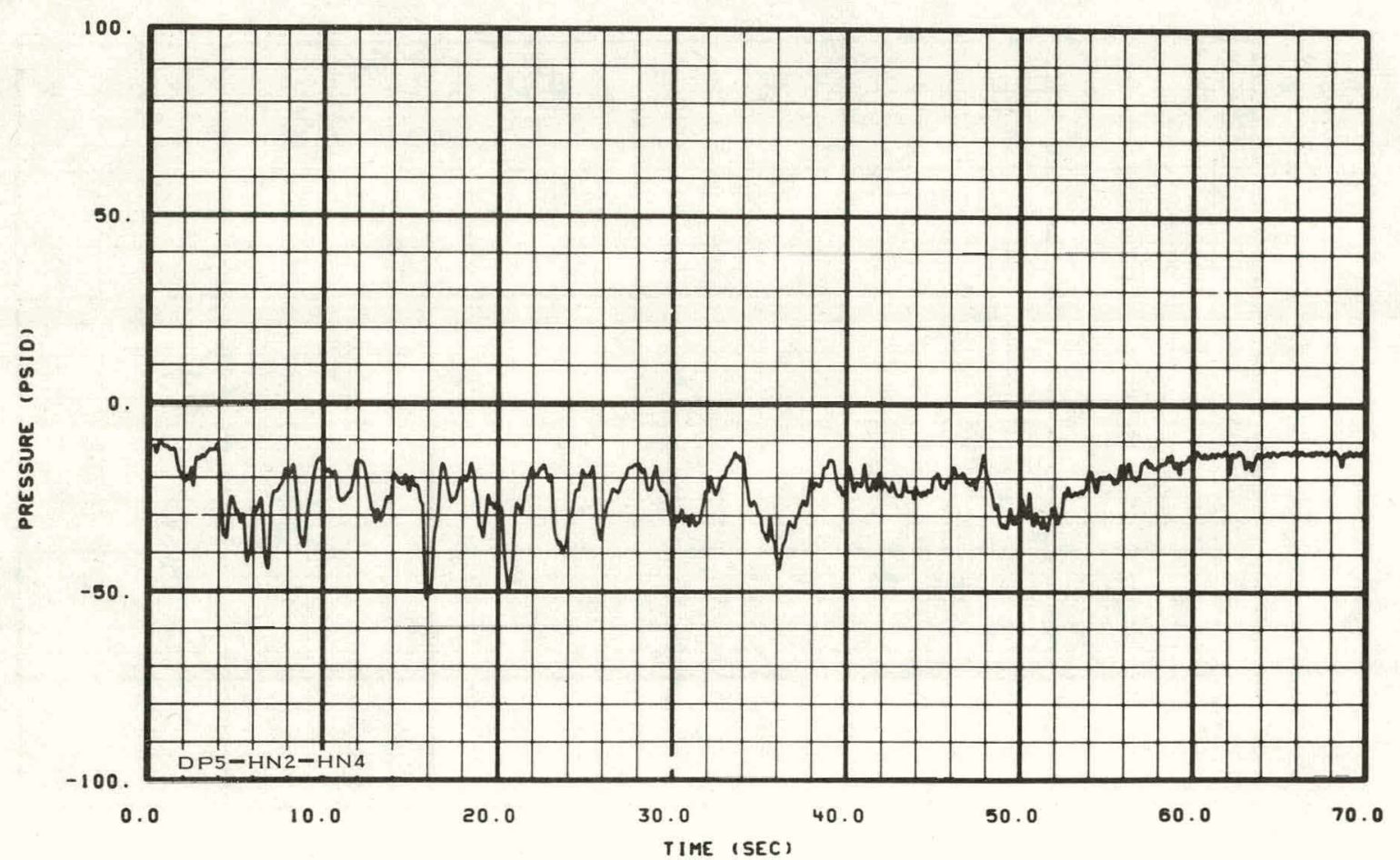

Fig. 321 Differential pressure across blowdown loop cold leg nozzle diverging section (DP5-HN2-HN4) -- Test 15.2. 


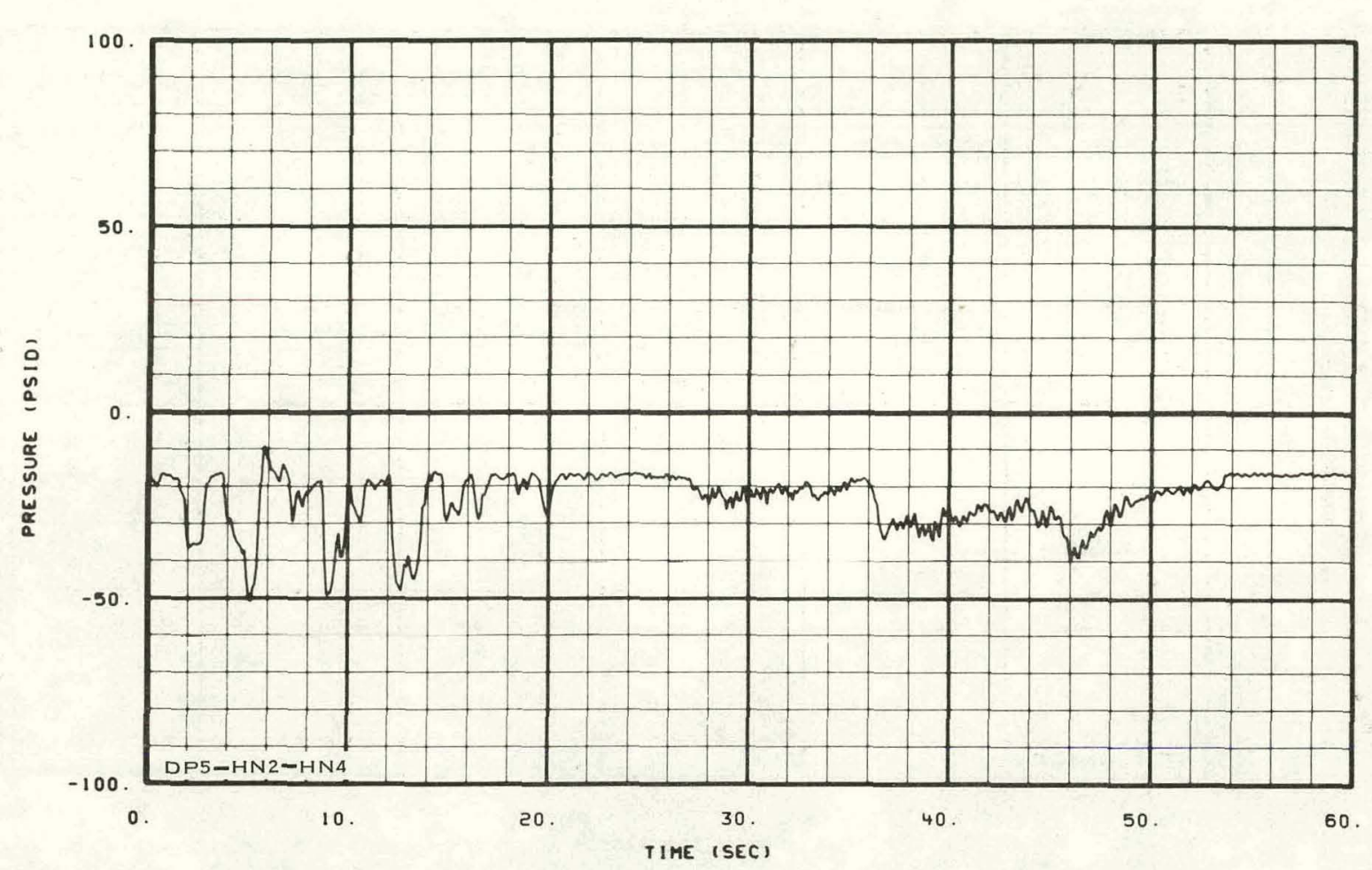

Fig. 322 Differential pressure across blowdown loop cold leg nozzle diverging section (DP5-HN2-HN4) -- Test 15.3 .

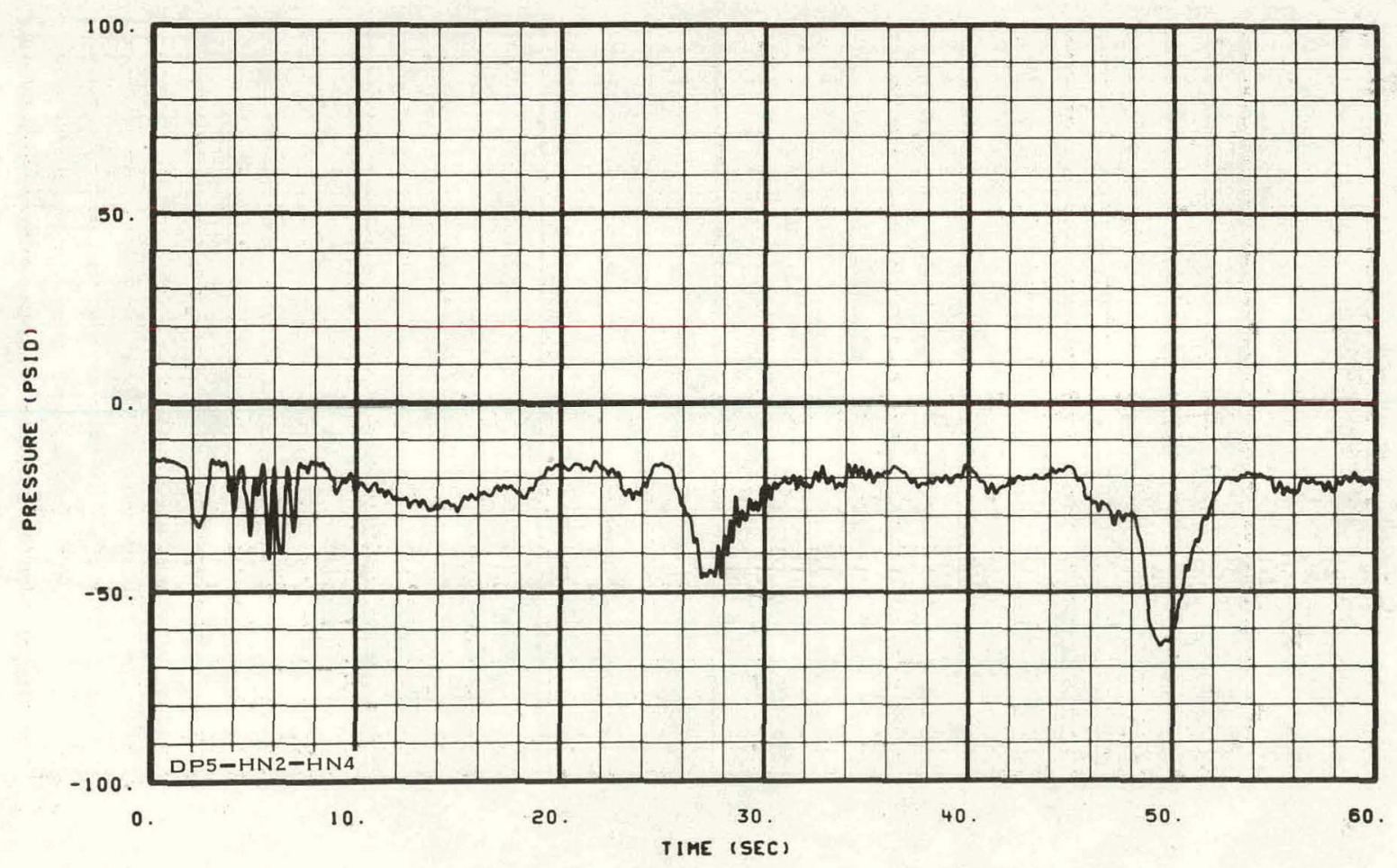

Fig. 323 Differential pressure across blowdown loop cold leg nozzle diverging section (DP5-HN2-HN4) -- Test 15.4 . 


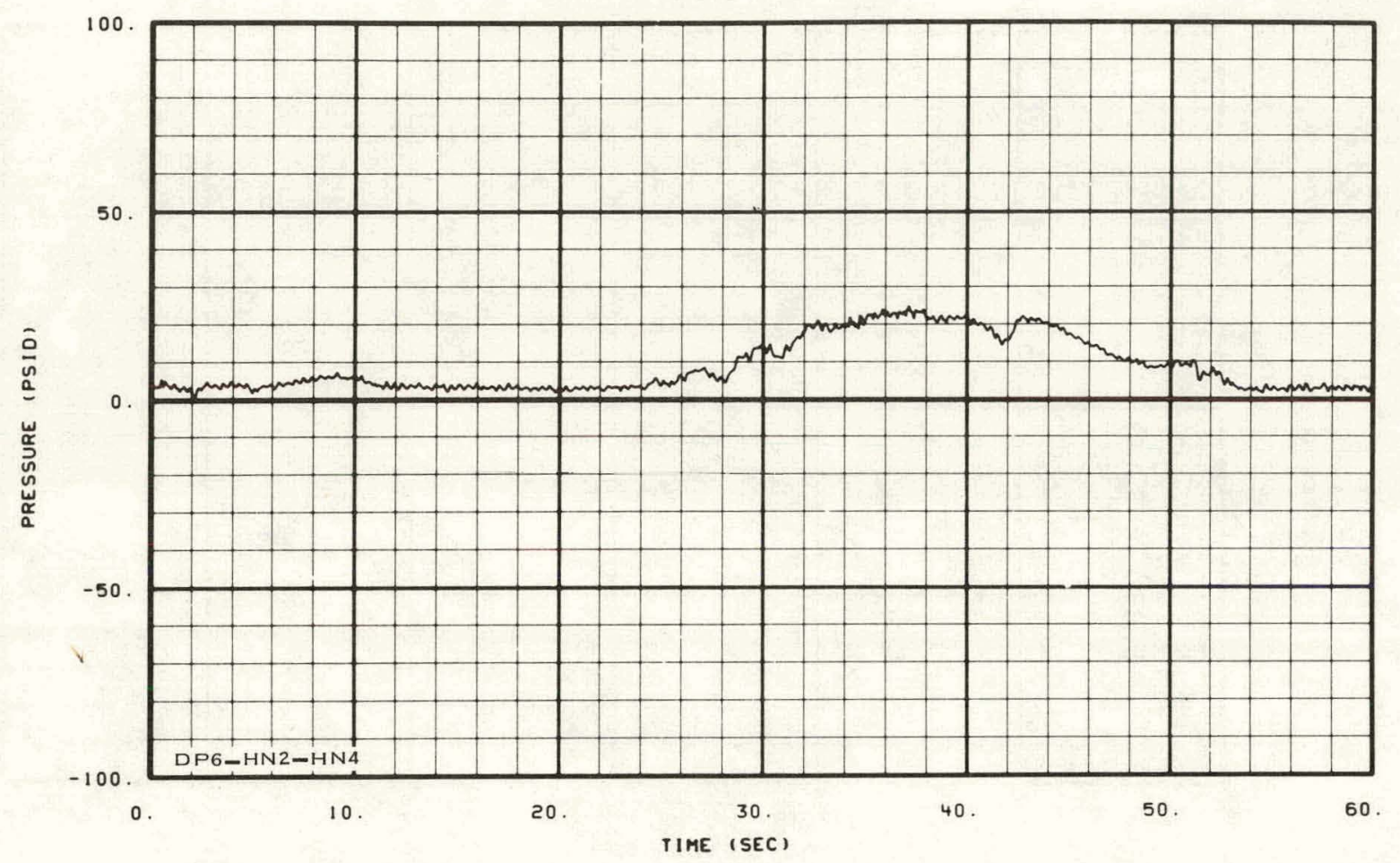

Fig. 324 Differential pressure across blowdown loop hot leg nozzle diverging section (DP6-HN2-HN4) -- Test 15.7 .

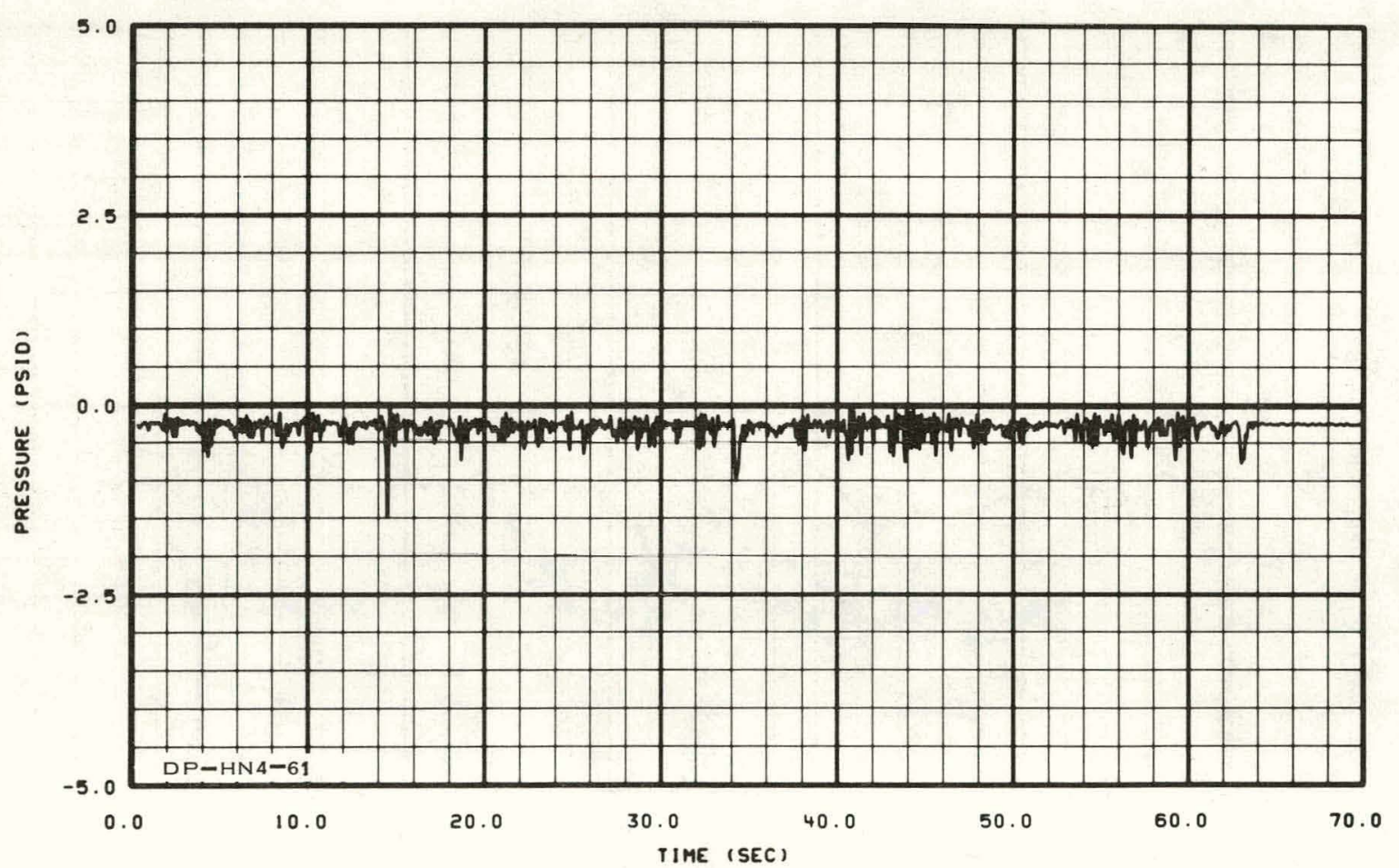

Fig. 325 Differential pressure across blowdown loop hot leg nozzle, Station 61 (DP-HN4-61) -- Test 15.2. 


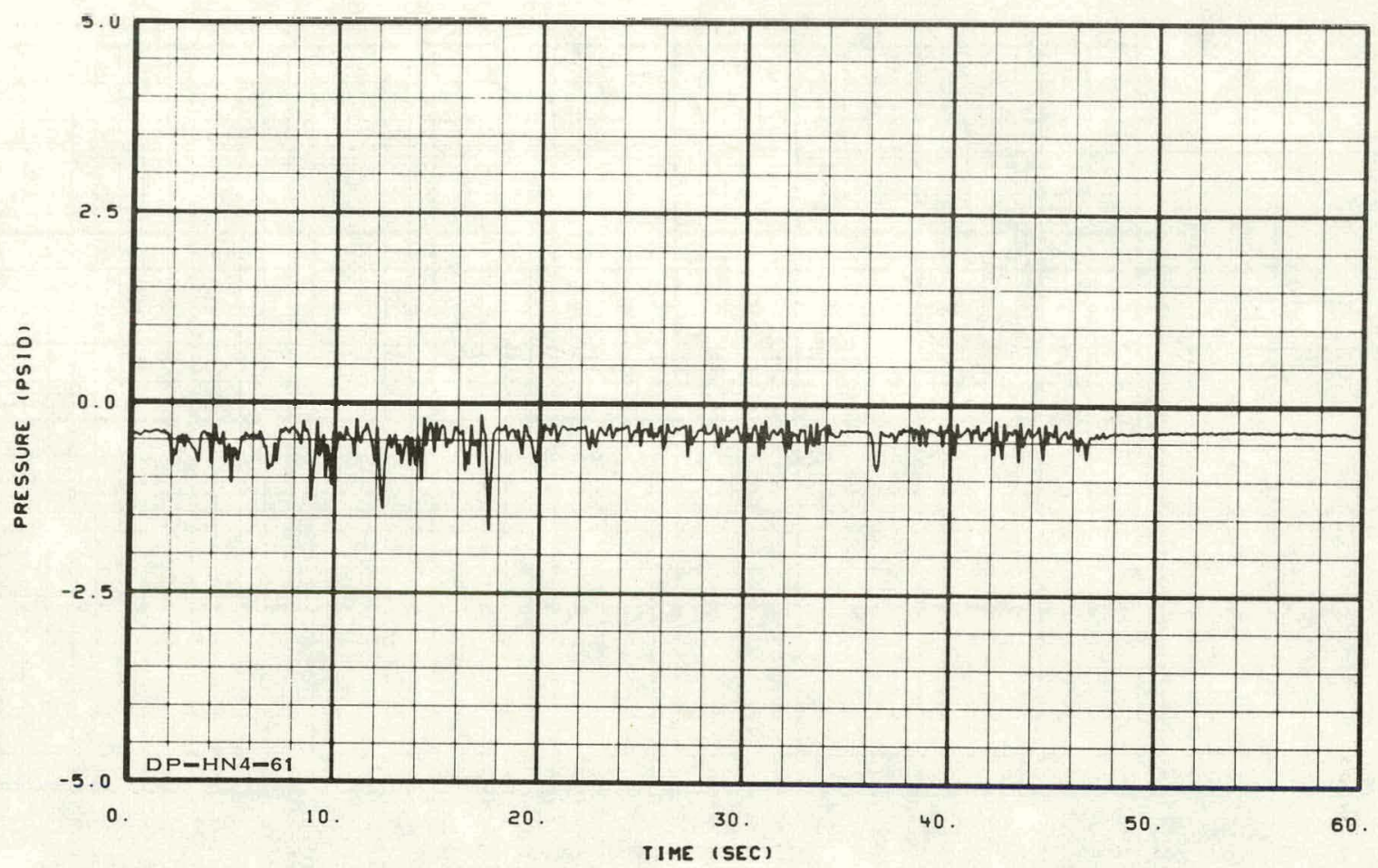

Fig. 326 Differential pressure across blowdown loop hot leg nozzle, Station 61 (DP-HN4-61) -- Test 15.3.

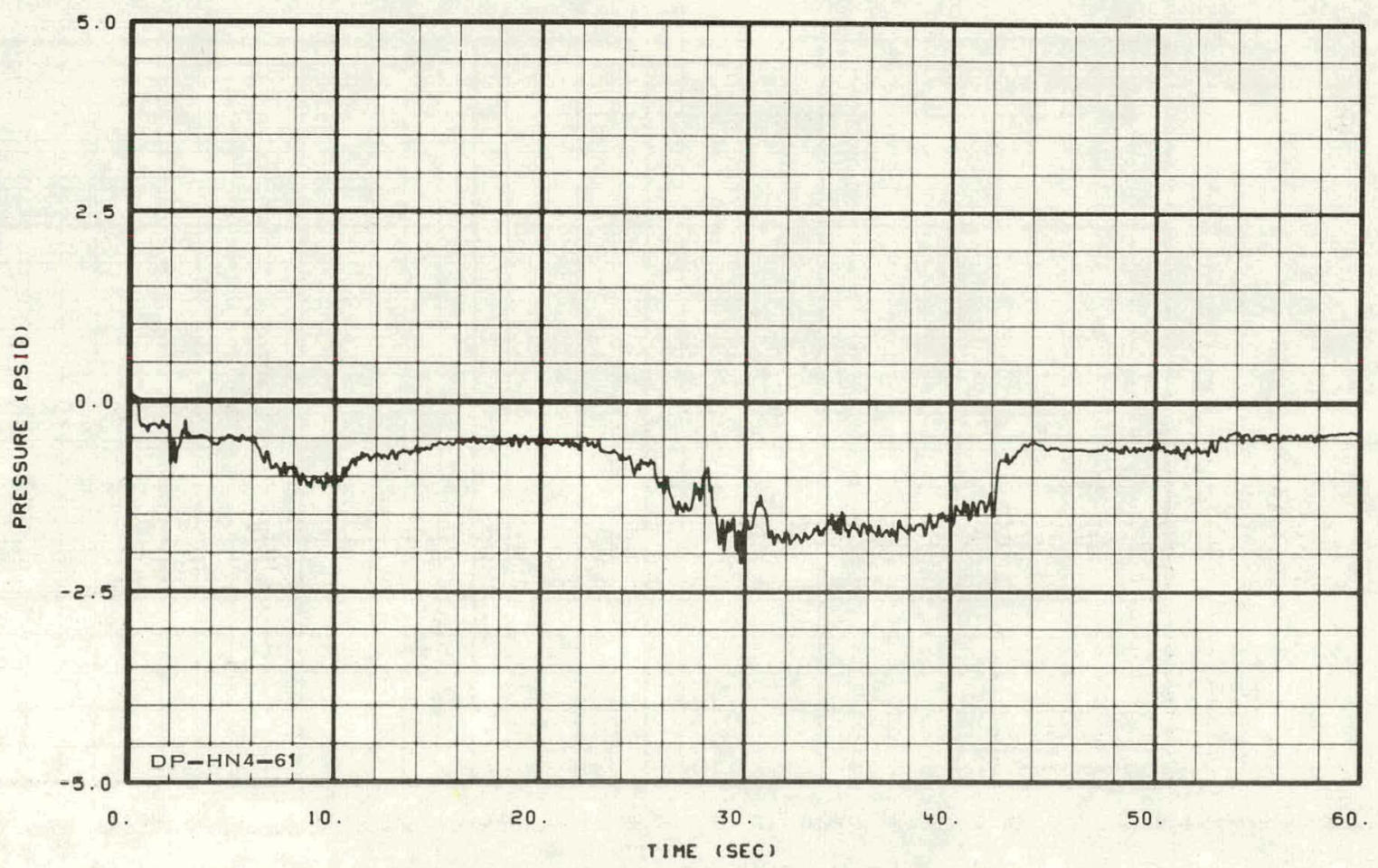

Fig. 327 Differential pressure across blowdown loop hot leg nozzle, Station 61 (DP-HN4-61) -- Test 15.7. 


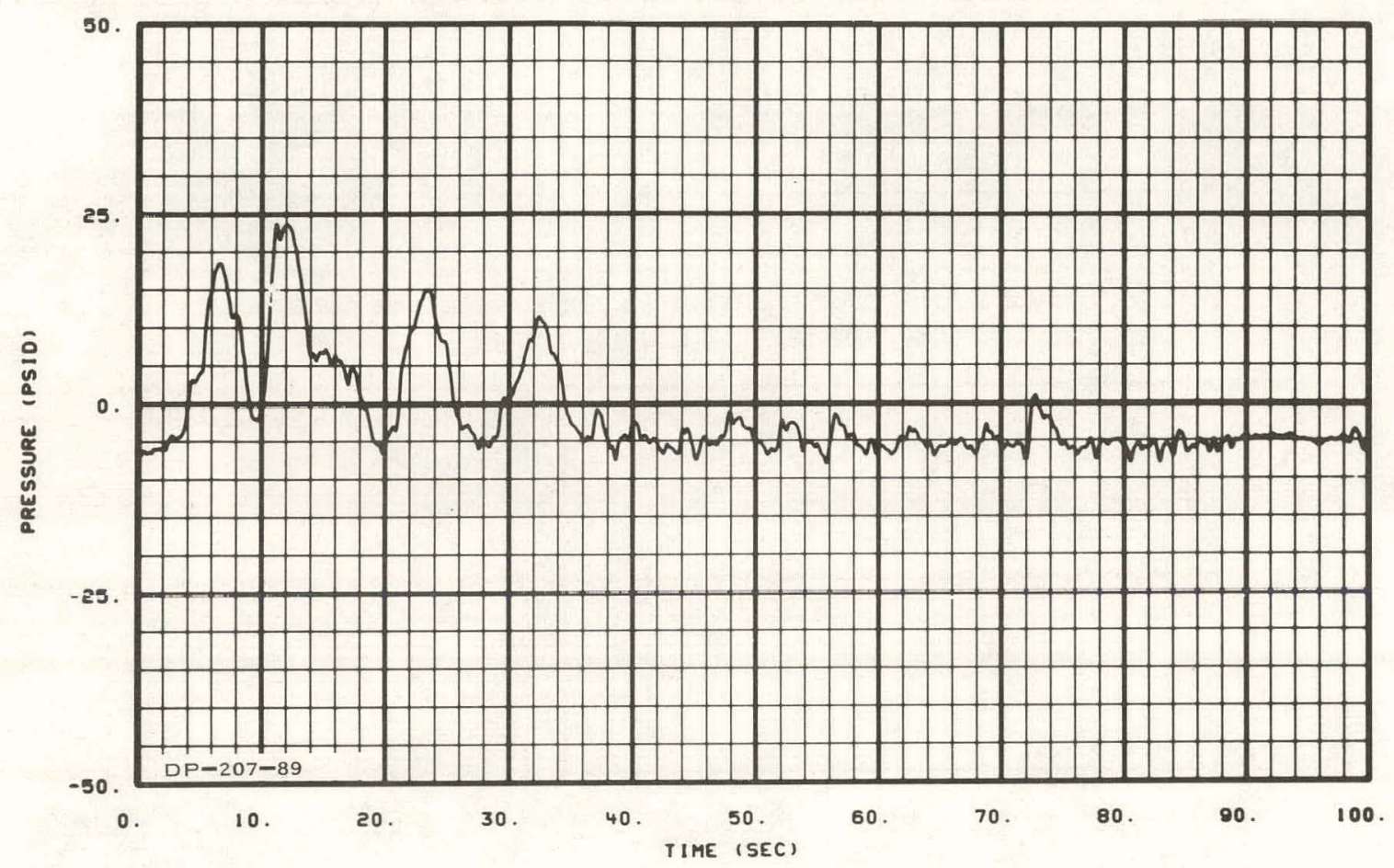

Fig. 328 Differential pressure between vessel upper plenum and pressure suppression tank vapor chamber (DP-207-89) -- Test 15.1 .

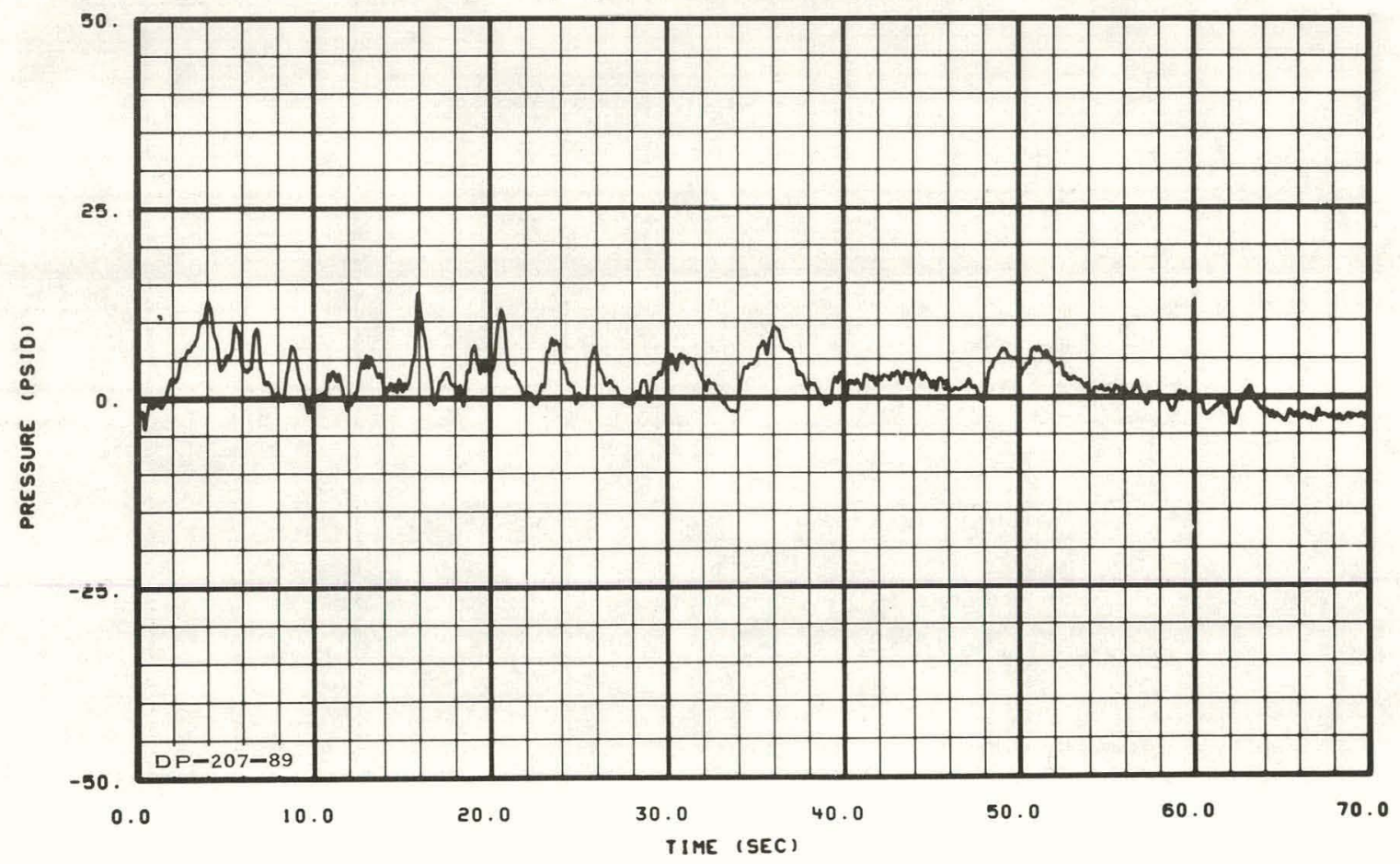

Fig. 329 Differential pressure between vessel upper plenum and pressure suppression tank vapor chamber (DP-207-89) -- Test 15.2. 


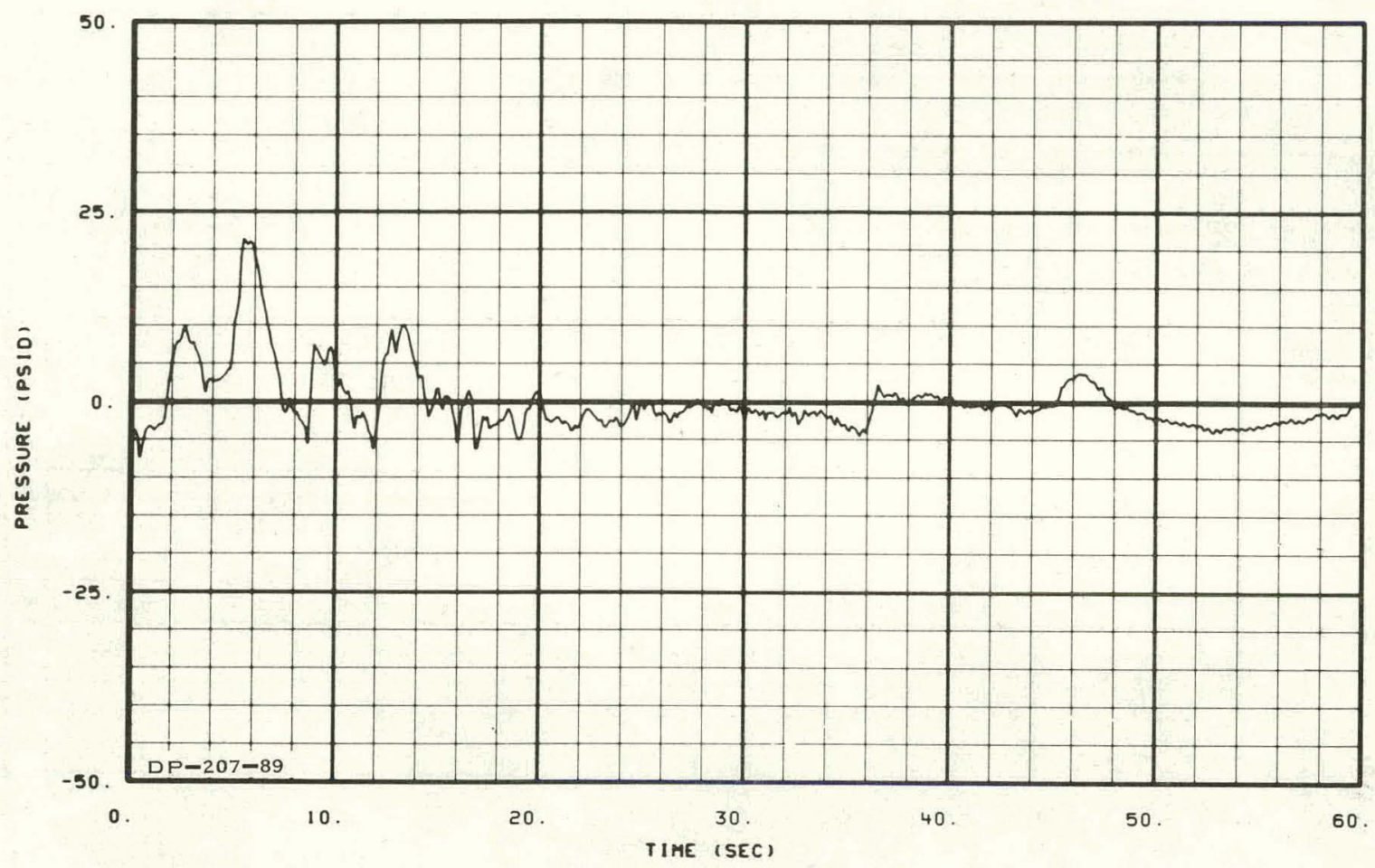

Fig. 330 Differential pressure between vessel upper plenum and pressure suppression tank vapor chamber (DP-207-89) -- Test 15.3.

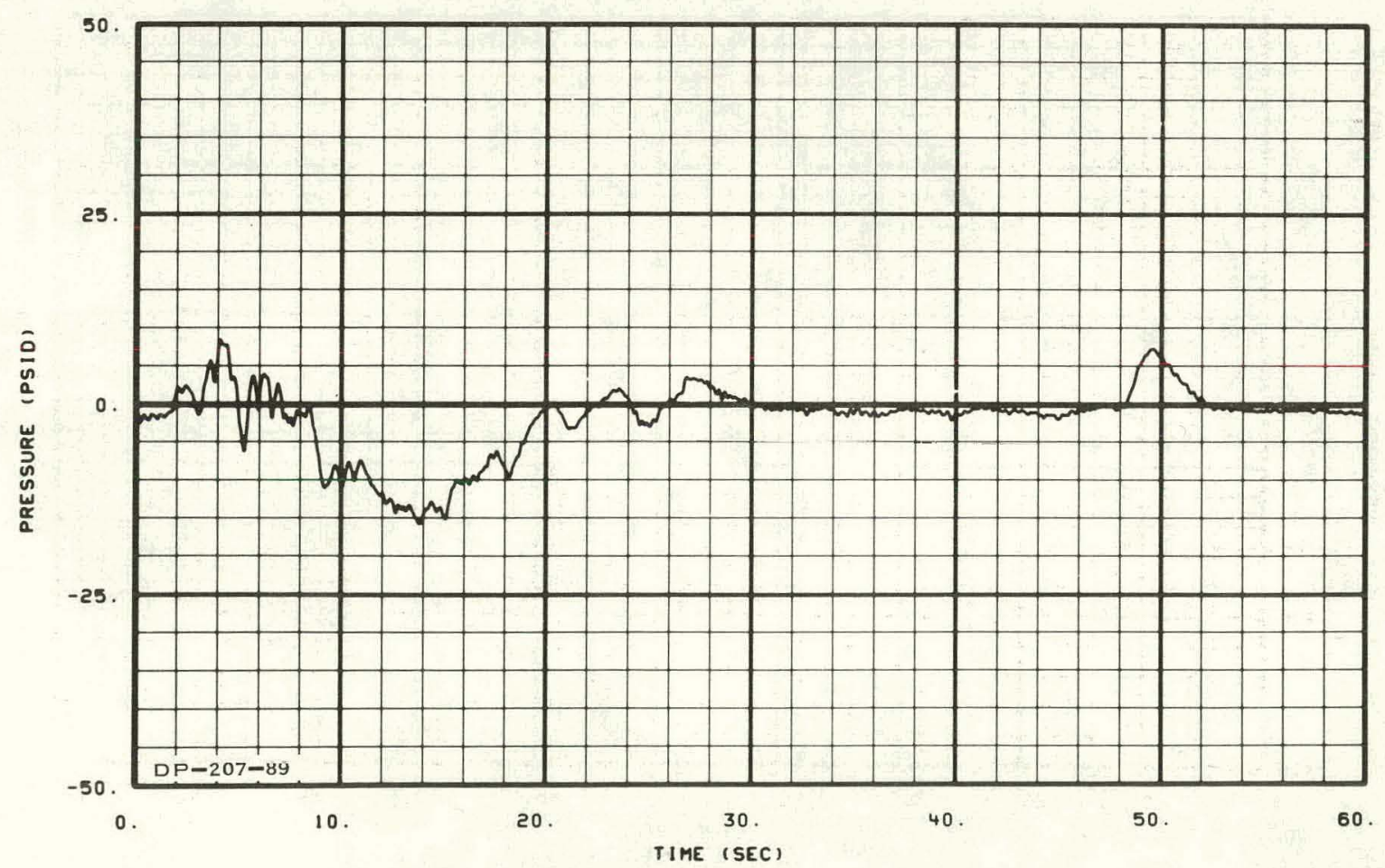

Fig. 331 Differential pressure between vessel upper plenum and pressure suppression tank vapor chamber (DP-207-89) -- Test 15.4 . 


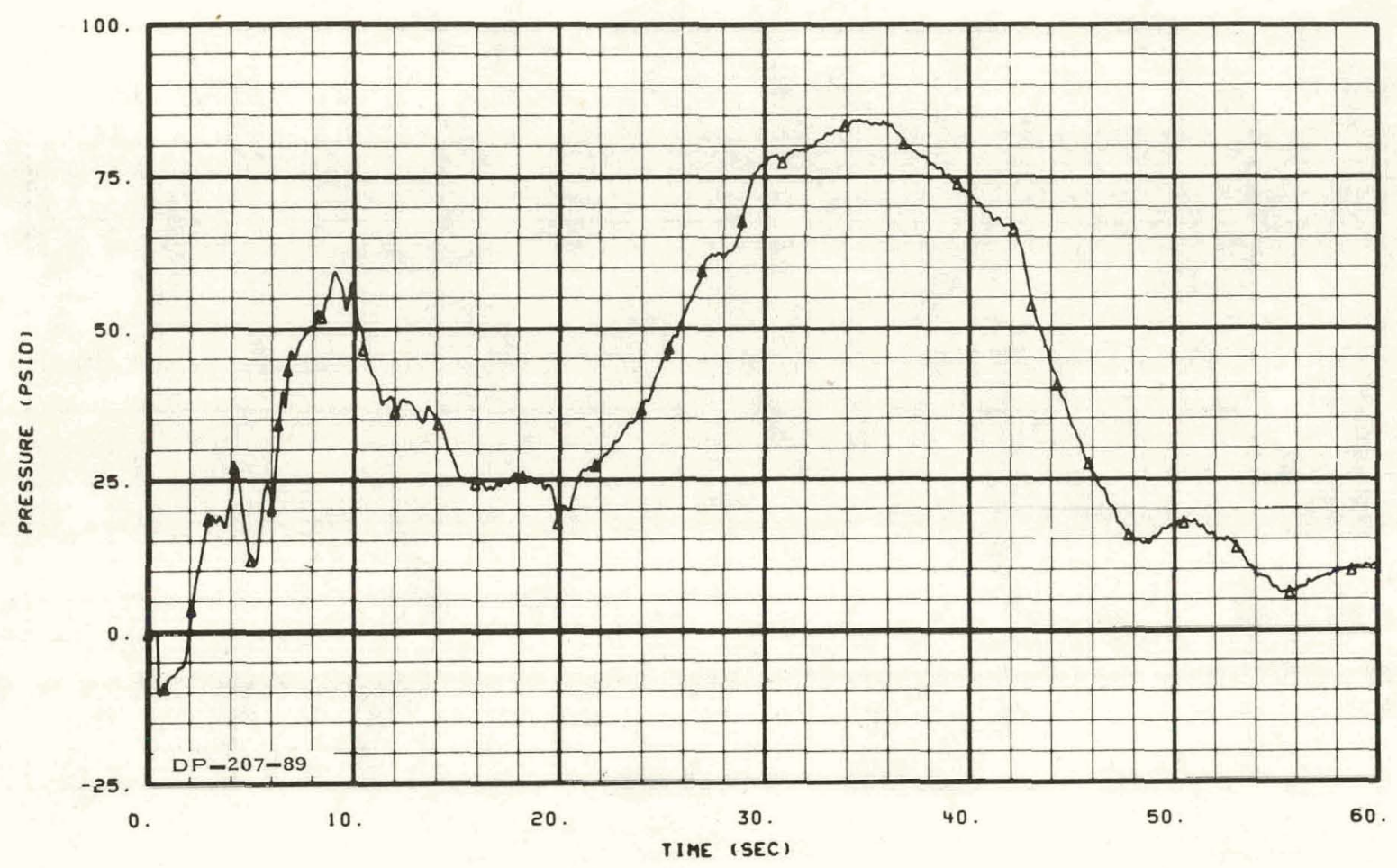

Fig. 332 Differential pressure between vessel upper plenum and pressure suppression tank vapor chamber (DP-207-89) -- Test 15.7.

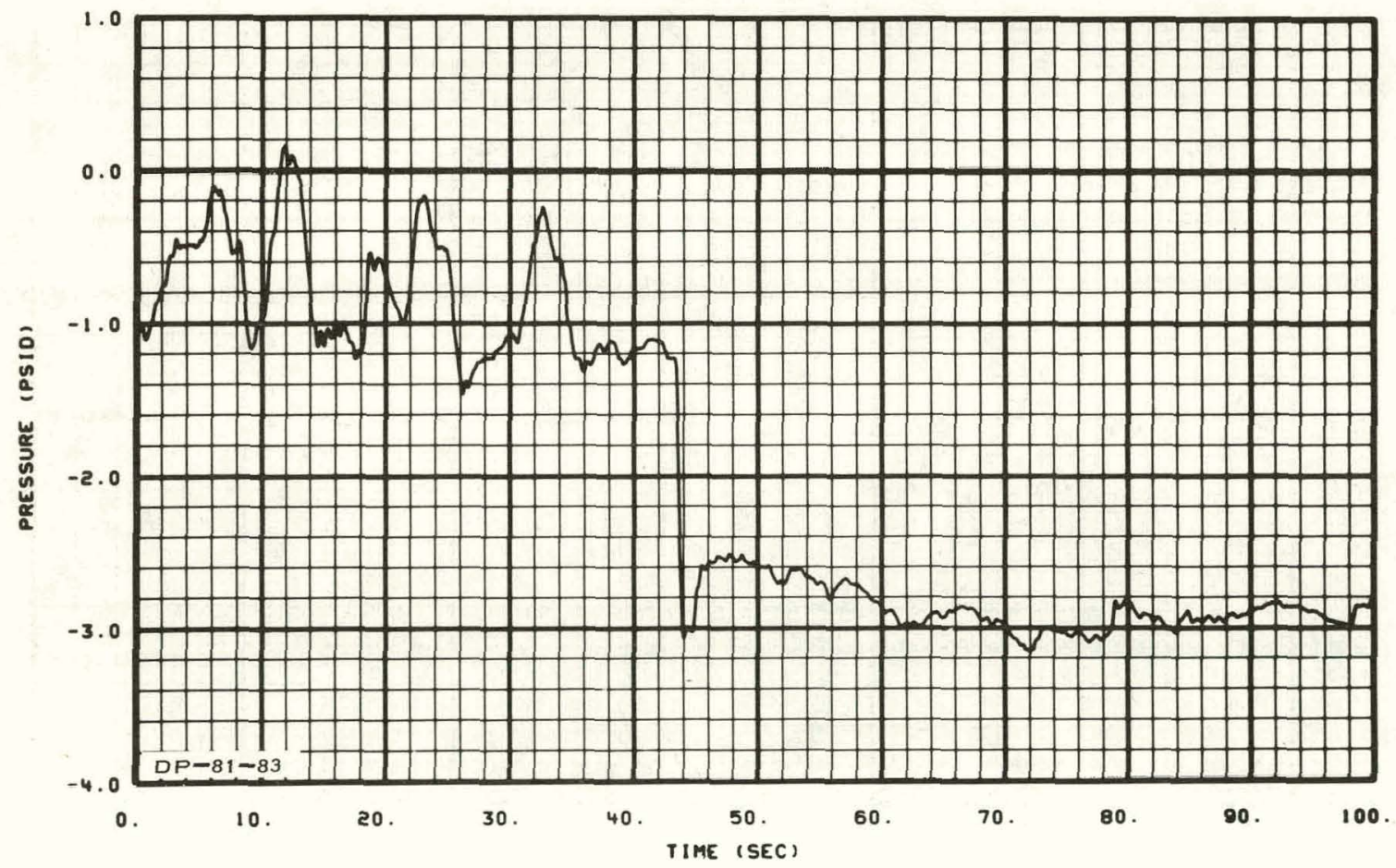

Fig. 333 Differential pressure between pressure suppression header and pressure suppression tank downcomer entrance (DP-81-83) -- Test 15.1. 


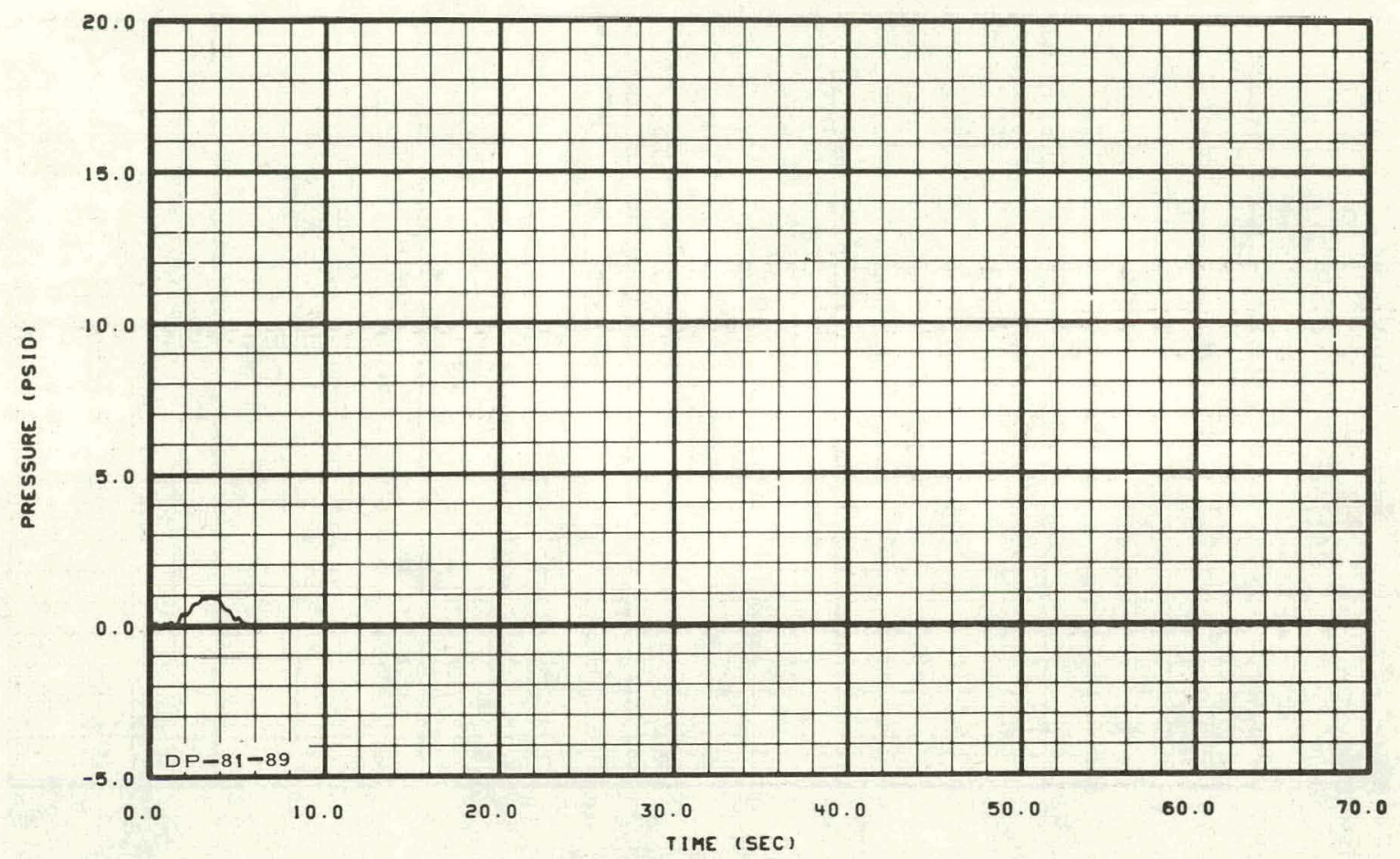

Fig. 334 Differential pressure between pressure suppression header and pressure suppression tank vapor chamber (DP-81-89) -- Test 15.2.

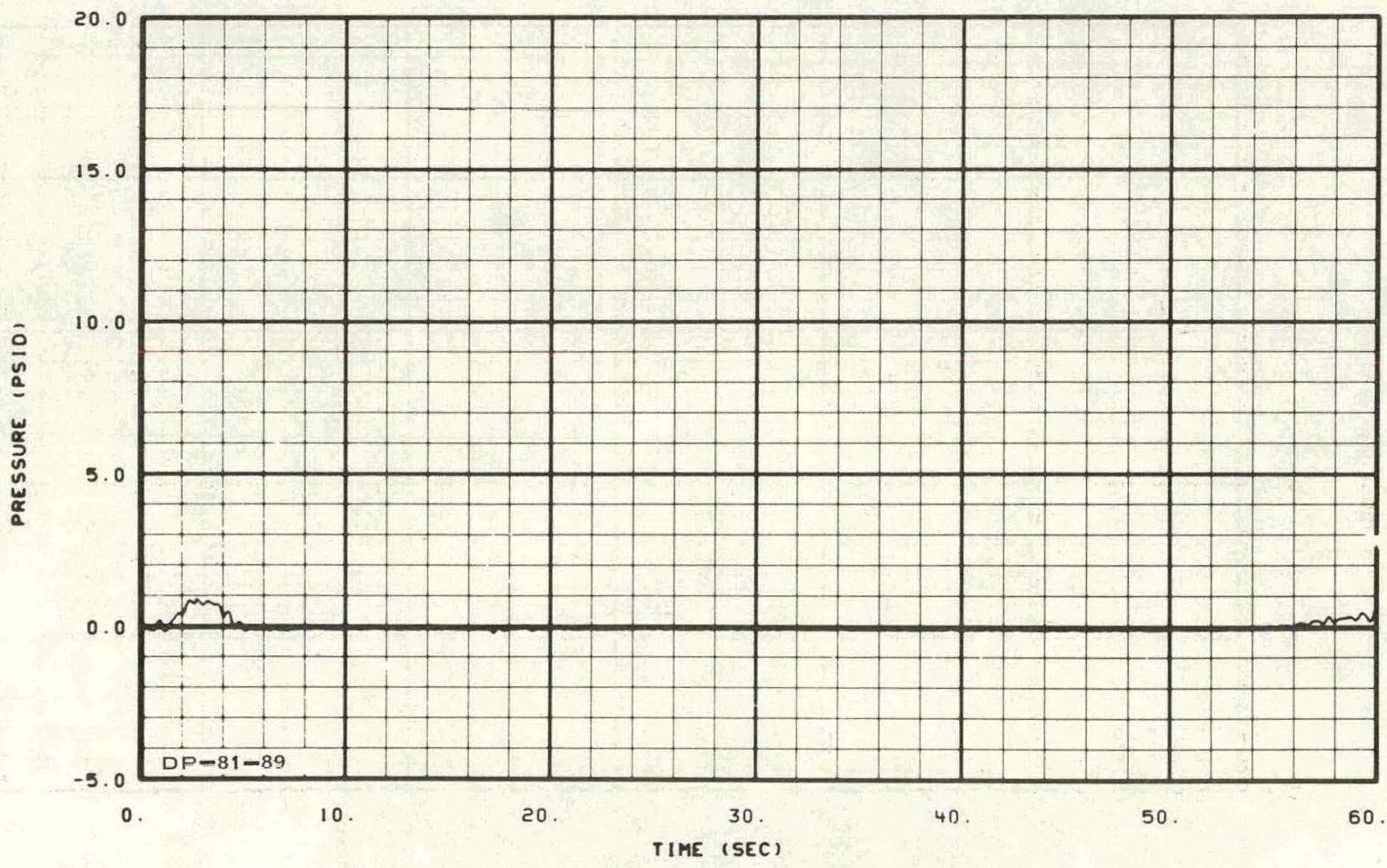

Fig. 335 Differential pressure between pressure suppression header and pressure suppression tank vapor chamber (DP-81-89) -- Test 15.3. 


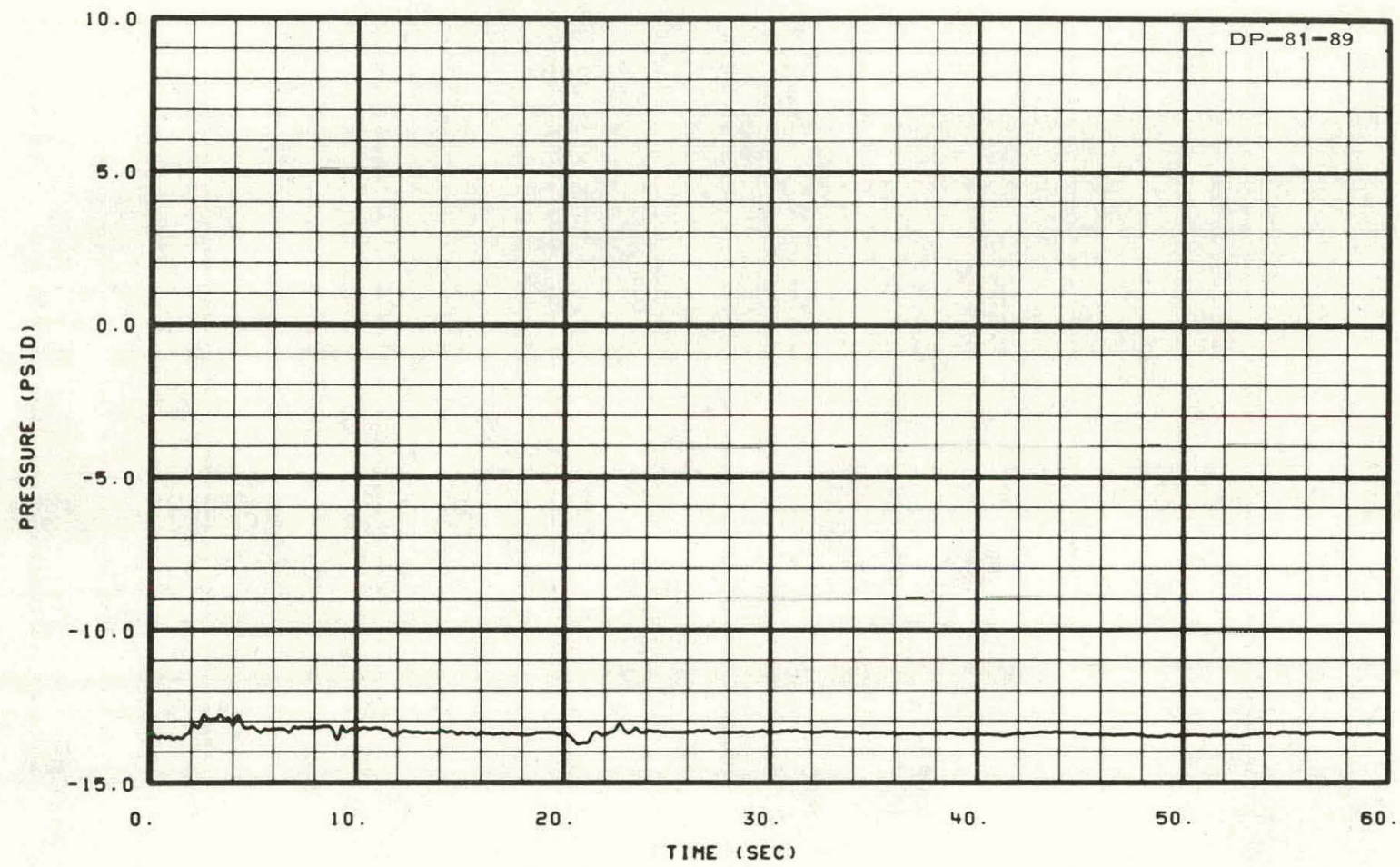

Fig. 336 Differential pressure between pressure suppression header and pressure suppression tank vapor chamber (DP-81-89) -- Test 15.4.

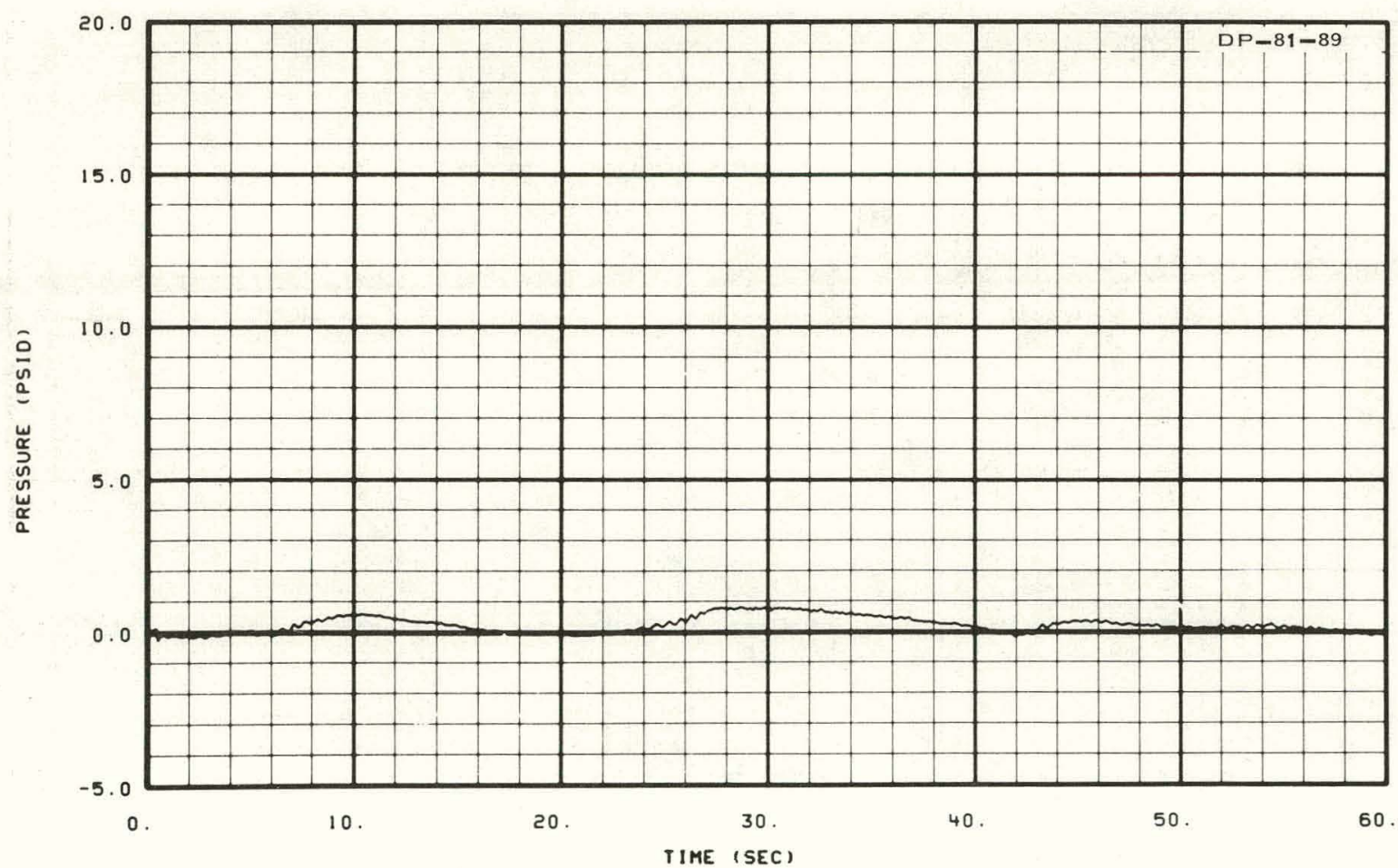

Fig. 337 Differential pressure between pressure suppression header and pressure suppression tank vapor chamber (DP-81-89) -- Test 15.7 . 


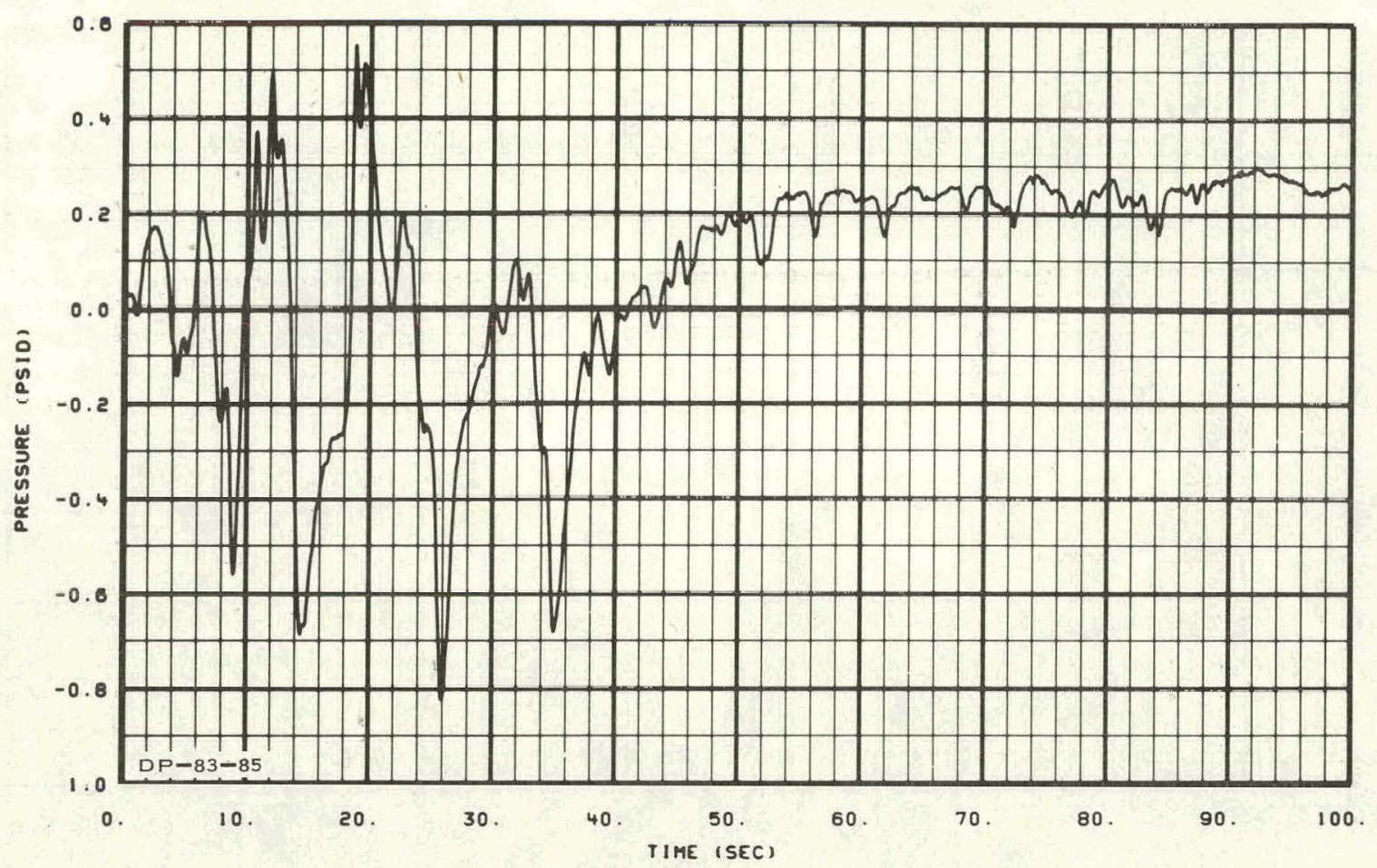

Fig. 338 Differential pressure between pressure suppression tank downcomer entrance and exit (DP-83-85) -- Test 15.1.

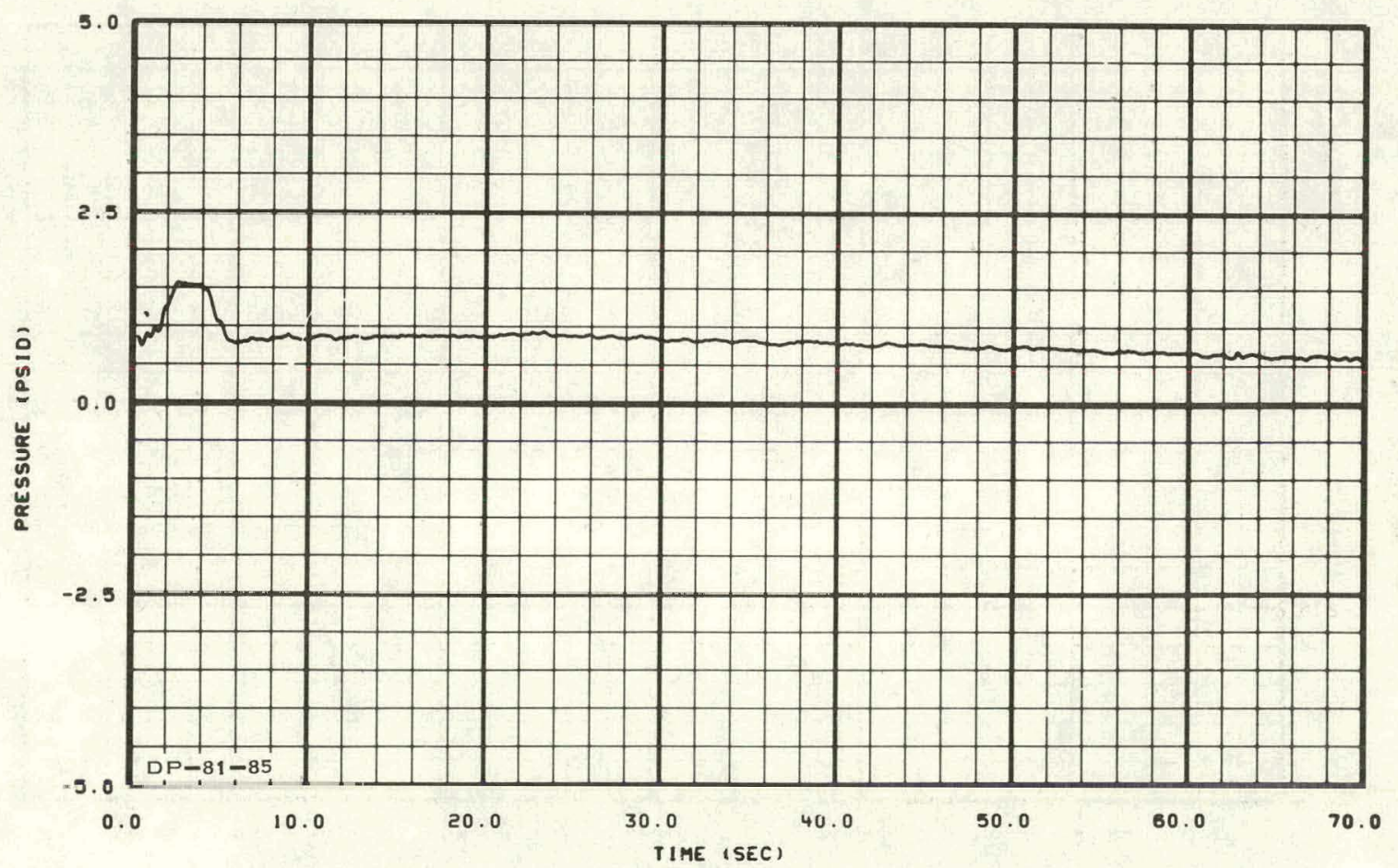

Fig. 339 Differential pressure between pressure suppression header and pressure suppression tank downcomer exit (DP-81-85) -- Test 15.2. 


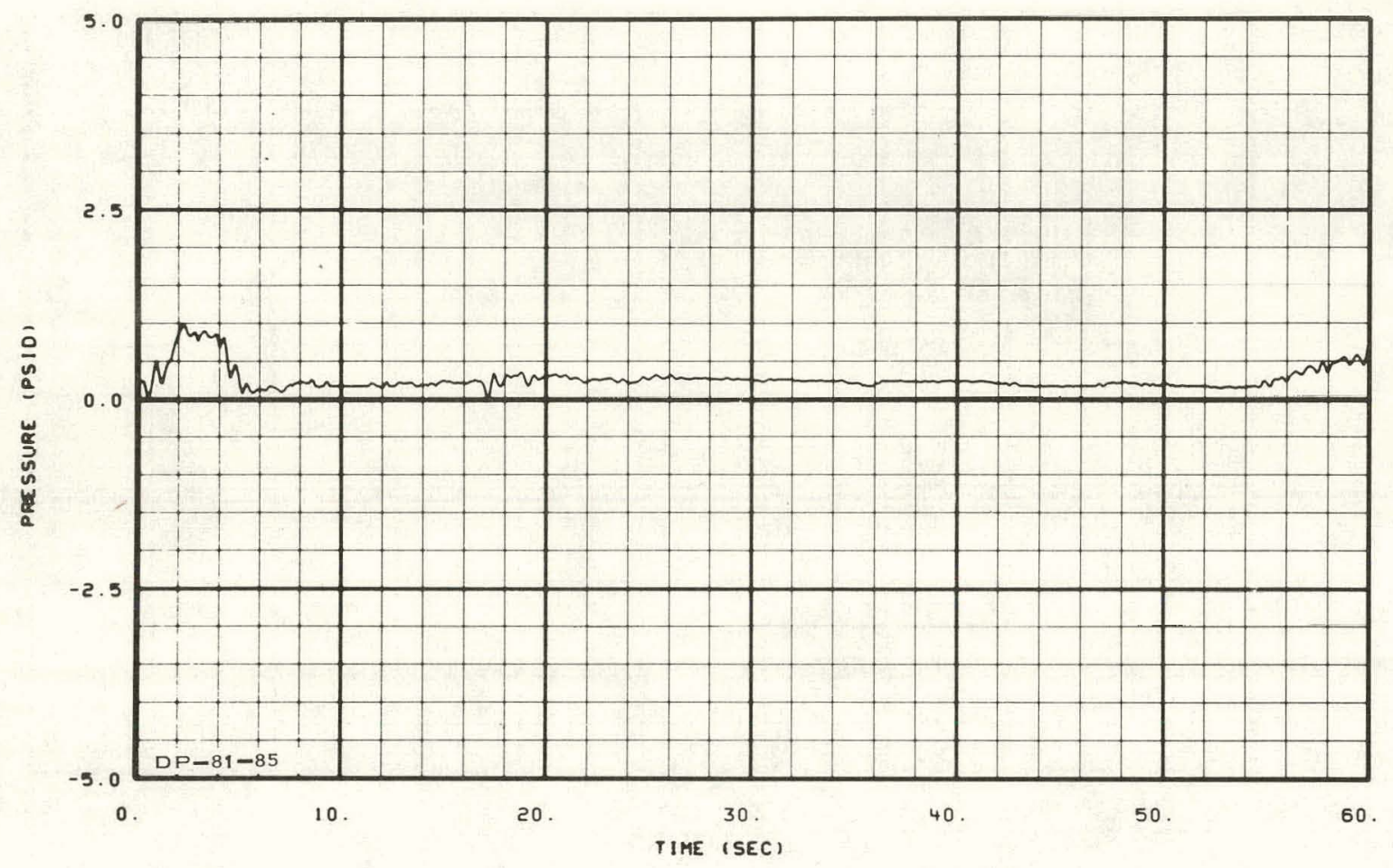

Fig. 340 Differential pressure between pressure suppression header and pressure suppression tank downcomer exit (DP-81-85) -- Test 15.3..

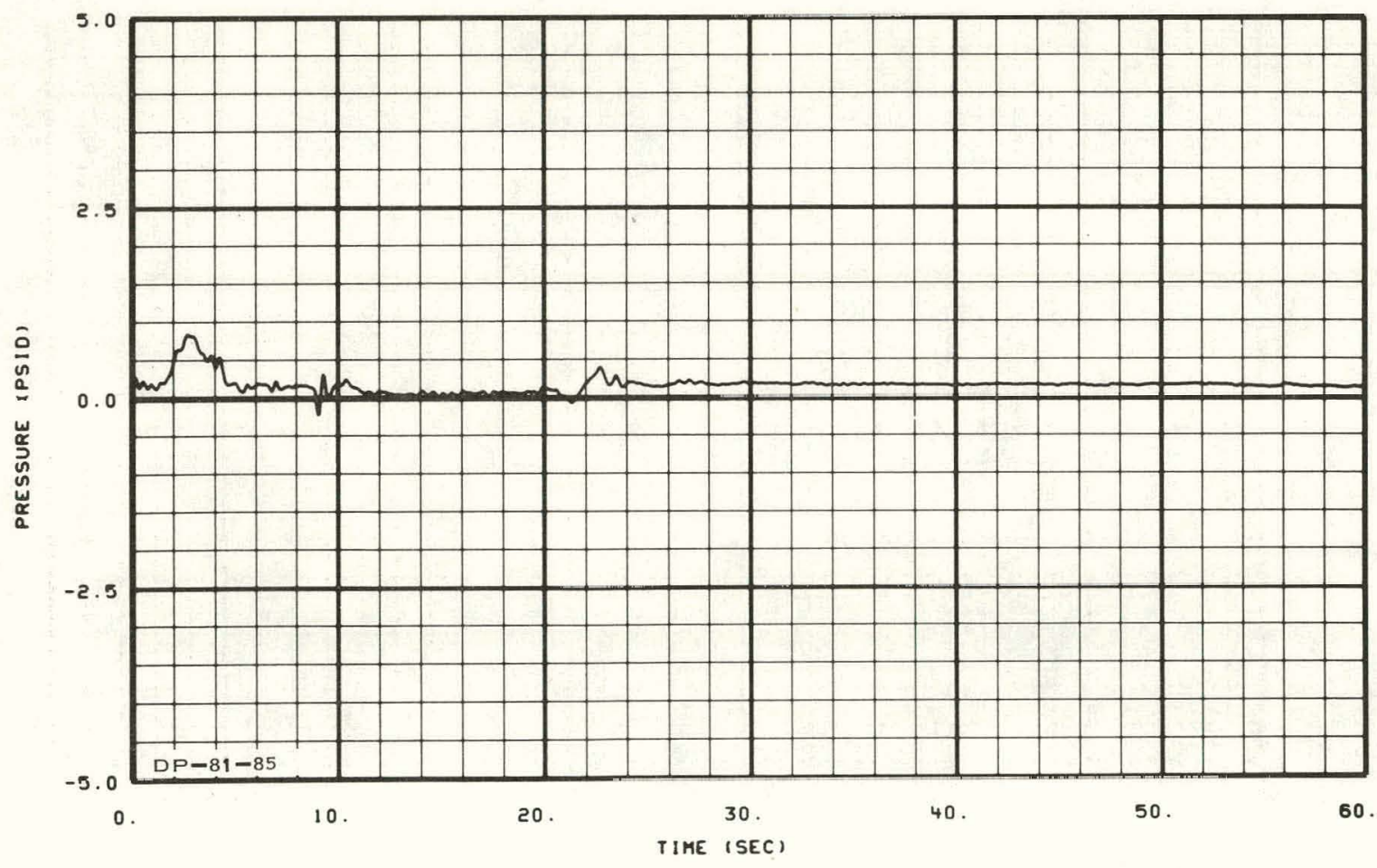

Fig. 341 Differential pressure between pressure suppression header and pressure suppression tank downcomer exit (DP-81-85) -- Test 15.4. 


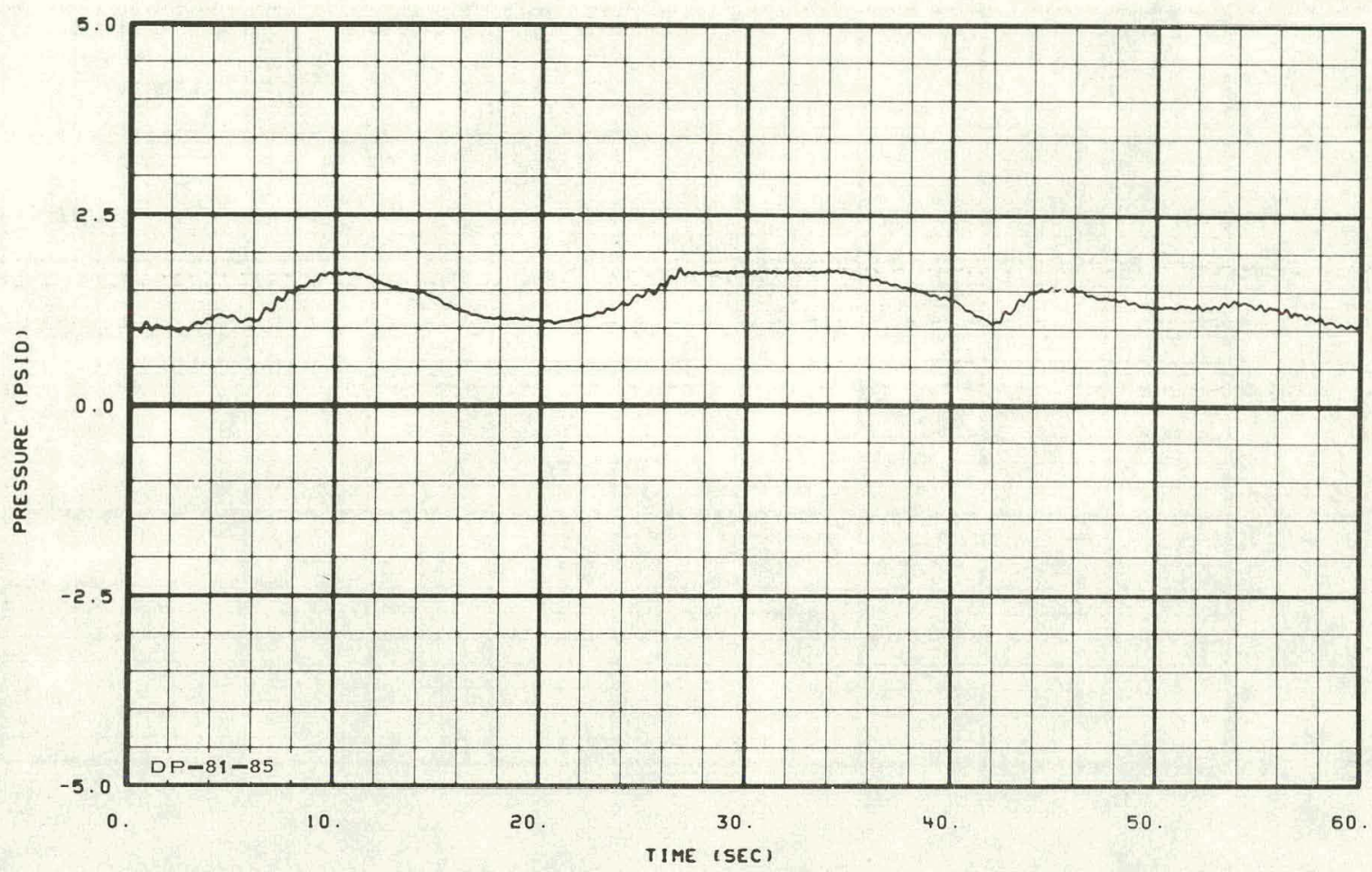

Fig. 342 Differential pressure between pressure suppression header and pressure suppression tank downcomer exit (DP-81-85) -- Test 15.7.

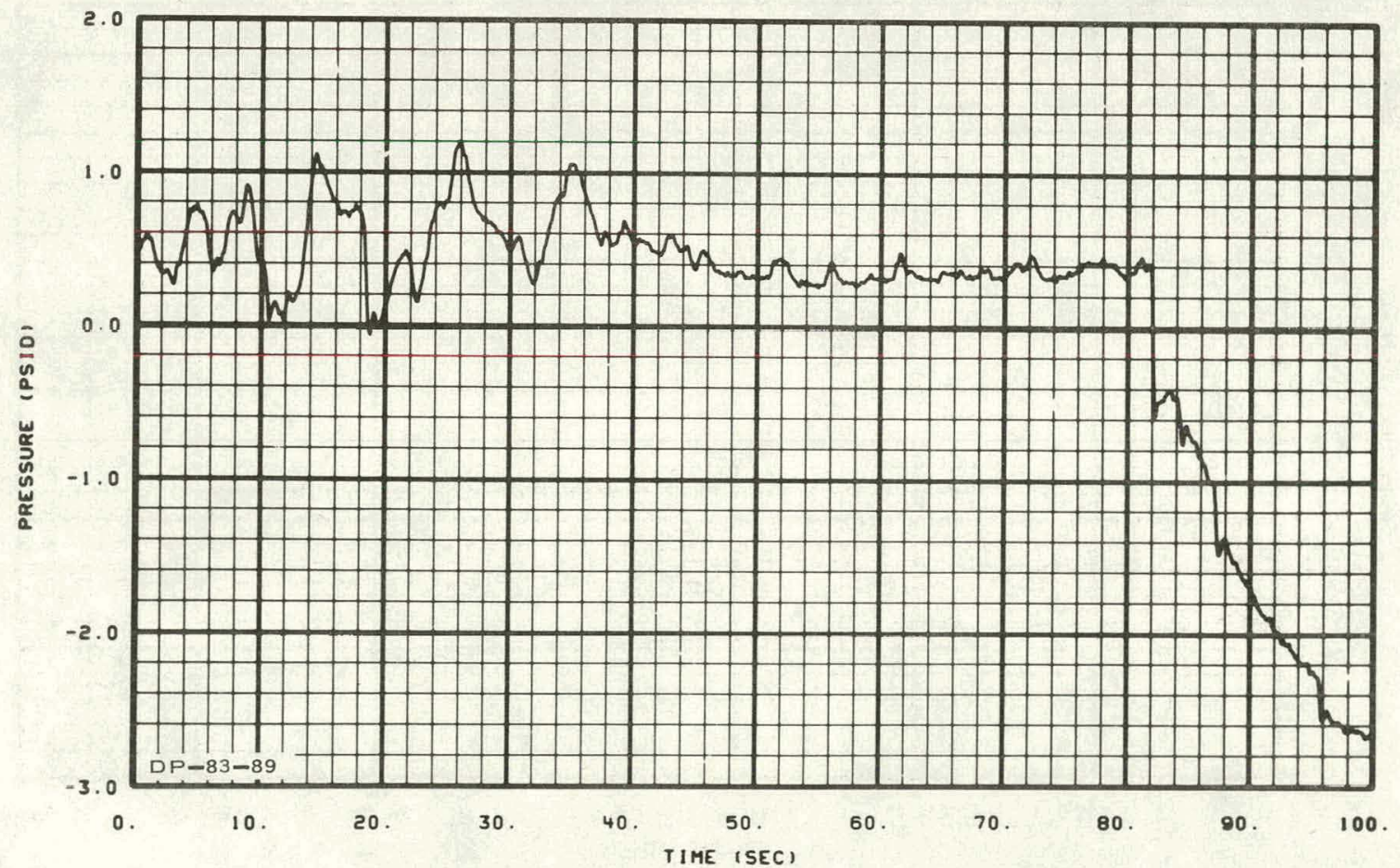

Fig. 343 Differential pressure between pressure suppression tank downcomer entrance and pressure suppression tank vapor chamber (DP-83-89) -Test 15.1 . 


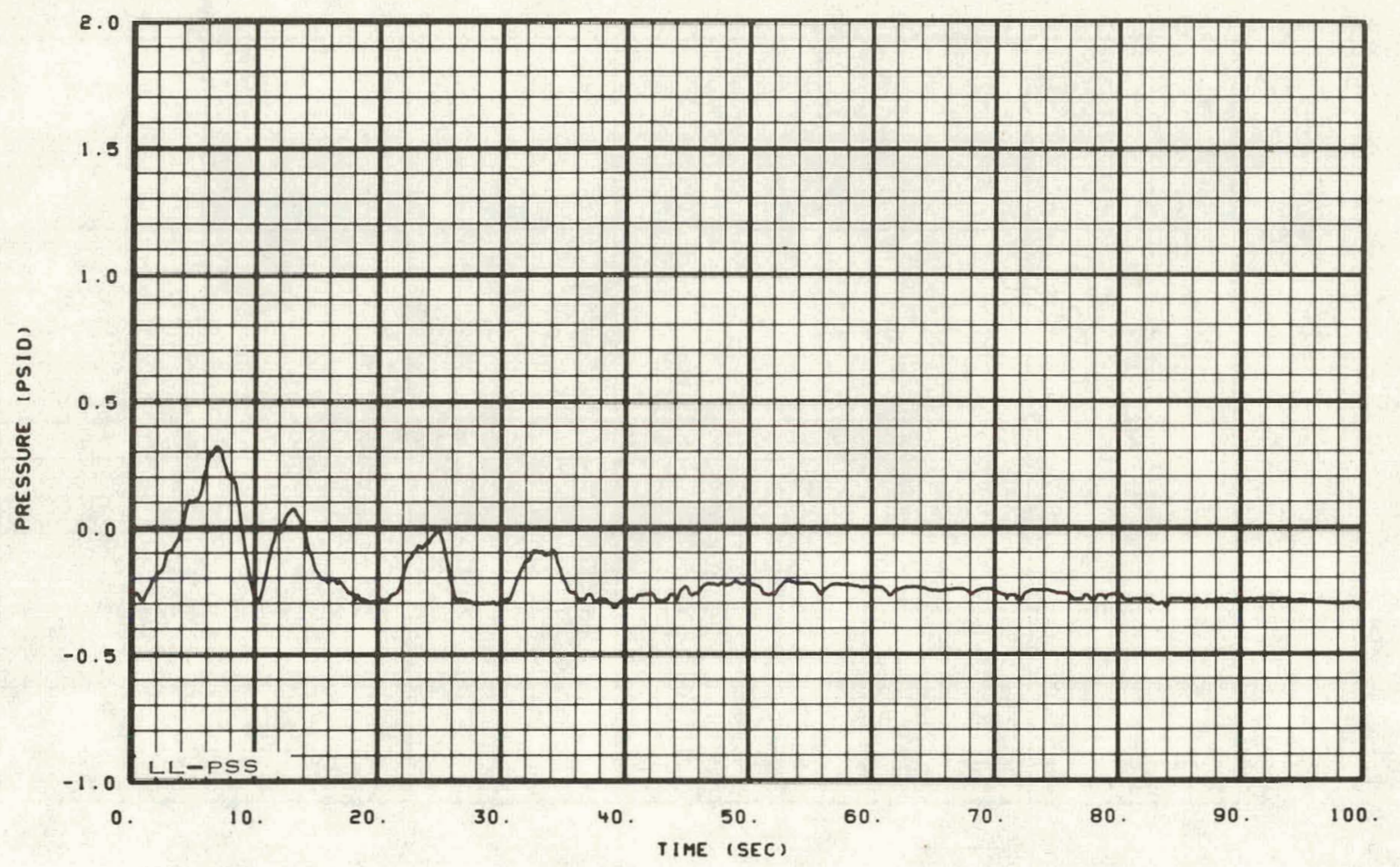

Fig. 344 Liquid level in pressure suppression tank -- Test 15.1.

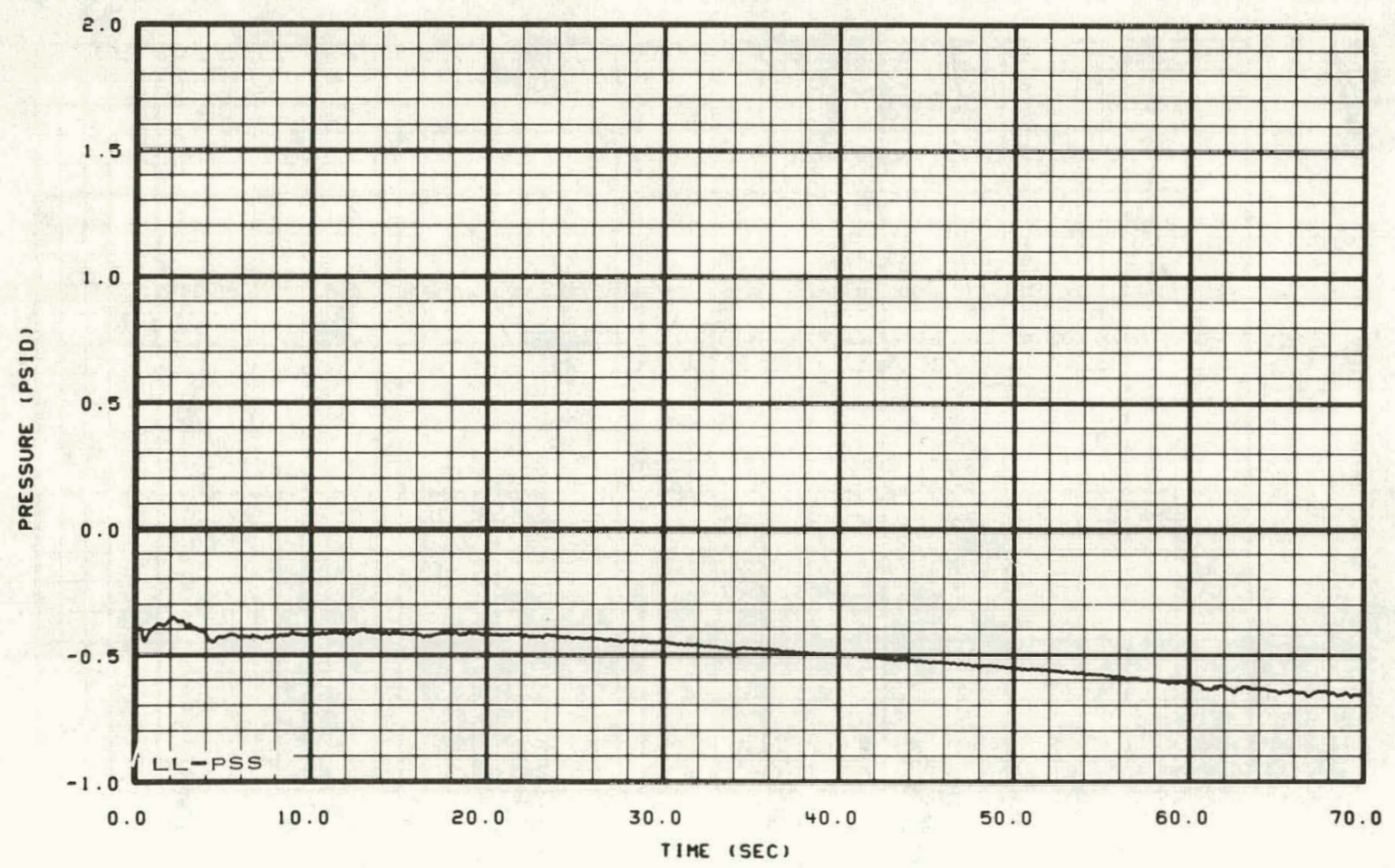

Fig. 345 Liquid leve1 in pressure suppression tank -- Test 15.2. 


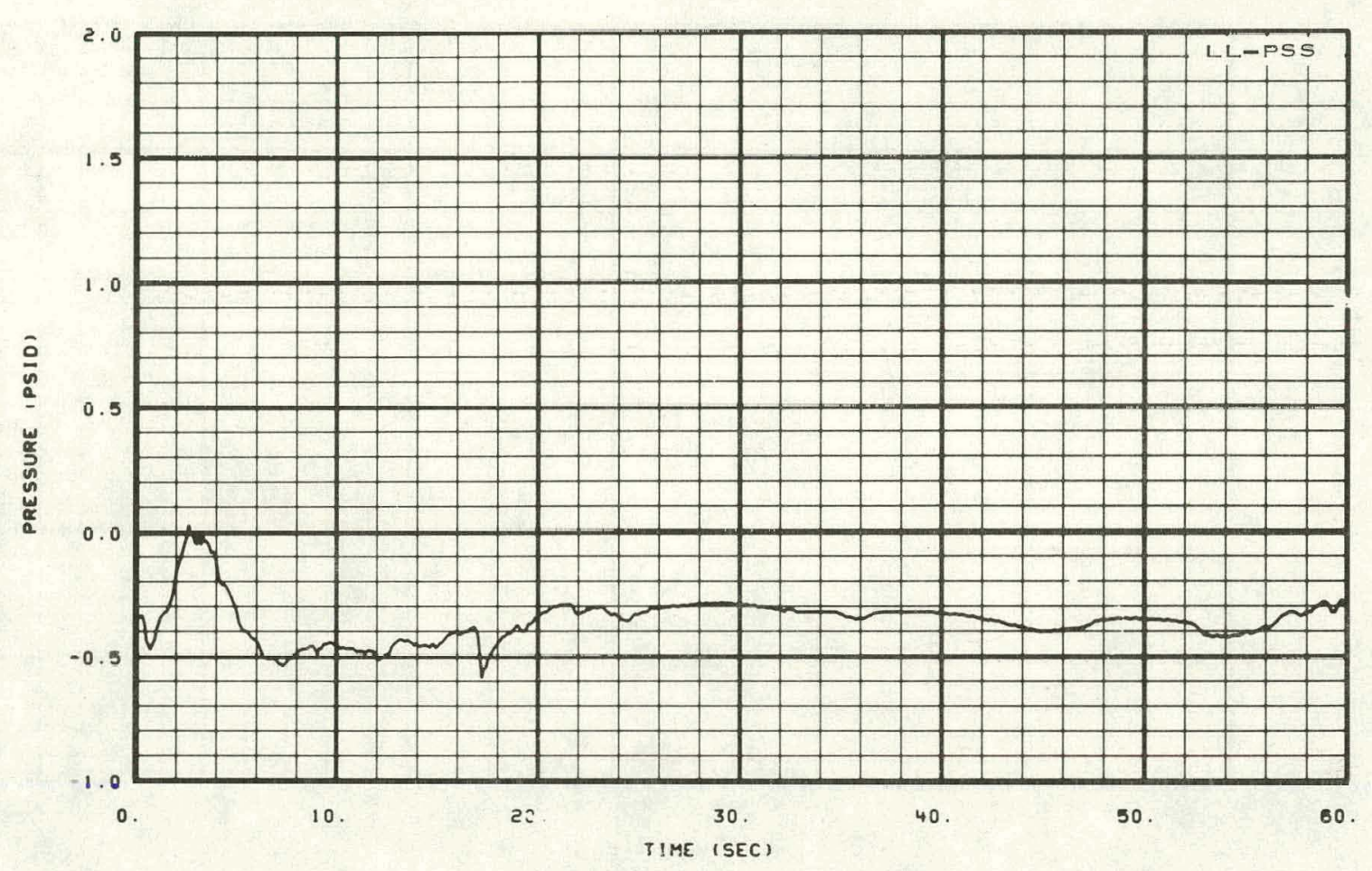

Fig. 346 Liquid level in pressure suppression tank -- Test 15.3.

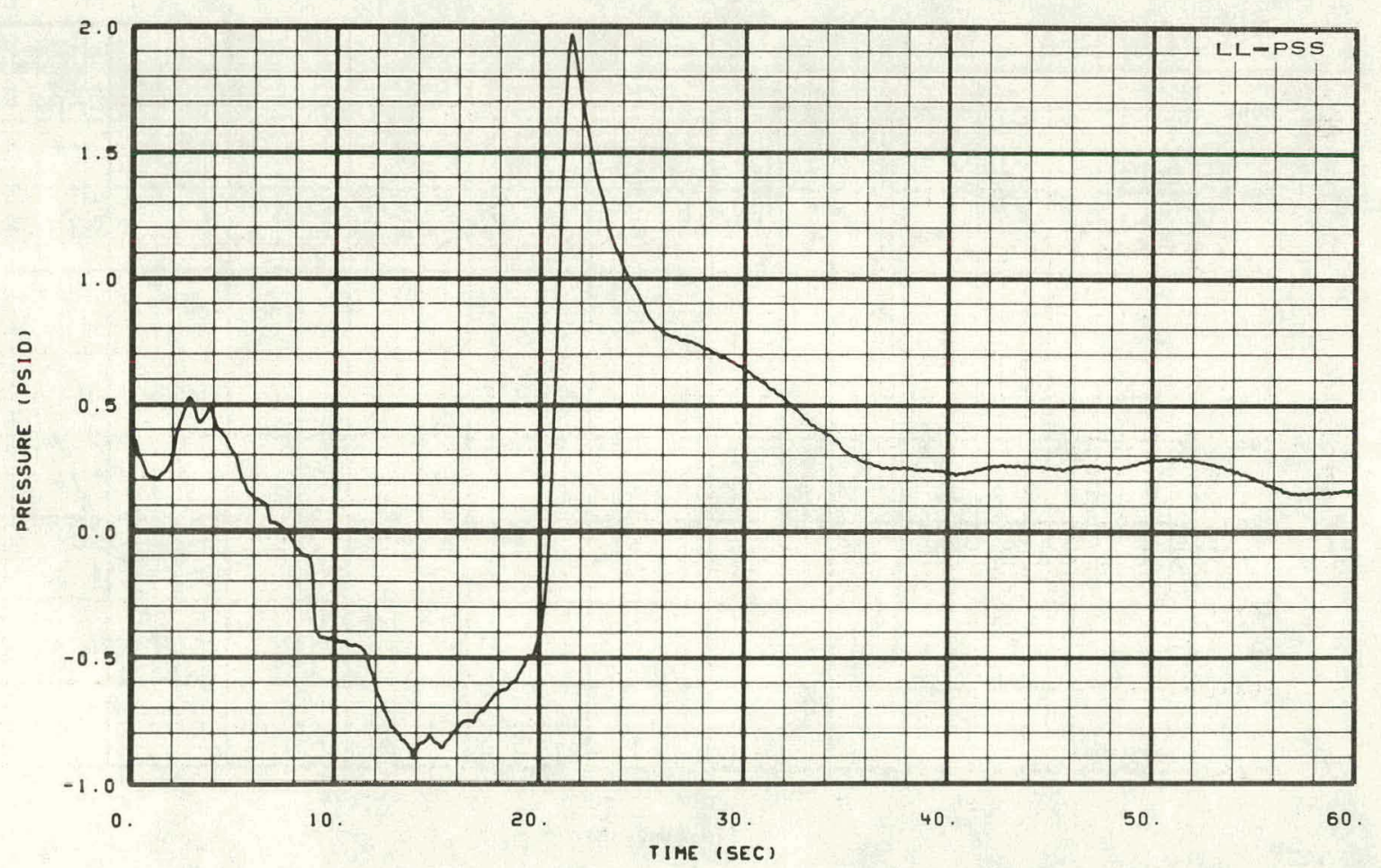

Fig. 347 Liquid level in pressure suppression tank -- Test 15.4. 


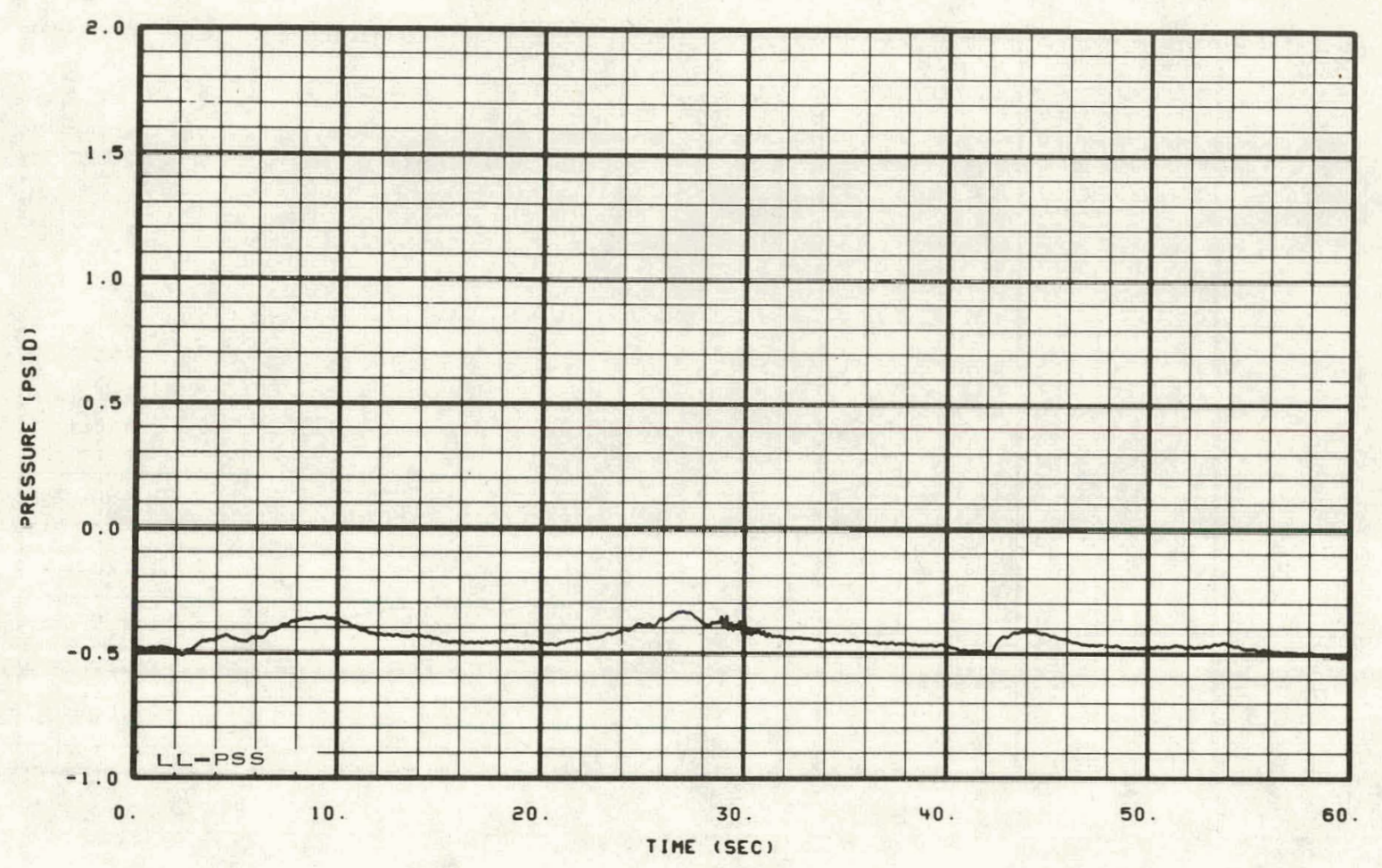

Fig. 348 Liquid leve1 in pressure suppression tank -- Test 15.7.

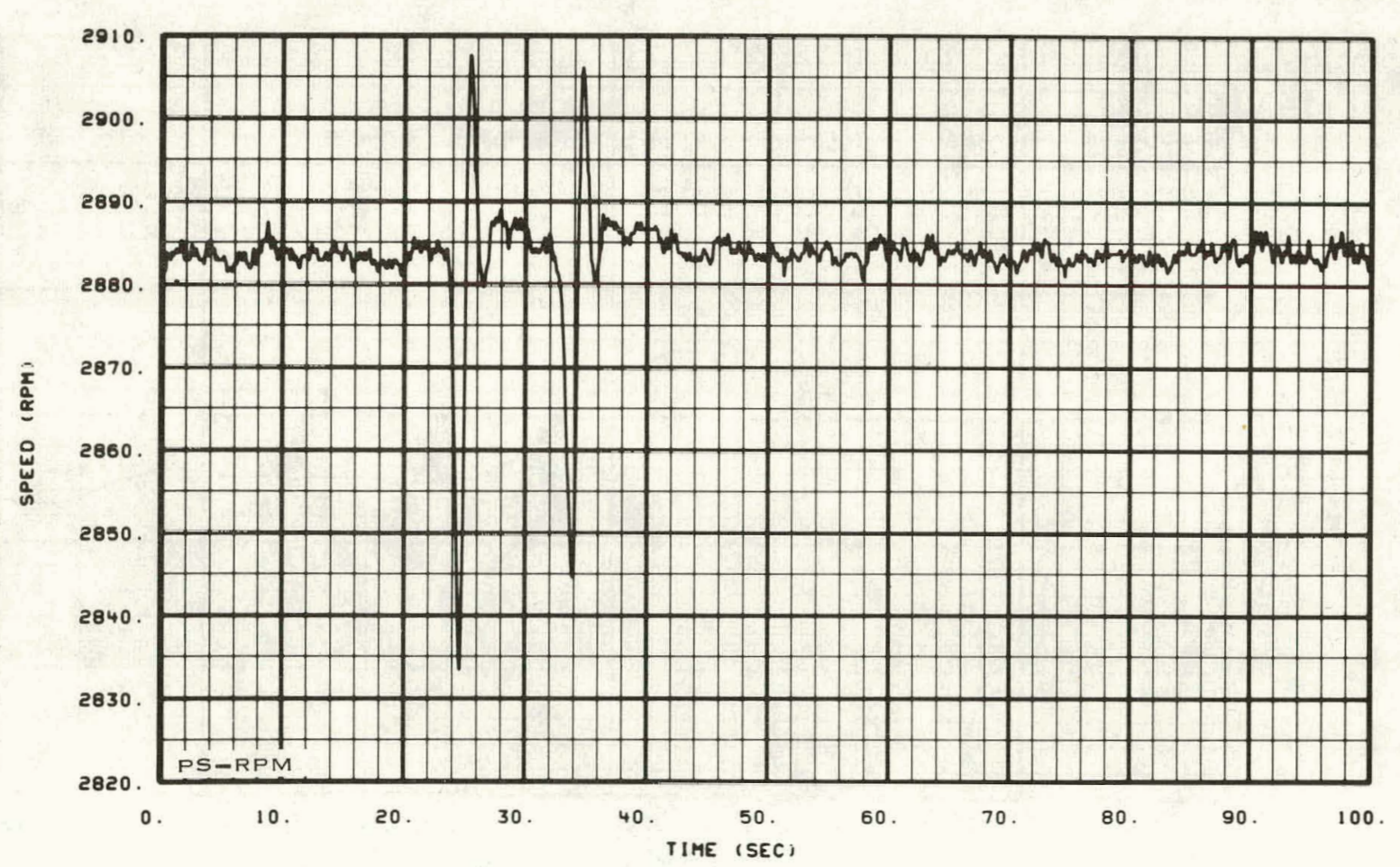

Fig. 349 Pump speed -- Test 15.1. 


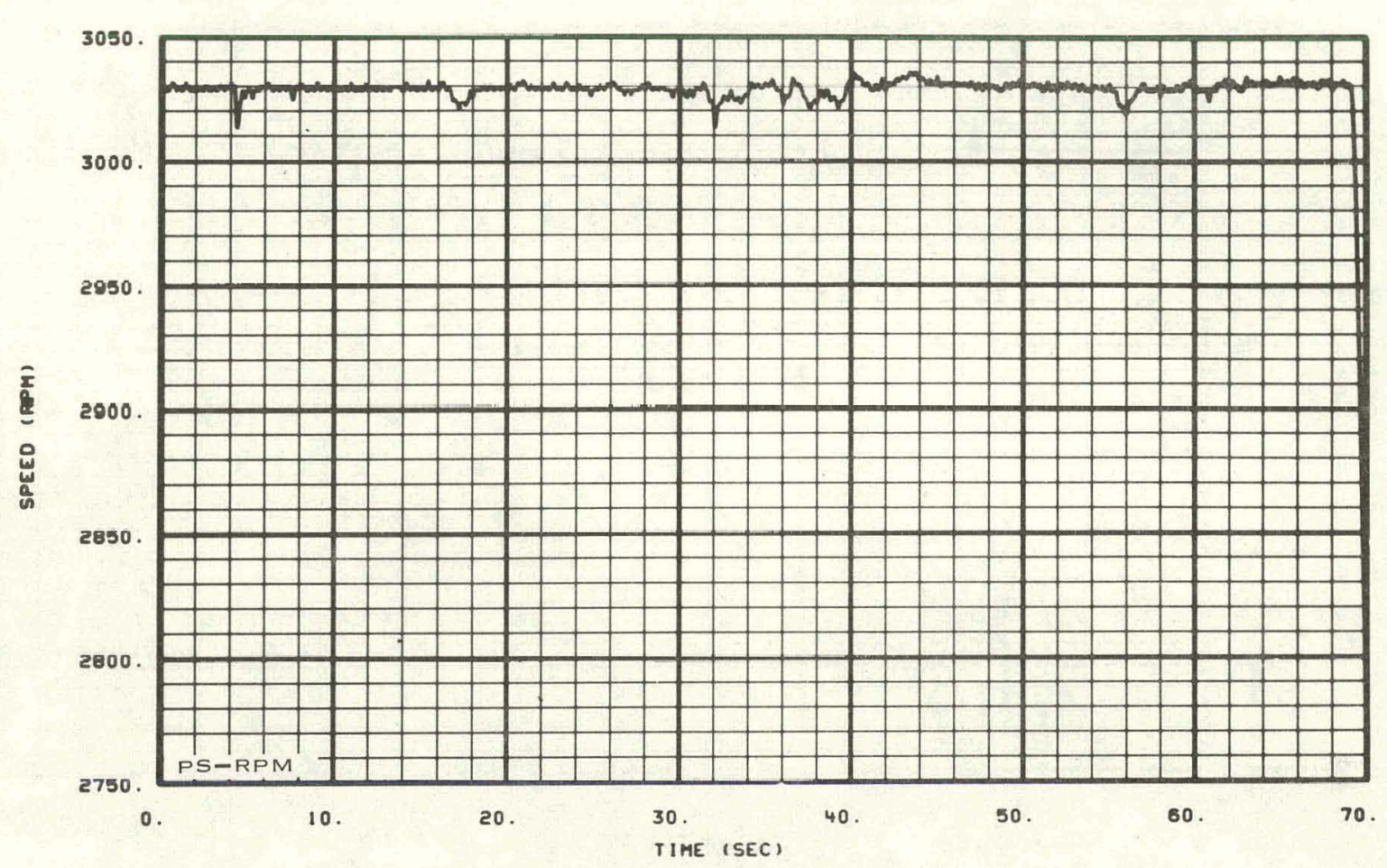

Fig. 350 Pump speed -- Test 15.2.

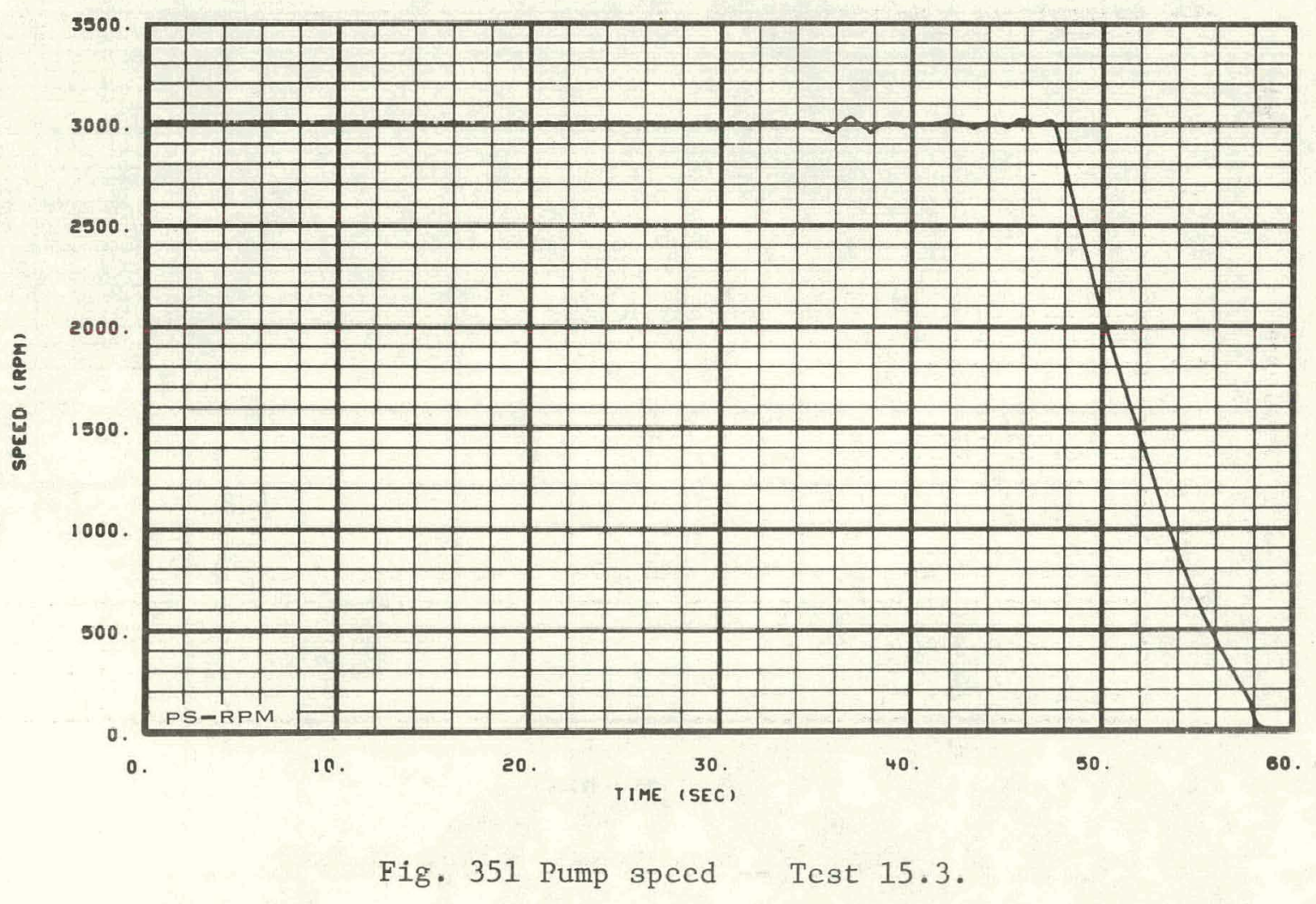




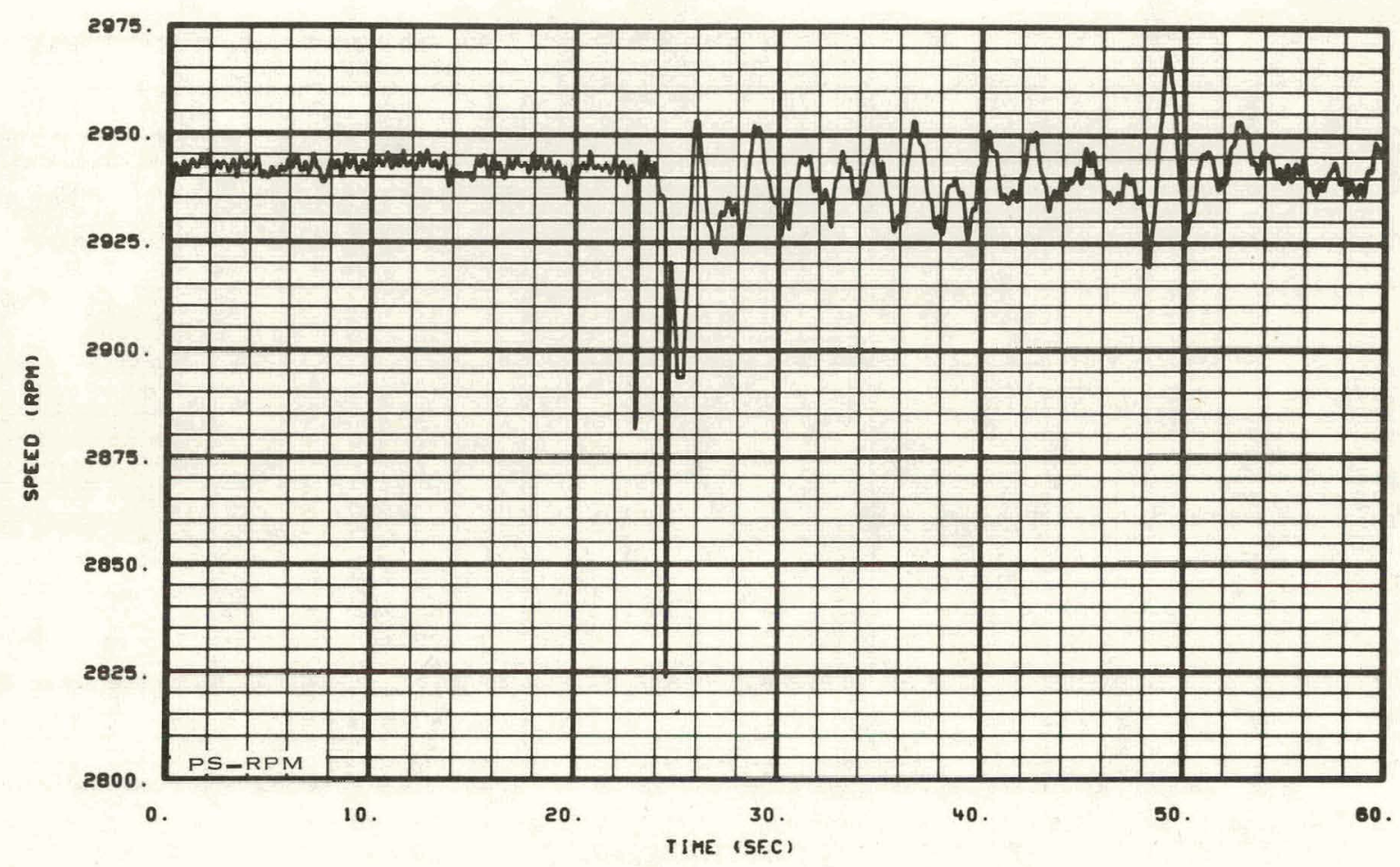

Fig. 352 Pump speed -- Test 15.4.

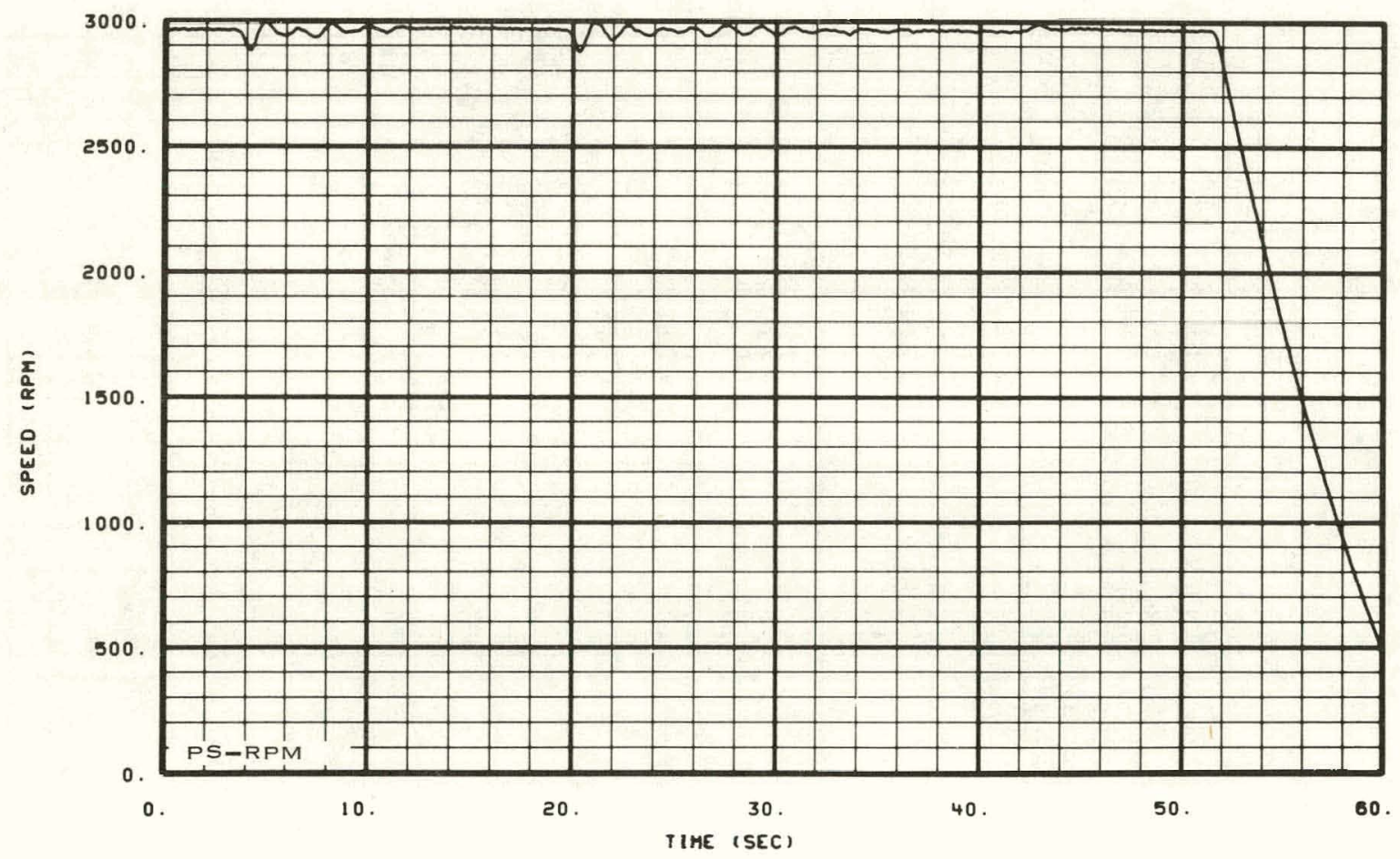

Fig. 353 Pump speed -- Test 15.7. 


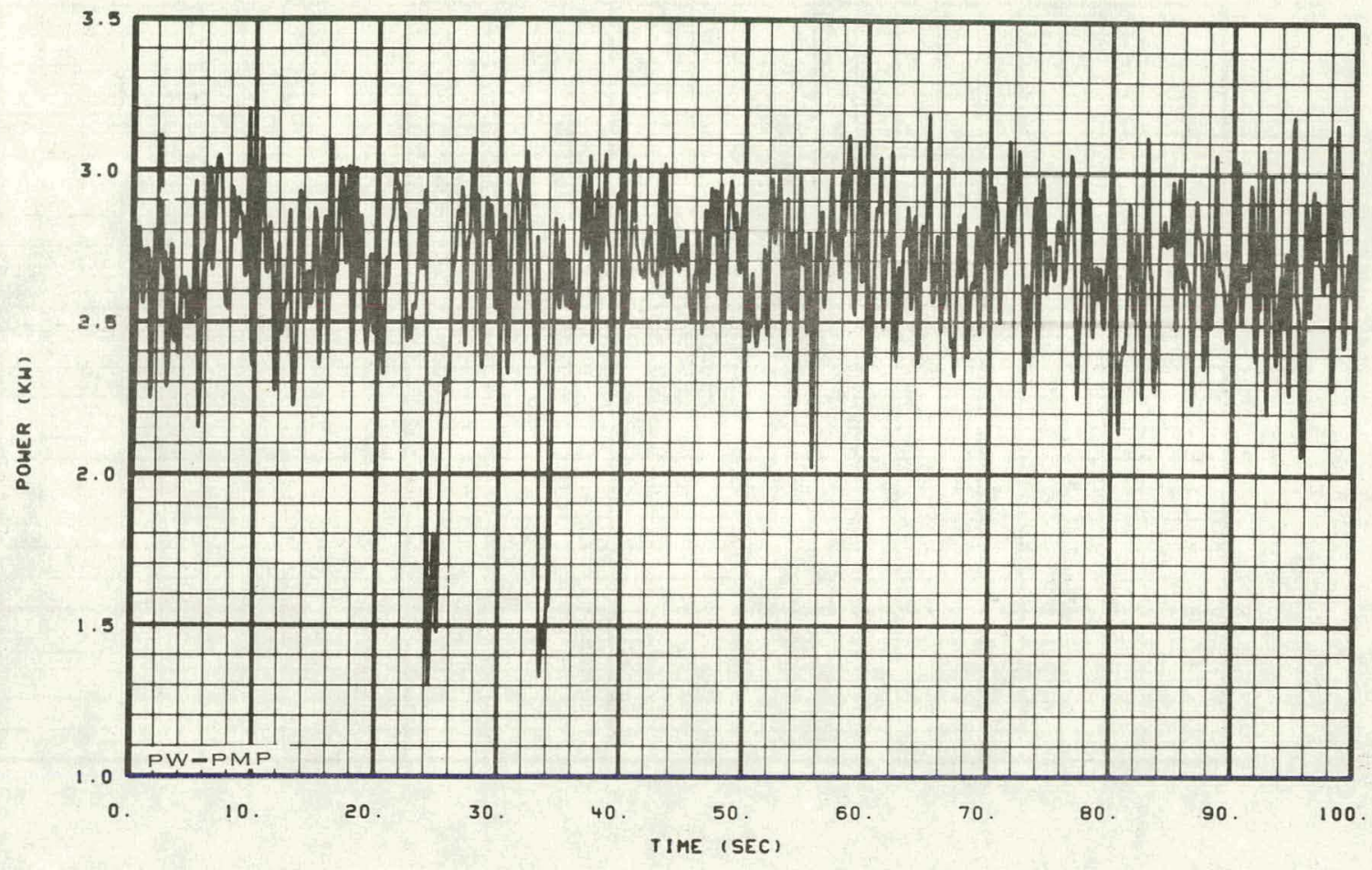

Fig. 354 Pump power -- Test 15.1.

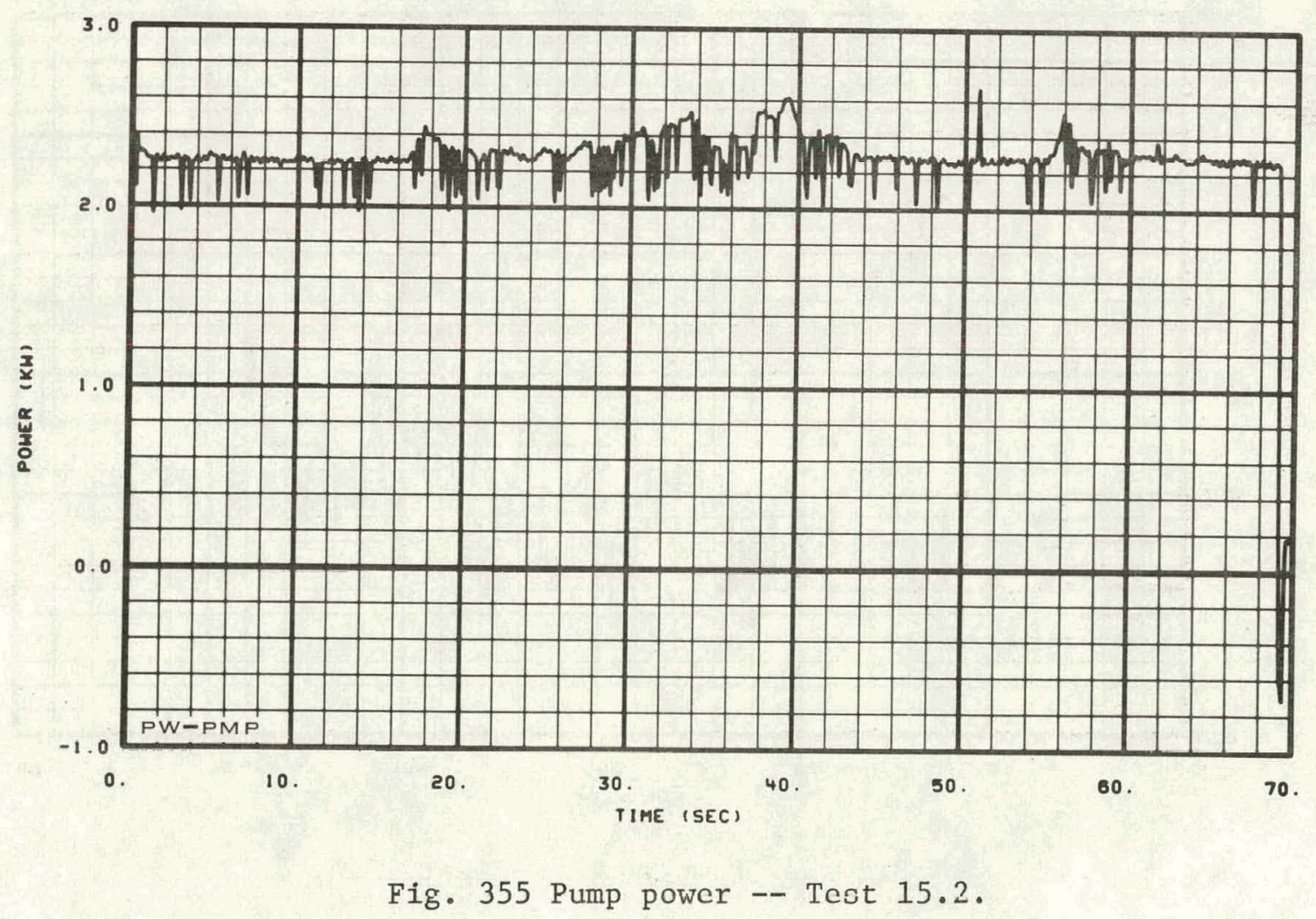




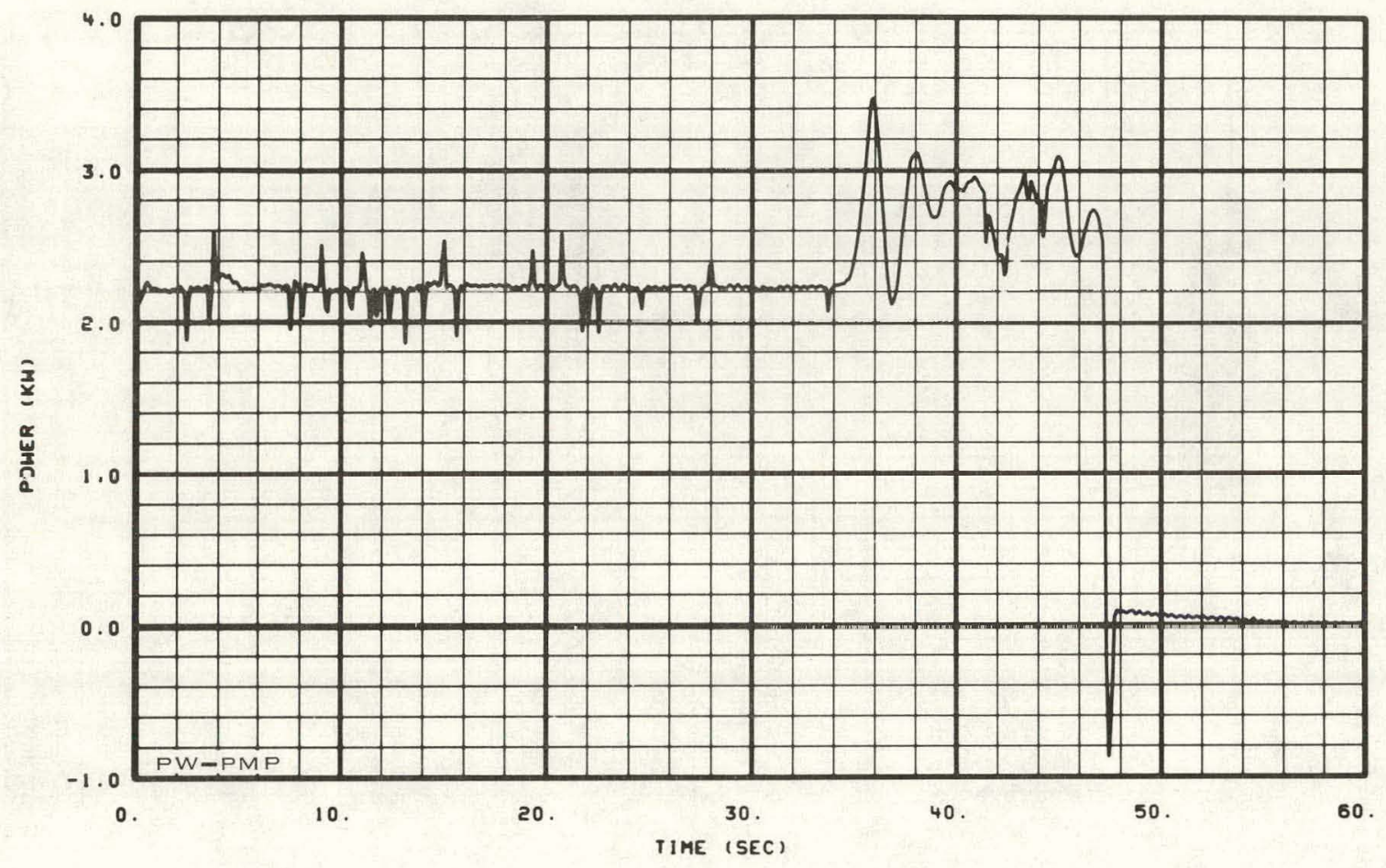

Fig. 356 Pump power -- Test 15.3.

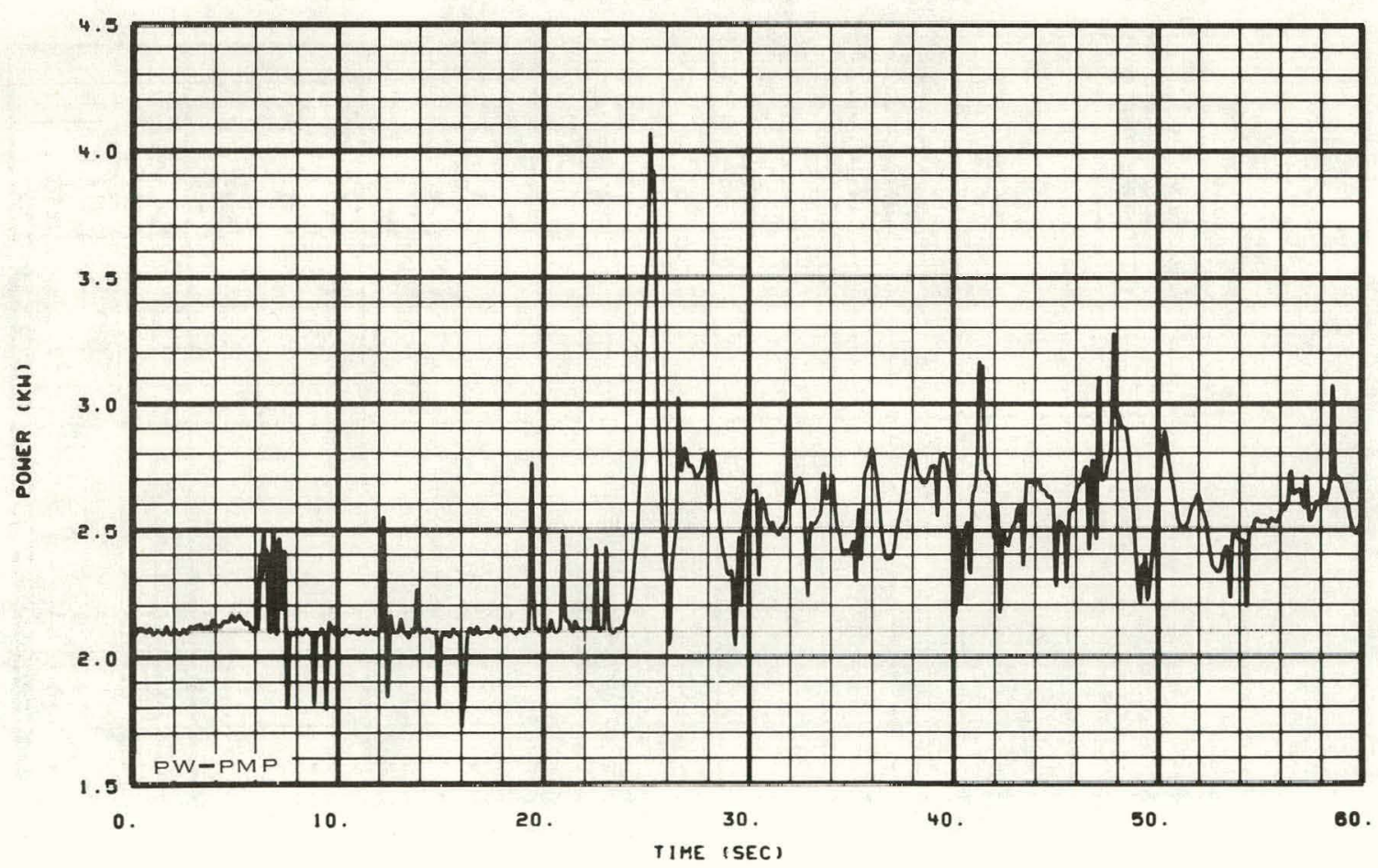

Fig. 357 Pump power -- Test 15.4. 


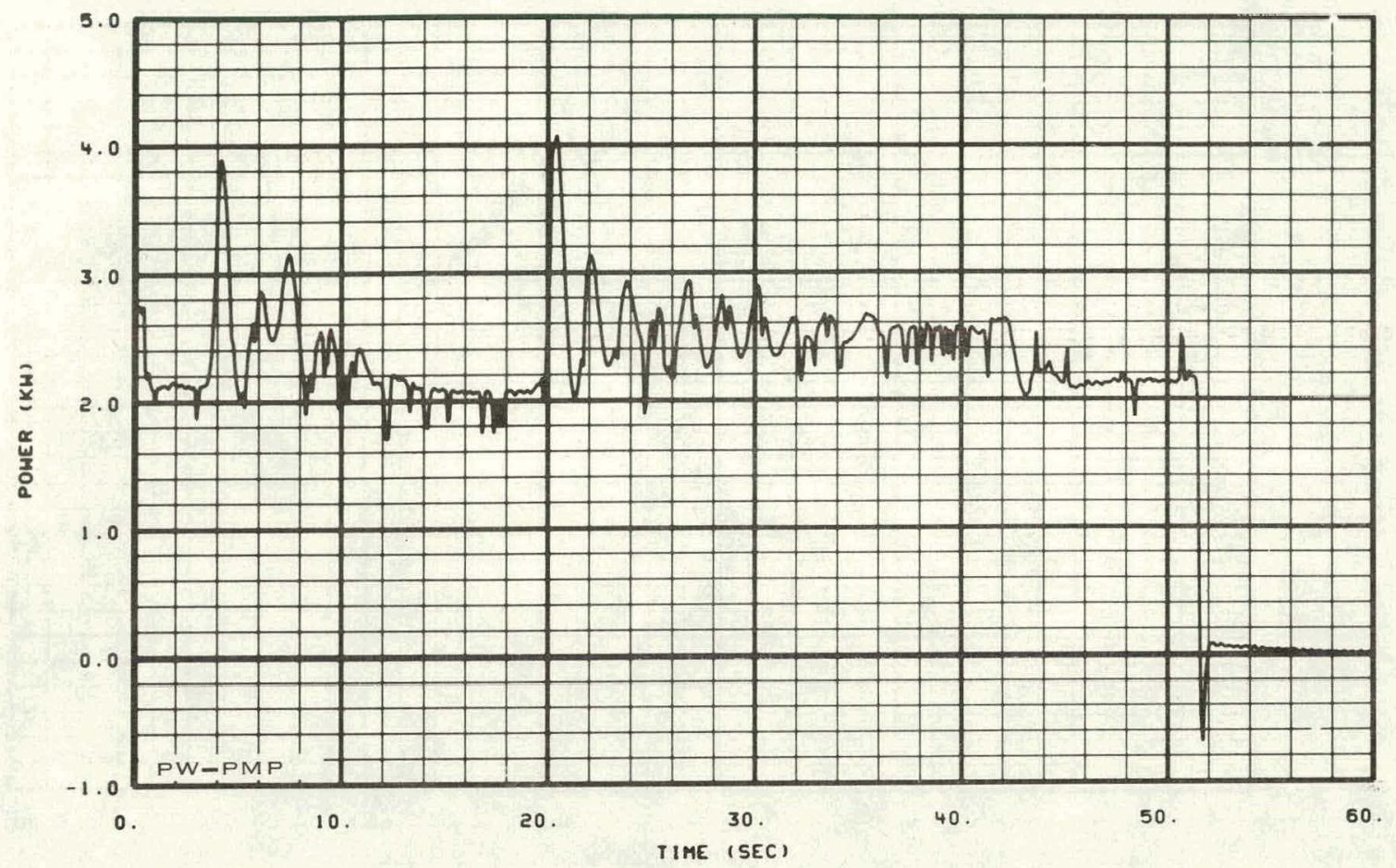

Fig. 358 Pump power -- Test 15.7.

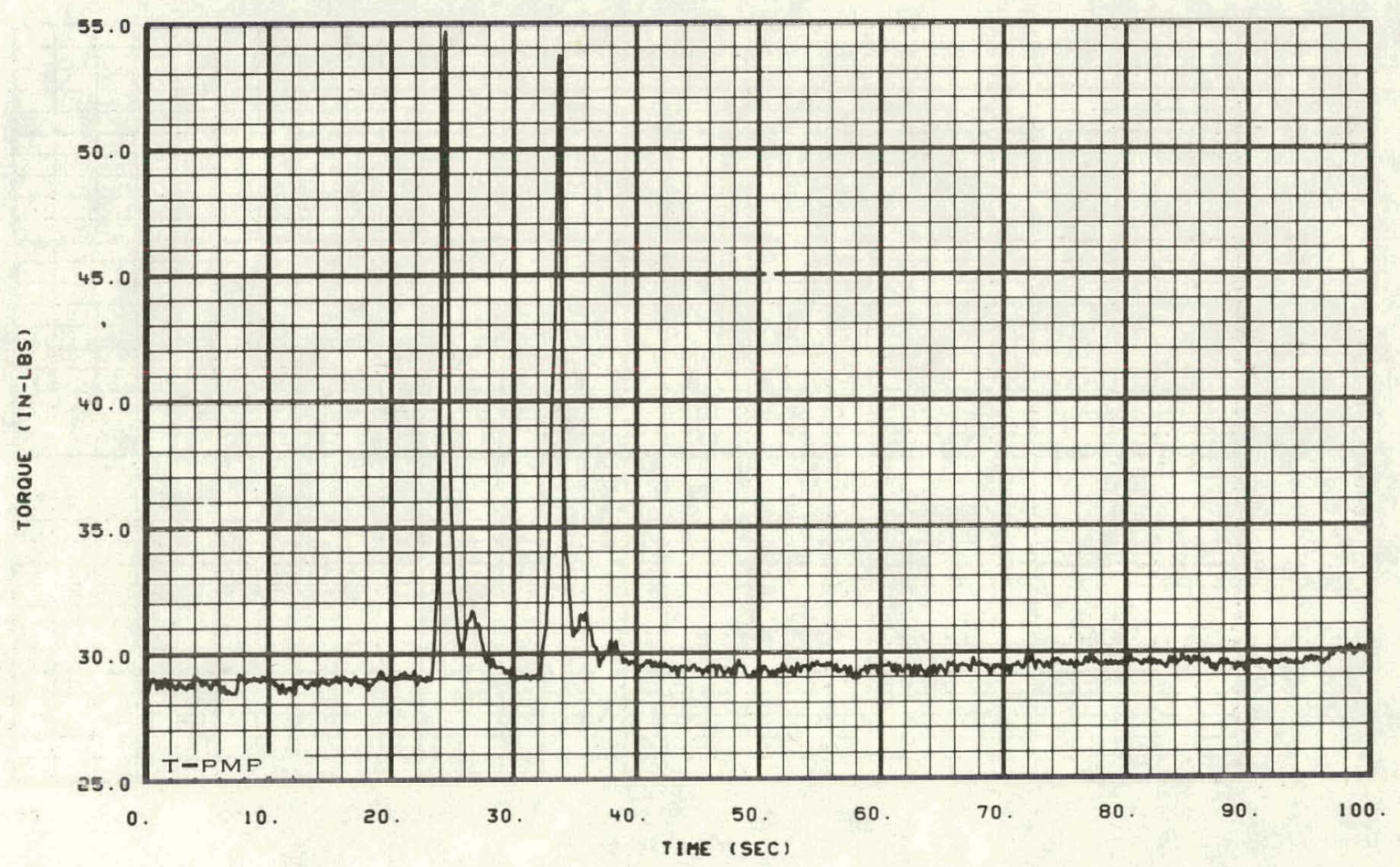

Fig. 359 Pump torque -- Test 15.1 


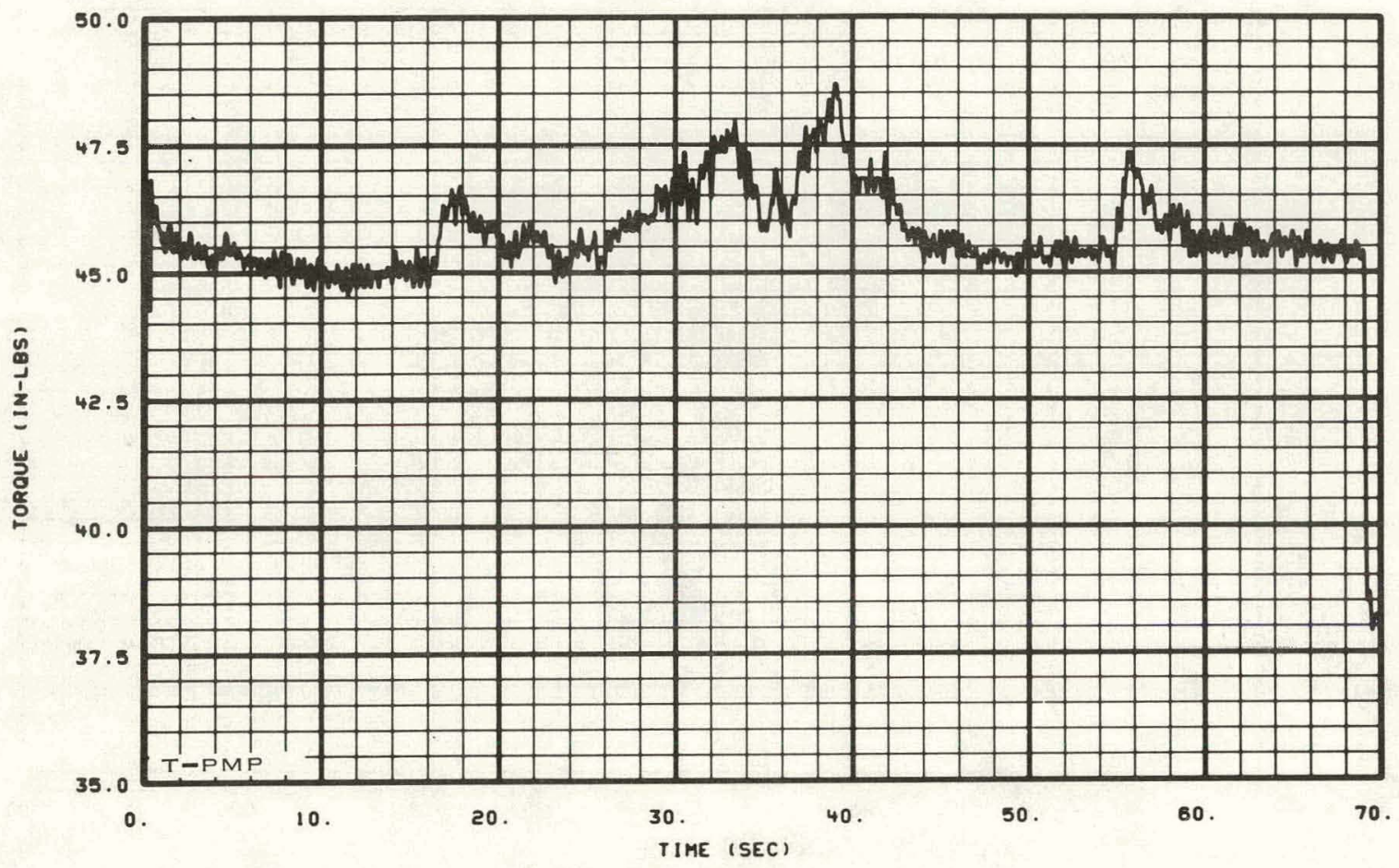

Fig. 360 Pump torque -- Test 15.2.

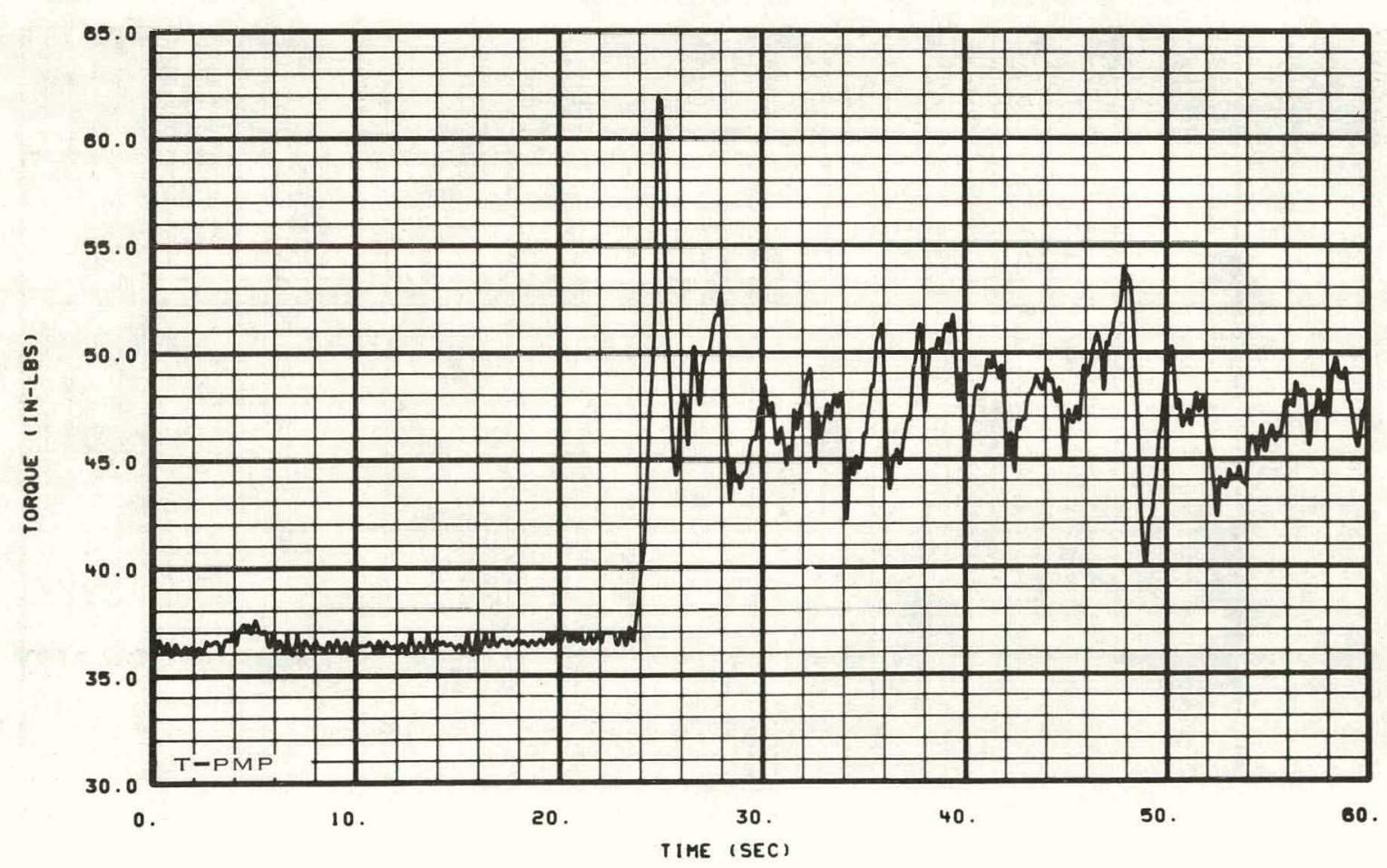

Fig. 361 Pump torque -- Test 15.4. 


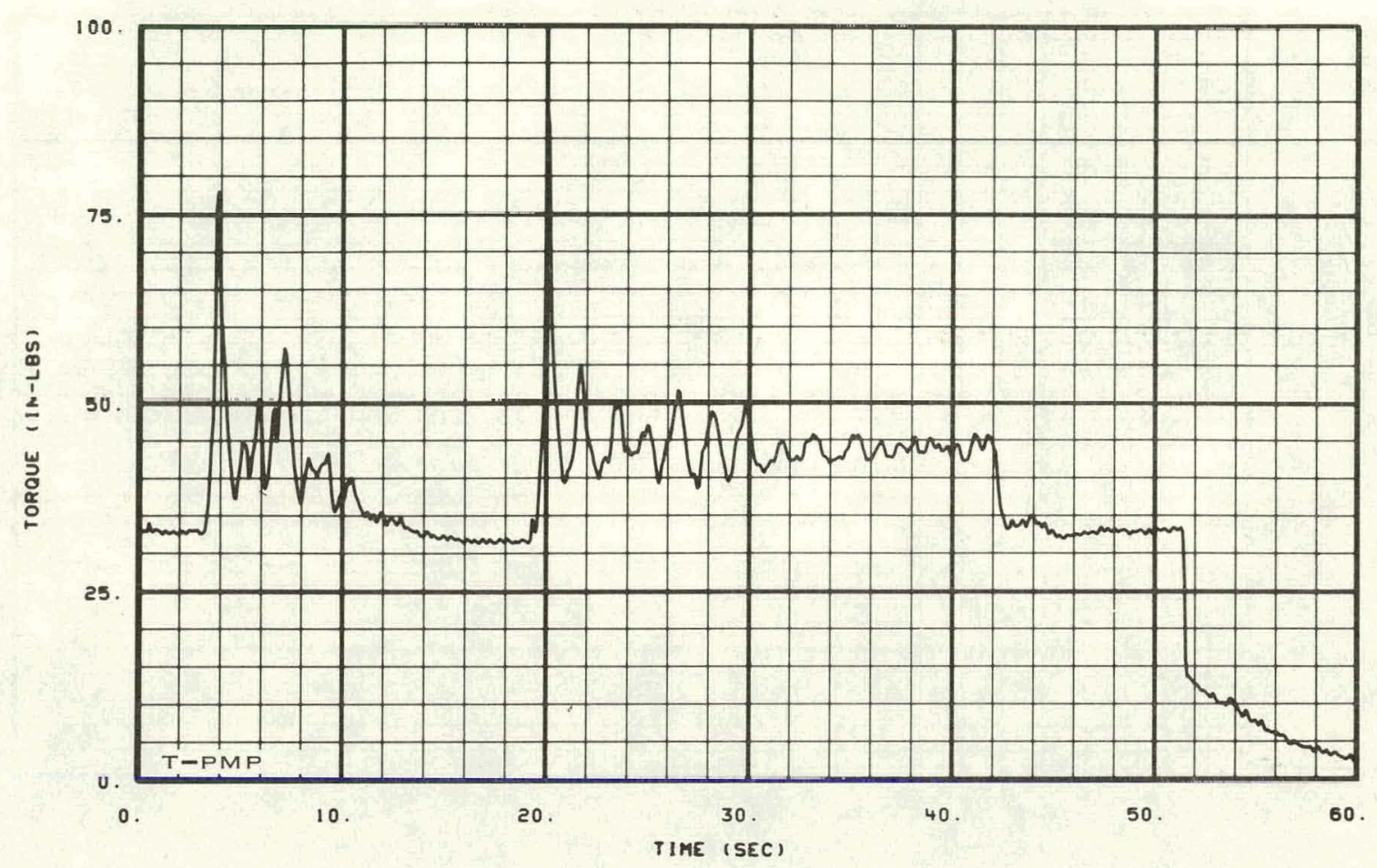

Fig. 362 Pump torque -- Test 15.7.

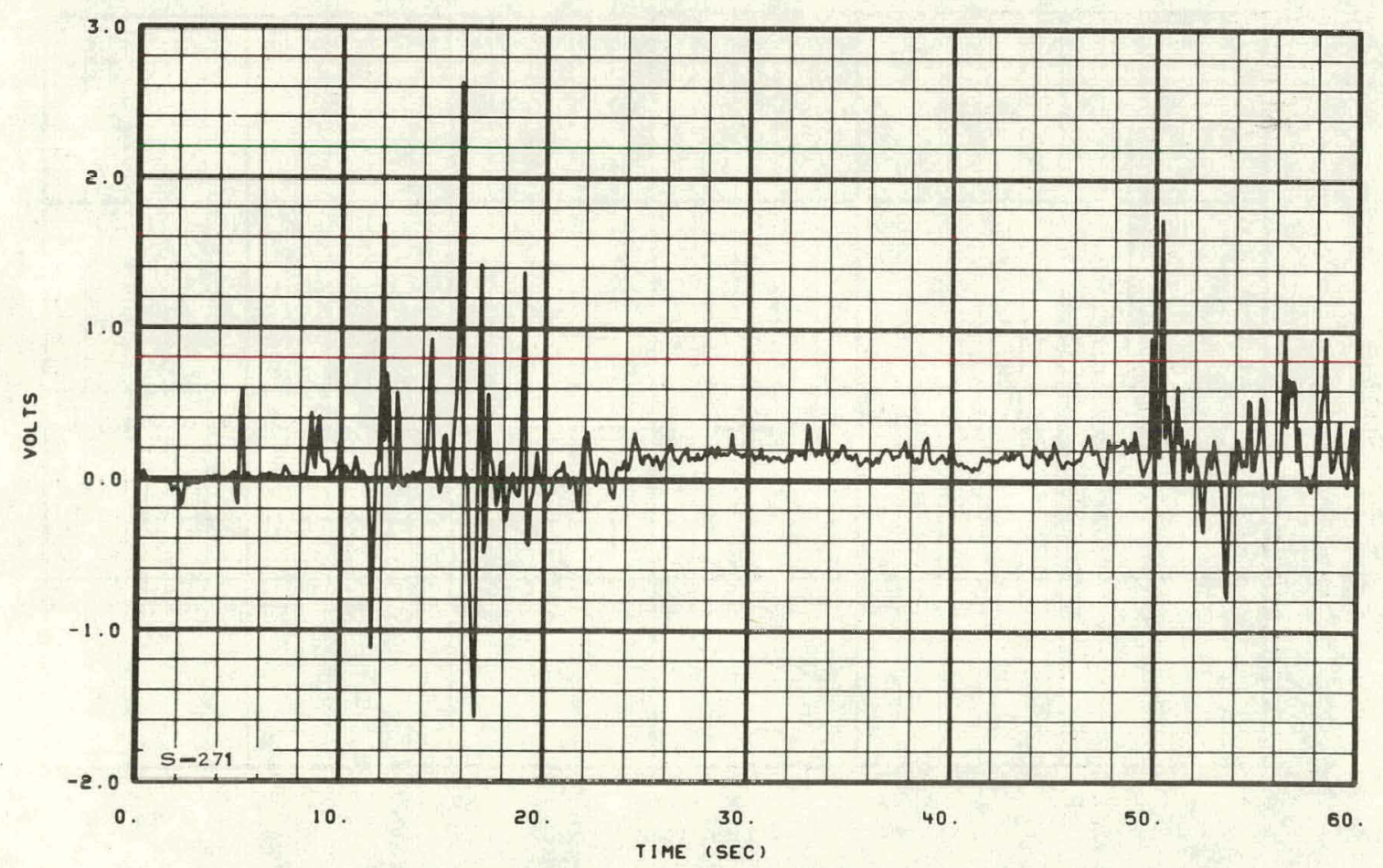

Fig. 363 Flow direction in downcomer gap -- Test 15.3. 


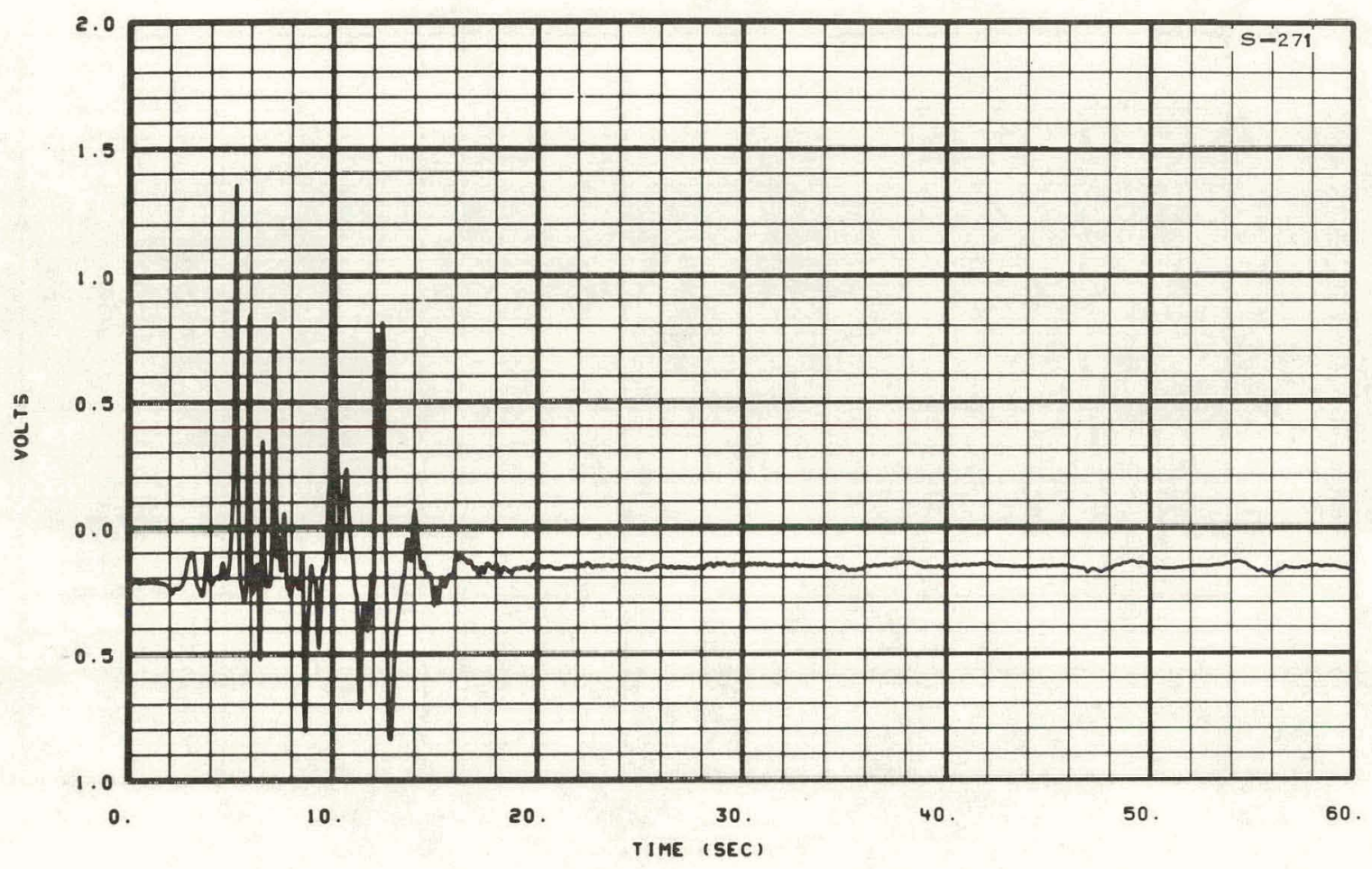

Fig. 364 Flow direction in downcomer gap -- Test 15.4 .

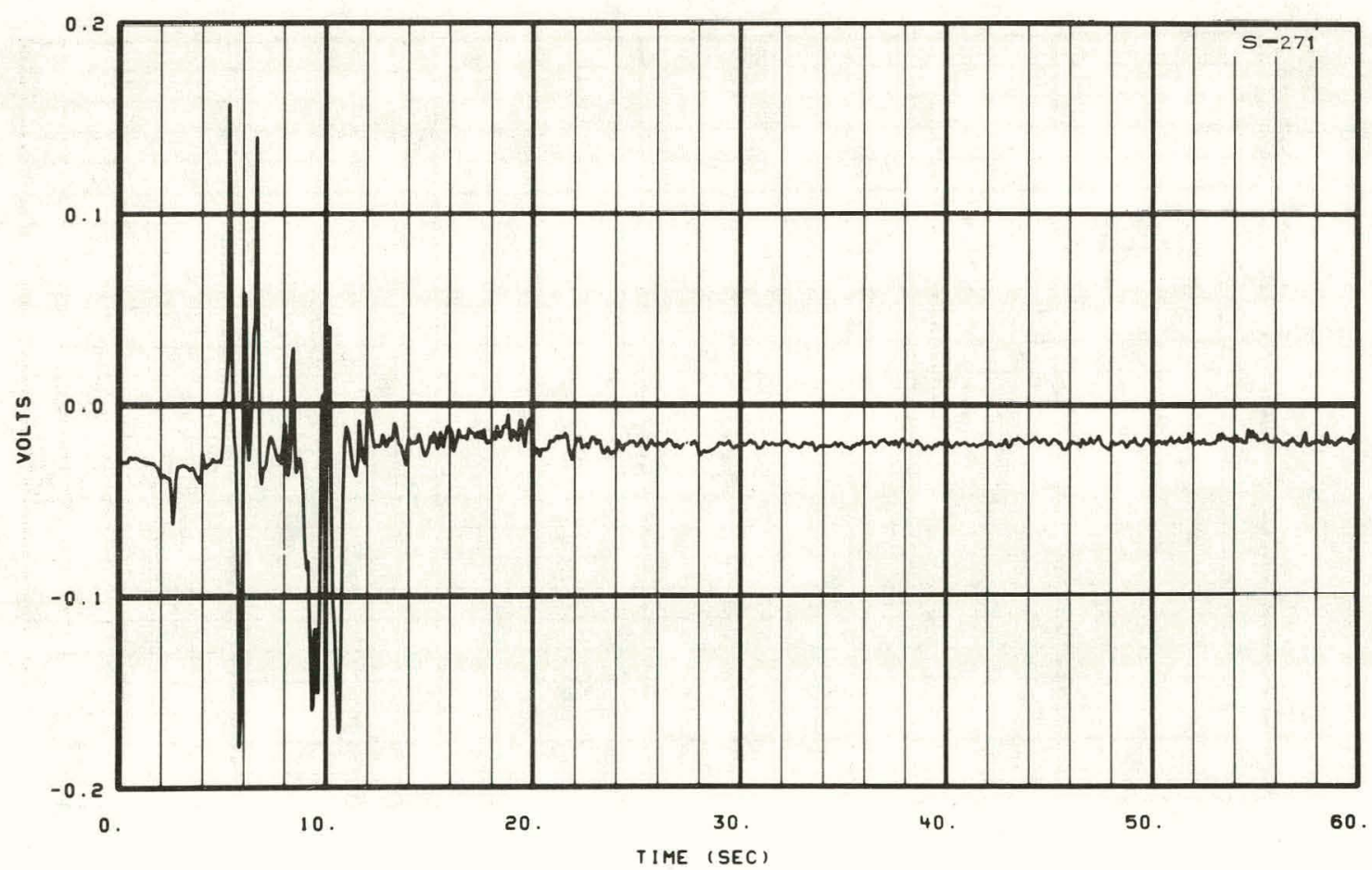

Fig. 365 Flow direction in downcomer gap -- Test 15.7. 


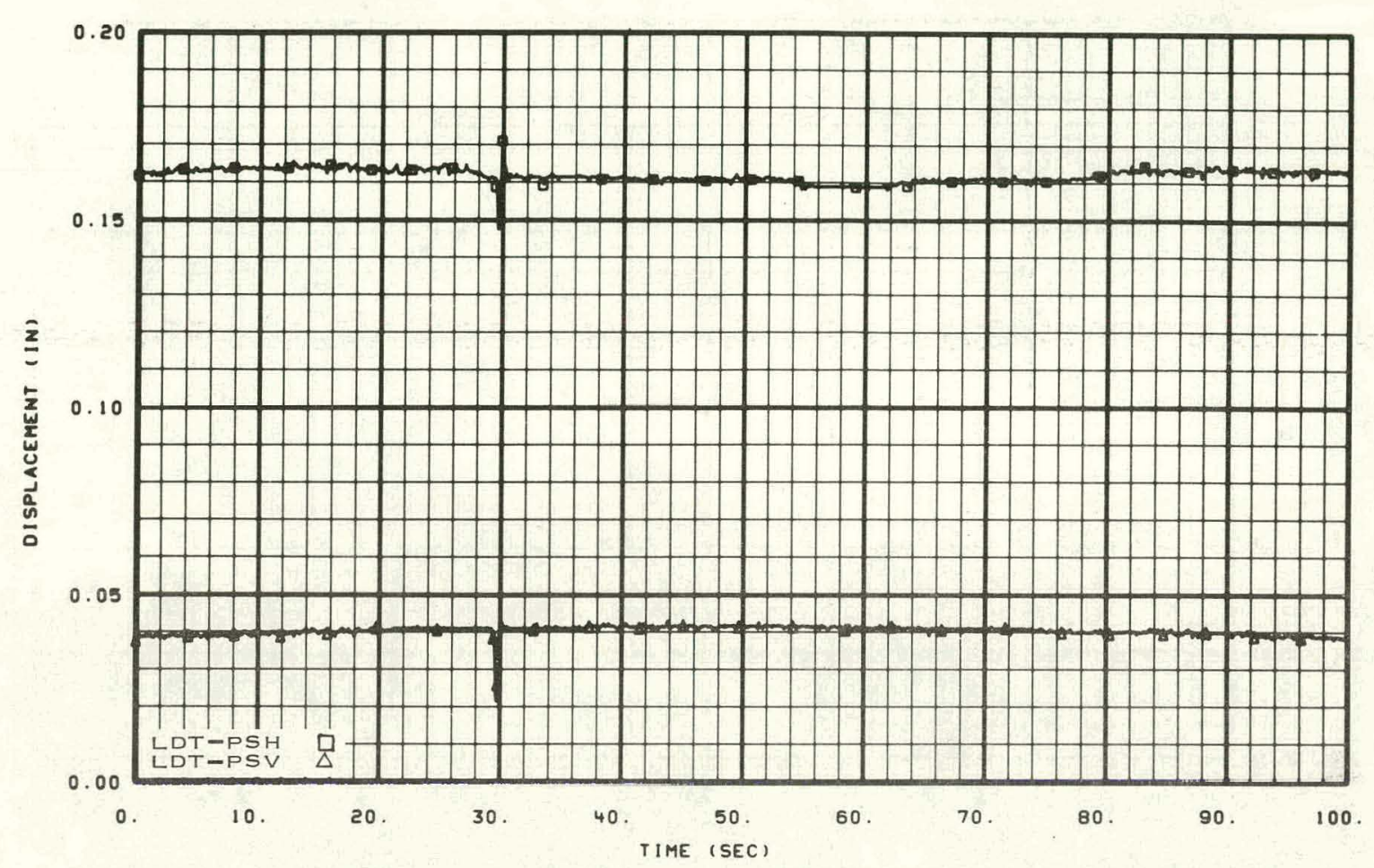

Fig. 366 Displacement of pressure suppression header -- Test 15.1.

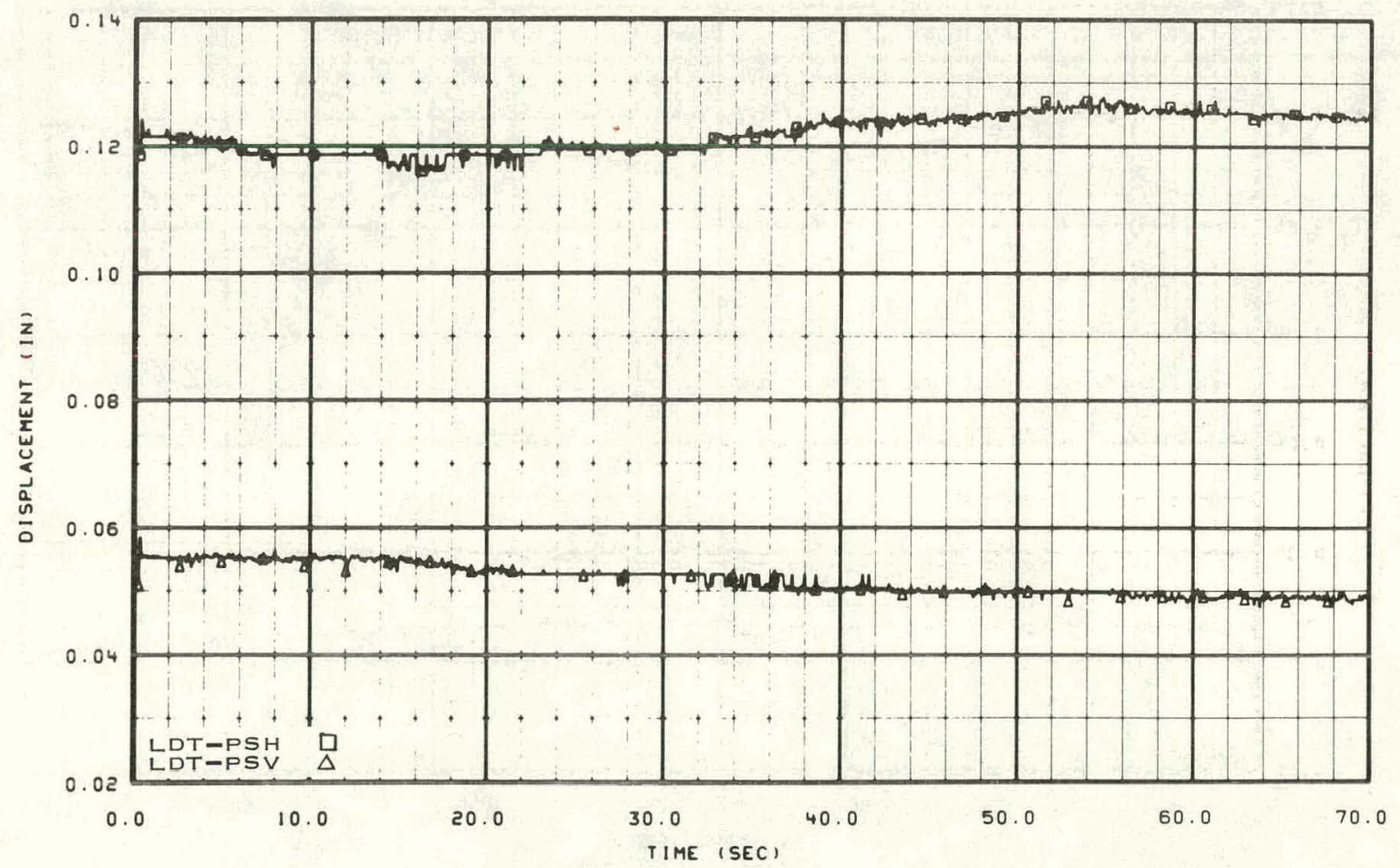

Fig. 367 Displacement of pressure suppression header -- Test 15.2. 


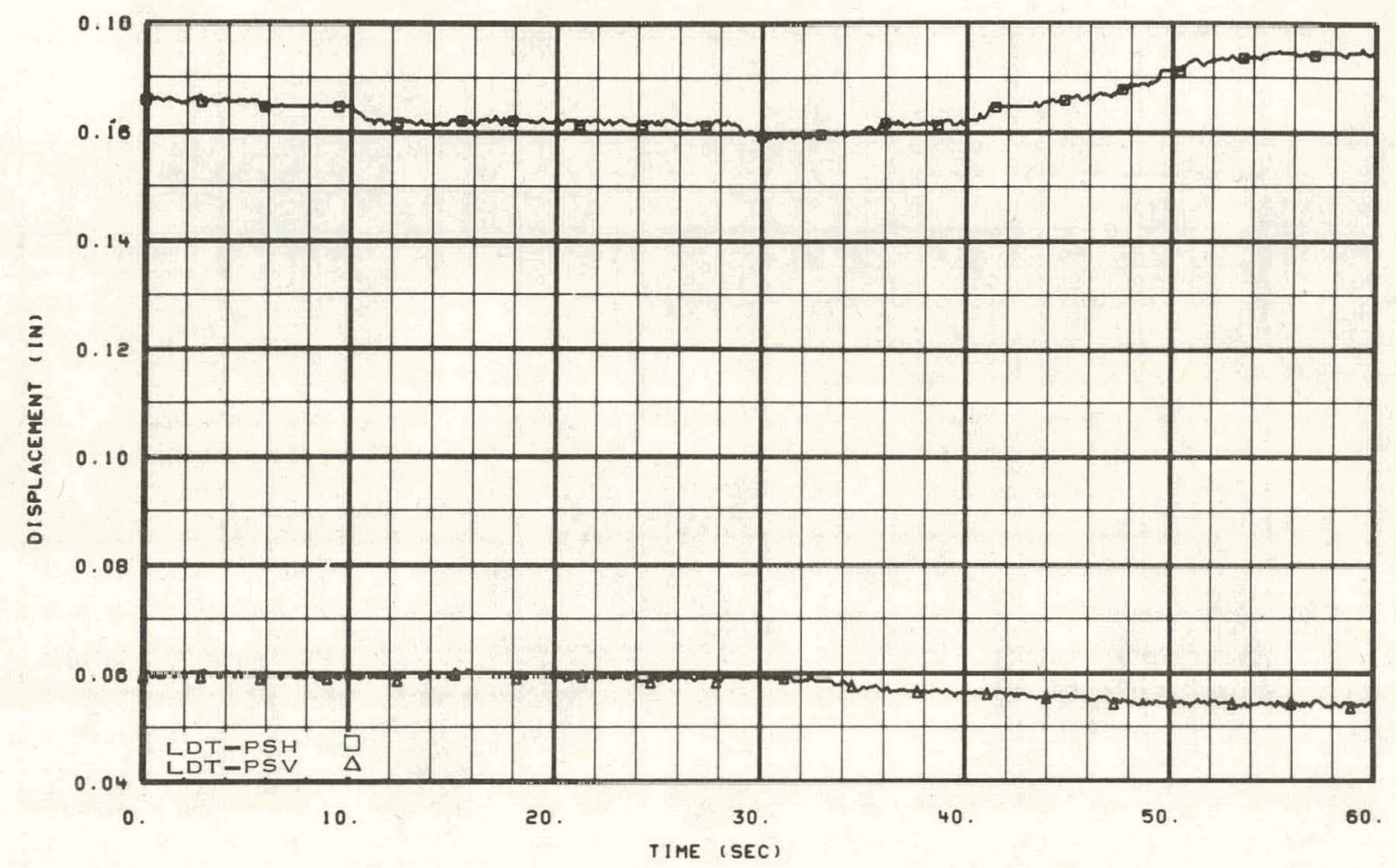

Fig. 368 Displacement of pressure suppression header -- Test 15.3.

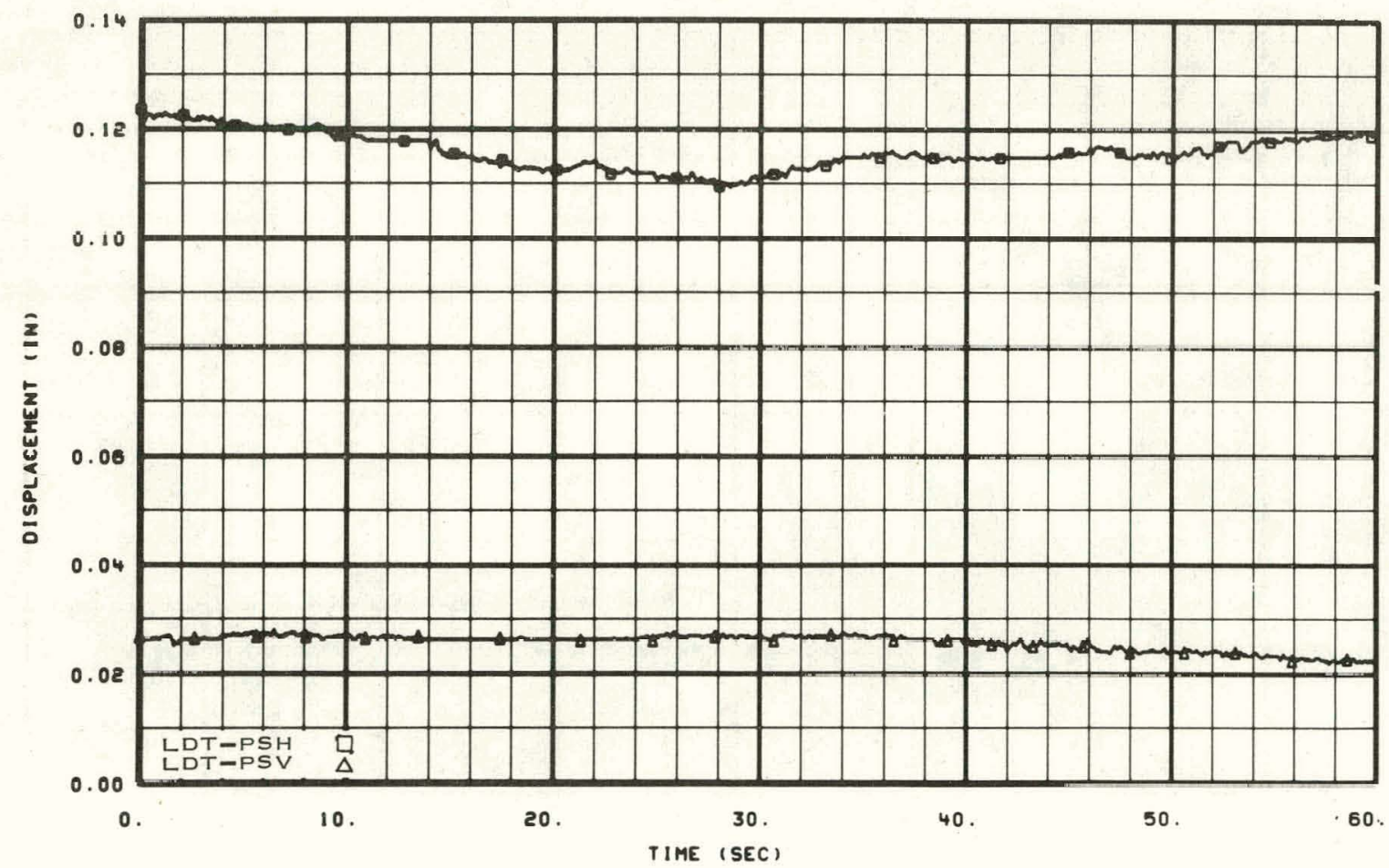

Fig. 369 Displacement of pressure suppression header -- Test 15.4. 


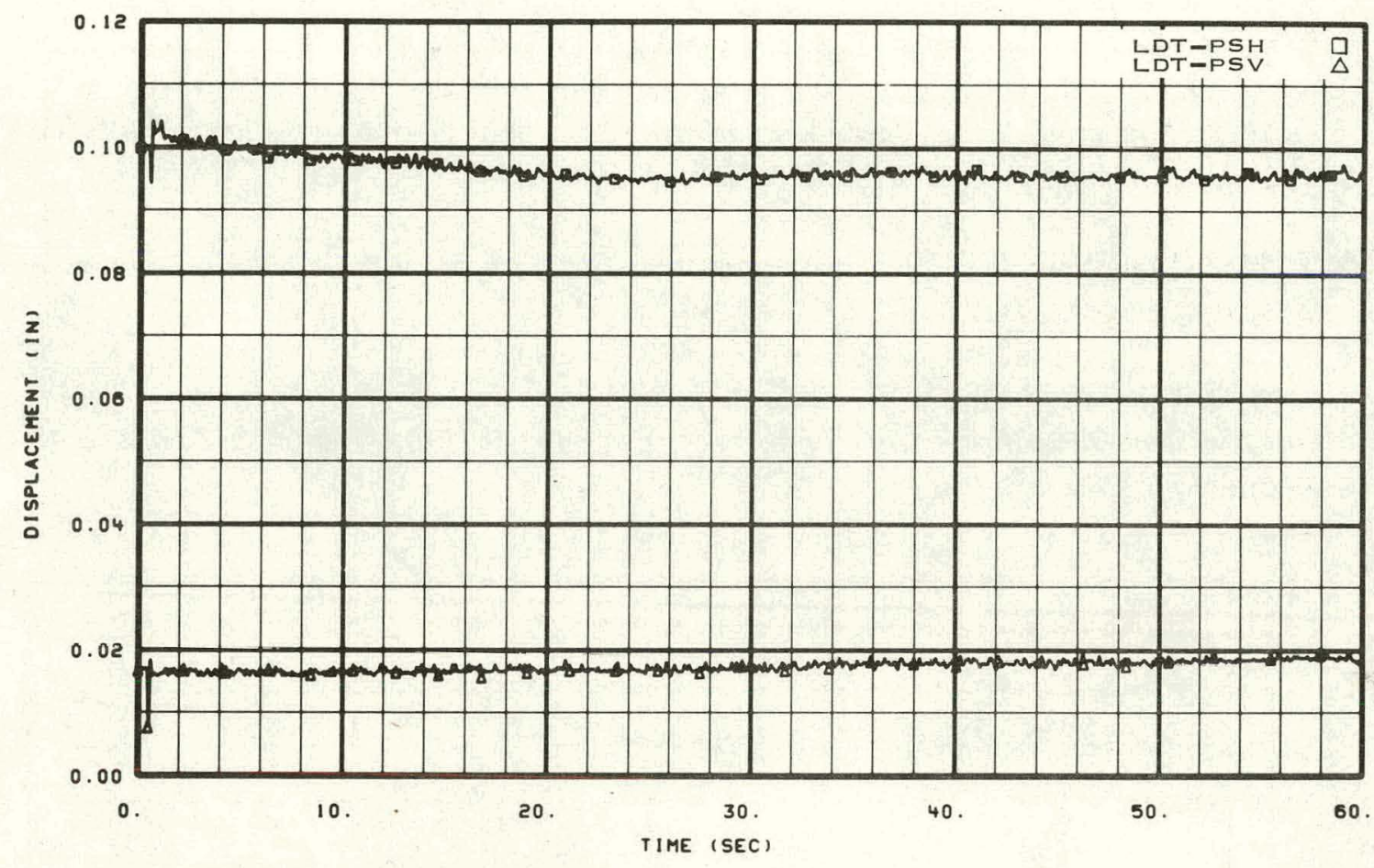

Fig. 370 Displacement of pressure suppression header -- Test 15.7 . 


\section{REFERENCES}

1. R. S. Alder, E. M. Feldman, D. J. Olson, P. A. Pinson, Experimental Data Report for 1-1/2-Loop Semiscale System Isothermal Tests 1001, 1002, and 1003, ANCR-1148 (May 1974).

2. R. S. Alder, E. M. Feldman, P. A. Pinson, Experiment Data Report for 1-1/2-Loop Semiscale System Isothermal Tests 1004 and 1006, ANCR-1144 (March 1974).

3. K. S. Alder, E. M. Feldman, P. A. Pinson, Experiment Data Report for 1-1/2-Loop Semiscale System Isothermal Tests 1008 and 1010, ANCR-1145 (March 1974).

4. E. M. Feldman and P. A. Pinson, Experiment Data Report for 1-1/2-Loop Semiscale System Isothermal Test 1011, ANCR-1146 (March 1974).

5. E. M. Feldman and P. A. Pinson, Experiment Data Report for 1-1/2-Loop Semiscale System Isothermal Test 1014, ANCR-1147 (March 1974).

6. S. A. Naff and P. A. Pinson, 1-1/2-Loop Semiscale Isothermal Test Program -- Program and System Description in Support of Experiment Data Reports, ANCR-1143 (February 1974). 
1 